\title{
The Development of $\mathrm{Pt}^{\mathrm{II}}$ Complexes as Catalyst Precursors for Transition Metal Mediated Olefin Hydroarylation
}

\author{
Bradley Aaron McKeown \\ Chattanooga, TN
}

B.S. Chemistry, University of Tennessee at Chattanooga, 2007

A Dissertation presented to the Graduate Faculty of the University of Virginia in Candidacy for the Degree of

Doctor of Philosophy

Department of Chemistry

University of Virginia

August 2013 


\begin{abstract}
MCKEOWN, BRADLEY A. The Development of $\mathrm{Pt}^{\mathrm{II}}$ Complexes as Catalyst Precursors for Transition Metal Mediated Olefin Hydroarylation. (Under the direction of Professor T. Brent Gunnoe)
\end{abstract}

Olefin hydroarylation is an important $\mathrm{C}-\mathrm{C}$ bond forming reaction for the synthesis of alkyl arenes. The transformation is traditionally catalyzed using acid-based methodologies, which suffer several deficiencies inherent to the reaction mechanism. Selective transition metal catalysts for olefin hydroarylation are potentially viable alternatives. However, such a process has been difficult to realize as catalysts for olefin hydroarylation via a non-acidic pathway must be able to mediate two fundamentally different reactions in the catalytic cycle, olefin insertion into $\mathrm{M}-\mathrm{Ar}$ bonds and aromatic $\mathrm{C}-\mathrm{H}$ activation. While several examples of transition metal mediated olefin hydroarylation have been realized for activated substrates, such as substituted olefins and arenes possessing heteroatomic functionality, the synthesis of alkyl arenes from unactivated substrates (e.g., ethylene and benzene) are more scarce. Current examples based on $\mathrm{Ru}^{\mathrm{II}}$ and $\mathrm{Ir}^{\mathrm{III}}$ have displayed marginal efficiency for catalytic olefin hydroarylation using unactivated substrates, but relatively rapid decomposition and reduced activity with substituted substrates such as $\alpha$-olefins limit a broader application of this methodology.

Extension of catalytic olefin hydroarylation to $\mathrm{Pt}^{\mathrm{II}}$ catalyst precursors has been investigated. Initial studies focus on formally cationic bipyridyl ligated $\mathrm{Pt}^{\mathrm{II}}$ complexes $\left[\left({ }^{\mathrm{t}} \mathrm{bpy}\right) \mathrm{Pt}(\mathrm{Ph})(\mathrm{L})\right]\left[\mathrm{BAr}_{4}{ }_{4}\right]\left({ }^{\mathrm{t}} \mathrm{bpy}=4,4^{\prime}-{ }^{\mathrm{t}} \mathrm{Bu}_{2}-2,2^{\prime}\right.$-bipyridyl; L = THF, $\mathrm{NC}_{5} \mathrm{~F}_{5}$ or NCMe; $\mathrm{Ar}^{\prime}$ $\left.=3,5-\left(\mathrm{CF}_{3}\right)_{2}-\mathrm{C}_{6} \mathrm{H}_{3}\right)$. These complexes were found to be active for catalytic 
hydrophenylation of ethylene, and mechanistic evidence presented supports an operative pathway that incorporates ethylene insertion and benzene $\mathrm{C}-\mathrm{H}$ activation into a single catalytic cycle.

The bipyridyl scaffold presents an excellent opportunity to develop catalyst structure/activity relationships for future catalyst design. Electronic effects on catalyst activity and selectivity have been isolated with negligible influence on the catalyst steric profile by incorporating various functionality in the 4,4'-positions of bipyridine. Moreover, the consequence of steric perturbations have been evaluated through modulating the dipyridyl chelate ring size and incorporating steric hinderance in the 6,6'positions of the pyridyl rings.

In addition, compatibility with functionalized substrates with bipyridyl based catalyst precursors and ligand sets outside the dipyridyl motif have been investigated for efficacy. 


\section{Acknowledgements}

I finally stand at the end of a long road that has taken almost six years to traverse. In all honesty, I did not think it would be a journey that I would get to see through to the end. There are so many people who have assisted me along the way and deserve more thanks than can adequately be expressed in a brief acknowledgement.

I was endowed with a fascination for science early in my primary education and found chemistry particularly enjoyable. Physics was also of great interest. However, it involves way too much math. Have you seen that stuff? It's hard. Upon entering college at the University of Tennessee at Chattanooga, my study of chemistry began. While I found the coursework interesting and, thanks to the amazing faculty, understandable, I didn't truly appreciate the art until participating in independent research. Dr. Kyle Knight took me under his wing and introduced me to what chemistry and research actually is. Dr. Greg Grant was equally fundamental in my successes up to this point in life. Both of these gentlemen are brilliant scientists, but even greater educators.

Dr. "Tommy" Brent Gunnoe (a.k.a. "Boss"), my mentor these past years, what can I say? You have been a fantastic advisor, and I predict that you will arguably be the best boss I will ever work for. All of your former students would agree, well at least most, I have to see if Joanna has changed her opinion. You go above and beyond for your students and truly aspire to see us succeed in graduate school and beyond. Your efforts to ensure this document came to existence have been an inspiration to me, and you will forever have my most sincere gratitude. This gratitude also extends to the rest of the Gunnoe family, Trecia and Leah. My life is definitely better for knowing you, maybe not for Leah though. 
To my family and friends, thank you for your support, even though you have no idea what it is that I have been doing. My parents, Kimberly and Charles, I am blessed to have parents as devoted to their children as you. To my grandmother, Leonis McKeown, you will be forever missed. I'm sorry that I will never get to be your "doctor." To Aaron Kemper, Squirrel, Maikel, Josh and Allyson, a guy could not ask for better friends. Well, I could, but I've grown fond of you.

Thanks have to also be extended to Steve "The Steve" Waller. He above all others is the reason that I am where I am today. You have been a mentor and a great friend. I will always remember my time on Ocoee St. fondly. In your wisdom, I learned much about life, the world and most importantly the ladies. Your generosity, despite the sacrifice, will never be forgotten. It is a debt that will be repaid, whether to you or an equal act of kindness to one in need of it in the future.

To past group members, Sam, Nick, Colleen and John for teaching me the skills I needed to be successful in the Gunnoe group, as well as, instilling a strong work ethic. To current group members Steve, Samantha, JJ, Kathleen, Mike, Tristan, Shawn, Ted, George and Ben thanks for keeping it interesting, and I have every confidence that you will keep this ship afloat. To my minions, Max and Anna I hope you found me to be a good mentor, but the truth is you both are too smart for your own good and didn't need my help but I needed yours. Evan thanks for being my office buddy. Joanna, even though you have already gone, you were always a bright spot to my day. Mostly, because you had food at the time. I would have gone hungry without you. We started this together and we both made it to the end. I'm so proud of you and glad to call you my friend. 
Katherine Bridge Decker. You constantly hindered my progress, caused me to neglect my studies and insolently violated the sanctity of the Forbidden Chamber. I wouldn't have had it any other way, and I'm glad to be embarking onto the next stage of my life with you...for now.

Last but not least, I would like to thank my committee Dr.'s Dean Harmon, Cassandra Fraser and Lin Pu for guidance and support throughout my tenure at UVa. Also Dr.'s Jim Demas and Matt Neurok deserve great thanks for agreeing to serve on my committee with short notice.

Cheers to you all and those whose direct mentioning were neglected but not forgotten! 
LIST OF CHARTS....................................................................

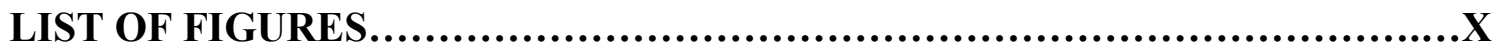

LIST OF SCHEMES.............................................................

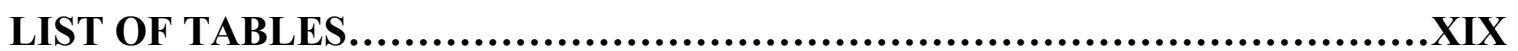

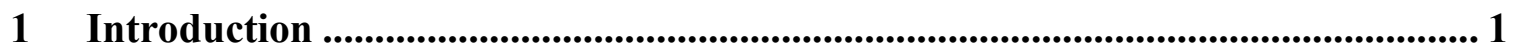

1.1 Overview of Catalysts and Classification ....................................................... 1

1.1.1 Efforts Toward Increasing the Viability of Homogeneous Catalysts for the Production of Commodity Chemicals...................................................................... 3

1.1.2 Olefin Hydroarylation: Historical and Conventional Synthesis of Alkyl

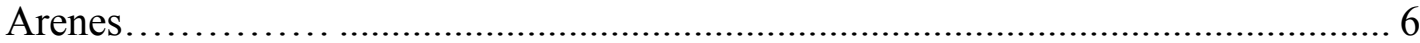

1.2 Transition Metal Mediated Reactions: The Emergence of $\mathrm{C}-\mathrm{H}$ activation as a Promising Alternative to Acid-catalyzed Pathways ................................................. 14

1.2.1 C-H Activation by Organometallic Routes ................................................ 15

1.2.2 Transition-Metal Mediated Olefin Hydroarylation: Challenges and Implications for Alkyl Arene Synthesis................................................................ 22

1.2.3 Olefin Hydroarylation Facilitated by Activated Aromatic Substrates and Directing Groups......................................................................................... 24

1.2.4 Intermolecular Transition-Metal Mediated Olefin Hydroarylation with Unactivated Substrates via a Non-Acid Catalyzed Pathway ……………................ 28

1.3 Platinum: Promising Candidate for Transition Metal Catalyzed Olefin

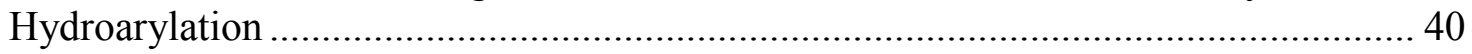

1.3.1 Mechanism Elucidation for Platinum Mediated Aromatic $\mathrm{C}-\mathrm{H}$ Activation 41

1.3.2 Examples of Olefin Hydroarylation Catalyzed by $\mathrm{Pt}^{\mathrm{II}}$............................... 46

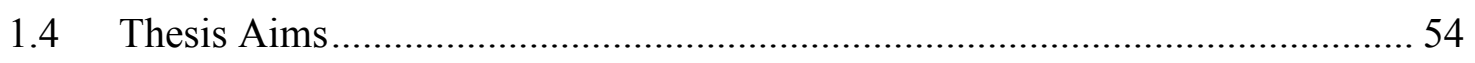

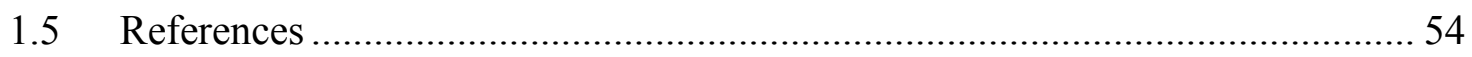

2 Mechanistic Studies of Ethylene Hydrophenylation Catalyzed by Cationic $\mathbf{P t}^{\mathrm{II}}$ Complexes Supported by 4,4'-di-tert-butyl-2,2'-bipyridine ............................................ 66

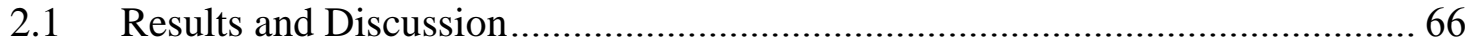

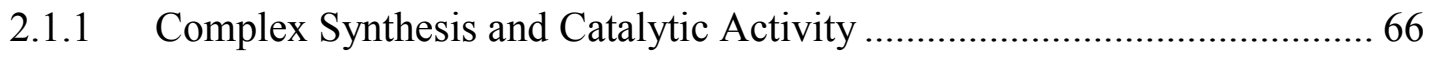

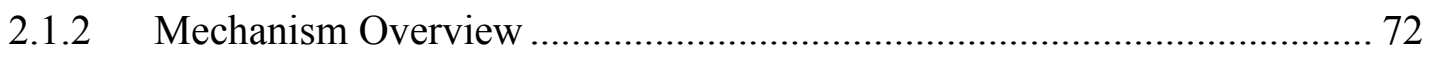

2.1.3 Kinetic Studies and Isotope Effects for the Catalytic Cycle ........................ 74

2.1.4 Stoichiometric Studies Modeling Elementary Steps of the Catalytic Cycle76

2.1.5 Computational Study of Benzene $\mathrm{C}-\mathrm{H}$ Activation by

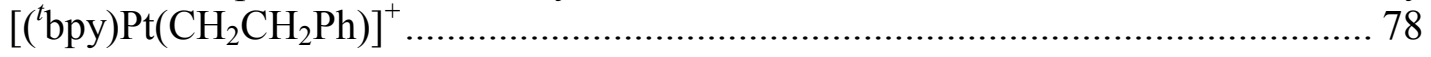

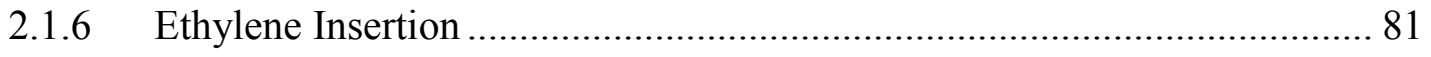


2.1.7 Calculated Energetics of the Catalytic Cycle............................................ 88

2.1.8 Competition between Cyclometallation and Benzene C-H/D Activation.. 92

2.1.9 Study of Multiple Insertions of Ethylene................................................... 96

2.1.10 $\beta$-Hydride Elimination ........................................................................ 99

2.1.11 C-H Bond Activation of Ethylene ........................................................... 101

2.1.12 Polyalkylation of Benzene …………………......................................... 103

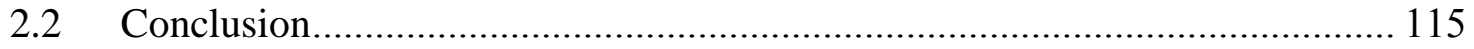

2.3 Experimental Section ....................................................................... 117

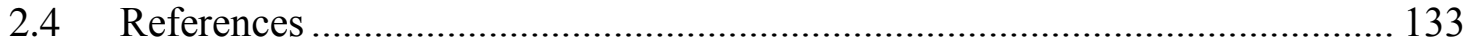

3 Control of Olefin Hydroarylation Catalysis via a Sterically and Electronically Flexible Pt ${ }^{\mathrm{II}}$ Catalyst Scaffold ....................................................................................... 139

3.1 Bipyridine as an Electronically Tunable Ligand for the Platinum Catalyzed Synthesis of Alkylbenzenes .................................................................................... 141

3.1.1 Synthesis of Pt Complexes and Probing Elementary Steps of Ethylene

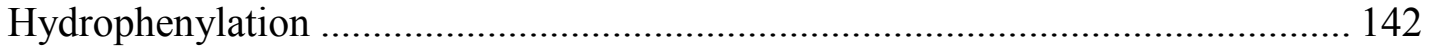

3.1.2 Evaluation of Catalytic Efficiency and Trends ........................................ 147

3.2 Using Dipyridyl Chelate Ring Size to Modulate $\mathrm{Pt}^{\mathrm{II}}$ Catalyzed Ethylene

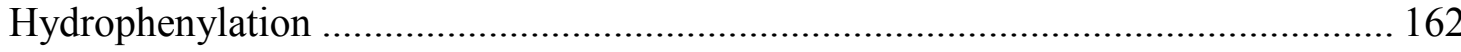

3.2.1 Evaluation of Catalytic Cycle Elementary Steps and Extraction of Activation Parameters 167

3.3 Further Steric and Electronic Ligand Modifications and the Influence on the Efficiency of $\mathrm{P}^{\mathrm{II}}$ Catalyzed Ethylene Hydroarylation............................................. 176

3.3.1 Complex Synthesis and Characterization .............................................. 177

3.3.2 Catalytic Ethylene Hydroarylation using Complexes 3.13-3.16 ….......... 180

3.3.3 Substitution of the Dipyridyl Linker of Dipyridylmethane ...................... 187

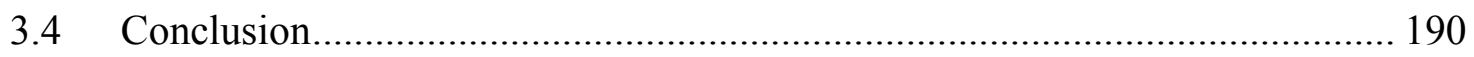

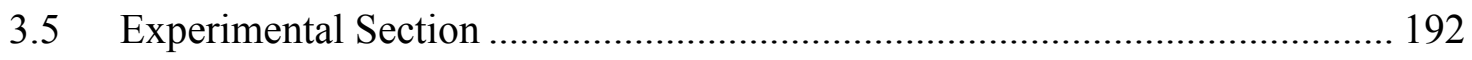

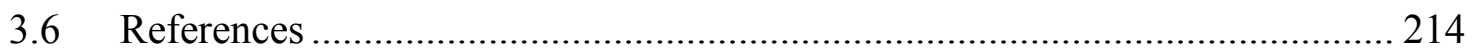

$4 \quad \mathrm{Pt}^{\mathrm{II}}$ Catalyzed Olefin Hydroarylation: Substrate and Ligand Scope........................................................................................................................217

4.1 Ethylene Hydroarylation using Activated Benzenes and Heteroaromatic

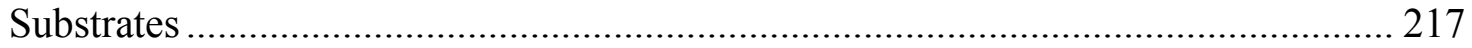

4.1.1 Dipyridyl $\mathrm{Pt}^{\mathrm{II}}$ Catalyzed Ethylene Hydroarylation with Heteroaromatic Substrates 222 
4.2 Catalytic Hydrophenylation of $\alpha$-olefins and Michael Acceptors with Dipyridyl

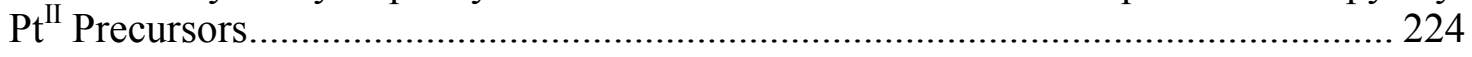

4.2.1 Catalytic Hydrophenylation of $\alpha$-olefins and Michael Acceptors using

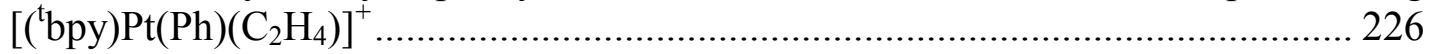

4.2.2 Influence of 4,4'-Bipyridyl Substituents on Product Selectivity for the Hydrophenylation of Propylene 232

4.2.3 Influence of Migrating Group Identity on the Selectivity of Propylene

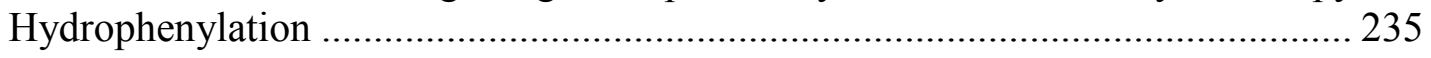

4.2.4 Ramifications of Steric Perturbations and Bridging Group Identity on Dipyridyl Pt ${ }^{\mathrm{II}}$ Catalyzed Propylene Hydrophenylation ....................................... 237

4.3 Ethylene Hydrophenylation Catalyzed by Cationic $\mathrm{Pt}^{\mathrm{II}}$ Complexes Supported by non-Bipyridyl $N$ - and $S$-Based Chelates

4.4 Viability of Cationic $\mathrm{Pt}^{\mathrm{II}}$ complexes Containing Phosphorous Ligands as Catalytic Precursors for Ethylene Hydrophenylation ....................................... 246

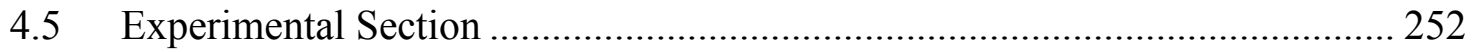

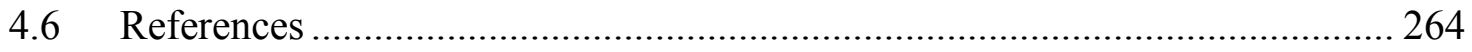

5 Summary and Future Outlook .............................................................................. 270

5.1 Olefin Hydroarylation by Dipyrdyl Ligated $\mathrm{Pt}^{\mathrm{II}}$ Complexes .......................... 270

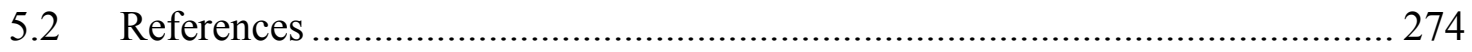




\section{LIST OF CHARTS}

Chart 1.1. Basic aluminosilicate structure of solid zeolite acid catalysts.

Chart 1.2. Structure of ZSM-5 zeolite. Lei, X.-g.; Jockusch, S.; Francesca Ottaviani, M.; Turro, N. J., Photochemical \& Photobiological Sciences 2003, 2, 1095-1100Reproduced by permission of The Royal Society of Chemistry (RSC) for the European Society for Photobiology, the European Photochemistry Association, and the RSC.

Chart 1.3. Acidic sites in ZSM-5. Site 1 is located at channel intersections, while Sites 2 and 3 are located within the channels. Broach, R. W., Zeolite Types and Structures. In Zeolites in Industrial Separation and Catalysis, Kulprathipanja, S., Ed. John Wiley \& Sons: 2010; pp 27-59. Copyright Wiley-VCH Verlag GmbH \& Co. KGaA. Reproduced with permission. 11

Chart 1.4. Crystalline structure of zeolite MCM-22 displaying the non-interconnected channels and egg-shaped cages (left). The surface is covered with 12-ring pockets in which the reaction is proposed to take place (right). Broach, R. W., Zeolite Types and Structures. In Zeolites in Industrial Separation and Catalysis, Kulprathipanja, S., Ed. John Wiley \& Sons: 2010; pp 27-59. Copyright Wiley-VCH Verlag GmbH \& Co. KGaA. Reproduced with permission.

Chart 1.5. Direct observation of a $\mathrm{Rh}^{\mathrm{I}}$ (methane) $\sigma$-complex by ${ }^{1} \mathrm{H}$ NMR spectroscopy with a proposed $\eta^{2}-\mathrm{C}, \mathrm{H}$ binding mode as elucidated from experimental and computational study $\left(\mathrm{Ar}^{\prime}=3,5-\left(\mathrm{CF}_{3}\right)_{2}-\mathrm{C}_{6} \mathrm{H}_{3}\right)$. 22

Chart 1.6. Reported catalyst precursors for olefin hydroarylation with unactivated substrates based upon $\mathrm{Ir}^{\mathrm{III}}$ and $\mathrm{Ru}^{\mathrm{II}}\left[\mathrm{L}=\mathrm{CO}, \mathrm{P}\left(\mathrm{OCH}_{2}\right)_{3} \mathrm{CEt}\right.$ or SPhos (SPhos = 2,6,7Trioxa-1-phosphabicyclo[2,2,1]heptane); $\mathrm{R}=\mathrm{Ph}$ or Me].

Chart 1.7. The $\mathrm{Ir}^{\mathrm{III}}$ complex (trop) ${ }_{2} \operatorname{Ir}(\mathrm{py}) \mathrm{Ph}\left(\operatorname{trop}=\kappa^{2}-O, O\right.$-tropolonato; Ir-trop). .......... 32

Chart 1.8. Neutral $\mathrm{Pt}^{\mathrm{IV}}(\mathrm{Pt10})$ and $\mathrm{Pt}^{\mathrm{II}}(\mathrm{Pt} 11)$ catalyst precursors utilized for catalytic olefin hydroarylation via a non-acid catalyzed mechanism................................... 52

Chart 3.1. Generic structure for dipyridyl ligated $\mathrm{Pt}^{\mathrm{II}}$ complexes, highlighting the substituents studied in this report $\left(\mathrm{E}=\mathrm{CH}_{2}, \mathrm{CH}_{2} \mathrm{CH}_{2}, \mathrm{C}=\mathrm{O}, \mathrm{NH}\right.$ or $\mathrm{O} ; \mathrm{R}^{1}, \mathrm{R}^{2}=\mathrm{H}$ or $\mathrm{Me})$. 177

Chart 4.1. Variations in dipyridyl $\mathrm{Pt}^{\mathrm{II}}$ catalyst precursor architecture.......................... 239

Chart 5.1. Potential ligands for future $\mathrm{Pt}^{\mathrm{II}}$ catalyzed olefin hydroarylation studies.....273 


\section{LIST OF FIGURES}

Figure 1.1. Plot of $k_{\text {obs }}$ for stoichiometric $\mathrm{C}_{6} \mathrm{D}_{6} \mathrm{C}-\mathrm{D}$ activation by $\mathrm{TpRu}(\mathrm{L})(\mathrm{NCMe}) \mathrm{Ph}(\mathrm{L}$ $=\mathrm{CO}, \mathrm{BPhos}$, SPhos or $\mathrm{PMe}_{3}$ ) at $60{ }^{\circ} \mathrm{C}$ with $0.065 \mathrm{mmol}$ of added NCMe versus $\mathrm{Ru}^{\mathrm{III} / \mathrm{II}}$ potentials (vs NHE, V). Reproduced from reference 128.............................. 37

Figure 2.1. ${ }^{1} \mathrm{H}$ NMR spectrum of $\left[\left({ }^{\mathrm{t}} \mathrm{bpy}\right) \mathrm{Pt}(\mathrm{Ph})(\mathrm{THF})\right]\left[\mathrm{BAr}_{4}{ }_{4}\right](2.1)$ in $\mathrm{CD}_{2} \mathrm{Cl}_{2} \ldots \ldots \ldots \ldots . . . .67$ Figure 2.2. ORTEP of [( $\left.\left.{ }^{\mathrm{b}} \mathrm{bpy}\right) \mathrm{Pt}(\mathrm{NCMe})(\mathrm{Ph})\right]\left[\mathrm{BAr}_{4}\right]$ (2.3) $(50 \%$ probability; $\mathrm{H}$ atoms and $\mathrm{BAr}_{4}$ anion omitted for clarity). Selected bond lengths ( $\AA$ ): Pt1-N1 2.092(4), Pt1-N2 2.000(4), Pt1-N3 1.969(4), Pt1-C19 2.004(5). Selected bond angles ( $\left.{ }^{\circ}\right)$ : N1-Pt1-N2

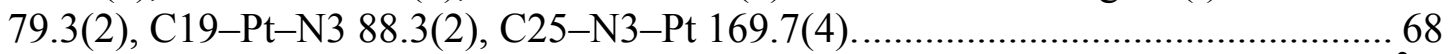

Figure 2.3. Catalysis using complex 2.1 and dynamic ethylene $(0.9 \mathrm{MPa})$ at $100{ }^{\circ} \mathrm{C}\left(\mathrm{R}^{2}=\right.$ $0.99)$. 72

Figure 2.4. Plot of [ethylbenzene] (M) versus [2.1] after 30 minutes at $100{ }^{\circ} \mathrm{C}$ with 0.1

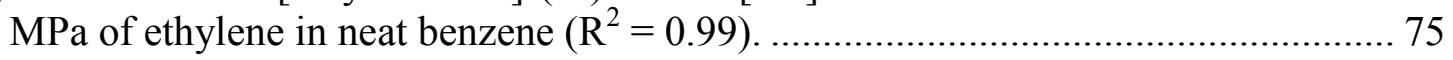

Figure 2.5. Plot of [ethylbenzene] (M) versus [benzene] (M) after 2 hours at $100{ }^{\circ} \mathrm{C}$ in

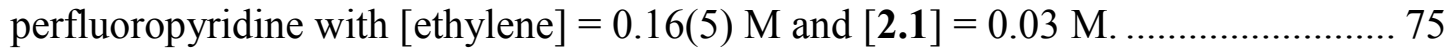

Figure 2.6. Plot of [ethylbenzene] (M) versus [ethylene] (M) after 2 hours at $100{ }^{\circ} \mathrm{C}$ in

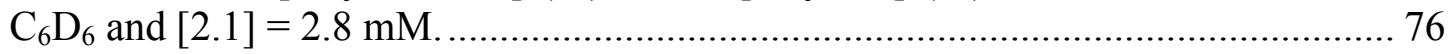

Figure 2.7. Observed rate of benzene $\mathrm{C}-\mathrm{D}$ activation by 2.1 as a function of THF

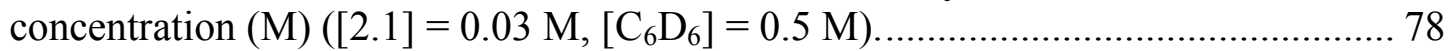

Figure 2.8. Calculated structures of pertinent stationary points (see Scheme 2.7) from $\left[(\text { bpy }) \mathrm{Pt}\left(\mathrm{CH}_{2} \mathrm{CH}_{2} \mathrm{Ph}\right)\left(\eta^{2}-C, C-\mathrm{C}_{6} \mathrm{H}_{6}\right)\right]^{+}$. Shown are the transition states for benzene $\mathrm{C}-$ $\mathrm{H}$ oxidative addition (A), ethylbenzene reductive elimination (B), and intermediate $\sigma$ bond metathesis $(\mathrm{C})$ in addition to a five-coordinate, Pt-hydride intermediate (D) that is the successor to the oxidative addition transition state and the precursor to the reductive elimination transition state. Only the two nitrogens of the bipyridyl ligand are shown to increase the clarity of the $\mathrm{Pt}$ core. ....................................................... 80

Figure 2.9. ${ }^{1} \mathrm{H}$ NMR spectrum of $\left[\left({ }^{t} \mathrm{bpy}\right) \mathrm{Pt}\left(\mathrm{CH}_{2} \mathrm{CH}_{2} \mathrm{Ph}\right)\left(\eta^{2}-\mathrm{C}_{2} \mathrm{H}_{4}\right)\right]\left[\mathrm{BAr}_{4}^{\prime}\right]$ (2.4) in $\mathrm{CD}_{2} \mathrm{Cl}_{2}$ at room temperature. Trace solvents $(*)$ are indicated. 82

Figure 2.10. ORTEP of [ ( $\left.\left.{ }^{b} \mathrm{bpy}\right) \mathrm{Pt}\left(\mathrm{CH}_{2} \mathrm{CH}_{2} \mathrm{Ph}\right)\left(\eta^{2}-\mathrm{C}_{2} \mathrm{H}_{4}\right)\right]\left[\mathrm{BAr}{ }_{4}\right](2.4)(50 \%$ probability; $\mathrm{H}$ atoms and $\mathrm{BAr}_{4}{ }_{4}$ anion omitted for clarity) Selected bond lengths $(\AA)$ : Pt1-N1 2.069(4), Pt1-N2 2.127(4), Pt1-C44 2.052(5), Pt1-C53 2.144(5), Pt1-C55 2.118(4), C53-C55 1.393(6). Selected bond angles $\left({ }^{\circ}\right)$ : N1-Pt-N2 78.4(1), Pt-C44-C45 111.3(3), C44-C45-C46 115.5(3). View on the right shows stacking of phenyl group of phenethyl ligand and pyridyl of ${ }^{t}$ bpy ligand. 83

Figure 2.11. Representative kinetic plot for the conversion of 2.1 to 2.4 ([2.1] $=0.031 \mathrm{M}$,

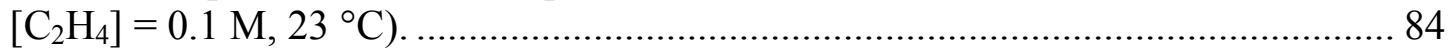

Figure 2.12. Plot of $k_{\mathrm{obs}}$ for the conversion of 2.1 and ethylene to 2.4 as a function of ethylene concentration $(\mathrm{M})\left([2.1]=0.03 \mathrm{M}, 23.0^{\circ} \mathrm{C}\right)$. 84

Figure 2.13. Ethylene insertion into the $\mathrm{Pt}-\mathrm{Ph}$ bond as a function of THF concentration

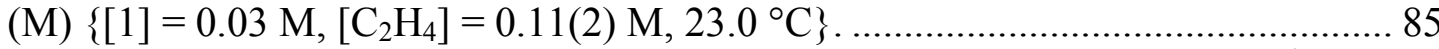

Figure 2.14. DFT calculated structures for $[(\mathrm{bpy}) \mathrm{Pt}(\mathrm{Ph})]^{+}\left(2.6^{\prime}\right),\left[(\mathrm{bpy}) \mathrm{Pt}(\mathrm{Ph})\left(\eta^{2}-\mathrm{C}_{2} \mathrm{H}_{4}\right)\right]^{+}$ (2.7') and the two conformers of the resulting product $\left[(\text { bpy }) \mathrm{Pt}\left(\mathrm{CH}_{2} \mathrm{CH}_{2} \mathrm{Ph}\right)\right]^{+}\left(2.8^{\prime} \beta\right.$ and $\left.2.8^{\prime}\right)$. 90 
Figure 2.15. Mass spectra highlighting the fragmentation of the ethyl ion from the thermolysis of 2.4- $d_{5}$ in $\mathrm{C}_{6} \mathrm{H}_{6}(\mathrm{~A}), 2.4$ in $\mathrm{C}_{6} \mathrm{H}_{6}(\mathrm{~B})$, and 2.4- $d_{5}$ in $\mathrm{C}_{6} \mathrm{H}_{6}$ with 100 equivalents of THF relative to $2.4-d_{5}$ 94

Figure 2.16. A) ${ }^{1} \mathrm{H}$ NMR spectrum for the thermolysis of 2.4 in $\mathrm{C}_{6} \mathrm{D}_{6}$, highlighting the benzylic resonances $(\delta=2.43 \mathrm{ppm})$ of the ethylbenzene isotopologues with $-\mathrm{CH}_{2} \mathrm{CH}_{3}$ and $-\mathrm{CH}_{2} \mathrm{CH}_{2} \mathrm{D}$ groups. The spectrum is consistent with an overlap of a quartet and a triplet $(1: 2: 1)$ of triplets $(1: 1: 1)$. B) ${ }^{1} \mathrm{H}$ NMR spectrum for the thermolysis of 2.4 in $\mathrm{C}_{6} \mathrm{D}_{6}$ with added THF- $d_{8}$. 95

Figure 2.17. Variable temperature ${ }^{1} \mathrm{H}$ NMR spectra in the region of resonances due to coordinated ethylene for $\left[\left({ }^{t} \mathrm{bpy}\right) \mathrm{Pt}\left(\mathrm{CH}_{2} \mathrm{CH}_{2} \mathrm{Ph}\right)\left(\eta^{2}-\mathrm{C}_{2} \mathrm{H}_{4}\right)\right]\left[\mathrm{BAr}_{4}{ }_{4}\right] \quad(2.4) \ldots \ldots \ldots \ldots \ldots . . . . .97$

Figure 2.18. SEI mass spectrum of ethylbenzene- $d_{\mathrm{n}}, \mathrm{n}=0-6$, produced by ethylene hydrophenylation catalyzed by 2.2 in the presence of $\mathrm{C}_{6} \mathrm{H}_{6}$ and $\mathrm{C}_{6} \mathrm{D}_{6}(1: 1 \mathrm{v}: \mathrm{v}) \ldots \ldots .106$

Figure 2.19. Selected mass spectra for the thermolysis of 2.4 in $\mathrm{C}_{6} \mathrm{D}_{6}$. (A) SEI mass spectrum of ethylbenzene. (B) Zoom of SEI mass spectrum highlighting the fragmentation of the ethyl ion. (C) NCI mass spectrum of ethylbenzene. ............... 109

Figure 2.20. ${ }^{2} \mathrm{H}$ NMR spectrum for the product of thermolysis of 2.4 in $\mathrm{C}_{6} \mathrm{D}_{6}$, highlighting the resonance $(\delta=1.03 \mathrm{ppm})$ of the ethylbenzene isotopologues possessing an ethyl fragment with a terminal $-\mathrm{CH}_{2} \mathrm{D}$ group. Incorporation of deuterium into the benzylic position is not observed.

Figure 2.21. (A) NCI mass spectrum for the thermolysis of 2.4 in $\mathrm{C}_{6} \mathrm{D}_{6}$ with 100 equivalents of THF- $d_{8}$ relative to 2.4. (B) NCI mass spectrum for the thermolysis of 2.4 in $\mathrm{C}_{6} \mathrm{D}_{6}$ without the presence of a Lewis base.

Figure 2.22. Selected mass spectra for the thermolysis of 2.4- $d_{5}$ in $\mathrm{C}_{6} \mathrm{H}_{6}$. (A) SEI mass spectrum of ethylbenzene (B) Zoom of SEI mass spectrum highlighting the fragmentation of the ethyl ion (C) NCI mass spectrum of ethylbenzene. ................ 112

Figure 3.1. ${ }^{1} \mathrm{H}$ NMR spectrum of $\left[\left({ }^{\mathrm{m}} \mathrm{bpy}\right) \mathrm{Pt}(\mathrm{Ph})(\mathrm{THF})\right]\left[\mathrm{BAr}_{4}{ }_{4}\right]\left({ }^{\mathrm{m}}\right.$ bpy $=4,4{ }^{\prime}-(\mathrm{OMe})_{2}-2,2^{\prime}-$ bipyridyl; 3.2a) in $\mathrm{CD}_{2} \mathrm{Cl}_{2}$ at room temperature. Trace solvents (*) are indicated. .. 143

Figure 3.2. ${ }^{1} \mathrm{H}$ NMR spectrum of $[(\mathrm{bpy}) \mathrm{Pt}(\mathrm{Ph})(\mathrm{THF})]\left[\mathrm{BAr}_{4}{ }_{4}\right](\mathrm{bpy}=2,2$ '-bipyridyl; 3.2c) in $\mathrm{CD}_{2} \mathrm{Cl}_{2}$ at room temperature.

Figure 3.3. ${ }^{1} \mathrm{H}$ NMR spectrum of $\left[\left({ }^{\mathrm{Br}} \mathrm{bpy}\right) \mathrm{Pt}(\mathrm{Ph})(\mathrm{THF})\right]\left[\mathrm{BAr}^{\prime}{ }_{4}\right]\left({ }^{\mathrm{Br}} \mathrm{bpy}=4,4^{\prime}-\mathrm{Br}_{2}-2,2^{\prime}-\right.$ bipyridyl; 3.2d) in $\mathrm{CD}_{2} \mathrm{Cl}_{2}$ at room temperature.

Figure 3.4. ${ }^{1} \mathrm{H}$ NMR spectrum of $\left[\left({ }^{c} \mathrm{bpy}\right) \mathrm{Pt}(\mathrm{Ph})(\mathrm{THF})\right]\left[\mathrm{BAr}_{4}{ }_{4}\right]\left({ }^{\mathrm{c}} \mathrm{bpy}=4,4{ }^{\prime}-\left(\mathrm{CO}_{2} \mathrm{Et}\right)_{2}-2,2^{\prime}-\right.$ bipyridyl; 3.2e) in $\mathrm{CD}_{2} \mathrm{Cl}_{2}$ at room temperature. Trace solvents (*) are indicated. .. 144

Figure 3.5. ${ }^{1} \mathrm{H}$ NMR spectrum of $\left[\left({ }^{\mathrm{NO} 2} \mathrm{bpy}\right) \mathrm{Pt}(\mathrm{Ph})(\mathrm{THF})\right]\left[\mathrm{BAr}_{4}{ }_{4}\right]\left({ }^{\mathrm{c}} \mathrm{bpy}=4,4^{\prime}-\left(\mathrm{NO}_{2}\right)_{2}-2,2^{\prime}-\right.$ bipyridyl; 3.2f) in $\mathrm{CD}_{2} \mathrm{Cl}_{2}$ at room temperature. Trace solvents $(*)$ are indicated.... 144

Figure 3.6. ORTEP of $\left[\left({ }^{\mathrm{Br}} \mathrm{bpy}\right) \mathrm{Pt}(\mathrm{Ph})(\mathrm{THF})\right]\left[\mathrm{BAr}_{4}{ }_{4}\right]$ (3.2d) (30\% probability; $\mathrm{H}$ atoms and $\mathrm{BAr}_{4}{ }_{4}$ anion omitted for clarity). Selected bond lengths $(\AA)$ : Pt-N1 1.998(6), Pt-N2 2.075(6), Pt-O1 2.060(7), Pt-C1 2.014(8). Selected bond angles $\left({ }^{\circ}\right)$ : N1-Pt-N2 79.4(2), C1-Pt-O1 89.4(3). 144

Figure 3.7. Representative kinetic plot for the conversion of $3.2 \mathrm{f}$ to $3.3 \mathrm{f}([3.2 \mathrm{f}]=0.03 \mathrm{M}$, $\left.\left[\mathrm{C}_{2} \mathrm{H}_{4}\right]=0.1 \mathrm{M},-15^{\circ} \mathrm{C}\right)$. 145

Figure 3.8. Plot of ethylbenzene and diethylbenzenes $\mathrm{TO}$ as a function of time for ethylene hydrophenylation catalyzed by complexes $3.2 \mathrm{a}-3.2 \mathrm{c}$ at $100{ }^{\circ} \mathrm{C}$ with $0.1 \mathrm{MPa}$ of ethylene pressure. 149 
Figure 3.9. Plot of ethylbenzene and diethylbenzenes $\mathrm{TO}$ as a function of time for ethylene hydrophenylation catalyzed by complexes $3.2 \mathrm{~d}-3.2 \mathrm{f}$ at $100{ }^{\circ} \mathrm{C}$ with $0.1 \mathrm{MPa}$ of ethylene pressure.

Figure 3.10. Hammett plot for the ratios of ethylbenzene to styrene from $\left[\left({ }^{\mathrm{B}} \text { bpy }\right) \mathrm{Pt}(\mathrm{Ph})(\mathrm{THF})\right]^{+}$catalyzed ethylene hydrophenylation after 4 hours at $100{ }^{\circ} \mathrm{C}$ with $0.1 \mathrm{MPa}$ of ethylene (slope $=-2.3, \mathrm{R}^{2}=0.77$ ). 151

Figure 3.11. Ratios of ethylbenzene:styrene from $\left[\left({ }^{x} \mathrm{bpy}\right) \mathrm{Pt}(\mathrm{Ph})(\mathrm{THF})\right]^{+}$catalyzed ethylene hydrophenylation after 4 hours at $100{ }^{\circ} \mathrm{C}$ with $0.1 \mathrm{MPa}$ and $0.3 \mathrm{MPa}$ of ethylene versus Hammett parameter $\left(\sigma_{\mathrm{p}}\right)$ for $4,4^{\prime}$-substituent. Complex $3.2 \mathrm{~d}(\mathrm{X}=\mathrm{Br})$ is not included in either linear fit $\left(0.1 \mathrm{MPa}, \mathrm{R}^{2}=0.98\right.$, slope $=-27.9 ; 0.3 \mathrm{MPa}, \mathrm{R}^{2}=$ 0.96 , slope $=-9.0)$. 151

Figure 3.12. ${ }^{13} \mathrm{C}\left\{{ }^{1} \mathrm{H}\right\}$ NMR spectrum (top) and ${ }^{1} \mathrm{H}$ NMR spectrum (top inset, ${ }^{1} J_{\mathrm{CH}}=120$ $\mathrm{Hz}$ ) of ${ }^{13} \mathrm{C}_{2} \mathrm{H}_{6}$ in $\mathrm{CD}_{3} \mathrm{NO}_{2}$ resulting from the formation of styrene by complex $3.2 \mathrm{~d}$ and benzene under ${ }^{13} \mathrm{C}_{2} \mathrm{H}_{4}$ pressure. ${ }^{13} \mathrm{C}\left\{{ }^{1} \mathrm{H}\right\}$ NMR spectrum (bottom) of analytically pure sample of $\mathrm{C}_{2} \mathrm{H}_{6}$ in a $\mathrm{CD}_{3} \mathrm{NO}_{2}$ /benzene solution............................................ 155

Figure 3.13. Hammett plot for styrene formation from $\left[\left({ }^{x} b p y\right) \mathrm{Pt}\left(\mathrm{CH}_{2} \mathrm{CH}_{2} \mathrm{Ph}\right)\left(\eta^{2}-\mathrm{C}_{2} \mathrm{H}_{4}\right)\right]^{+}$ at $45^{\circ} \mathrm{C}$ with $0.3 \mathrm{MPa}$ of ethylene $\left(\mathrm{R}^{2}=0.83\right)$ 158

Figure 3.14. Plot of pseudo first-order rate constants $\left(k_{\mathrm{obs}}\right)$ for styrene formation from $\left[\left({ }^{\mathrm{x}} \text { bpy }\right) \mathrm{Pt}\left(\mathrm{CH}_{2} \mathrm{CH}_{2} \mathrm{Ph}\right)\left(\eta^{2}-\mathrm{C}_{2} \mathrm{H}_{4}\right)\right]^{+}$at $45^{\circ} \mathrm{C}$ with $0.3 \mathrm{MPa}$ of ethylene versus Hammett $\sigma_{\mathrm{p}}$ parameter of the 4,4'-bipyridyl functionality. 159

Figure 3.15. ORTEP of $\left[{ }^{\mathrm{NO} 2}\right.$ bpy) $\left.\mathrm{Pt}\left(\eta^{2}-\mathrm{C}_{2} \mathrm{H}_{4}\right)(\mathrm{Me})\right]\left[\mathrm{BAr}_{4}^{\prime}\right]$ (3.5f) (50\% probability; $\mathrm{H}$ atoms and $\mathrm{BAr}_{4}$ anion omitted for clarity). Selected bond lengths $(\AA)$ : Pt-N1 2.113(7), Pt-N2 2.063(6), Pt-C1 2.021(9), Pt-C2 2.073(13), Pt-C3 2.113(12), C2-C3 1.349(16). Selected bond angles ( $\left.{ }^{\circ}\right)$ : N1-Pt-N2 77.5(2), N1-Pt-C1 173.1(3). 160

Figure 3.16. Comparison of TO versus time for ethylene hydrophenylation $\left(100{ }^{\circ} \mathrm{C}\right)$ catalyzed by $[(\mathrm{N} \sim \mathrm{N}) \mathrm{Pt}(\mathrm{Ph})(\mathrm{THF})]^{+}(\mathrm{N} \sim \mathrm{N})=$ tbpy $(\boldsymbol{\bullet})$; dpm $(\bullet) .0 .01 \mathrm{~mol} \% \mathrm{Pt}$ in $\mathrm{C}_{6} \mathrm{H}_{6}$ with $0.1 \mathrm{MPa}_{2} \mathrm{H}_{4}$ and $\mathrm{HMB}$ as an internal standard. 165

Figure 3.17. Comparison of TO versus time ( $\leq 4$ hours) for ethylene hydrophenylation $\left(100{ }^{\circ} \mathrm{C}\right)$ catalyzed by $[(\mathrm{N} \sim \mathrm{N}) \mathrm{Pt}(\mathrm{Ph})(\mathrm{THF})]^{+}\left(\mathrm{N} \sim \mathrm{N}={ }^{t}\right.$ bpy $(\boldsymbol{\bullet}), \mathrm{R}^{2}=0.98 ; \mathrm{dpm}(\bullet)$, $\left.\mathrm{R}^{2}=0.99\right) .0 .01 \mathrm{~mol} \% \mathrm{Pt}$ in $\mathrm{C}_{6} \mathrm{H}_{6}$ with $0.1 \mathrm{MPa}_{2} \mathrm{H}_{4}$ and $\mathrm{HMB}$ as an internal standard. 166

Figure 3.18. Plot of $1 /(\mathrm{TOF})$ as a function of time for ethylene hydrophenylation $\left(100{ }^{\circ} \mathrm{C}\right)$ catalyzed by $[(\mathrm{N} \sim \mathrm{N}) \mathrm{Pt}(\mathrm{Ph})(\mathrm{THF})]^{+}\left(\mathrm{N} \sim \mathrm{N}={ }^{\mathrm{t}}\right.$ bpy $\left.(\boldsymbol{\bullet}), \mathrm{R}^{2}=0.98 ; \operatorname{dpm}(\bullet), \mathrm{R}^{2}=0.98\right)$ indicates a pathway for decomposition that is second-order in Pt. 166

Figure 3.19. Representative kinetic plot for the conversion of 3.7 to $3.8([3.7]=0.03 \mathrm{M}$, $\left.\left[\mathrm{C}_{2} \mathrm{H}_{4}\right]=0.4 \mathrm{M}, 23^{\circ} \mathrm{C}\right)$. 168

Figure 3.20. Representative kinetic plot for the conversion of 3.7 to 3.7- $d_{5}([3.7]=0.03$ $\left.\mathrm{M},\left[\mathrm{C}_{6} \mathrm{H}_{6}\right]=0.5 \mathrm{M}, 29^{\circ} \mathrm{C}\right)$. 169

Figure 3.21. Eyring plots for ethylene hydrophenylation catalyzed by $[(\mathrm{N} \sim \mathrm{N}) \mathrm{Pt}(\mathrm{Ph})(\mathrm{THF})]^{+}\left(\mathrm{N} \sim \mathrm{N}={ }^{t}\right.$ bpy $\left.(\bullet), \mathrm{R}^{2}=0.98 ; \operatorname{dpm}(\bullet), \mathrm{R}^{2}=0.98\right) \ldots \ldots \ldots \ldots \ldots \ldots . .171$

Figure 3.22. Eyring plots for $\mathrm{C}_{6} \mathrm{D}_{6} \mathrm{C}-\mathrm{D}$ activation by $[(\mathrm{N} \sim \mathrm{N}) \mathrm{Pt}(\mathrm{Ph})(\mathrm{THF})]^{+}$. $\mathrm{N} \sim \mathrm{N}={ }^{\mathrm{t}}$ bpy $(\boldsymbol{\bullet}), \mathrm{R}^{2}=0.98 ; \mathrm{dpm}(\bullet), \mathrm{R}^{2}=0.99$. Due to their small value, the deviations are obscured by the size of the data point markers. 173 
Figure 3.23. ORTEP of $\left[(\mathrm{dpm}) \mathrm{Pt}\left(\mathrm{CH}_{2} \mathrm{CH}_{2} \mathrm{Ph}\right)\left(\eta^{2}-\mathrm{C}_{2} \mathrm{H}_{4}\right)\right]\left[\mathrm{BAr}_{4}^{\prime}\right]$ (3.8) (50\% probability; $\mathrm{H}$ atoms and $\mathrm{BAr}_{4}{ }_{4}$ anion omitted for clarity) Selected bond lengths $(\AA)$ : Pt-N1 2.135(7), Pt-N2 2.068(6), Pt-C3 2.049(8), Pt-C1 2.113(9), Pt-C2 2.113(9), C1-C2 1.37(2). Selected bond angles $\left({ }^{\circ}\right)$ : N1-Pt-N2 85.3(3), Pt-C3-C4 118.9(8), C3-C4-C5 $125.0(1)$. 174

Figure 3.24. ORTEP of complexes (dpm) $\mathrm{Pt}(\mathrm{Ph})_{2}$ (3.6), $\left(\mathrm{Me}_{2}-\mathrm{dpm}\right) \mathrm{Pt}(\mathrm{Ph})_{2}$ (3.10) and (dpe) $\mathrm{Pt}(\mathrm{Ph})_{2}$ (3.12) (50\% probability; $\mathrm{H}$ atoms omitted for clarity)........................ 178

Figure 3.25. ORTEP of $[(\mathrm{dpe}) \mathrm{Pt}(\mathrm{Ph})(\mathrm{THF})]\left[\mathrm{BAr}_{4}\right]$ (3.16) $\left(50 \%\right.$ probability; $\mathrm{BAr}_{4}{ }_{4}$ anion and $\mathrm{H}$ atoms omitted for clarity). Selected bond lengths $(\AA)$ : Pt-N1 2.141(4), Pt-N2 1.980(4), Pt-O1 2.048(4), Pt-C13 2.001(5). Selected bond angles ( $\left.{ }^{\circ}\right)$ : N1-Pt-N2 87.9(2), O1-Pt-C13 93.2(2). 180

Figure 3.26. Plot of TO versus time for ethylene hydrophenylation $\left(100{ }^{\circ} \mathrm{C}\right)$ catalyzed by complexes 3.7, 3.13 and 3.14 using $0.01 \mathrm{~mol} \%$ catalyst dissolved in $\mathrm{C}_{6} \mathrm{H}_{6}$ with 0.1 $\mathrm{MPa} \mathrm{C}_{2} \mathrm{H}_{4}$ and hexamethylbenzene as an internal standard. Inset highlights $\mathrm{TO}$ as function of time for the first 4 hours of catalysis. 182

Figure 4.1. Observation of $\mathrm{Pt}^{\mathrm{II}}$ mediated ortho-C- $\mathrm{H} / \mathrm{D}$ activation of $\mathrm{C}_{6} \mathrm{H}_{5} \mathrm{Br}$ or $\mathrm{C}_{6} \mathrm{D}_{5} \mathrm{Br}$ by

${ }^{1} \mathrm{H}$ NMR spectroscopy. 221

Figure 4.2. Observation of $\mathrm{Pt}^{\mathrm{II}}$ catalyzed isomerization of allylbenzene to 1-phenyl-1propylene (denoted by *) using complex 4.1b. (A) ${ }^{1} \mathrm{H}$ NMR spectrum of [('bpy) $\mathrm{Pt}(\mathrm{Ph})(\mathrm{THF})]\left[\mathrm{BAr}_{4}\right]$ (4.1b). (B) 15 minutes after addition of allylbenzene. (C) 1 hour after addition. (D) ${ }^{1} \mathrm{H}$ NMR spectrum of an allylbenzene standard. ............. 230

Figure 4.3. Hammett plot for the ratios of cumene to $n$-propylbenzene from $\left[\left({ }^{\mathrm{x}} \mathrm{bpy}\right) \mathrm{Pt}(\mathrm{Ph})(\mathrm{THF})\right]^{+}$catalyzed propylene hydrophenylation after 4 hours at $100{ }^{\circ} \mathrm{C}$ with $0.1 \mathrm{MPa}$ of ethylene ( 234

Figure 4.4. Hammett plot for the ratios of para-substituted isomers of benzene from $\left[\left({ }^{\mathrm{t}} \mathrm{bpy}\right) \mathrm{Pt}(\mathrm{Ph})(\mathrm{THF})\right]^{+}$catalyzed propylene hydroarylation after 4 hours at $100{ }^{\circ} \mathrm{C}$ with $0.1 \mathrm{MPa}$ of propylene versus Hammett parameter $\left(\sigma_{\mathrm{p}}\right)$ for the benzene substituent. 236 Figure 4.5. ORTEP of (DIQ) $\mathrm{Pt}(\mathrm{Ph})_{2}$ (4.17) (50\% probability; $\mathrm{H}$ atoms omitted for clarity). Selected bond lengths (̊): $\mathrm{Pt}-\mathrm{P} 1$ 2.2739(7), Pt-N1 2.152(2), Pt-C1 2.011(3), Pt-C7 2.051(3). Selected bond angles $\left(^{\circ}\right)$ : P1-Pt-N1 83.01(7), C1-Pt-C7 89.1(1). 250

Figure 4.6. ORTEP of (dats) $\mathrm{Pt}(\mathrm{Ph})_{2}$ (4.19) (50\% probability; H atoms omitted for clarity). Selected bond lengths ( $\mathrm{A})$ : Pt-P1 2.2787(8), Pt-P2 2.2666(8), Pt-C36 2.052(3), $\mathrm{Pt}-\mathrm{C} 42$ 2.057(3). Selected bond angles $\left(^{\circ}\right)$ : $\mathrm{P} 1-\mathrm{Pt}-\mathrm{P} 2$ 93.43(3), P2-Pt-C36 170.88(9), C36-Pt-C42 83.7(1)..... 251

Figure 4.7. ORTEP of (bma) $\mathrm{Pt}(\mathrm{Ph})_{2}$ (4.20) (50\% probability; $\mathrm{H}$ atoms omitted for clarity). Selected bond lengths $(\AA)$ : $\mathrm{Pt}-\mathrm{P} 4$ 2.301(1), Pt-P2 2.288(1), Pt-C100 2.047(5), Pt-C2 2.076(4). Selected bond angles $\left(^{\circ}\right)$ : P4-Pt-P5 94.39(4), P5-Pt-C100 174.1(2), C100-Pt-C2 85.8(2). 252 


\section{LIST OF SCHEMES}

Scheme 1.1. Mechanisms for Friedel-Crafts alkylation of benzene using olefins (A) or alkyl halides (B). LA = Lewis acid; $\mathrm{R}=$ alkyl; $\mathrm{X}=$ halogen. .................................. 7

Scheme 1.2. Traditional industrial process for ethylene hydrophenylation to produce ethylbenzene catalyzed by a Friedel-Crafts catalyst.

Scheme 1.3. "Ideal" synthetic chemistry via direct and selective functionalization of hydrocarbyl $\mathrm{C}-\mathrm{H}$ bonds.

Scheme 1.4. First reported examples of $\mathrm{C}-\mathrm{H}$ activation involving oxidative addition of phosphinomethyl $\mathrm{sp}^{3} \mathrm{C}-\mathrm{H}$ bonds or $\mathrm{sp}^{2} \mathrm{C}-\mathrm{H}$ bonds of naphthalene. 16

Scheme 1.5. Catalytic cycle for Shilov's partial oxidation of alkanes using a $\mathrm{Pt}^{\mathrm{II}}$ catalyst. Reproduced from reference 66; complete stoichiometry of the reaction was not provided.

Scheme 1.6. Formation of bicyclooctadiene and cyclopentadienyl from [2.2.2] bicyclooctene and cyclopentane via activation of $\mathrm{C}_{\mathrm{sp} 3}-\mathrm{H}$ bonds by an $\operatorname{Ir}^{\text {III }}$ catalyst precursor.

Scheme 1.7. Generally invoked mechanisms for transition metal-mediated $\mathrm{C}-\mathrm{H}$ bond activation.

Scheme 1.8. $\sigma$-Alkane/Arene complexes are implicated as intermediates preceding $\mathrm{C}-\mathrm{H}$ bond cleavage. Proposed geometries of alkane and arene binding modes. ............... 21

Scheme 1.9. General mechanism for olefin hydroarylation combining metal mediated olefin insertion into $\mathrm{M}$-aryl bonds and aromatic $\mathrm{C}-\mathrm{H}$ activation. ............................ 24

Scheme 1.10. Early example of chelate-assisted ethylene hydroarylation using a cyclometalated $\mathrm{Ru}^{\mathrm{II}}$ catalyst precursor................................................................ 25

Scheme 1.11. Chelate-assisted hydroarylation of aromatic ketones catalyzed by $\mathrm{Ru}(\mathrm{H})_{2}(\mathrm{CO})\left(\mathrm{PPh}_{3}\right)_{3}$ and proposed mechanism using acetophenone for illustrative purposes $\left(\mathrm{R}=\mathrm{H},{ }^{\mathrm{t}} \mathrm{Bu}, \mathrm{Si}(\mathrm{OEt})_{3}, \mathrm{CH}_{2} \mathrm{SiMe}_{3}\right.$ or aryl $)$.

Scheme 1.12. Proposed mechanism for chelate-assisted olefin hydroarylation of aromatic ketones using $\left(\eta^{5}-\mathrm{C}_{5} \mathrm{Me}_{5}\right) \mathrm{Rh}\left(\eta^{2}-\mathrm{C}_{2} \mathrm{H}_{3} \mathrm{SiMe}_{3}\right)_{2}$.

Scheme 1.13. Ru-Ag catalyst system for catalytic intramolecular olefin hydroarylation. 28

Scheme 1.14. Hydrophenylation of ethylene using $\left[\operatorname{Ir}\left(\mu\right.\right.$-acac- $\left.O, O, C_{3}\right)-(\operatorname{acac}-O, O)-($ acac$\left.\left.C_{3}\right)\right]_{2}$

Scheme 1.15. Proposed mechanism for ethylene hydrophenylation catalyzed by $c i s--\left(\kappa^{2}-\right.$ $O, O$-acac $)_{2} \operatorname{Ir}\left(\eta^{2}-\mathrm{C}_{2} \mathrm{H}_{4}\right)(\mathrm{Ph})$. 31

Scheme 1.16. Hydrophenylation of ethylene using $0.1 \mathrm{~mol} \% \mathrm{TpRu}(\mathrm{CO})(\mathrm{NCMe})(\mathrm{Ph})$ (TpRu-CO).

Scheme 1.17. Proposed catalytic cycle for the hydrophenylation of ethylene using $\mathrm{TpRu}(\mathrm{L})(\mathrm{NCMe}) \mathrm{Ph}\left[\mathrm{L}=\mathrm{CO}, \mathrm{P}\left(\mathrm{OCH}_{2}\right)_{3} \mathrm{CEt}\right.$, or SPhos (SPhos $=2,6,7$-Trioxa-1phosphabicyclo[2,2,1]heptane)].

Scheme 1.18. Comparison of calculated enthalpies $(\mathrm{kcal} / \mathrm{mol})$ of activation for ethylene insertion and benzene $\mathrm{C}-\mathrm{H}$ activation during ethylene hydrophenylation catalyzed by cis- $(O, O \text {-acac })_{2} \operatorname{Ir}$ and $\mathrm{TpRu}(\mathrm{CO})$. 
Scheme 1.19. $\mathrm{Pt}^{\mathrm{II}}$ diimine oxidative addition of a $\mathrm{C}-\mathrm{H}$ bond of benzene via intermediacy of a $\eta^{2}-C, C$-benzene adduct $(\mathrm{OA}=$ Oxidative Addition and $\mathrm{RE}=$ Reductive Elimination). 43

Scheme 1.20. Facile reductive elimination from in situ generated 5-coordinate $\mathrm{Pt}^{\mathrm{IV}}$ complexes to produce $\mathrm{Pt}^{\mathrm{II}}-\left(\eta^{2}\right.$-benzene) adducts enabled the determination of the activation barriers to benzene $\mathrm{C}-\mathrm{H}$ oxidative addition.

Scheme 1.21. Two calculated mechanistic pathways for degenerate proton transfer between two phenyl groups mediated by $\mathrm{Pt}^{\mathrm{II}}$. Calculated activation energies are given in $\mathrm{kcal} / \mathrm{mol}$. 46

Scheme 1.22. Product distribution upon reaction of $\left[(\mathrm{PNP}) \mathrm{Pt}\left(\eta^{2} \text {-olefin }\right)\right]^{2+}$ with $1,3-$ dimethoxybenzene and either ethylene or propylene. Reaction yields and product distribution were determined by ${ }^{1} \mathrm{H}$ NMR spectroscopy. Reaction mechanism involves an electrophilic aromatic substitution (EAS) and protonolysis steps to

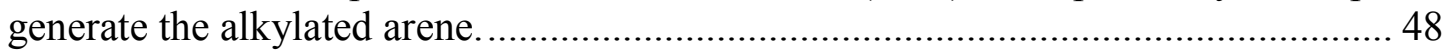

Scheme 1.23. Pt-Ag co-catalyst system for norbornene hydrophenylation to produce exophenylnorbornane. Product yields were determined by GC using naphthalene as an integration standard.

Scheme 1.24. Dependence on the yield of 1-cyclohexyl-2,4,6-trimethylbenzene from the reaction of mesitylene and cyclohexene from catalysis with $\mathrm{Pt} 7$ in the presence of a proton scavenger, 2,6-di-tert-butyl-4-methylpyridine. 50

Scheme 1.25. Triflic acid formation from the homocoupling of cyclohexene catalyzed by Pt7. 50

Scheme 1.26. Proposed mechanism for olefin hydroarylation catalyzed by neutral $\mathrm{Pt}^{\mathrm{II}}$ catalyst precursor Pt10. $[\mathrm{Pt}]=(2-(2-$ pyridyl $)$ pyrolide $) \mathrm{Pt}$........................................ 53

Scheme 2.1 Synthesis of [( $\left.\left.{ }^{t} \mathrm{bpy}\right) \mathrm{Pt}(\mathrm{Ph})(\mathrm{L})\right]^{+}\left[\mathrm{L}=\mathrm{NC}_{5} \mathrm{~F}_{5}\right.$ (2.2) or NCMe (2.3)] from ligand

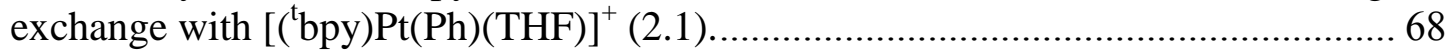

Scheme 2.2. Results of ethylene hydrophenylation using complex 2.1 and ethylene $(0.03$

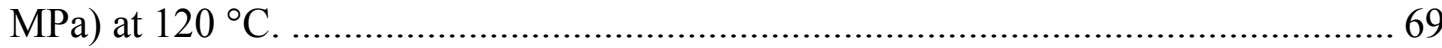

Scheme 2.3. Proposed mechanism for ethylene hydrophenylation catalyzed by $\left[\left({ }^{t} \text { bpy }\right) \mathrm{Pt}(\mathrm{L})(\mathrm{Ph})\right]^{+}\left[\mathrm{L}=\mathrm{THF}(2.1), \mathrm{NC}_{5} \mathrm{~F}_{5}(2.2)\right.$ or $\left.\mathrm{NCMe}(2.3)\right] \ldots \ldots \ldots \ldots \ldots \ldots \ldots \ldots \ldots \ldots . . .74$

Scheme 2.4. Rates of degenerate benzene $\mathrm{C}-\mathrm{H} / \mathrm{D}$ activation by 2.1 and $2.1-d_{5}$ in $\mathrm{CD}_{2} \mathrm{Cl}_{2}$

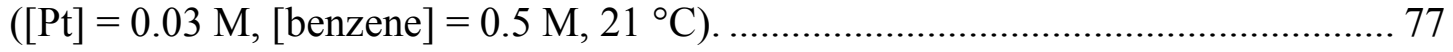

Scheme 2.5. Proposed pathway for degenerate benzene activation by

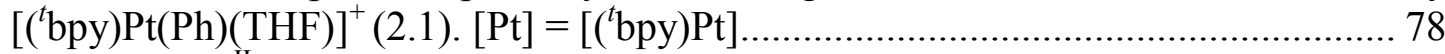

Scheme 2.6. $\mathrm{Pt}^{\mathrm{II}}$-mediated $\mathrm{C}-\mathrm{H}$ activation via electrophilic substitution, oxidative addition or $\sigma$-bond metathesis. 79

Scheme 2.7. Calculated reaction coordinate $(\Delta \mathrm{G}$ in $\mathrm{THF}, \mathrm{kcal} / \mathrm{mol})$ comparing a two-step (oxidative addition/reductive elimination) pathway via a $\mathrm{Pt}^{\mathrm{IV}}$-hydride with a one-step ( $\sigma$-bond metathesis, in red) pathway for benzene $\mathrm{C}-\mathrm{H}$ activation from

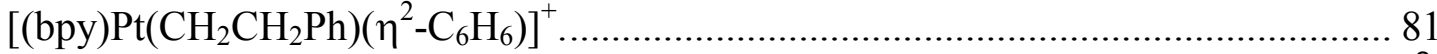

Scheme 2.8. Conversion of complex 2.1 and ethylene to [( $\left.{ }^{\mathrm{b}} \mathrm{by}\right) \mathrm{Pt}\left(\mathrm{CH}_{2} \mathrm{CH}_{2} \mathrm{Ph}\right)\left(\eta^{2}\right.$ $\left.\left.\mathrm{C}_{2} \mathrm{H}_{4}\right)\right]^{+}(2.4)$. 82

Scheme 2.9. Two possible mechanisms for the formation of 2.4 from 2.1 and ethylene. The kinetic data are consistent with the associative pathway. $\left.[\mathrm{Pt}]=\left[{ }^{t} \mathrm{bpy}\right) \mathrm{Pt}\right] . \ldots \ldots . . .85$ 
Scheme 2.10. Calculated energetics $(\Delta \mathrm{G}$ in THF, $\mathrm{kcal} / \mathrm{mol})$ for two possible mechanisms for ethylene insertion into $\mathrm{Pt}-\mathrm{Ph}$ bond starting from [(bpy) $\mathrm{Pt}(\mathrm{Ph})(\mathrm{THF})]\left[\mathrm{BAr}_{4}{ }_{4}\right]\left(2.1^{\prime}\right)$. 87

Scheme 2.11. Comparison of calculated Gibbs free energies (kcal/mol, in THF) for proposed intermediates and transition states in catalytic ethylene hydrophenylation by $[(\mathrm{bpy}) \mathrm{Pt}(\mathrm{Ph})(\mathrm{THF})]^{+}$. 88

Scheme 2.12. DFT calculated structures for $\left[(\mathrm{bpy}) \mathrm{Pt}\left(\eta^{2}-C, C-\mathrm{C}_{6} \mathrm{H}_{5} \mathrm{Et}\right)(\mathrm{Ph})\right]^{+}\left(2.9^{\prime}\right)$ and $\left[(\text { bpy }) \operatorname{Pt}\left(\eta^{2}-C, H-\mathrm{C}_{6} \mathrm{H}_{5} \mathrm{Et}\right)(\mathrm{Ph})\right]^{+}\left(2.9^{\prime}\right.$ ag $)$ with the relative energy difference between them $(\mathrm{kcal} / \mathrm{mol})$. 91

Scheme 2.13. Calculated difference in $\Delta G(\mathrm{kcal} / \mathrm{mol})$ for the formation of the proposed catalyst resting state $2.4^{\prime}$ upon coordination of ethylene to $2.8^{\prime} \pi \ldots \ldots \ldots \ldots \ldots \ldots \ldots \ldots \ldots \ldots . . . . .92$

Scheme 2.14. The formation of ethylbenzene with an all protio $-\mathrm{CH}_{2} \mathrm{CH}_{3}$ group during the thermolysis of 2.4 in $\mathrm{C}_{6} \mathrm{D}_{6}$ contrasts with our proposed mechanism and suggests that orthometallation of the phenethyl group competes with direct C-D activation. . 94

Scheme 2.15. Complex 2.4 undergoes rapid ethylene exchange at room temperature to $90{ }^{\circ} \mathrm{C}$. 98

Scheme 2.16. Calculated Gibbs free energies $(\mathrm{kcal} / \mathrm{mol})$ for consecutive ethylene insertion from 2.4'..................................................................................... 99

Scheme 2.17. Heating 2.4 in $\mathrm{CD}_{3} \mathrm{NO}_{2}$ produces styrene and a Pt-ethyl complex........ 100

Scheme 2.18. $\Delta G^{\prime} \mathrm{s}(\mathrm{kcal} / \mathrm{mol})$ for styrene production via $\beta$-elimination from $2.8^{\prime}{ }_{\beta} \ldots \ldots . . .101$

Scheme 2.19. Comparison of calculated Gibbs free energies ( $\mathrm{kcal} / \mathrm{mol}$, THF) for ethylene insertion and ethylene $\mathrm{C}-\mathrm{H}$ activation by $\left[(\text { bpy }) \mathrm{Pt}(\mathrm{Ph})\left(\eta^{2}-\mathrm{C}_{2} \mathrm{H}_{4}\right)\right]^{+}\left(2.7^{\prime}\right) \ldots \ldots \ldots \ldots \ldots . .102$

Scheme 2.20. Comparison of the calculated $\Delta G^{\ddagger}(\mathrm{kcal} / \mathrm{mol})$ for olefin insertion versus olefin $\mathrm{C}-\mathrm{H}$ activation between several reported olefin hydroarylation catalysts, with the $\Delta \Delta G^{\ddagger}$ between the two transformations highlighted............................................ 103

Scheme 2.21. Proposed pathway by which diethylbenzenes are formed during catalytic ethylene hydrophenylation catalyzed by $\left.\left[{ }^{t} \mathrm{bpy}\right) \mathrm{Pt}(\mathrm{Ph})\right]^{+}\left(\mathrm{Ar}=\mathrm{C}_{6} \mathrm{H}_{4} \mathrm{Et}\right.$; note: three isomers of the $\mathrm{C}_{6} \mathrm{H}_{4} \mathrm{Et}$ ligand of $\mathrm{B}$ are possible). 105

Scheme 2.22. Expected isotopologues of ethylbenzene- $d_{\mathrm{n}}(\mathrm{n}=0,1,5,6)$ that are produced from ethylene insertion into a Pt-Ph or Pt-Ph- $d_{5}$ and subsequent $\mathrm{C}-\mathrm{H} / \mathrm{D}$ activation of

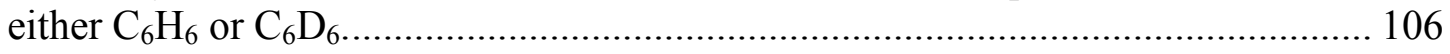

Scheme 2.23. Quantitative production of ethylbenzene (as determined by GC/MS) during the thermolysis of complex 2.4 in benzene............................................................ 108

Scheme 2.24. Proposed mechanism for $\mathrm{H} / \mathrm{D}$ scrambling occurs during the thermolysis of

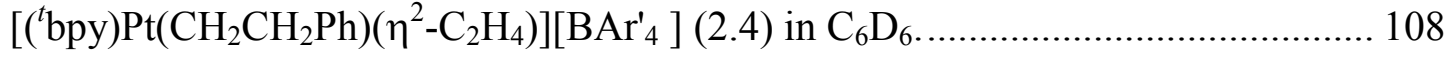

Scheme 2.25. Distribuition of regioisomers of diethylbenzene formed during ethylene hydroarylation using ethylbenzene and complex 2.1 . 114

Scheme 2.26. Pathway for diethylbenzene formation from $\mathrm{C}_{6} \mathrm{H}_{6}$ and $\mathrm{C}_{2} \mathrm{H}_{4}$ requires $\mathrm{Pt}$ to

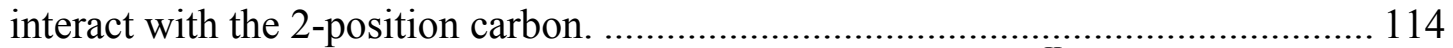

Scheme 3.1. Proposed catalytic cycle for cationic $\mathrm{Pt}^{\mathrm{II}}$ catalyzed ethylene

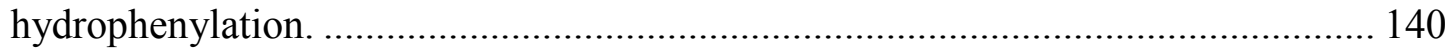

Scheme 3.2. The selectivity of alkyl arenes versus vinyl arenes (ethylbenzene versus styrene in this scheme) during catalytic ethylene hydrophenylation is likely controlled 
by the relative kinetics of divergent pathways (A and B) that follow olefin insertion. 141

Scheme 3.3. Synthesis of $\left[\left({ }^{\mathrm{x}} \mathrm{bpy}\right) \mathrm{Pt}(\mathrm{Ph})(\mathrm{THF})\right]\left[\mathrm{BAr}_{4}\right]$. 142

Scheme 3.4. Comparison of observed rates of ethylene insertion at $-15{ }^{\circ} \mathrm{C}$ for complexes $3.2 \mathrm{~b}$ and $3.2 \mathrm{f}$. 146

Scheme 3.5. Comparison of observed rates of C-D activation using complexes 3.2b-3.2e. 146

Scheme 3.6. Ethylene hydrophenylation using complex $3.2 \mathrm{f}$ is selective for styrene formation under $0.3 \mathrm{MPa}$ of ethylene. ............................................................. 152

Scheme 3.7. Without the presence of ethylene, the Thermolysis of complex $3.3 \mathrm{f}$ in benzene results in quantitative ethylbenzene production........................................ 156

Scheme 3.8. Styrene formation occurs during the thermolysis $\left(45{ }^{\circ} \mathrm{C}\right)$ of [('bpy) $\left.\mathrm{Pt}\left(\mathrm{CH}_{2} \mathrm{CH}_{2} \mathrm{Ph}\right)\left(\eta^{2}-\mathrm{C}_{2} \mathrm{H}_{4}\right)\right]\left[\mathrm{BAr}_{4}\right]$ in the absence of benzene under $0.3 \mathrm{MPa}$ of ethylene. Observed rate constants were determined by ${ }^{1} \mathrm{H}$ NMR spectroscopy using hexamethyldisilane as an internal standard............................................................ 158

Scheme 3.9. Styrene displacement by ethylene $(0.3 \mathrm{MPa})$ from $\left[\left({ }^{\mathrm{x}} \mathrm{bpy}\right) \mathrm{Pt}(\mathrm{Me})\left(\eta^{2}-\right.\right.$ sytrene)][BAr' $]$ [ $\left[\mathrm{X}={ }^{\mathrm{t}} \mathrm{Bu}(3.4 \mathrm{~b})\right.$ or $\left.\mathrm{NO}_{2}(3.4 \mathrm{f})\right]$ at $-120{ }^{\circ} \mathrm{C}$ to generate $\left[\left({ }^{\mathrm{x}} \mathrm{bpy}\right) \mathrm{Pt}(\mathrm{Me})\left(\eta^{2}-\mathrm{C}_{2} \mathrm{H}_{4}\right)\right]\left[\mathrm{BAr}{ }_{4}\right]\left[\mathrm{X}={ }^{\mathrm{t}} \mathrm{Bu}(3.4 \mathrm{~b})\right.$ or $\left.\mathrm{NO}_{2}(3.5 \mathrm{f})\right]$. 160

Scheme 3.10. Proposed mechanism for styrene formation during $\mathrm{Pt}^{\mathrm{II}}$ catalyzed ethylene hydrophenylation. 161

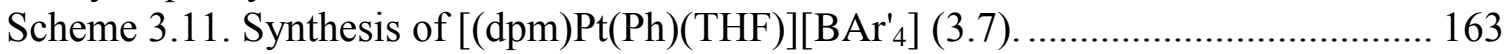

Scheme 3.12. Ethylene insertion into the $\mathrm{Pt}-\mathrm{Ph}$ bond of complex 3.7 to form $\left[(\mathrm{dpm}) \mathrm{Pt}\left(\mathrm{CH}_{2} \mathrm{CH}_{2} \mathrm{Ph}\right)\left(\eta^{2}-\mathrm{C}_{2} \mathrm{H}_{4}\right)\right]\left[\mathrm{BAr}_{4}\right]$ (3.8). 167

Scheme 3.13. Observation of stoichiometric benzene $\mathrm{C}-\mathrm{D}$ activation by complex 3.7 to form 3.7- $d_{5}$ in $\mathrm{CD}_{2} \mathrm{Cl}_{2}$ at $29^{\circ} \mathrm{C}$. 168

Scheme 3.14. Calculated equilibria $\left(100{ }^{\circ} \mathrm{C}\right)$ between conformations of catalyst resting states containing or lacking $\pi-\pi$ arene interaction. .............................................. 175

Scheme 3.15. Synthesis and isolated yields for complexes 3.9-3.12........................... 178

Scheme 3.16. Synthesis and isolated yields of $[(\mathrm{N} \sim \mathrm{N}) \mathrm{Pt}(\mathrm{Ph})(\mathrm{THF})]\left[\mathrm{BAr}_{4}\right]$ (3.13-3.16). 180

Scheme 3.17. The reaction of complex 3.15 and ethylene $(0.3 \mathrm{MPa})$ in $\mathrm{CD}_{2} \mathrm{Cl}_{2}$ at room temperature readily produces styrene quantitatively. 184

Scheme 3.18. Expansion to a six-membered chelate for $\mathrm{Pt}^{\mathrm{II}}$ catalyzed ethylene hydrophenylation decreases the extent of ortho-diethylbenzene formation, relative to the bipyridyl catalyst variants, which form 5-membered chelate rings. 185

Scheme 3.19. Synthesis and isolated yields of $[(\mathrm{N} \sim \mathrm{N}) \mathrm{Pt}(\mathrm{Ph})(\mathrm{THF})]\left[\mathrm{BAr}_{4}\right]$ (3.17-3.19). 188

Scheme 4.1. Comparison of ethylene hydroarylation using chlorobenzene catalyzed by $\left[\left({ }^{\prime} \mathrm{bpy}\right) \mathrm{Pt}(\mathrm{Ph})(\mathrm{THF})\right]\left[\mathrm{BAr}_{4}\right]$ (4.1b) and [(dpm) $\left.\mathrm{Pt}(\mathrm{Ph})(\mathrm{THF})\right]\left[\mathrm{BAr}_{4}\right](4.2 \mathrm{a}) \ldots \ldots \ldots \ldots . .220$

Scheme 4.2. Transition metal mediated olefin hydroarylation offers an opportunity to control the selectivity of alkyl arene products. Product selectivity could be dictated by the regioselectivity of $\alpha$-olefin insertion into the $\mathrm{Pt}-\mathrm{Ph}$ bond................................. 225

Scheme 4.3. Comparison of catalytic hydrophenylation of 1-pentene (150 equivalents relative to $\mathrm{Pt}$ ) using complexes $4.1 \mathrm{~b}$ and $4.2 \mathrm{a}$ and hexamethylbenzene as an internal standard. 228 
Scheme 4.4. Comparison of catalytic hydrophenylation of cyclohexene (150 equivalents relative to $\mathrm{Pt}$ ) using complexes $4.1 \mathrm{~b}$ and $4.2 \mathrm{a}$ and hexamethylbenzene as an internal standard. 228

Scheme 4.5. Pathways leading to linear and branched alkyl benzene products during bipyridyl $\mathrm{Pt}^{\mathrm{II}}$ catalyzed propylene hydropyhenylation.

Scheme 4.6. Comparison of branched to linear ratios of propylene $(0.1 \mathrm{MPa})$ hydroarylation using substituted xylenes......................................................... 235

Scheme 4.7. Comparison of branched to linear ratios of propylene $(0.1 \mathrm{MPa})$

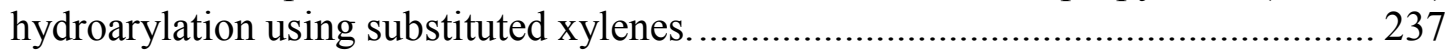

Scheme 4.8. Ratio of 2-isopropylfuran and 2- $n$-propylfuran from propylene $(0.1 \mathrm{MPa})$ hydroarylation with furan and $\left[\left({ }^{\mathrm{t}} \mathrm{bpy}\right) \mathrm{Pt}(\mathrm{Ph})(\mathrm{THF})\right]^{+}$at $100{ }^{\circ} \mathrm{C}$ after 4 hours, as determined from peak area ratios from analysis by $\mathrm{GC} / \mathrm{MS}$................................. 237

Scheme 4.9. Synthesis of cationic $\mathrm{Pt}^{\mathrm{II}}$ catalyst complexes with bis-chelating nitrogen

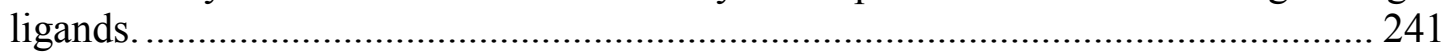

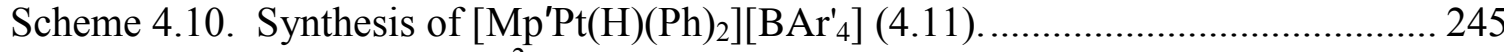

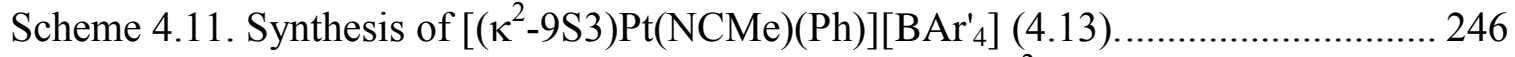

Scheme 4.12. Propylene hydrophenylation catalyzed by $\left[\left(\kappa^{2}-9 \mathrm{~S} 3\right) \mathrm{Pt}(\mathrm{NCMe})(\mathrm{Ph})\right]\left[\mathrm{BAr}{ }_{4}\right]$ (4.13). 246

Scheme 4.13. Synthesis of cationic $\mathrm{Pt}^{\mathrm{II}}$ catalyst complexes with bis-chelating phosphorus ligands. 247

Scheme 4.14. Previously reported aryl coupling leading to a stable biphenyl-bridged dicationic bis- $\mathrm{Pt}{ }^{\mathrm{II}}$ complex following benzene $\mathrm{C}-\mathrm{H}$ activation. ${ }^{58}$....... 


\section{LIST OF TABLES}

Table 1.1. Distribution of dodecylbenzene isomers obtained from the reaction of 1-

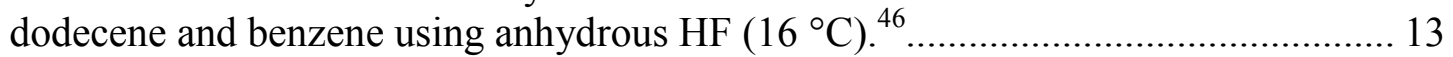

Table 1.2. Production of basic petrochemicals in the United States in 2007................... 15

Table 1.3. Comparison of $\mathrm{TpRu}(\mathrm{L})(\mathrm{NCMe})(\mathrm{Ph})$ steric and electronic properties, in addition to, rates for $\mathrm{C}_{6} \mathrm{D}_{6} \quad \mathrm{C}-\mathrm{D}$ activation and turnovers for ethylene

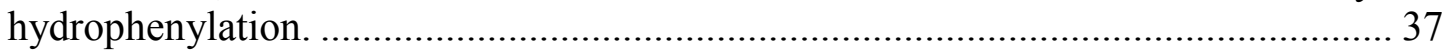

Table 2.1. Catalytic hydrophenylation of ethylene using complexes $2.1-2.3$ as catalysts. ${ }^{a}$

Table 2.2. Impact of temperature and ethylene pressure on catalysis using

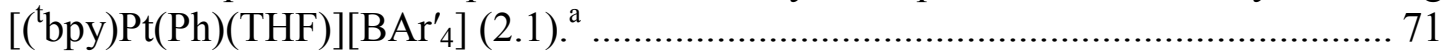

Table 3.1. Catalytic ethylene hydrophenylation using complexes 3.2a-3.2f with $0.1 \mathrm{MPa}$ of ethylene. ${ }^{\text {a }}$ 148

Table 3.2. Catalytic ethylene hydrophenylation using complexes 3.2a-3.2f with $0.3 \mathrm{MPa}$ of ethylene. ${ }^{\mathrm{a}}$ 153

Table 3.3. Ratio of ethylbenzene to styrene as a function of ethylene pressure............. 154

Table 3.4. Catalytic ethylene hydrophenylation using complex 3.7. …………........... 163

Table 3.5. Turnover frequencies for ethylene hydrophenylation $\left(50-100{ }^{\circ} \mathrm{C}\right)$ and

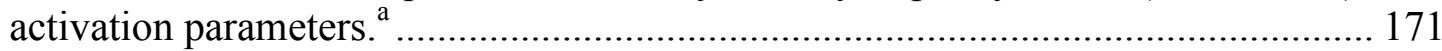

Table 3.6. Activation parameters and $k_{\text {obs }}$ for $\mathrm{C}_{6} \mathrm{D}_{6} \mathrm{C}-\mathrm{D}$ activation $\left(29-59^{\circ} \mathrm{C}\right) .{ }^{\mathrm{a}} \ldots \ldots \ldots . .172$

Table 3.7. Calculated activation parameters $\left(100{ }^{\circ} \mathrm{C}\right)$ for benzene activation by

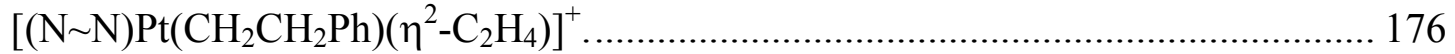

Table 3.8. Comparison of selected bond lengths and angles between complexes $(\mathrm{dpm}) \mathrm{Pt}(\mathrm{Ph})_{2}$ (3.6), $\left(\mathrm{Me}_{2}-\mathrm{dpm}\right) \mathrm{Pt}(\mathrm{Ph})_{2}$ (3.10), (dpe) $\mathrm{Pt}(\mathrm{Ph})_{2}$ (3.12) and ('bpy) $\mathrm{Pt}(\mathrm{Ph})_{2}$. 179

Table 3.9. Comparison of catalytic ethylene hydrophenylation using complexes 3.7 and 3.13-3.16. ${ }^{\mathrm{a}}$ 181

Table 3.10. Comparison of catalytic ethylene hydroarylation with ethylbenzene using complexes 3.7 and 3.13-3.16. ${ }^{\mathrm{a}}$ 186

Table 3.11. Comparison of catalytic ethylene hydrophenylation using complexes 3.17$3.19 .^{\mathrm{a}}$ 189

Table 3.12. Comparison of catalytic ethylene hydroarylation with ethylbenzene using complexes 3.17-3.19. ${ }^{\mathrm{a}}$

Table 4.1. Comparison of ethylene hydroarylation using substituted benzenes catalyzed by [('bpy)Pt(Ph)(THF)][BAr' $\left.{ }_{4}\right](4.1 \mathrm{~b}){ }^{\mathrm{a}}$.

Table 4.2. Ethylene hydroarylation using heteroaromatic substrates catalyzed by complex 4.1b. ${ }^{\mathrm{a}}$ 223

Table 4.3. Ethylene hydroarylation using heteroaromatic substrates catalyzed by complex 4.1f. ${ }^{\mathrm{a}}$ 224

Table 4.4. Hydrophenylation of alkenes with [('bpy)Pt(Ph)(THF)][BAr' $\left.{ }_{4}\right](4.1 \mathrm{~b}){ }^{\mathrm{a}} . \ldots \ldots .227$

Table 4.5. Hydrophenylation of Michael Acceptors using [( $\left.\left.{ }^{\mathrm{t}} \mathrm{bpy}\right) \mathrm{Pt}(\mathrm{Ph})(\mathrm{THF})\right]\left[\mathrm{BAr}_{4}{ }_{4}\right]$ $(4.1 \mathrm{~b}){ }^{\mathrm{a}}$ 
Table 4.6. Comparison of catalytic propylene hydrophenylation using complexes 4.1a-f.a 233

Table 4.7. Comparison of catalytic propylene hydrophenylation using complexes $4.2 \mathrm{a}-$ $4.2 \mathrm{e}^{\mathrm{a}}$

Table 4.8. Comparison of catalytic propylene hydrophenylation using complexes $4.3 \mathrm{a}-$ $4.3 \mathrm{c} .{ }^{\mathrm{a}}$

Table 4.9. Ethylene hydrophenylation catalyzed by $\mathrm{Pt}^{\mathrm{II}}$ precursors $4.4-4.9{ }^{\mathrm{a}}$.................. 242

Table 4.10. Ethylene hydrophenylation from catalyst precursors bearing potential for $\kappa^{3}-$ coordination. ${ }^{\text {a }}$ 244

Table 4.11. Ethylene hydrophenylation catalyzed by phosphine ligated $\mathrm{Pt}^{\mathrm{II}}$ precursors. ${ }^{\mathrm{a}}$ 


\section{Introduction}

\subsection{Overview of Catalysts and Classification}

Thermodynamically viable reactions $(\Delta G<0)$ often proceed so slowly under ambient conditions, due to large activation energies, that their synthetic use is limited. Raising the reaction temperature enhances the rate of the reaction by imbuing the molecules with greater kinetic energy, however, this often leads to the formation of undesired byproducts and can require substantial energy input for large scale reactions. In principle, large activation barriers can be circumvented using a catalyst, which acts to either destabilize the reactants or to stabilize the transition state of a reaction. This lowers activation barriers and leads to increased rates of reaction. Ever since Johann Döbereiner reported the first catalysis in 1823 by reacting hydrogen and oxygen at ambient conditions over platinum powder, ${ }^{1}$ catalysts have been an integral part of organic synthesis from small scale laboratory research and development to industrial production of commodity chemicals. In fact, the majority of all chemical products have at least one catalytic step in their production with at least $85 \%$ of all chemical processes being catalytic. $^{2}$ With increasing public concern over environmental issues, the chemical industry has an increasingly difficult time meeting stringent regulations. ${ }^{3}$ Therefore, the importance of process optimization (e.g., new catalyst development or refinement of the process engineering and reaction conditions) and the recovery of and ability to recycle catalysts will continue to increase.

There are several criteria for evaluating a catalyst. The most common properties by which a catalyst is evaluated are its activity (i.e., turnover frequency) and yield of desired 
product (i.e., \% conversion and selectivity). Maintaining catalytic activity and selectivity over an extended period of time is highly desired (i.e., high total turnover number), which emphasizes the importance of catalyst lifetime or longevity.

Traditionally, catalysts have been subdivided into two categories: homogeneous and heterogeneous. Homogeneous catalysts operate in the same phase as the reactants and offer important advantages over heterogeneous catalysts, which are in a distinct phase from the reaction medium. Heterogeneous catalysts are usually solid materials catalyzing the conversion of either gaseous or liquid substrates. Homogeneous catalysts are generally superior in terms of activity and selectivity. ${ }^{4-6}$ The increased activity enables catalytic processes to be conducted under less intense reaction conditions (e.g., lower temperatures and pressures). Homogeneous catalysts are easily characterized using routine spectroscopic techniques. Furthermore, the catalytic process can often be monitored by these techniques in order to elucidate a mechanistic understanding of the catalytic cycle. With well understood mechanisms, homogeneous catalysts can be modified to increase activity as well as chemo-, regio- and/or enantioselectivity, which is challenging for heterogeneous catalysts. ${ }^{7}$

Despite the inherent advantages of homogeneous catalysts, heterogeneous catalysts are more heavily utilized in industry, especially for refining and the petrochemicals industry but also for environmental and agricultural applications, such as catalytic converters and the Haber-Bosh process. ${ }^{8-9}$ It is estimated that between $75-90 \%$ of chemical processes utilize heterogeneous catalysts. ${ }^{2,}{ }^{10}$ Although catalyst optimization is typically more challenging compared to homogeneous analogues, the major advantages of heterogeneous catalysts over homogenous systems are catalyst stability and recovery 
from the reaction medium. This fact accounts for the largest impediment to the commercialization of homogeneous catalytic processes on a commodity scale. ${ }^{5}$

\subsubsection{Efforts Toward Increasing the Viability of Homogeneous Catalysts for the Production of Commodity Chemicals}

Most industrial implementations of homogeneous catalysis for commodity chemicals, such as the production of adiponitrile by Dupont, ${ }^{11-12}$ acetic acid by Monsanto, ${ }^{13-14}$ and butanal by Ruhr Chemie, ${ }^{15}$ rely on highly active catalysts that can be used in parts-permillion quantities and therefore do not have to be removed from the product stream. The commercialization of the Heck reaction has not been hindered by the costs of the palladium catalyst but the expensive bromo and iodo starting compounds. ${ }^{16}$ In fact, Albemarle has developed a process for the production of Naproxen ${ }^{\mathrm{TM}}$, a popular nonsteroidal anti-inflammatory drug, ${ }^{17}$ that uses the Heck reaction of 2-bromo-6methoxynaphthalene with ethylene. ${ }^{16}, 18$ As the bromide substrate was already an intermediate in the existing synthesis, the overall cost of the process is reduced compared to the previous methodology. ${ }^{18}$ Most homogeneous catalysts possess high sensitivity to thermal stress and decompose at elevated temperatures, and the most common separation method in industry is distillation. For example, the hydroformylation of propylene to yield butanal is performed on a scale of $\sim 5$ million tons per year using a rhodium catalyst with high activity and selectivity for linear isomers. ${ }^{19}$ In this process, the substrate is continuously introduced into the reactor as the highly volatile product is removed by distillation. For the hydroformylation of long-chain alkenes to produce aldehydes used in 
the manufacture of plasticizers and detergents, cobalt catalysts are employed in all industrial processes. Compared to the cobalt analogues, the rhodium catalysts are more active, more selective for the preferred linear aldehyde, and require less intensive reaction conditions. However, at the temperatures required to distill the product from the reaction mixture, the rhodium catalyst decomposes.

One avenue to solve the separation issue is the use of biphasic catalyst systems. ${ }^{5,19-27}$ The more well-known types of biphasic systems include aqueous biphasic systems (ABS), fluorous biphasic systems (FBS), supercritical fluids and ionic liquids. Due to the industrial importance of hydroformylation, many studies of biphasic catalysis are focused on this transformation. An ABS for water-soluble rhodium complexes for the hydroformylation of propene and $n$-butene has been commercialized by Ruhrchemie AG. ${ }^{28}$ An advantage of this process, compared to the classical homogeneous process, is that after separation the aqueous phase is passed through an exchanger to provide the heat source used by the distillation column for the separation of linear and branched aldehyde products. ${ }^{19}$ This methodology is not applicable for longer chain $\alpha$-olefins $\left(>\mathrm{C}_{5}\right.$ olefins $)$ due to increased hydrophobicity of the olefins and their low solubility in the aqueous phase. $^{25}$ Ethylene oligomerization to produce $\alpha$-olefins has also benefitted from a biphasic process. The Shell Higher Olefin Process (SHOP) for ethylene oligomerization to produce $\alpha$-olefins substitutes water for highly polar alkanediols in which the nickel catalyst, but not the hydrophobic $\alpha$-olefins, is soluble. ${ }^{29}$ Unfortunately, rigorous mixing is required to maximize the interaction between catalyst and substrate in ABS, and mechanical stirring is not suitable for conditions involving high pressures ( $>250$ bar). 
Therefore, the applicability of ABS is limited to low pressure operations. ${ }^{19}$ FBS and supercritical fluids (e.g., supercritical carbon dioxide) are attractive alternatives to ABS. In both cases, rapid mixing is not necessary to achieve a monophasic medium under reaction conditions. ${ }^{5}$ However, these systems typically require exotic ancillary ligands to render the catalyst soluble, which are often accompanied by difficult synthesis and inflated costs. $^{21-22}$ The use of ionic liquids for biphasic catalysis has been studied. ${ }^{23,25}$ Longer-chain $\alpha$-olefins have increased miscibility with ionic liquids, compared to ABS, and the exclusion of water from the reaction medium mitigates potential degradation of the ancillary ligands (e.g., by hydrolysis). ${ }^{23,25}$ As with the other alternatives, ligands are required that are designed for ionic liquids. Like $\mathrm{ABS}$, vigorous mixing is required for biphasic catalysis using ionic liquids, which are often viscous, and limits their application to low pressure operations.

Another area of significant interest is to "heterogenize" homogeneous systems by attachment to a solid support. These supports can be soluble or insoluble in the reaction medium. Soluble supports are attractive because the catalyst is evenly distributed throughout the reaction solution, which maximizes catalyst-substrate interactions. These supports can be soluble polymers or dendrimers that result in macromolecular homogeneous catalysts that can be removed by ultra- or nanofiltration techniques that require sophisticated membranes. ${ }^{4-5,15}$ The application of soluble macromolecular homogeneous catalysts has been hindered do to immature membrane technology. Often the membrane is not compatible with the relatively harsh reaction conditions employed in homogeneous catalytic processes, including detrimental interactions with the catalyst itself or materials composing the reactor. ${ }^{4}$ Grafting homogeneous catalysts to insoluble 
supports (e.g., inorganic oxides, mesoporous silica nanoparticles, or polymers) is being investigated as the catalyst can readily be removed from the reaction mixture by conventional filtration, and catalytically active sites are often accessible since the catalyst is confined to "accessible" sites of the solid. Perhaps the foremost challenge to anchoring catalysts to solid materials is catalyst leaching. ${ }^{5}$ Leaching involves the catalyst breaking away from the support and diffusing into the reaction medium, resulting in a continuous decrease in catalytic activity over time as well as introducing difficult to separate contaminants into the product stream. This is a challenging obstacle to overcome since metal ligand bonds are often broken and reformed in catalytic cycles. ${ }^{30-33}$

\subsubsection{Olefin Hydroarylation: Historical and Conventional Synthesis of Alkyl Arenes}

Ethylbenzene, cumene, para-diisopropylbenzene, $\mathrm{C}_{10}-\mathrm{C}_{14}$ linear alkylbenzenes, cymene and para-ethyltoluene are just a few of the important chemical aromatics obtained by acid-catalyzed alkylation reactions. ${ }^{34}$ It is estimated that approximately $40 \%$ of the global benzene production is consumed by industrial processes for ethylbenzene. ${ }^{34}$ Thus, it is the most important alkylated aromatic compound produced, and $\sim 99 \%$ of ethylbenzene is dehydrogenated for styrene production. ${ }^{35}$ Traditional methodologies for ethylbenzene formation in industry are founded on Friedel-Crafts catalysis utilizing strong Lewis acids for the alkylation of aromatic substrates with either olefins, often requiring a Brønsted acid co-catalyst, or alkyl halides. Despite their pivotal role in the chemical industry, processes based on acids such as $\mathrm{AlCl}_{3}$, $\mathrm{HF}$ or $\mathrm{H}_{2} \mathrm{SO}_{4}$ suffer several deficiencies. 
The mechanism of acid-catalyzed processes involves the generation of carbocation intermediates along the reaction coordinate, and selectivity is difficult to control (Scheme 1.1). These reactions are highly prone to carbocation rearrangement and are generally $100 \%$ selective for the formation of Markovnikov addition products. ${ }^{36}$ Therefore, the selective formation of straight-chain alkyl arenes with acid catalysts is not possible. Polyalkylation is another disadvantage of the mechanism. The alkylated aromatic is typically more reactive than the starting arene. Ethylbenzene produced from benzene and ethylene in the presence of an $\mathrm{AlCl}_{3} / \mathrm{HCl}$ combination is accompanied by a substantial amount of di- and tri-ethylbenzenes, which necessitates an energy intensive transalkylation process to increase the yield for the monoalkylated product (Scheme 1.2).

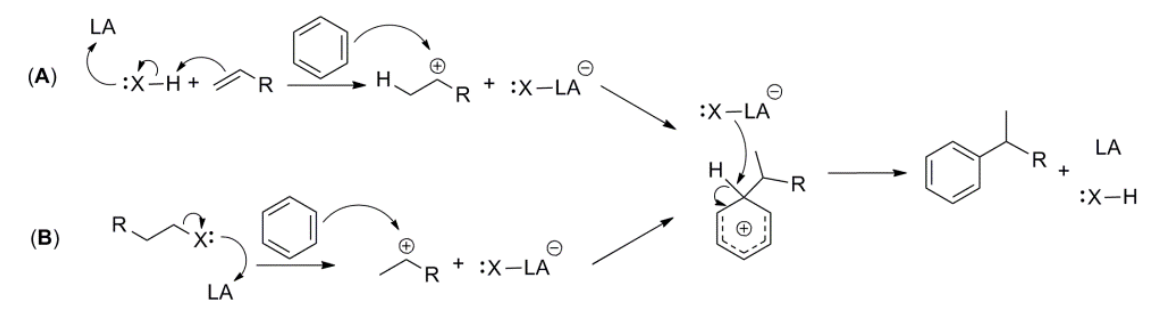

Scheme 1.1. Mechanisms for Friedel-Crafts alkylation of benzene using olefins (A) or alkyl halides (B). LA = Lewis acid; $\mathrm{R}=$ alkyl; $\mathrm{X}=$ halogen.

Mineral and Lewis acids are corrosive and difficult to store and transport. For example, $\mathrm{AlCl}_{3}$ is proposed to behave in the presence of a Brønsted acid $\mathrm{HX}(e . g ., \mathrm{HCl})$, not as a simple Lewis Acid, but as a superacid in the form of $[\mathrm{H}]\left[\mathrm{AlCl}_{3} \mathrm{X}\right]$ with an estimated acidity 1000 times greater than that of concentrated sulfuric acid. ${ }^{37-38}$ Also, these catalysts cannot be recycled. The reaction is often neutralized due to the challenge of separating the acid catalyst from the product, and the resulting salts represent a significant amount 
of waste requiring disposal. It is estimated that $24 \%$ of the global ethylbenzene production currently utilizes $\mathrm{AlCl}_{3} / \mathrm{HCl}$ technologies, despite the drawbacks associated with the process. ${ }^{34}$

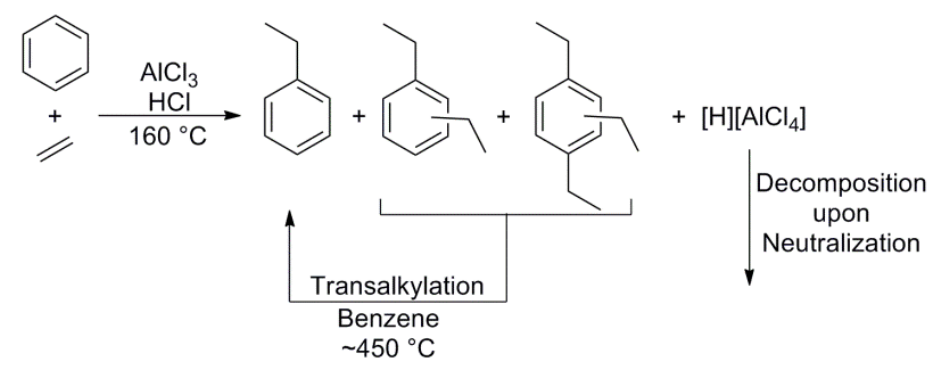

Scheme 1.2. Traditional industrial process for ethylene hydrophenylation to produce ethylbenzene catalyzed by a Friedel-Crafts catalyst.

In an effort to overcome the aforementioned deficiencies, recent industrial processes for the alkylation of simple aromatics with light olefins have turned to solid acid catalysts. $^{34,39-42}$ Solid acid catalysts are attractive as they are readily isolated from the product mixture and easily handled, transported and recycled. However, the acidity is significantly reduced from traditional mineral and Lewis acids, ${ }^{38}$ and the process requires more forcing conditions (e.g., temperatures of $\left.\sim 450{ }^{\circ} \mathrm{C}\right)$.

The most common class of solid acid catalysts implemented in industrial applications is zeolites. Zeolites are crystalline microporous aluminosilicates consisting of interlocking $\left[\mathrm{AlO}_{4}\right]$ and $\left[\mathrm{SiO}_{4}\right]$ tetrahedra joined by oxygen linkages with each oxygen atom in the framework connecting two tetrahedra (Chart 1.1). ${ }^{38,42}$ This results in an open porous structure containing highly regular channels of variable dimension between 0.3 and 1.0 nm..$^{43}$ As the aluminum has a coordination number of 4 and a valency of 3 , it is endowed 
with a formal negative charge. The introduction of monovalent cations within the structural pores provides the charge balance. Using a proton $\left(\mathrm{H}^{+}\right)$to neutralize the aluminum tetrahedron provides the Brønsted acidity of the solid, and the overall acidity depends on the aluminum content as each aluminate tetrahedra theoretically constitutes one Brønsted acid site. ${ }^{38}$ The zeolite structure can be modulated by adjusting the $\mathrm{Si} / \mathrm{Al}$ ratios or with the addition of other elements (e.g., Ge, Ga, P, Fe, Mn, Co, Ni or V) to be incorporated into the zeolite structure. There are over 190 known different zeolite structure types ${ }^{43}$ and about a dozen have found application in industry as catalysts. ${ }^{38}$

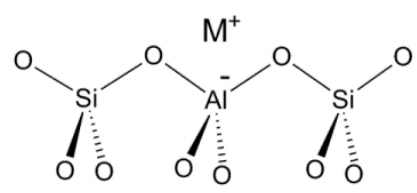

Chart 1.1. Basic aluminosilicate structure of solid zeolite acid catalysts.

The zeolite ZSM-5 was developed in 1960 by Mobil Oil and is still currently used in many industrial petrochemical processes, including the alkylation of benzene and other aromatics. ${ }^{38}$ The structure of ZSM-5 is based upon 5-membered interlocking rings, which organize into a 3-dimentional network featuring cavities connected via cylindrical channel systems with openings $\sim 5 \mathrm{~nm}$ in size (Chart 1.2).$^{38,43-44}$ The Brønsted acid sites are located in the cavities at the intersection of two ring channels and also within the channels themselves (Chart 1.3). These zeolites have high silicon content with the Si/Al ratio typically $>>10$. This is advantageous because the number of acidic sites is not as important as the acidity of the sites themselves. Reducing the aluminate content results in a more electronegative zeolite framework and an increase in the acidity of the Brønsted 
acid site. ${ }^{38}$ The catalytic activity of zeolite catalysts are also dictated by their porosity and the electrostatic field inside the pores, which also have to be considered in choosing the appropriate structure for a specific catalytic application. ${ }^{38}$

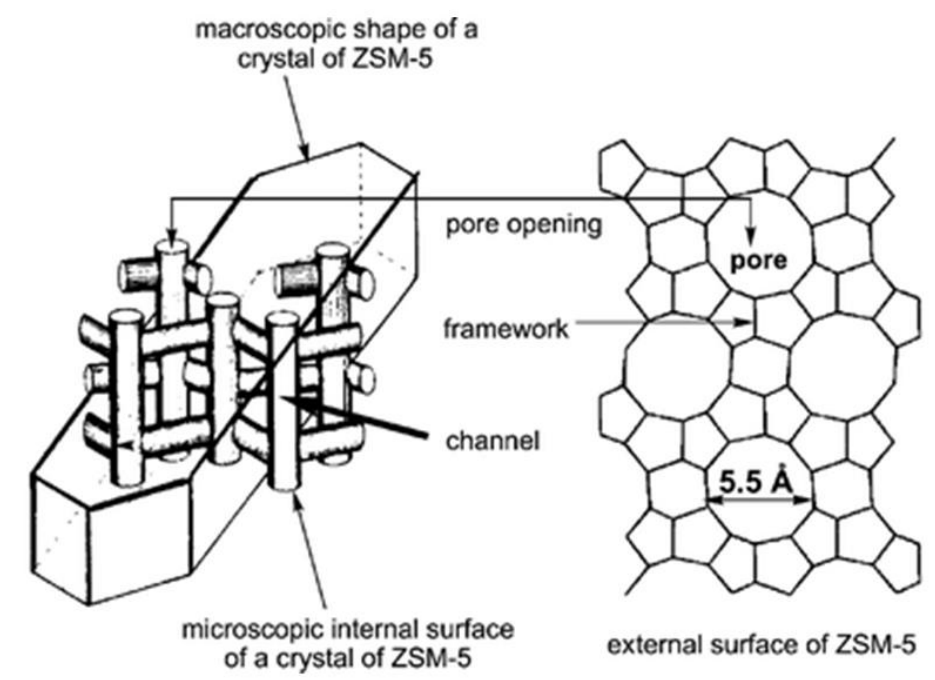

Chart 1.2. Structure of ZSM-5 zeolite. Lei, X.-g.; Jockusch, S.; Francesca Ottaviani, M.; Turro, N. J., Photochemical \& Photobiological Sciences 2003, 2, 1095-1100Reproduced by permission of The Royal Society of Chemistry (RSC) for the European Society for Photobiology, the European Photochemistry Association, and the RSC. 

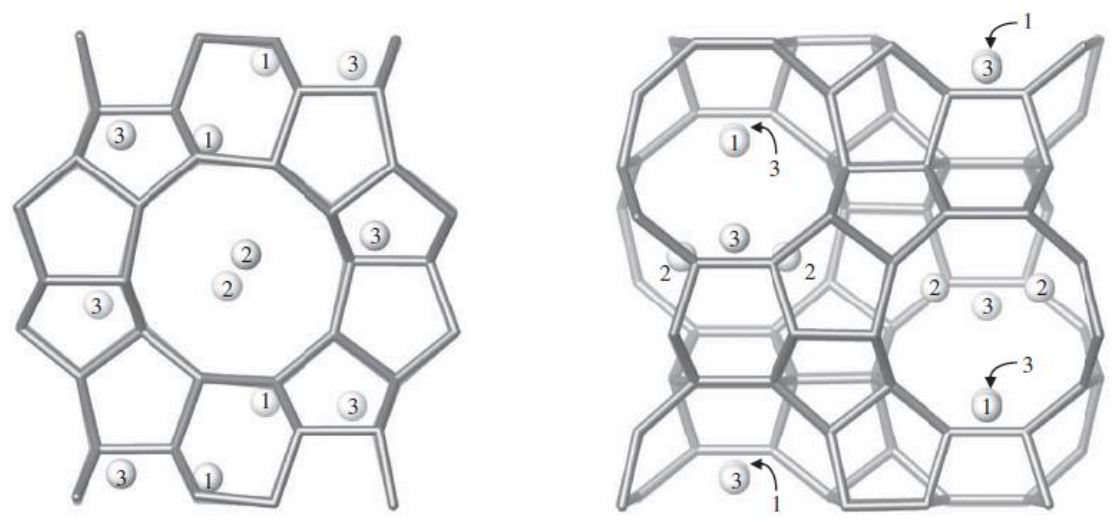

Chart 1.3. Acidic sites in ZSM-5. Site 1 is located at channel intersections, while Sites 2 and 3 are located within the channels. Broach, R. W., Zeolite Types and Structures. In Zeolites in Industrial Separation and Catalysis, Kulprathipanja, S., Ed. John Wiley \& Sons: 2010; pp 27-59. Copyright Wiley-VCH Verlag GmbH \& Co. KGaA. Reproduced with permission.

Using ethylbenzene as an example, the alkylation of benzene with ethylene using ZSM5 was traditionally performed in the vapor phase under $\sim 2-20 \mathrm{MPa}$ at temperatures between 400 and $450{ }^{\circ} \mathrm{C} .{ }^{34,} 45$ The network of interconnecting channels of the ZSM-5 structure greatly increases the longevity of the catalysts as it prevents condensation and hydrogen transfer reactions. ${ }^{46}$ Other major advantages, relative to the aforementioned mineral and Lewis acids, include the absence of corrosive properties and salts resulting from reaction neutralization, which requires disposal, and increased efficiency as only small quantities of polyethylated benzenes are produced. The transalkylation of polyethylbenzenes, also acid catalyzed, can be performed in the same reactor as the alkylation.

Mobil-Badger brought a more efficient process for ethylbenzene production online in 1995 that can be operated in the liquid phase. ${ }^{46}$ In this process, ZSM-5 was replaced with a more active and selective zeolite catalyst, designated MCM-22, which achieves $>95 \%$ 
selectivity for ethylbenzene production from benzene and ethylene. ${ }^{46}$ This lamellar zeolite, meaning containing separate layers, is an aluminosilicate doped with boron. ${ }^{43}$ It is composed of plates with unconnected channels that form egg-shaped cages shared between adjacent layers or plates. ${ }^{43,46}$ The surfaces of the plates are decorated with large pockets in which the reactions takes place (Chart 1.4). The process was further improved by performing the transalkylation of polyethylbenzenes in the gas phase in a separate reactor using ZSM-5. Another zeolite structure quickly replaced ZSM-5, which enabled the transalkylation step to also be performed in the liquid phase and for overall yields of $>99 \%$ for ethylbenzene to be obtained. ${ }^{46-47}$ The continued process optimization has extended the lifetime of these catalysts to $\sim 3$ years before replacement.

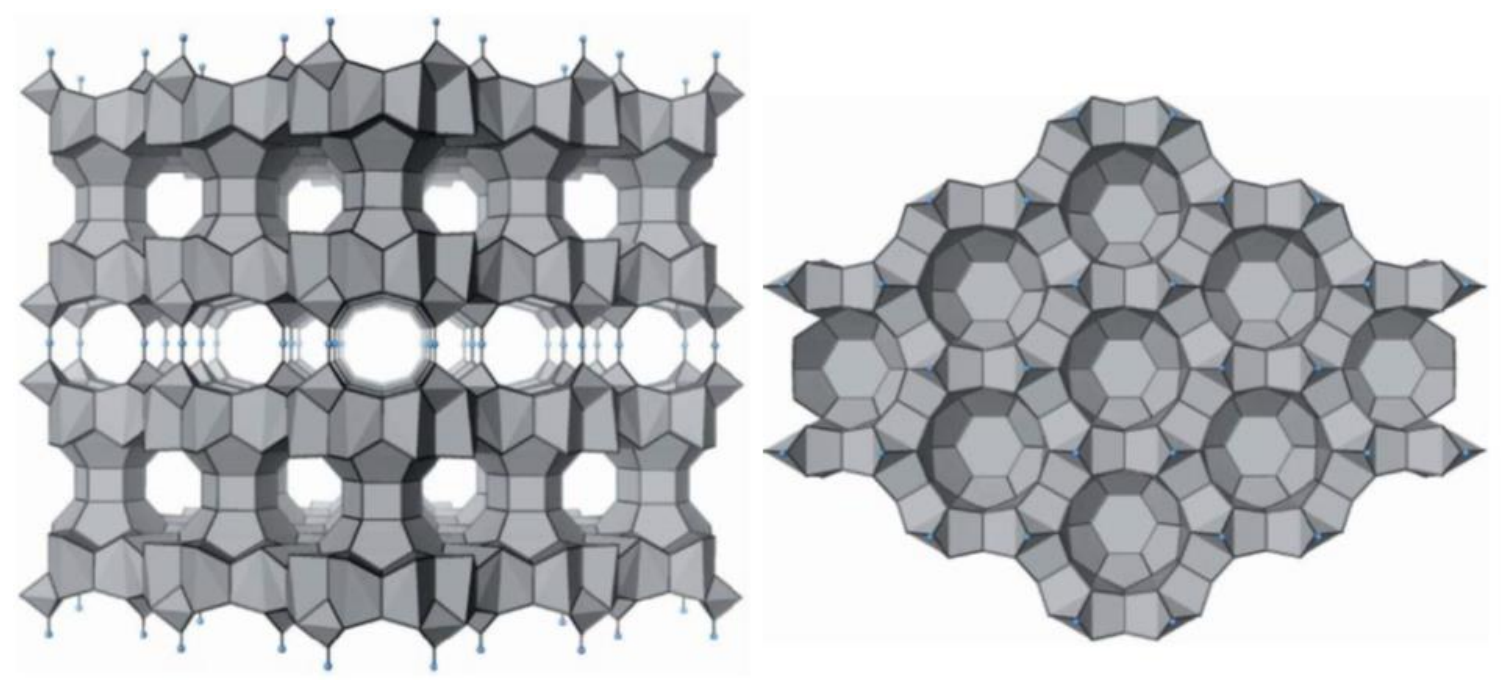

Chart 1.4. Crystalline structure of zeolite MCM-22 displaying the non-interconnected channels and egg-shaped cages (left). The surface is covered with 12-ring pockets in which the reaction is proposed to take place (right). Broach, R. W., Zeolite Types and Structures. In Zeolites in Industrial Separation and Catalysis, Kulprathipanja, S., Ed. John Wiley \& Sons: 2010; pp 27-59. Copyright Wiley-VCH Verlag GmbH \& Co. KGaA. Reproduced with permission. 
Despite the dramatic improvements in the alkylation of benzene with simple olefins, such as ethylene and propylene, solid acid catalysts are deficient with regards to the synthesis of linear alkylbenzenes (LABs), which are precursors to synthetic surfactants with $\mathrm{C}_{10}-\mathrm{C}_{13}$ carbon chains. The preferred industrial catalytic system for the synthesis of LABs uses anhydrous HF and produces a fairly even distribution of constitutional isomers (Table 1.1). ${ }^{34,}$ 46, 48 The more externally substituted isomers (2- and 3phenylalkanes) are more biodegradable, but their toxicities must also be taken into consideration. Relative to $n$-phenylalkanes, the toxicity increases for constitutional isomers of phenylalkanes with $\mathrm{C}_{8}-\mathrm{C}_{12}$ carbons in the order 2- $>3->6->4-{ }^{46}$ Since the composition of isomers of LAB can fluctuate depending on the required application, efforts to replace HF acid with zeolites have been met with little success. The main impediment is that zeolites are too selective, favoring 2-phenylalkanes over all other isomers. ${ }^{46}$ In fact, with zeolites such as ZSM-5, no isomers greater than 3-phenylalkanes are produced in any significant quantity, and they possess significantly reduced activity (relative to $\mathrm{HF}$ ) and rapidly deactivate. ${ }^{46}$

Table 1.1. Distribution of dodecylbenzene isomers obtained from the reaction of 1dodecene and benzene using anhydrous $\mathrm{HF}\left(16^{\circ} \mathrm{C}\right) .{ }^{46}$

\begin{tabular}{cc}
\hline $\begin{array}{c}\text { Isomer } \\
\text { of } \\
\text { Phenyldodecane }\end{array}$ & \% Composition \\
\hline $1-$ & \\
$2-$ & 0 \\
$3-$ & 20 \\
$4-$ & 17 \\
$5-$ & 16 \\
$6-$ & 23 \\
\hline
\end{tabular}




\subsection{Transition Metal Mediated Reactions: The Emergence of $\mathrm{C}-\mathrm{H}$ activation as a Promising Alternative to Acid-catalyzed Pathways}

Transition metal-mediated reactions have evolved over recent decades to become powerful tools to achieve transformations that are inaccessible by standard organic methodologies. The relevance of transition metal complexes in organic synthesis has been emphasized with eight Nobel Prizes in the past decade. ${ }^{49-54}$ Yet many processes for synthesizing chemical products remain inefficient. For example, it is estimated that for every kilogram of fine chemicals, the amount of chemical waste generated exceeds the product and in some cases by 100 -fold. ${ }^{55-56}$ Future challenges regarding resource, environmental and societal sustainability demand more efficient and benign technologies. In an attempt to address these challenges, green chemistry works to develop novel processes that maximize selectivity for desired products, atom economy and energy efficiency, while minimizing chemical waste. ${ }^{57-58}$ An ever-growing area of research is toward the direct derivatization of unactivated hydrocarbon $\mathrm{C}-\mathrm{H}$ bonds (Scheme 1.3). Aliphatic hydrocarbons are readily available from fossil feedstocks and, together with arenes and olefins, form the basis of the chemical industry with the majority of materials originating from seven basic hydrocarbon building blocks (Table 1.2). ${ }^{59}$ Transformations of hydrocarbons are problematic because of the low reactivity of most $\mathrm{C}-\mathrm{H}$ bonds. For example, the $\mathrm{pK}_{\mathrm{a}}$ of methane is $48,{ }^{60}$ and the $\mathrm{C}-\mathrm{H}$ bond dissociation energy is 105 $\mathrm{kcal} / \mathrm{mol}^{61}$ Thus, highly reactive species, such as super acids or free radicals, are typically needed to derivatize these chemically inert bonds, but such reagents allow negligible control over product selectivity. ${ }^{62}$ The discovery of transition metal complexes 
that are capable of activating $\mathrm{C}-\mathrm{H}$ bonds for further transformation has spurred a significant amount of research into organometallic routes.

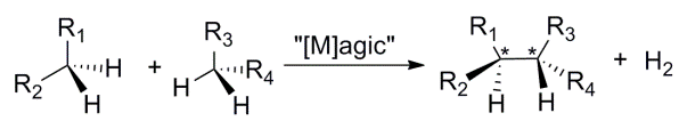

Scheme 1.3. "Ideal" synthetic chemistry via direct and selective functionalization of hydrocarbyl $\mathrm{C}-\mathrm{H}$ bonds.

Table 1.2. Production of basic petrochemicals in the United States in 2007.

\begin{tabular}{lc}
\hline Chemical & $\begin{array}{c}\text { Production } \\
\text { (millions of tonnes) }\end{array}$ \\
\hline Ethylene & 25.4 \\
Propylene & 17.0 \\
Benzene & 7.40 \\
Toluene & 5.20 \\
Methanol & 0.90 \\
Butadiene & 2.20 \\
Xylenes & 6.20 \\
\hline
\end{tabular}

\subsubsection{C-H Activation by Organometallic Routes}

The first reported example of transition metal mediated $\mathrm{C}-\mathrm{H}$ activation is accredited to Chatt and Davidson, who observed that $(\mathrm{DMPE})_{2} \mathrm{Ru}^{0} \quad(\mathrm{DMPE}=1,2-$ bis(dimethylphosphino)ethane) undergoes intermolecular $\mathrm{C}-\mathrm{H}$ activation of a phosphinomethyl group to provide a $\mathrm{Ru}^{\mathrm{II}}$ dimer or activate aryl $\mathrm{C}-\mathrm{H}$ bonds of naphthalene (Scheme 1.4). ${ }^{63}$ 


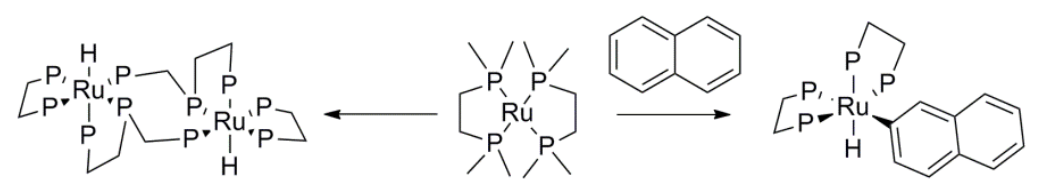

Scheme 1.4. First reported examples of $\mathrm{C}-\mathrm{H}$ activation involving oxidative addition of phosphinomethyl $\mathrm{sp}^{3} \mathrm{C}-\mathrm{H}$ bonds or $\mathrm{sp}^{2} \mathrm{C}-\mathrm{H}$ bonds of naphthalene.

In 1969, Shilov and co-workers discovered that $\mathrm{Pt}^{\mathrm{II}}$ salts could activate alkane $\mathrm{C}-\mathrm{H}$ bonds, including methane, and catalyze $\mathrm{H} / \mathrm{D}$ exchange between the alkane and $\mathrm{D}_{2} \mathrm{O}$ in an acidic medium. ${ }^{64} \mathrm{~A}$ few years later, the functionalization of methane to yield methanol or methylchloride by $\mathrm{Pt}^{\mathrm{II}}$ was made catalytic by incorporating $\mathrm{Pt}^{\mathrm{IV}}$ as a stoichiometric oxidant. ${ }^{65}$ A proposed mechanism emerged that consisted of three key transformations (Scheme 1.5). ${ }^{66}$ In the initial and rate-determining step, ${ }^{67}$ alkane $\mathrm{C}-\mathrm{H}$ activation by $\mathrm{Pt}^{\mathrm{II}}$ via a presumed electrophilic substitution mechanism generates an $\mathrm{Pt}^{\mathrm{II}}$-alkyl intermediate. However, a mechanism for $\mathrm{C}-\mathrm{H}$ activation that involves oxidative addition followed by Pt deprotonation has been proposed. ${ }^{68}$ In the subsequent steps, a two-electron oxidation produces a $\mathrm{Pt}^{\mathrm{IV}}$-alkyl species, which undergoes nucleophilic attack at the alkyl substituent to provide the functionalized product and formal reduction of the metal from $\mathrm{Pt}^{\mathrm{IV}}$ to $\mathrm{Pt}^{\mathrm{II}}$. Due to the difficulty of studying the catalytic cycle as a result of the harsh reaction conditions, it was not until almost a decade later that the elementary reaction steps were confirmed. $^{69}$ 


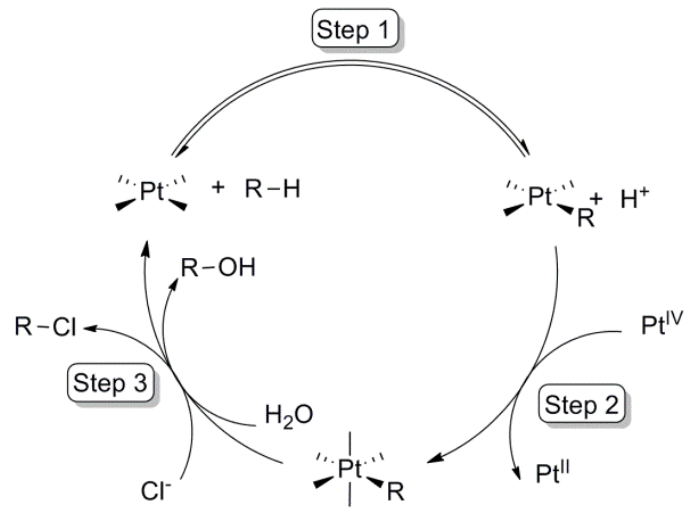

Scheme 1.5. Catalytic cycle for Shilov's partial oxidation of alkanes using a $\mathrm{Pt}^{\mathrm{II}}$ catalyst. Reproduced from reference 66; complete stoichiometry of the reaction was not provided.

In 1979, Crabtree et al. reported that an iridium complex containing labile solvent ligands could induce alkane activation (Scheme 1.6) ${ }^{70}$ Cyclic alkenes react with $\left[\operatorname{Ir}(\mathrm{H})_{2}(\text { acetone })_{2}\left(\mathrm{PPh}_{3}\right)_{2}\right]\left[\mathrm{BF}_{4}\right]$ to form cyclodiene analogues. For example, [2.2.2]bicyclooctene reacts quantitatively with the Ir complex to give a coordinated bicyclooctadiene $\operatorname{Ir}^{\mathrm{I}}$ adduct. The authors note that due to the fused ring structure of this substrate, a $\pi$-allyl intermediate is implausible and suggests direct activation of the alkyl side chains. Moreover, this system was observed to activate alkanes at $\sim 85{ }^{\circ} \mathrm{C}$ in the presence of a hydrogen acceptor. Cyclopentane was effectively dehydrogenated to form an $\eta^{5}$-cyclopentadienyl Ir ${ }^{\mathrm{III}}$ complex but only in $5 \%$ isolated yield.

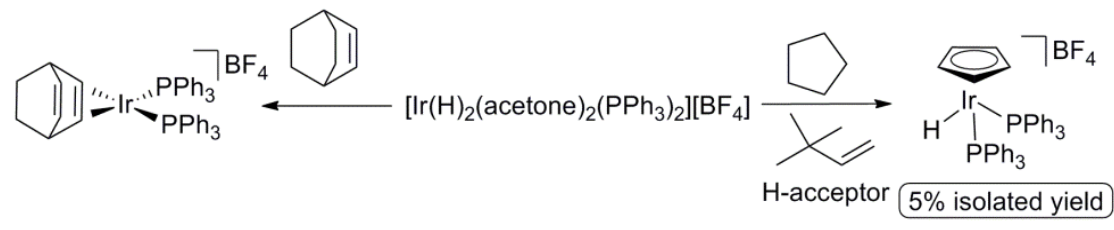

Scheme 1.6. Formation of bicyclooctadiene and cyclopentadienyl from [2.2.2] bicyclooctene and cyclopentane via activation of $\mathrm{C}_{\mathrm{sp} 3}-\mathrm{H}$ bonds by an $\mathrm{Ir}^{\mathrm{III}}$ catalyst precursor. 
These early reports precipitated a flurry of interest in understanding the driving force behind transition metal mediated $\mathrm{C}-\mathrm{H}$ activation in an effort to exploit a novel means of hydrocarbon functionalization, which is evident by the numerous reviews on the subject. 69, 71-76, 77 It seemed unlikely that the nucleophilic (electron-rich) metal center, (i.e., $\mathrm{Ru}^{0}$ ) and electrophilic metal centers (i.e., $\mathrm{Pt}^{\mathrm{II}}$ and $\mathrm{Ir}^{\mathrm{III}}$ ) would proceed to activate hydrocarbyl $\mathrm{C}-\mathrm{H}$ bonds via the same mechanism. In fact, several mechanisms for the $\mathrm{C}-\mathrm{H}$ activation have been identified. The more commonly invoked mechanisms for $\mathrm{C}-\mathrm{H}$ activation are oxidative addition, $\sigma$-bond metathesis, 1,2-addition across metal-heteroatom multiple bonds and electrophilic substitution (Scheme 1.7). All but the former can be considered electrophilic mechanisms (i.e., oxidative addition is typically considered nucleophilic in nature), but the distinction between them is continuously blurring with the advent of other possible mechanisms such as oxidative hydrogen migration (OHM, see Section 1.2.4 $)^{78-80}$ and $\sigma$-CAM ( $\sigma$-complex assisted metathesis $)^{81-83}$ that imply a hybridization of the aforementioned pathways for $\mathrm{C}-\mathrm{H}$ activation. 

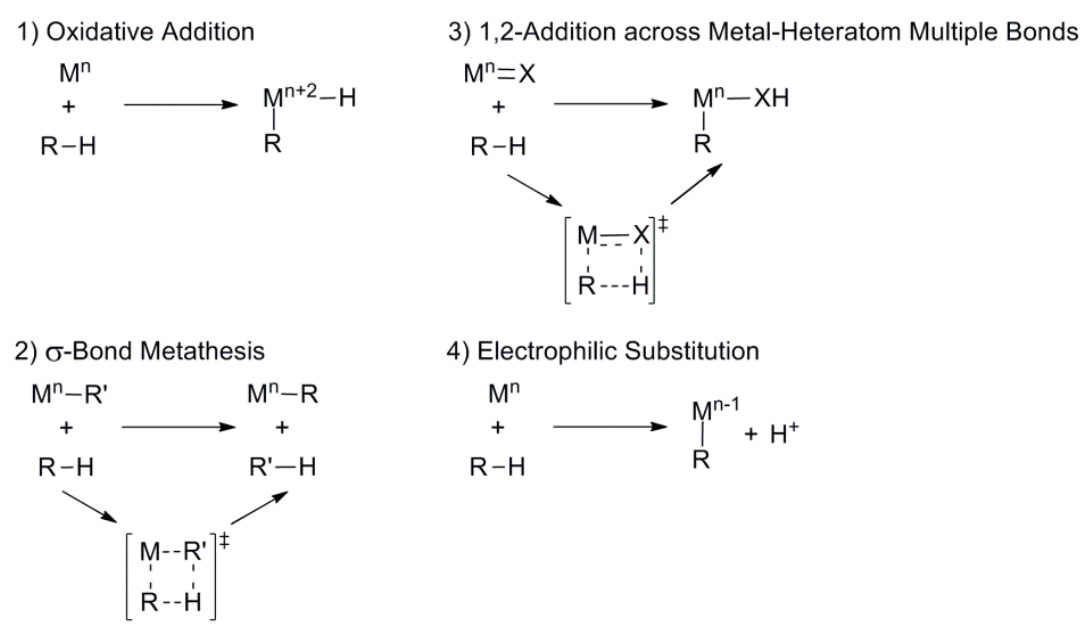

4) Electrophilic Substitution

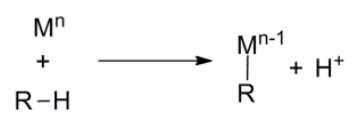

Scheme 1.7. Generally invoked mechanisms for transition metal-mediated $\mathrm{C}-\mathrm{H}$ bond activation.

Oxidative addition ( $\mathbf{1}$ in Scheme 1.7) is typically the operative mechanism for $\mathrm{C}-\mathrm{H}$ activation at low-valent and nucleophilic metal centers. The metal inserts into the $\mathrm{C}-\mathrm{H}$ bond forming new $\mathrm{M}-\mathrm{H}$ and $\mathrm{M}-\mathrm{C}$ bonds. As the $\mathrm{C}-\mathrm{H}$ bond only contains two electrons and four electrons are required for the formation of two new bonds to the metal, the metal must be able to contribute two of its electrons to the process. Therefore, the metal is formally oxidized, increasing its valency by two, and increases the metal coordination number.

The other general mechanisms, as previously stated, are electrophilic in nature. The $\sigma-$ bond metathesis mechanism involves a concerted process in which a hydrogen atom is transferred from a $\mathrm{C}-\mathrm{H}$ bond to a ligand on the metal center without a change in the oxidation state of the metal. This mechanism is typically observed with high-valent, often $\mathrm{d}^{0}$, transition metal complexes that do not possess access to a formal two-electron oxidation of the metal center, common for metals early in the transition series. In the case of electrophilic substitution, interaction with the metal center weakens and acidifies the 
$\mathrm{C}-\mathrm{H}$ bond to facilitate the loss of a proton and generate a $\mathrm{M}-\mathrm{C}$ bond. $\mathrm{C}-\mathrm{H}$ bond activation by 1,2 -addition across a $\mathrm{M}-\mathrm{X}$ bond (e.g., $\mathrm{X}=\mathrm{O}$ or $\mathrm{N}$ ) can formally be considered electrophilic substitution, except the base is a ligand within the coordination sphere of the metal.

The observation of inverse kinetic isotope effects from the reductive elimination of alkanes from $M(R)(H)$ and $M(R)(D)$ complexes, in addition to observed H/D exchange into the methyl ligand of $\mathrm{M}(\mathrm{D})\left(\mathrm{CH}_{3}\right)$ complexes, is consistent with the formation of intermediate $\sigma$-alkane complexes, in which a $\sigma$ bond of the saturated hydrocarbon serves as a dative ligand (Scheme 1.8). ${ }^{69,71,74,76,84}$ These intermediates are typically highly reactive species. When the thermodynamically preferred product is the alkyl hydride, the cleavage of the $\mathrm{C}-\mathrm{H}$ bond and conversion to the more stable product is rapid. ${ }^{69,85}$ If the alkyl hydride is not thermodynamically preferred, the high reactivity of the complex with competing ligands quickly leads to the substituted product. ${ }^{69,85-86}$ Due to their short lifetimes, these $\sigma$-alkane complexes were initially observed using time-resolved infrared spectroscopy (TRIR) to detect shifts in the absorption band of carbonyl ligands, ${ }^{86}$ but seminal studies by George and Ball using rhenium complexes have shown them to be observable on the NMR timescale at low temperatures. ${ }^{85}$ 

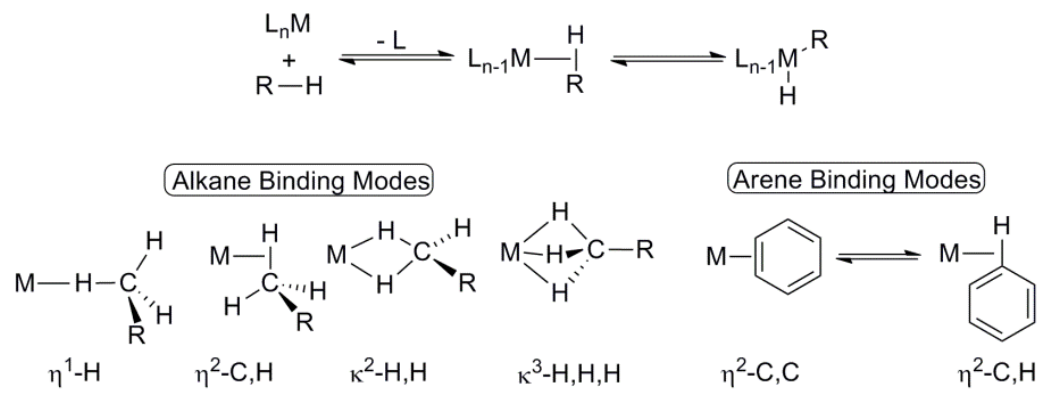

Scheme 1.8. $\sigma$-Alkane/Arene complexes are implicated as intermediates preceding $\mathrm{C}-\mathrm{H}$ bond cleavage. Proposed geometries of alkane and arene binding modes.

Initial ${ }^{1} \mathrm{H}$ NMR studies provided evidence for interaction of a metal center with $\mathrm{C}-\mathrm{H}$ bonds of cyclic hydrocarbons using $\mathrm{Cp}(\mathrm{CO})_{2} \operatorname{Re}($ cyclopentane $) \quad\left(\mathrm{Cp}=\eta^{5}-\right.$ cyclopentadienyl). The data suggested that Re coordinated cyclopentane in an $\eta^{2}-\mathrm{C}, \mathrm{H}$ fashion with the two $\mathrm{C}-\mathrm{H}$ bonds of the associated methylene fragment in rapid exchange, but definite conclusions about the binding mode of the Re-cyclopentane adduct could not be drawn. ${ }^{85}$ As a result, a similar complex $\left[{ }^{i} \mathrm{Cp}(\mathrm{CO})_{2} \operatorname{Re}(n\right.$-pentane $\left.)\right]\left({ }^{i} \mathrm{Cp}=\eta^{5}-\right.$ isopropylcylcopentadienyl) was used to investigate the preferred modes of interaction (Scheme 1.8) and regioselectivity of alkane binding to a transition metal.

The fragment, $\left[{ }^{i} \mathrm{CpRe}(\mathrm{CO})_{2}\right]$ was observed to coordinate all three types of $\mathrm{C}-\mathrm{H}$ bonds present in $n$-pentane with a slight preference for methylene units. ${ }^{87}$ Examination of the coupling constants $\left({ }^{1} J_{\mathrm{CH}}\right)$ for the bound methyl group in isotopomers of $n$-pentane demonstrated that they decreased in the order $\mathrm{CH}_{3}>\mathrm{CH}_{2} \mathrm{D}>\mathrm{CHD}_{2}$, which supports an asymmetric $\eta^{2}-\mathrm{C}, \mathrm{H}$ interaction. The preference for binding the methlyene units of $n$ pentane coincides with the observation that the strength of the binding interaction for alkane $\sigma$-complexes increases with the size of the hydrocarbon. ${ }^{88}$ Such a binding 
preference does conflict with the observation that terminal $\mathrm{C}-\mathrm{H}$ bonds of methyl groups are the most common site for $\mathrm{C}-\mathrm{H}$ activation. ${ }^{87}$

The observation of a $\sigma$-complex of methane with a formally cationic (PNP) $\mathrm{Rh}^{\mathrm{I}}$ fragment by NMR spectroscopy has recently been communicated (Chart 1.5). ${ }^{89}$ The methane ligand is generated in the coordination sphere of the metal by protonolysis of an initial $\mathrm{Rh}-\mathrm{Me}$ bond, and the resulting methane $\sigma$-complex is more stable than the formation of the corresponding oxidative addition product, a $\mathrm{Rh}^{\mathrm{III}}$ methyl hydride complex. Similar to the conclusions by Ball, an $\eta^{2}-\mathrm{C}, \mathrm{H}$ coordination is proposed based on isotopic substitution and DFT calculations. A relatively large barrier to methane loss $\left(\Delta G^{\ddagger}=14.5(4) \mathrm{kcal} / \mathrm{mol}\right)$ was determined and is comparable with the predicted barriers of methane loss from $\mathrm{Pt}^{\mathrm{II}}$ centers. ${ }^{90}$

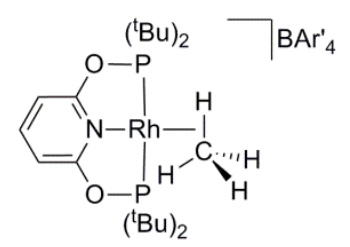

Chart 1.5. Direct observation of a $\mathrm{Rh}^{\mathrm{I}}$ (methane) $\sigma$-complex by ${ }^{1} \mathrm{H}$ NMR spectroscopy with a proposed $\eta^{2}-\mathrm{C}, \mathrm{H}$ binding mode as elucidated from experimental and computational study $\left(\mathrm{Ar}^{\prime}=3,5-\left(\mathrm{CF}_{3}\right)_{2}-\mathrm{C}_{6} \mathrm{H}_{3}\right)$.

\subsubsection{Transition-Metal Mediated Olefin Hydroarylation: Challenges and Implications for Alkyl Arene Synthesis}

The greatest challenges to developing transition metal catalysts for olefin hydroarylation are combining two fundamentally different metal mediated processes (i.e., 
olefin insertion and $\mathrm{C}-\mathrm{H}$ activation) into a single catalytic cycle (Scheme 1.9) and avoiding side reactions that ultimately lead to undesired products or catalyst decomposition. These side reactions are likely to have similar energetic profiles compared to olefin insertion and aromatic $\mathrm{C}-\mathrm{H}$ activation. For example, highly efficient olefin insertion is apt to result in olefin oligomerization or polymerization. However, the formation of more stable metal-olefin complexes may raise the activation barriers for olefin insertion and avoid oligomer/polymer formation, but the risk of olefinic $\mathrm{C}-\mathrm{H}$ activation increases. Installing selectivity for olefin insertion into the metal-aryl bond over olefinic $\mathrm{C}-\mathrm{H}$ activation is especially challenging since metal-mediated $\mathrm{C}-\mathrm{H}$ activation is one of the required steps in the catalytic cycle. Therefore, the catalyst must be able to activate aromatic $\mathrm{sp}^{2} \mathrm{C}-\mathrm{H}$ bonds, but not those of the olefin. Following olefin insertion, the newly formed $\mathrm{M}$-alkyl moiety can be susceptible toward $\beta$-hydride elimination, resulting in vinyl arene formation. The possibility that these undesirable side reactions would have similar, or reduced, activation energies compared with steps along the desired catalytic cycle results in a narrow window of success for efficient production of alkyl arenes. Despite these challenges, significant achievements in the area of transition metal-mediated olefin hydroarylation have been reported, including recent successes with unactivated substrates such as ethylene and benzene. 


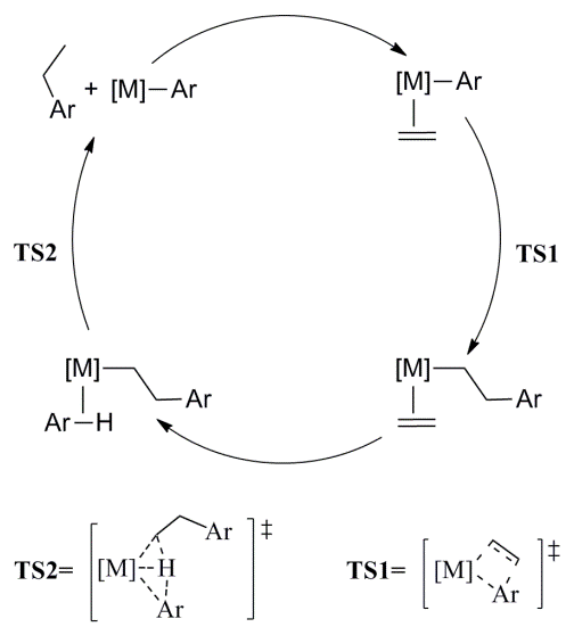

Scheme 1.9. General mechanism for olefin hydroarylation combining metal mediated olefin insertion into $\mathrm{M}-$ aryl bonds and aromatic $\mathrm{C}-\mathrm{H}$ activation.

\subsubsection{Olefin Hydroarylation Facilitated by Activated Aromatic Substrates and Directing Groups}

Transition metal complexes based on $\mathrm{Ru}, \mathrm{Rh}$ and $\mathrm{Pd}$ have been the most heavily utilized catalysts for the addition of aromatic $\mathrm{C}-\mathrm{H}$ bonds across $\mathrm{C}-\mathrm{C}$ multiple bonds of alkenes or alkynes to yield alkyl or vinyl arenes. ${ }^{91-100}$ Examples of Au and Ir catalyzed olefin hydroarylation with activated benzenes and/or olefins have also emerged recently. ${ }^{101-102}$ Herein, the discussion is limited to examples of intermolecular catalytic hydroarylation of unactivated olefins to yield alkyl arenes through a chelation-assisted pathway or aromatic substrates with a tethered olefinic moiety (i.e., intramolecular hydroarylation).

An early example of using an ortho-metalated complex for catalytic $\mathrm{C}-\mathrm{C}$ bond formation was reported in 1986 by Lewis and Smith. ${ }^{103}$ Using a cyclometalated $\mathrm{Ru}^{\mathrm{II}}$ phosphite complex with ethylene ( 0.7 MPa) and potassium phenoxide, regioselective ortho-alkylation of phenol was observed in $\sim 86 \%$ overall yield at $\sim 180{ }^{\circ} \mathrm{C}$ with greater 
selectivity for the doubly alkylated product (Scheme 1.10). This system was only observed to be active with ethylene as the olefin. Similarly, a chiral $\operatorname{Ir}^{\mathrm{I}}$ diphosphine complex also regioselectively alkylates the ortho-position of phenol using norbornene at $100{ }^{\circ} \mathrm{C}$ in an overall $82 \%$ yield but with low stereoselectivity. ${ }^{102}$ In contrast to the $\mathrm{Ru}^{\mathrm{II}}$ complex, the mono- over di-alkylation was preferred in an approximate 5:1 ratio, but substrates other than norbornene were not examined.

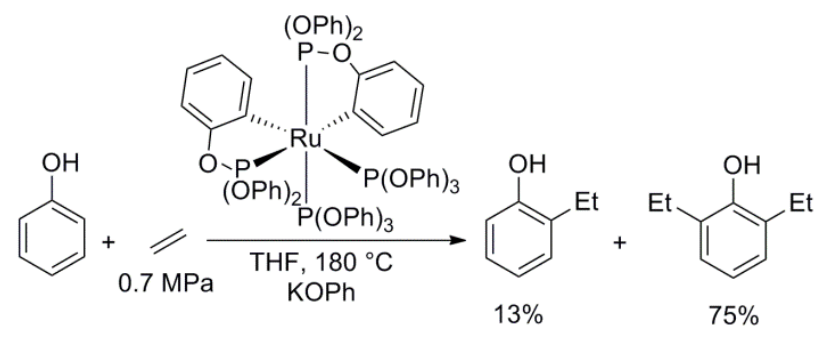

Scheme 1.10. Early example of chelate-assisted ethylene hydroarylation using a cyclometalated $\mathrm{Ru}$ II catalyst precursor.

A significant advancement in chelate-assisted olefin hydroarylation was achieved with the observation that a $\mathrm{Ru}$ II precursor $\mathrm{Ru}(\mathrm{CO})(\mathrm{H})_{2}\left(\mathrm{PPh}_{3}\right)_{3}$ could catalyze ortho- $\mathrm{C}-\mathrm{H}$ bond addition of a variety of aromatic ketones to olefins in high yields (Scheme 1.11). ${ }^{104}$ Even more remarkable, the reaction is regioselective for the anti-Markovnikov addition product, except in two observed cases in which styrene was used. ${ }^{104-105}$ The mechanism for ortho-alkylation of aromatic ketones catalyzed by the Ru catalyst has been elucidated with further experimental and theoretical study (Scheme 1.11). ${ }^{106-109}$ The catalytic cycle initializes with olefin hydrogenation and the loss of $\mathrm{CO}$ to generate the active catalyst that is proposed to be stabilized by weakly coordinating a solvent molecule. Coordination of the carbonyl group of the substrate orients the ortho- $\mathrm{C}-\mathrm{H}$ bond proximal to the metal 
center. The $\mathrm{C}-\mathrm{H}$ bond is then predicted to be cleaved in a two-step oxidative process. First, the $\mathrm{Ru}-\mathrm{C}$ bond is formed, and then the $\mathrm{H}$ atom is transferred to the metal center to produce a formal Ru-hydride. Following coordination of the olefin, it is inserted into the $\mathrm{Ru}-\mathrm{H}$ bond, as opposed to the $\mathrm{Ru}-$ aryl bond. Reductive elimination and dissociation of the coupling product regenerates the catalyst.
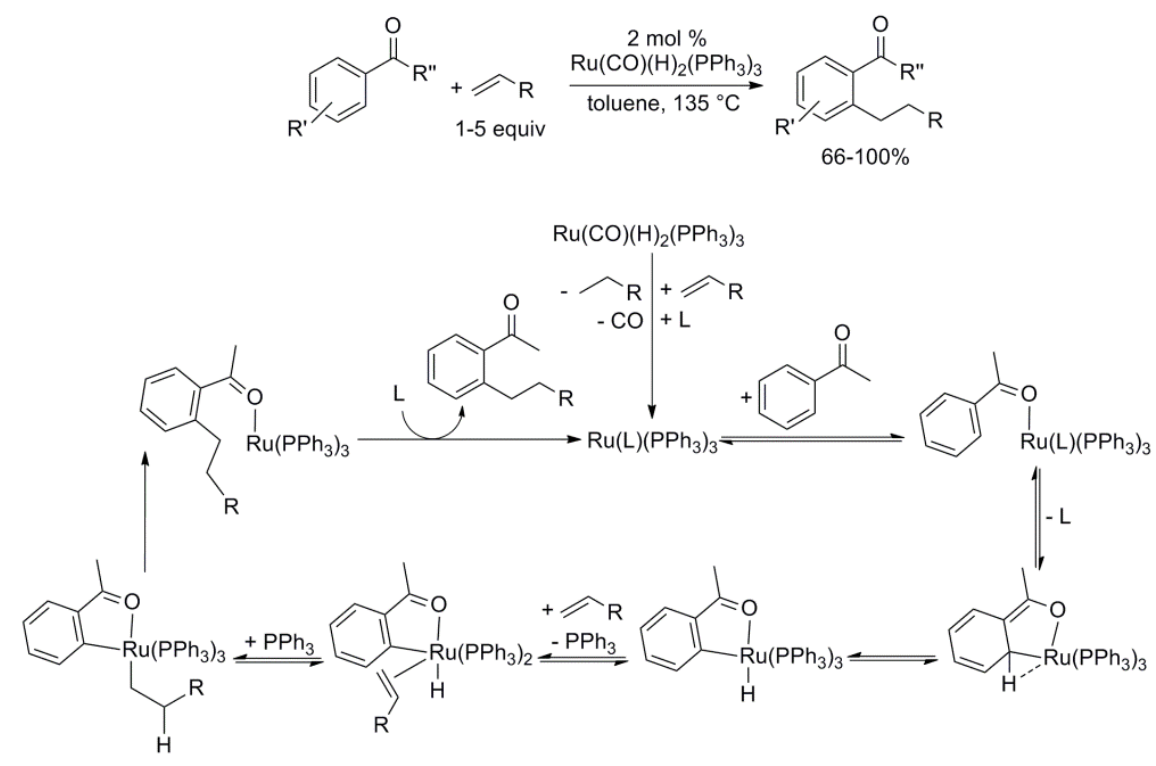

Scheme 1.11. Chelate-assisted hydroarylation of aromatic ketones catalyzed by $\mathrm{Ru}(\mathrm{H})_{2}(\mathrm{CO})\left(\mathrm{PPh}_{3}\right)_{3}$ and proposed mechanism using acetophenone for illustrative purposes $\left(\mathrm{R}=\mathrm{H},{ }^{\mathrm{B}} \mathrm{Bu}, \mathrm{Si}(\mathrm{OEt})_{3}, \mathrm{CH}_{2} \mathrm{SiMe}_{3}\right.$ or aryl $)$.

Chelate-assisted olefin hydroarylation of aromatic ketones has also been observed with $\mathrm{Rh}^{\mathrm{I}}$ half-sandwich complexes, as reported by Brookhart and coworkers. ${ }^{110}$ For example, the complex $\left(\eta^{5}-\mathrm{C}_{5} \mathrm{Me}_{5}\right) \mathrm{Rh}\left(\eta^{2}-\mathrm{C}_{2} \mathrm{H}_{3} \mathrm{SiMe}_{3}\right)_{2}(5 \mathrm{~mol} \%)$ catalyzes the addition of benzophenone to vinyltrimethylsilane $\left(1: 1\right.$ molar ratio) in cyclohexane at $120{ }^{\circ} \mathrm{C}$ in an overall 99\% yield of anti-Markovnikov addition products, as determined by ${ }^{1} \mathrm{H}$ NMR spectroscopy, with the ratio of mono- to dialkyated products being $~ 8: 1$. 
For both the $\mathrm{Rh}$ and $\mathrm{Ru}$ systems, the rate limiting step in the catalytic cycle is proposed to be $\mathrm{C}-\mathrm{C}$ bond formation via reductive coupling. However, there is a key difference between the two systems. For the $\mathrm{Ru}$ system, H/D exchange studies revealed isotopic scrambling only into the ortho- $\mathrm{C}-\mathrm{H}$ bonds. Similar studies for the $\mathrm{Rh}$ catalyst demonstrate that the metal center does not discriminate between aromatic $\mathrm{C}-\mathrm{H}$ bonds as isotopic scrambling was observed in the meta and para positions as well as the ortho $\mathrm{C}-\mathrm{H}$ bonds, which has led to the proposal of a distinctly different mechanistic pathway (Scheme 1.12). ${ }^{110}$ This implies that chelation of the carbonyl group is not required prior to $\mathrm{C}-\mathrm{H}$ activation for $\mathrm{Rh}$ as it is for $\mathrm{Ru}$. However, chelation of the carbonyl group is believed to be required for product release as it significantly reduces the activation barrier for reductive elimination. ${ }^{99,110}$

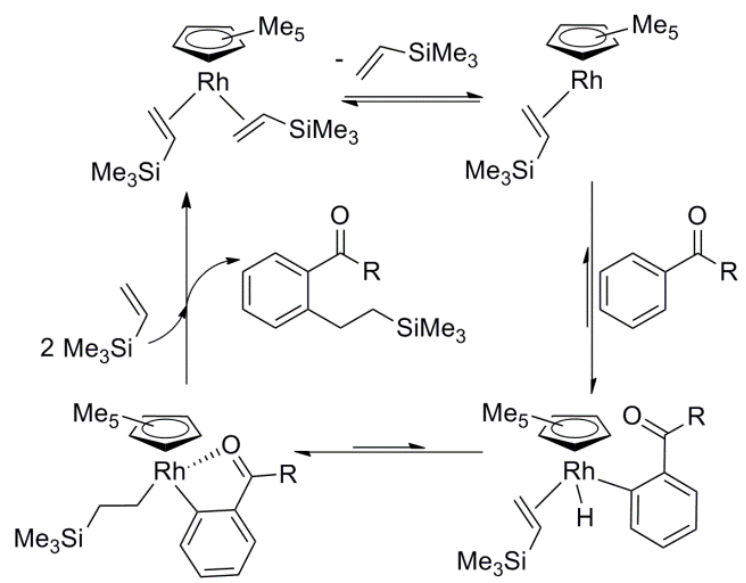

Scheme 1.12. Proposed mechanism for chelate-assisted olefin hydroarylation of aromatic ketones using $\left(\eta^{5}-\mathrm{C}_{5} \mathrm{Me}_{5}\right) \mathrm{Rh}\left(\eta^{2}-\mathrm{C}_{2} \mathrm{H}_{3} \mathrm{SiMe}_{3}\right)_{2}$. 
Intramolecular hydroarylation using allylic benzenes was found to be catalyzed by $\mathrm{RuCl}_{3}$ upon activation by AgOTf in dichloromethane. ${ }^{111}$ For example, the reaction of 5phenylpentene at $60{ }^{\circ} \mathrm{C}$ in the presence of $1 \mathrm{~mol} \% \mathrm{RuCl}_{3} / \mathrm{AgOTf}$ resulted in the formation of 1-methyl-1,2,3,4-tetrahydronaphthalene in $82 \%$ yield (Scheme 1.13). The reaction was found to be tolerant of a variety of functional groups on the aryl backbone, including methoxy, bromo and protected amine moieties. The formation of HOTf in situ as the active catalyst was deemed unlikely as the analogous reaction in which HOTf was substituted for $\mathrm{RuCl}_{3}$ only resulted in a $16 \%$ yield of the cyclized product. An electrophilic mechanism was proposed. In this scenario, the metal center activates the olefin towards electrophilic attack on the arene, and protonolysis of the resulting $\mathrm{Ru}-\mathrm{C}$ bond liberates the cyclized product.

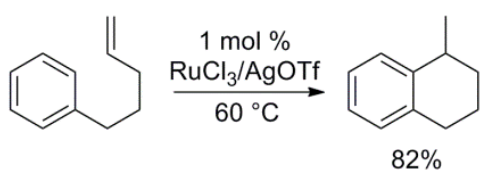

Scheme 1.13. Ru-Ag catalyst system for catalytic intramolecular olefin hydroarylation.

\subsubsection{Intermolecular Transition-Metal Mediated Olefin Hydroarylation with Unactivated Substrates via a Non-Acid Catalyzed Pathway}

To date, only two examples of non-platinum based transition metal complexes have been reported to successfully catalyze intermolecular olefin hydroarylation with unactivated substrates (e.g., benzene and ethylene). These catalysts are based on 
octahedral $\mathrm{Ru}^{\mathrm{II}}$ and $\mathrm{Ir}^{\mathrm{III}}$ complexes, and extensive study has elucidated that they likely adhere to the same general mechanism (Chart 1.6; Scheme 1.9).

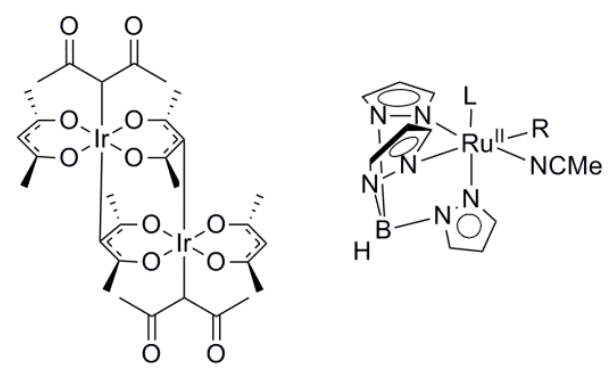

Chart 1.6. Reported catalyst precursors for olefin hydroarylation with unactivated substrates based upon $\mathrm{Ir}^{\mathrm{III}}$ and $\mathrm{Ru}^{\mathrm{II}}\left[\mathrm{L}=\mathrm{CO}, \mathrm{P}\left(\mathrm{OCH}_{2}\right)_{3} \mathrm{CEt}\right.$ or $\mathrm{SPhos}$ (SPhos $=2,6,7$ Trioxa-1-phosphabicyclo[2,2,1]heptane); $\mathrm{R}=\mathrm{Ph}$ or $\mathrm{Me}]$.

Periana, Goddard and coworkers have developed Ir ${ }^{\mathrm{III}}$ complexes that serve as catalyst precursors for olefin hydroarylation..$^{78,}{ }^{112-116}$ Initial reports showed that $[\operatorname{Ir}(\mu$-acac$\left.\left.O, O, C^{3}\right)-(\operatorname{acac}-O, O)-\left(\operatorname{acac}-\mathrm{C}^{3}\right)\right]_{2} \quad($ acac $=$ acetylacetonate $)$ catalyzes the formation of ethylbenzene at $180^{\circ} \mathrm{C}$ from ethylene and benzene with a turnover frequency (TOF) of $4.2 \times 10^{-2} \mathrm{~s}^{-1}$ (Scheme 1.14). ${ }^{112}$ The free energy of activation for the catalyzed hydrophenylation of ethylene was determined to be $28.7 \mathrm{kcal} / \mathrm{mol} .{ }^{113}$ The active catalyst is proposed to be cis- $(O, O \text {-acac })_{2} \operatorname{Ir}(\mathrm{Ph})\left(\eta^{2}\right.$-ethylene $)$, formed in situ from benzene $\mathrm{C}-\mathrm{H}$ activation and ethylene coordination. A mononuclear species as the active catalyst is supported by the independent synthesis of mononuclear $\operatorname{Ir}(\operatorname{acac})_{2} \mathrm{Ph}(\mathrm{L})\left(\mathrm{L}=\right.$ acac, $\mathrm{H}_{2} \mathrm{O}$ or pyridine) complexes that exhibit catalytic activity similar to that for the binuclear Ir catalyst precursor, and the slight differences in activity are assumed to be a result of ground state effects. $^{78}$ 


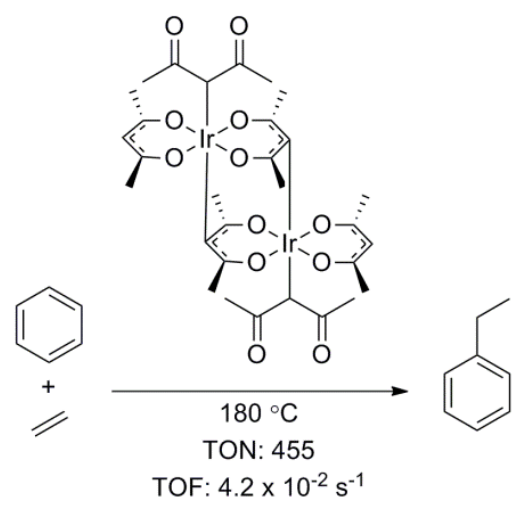

Scheme 1.14. Hydrophenylation of ethylene using $\left[\operatorname{Ir}\left(\mu\right.\right.$-acac- $\left.O, O, C_{3}\right)$-(acac- $\left.O, O\right)$-(acac$\left.\left.C_{3}\right)\right]_{2}$.

In addition to ethylene, the $\mathrm{Ir}^{\mathrm{III}}$ catalyst is active for the hydrophenylation of propylene, 1-butene and 1-hexene, albeit at reduced rates compared to the reactions with ethylene. ${ }^{112-113}$ For $\alpha$-olefins, linear alkyl arenes were the major product with an $\sim 1.5: 1$ ratio of linear to branched products, which is nearly identical to the observed selectivity of a Ru ${ }^{\text {II }}$ catalyst. ${ }^{117}$ This result, coupled with the observation of decreased reaction rates for substituted $\alpha$-olefins and other mechanistic studies, indicates a non-Friedel-Crafts mechanism is operative. ${ }^{113}$ All of the $\mathrm{Ir}^{\mathrm{III}}$ catalysts studied have similar linear:branched selectivity for hydrophenylation of $\alpha$-olefins, which indicates that they likely proceed through a similar catalytic pathway. The activity of ethylene hydroarylation with substituted arenes such as toluene and ethylbenzene was also investigated. ${ }^{113}$ Catalytic activity, as observed with olefins other than ethylene, was significantly reduced. The regioselectivity for monosubstituted arene $\mathrm{C}-\mathrm{H}$ activation was observed to be $\sim 65: 35$ for meta- versus para-substituted benzenes. No ortho addition products were detected. The approximate 2:1 ratio between meta and para addition is quite similar to that observed for other $\mathrm{C}-\mathrm{H}$ activating systems. ${ }^{79,} 118-122$ 
Experimental studies and DFT calculations have been used to probe the mechanism of $\mathrm{Ir}^{\mathrm{III}}$ catalyzed ethylene hydrophenylation, and the proposed pathway is shown in Scheme 1.15. The catalyst precursor, trans $-\left(\kappa^{2}-O, O \text {-acac }\right)_{2} \operatorname{Ir}(\mathrm{Ph})$ undergoes trans/cis isomerization of the acac ligands. Next, migratory insertion of the olefin into the $\mathrm{Ir}-\mathrm{Ph}$ bond occurs to produce the five-coordinate intermediate cis- $(O, O \text {-acac })_{2} \operatorname{Ir}\left(\mathrm{CH}_{2} \mathrm{CH}_{2} \mathrm{Ph}\right)$, which has been determined to be the rate limiting step of the catalytic cycle. Coordination of benzene and subsequent aromatic $\mathrm{C}-\mathrm{H}$ activation liberates ethylbenzene and regenerates the $\mathrm{Ir}-\mathrm{Ph}$ bond, closing the catalytic cycle.

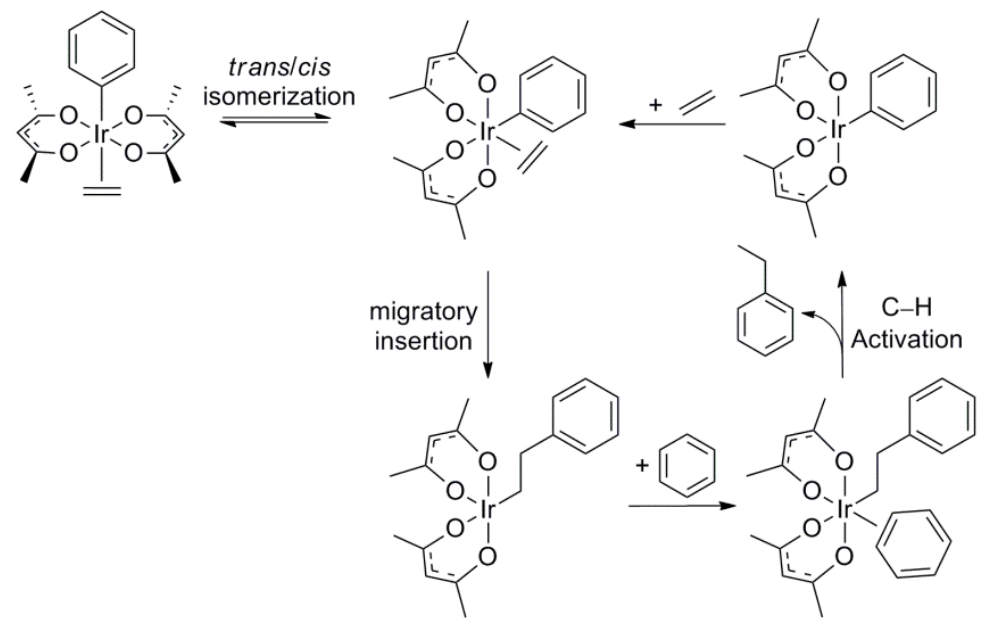

Scheme 1.15. Proposed mechanism for ethylene hydrophenylation catalyzed by cis-- $\left(\kappa^{2}-\right.$ $O, O-\mathrm{acac})_{2} \operatorname{Ir}\left(\eta^{2}-\mathrm{C}_{2} \mathrm{H}_{4}\right)(\mathrm{Ph})$.

Other ligand motifs were explored with $\operatorname{Ir}^{\mathrm{III}}$ olefin hydroarylation including bipyrimidine and cyclopentadienyl, but these complexes were found to be inactive for catalytic olefin hydroarylation. ${ }^{113}$ The effect of O-donor ligand variation on catalytic activity was explored by substitution of the $O, O$-donor bidentate ligand from acac to trop $\left(\right.$ trop $=\kappa^{2}-O, O$-tropolonato, Chart 1.7). ${ }^{123}$ The tropolone based ligand is expected to be 
less electron donating than acac due to increased aromatic delocalization, and the smaller bite angle of the trop ligand (5-membered chelate compared to the 6-membered for acac) should provide a different steric environment compared to that of acac. The complex $(\text { trop })_{2} \mathrm{Ir}(\mathrm{Ph})(\mathrm{Py})(\mathrm{Ir}-$ trop, $\mathrm{Py}=$ pyridine$)$ was found to catalyze aromatic $\mathrm{C}-\mathrm{H}$ activation faster than the acac variant. However, upon evaluation of catalytic activity for ethylene hydrophenylation, it displayed a lower turnover number than the Ir-acac analogue. It was proposed from computational study that the activation barrier for aromatic $\mathrm{C}-\mathrm{H}$ activation is significantly lower for Ir-trop, but the activation barrier for olefin insertion (i.e., the rate determining step) is increased compared to $(\mathrm{acac})_{2} \operatorname{Ir}(\mathrm{Ph}) .{ }^{123}$

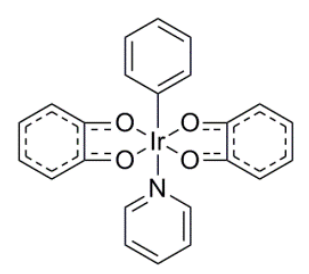

Chart 1.7. The $\mathrm{Ir}^{\mathrm{III}}$ complex (trop) $)_{2} \mathrm{Ir}(\mathrm{py}) \mathrm{Ph}$ (trop $=\kappa^{2}-O, O$-tropolonato; Ir-trop).

The Gunnoe group has been studying $\mathrm{Ru}^{\mathrm{II}}$ complexes with the general formula $\mathrm{TpRu}(\mathrm{L})(\mathrm{NCMe})(\mathrm{R}) \quad\left[\mathrm{Tp}=\right.$ hydridotris $\left(\right.$ pyrazolyl)borate; $\quad \mathrm{L}=\mathrm{CO}, \quad \mathrm{PMe}_{3}, \quad \mathrm{P}(\mathrm{pyr})_{3}$ $($ pyr $=N$-pyrrolyl $), \quad \mathrm{P}\left(\mathrm{OCH}_{2}\right)_{3} \mathrm{CEt} \quad$ or $\quad$ SPhos $\quad(\mathrm{SPhos} \quad=\quad 2,6,7$-trioxa-1phosphabicyclo[2,2,1]heptane; $\mathrm{R}=\mathrm{Me}$ or $\mathrm{Ph}$ (Chart 1.6) as catalysts for olefin hydroarylation. ${ }^{79}, 117,124-128$ The initially reported complex $\operatorname{TpRu}(\mathrm{CO})(\mathrm{NCMe})(\mathrm{Ph})$ (TpRu-CO) catalyzes ethylene hydrophenylation under mild conditions with selectivity for monoalkylated products. ${ }^{117}$ At $90{ }^{\circ} \mathrm{C}$ and 25 psi of ethylene, TpRu-CO $(0.1 \mathrm{~mol} \%$ relative to benzene) catalyzes 51 and 77 turnovers (TO) of ethylbenzene after 4 and 24 
hours, respectively, with only trace quantities of 1,3- and 1,4-diethylbenzene products detected.

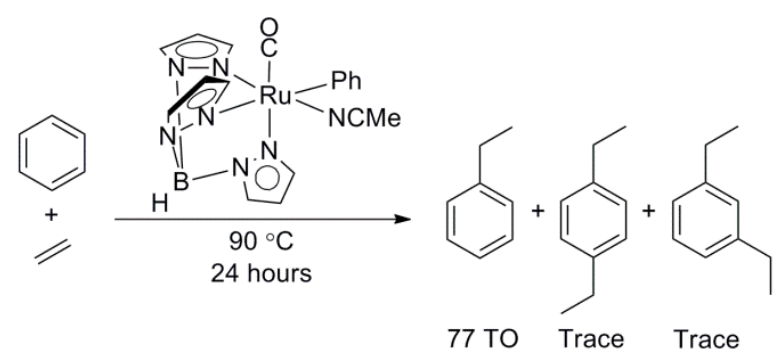

Scheme 1.16. Hydrophenylation of ethylene using $0.1 \mathrm{~mol} \% \mathrm{TpRu}(\mathrm{CO})(\mathrm{NCMe})(\mathrm{Ph})$ (TpRu-CO).

Extensive mechanistic studies are consistent with the proposed catalytic cycle in Scheme $1.17 .^{79,117,124,128}$ The catalytic cycle is initiated by acetonitrile dissociation followed by ethylene coordination and insertion into the $\mathrm{Ru}-\mathrm{Ph}$ bond. Benzene coordination and subsequent $\mathrm{C}-\mathrm{H}$ activation results in ethylbenzene formation. Ethylbenzene dissociation and coordination of ethylene close the catalytic cycle. The Gunnoe group has proposed that the $\mathrm{C}-\mathrm{H}$ activation step is rate limiting. ${ }^{79}$ However, this is contested by DFT calculations performed by Goddard that suggest, for both TpRu-CO and the $\mathrm{Ir}^{\mathrm{III}}$ catalyst systems, ethylene insertion into the $\mathrm{M}-\mathrm{Ph}$ bond is rate limiting. ${ }^{80,129}$ Ethylene insertion has been observed in stoichiometric reactions of TpRu-CO and ethylene to produce $\mathrm{TpRu}(\mathrm{CO})\left(\mathrm{CH}_{2} \mathrm{CH}_{2} \mathrm{Ph}\right)(\mathrm{NCMe})$, which indicates that the $\mathrm{TpRu}(\mathrm{CO})(\mathrm{Ph})$ fragment can indeed coordinate and insert ethylene into the $\mathrm{Ru}-\mathrm{Ph}$ bond. $\mathrm{TpRu}(\mathrm{CO})\left(\mathrm{CH}_{2} \mathrm{CH}_{2} \mathrm{Ph}\right)\left(\eta^{2}-\mathrm{C}_{2} \mathrm{H}_{4}\right)$ has been observed while monitoring catalysis by ${ }^{1} \mathrm{H}$ NMR spectroscopy and is proposed as the catalyst resting state. Comparison of the rate of 
hydrophenylation of ethylene in $\mathrm{C}_{6} \mathrm{H}_{6}$ versus $\mathrm{C}_{6} \mathrm{D}_{6}$ revealed a kinetic isotope effect of 2.1(1) suggesting that benzene $\mathrm{C}-\mathrm{H}$ activation is rate limiting, instead of olefin insertion as suggested for Ir-acac. ${ }^{117}$

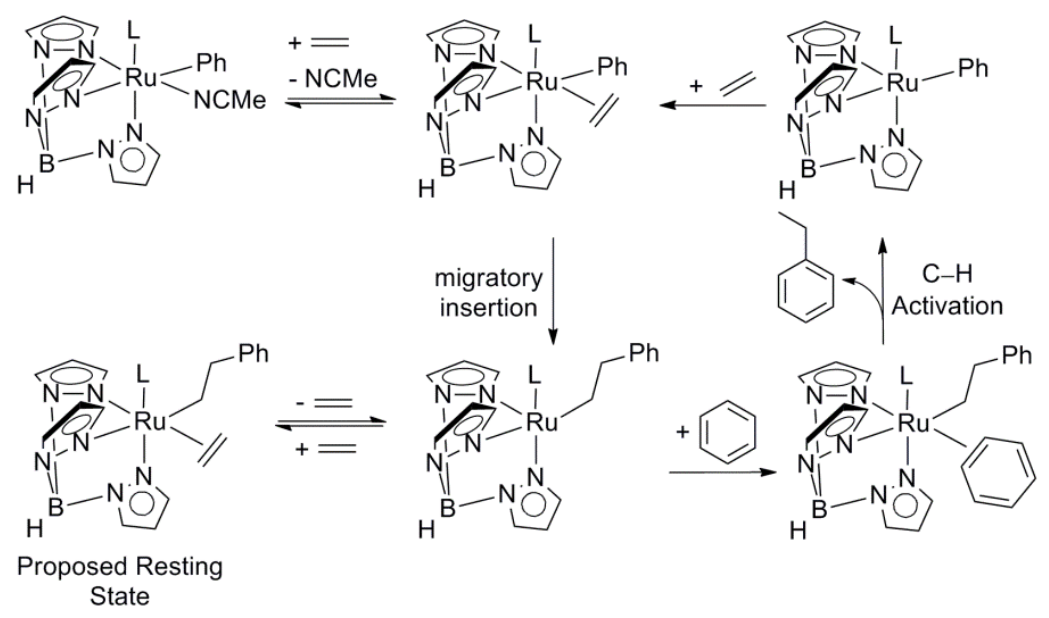

Scheme 1.17. Proposed catalytic cycle for the hydrophenylation of ethylene using $\mathrm{TpRu}(\mathrm{L})(\mathrm{NCMe}) \mathrm{Ph} \quad\left[\mathrm{L}=\mathrm{CO}, \mathrm{P}\left(\mathrm{OCH}_{2}\right)_{3} \mathrm{CEt}\right.$, or SPhos $\quad$ SPhos = 2,6,7-Trioxa-1phosphabicyclo[2,2,1]heptane)].

Under the same conditions as the hydrophenylation of ethylene, catalytic activity decreased approximately $80 \%$ for the conversion of ethylbenzene and ethylene to diethylbenzenes (2:1 ratio of 1,3-diethylbenzene and 1,4-diethylbenzene) after 4 hours. The lack of formation of 1,2-diethylbenzene in the reaction of ethylbenzene with ethylene supports a non-acid catalyzed pathway. Also, transalkylation to produce ethylbenzene in a 1:1 mixture of 1,4-diethylbenzene and benzene at $90{ }^{\circ} \mathrm{C}$ in the presence of TpRu-CO does not occur as is often observed for FC catalysts.

The hydrophenylation of propylene and 1-hexene by $\mathbf{T p R u - C O}$ provides propylbenzenes and hexylbenzenes with linear to branched ratios of 1.6:1 and 1.7:1. For 
the reaction with 1 -hexene, the formation of the 3-phenyl isomer is not observed, suggesting that olefin isomerization is not competitive with catalytic olefin hydrophenylation. For the TpRu-CO system, a computational study suggests that the regioselectivity for linear alkyl arenes may be the result of the ancillary ligands directing a preferred olefin orientation prior to the insertion step. ${ }^{80}$ However, a detailed analysis of the various factors that control the regioselectivity has not been undertaken, and origin of the linear/branched ratio is not currently understood. ${ }^{129}$

The $\mathrm{TpRu}(\mathrm{L})(\mathrm{NCMe})(\mathrm{Ph})$ architecture allows for the systematic manipulation of the electronic and steric properties of the catalyst by altering the identity of the ancillary ligand (L). The complex TpRu(NCMe)(Ph)(PMe $)_{3}$ ( $\left.\mathbf{T p R u}-\mathbf{P M e}_{3}\right)$ provides a more electron-rich metal center due to the phosphine $\sigma$-donor, compared to $\mathbf{T p R u - C O}$ with $\pi$ acidic carbon monoxide, and was found to mediate stoichiometric $\mathrm{C}-\mathrm{D}$ activation of $\mathrm{C}_{6} \mathrm{D}_{6} \sim 3$ times faster than TpRu-CO. ${ }^{126}$ While $\mathrm{C}-\mathrm{H} / \mathrm{D}$ activation is more rapid for TpRu-PMe 3 , it is a poor catalytic precursor for ethylene hydrophenylation and results in very few catalytic turnovers, even at temperatures exceeding $90{ }^{\circ} \mathrm{C}$. For the more electron-rich $\mathrm{Ru}$ center of $\mathbf{T p R u}-\mathbf{P M e} \mathbf{e}_{3}$ ethylene $\mathrm{C}-\mathrm{H}$ activation is competitive with benzene $\mathrm{C}-\mathrm{H}$ activation and results in catalyst deactivation due to the formation of $\operatorname{TpRu}\left(\eta^{3}-\mathrm{C}_{4} \mathrm{H}_{7}\right)\left(\mathrm{PMe}_{3}\right){ }^{79,}{ }^{126-128}$ The use of $\mathrm{TpRu}\left(\eta^{3}-\mathrm{C}_{4} \mathrm{H}_{7}\right)\left(\mathrm{PMe}_{3}\right)$ as a catalyst for ethylene hydrophenylation produces no alkyl benzenes. At increased temperatures (180 $\left.{ }^{\circ} \mathrm{C}\right)$ and ethylene pressures $(1-5.5 \mathrm{MPa})$, the dimerization and trimerization of ethylene was observed to produce butenes and hexenes but only in small quantities and with no regioselectivity. ${ }^{126}$ 
To further probe the effects of varying the sterics and electronics on catalysis, complexes bearing $\mathrm{P}(\mathrm{pyr})_{3}\left(\mathrm{pyr}=N\right.$-pyrrolyl) or phosphites $\left[\mathrm{P}\left(\mathrm{OCH}_{2}\right)_{3} \mathrm{CEt}(\mathrm{BPhos})\right.$ and 2,6,7-trioxa-1-phosphabicyclo[2,2,1]heptane (SPhos)] were studied. For $\mathrm{TpRu}(\mathrm{L})(\mathrm{NCMe})(\mathrm{Ph})$ complexes, cyclic voltammetry has been used to determine the impact of the ancillary ligand (L) on the electron density at the ruthenium center (Table 1.3). A comparison of stoichiometric $\mathrm{C}-\mathrm{D}$ activation of $\mathrm{C}_{6} \mathrm{D}_{6}$ by $\mathrm{TpRu}(\mathrm{L})(\mathrm{NCMe}) \mathrm{Ph}$ complexes reveals that the trend in the rate of reaction is $\mathrm{PMe}_{3}>\mathrm{BPhos}>\mathrm{SPhos}>\mathrm{CO}$, which correlates with the donor ability of the ligand L (Figure 1.1). ${ }^{79,}{ }^{128}$ For $\mathrm{TpRu}(\mathrm{L})(\mathrm{NCMe}) \mathrm{Ph}$, more electron rich metal centers facilitate faster overall benzene $\mathrm{C}-$ $\mathrm{H}$ activation. Catalytic studies reveal that $\mathrm{TpRu}(\mathrm{BPhos})(\mathrm{NCMe})(\mathrm{Ph})$ is active for ethylene hydrophenylation, but cessation of catalytic activity is observed after $\sim 20$ TO. Similar to $\mathbf{T p R u}-\mathbf{P M e}_{3}$, catalyst deactivation is a result of competitive ethylene $\mathrm{C}-\mathrm{H}$ activation, which leads to the formation of the $\eta^{3}$-allyl complex $\mathrm{TpRu}(\mathrm{BPhos})\left(\eta^{3}-\mathrm{C}_{4} \mathrm{H}_{7}\right)$. This is also the case for $\mathrm{TpRu}(\mathrm{NCMe})(\mathrm{Ph})(\mathrm{SPhos})$. While SPhos is less electron donating than BPhos, competitive ethylene $\mathrm{C}-\mathrm{H}$ activation results in the formation of an $\eta^{3}$-allyl complex, halting catalysis after 90 TO. The $\mathrm{P}(\mathrm{pyr})_{3}$ complex $\mathrm{TpRu}\left(\mathrm{P}(\mathrm{pyr})_{3}\right)(\mathrm{NCMe})(\mathrm{Ph})$ is not a catalyst for the hydrophenylation of ethylene. Combined experimental and computational studies reveal that the large steric profile of the $\mathrm{P}(\mathrm{pyr})_{3}$ ligand hinders coordination of $\mathrm{C}_{6} \mathrm{D}_{6}$ for stoichiometric $\mathrm{C}-\mathrm{D}$ activation $(\sim 70 \%$ yield of $\left.\mathrm{TpRu}\left(\mathrm{P}(\mathrm{pyr})_{3}\right)(\mathrm{NCMe})\left(\mathrm{Ph}-d_{5}\right)\right)$ and prevents the binding of ethylene under catalytic conditions. $^{130}$ 
Table 1.3. Comparison of $\mathrm{TpRu}(\mathrm{L})(\mathrm{NCMe})(\mathrm{Ph})$ steric and electronic properties, in addition to, rates for $\mathrm{C}_{6} \mathrm{D}_{6} \mathrm{C}-\mathrm{D}$ activation and turnovers for ethylene hydrophenylation.

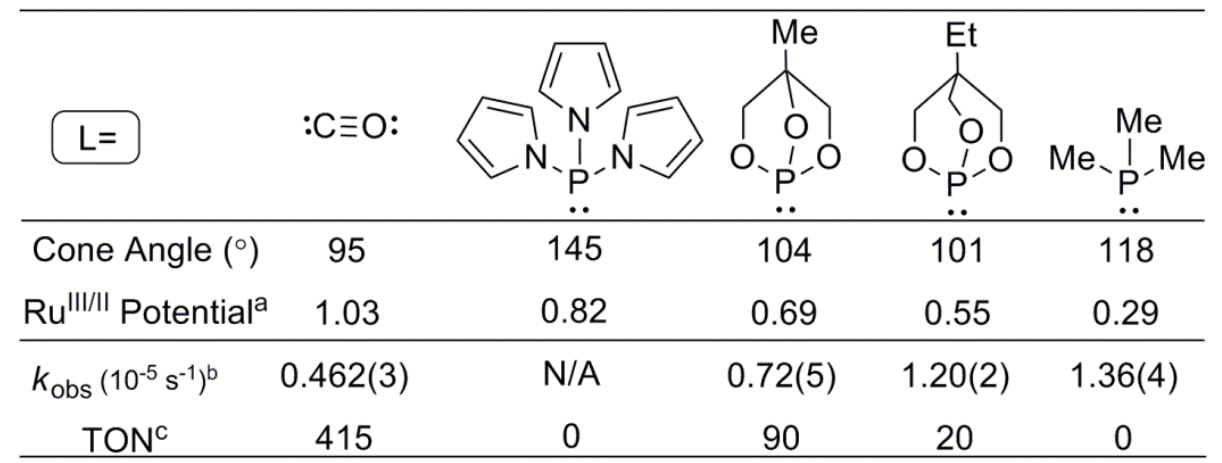

${ }^{\mathrm{a}}$ Referenced versus NHE. ${ }^{\mathrm{b}}$ Reactions performed in $\mathrm{C}_{6} \mathrm{D}_{6}$ with $0.065 \mathrm{mmol}$ of added $\mathrm{NCMe}$ at $60{ }^{\circ} \mathrm{C}$. ${ }^{\mathrm{C}}$ Final turnover number of ethylbenzene for ethylene hydrophenylation with $0.025 \mathrm{~mol} \% \mathrm{Ru}$, relative to $\mathrm{C}_{6} \mathrm{H}_{6}$, at $90{ }^{\circ} \mathrm{C}$.

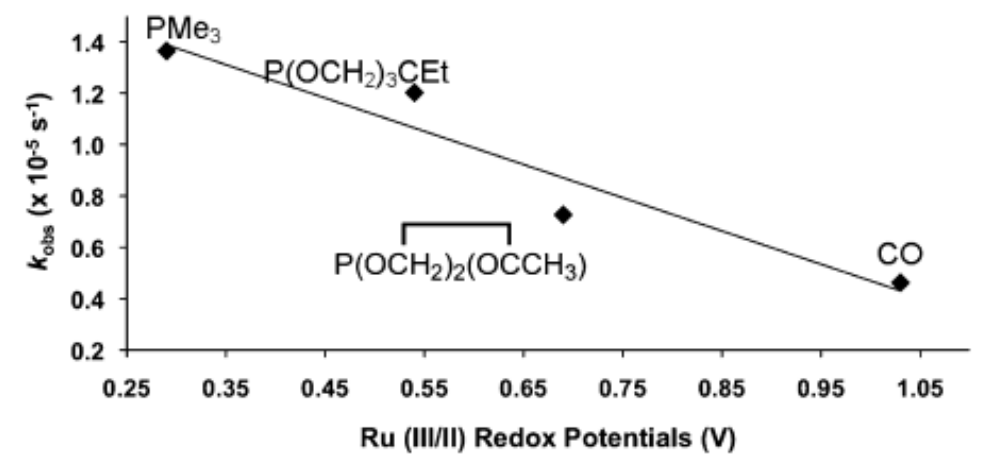

Figure 1.1. Plot of $k_{\text {obs }}$ for stoichiometric $\mathrm{C}_{6} \mathrm{D}_{6} \mathrm{C}-\mathrm{D}$ activation by $\mathrm{TpRu}(\mathrm{L})(\mathrm{NCMe}) \mathrm{Ph}(\mathrm{L}$ $=\mathrm{CO}$, BPhos, SPhos or $\mathrm{PMe}_{3}$ ) at $60{ }^{\circ} \mathrm{C}$ with $0.065 \mathrm{mmol}$ of added NCMe versus $\mathrm{Ru}^{\mathrm{III} / \mathrm{LI}}$ potentials (vs NHE, V). Reproduced from reference 128.

Despite the proposal that benzene $\mathrm{C}-\mathrm{H}$ activation is the rate limiting step for hydrophenylation of ethylene catalyzed by $\mathrm{TpRu}(\mathrm{CO})(\mathrm{NCMe})(\mathrm{Ph})$, the influence of the ancillary ligand (L) on the activation barrier for ethylene insertion is critical for catalyst performance. For instance, the $\mathrm{PMe}_{3}$, BPhos and SPhos ligands increase the rate of benzene $\mathrm{C}-\mathrm{D}$ activation by $\mathrm{TpRu}(\mathrm{L})(\mathrm{NCMe})(\mathrm{Ph})$, relative to $\mathrm{CO}$, but the activation barrier to ethylene insertion increases as the electron density at the Ru center increases 
(i.e., increased basicity of the $\mathrm{Ru}$ center). Retarding the rate of olefin insertion allows ethylene $\mathrm{C}-\mathrm{H}$ activation to compete with catalytic turnover. ${ }^{126-128}$ For example, the decreased electron donating ability BPhos, relative to $\mathrm{PMe}_{3}$, provides a more efficient catalyst, but the phosphite ligand is a sufficiently $\sigma$-donating for ethylene $\mathrm{C}-\mathrm{H}$ activation to compete. While the SPhos ligand is even less $\sigma$-donating than BPhos and provides prolonged catalytic activity, the $\eta^{3}$-allyl complex is inevitably formed. This systematic structure/activity relationship addressing both ancillary ligand electronics and sterics illustrates a delicate balance between olefin insertion and arene $\mathrm{C}-\mathrm{H}$ activation for efficient catalysis.

Computational studies of the Ir and Ru catalysts allow a comparison of the two closely related systems. The Ru and Ir systems adhere to similar reaction pathways. ${ }^{80}$ Moreover, both complexes are predicted to activate aromatic $\mathrm{C}-\mathrm{H}$ bonds by a mechanism that is a hybridization of $\sigma$-bond metathesis and oxidative addition. The transition state features a concerted four-membered transition state in which the metal center directly interacts with the proton being transferred from the arene to the alkyl substituent (TS2 in Scheme 1.9). ${ }^{78-79}$ As the transition state is oxidative in character with respect to the metal, the $\mathrm{C}-\mathrm{H}$ activation process could be argued to possess transient $\mathrm{Ru}^{\mathrm{IV}}$ and $\mathrm{Ir}^{\mathrm{V}}$ formal oxidation states. Oxidative addition of aromatic $\mathrm{C}-\mathrm{H}$ bonds to form discrete $\mathrm{M}(\mathrm{H})(\mathrm{R})(\mathrm{Ph})$ intermediates is predicted have a higher activation barrier for both $\mathrm{TpRu}$ and $(\mathrm{O}, \mathrm{O}-\mathrm{acac})_{2} \mathrm{Ir}$ complexes due to unlikely formation of seven-coordinate intermediates. Examples of seven coordinate $\mathrm{Ir}^{\mathrm{V}}$ systems as a result of $\mathrm{C}-\mathrm{H}$ oxidative addition are known, ${ }^{131-133}$ but the increased steric profile and reduced basicity of the $\mathrm{Ir}^{\mathrm{III}}$ 
center (compared to those examples) due to the acac ligand framework result in aromatic $\mathrm{C}-\mathrm{H}$ oxidative addition being higher in energy than the $\sigma$-bond metathesis pathway. ${ }^{78}$

Based upon computational study by Periana, Goddard and coworkers, the ratedetermining step for $\mathrm{Ir}^{\mathrm{III}}$ and $\mathrm{Ru}^{\mathrm{II}}$ catalyzed ethylene hydrophenylation is proposed to be olefin insertion. ${ }^{80}$ Starting from the $\eta^{2}$-ethylene complexes, the $\Delta H^{\ddagger}$ for ethylene insertion is calculated to be lower for $\mathrm{TpRu}(\mathrm{CO})\left(\eta^{2}-\mathrm{C}_{2} \mathrm{H}_{4}\right) \mathrm{Ph}$ by $\sim 3.4 \mathrm{kcal} / \mathrm{mol}$, compared to cis$(O, O \text {-acac })_{2} \operatorname{Ir}(\mathrm{Ph})\left(\eta^{2}-\mathrm{C}_{2} \mathrm{H}_{4}\right)$. Whereas, benzene $\mathrm{C}-\mathrm{H}$ activation from $\mathrm{M}\left(\mathrm{CH}_{2} \mathrm{CH}_{2} \mathrm{Ph}\right)\left(\eta^{2}-\right.$ $\left.\mathrm{C}_{6} \mathrm{H}_{6}\right)\left(\mathrm{M}=\mathrm{TpRu}(\mathrm{CO})\right.$ or cis- $\left.(O, O \text {-acac })_{2} \mathrm{Ir}\right)$ is calculated to have a lower barrier for the Ir $^{\text {III }}$ system by $6.2 \mathrm{kcal} / \mathrm{mol}$. The increased barrier to olefin insertion and overall decreased activity of the $c i s-(O, O \text {-acac })_{2} \mathrm{IrPh}$ catalyst relative to $\mathrm{TpRu}(\mathrm{CO})(\mathrm{NCMe})(\mathrm{Ph})$ is primarily attributed to ligand effects rather than the metal identity and oxidation state of the metal center. Stated another way, the $\mathrm{TpRu}(\mathrm{CO})(\mathrm{NCMe})(\mathrm{Ph})$ catalyst achieves greater harmony between activation barriers for olefin insertion and benzene $\mathrm{C}-\mathrm{H}$ activation than does the bis-acac ligand motif.

An important point to be taken from the extensive experimental and computational study of these catalysts for olefin hydroarylation is the inverse relationship between activation barriers for olefin insertion and aromatic $\mathrm{C}-\mathrm{H}$ activation. Tuning the ancillary ligand set to decrease the activation barrier for one process along the catalytic cycle $(e . g$, olefin insertion) results in an increase in the activation barrier for its companion transformation (e.g., aromatic $\mathrm{C}-\mathrm{H}$ activation). There is a narrow window for complex optimization, as significant changes in metal basicity will result in a decrease in catalytic activity and a reversal of the rate limiting step for catalysis. This realization has prompted 
this study of catalyst systems outside the octahedral $d^{6}$ catalyst motif with an emphasis on $\mathrm{Pt}^{\mathrm{II}}$ precursors.

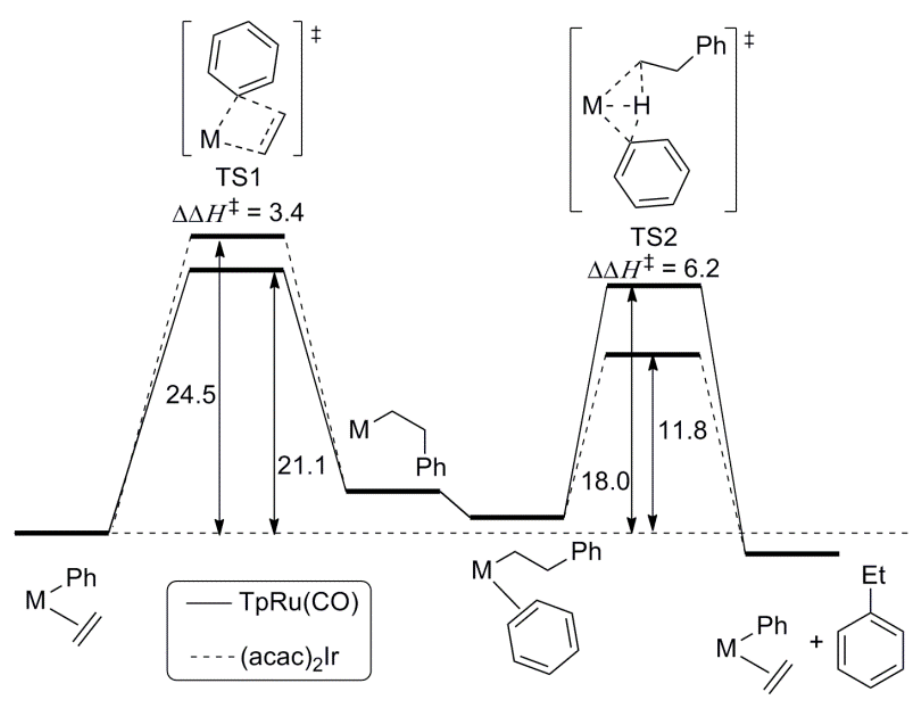

Scheme 1.18. Comparison of calculated enthalpies ( $\mathrm{kcal} / \mathrm{mol})$ of activation for ethylene insertion and benzene $\mathrm{C}-\mathrm{H}$ activation during ethylene hydrophenylation catalyzed by $c i s$ $(\mathrm{O}, \mathrm{O} \text {-acac })_{2} \mathrm{Ir}$ and $\mathrm{TpRu}(\mathrm{CO})$.

\subsection{Platinum: Promising Candidate for Transition Metal Catalyzed Olefin Hydroarylation}

Platinum in its divalent state has emerged as a promising candidate for catalytic olefin hydroarylation with precedent for olefin insertion, ${ }^{134-139}$ but inefficient olefin oligomerization/polymerization, ${ }^{138,}{ }^{140-142}$ and aromatic $\mathrm{C}-\mathrm{H}$ activation. ${ }^{76}$ Thus, platinum complexes appear suited to combine olefin insertion and aromatic $\mathrm{C}-\mathrm{H}$ activation into a single catalytic cycle. In addition, the electrophilic nature and the difference in the frontier molecular orbitals of $\mathrm{Pt}^{\mathrm{II}} \mathrm{d}^{8}$ square planar complexes could result in substantially 
different structure/activity relationships when compared to $\mathrm{Ru}^{\mathrm{II}}$ and $\mathrm{Ir}^{\mathrm{III}}$ octahedral, $\mathrm{d}^{6}$ catalysts (see above). Examples of olefin hydroarylation using $\mathrm{Pt}^{\mathrm{II}}$ catalyst precursors have been reported, ${ }^{143-149}$ but outside of this work, mechanistic evidence supporting a non-acid-catalyzed pathway has been disclosed for only one complexe. ${ }^{147}$

\subsubsection{Mechanism Elucidation for Platinum Mediated Aromatic C-H Activation}

The reports of "Shilov" Pt catalysts for hydrocarbon functionalization initiated substantial interest in Pt-mediated $\mathrm{C}-\mathrm{H}$ activation. Typically, the $\mathrm{C}-\mathrm{H}$ activation step dictates the catalyst activity and regio-/chemoselectivity of the reaction. Due to the breadth and depth of accumulated knowledge regarding hydrocarbon activation by platinum complexes, it cannot be concisely summarized in this section. Therefore, hydrocarbon activation by platinum complexes containing halogen ligands or proceeding via electrophilic mechanisms, typical of platinum complexes containing chloride ligands, will not be included. ${ }^{150-152}$ The main focus will be towards understanding the mechanism by which $\mathrm{Pt}^{\mathrm{II}}$ complexes containing $\sigma$-alkyl and $\sigma$-aryl moieties activate aromatic hydrocarbons, which is most relevant for the development of successful $\mathrm{Pt}^{\mathrm{II}}$ complexes for catalytic olefin hydroarylation.

Most of the knowledge about $\mathrm{Pt}$ mediated alkyl and aromatic $\mathrm{C}-\mathrm{H}$ activation comes from studying the microscopic reverse reaction, $\mathrm{C}-\mathrm{H}$ reductive coupling and elimination. In the following examples, it is of interest to note that $\mathrm{Pt}^{\mathrm{II}}$ complexes containing nitrogen chelates have had the most success in generating $\mathrm{Pt}^{\mathrm{II}}$ complexes that are active towards aromatic hydrocarbon $\mathrm{C}-\mathrm{H}$ activation. Another important common factor in generating a 
reactive $\mathrm{Pt}^{\mathrm{II}}$ center towards oxidatively activating aromatic $\mathrm{C}-\mathrm{H}$ bonds is achieving a coordinately unsaturated 14-electron intermediate.

Bercaw and co-workers have provided strong evidence for the oxidative addition of benzene $\mathrm{C}-\mathrm{H}$ bonds via intermediate $\mathrm{Pt} \sigma$-alkane complexes from the reaction of the $\mathrm{Pt}^{\mathrm{II}}$ methyl cation $[(\mathrm{N} \sim \mathrm{N}) \mathrm{Pt}(\mathrm{Me})(\mathrm{L})]\left[\mathrm{BF}_{4}\right](\mathbf{P t 1}, \mathrm{N} \sim \mathrm{N}=\mathrm{ArN}=\mathrm{C}(\mathrm{Me}) \mathrm{C}(\mathrm{Me})=\mathrm{NAr}, \mathrm{Ar}=2,6-$ $\left.(\mathrm{Me})_{2} \mathrm{C}_{6} \mathrm{H}_{3}\right), \mathrm{L}=\mathrm{H}_{2} \mathrm{O}$ or $\mathrm{CF}_{3} \mathrm{CH}_{2} \mathrm{OH}$ ) with benzene to yield the corresponding phenyl cation $[(\mathrm{N} \sim \mathrm{N}) \mathrm{Pt}(\mathrm{Ph})(\mathrm{L})]\left[\mathrm{BF}_{4}\right] \quad\left(\mathbf{P t 2}\right.$, Scheme 1.19). ${ }^{153}$ Kinetic studies and isotopic labeling suggest that reaction of Pt1 with benzene proceeds via benzene coordination, reversible oxidative addition of benzene $\mathrm{C}-\mathrm{H}$ bonds, reversible formation of a methane $\sigma-\mathrm{C}, \mathrm{H}$ complex, and final dissociation of methane to yield Pt2. For this system, the ratedetermining step is projected to be benzene coordination to $\mathrm{Pt}^{\mathrm{II}}$, as a kinetic isotope effect of almost unity $\left(k_{\mathrm{H}} / k_{\mathrm{D}}=1.06(5)\right)$ is observed. In addition, the reaction is observed to be inverse first order in $\left[\mathrm{H}_{2} \mathrm{O}\right]$ and first order in $\left[\mathrm{C}_{6} \mathrm{H}_{6}\right]$ under the conditions studied. When $\mathrm{C}_{6} \mathrm{D}_{6}$ or $1,3,5-\mathrm{C}_{6} \mathrm{H}_{3} \mathrm{D}_{3}$ are used, extensive $\mathrm{H} / \mathrm{D}$ exchange is observed from the aromatic into methane before liberation from the Pt center. This implies that the barrier for hydrocarbon dissociation (i.e., benzene or methane) is higher than the conversion between $\mathrm{Pt}-\mathrm{Me}$ and $\mathrm{Pt}-\mathrm{Ph}$ species via a 5-coordinate $[(\mathrm{N} \sim \mathrm{N}) \mathrm{Pt}(\mathrm{Ph})(\mathrm{Me}) \mathrm{H}]^{+}$ intermediate. When an independently prepared $(\mathrm{N} \sim \mathrm{N}) \mathrm{Pt}(\mathrm{Me})(\mathrm{Ph})$ complex is protonated with $\mathrm{HOTF}(\mathrm{OTF}=$ trifluoromethanesulfonate) at low temperature (approximately -70 $\left.{ }^{\circ} \mathrm{C}\right)$, a Pt- $\left(\eta^{2}\right.$-benzene) adduct $\left[(\mathrm{N} \sim \mathrm{N}) \mathrm{Pt}\left(\eta^{2}-C, C-\mathrm{C}_{6} \mathrm{H}_{6}\right)(\mathrm{Me})\right]^{+}$is observed by ${ }^{1} \mathrm{H} \mathrm{NMR}$ spectroscopy. In a following study it was observed that the rate limiting step could be shifted to benzene $\mathrm{C}-\mathrm{H}$ activation with slight modification of the diimine ligand. ${ }^{154}$ 


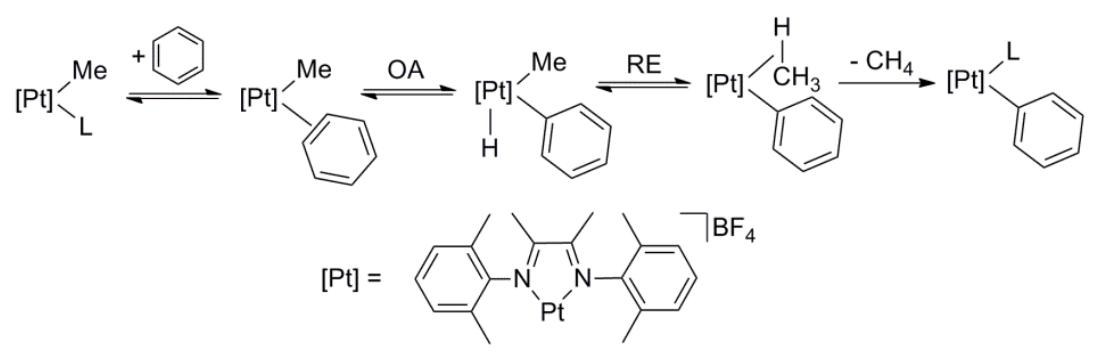

Scheme 1.19. $\mathrm{Pt}^{\mathrm{II}}$ diimine oxidative addition of a $\mathrm{C}-\mathrm{H}$ bond of benzene via intermediacy of a $\eta^{2}-C, C$-benzene adduct $(\mathrm{OA}=$ Oxidative Addition and $\mathrm{RE}=$ Reductive Elimination $)$.

A series of studies were undertaken by Goldberg, Brookhart and Templeton using $\mathrm{Pt}^{\mathrm{II}}$ complexes ligated by hydridotris(3,5-dimethylpyrazolyl)borate (Tp') with the goal of trapping $\mathrm{Pt}^{\mathrm{IV}}$ hydride intermediates following aromatic $\mathrm{C}-\mathrm{H}$ activation. ${ }^{90,}{ }^{155-160}$ This ligand typically coordinates $\mathrm{Pt}^{\mathrm{II}}$ complexes in a $\kappa^{2}$ fashion, but upon oxidative addition of an aromatic substrate, the ligand can assume a $\kappa^{3}$-coordination mode and coordinate facially to the metal center, which renders reductive elimination inaccessible. ${ }^{161-163}$ The resulting 6-coordinate $\mathrm{Pt}^{\mathrm{IV}}$-complexes $\left(\mathrm{Tp}^{\prime}\right) \mathrm{Pt}(\mathrm{H})(\mathrm{Ph})(\mathrm{R})(\mathrm{R}=\mathrm{H}$ or $\mathrm{Ph})$ were isolated and characterized by X-ray crystallography. ${ }^{90,157}$ The addition of the Brønsted acid $\left[\mathrm{H}\left(\mathrm{Et}_{2} \mathrm{O}\right)_{2}\right]\left[\mathrm{BAr}_{4}^{\prime}\right]\left(\mathrm{Ar}^{\prime}=3,5-\left(\mathrm{CF}_{3}\right)_{2} \mathrm{C}_{6} \mathrm{H}_{3}\right)$ to these complexes results in protonation of a pyrazolyl ring of $\mathrm{Tp}^{\prime}$ that induces dissociation from the $\mathrm{Pt}^{\mathrm{IV}}$ center, creating a 5coordinate complex that undergoes facile reductive elimination to generate the $\mathrm{Pt}^{\mathrm{II}}$ complexes $\left[\kappa^{2}-\left(\mathrm{HTp}^{\prime}\right) \mathrm{Pt}\left(\eta^{2}-\mathrm{C}_{6} \mathrm{H}_{6}\right)(\mathrm{R})\right]\left[\mathrm{BAr}_{4}^{\prime}\right](\mathrm{R}=\mathrm{Ph}$ or $\mathrm{H}$, Scheme 1.20). Templeton and co-workers determined the activation barriers for the oxidative addition of a benzene $\mathrm{C}-\mathrm{H}$ bond in the complexes $\left[\mathrm{Tp}^{\prime} \mathrm{Pt}\left(\eta^{2}-\mathrm{C}_{6} \mathrm{H}_{6}\right)(\mathrm{H})\right]\left[\mathrm{BAr}{ }_{4}\right]$ and $\left[\mathrm{Tp}^{\prime} \mathrm{Pt}\left(\eta^{2}-\mathrm{C}_{6} \mathrm{H}_{6}\right)(\mathrm{Ph})\right]\left[\mathrm{BAr}{ }_{4}\right]$ to be 12.7 and $12.9 \mathrm{kcal} / \mathrm{mol}$, respectively (Scheme 1.20$).{ }^{157,}{ }^{159}$ The studies were then expanded to alkylated benzenes and the barriers of aromatic $\mathrm{C}-\mathrm{H}$ activation of toluene 
$(13.6 \mathrm{kcal} / \mathrm{mol})$ and $x y l e n e(14.2 \mathrm{kcal} / \mathrm{mol})$ to $\mathrm{Pt}^{\mathrm{II}}$ were also determined using this ligand motif. ${ }^{159}$ The combined evidence of these studies argues against a mechanism for aromatic $\mathrm{C}-\mathrm{H}$ activation by $\sigma$-bond metathesis.
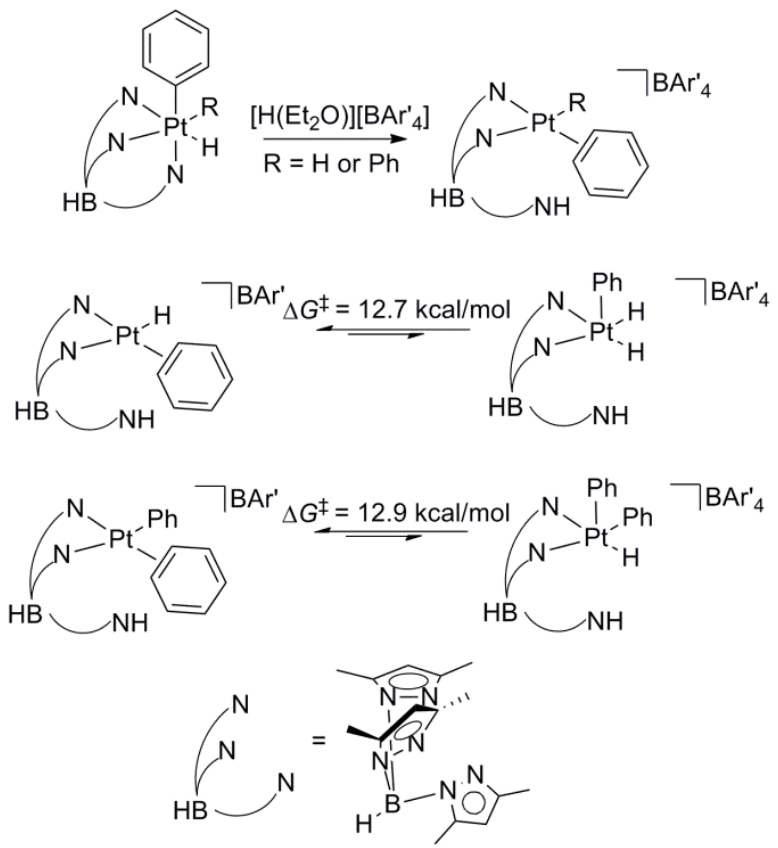

Scheme 1.20. Facile reductive elimination from in situ generated 5-coordinate $\mathrm{Pt}^{\mathrm{IV}}$ complexes to produce $\mathrm{Pt}^{\mathrm{II}}-\left(\eta^{2}\right.$-benzene $)$ adducts enabled the determination of the activation barriers to benzene $\mathrm{C}-\mathrm{H}$ oxidative addition.

A recent report by Tilset appears to contradict an oxidative addition/reductive elimination mechanism for benzene $\mathrm{C}-\mathrm{H}$ activation by $\mathrm{Pt}^{\mathrm{II}}$ established by the aforementioned studies. ${ }^{81}$ Using the same diimine ligand that Bercaw employed (see above), the protonation of a (diimine) $\mathrm{Pt}{ }^{\mathrm{II}}$ diphenyl complex $(\mathrm{N} \sim \mathrm{N}) \mathrm{Pt}(\mathrm{Ph})_{2}$ with $\mathrm{HBF}_{4}$ in the presence of acetonitrile at $-78^{\circ} \mathrm{C}$ results in the formation of the trapped $\mathrm{Pt}^{\mathrm{IV}}$ hydride intermediate $\left[(\mathrm{N} \sim \mathrm{N}) \mathrm{Pt}(\mathrm{H})(\mathrm{NCMe})(\mathrm{Ph})_{2}\right]\left[\mathrm{BF}_{4}\right]$ (Pt3). Upon warming, the complex readily eliminates benzene via rate determining NCMe dissociation to form the four-coordinate 
complex $[(\mathrm{N} \sim \mathrm{N}) \mathrm{Pt}(\mathrm{NCMe})(\mathrm{Ph})]\left[\mathrm{BF}_{4}\right](\mathbf{P t 4})$. Protonation of the diphenyl complex in the absence of NCMe results in the formation of the $\eta^{2}$-benzene adduct $\left[(\mathrm{N} \sim \mathrm{N}) \operatorname{Pt}\left(\eta^{2}-C, C-\right.\right.$ $\left.\left.\mathrm{C}_{6} \mathrm{H}_{6}\right)(\mathrm{Ph})\right]\left[\mathrm{BF}_{4}\right](\mathbf{P t 5})$, and the addition of NCMe results in the associative displacement of benzene to yield Pt4. Monitoring Pt5 by NMR spectroscopy revealed rapid site exchange of protons between the phenyl and $\eta^{2}$-benzene ligands. The kinetics of the exchange were measured and originally proposed to proceed through the formation of $\left[(\mathrm{N} \sim \mathrm{N}) \mathrm{Pt}(\mathrm{H})(\mathrm{L})(\mathrm{Ph})_{2}\right]\left[\mathrm{BF}_{4}\right](\mathrm{L}=$ vacant site or labile ligand $) .{ }^{164}$ Since this report, DFT calculations have been performed that suggest a direct proton transfer by a $\sigma$-bond metathesis or a $\sigma$-complex assisted metathesis pathway $^{82}$ is preferred over oxidative addition by $\sim 6 \mathrm{kcal} / \mathrm{mol}$ (Scheme 1.21$).{ }^{83}$ This warranted a reexamination of the reaction and a thorough reckoning of the effects of acid and NCMe concentrations, temperature and pressure. It was determined that the rate of site exchange in Pt5 was 500 times faster than benzene associative displacement by NCMe to form Pt4. As Pt3 is not observed after the addition of NCMe to Pt5, this indicates that the rate of benzene substitution is much faster than oxidative addition of a benzene $\mathrm{C}-\mathrm{H}$ bond. Furthermore, rapid site exchange in $\mathbf{P t 5}$ is still observed after the addition of NCMe to form Pt4. This provides strong evidence against $\mathrm{Ph}$ site exchange via an oxidative addition/reductive elimination pathway. The authors do note that this $\sigma$-bond metathesis process for degenerate proton site exchange between two phenyl groups is likely unique and not operative in exchanges between two methyl groups or between phenyl and methyl (alkyl) groups. ${ }^{153-154,165-166}$ 


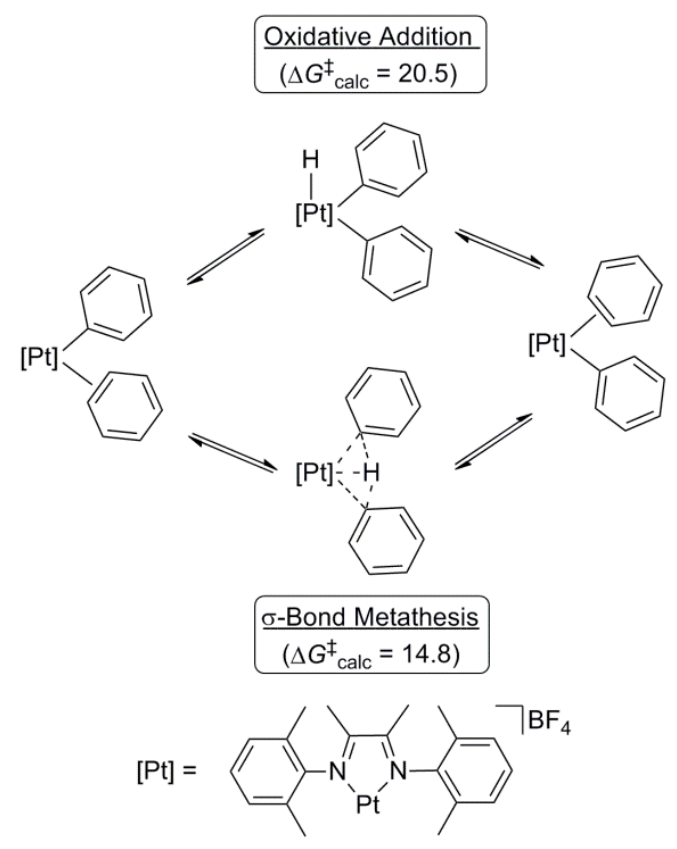

Scheme 1.21. Two calculated mechanistic pathways for degenerate proton transfer between two phenyl groups mediated by $\mathrm{Pt}^{\mathrm{II}}$. Calculated activation energies are given in $\mathrm{kcal} / \mathrm{mol}$.

\subsubsection{Examples of Olefin Hydroarylation Catalyzed by $\mathrm{Pt}^{\mathrm{II}}$}

Vitagliano et al. reported catalytic olefin hydroarylation of arenes activated with methoxy substituents utilizing formally dicationic $\mathrm{Pt}^{\mathrm{II}}$ precursors $\left[(\operatorname{PNP}) \mathrm{Pt}\left(\eta^{2}-\right.\right.$ $\left.\left.\mathrm{CH}_{2} \mathrm{CHR}\right)\right]\left[\mathrm{SbF}_{6}\right]_{2}(\mathrm{PNP}=2,6$-bis(diphenylphosphinomethyl)pyridine, $\mathrm{R}=\mathrm{H}$ or $\mathrm{Me}$, Scheme 1.22). ${ }^{143}$ Methoxy substituents on the arene were chosen due to the fact that other activating groups, such as hydroxyl or amine, could potentially undergo nucleophilic attack on the activated olefin. Alkylation of 1,3-dimethoxybenzene (30 equivalents relative to $\left.\mathrm{Pt}^{\mathrm{II}}\right)$ with ethylene $(0.7 \mathrm{MPa})$ proceeded in high yields $\left(\sim 100 \%\right.$ by ${ }^{1} \mathrm{H} \mathrm{NMR}$ spectroscopy in $\mathrm{CD}_{3} \mathrm{NO}_{2}$ ) to produce 1,3-dimethoxy-4-ethylbenzene and 1,3-dimethoxy- 
4,6-diethylbenzene in a 35:65 ratio. Using propylene (0.2 MPa), the reaction proceeds in quantitative yield to give mono- and di-isopropyl substituted arenes in a 85:15 ratio. Interestingly for this Friedel-Crafts type pathway, 1,3-dimethoxy-4- $n$-propylbenzene was also observed, comprising $15 \%$ of the total alkylated product. The authors attribute steric hindrance during nucleophilic attack by the arene on $\mathrm{Pt}-$ propylene adduct between the methyl group of propylene and the ortho-methoxy substituent of the arene as the source of the anti-Markovnikov addition product. Thus, the proposed catalytic cycle involves olefin coordination to the metal center, electrophilic attack on the aromatic ring, and cleavage of the $\mathrm{Pt}-\mathrm{C}$ bond by the proton released by the arenium intermediate. A similar mechanism has also been proposed for $\mathrm{Pt}^{\mathrm{II}}$ catalyzed intra- and intermolecular hydroarylation of indoles. ${ }^{167-169}$ 

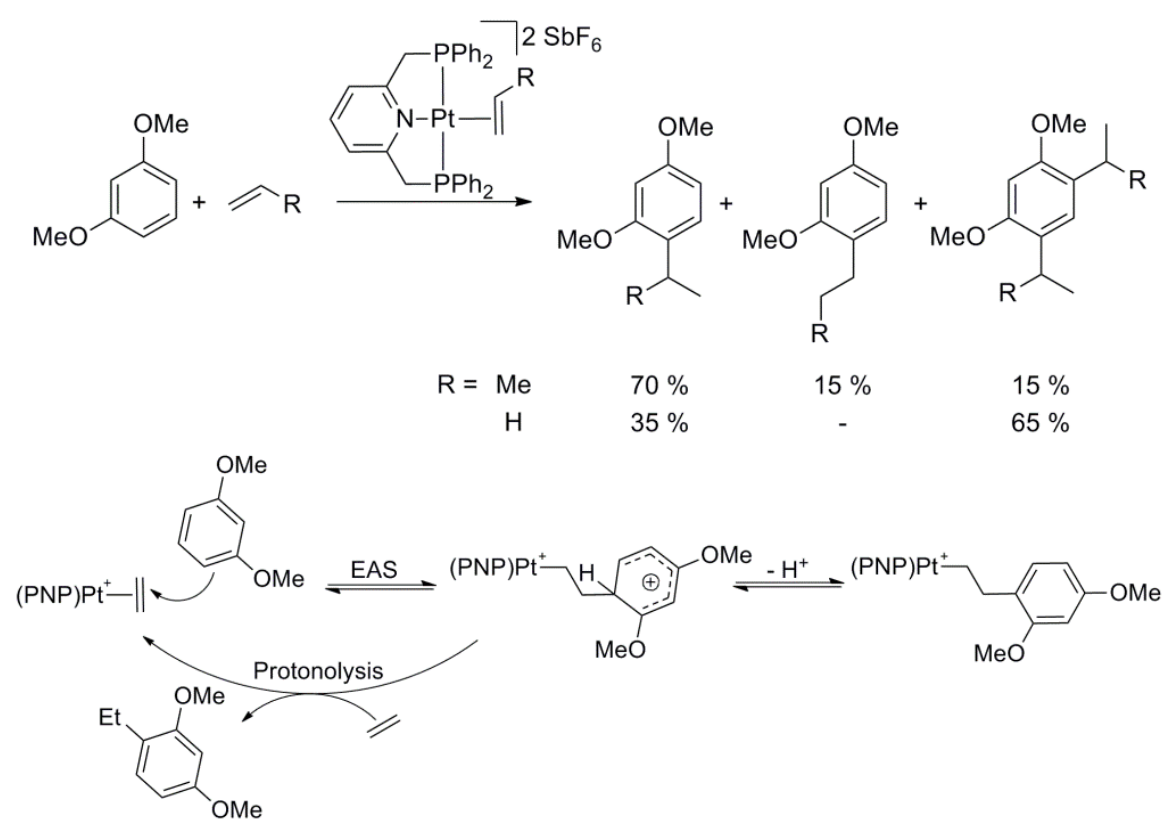

Scheme 1.22. Product distribution upon reaction of $\left[(\operatorname{PNP}) \operatorname{Pt}\left(\eta^{2} \text {-olefin }\right)\right]^{2+}$ with $1,3-$ dimethoxybenzene and either ethylene or propylene. Reaction yields and product distribution were determined by ${ }^{1} \mathrm{H}$ NMR spectroscopy. Reaction mechanism involves an electrophilic aromatic substitution (EAS) and protonolysis steps to generate the alkylated arene.

A series of reports by Tilley et al. demonstrated that the mechanism of $\mathrm{Pt}^{\mathrm{II}}$ olefin hydroarylation can vary depending on the reaction conditions and substrate identity. ${ }^{145-}$ 146, 170 Activation of (2-(2-pyridyl)indole) $\mathrm{Pt}\left(\eta^{2}-\mathrm{C}_{2} \mathrm{H}_{4}\right)(\mathrm{Cl})(\mathbf{P t 6})$ by $\mathrm{Ag}^{+}$salts in a solvent mixture of $o$-dichlorobenzene and benzene $(2: 1 \mathrm{v}: \mathrm{v})$ results in catalytic hydrophenylation of norbornene. ${ }^{146}$ With $10 \mathrm{~mol} \%$ of Pt6/AgOTf or Pt6/AgBF 4 , relative to norbornene, exo-phenylnorbornane is formed in a $79 \%\left(115{ }^{\circ} \mathrm{C}, 20\right.$ hours $)$ and $92 \%\left(80{ }^{\circ} \mathrm{C}, 2\right.$ hours $)$ yield, respectively (Scheme 1.23). The efficacy of other electrophilic $\mathrm{Pt}^{\mathrm{II}}$ complexes lacking nitrogen chelates was then studied. For example, using $(\mathrm{COD}) \mathrm{Pt}(\mathrm{Cl})_{2}(\mathrm{COD}=$ $(\mathrm{COD}=1,5$-cyclooctadiene $)$ and three equivalents of $\mathrm{AgBF}_{4}$, the conversion of benzene and norbornene was similar to that for $\mathbf{P t 6}$ and $\mathrm{AgBF}_{4}$. The $\mathrm{Pt}^{\mathrm{II}}$ triflate salt 
$(\mathrm{COD}) \mathrm{Pt}(\mathrm{OTf})_{2}(\mathbf{P t} 7)$ was also examined. ${ }^{146,170}$ Due to the lack of halide ligands, this complex was not expected to require activation by $\operatorname{Ag}(\mathrm{I})$ salts, and the hydrophenylation of norbornene occurred with an $81 \%$ yield at $90{ }^{\circ} \mathrm{C}$ after 20 hours. If AgOTf was used as an additive, the reaction proceeded more rapidly with a nearly identical yield in only 7 hours. The addition of $\eta^{2}: \eta^{2}-\mu-\left(\mathrm{C}_{7} \mathrm{H}_{8}\right) \mathrm{Cu}_{2} \mathrm{OTf}_{2}$ was also found to provide a rate enhancement. However, the concentration of the triflate anion was found to have no influence on catalytic activity, which suggests that the $\mathrm{Ag}^{+} / \mathrm{Cu}^{+}$salts may play a role beyond abstraction of chloride from the Pt precursors. As with the above mentioned example, a Friedel-Crafts type mechanism, in which the coordination of norbornene to the metal center activates it towards nucleophilic attack by benzene followed by proton transfer to liberate the alkylated benzene, has been proposed. ${ }^{145-146}$

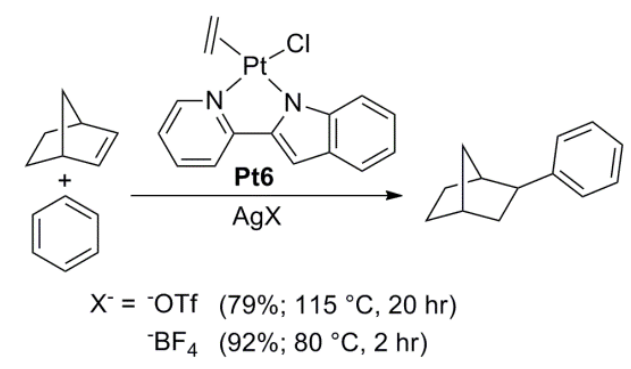

Scheme 1.23. Pt-Ag co-catalyst system for norbornene hydrophenylation to produce exophenylnorbornane. Product yields were determined by GC using naphthalene as an integration standard.

In addition to norbornene, complex Pt7 was tested for olefin hydroarylation using cyclohexene. ${ }^{170}$ At $100{ }^{\circ} \mathrm{C}, 1$-cyclohexyl-2,4,6-trimethylbenzene is produced in nearly quantitative yield from cyclohexene and mesitylene with $10 \mathrm{~mol} \% \mathbf{P t 7}$, relative to cyclohexene (Scheme 1.24). Control reactions with triflic acid also produced the 
hydroarylated product in nearly quantitative yield, which led to the suspicion that a Brønsted acid generated in situ was responsible for catalytic activity. ${ }^{171}$ To test this proposal, the weakly coordinating base 2,6-di-tert-butyl-4-methylpyridine was added to the reaction mixture to serve as a proton scavenger. With increasing concentrations of the Lewis base, catalysis was significantly retarded (Scheme 1.24). Furthermore, monitoring the reaction via ${ }^{1} \mathrm{H}$ NMR spectroscopy revealed the formation of the conjugate acid of the added Lewis base. The reaction of cyclohexene in the presence of Pt7 and the base additive revealed homocoupling of the olefin and the generation of the conjugate acid. As had been observed by Sharp, ${ }^{172}$ the reaction of $\mathbf{P t} 7$ with the olefin was revealed as the proton source under catalytic conditions and confirmed a Brønsted acid catalyzed pathway for the hydroarylation of cyclic olefins.

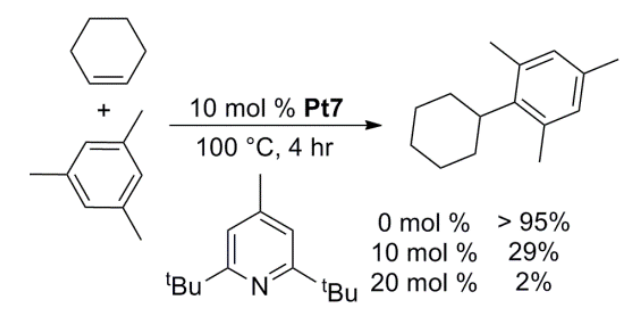

Scheme 1.24. Dependence on the yield of 1-cyclohexyl-2,4,6-trimethylbenzene from the reaction of mesitylene and cyclohexene from catalysis with Pt7 in the presence of a proton scavenger, 2,6-di-tert-butyl-4-methylpyridine.

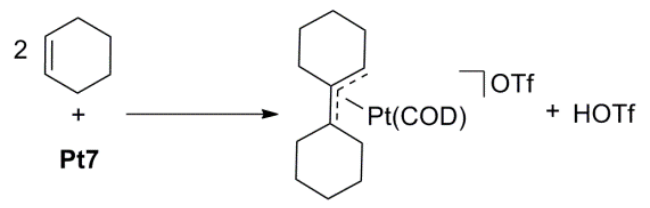

Scheme 1.25. Triflic acid formation from the homocoupling of cyclohexene catalyzed by Pt7. 
Returning to the 2-(2-pyridyl)indole framework, Tilley demonstrated that formally anionic $\mathrm{Pt}$ II complexes can undergo oxidative addition of benzene $\mathrm{C}-\mathrm{H}$ bonds to a 16 electron platinum center, which contrasts the precedent that this reaction typically requires the generation of a 14-electron unsaturated intermediate. ${ }^{145}$ For example, the reaction of $\mathrm{K}\left[(2-(2-p y r i d y l) i n d o l e) \operatorname{Pt}(\mathrm{Me})_{2}\right]$ (Pt8) with benzene undergoes sequential oxidative addition/reductive elimination reactions to generate the corresponding diphenyl complex $\mathrm{K}\left[\left(2-(2-\right.\right.$ pyridyl)indole $\left.) \mathrm{Pt}(\mathrm{Ph})_{2}\right]$ at $150{ }^{\circ} \mathrm{C}$. The overall neutral complex (2-(2pyridyl)indole)Pt(Me)(NCMe) (Pt9) was also prepared as a single isomer with the labile NCMe ligand trans to the indole functionality via protonation with a relatively weak acid. These catalysts were screened for the hydrophenylation of norbornene. At $140{ }^{\circ} \mathrm{C}$ in neat benzene with $10 \mathrm{~mol} \%$ catalyst relative to norbornene, the formation of exophenylnorbornane proceeded in $27 \%$ and $26 \%$ yield for complexes Pt8 and Pt9, respectively. Complex Pt8 was activated using a strong Lewis acid $\mathrm{B}\left(\mathrm{C}_{6} \mathrm{~F}_{5}\right)_{3}$ to abstract a methyl group and provide an open coordination site. In addition, norbornene hydroarylation using toluene at $140{ }^{\circ} \mathrm{C}$ for 16 hours resulted in the formation of exotolylnorbornane as a mixture of isomers with an $o: m: p$ distribution of $0.4: 1.0: 0.6$. The distribution is a marked change from previous reactions using halogenated $\mathrm{Pt}^{\mathrm{II}}$ complexes with $\mathrm{Ag}^{\mathrm{I}}$ co-catalysts, which preferred ortho- and para- over meta-substitution. ${ }^{146}$ The change in selectivity, in addition to the observation that Pt8 can oxidatively add $\mathrm{C}-\mathrm{H}$ bonds of benzene, led to the proposal that the catalytic cycle incorporates olefin insertion into the $\mathrm{Pt}$-aryl bond, aromatic $\mathrm{C}-\mathrm{H}$ activation by oxidative addition and $\mathrm{C}-\mathrm{H}$ bond reductive elimination to release the hydroarylation product. However, a thorough 
mechanistic investigation was not performed and a pathway involving olefin activation with subsequent nucleophilic attack by the arene cannot be fully discounted.

Neutral $\mathrm{Pt}^{\mathrm{II}}$ catalysts utilizing a 2-(2-pyridyl)pyrolide ligand have been studied by Goldberg (Chart 1.8). ${ }^{147}$ Initial studies revealed that heating a $\mathrm{C}_{6} \mathrm{D}_{6}$ solution of (dmpp)PtMe 3 (Pt10) (dmpp = 3,5-dimethyl-2-(2-pyridyl)pyrrolide) at $100{ }^{\circ} \mathrm{C}$ in the presence of ethylene leads to (dmpp) $\mathrm{Pt}\left(\mathrm{CH}_{2} \mathrm{CH}_{2} \mathrm{Ph}-d_{5}\right)\left(\eta^{2}-\mathrm{C}_{2} \mathrm{H}_{4}\right)$ in $\sim 50 \%$ yield as determined by ${ }^{1} \mathrm{H}$ NMR spectroscopy. Heating a 3 mol \% benzene solution of Pt10 at $100{ }^{\circ} \mathrm{C}$ in the presence of excess ethylene results in the formation of ethylbenzene with a TON of 26 after 50 hours, as determined by GC-FID. The hydrophenylation of propylene is less efficient with only 8 turnovers of cumene to $n$-propylbenzene observed in an $\sim 6: 1$ ratio. Utilizing the $\mathrm{Pt}^{\mathrm{II}}$ precursor $(\mathrm{dmpp}) \mathrm{Pt}\left(\mathrm{SMe}_{2}\right) \mathrm{Ph}$ (Pt11), a slight enhancement in catalytic turnover was observed. The hydrophenylation of ethylene and propylene at 100 ${ }^{\circ} \mathrm{C}$ in benzene using Pt11 provided ethylbenzene and propylbenzene ( $\sim 6: 1$ ratio of cumene to $n$-propylbenzene) with TONs of 36 and 18, respectively. Although the reaction of propylene with benzene for both catalysts yielded Markovnikov addition products predominately, the observation of some anti-Markovnikov addition products (i.e., $n$ propylbenzene) indicates a non-Friedel-Crafts mechanism.

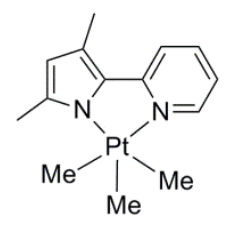

Pt10

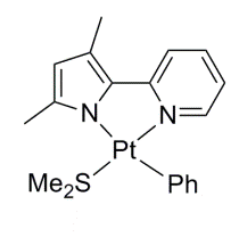

Pt11

Chart 1.8. Neutral $\mathrm{Pt}^{\mathrm{IV}}$ (Pt10) and $\mathrm{Pt}^{\mathrm{II}}$ (Pt11) catalyst precursors utilized for catalytic olefin hydroarylation via a non-acid catalyzed mechanism. 
The proposed mechanism for olefin hydroarylation by Pt10 and Pt11 complexes is similar to that suggested for the $\mathrm{Ir}^{\mathrm{III}}$ and $\mathrm{Ru}^{\mathrm{II}}$ catalysts previously discussed (Scheme 1.26). For both complexes, the catalytic cycle is initiated by the formation of (dmpp)Pt $(\mathrm{Ph})\left(\eta^{2}-\mathrm{C}_{2} \mathrm{H}_{4}\right)$. Insertion of ethylene into the $\mathrm{Pt}-\mathrm{Ph}$ bond to form (dmpp)Pt $\left(\mathrm{CH}_{2} \mathrm{CH}_{2} \mathrm{Ph}\right)$ is followed by ortho-metalation to form a cyclometalated $\mathrm{Pt}-\mathrm{H}$ intermediate. Stoichiometric ethylbenzene production from the thermolysis of (dmpp)Pt $\left(\mathrm{CH}_{2} \mathrm{CH}_{2} \mathrm{Ph}\right)\left(\eta^{2}-\mathrm{C}_{2} \mathrm{H}_{4}\right)$ or $(\mathrm{dmpp}) \mathrm{Pt}\left(\mathrm{CH}_{2} \mathrm{CH}_{2} \mathrm{Ph}-d_{5}\right)\left(\eta^{2}-\mathrm{C}_{2} \mathrm{H}_{4}\right)$ in $\mathrm{C}_{6} \mathrm{D}_{6}$ results in the respective formation of $\mathrm{PhCH}_{2} \mathrm{CH}_{3}$ and $\mathrm{PhCH}_{2} \mathrm{CH}_{2} \mathrm{D}$. Therefore, deuterium incorporation into the terminal methyl group of ethylbenzene is dependent upon deuterium being present in the $\mathrm{Ph}$ ring and eliminates direct activation of benzene from the Pt-phenethyl moiety to produce ethylbenzene, indicating initial orthometalation. Reductive coupling and coordination of benzene leads to (dmpp) Pt $\left(o-\mathrm{C}_{6} \mathrm{H}_{4} \mathrm{Et}\right)\left(\eta^{2}-\mathrm{C}_{6} \mathrm{H}_{6}\right)$. Subsequent $\mathrm{C}-\mathrm{H}$ activation of coordinated benzene with displacement of ethylbenzene by ethylene completes the catalytic cycle.

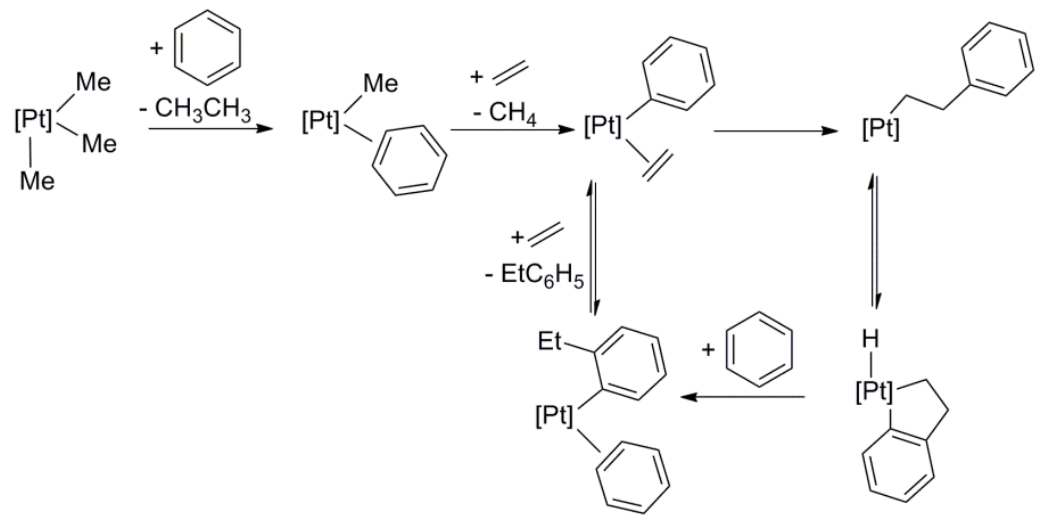

Scheme 1.26. Proposed mechanism for olefin hydroarylation catalyzed by neutral $\mathrm{Pt}^{\mathrm{II}}$ catalyst precursor Pt10. [Pt] = (2-(2-pyridyl)pyrolide)Pt. 


\subsection{Thesis Aims}

The aim of the work in this dissertation is to probe the validity of formally cationic $\mathrm{Pt}^{\mathrm{II}}$ complexes as catalyst precursors for olefin hydroarylation via a non Brønsted-acid catalyzed pathway. Beginning contributions focus on the development of dipyridyl ligated precursors and probing the catalytic cycle for evidence to support a mechanism that incorporates olefin insertion and subsequent aromatic $\mathrm{C}-\mathrm{H}$ activation to yield alkyl arenes using simple substrates such as benzene and ethylene. Dipyridyl ligands offer extensive opportunity to develop structure/activity relationships for the rational design of new catalytic systems, which are relatively rare. Electronic effects such as the influence of ligand donor ability on catalyst selectivity can be modulated via $4 / 4^{\prime}$-substitution of the pyridyl rings with negligible impact on the catalyst steric properties. Likewise, steric effects can be evaluated by substitution in the $6 / 6^{\prime}$-positions, proximal to the metal center, and chelate ring size. Ligand motifs outside the dipyridyl framework have been explored, such as diimines and phosphines. The reactivity with activated substrates (e.g., substituted benzenes, heteroaromatics and substituted olefins) has been studied to gauge their influence on product regio- and chemoselectivty, as well as, overall catalyst functional group tolerance.

\subsection{References}

1. Collins, P. M. D., Platinum Metals Rev. 1986, 30, 141-146.

2. Cornils, B.; Herrmann, W. A., J. Catal. 2003, 216, 23-31.

3. Manzer, L. E., Catal. Today 1993, 18, 199-207. 
4. Dijkstra, H. P.; van Klink, G. P. M.; van Koten, G., Acc. Chem. Res. 2002, 35, 798-810.

5. Cole-Hamilton, D. J., Science 2003, 299, 1702-1706.

6. Herrmann, W. A.; Cornils, B., Angew. Chem. Int. Ed. Engl. 1997, 36, 1048-1067.

7. van Leeuwen, P. W. N. M., Homogeneous Catalysis: Understanding the Art. Kluwer Academic Publishers: Netherlands, 2004.

8. Handbook of Heterogeneous Catalysis. VCH Verlagsgesellschaft: Weinheim, 1997; Vol. IV.

9. Marcilly, C., Acido-Basic Catalysis: Application to Refining and Petrochemistry. Editions Technip: Paris, 2006; Vol. I.

10. Yilmaz, B.; Müller, U., Top. Catal. 2009, 52, 888-895.

11. Li, T.; Jones, W. D., Organometallics 2010, 30, 547-555.

12. Casalnuovo, A. L.; McKinney, R. J.; Tolman, C. A., Hydrocyanation by Homogeneous Catalysis. In Encyclopedia of Inorganic and Bioinorganic Chemistry, John Wiley \& Sons, Ltd: 2011.

13. Jones, J. H., Platinum Met. Rev. 2000, 44, 94-105.

14. Yoneda, N.; Kusano, S.; Yasui, M.; Pujado, P.; Wilcher, S., Applied Catalysis A: General 2001, 221, 253-265.

15. Ronde, N. J.; Vogt, D., Separation by Size-Exclusion Filtration. In Catalyst Separation, Recovery and Recycling, Cole-Hamilton, D.; Tooze, R., Eds. Springer Netherlands: 2006; Vol. 30, pp 73-104.

16. Herrmann, W., Catalytic Carbon-Carbon Coupling by Palladium Complexes: Heck Reactions. In Applied Homogeneous Catalysis with Organometallic Compounds: A Comprehensive Handbook Wiley-VCH: Weinheim, 2000.

17. Todd, P. A.; Clissold, S. P., Drugs 1990, 40, 91-137.

18. de Vries, J. G., Can. J. Chem. 2001, 79, 1086-1092.

19. Frohning, C. D.; Kohlpaintner, C. W., Hydroformylation (Oxo Synthesis, Roelen Reaction). In Applied Homogeneous Catalysis with Organometallic Compounds: A Comprehensive Handbook, Cornils, B.; Herrmann, W., Eds. Wiley-VCH: Weinheim, 2000; pp 29-104. 
20. Cornils, B.; Kuntz, E. G., J. Organomet. Chem. 1995, 502, 177-186.

21. Cornils, B., Angew. Chem. Int. Ed. 1997, 36, 2057-2059.

22. Sellin, M. F.; Bach, I.; Webster, J. M.; Montilla, F.; Rosa, V.; Aviles, T.; Poliakoff, M.; Cole-Hamilton, D. J., J. Chem. Soc., Dalton Trans. 2002, 0, 45694576.

23. Bronger, R. P. J.; Silva, S. M.; Kamer, P. C. J.; Leeuwen, P. W. N. M. v., Chem. Commun. 2002, 0, 3044-3045.

24. Keim, W.; Vogt, D.; Waffenschimidt, H.; Wasserscheid, P., J. Catal. 1999, 186, 481-484.

25. Brasse, C. C.; Englert, U.; Salzer, A.; Waffenschmidt, H.; Wasserscheid, P., Organometallics 2000, 19, 3818-3823.

26. Horváth, I. T.; Rábai, J., Science 1994, 266, 72-75.

27. Horváth, I. T., Acc. Chem. Res. 1998, 31, 641-650.

28. Blaser, H.; Indolese, A.; Schnyder, A., Curr. Sci. India 2000, 78, 1336-1344.

29. Vogt, D., Oligomerization of Ethylene to Higher Linear $\alpha$-Olefins. In Applied Homogeneous Catalysis with Organometallic Compounds, Cornils, B.; Herrmann, W., Eds. Wiley-VHC: Weinheim, 2000; pp 245-258.

30. Kuhn, P.; Semeril, D.; Matt, D.; Chetcuti, M. J.; Lutz, P., Dalton Transactions 2007, 0, 515-528.

31. Johnson, N. B.; Lennon, I. C.; Moran, P. H.; Ramsden, J. A., Acc. Chem. Res. 2007, 40, 1291-1299.

32. James, B. R.; Markham, L. D.; Hui, B. C.; Rempel, G. L., J. Chem. Soc, Dalton Trans. 1973, 2247-2252.

33. James, B. R., Homogeneous Hydrogenation. John Wiley \& Sons: New York, 1973.

34. Perego, C.; Ingallina, P., Catal. Today 2002, 73, 3-22.

35. O'Connor, C. T.; Van Steen, E.; Dry, M. E., New Catalytic Applications of Zeolites for Petrochemicals. In Recent Advances and New Horizons in Zeolite 
Science and Technology, Chon, H.; Woo, S. I.; Park, S. E., Eds. Elsevier: 1996; Vol. 102, pp 323-362.

36. Carey, F. A., Alcohols and Alkyl Halides. In Organic Chemistry, McGraw-Hill: New York, 2000; pp 126-167.

37. Olah, G. A.; Prakash, G. K. S.; Somner, J., Science 1979, 5, 13-20.

38. Marcilly, C., Main Acids, Superacids and Bases of Interest in Catalysis. In AcidoBasic Catalysis Editions Technip: France, 2006; Vol. 1, pp 57-130.

39. Perego, C.; Ingallina, P., Green Chem. 2004, 6, 274-279.

40. Vermeiren, W.; Gilson, J. P., Top. Catal. 2009, 52, 1131-1161.

41. Macquarrie, D. J., Industrial Friedel-Crafts Chemistry. In Catalytic Asymmetric Friedel-Crafts Alkylations, Bandini, M.; Umani-Ronchi, A., Eds. Wiley-VCH: Weinheim, 2009; pp 271-288.

42. Perego, C.; Pollesel, P., Chapter 2 - Advances in Aromatics Processing Using Zeolite Catalysts. In Advances in Nanoporous Materials, Stefan, E., Ed. Elsevier: 2010; Vol. Volume 1, pp 97-149.

43. Broach, R. W., Zeolite Types and Structures. In Zeolites in Industrial Separation and Catalysis, Kulprathipanja, S., Ed. John Wiley \& Sons: 2010; pp 27-59.

44. Lei, X.-g.; Jockusch, S.; Francesca Ottaviani, M.; Turro, N. J., Photochemical \& Photobiological Sciences 2003, 2, 1095-1100.

45. Al-Kinany, M. C.; Al-Megren, H. A.; Al-Ghilan, E. A.; Edwards, P. P.; Xiao, T.; Al-Shammari, A. S.; Al-Drees, S. A., Appl. Petrochem. Res. 2012, 2, 73-83.

46. Marcilly, C., Main Acids, Superacids and Bases of Interest in Catalysis. In AcidoBasic Catalysis Editions Technip: France, 2006; Vol. 2, pp 515-534.

47. Jan, D. Y.; Barger, P. T., Processes on Industrial C-C Bond Formation. In Zeolites in Industrial Separation and Catalysis, Kulprathipanja, S., Ed. John Wiley \& Sons: 2010; pp 505-533.

48. Kosswig, K., Surfactants. In Ullmann's Encyclopedia of Industrial Chemistry, 7th ed.; John Wiley \& Sons: Berlin, 2010; pp 1-71.

49. Chauvin, Y., Angew. Chem. Int. Ed. 2006, 45, 3740-3747.

50. Grubbs, R. H., Angew. Chem. Int. Ed. 2006, 45, 3760-3765. 
51. Schrock, R. R., Angew. Chem. Int. Ed. 2006, 45, 3748-3759.

52. Heck, R. F., Synlett 2006, 2006, 2855-2860.

53. Negishi, E.-i., Angew. Chem. Int. Ed. 2011, 50, 6738-6764.

54. Suzuki, A., Angew. Chem. Int. Ed. 2011, 50, 6722-6737.

55. Trost, B. M., Acc. Chem. Res. 2002, 35, 695-705.

56. Li, C.-J.; Trost, B. M., Proc. Natl. Acad. Sci. 2008, 105, 13197-13202.

57. Anastas, P. T.; Warner, J. C., Green Chemistry: Theory and Practice. Oxford University Press: New York, 1998.

58. Horváth, I. T.; Anastas, P. T., Chem. Rev. 2007, 107, 2169-2173.

59. Davis, S. Petrochemical Industry Overview; 350.000; SRI Consulting: 2008.

60. Daasbjerg, K., Acta Chem. Scand. 1995, 49,

61. Anslyn, E. V.; Dougherty, D. A., Modern Physical Organic Chemistry. University Science Books: Sausalito, 2006.

62. Bergman, R. G., Science 1984, 223, 902-908.

63. Chatt, J.; Davidson, J. M., J. Chem. Soc. 1965, 843-855.

64. Gol'dshleger, N. F.; Tyabin, M. B.; Shilov, A. E.; Shteinman, A. A., Zh. Fiz. Khim. 1969, 43, 2174.

65. Gol'dshleger, N. F.; Es'kova, V. V.; Shilov, A. E.; Shteinman, A. A., Zh. Fiz. Khim. 1972, 46, 1353.

66. Kushch, L. A.; Lavrushko, V. V.; Misharin, Y. S.; Moravskii, A. P.; Shilov, A. E., Nouveau Journal de Chimie 1983, 7, 729.

67. Zhu, H.; Ziegler, T., J. Organomet. Chem. 2006, 691, 4486-4497.

68. Siegbahn, P. E. M.; Crabtree, R. H., J. Am. Chem. Soc. 1996, 118, 4442-4450.

69. Labinger, J. A.; Bercaw, J. E., Nature 2002, 417, 507-514. 
70. Crabtree, R. H.; Mihelcic, J. M.; Quirk, J. M., J. Am. Chem. Soc. 1979, 101, 77387740 .

71. Shilov, A. E.; Shul'pin, G. B., Chem. Rev. 1997, 97, 2879-2932.

72. Jones, W. D., Activation of C-H Bonds: Stoichiometric Reactions. In Topics in Organometallic Chemistry, Murai, S., Ed. Springer: Berlin, 1999; Vol. 3, pp 9-46.

73. Crabtree, R. H., J. Chem. Soc., Dalton Trans. 2001, 2437-2450.

74. Jones, W. D., Acc. Chem. Res. 2003, 36, 140-146.

75. Goldberg, K. I.; Goldman, A. S., Activation and Functionalization of $C$ - $H$ Bonds. American Chemical Society: Washington, DC, 2004; Vol. 885.

76. Lersch, M.; Tilset, M., Chem. Rev. 2005, 105, 2471-2526.

77. Vastine, B. A.; Hall, M. B., J. Am. Chem. Soc. 2007, 129, 12068-12069.

78. Oxgaard, J.; Muller, R. P.; Goddard III, W. A.; Periana, R. A., J. Am. Chem. Soc. 2004, 126, 352-363.

79. Foley, N. A.; Lee, J. P.; Ke, Z.; Gunnoe, T. B.; Cundari, T. R., Acc. Chem. Res. 2009, 42, 585-597.

80. Oxgaard, J.; Periana, R. A.; Goddard III, W. A., J. Am. Chem. Soc. 2004, 126, 11658-11665.

81. Parmene, J.; Ivanovic-Burmazovic, I.; Tilset, M.; van Eldik, R., Inorg. Chem. 2009, 48, 9092-9103.

82. Perutz, R. N.; Sabo-Etienne, S., Angew. Chem. Int. Ed. 2007, 46, 2578-2592.

83. Li, J.-L.; Geng, C.-Y.; Huang, X.-R.; Zhang, X.; Sun, C.-C., Organometallics 2007, 26, 2203-2210.

84. Gómez-Gallego, M.; Sierra, M. A., Chem. Rev. 2011, 111, 4857-4963.

85. Geftakis, S.; Ball, G. E., J. Am. Chem. Soc. 1998, 120, 9953-9954.

86. Sun, X.-Z.; Grills, D. C.; Nikiforov, S. M.; Poliakoff, M.; George, M. W., J. Am. Chem. Soc. 1997, 119, 7521-7525.

87. Lawes, D. J.; Geftakis, S.; Ball, G. E., J. Am. Chem. Soc. 2005, 127, 4134-4135. 
88. McNamara, B. K.; Yeston, J. S.; Bergman, R. G.; Moore, C. B., J. Am. Chem. Soc. 1999, 121, 6437-6443.

89. Bernskoetter, W. H.; Schauer, C. K.; Goldberg, K.; Brookhart, M., Science 2009, 326, 553-556.

90. Jensen, M. P.; Wick, D. D.; Reinartz, S.; White, P. S.; Templeton, J. L.; Goldberg, K. I., J. Am. Chem. Soc. 2003, 125, 8614-8624.

91. Fujiwara, Y.; Moritani, I.; Danno, S.; Asano, R.; Teranishi, S., J. Am. Chem. Soc. 1969, 91, 7166-7169.

92. Naota, T.; Takaya, H.; Murahashi, S.-I., Chem. Rev. 1998, 98, 2599-2660.

93. Guari, Y.; Sabo-Etienne, S.; Chaudret, B., Eur. J. Inorg. Chem. 1999, 1047-1055.

94. Dyker, G., Angew. Chem. Int. Ed. 1999, 38, 1698-1712.

95. Jia, C.; Lu, W.; Kitamura, T.; Fujiwara, Y., Org. Lett. 1999, 1, 2097-2100.

96. Jia, C.; Piao, D.; Oyamada, J.; Lu, W.; Kitamura, T.; Fujiwara, Y., Science 2000, 287, 1992-1995.

97. Trost, B. M.; Toste, F. D.; Pinkerton, A. B., Chem. Rev. 2001, 101, 2067-2096.

98. Jia, C.; Kitamura, T.; Fujiwara, Y., Acc. Chem. Res. 2001, 34, 633-639.

99. Ritleng, V.; Sirlin, C.; Pfeffer, M., Chem. Rev. 2002, 102, 1731-1769.

100. Goj, L. A.; Gunnoe, T. B., Curr. Org. Chem. 2005, 9, 671-685.

101. Dyker, G.; Muth, E.; Hashmi, A. S. K.; Ding, L., Adv. Synth. Catal. 2003, 345, 1247-1252.

102. Dorta, R.; Togni, A., Chem. Comm. 2003, 760-761.

103. Lewis, L. N.; Smith, J. F., J. Am. Chem. Soc. 1986, 108, 2728-2735.

104. Murai, S.; Kakiuchi, F.; Sekine, S.; Tanaka, Y.; Kamatani, A.; Sonoda, M.; Chatani, N., Nature 1993, 366, 529-531.

105. Murai, S.; Naoto, C.; Kakiuchi, F., Pure and App. Chem. 1997, 69, 589-594.

106. Trost, B. M.; Imi, K.; Davies, I. W., J. Am. Chem. Soc. 1995, 117, 5371-5372. 
107. Kakiuchi, F.; Sekine, S.; Tanaka, Y.; Kamatani, A.; Sonoda, M.; Chatani, N.; Murai, S., Bull. Chem. Soc. Jpn. 1995, 68, 62-83.

108. Guari, Y.; Sabo-Etienne, S.; Chaudret, B., J. Am. Chem. Soc. 1998, 120, 42284229.

109. Matsubara, T.; Koga, N.; Musaev, D. G.; Morokuma, K., J. Am. Chem. Soc. 1998, $120,12692-12693$.

110. Lenges, C. P.; Brookhart, M., J. Am. Chem. Soc. 1999, 121, 6616-6623.

111. Youn, S. W.; Pastine, S. J.; Sames, D., Org. Lett. 2004, 6, 581-584.

112. Matsumoto, T.; Taube, D. J.; Periana, R. A.; Taube, H.; Yoshida, H., J. Am. Chem. Soc. 2000, 122, 7414-7415.

113. Matsumoto, T.; Periana, R. A.; Taube, D. J.; Yoshida, H., J. Mol. Catal. A.: Chem. 2002, 180, 1-18.

114. Periana, R. A.; Liu, X. Y.; Bhalla, G., Chem. Commun. 2002, 24, 3000-3001.

115. Bhalla, G.; Oxgaard, J.; Goddard III, W. A.; Periana, R. A., Organometallics 2005, 24, 3229 - 3232 .

116. Bhalla, G.; Bischof, S. M.; Ganesh, S. K.; Liu, X. Y.; Jones, C. J.; Borzenko, A.; Tenn III, W. J.; Ess, D. H.; Hashiguchi, B. G.; Lokare, K. S.; Leung, C. H.; Oxgaard, J.; Goddard III, W. A.; Periana, R. A., Green Chem. 2011, 13, 69-81.

117. Lail, M.; Bell, C. M.; Conner, D.; Cundari, T. R.; Gunnoe, T. B.; Petersen, J. L., Organometallics 2004, 23, 5007-5020.

118. Shul'pin, G. B.; Kitaigorodskii, A. N., J. Organomet. Chem. 1981, 212, 275.

119. Shul'pin, G. B.; Nizova, G. V.; Nikitaev, A. T., J. Organomet. Chem. 1984, 276, 115.

120. Hackett, M.; Ibers, J. A.; Whitesides, G. M., J. Am. Chem. Soc. 1988, 110, 1449.

121. Jones, W. D.; Feher, F. J., J. Am. Chem. Soc. 1984, 106, 1650-1663.

122. Burger, P.; Bergman, R. G., J. Am. Chem. Soc. 1993, 115, 10462-10463.

123. Bhalla, G.; Oxgaard, J.; Goddard III, W. A.; Periana, R. A., Oragnometallics 2005, 24, 3229-3232. 
124. Lail, M.; Arrowood, B. N.; Gunnoe, T. B., J. Am. Chem. Soc. 2003, 125, 75067507.

125. Pittard, K. A.; Lee, J. P.; Cundari, T. R.; Gunnoe, T. B.; Petersen, J. L., Organometallics 2004, 23, 5514-5523.

126. Foley, N. A.; Lail, M.; Lee, J. P.; Gunnoe, T. B.; Cundari, T. R.; Petersen, J. L., J. Am. Chem. Soc. 2007, 129, 6765-6781.

127. Foley, N. A.; Ke, Z.; Gunnoe, T. B.; Cundari, T. R.; Petersen, J. L., Organometallics 2008, 27, 3007-3017.

128. Joslin, E. E.; McMullin, C. L.; Gunnoe, T. B.; Cundari, T. R.; Sabat, M.; Myers, W. H., Organometallics 2012, 31, 6851-6860.

129. Andreatta, J. R.; McKeown, B. A.; Gunnoe, T. B., J. Organomet. Chem. 2011, 696, 305-315.

130. Foley, N. A.; Lail, M.; Gunnoe, T. B.; Cundari, T. R.; Boyle, P. D.; Petersen, J. L., Organometallics 2007, 26, 5507-5516.

131. Alaimo, P. J.; Bergman, R. G., Organometallics 1999, 18, 2707-2717.

132. Klei, S. R.; Tilley, T. D.; Bergman, R. G., J. Am. Chem. Soc. 2000, 122, 18161817.

133. Tellers, D. M.; Yung, C. M.; Arndtsen, B. A.; Adamson, D. R.; Bergman, R. G., J. Am. Chem. Soc. 2002, 124, 1400-1410.

134. De Felice, V.; De Renzi, A.; Tesauro, D.; Vitagliano, A., Organometallics 1992, 11, 3669-3676.

135. De Felice, V.; Cucciolito, M. E.; De Renzi, A.; Ruffo, F.; Tesauro, D., J. Organomet. Chem. 1995, 493, 1-11.

136. Cucciolito, M. E.; De Renzi, A.; Orabona, I.; Ruffo, F.; Tesauro, D., J. Chem. Soc., Dalton Trans. 1998, 1675-1678.

137. Ganis, P.; Orabona, I.; Ruffo, F.; Vitagliano, A., Organometallics 1998, 17, 26462650 .

138. MacDonald, M. G.; Kostelansky, C. N.; White, P. S.; Templeton, J. L., Organometallics 2006, 25, 4560-4570. 
139. Shiotsuki, M.; White, P. S.; Brookhart, M.; Templeton, J. L., J. Am. Chem. Soc. 2007, 129, 4058-4067.

140. Strömberg, S.; Zetterberg, K.; Siegbahn, P. E. M., J. Chem. Soc., Dalton Trans. 1997, 22, 4147-4152.

141. van Gemert, J. T.; Wilkinson, P. R., J. Phys. Chem.-US 1964, 68, 645-647.

142. Hartley, F. R., Chem. Rev. 1969, 69, 799-844.

143. Cucciolito, M. E.; D'Amora, A.; Tuzi, A.; Vitagliano, A., Organometallics 2007, 26, 5216-5223.

144. Bowring, M. A.; Bergman, R. G.; Tilley, T. D., Organometallics 2011, 30, $1295-$ 1298.

145. Karshtedt, D.; McBee, J. L.; Bell, A. T.; Tilley, T. D., Organometallics 2006, 25, 1801-1811.

146. Karshtedt, D.; Bell, A. T.; Tilley, T. D., Organometallics 2004, 23, 4169-4171.

147. Luedtke, A. T.; Goldberg, K. I., Angew. Chem. 2008, 120, 7808-7810.

148. McKeown, B. A.; Foley, N. A.; Lee, J. P.; Gunnoe, T. B., Organometallics 2008, 27, 4031-4033.

149. McKeown, B. A.; Gonzalez, H. E.; Friedfeld, M. R.; Gunnoe, T. B.; Cundari, T. R.; Sabat, M., J. Am. Chem. Soc. 2011, 133, 19131-19152.

150. Stahl, S. S.; Labinger, J. A.; Bercaw, J. E., J. Am. Chem. Soc. 1995, 117, 93719372.

151. Stahl, S. S.; Labinger, J. A.; Bercaw, J. E., J. Am. Chem. Soc. 1996, 118, 59615976.

152. Shilov, A. E.; Shul'pin, G. B., Activation of Hydrocarbons by Platinum Complexes. In Activation and Catalytic Reactions of Saturated Hydrocarbons in the Presence of Metal Complexes, Kluwer Academic Publishers: Dordrecht, 2000; Vol. 21, pp 259-317.

153. Johansson, L.; Tilset, M.; Labinger, J. A.; Bercaw, J. E., J. Am. Chem. Soc. 2000, $122,10846-10855$.

154. Zhong, H. A.; Labinger, J. A.; Bercaw, J. E., J. Am. Chem. Soc. 2002, 124, 13781399. 
155. Wick, D. D.; Goldberg, K. I., J. Am. Chem. Soc. 1997, 119, 10235-10236.

156. Reinartz, S.; White, P. S.; Brookhart, M.; Templeton, J. L., Organometallics 2000, 19, 3854-3866.

157. Reinartz, S.; White, P. S.; Brookhart, M.; Templeton, J. L., J. Am. Chem. Soc. 2001, 123, 12724-12725.

158. Reinartz, S.; White, P. S.; Brookhart, M.; Templeton, J. L., Organometallics 2001, 20, 1709-1712.

159. Norris, C. M.; Reinartz, S.; White, P. S.; Templeton, J. L., Organometallics 2002, $21,5649-5656$.

160. Reinartz, S.; White, P. S.; Brookhart, M.; Templeton, J. L., J. Am. Chem. Soc. 2002, 124, 7249-7249.

161. Goldberg, K. I.; Yan, J. Y.; Breitung, E. M., J. Am. Chem. Soc. 1995, 117, 68896896.

162. Williams, B. S.; Holland, A. W.; Goldberg, K. I., J. Am. Chem. Soc. 1999, 121, 252-253.

163. Bartlett, K. L.; Goldberg, K. I.; Borden, W. T., J. Am. Chem. Soc. 2000, 122, 1456-1465.

164. Wik, B. J.; Lersch, M.; Krivokapic, A.; Tilset, M., J. Am. Chem. Soc. 2006, 128, 2682-2696.

165. Heiberg, H.; Johansson, L.; Gropen, O.; Ryan, O. B.; Swang, O.; Tilset, M., J. Am. Chem. Soc. 2000, 122, 10831-10845.

166. Wik, B. J.; Lersch, M.; Tilset, M., J. Am. Chem. Soc. 2002, 124, 12116-12117.

167. Liu, C.; Han, X.; Wang, X.; Widenhoefer, R. A., J. Am. Chem. Soc. 2004, 126, 3700-3701.

168. Han, X.; Widenhoefer, R. A., Org. Lett. 2006, 8, 3801 - 3804.

169. Zhang, Z.; Xiang, W.; Widenhoefer, R. A., Chem. Comm. 2006, 3717.

170. Bowring, M. A.; Bergman, R. G.; Tilley, T. D., Organometallics 2011, 30, 12951298. 
171. Booth, B. L.; Al-Kinany, M.; Laali, K., J. Chem. Soc., Perk. T. 1 1987, 20492055.

172. Szuromi, E.; Sharp, P. R., Organometallics 2006, 25, 558-559. 


\section{Mechanistic Studies of Ethylene Hydrophenylation Catalyzed by Cationic Pt ${ }^{\text {II }}$ Complexes Supported by 4,4'-di-tert-butyl-2,2'-bipyridine}

Despite the importance of aromatic alkylation reactions, detailed mechanistic studies of transition metal catalysts that are active for conversion of alkenes and arenes to alkyl arenes remain relatively rare. ${ }^{1-6} \mathrm{~A}$ series of studies on $\mathrm{TpRu}(\mathrm{L})(\mathrm{NCMe})(\mathrm{Ph})[\mathrm{Tp}=$ hydridotris(pyrazolyl)borate, $\mathrm{L}=\mathrm{CO}, \mathrm{PMe}_{3}, \mathrm{P}(\mathrm{N} \text {-pyrrolyl })_{3}$, or $\left.\mathrm{P}\left(\mathrm{OCH}_{2}\right)_{3} \mathrm{CEt}\right]$ catalysts for olefin hydroarylation sought to elucidate the effect of the donor and steric properties of the ligand L on the key steps of the catalytic cycle (i.e., olefin insertion and aromatic/olefin $\mathrm{C}-\mathrm{H}$ activation). ${ }^{4-10}$

In an effort to more broadly understand transition metal catalyzed olefin hydroarylation, we targeted catalysts outside the octahedral $/ \mathrm{d}^{6}$ motif and based on group 10 metals. Platinum(II) seems well suited for this transformation as it is known to readily activate $\mathrm{C}-\mathrm{H}$ bonds as well as undergo olefin insertion. ${ }^{11-21}$ Herein, a detailed experimental/computational investigation of catalytic hydrophenylation of ethylene by $\left[\left({ }^{t} \text { bpy }\right) \mathrm{Pt}(\mathrm{Ph})(\mathrm{L})\right]^{+}$('bpy = 4,4'-di-tert-butyl-2,2'-bipyridine; $\mathrm{L}=\mathrm{NCMe}, \mathrm{NC}_{5} \mathrm{~F}_{5}$ or $\mathrm{THF}$ ) complexes is disclosed in an effort to delineate the reaction mechanism and develop a better understanding of the individual steps in the catalytic cycle.

\subsection{Results and Discussion}

\subsubsection{Complex Synthesis and Catalytic Activity}

The complex $\left[\left({ }^{t} \mathrm{bpy}\right) \mathrm{Pt}(\mathrm{Ph})(\mathrm{THF})\right]\left[\mathrm{BAr}_{4}\right]$ (2.1) has been isolated in 93\% yield from the reaction $\left(-60^{\circ} \mathrm{C}\right)$ of $\left({ }^{t}\right.$ bpy $) \mathrm{Pt}(\mathrm{Ph})_{2}$ with $\mathrm{HBAr}_{4}$ in tetrahydrofuran. $\mathrm{In}_{\mathrm{CD}} \mathrm{Cl}_{2}$, the ${ }^{1} \mathrm{H}$ and 
${ }^{13} \mathrm{C}$ NMR spectra of $\mathbf{2 . 1}$ reveal inequivalent pyridyl groups, and the resonances for coordinated THF ( ${ }^{1} \mathrm{H}$ NMR) are observed as multiplets at 4.14 and $1.86 \mathrm{ppm}$.

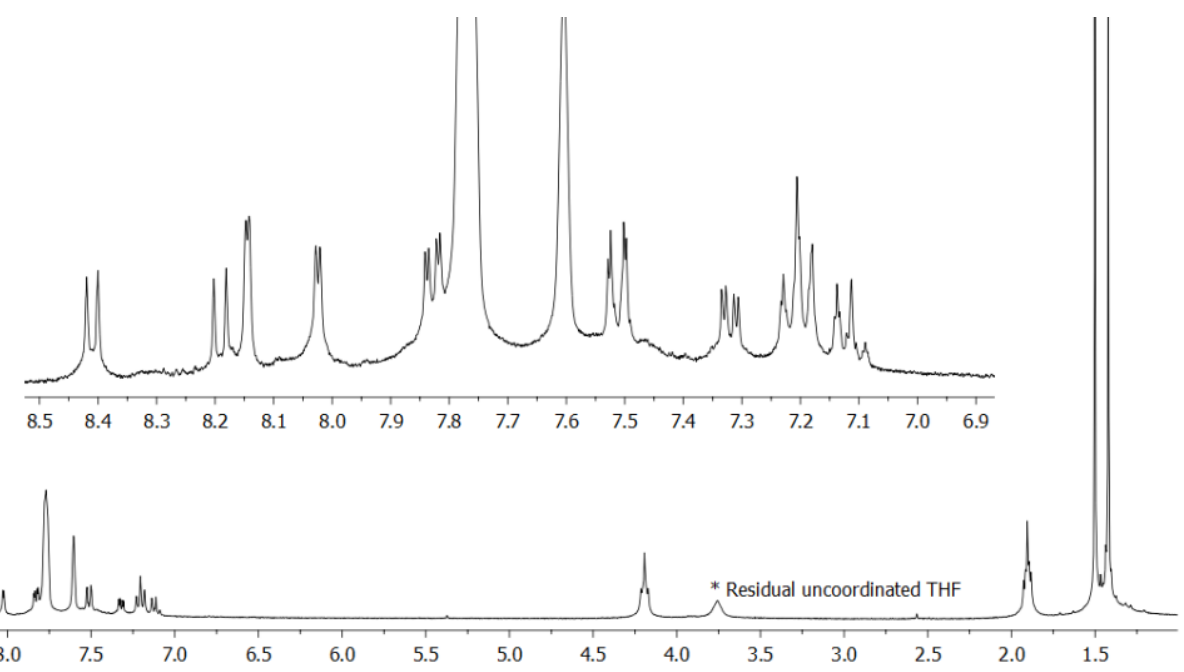

Figure 2.1. ${ }^{1} \mathrm{H}$ NMR spectrum of $\left[\left({ }^{t} \mathrm{bpy}\right) \mathrm{Pt}(\mathrm{Ph})(\mathrm{THF})\right]\left[\mathrm{BAr}_{4}{ }_{4}\right]$ (2.1) in $\mathrm{CD}_{2} \mathrm{Cl}_{2}$.

From complex 2.1, [( ${ }^{t}$ bpy $\left.) \mathrm{Pt}(\mathrm{Ph})(\mathrm{L})\right]^{+}$variants can be prepared by substitution of THF with other ligands. For example, stirring complex 2.1 in neat perfluoropyridine or acetonitrile yields the complexes $\quad\left[\left({ }^{t} \mathrm{bpy}\right) \mathrm{Pt}(\mathrm{Ph})\left(\mathrm{NC}_{5} \mathrm{~F}_{5}\right)\right]\left[\mathrm{BAr}_{4}^{\prime}\right] \quad$ (2.2) and $\left[\left({ }^{t}\right.\right.$ bpy $\left.) \mathrm{Pt}(\mathrm{Ph})(\mathrm{NCMe})\right]\left[\mathrm{BAr}_{4}{ }_{4}\right]$ (2.3) (Scheme 2.1). A crystal of complex 2.3 suitable for an X-ray diffraction study was grown (Figure 2.2). The N1-Pt-N2 bond angle is compressed to $79.3(2)^{\circ}$ relative to the ideal $90^{\circ}$ bond angles, which is characteristic of $\mathrm{Pt}^{\mathrm{II}}$ bipyridyl and diimine complexes. ${ }^{14,}{ }^{22-23}$ The Pt-N2 bond is $0.09 \AA$ shorter than the Pt-N1 bond, indicative of a greater trans influence of the phenyl ligand relative to acetonitrile. 


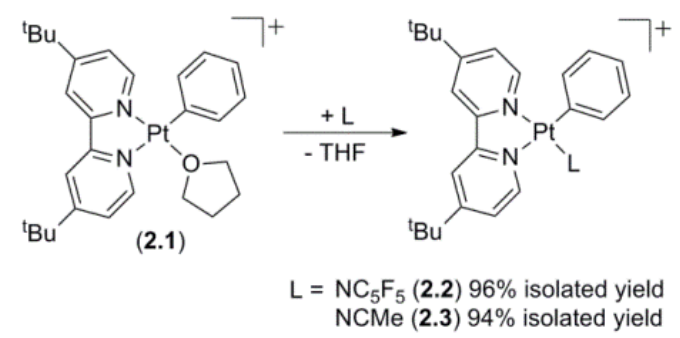

Scheme 2.1 Synthesis of $\left[\left({ }^{t} b p y\right) P t(P h)(L)\right]^{+}\left[\mathrm{L}=\mathrm{NC}_{5} \mathrm{~F}_{5}\right.$ (2.2) or NCMe (2.3)] from ligand exchange with $\left[\left({ }^{t} \mathrm{bpy}\right) \mathrm{Pt}(\mathrm{Ph})(\mathrm{THF})\right]^{+}(\mathbf{2 . 1})$.

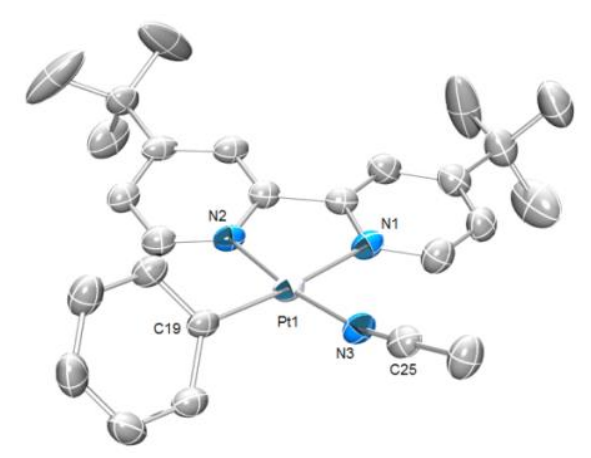

Figure 2.2. ORTEP of [ ( $\left.\left.{ }^{\mathrm{b} b p y}\right) \mathrm{Pt}(\mathrm{NCMe})(\mathrm{Ph})\right]\left[\mathrm{BAr}_{4}\right]$ (2.3) (50\% probability; $\mathrm{H}$ atoms and $\mathrm{BAr}_{4}{ }_{4}$ anion omitted for clarity). Selected bond lengths $(\AA)$ : Pt1-N1 2.092(4), Pt1-N2 2.000(4), Pt1-N3 1.969(4), Pt1-C19 2.004(5). Selected bond angles $\left({ }^{\circ}\right)$ : N1-Pt1-N2 79.3(2), C19-Pt-N3 88.3(2), C25-N3-Pt 169.7(4).

We probed complexes $\mathbf{2 . 1}-\mathbf{2 . 3}$ as catalyst precursors for the hydrophenylation of ethylene. Heating a benzene solution of 2.1, 2.2 or 2.3 in the presence of ethylene results in the production of ethylbenzene and diethylbenzenes (Table 2.1). At $100{ }^{\circ} \mathrm{C}$ under 0.1 $\mathrm{MPa}$ of ethylene, a solution of $0.025 \mathrm{~mol} \% \mathbf{2 . 1}$ (relative to benzene) results in 15.7 turnovers (TO) of ethylbenzene and 3.6 TO of diethylbenzenes after 4 hours, corresponds to a turnover frequency (TOF) of $1.3 \times 10^{-3} \mathrm{~s}^{-1}$ (the formation of diethylbenzenes is counted as a single catalytic TO; unless stated otherwise all TOF are calculated in this manner). After 16 hours, 63.5 TO (ethylbenzene and diethylbenzenes) were observed. 
Catalysis using 2.1 appears to tolerate air. Setting up the reaction of benzene and ethylene $\left(100{ }^{\circ} \mathrm{C}, 0.025 \mathrm{~mol} \% \mathbf{2 . 1}\right)$ on the bench top (i.e., aerobic conditions) resulted in 17.4 and 55.7 total TO after 4 and 16 hours, respectively (compared to 19.3 and 63.5 total TO for the reaction prepared under a dinitrogen atmosphere). Using a calibrated gas burette, a catalytic reaction with a known quantity of ethylene $(0.03 \mathrm{MPa}, 4.2 \mathrm{mmol})$ as the limiting reagent was arranged. Heating the reaction mixture at $120^{\circ} \mathrm{C}$ for 4 hours resulted in the production of 119.3 TO of ethylbenzene, diethylbenzenes, and styrene, which corresponds to an $89 \%$ yield (Scheme 2.2). In this reaction, since ethylene was the limiting reagent, diethylbenzene production was counted as two TO.

Table 2.1. Catalytic hydrophenylation of ethylene using complexes $\mathbf{2 . 1}-\mathbf{2 . 3}$ as catalysts. ${ }^{\text {a }}$

\begin{tabular}{ccccccc}
\hline Catalyst $^{\mathrm{a}}$ & $15.7^{\mathrm{d}}$ & 0.7 & 1.8 & 1.1 & $1: 2.6: 1.6$ & 1.3 \\
\hline$\left.\left[{ }^{\mathrm{t}} \mathrm{bpy}\right) \mathrm{Pt}(\mathrm{Ph})(\mathrm{THF})\right]\left[\mathrm{BAr}_{4}\right](\mathbf{2 . 1})$ & $(52.7)^{\mathrm{e}}$ & $(1.5)$ & $(5.8)$ & $(3.5)$ & & \\
& 8.1 & 0.6 & 1.1 & 0.7 & $1: 1.8: 1.2$ & 0.7 \\
$\left.\left[{ }^{\mathrm{t}} \mathrm{bpy}\right) \mathrm{Pt}(\mathrm{Ph})\left(\mathrm{NC}_{5} \mathrm{~F}_{5}\right)\right]\left[\mathrm{BAr}_{4}\right](\mathbf{2 . 2})$ & $(19.7)$ & $(1.1)$ & $(2.2)$ & $(1.3)$ & & \\
& 7.4 & 0.5 & 0.7 & 0.6 & $1: 1.4: 1.2$ & 0.6 \\
$\left.\left[{ }^{\mathrm{t}} \mathrm{bpy}\right) \mathrm{Pt}(\mathrm{Ph})(\mathrm{NCMe})\right]\left[\mathrm{BAr}_{4}\right](\mathbf{2 . 3})$ & $(21.3)$ & $(1.2)$ & $(1.7)$ & $(1.3)$ & $1: 1.4: p^{\mathrm{b}}$ & $\begin{array}{c}\mathrm{TOF}^{\mathrm{c}} \\
\left(10^{-3} \mathrm{~s}^{-1}\right)\end{array}$ \\
\hline
\end{tabular}

${ }^{a} 0.025 \mathrm{~mol} \%$ catalyst dissolved in $\mathrm{C}_{6} \mathrm{H}_{6}$ with hexamethylbenzene as internal standard at $100{ }^{\circ} \mathrm{C}$. ${ }^{\mathrm{b}}$ Ratio of 1,2-, 1,3- and 1,4-diethylbenzene after 4 hours. ${ }^{\mathrm{c}}$ Turnover frequency calculated after 4 hours with the formation of diethylbenzenes counted as one turnover. ${ }^{d}$ Turnovers after 4 hours as determined by GC/MS. ${ }^{\mathrm{e}}$ Numbers in parentheses are turnovers after 16 hours.

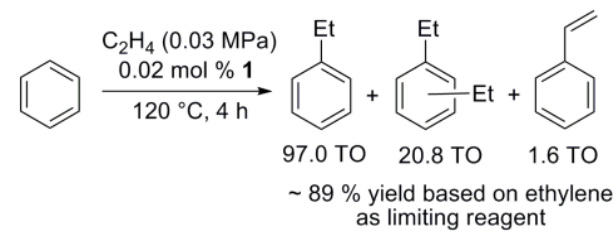

Scheme 2.2. Results of ethylene hydrophenylation using complex 2.1 and ethylene $(0.03$ $\mathrm{MPa})$ at $120{ }^{\circ} \mathrm{C}$. 
Substitution of THF with $\mathrm{NC}_{5} \mathrm{~F}_{5}$ reduces the rate of ethylbenzene production after 4 hours by approximately $50 \%$ (Table 2.1). For example, using 2.2 at $100{ }^{\circ} \mathrm{C}$ results in 8.1 TO of ethylbenzene and 2.4 TO of diethylbenzenes, which gives a TOF of $0.7 \times 10^{-3} \mathrm{~s}^{-1}$. Complex $\mathbf{2 . 3}$ performed similarly to $\mathbf{2 . 2}$ with a TOF of $0.6 \times 10^{-3} \mathrm{~s}^{-1}$ and $\sim 9.2$ TO after 4 hours.

Using complex 2.1, the influence of temperature and pressure on catalysis was investigated (Table 2.2). With increasing temperature, the TOF of ethylbenzene production increases but catalyst decomposition is accelerated. At $90{ }^{\circ} \mathrm{C}$ under $0.1 \mathrm{MPa}$ of ethylene pressure, a solution of 2.1 in benzene results in a TOF of $0.4 \times 10^{-3} \mathrm{~s}^{-1}$. Increasing the temperature to $100{ }^{\circ} \mathrm{C}$ effectively triples the rate of ethylene hydrophenylation compared to the reaction at $90^{\circ} \mathrm{C}$, and at $120^{\circ} \mathrm{C}$ the rate increases by a factor of $\sim 18$ (compared to this reaction at $90^{\circ} \mathrm{C}$ ) with a TOF of $7.1 \times 10^{-3} \mathrm{~s}^{-1}$. At $90^{\circ} \mathrm{C}$, $100{ }^{\circ} \mathrm{C}$ and $120^{\circ} \mathrm{C}$, increasing the olefin pressure from $0.1 \mathrm{MPa}$ to $0.3 \mathrm{MPa}$ of ethylene leads to an approximate $75 \%$ reduction in the amount of alkylated products. 
Table 2.2. Impact of temperature and ethylene pressure on catalysis using $\left[\left({ }^{(} \mathrm{bpy}\right) \mathrm{Pt}(\mathrm{Ph})(\mathrm{THF})\right]\left[\mathrm{BAr}_{4}^{\prime}\right](\mathbf{2 . 1}){ }^{\mathrm{a}}$

\begin{tabular}{|c|c|c|c|c|c|c|c|}
\hline $\begin{array}{c}\text { Temp } \\
\left({ }^{\circ} \mathrm{C}\right)\end{array}$ & $\begin{array}{c}\mathrm{C}_{2} \mathrm{H}_{4} \\
(\mathrm{MPa})\end{array}$ & & & & & $o: m: p^{b}$ & $\begin{array}{l}\mathrm{TOF}^{c} \\
\left(10^{-3} \mathrm{~s}^{-1}\right)\end{array}$ \\
\hline 90 & 0.1 & $\begin{array}{c}4.9^{\mathrm{d}} \\
(14.3)^{\mathrm{e}}\end{array}$ & $\begin{array}{c}0.4 \\
(0.9)\end{array}$ & $\begin{array}{c}0.6 \\
(1.4)\end{array}$ & $\begin{array}{c}0.4 \\
(0.9)\end{array}$ & 1:1.5:1.1 & 0.4 \\
\hline 90 & 0.3 & $\begin{array}{c}1.6 \\
(3.7)\end{array}$ & $\begin{array}{c}0.3 \\
(0.5)\end{array}$ & $\begin{array}{c}0 \\
(0.5)\end{array}$ & $\begin{array}{c}0.3 \\
(0.4)\end{array}$ & $1: 0: 1^{f}$ & 0.2 \\
\hline 100 & 0.1 & $\begin{array}{c}15.7 \\
(52.7)\end{array}$ & $\begin{array}{c}0.7 \\
(1.5)\end{array}$ & $\begin{array}{c}1.8 \\
(5.8)\end{array}$ & $\begin{array}{c}1.1 \\
(3.5)\end{array}$ & 1:2.6:1.6 & 1.3 \\
\hline 100 & 0.3 & $\begin{array}{c}4.0 \\
(8.4)\end{array}$ & $\begin{array}{c}0.3 \\
(0.7)\end{array}$ & $\begin{array}{c}0.3 \\
(0.5)\end{array}$ & $\begin{array}{c}0.3 \\
(0.6)\end{array}$ & 1:1.1:0.8 & 0.3 \\
\hline 120 & 0.1 & $\begin{array}{c}89.6 \\
(107.5)\end{array}$ & $\begin{array}{c}2.7 \\
(3.5)\end{array}$ & $\begin{array}{c}6.6 \\
(8.7)\end{array}$ & $\begin{array}{c}3.7 \\
(4.7)\end{array}$ & $1: 2.5: 1.4$ & 7.1 \\
\hline 120 & 0.3 & $\begin{array}{c}23.4 \\
(71.8)\end{array}$ & $\begin{array}{c}1.4 \\
(3.8)\end{array}$ & $\begin{array}{c}2.6 \\
(8.2)\end{array}$ & $\begin{array}{c}1.7 \\
(4.6)\end{array}$ & 1:1.9:1.2 & 2.0 \\
\hline
\end{tabular}

${ }^{a} 0.025 \mathrm{~mol} \%$ catalyst dissolved in $\mathrm{C}_{6} \mathrm{H}_{6}$ with hexamethylbenzene as an internal standard at $100{ }^{\circ} \mathrm{C} .{ }^{\mathrm{b}}$ Ratio of 1,2-, 1,3- and 1,4-diethylbenzene after 4 hours. ${ }^{\mathrm{c}}$ Turnover frequency calculated after 4 hours; formation of diethylbenzenes counted as one turnover. ${ }^{d}$ Turnovers after 4 hours as determined by GC/MS. ${ }^{\mathrm{e}}$ Numbers in parentheses are turnovers after 16 hours. ${ }^{\mathrm{f}}$ 1,3-diethylbenzene not detected.

Although increased ethylene pressure suppresses the rate of catalysis, we postulated that catalyst longevity might be enhanced by continuous presence of ethylene. A catalytic reaction under dynamic ethylene pressure was analyzed over $\sim 70$ hours. After purging the reaction vessel with ethylene and pressurizing with $\mathrm{N}_{2}(0.9 \mathrm{MPa})$, the reaction was then exposed to a constant source of ethylene $(0.9 \mathrm{MPa})$ and heated at $100{ }^{\circ} \mathrm{C}$. A plot of TO versus time demonstrates a linear relationship with no evidence of catalyst decomposition (Figure 2.3). 


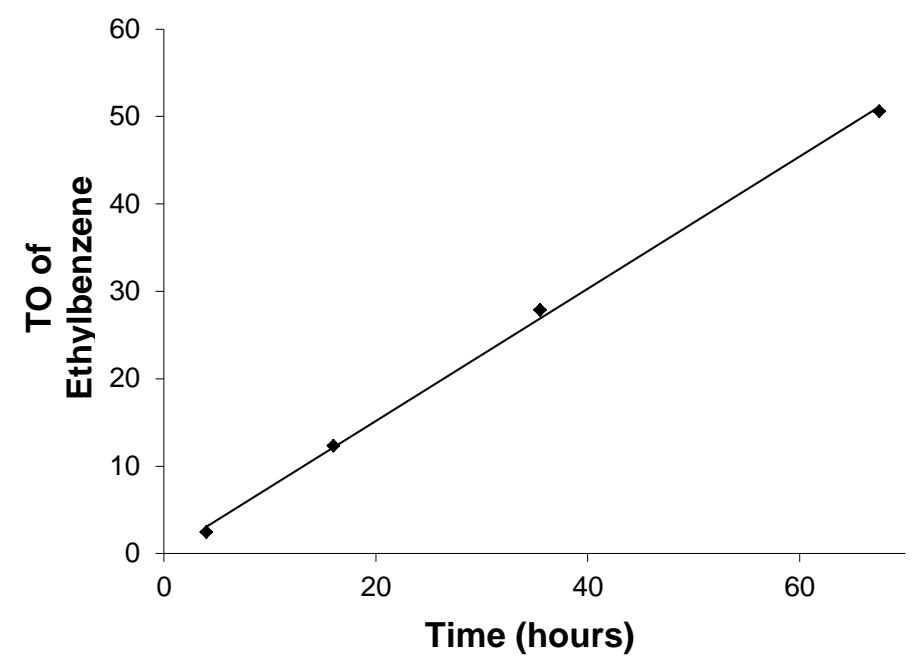

Figure 2.3. Catalysis using complex 2.1 and dynamic ethylene $(0.9 \mathrm{MPa})$ at $100{ }^{\circ} \mathrm{C}\left(\mathrm{R}^{2}=\right.$ $0.99)$.

\subsubsection{Mechanism Overview}

Metal-mediated olefin hydroarylation can proceed by a Friedel-Crafts pathway or by metal-mediated olefin insertion into a metal-phenyl bond followed by aromatic $\mathrm{C}-\mathrm{H}$ activation. As anticipated for relatively electron-rich octahedral $\mathrm{d}^{6}$ systems, results from

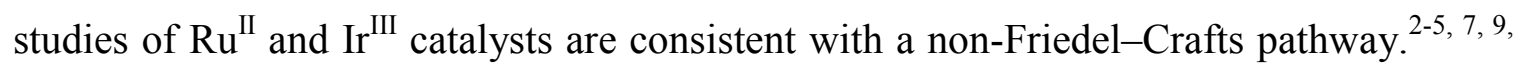
24 In contrast, reaction pathways are likely to be less predictable with later transition metals that, in general, have enhanced electrophilicity such as $\mathrm{Pt}^{\mathrm{II}}$. For example, Vitagliano et al. have reported that $\mathrm{Pt}-$ ethylene complexes are susceptible to nucleophilic addition by electron-rich benzenes that are activated by methoxy substituents. ${ }^{25}$ Goldberg et al. have reported a non-Friedel-Crafts mechanism for charge neutral $\mathrm{Pt}^{\mathrm{II}}$ catalysts supported by pyridyl-pyrrolyl ligands. ${ }^{1}$ Evidence that the hydroarylation of cyclohexene using $\mathrm{L}_{2} \mathrm{Pt}(\mathrm{OTf})_{2}\left(\mathrm{~L}_{2}=1,5\right.$-cyclooctadiene or ${ }^{t} \mathrm{bpy}$, OTf $=$ trifluoromethanesulfonate $)$ likely proceeds via the generation of HOTf, which is the active catalyst, has been disclosed. ${ }^{26}$ We attempted the hydrophenylation of ethylene $(0.1 \mathrm{MPa})$ using $0.025 \mathrm{~mol}$ 
$\%$ HOTf and did not observe ethylbenzene production after 4 hours at $100{ }^{\circ} \mathrm{C}$. In addition, catalysis with $\mathbf{2 . 1}$ in the presence of 2,6-di-tert-butyl-4-methylpyridine (1.5 equivalents relative to $\mathbf{2 . 1}$ ) was not suppressed, which gave $16.8 \mathrm{TO}$ of ethylbenzenes after 4 hours. These results in combination with the experiments discussed below provide strong evidence against the generation of a Brønsted acid as the active catalyst using $\left[\left({ }^{t} \mathrm{bpy}\right) \mathrm{Pt}(\mathrm{L})(\mathrm{Ph})\right]^{+}$systems.

A plausible mechanism for catalysis by $\left[\left({ }^{t} \mathrm{bpy}\right) \mathrm{Pt}(\mathrm{Ph})\right]^{+}$is shown in Scheme 2.3. The catalytic cycle is initiated by the substitution of THF, $\mathrm{NC}_{5} \mathrm{~F}_{5}$, or NCMe with ethylene to give $\left[\left({ }^{t} \text { bpy }\right) \mathrm{Pt}\left(\eta^{2}-\mathrm{C}_{2} \mathrm{H}_{4}\right)(\mathrm{Ph})\right]^{+}$. Insertion of ethylene into the $\mathrm{Pt}-$ phenyl bond generates the coordinatively unsaturated complex $\left[\left({ }^{t} \mathrm{bpy}\right) \mathrm{Pt}\left(\mathrm{CH}_{2} \mathrm{CH}_{2} \mathrm{Ph}\right)\right]^{+}$. Subsequent aromatic $\mathrm{C}-$ $\mathrm{H}$ activation with transfer of the $\mathrm{H}$ atom from benzene to the phenethyl ligand produces coordinated ethylbenzene, which is displaced by ethylene, regardless of the pathway (e.g., associative versus dissociative ligand exchange), to regenerate the catalyst. The coordination of ethylene to $\left[\left({ }^{t} \mathrm{bpy}\right) \mathrm{Pt}\left(\mathrm{CH}_{2} \mathrm{CH}_{2} \mathrm{Ph}\right)\right]^{+}$to form $\left[\left({ }^{t} \mathrm{bpy}\right) \mathrm{Pt}\left(\mathrm{CH}_{2} \mathrm{CH}_{2} \mathrm{Ph}\right)\left(\eta^{2}-\right.\right.$ $\left.\mathrm{C}_{2} \mathrm{H}_{4}\right]^{+}$, which is the proposed catalyst resting state, removes $\mathrm{Pt}$ from the catalytic cycle. 


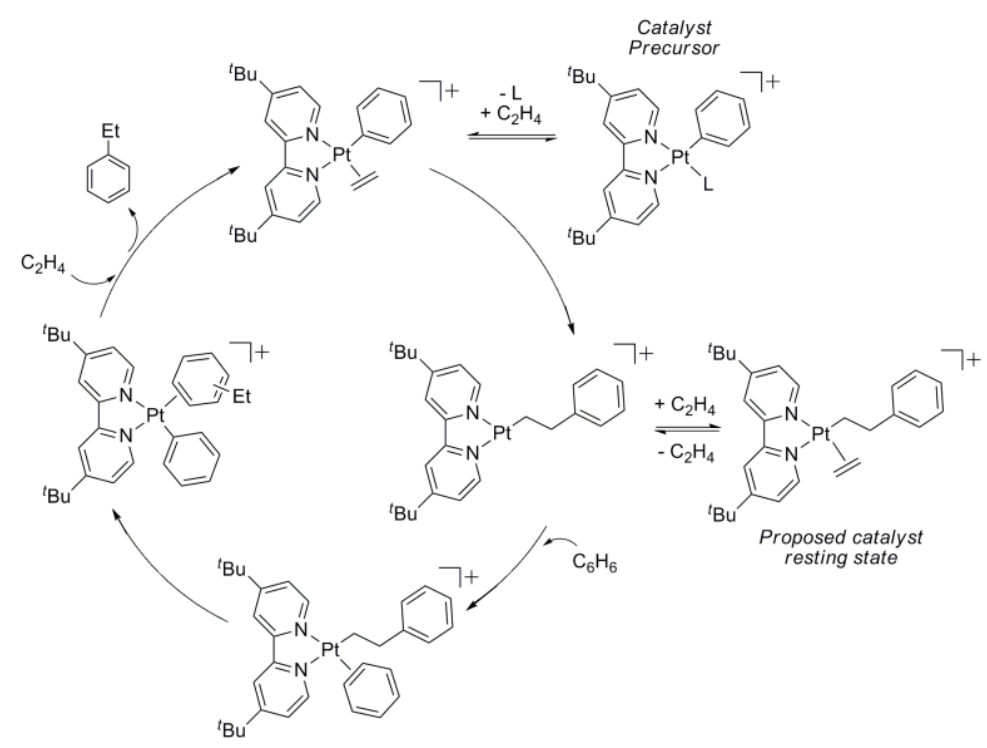

Scheme 2.3. Proposed mechanism for ethylene hydrophenylation catalyzed by $\left[\left({ }^{t} \text { bpy }\right) \mathrm{Pt}(\mathrm{L})(\mathrm{Ph})\right]^{+}\left[\mathrm{L}=\mathrm{THF}(\mathbf{2 . 1}), \mathrm{NC}_{5} \mathrm{~F}_{5}(\mathbf{2 . 2})\right.$ or $\left.\mathrm{NCMe}(\mathbf{2 . 3})\right]$.

\subsubsection{Kinetic Studies and Isotope Effects for the Catalytic Cycle}

To determine the dependence of ethylbenzene production on the concentrations of 2.1, ethylene and benzene, three sets of kinetic experiments were performed where the concentrations of two species were held constant and the concentration of the third species was varied. We used conditions where the rate of catalysis was monitored through $\leq 5$ TOs, since data from early in the reaction would mitigate the influence of catalyst decomposition. To show the concentration dependence of each substrate, we plotted the concentration of ethylbenzene at a specified time versus the concentration of 2.1, ethylene or benzene. The production of ethylbenzene displays a first order dependence on the concentration of $\mathbf{2 . 1}$ (Figure 2.4). Catalytic reactions performed in $\mathrm{NC}_{5} \mathrm{~F}_{5}$ with varying concentrations of benzene $(0.1$ to $2.7 \mathrm{M})$ display saturation kinetics (Figure 2.5). Catalysis was studied over an ethylene concentration range of 0.04 to 0.13 
M. Catalyst activity decreases with increasing ethylene concentration (Figure 2.6), which is consistent with the proposed catalyst resting state (see below). Similar effects of increased olefin concentration on catalysis have been observed with $\mathrm{Ru}^{\mathrm{II}}$ systems for olefin hydroarylation. ${ }^{5}$

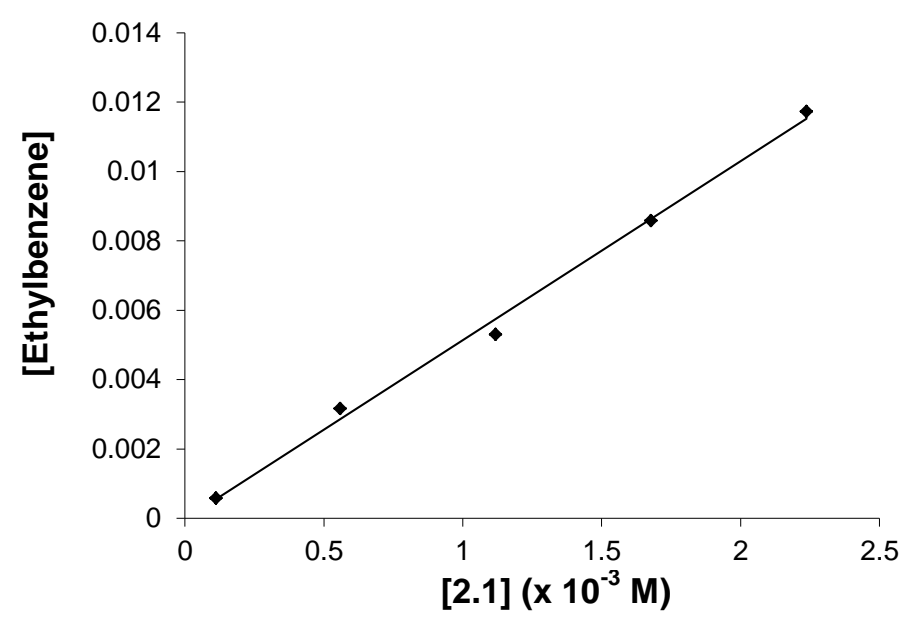

Figure 2.4. Plot of [ethylbenzene] (M) versus [2.1] after 30 minutes at $100{ }^{\circ} \mathrm{C}$ with 0.1 $\mathrm{MPa}$ of ethylene in neat benzene $\left(\mathrm{R}^{2}=0.99\right)$.

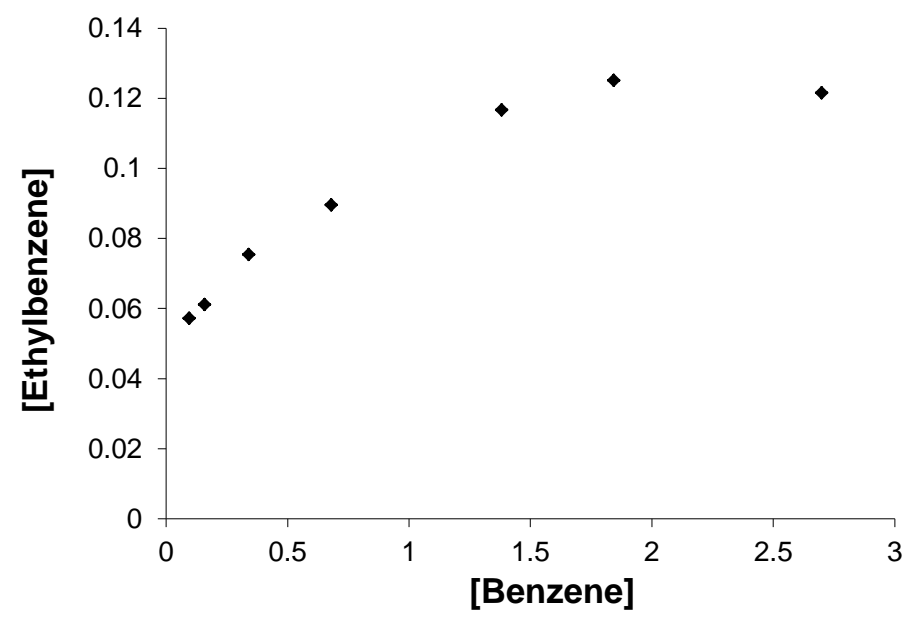

Figure 2.5. Plot of [ethylbenzene] (M) versus [benzene] (M) after 2 hours at $100{ }^{\circ} \mathrm{C}$ in perfluoropyridine with [ethylene] $=0.16(5) \mathrm{M}$ and $[\mathbf{2 . 1}]=0.03 \mathrm{M}$. 


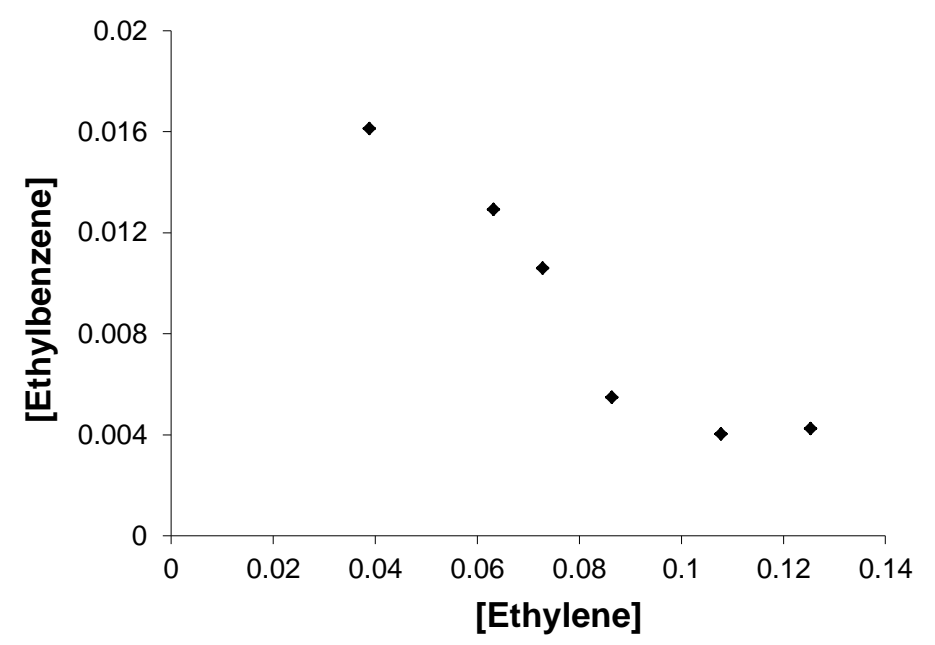

Figure 2.6. Plot of [ethylbenzene] (M) versus [ethylene] (M) after 2 hours at $100{ }^{\circ} \mathrm{C}$ in $\mathrm{C}_{6} \mathrm{D}_{6}$ and $[2.1]=2.8 \mathrm{mM}$.

Comparative rates of ethylene hydrophenylation with $\mathrm{C}_{6} \mathrm{H}_{6}$ and $\mathrm{C}_{6} \mathrm{D}_{6}$ were used to determine the kinetic isotope effect (KIE) for catalytic reactions. In separate experiments that incorporated either neat $\mathrm{C}_{6} \mathrm{H}_{6}$ or $\mathrm{C}_{6} \mathrm{D}_{6}$, using the ratio of $\mathrm{TO}$ after 4 hours of reaction (taken from multiple experiments under identical conditions), a catalytic KIE of 1.8(4) was determined. This $\mathrm{KIE}$ is statistically indistinguishable from the KIE for stoichiometric benzene $\mathrm{C}-\mathrm{H} / \mathrm{C}-\mathrm{D}$ activation by $\left[\left({ }^{t} \mathrm{bpy}\right) \mathrm{Pt}\left(\mathrm{Ph}-d_{\mathrm{n}}\right)(\mathrm{THF})\right]^{+}(\mathrm{n}=0$ or 5$)$ (see below).

\subsubsection{Stoichiometric Studies Modeling Elementary Steps of the Catalytic Cycle}

To study stoichiometric benzene $\mathrm{C}-\mathrm{H}$ activation by $\left[\left({ }^{\mathrm{t}} \mathrm{bpy}\right) \mathrm{Pt}(\mathrm{R})\right]^{+}$systems, we used the reaction of $\left[\left({ }^{t} \mathrm{bpy}\right) \mathrm{Pt}\left(\mathrm{Ph}-d_{5}\right)(\mathrm{THF})\right]^{+}\left(\mathbf{2 . 1}-\boldsymbol{d}_{5}\right)$ with $\mathrm{C}_{6} \mathrm{H}_{6}$. The reaction of $\mathbf{2 . 1}-\boldsymbol{d}_{\mathbf{5}}$ with excess benzene at $21{ }^{\circ} \mathrm{C}$ in $\mathrm{CD}_{2} \mathrm{Cl}_{2}$ leads to the formation of $\mathbf{2 . 1}$ and $\mathrm{C}_{6} \mathrm{D}_{5} \mathrm{H}$ with an observed rate constant of 7.1(4) $\times 10^{-5} \mathrm{~s}^{-1}$. A rate constant of $5.0(3) \times 10^{-5} \mathrm{~s}^{-1}$ is observed 
for the same reaction between 2.1 and $\mathrm{C}_{6} \mathrm{D}_{6}$ to form $\mathbf{2 . 1}-\boldsymbol{d}_{5}$ and $\mathrm{C}_{6} \mathrm{H}_{5} \mathrm{D}$. The activation of a benzene $\mathrm{C}-\mathrm{H} / \mathrm{D}$ bond results in a KIE of 1.4(1) (Scheme 2.4). Experiments described below demonstrate that the $\left[\left({ }^{\mathrm{t}} \mathrm{bpy}\right) \mathrm{Pt}(\mathrm{R})\right]^{+}$fragment can coordinate a deuterated aromatic substrate and initiate multiple $H / D$ exchange reactions prior to dissociation of $R-H(D)$. Thus, these multiple exchanges are likely occurring during the conversions shown in Scheme 2.4. The magnitude of the KIE is similar to that previously observed for arene and aliphatic $\mathrm{C}-\mathrm{H}$ activation by $\mathrm{Pt}^{\mathrm{II}}$ systems. ${ }^{11,13,27-28}$

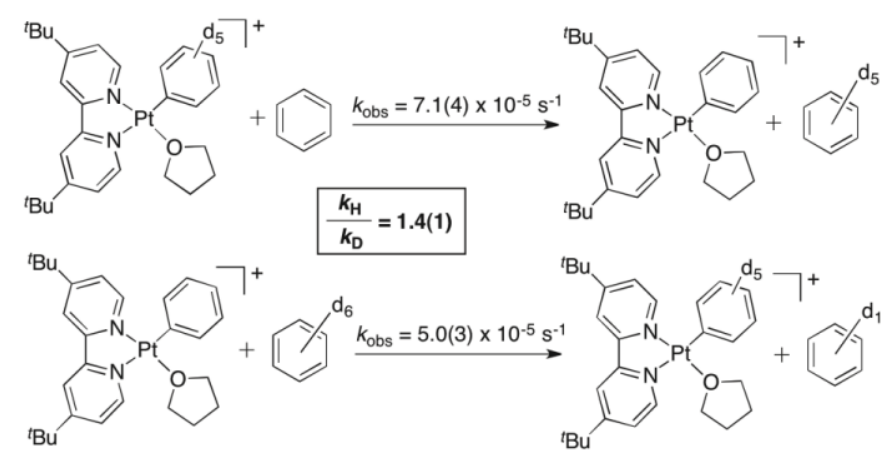

Scheme 2.4. Rates of degenerate benzene $\mathrm{C}-\mathrm{H} / \mathrm{D}$ activation by $\mathbf{2 . 1}$ and $\mathbf{2 . 1}-\boldsymbol{d}_{5}$ in $\mathrm{CD}_{2} \mathrm{Cl}_{2}$ $([\mathrm{Pt}]=0.03 \mathrm{M}$, [benzene $\left.]=0.5 \mathrm{M}, 21^{\circ} \mathrm{C}\right)$.

The impact of the weakly coordinating Lewis base THF on the rate of benzene C-D activation by 2.1 was investigated. At $45^{\circ} \mathrm{C}$, the conversion of $\mathbf{2 . 1}$ to $\mathbf{2 . 1}-\boldsymbol{d}_{\mathbf{5}}$ and $\mathrm{C}_{6} \mathrm{H}_{5} \mathrm{D}$ occurs with an observed rate of $8.1(9) \times 10^{-4} \mathrm{~s}^{-1}$, which corresponds to an apparent $\Delta G^{\ddagger}$ of 23.2(1) $\mathrm{kcal} / \mathrm{mol}$. The reaction rate decreases with increasing THF concentration (Figure 2.7). From these data and the KIEs, we propose a mechanism for benzene $\mathrm{C}-\mathrm{H}$ activation by $\left[\left({ }^{t} \text { bpy }\right) \mathrm{Pt}(\mathrm{L})(\mathrm{R})\right]^{+}$systems that is shown in Scheme 2.5 . Reversible dissociation of THF and benzene coordination precede rate determining $\mathrm{C}-\mathrm{H}$ activation of benzene. The 
corresponding rate law is depicted in Scheme 2.5. Studies of $\mathrm{C}-\mathrm{H}$ activation by other cationic $\mathrm{Pt}^{\mathrm{II}}$ systems with hydrocarbyl ligands suggest similar pathways that likely involve three-coordinate Pt complexes. ${ }^{20}$

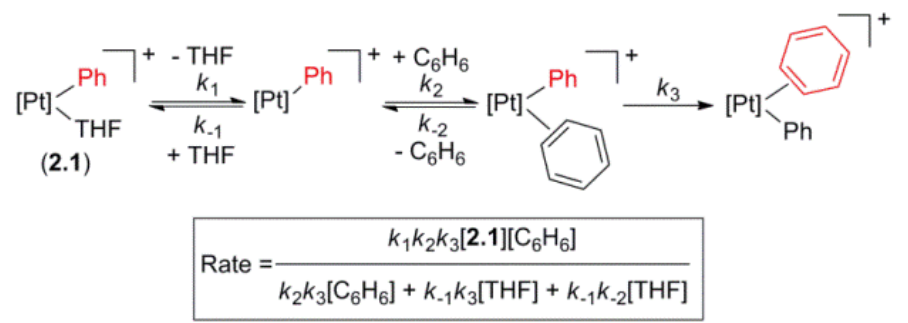

Scheme 2.5. Proposed pathway for degenerate benzene activation by $\left[\left({ }^{t} \mathrm{bpy}\right) \mathrm{Pt}(\mathrm{Ph})(\mathrm{THF})\right]^{+}(\mathbf{2 . 1}) .[\mathrm{Pt}]=\left[\left({ }^{t} \mathrm{bpy}\right) \mathrm{Pt}\right]$.

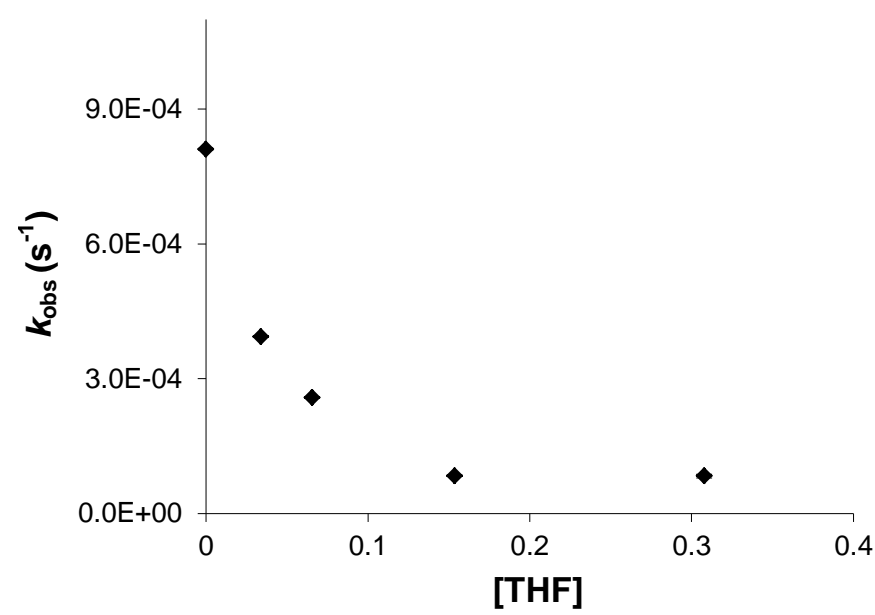

Figure 2.7. Observed rate of benzene $\mathrm{C}-\mathrm{D}$ activation by $\mathbf{2 . 1}$ as a function of THF concentration $(\mathrm{M})\left([\mathbf{2 . 1}]=0.03 \mathrm{M},\left[\mathrm{C}_{6} \mathrm{D}_{6}\right]=0.5 \mathrm{M}\right)$.

\subsubsection{Computational Study of Benzene C-H Activation by $\left[\left({ }^{t} \mathrm{bpy}\right) \mathrm{Pt}\left(\mathrm{CH}_{2} \mathrm{CH}_{2} \mathrm{Ph}\right)\right]^{+}$}

The mechanisms by which $\mathrm{Pt}^{\mathrm{II}}$ systems activate the $\mathrm{C}-\mathrm{H}$ bonds of hydrocarbons have been studied extensively. ${ }^{20,29-31}$ The two mechanisms for $\mathrm{Pt}^{\mathrm{II}}-$ mediated $\mathrm{C}-\mathrm{H}$ activation most commonly invoked are electrophilic substitution and oxidative addition (Scheme 
2.6). ${ }^{11,20,27,32-35}$ In addition, recent mechanistic studies suggest that the exchange of phenyl groups in $\left[(\mathrm{N} \sim \mathrm{N}) \mathrm{Pt}(\mathrm{Ph})\left(\mathrm{C}_{6} \mathrm{H}_{6}\right)\right]^{+}(\mathrm{N} \sim \mathrm{N}=\mathrm{ArN}=\mathrm{CMe}-\mathrm{CMe}=\mathrm{NAr}, \mathrm{Ar}=2,6-$ $\mathrm{Me}_{2} \mathrm{C}_{6} \mathrm{H}_{3}$ ) occurs by a $\sigma$-bond metathesis pathway with a calculated activation energy $\sim 5.0 \mathrm{kcal} / \mathrm{mol}$ lower than that calculated for oxidative addition. ${ }^{36}$ The calculated transition state is similar to that proposed for $\sigma$-bond metathesis type transition states in which the metal appears to interact with the activated hydrogen, which have been coined " $\sigma$-complex assisted metathesis" ( $\sigma-\mathrm{CAM})$ or oxidative hydrogen migration. ${ }^{2,37-43}$

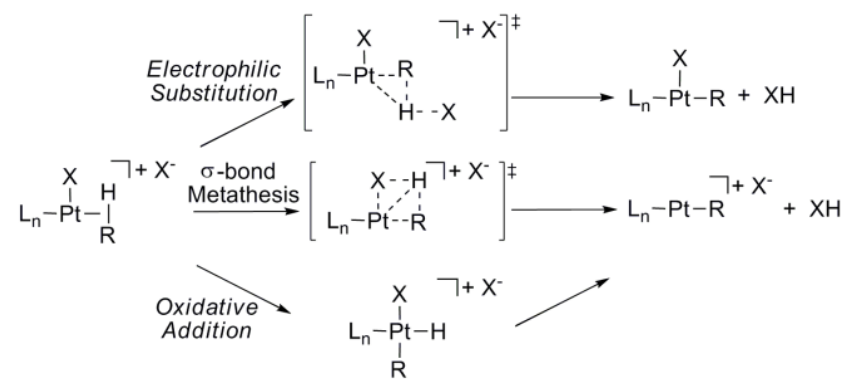

Scheme 2.6. $\mathrm{Pt}^{\mathrm{II}}$-mediated $\mathrm{C}-\mathrm{H}$ activation via electrophilic substitution, oxidative addition or $\sigma$-bond metathesis.

In our computational modeling, performed by Dr. Thomas Cundari at the University of North Texas, we considered aromatic $\mathrm{C}-\mathrm{H}$ activation by $\left[\left({ }^{t} \text { bpy }\right) \mathrm{Pt}\left(\mathrm{CH}_{2} \mathrm{CH}_{2} \mathrm{Ph}\right)\right]^{+}$via $\sigma-$ bond metathesis and oxidative addition/reductive elimination pathways (Scheme 2.6). Calculations were performed with B3LYP ${ }^{44-46}$ using the Stevens valence basis sets, CEP$31 \mathrm{G}(\mathrm{d}),{ }^{47-50}$ and pseudopotentials. For all simulations, the parent 2,2'-bipyridine (bpy) was used in place of ${ }^{t}$ bpy. A two-step oxidative addition/reductive elimination pathway was calculated to be favored over a one-step $\sigma$-bond metathesis mechanism by 2.3 $\mathrm{kcal} / \mathrm{mol}$ (Scheme 2.7). The core geometries of the three transition states (i.e., transition 
states for $\sigma$-bond metathesis, oxidative addition and reductive elimination), plus the fivecoordinate hydride intermediate, are shown in Figure 2.8. All of these species are calculated to have short Pt-H distances, with the longest (1.68 $\AA$ ) being the kite-shaped $\sigma$-bond metathesis transition state, for which the $\mathrm{H}$ atom is transferred in the equatorial plane from the aryl ring to the alkyl fragment. This distance is similar to bona fide bond distances of isolated Pt-hydride complexes, which are in the range of $1.63-1.68 \AA .^{51-52}$

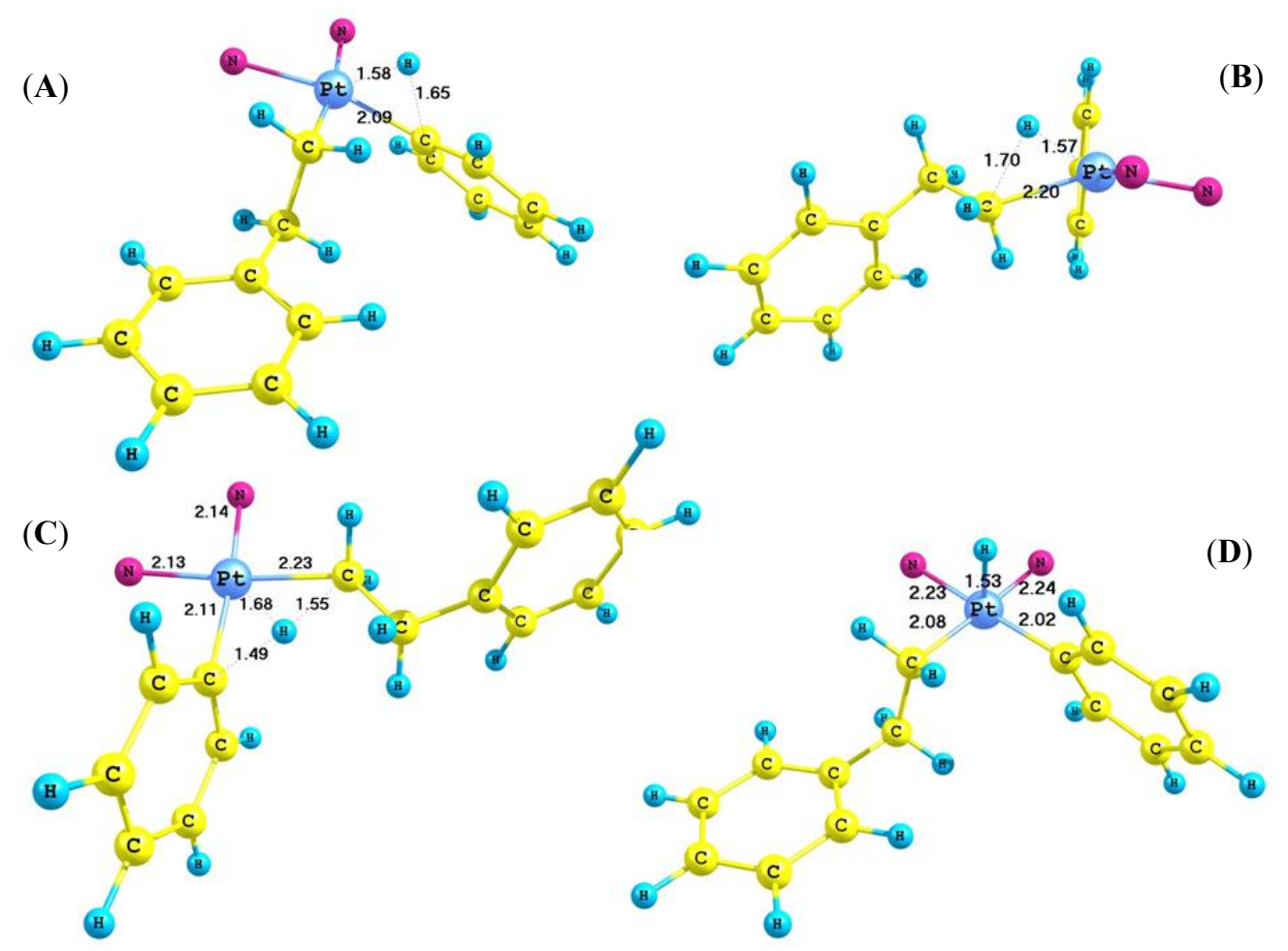

Figure 2.8. Calculated structures of pertinent stationary points (see Scheme 2.7) from $\left[(\text { bpy }) \mathrm{Pt}\left(\mathrm{CH}_{2} \mathrm{CH}_{2} \mathrm{Ph}\right)\left(\eta^{2}-C, C-\mathrm{C}_{6} \mathrm{H}_{6}\right)\right]^{+}$. Shown are the transition states for benzene $\mathrm{C}-\mathrm{H}$ oxidative addition (A), ethylbenzene reductive elimination (B), and intermediate $\sigma$-bond metathesis (C) in addition to a five-coordinate, $\mathrm{Pt}$-hydride intermediate (D) that is the successor to the oxidative addition transition state and the precursor to the reductive elimination transition state. Only the two nitrogens of the bipyridyl ligand are shown to increase the clarity of the Pt core. 


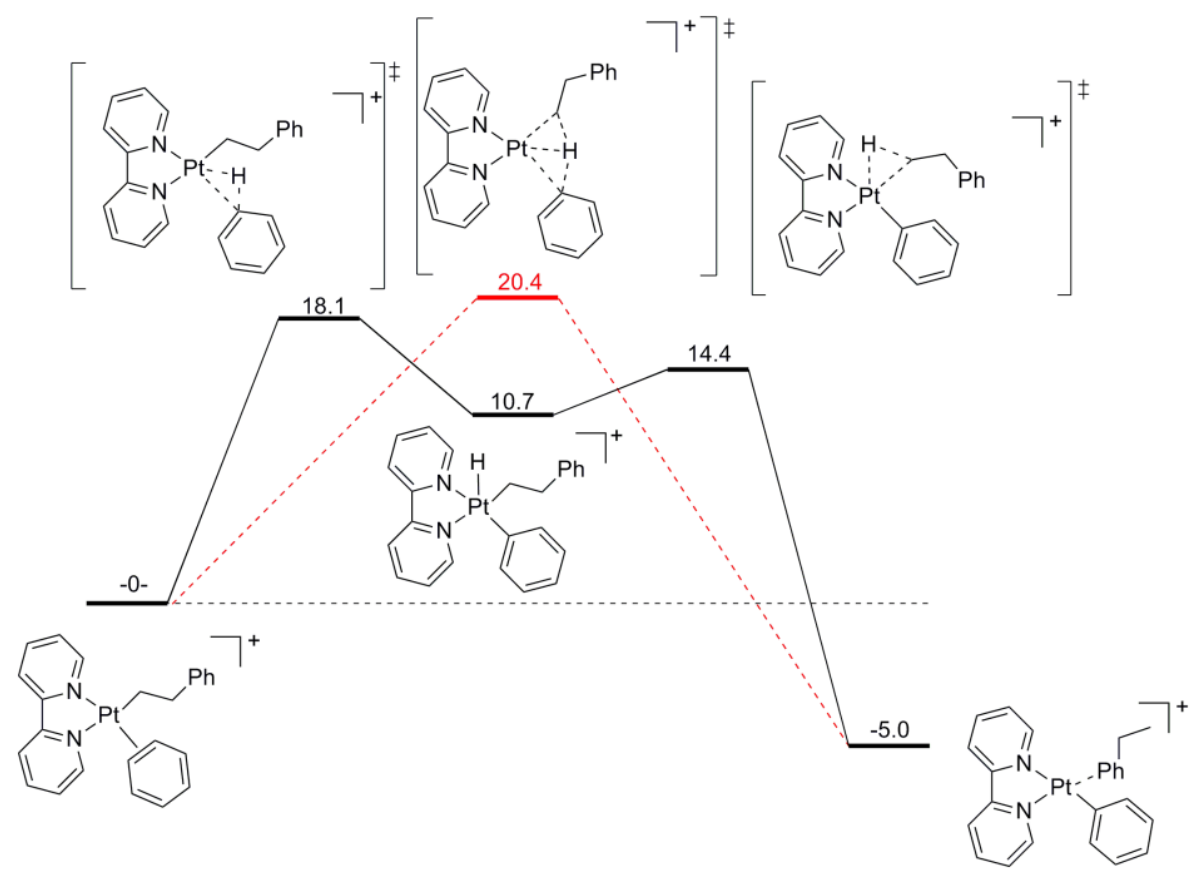

Scheme 2.7. Calculated reaction coordinate $(\Delta \mathrm{G}$ in THF, $\mathrm{kcal} / \mathrm{mol})$ comparing a two-step (oxidative addition/reductive elimination) pathway via a $\mathrm{Pt}^{\mathrm{IV}}$-hydride with a one-step $(\sigma-$ bond metathesis, in red) pathway for benzene $\mathrm{C}-\mathrm{H}$ activation from $\left[(\mathrm{bpy}) \mathrm{Pt}\left(\mathrm{CH}_{2} \mathrm{CH}_{2} \mathrm{Ph}\right)\left(\eta^{2}-\mathrm{C}_{6} \mathrm{H}_{6}\right)\right]^{+}$.

\subsubsection{Ethylene Insertion}

As complex 2.1 was verified to activate $\mathrm{C}-\mathrm{H}$ bonds of benzene, ethylene insertion into the $\mathrm{Pt}-\mathrm{Ph}$ bond was investigated. The reaction of $\mathbf{2 . 1}$ with ethylene at room temperature in dichloromethane produces $\left[\left({ }^{t} \mathrm{bpy}\right) \mathrm{Pt}\left(\mathrm{CH}_{2} \mathrm{CH}_{2} \mathrm{Ph}\right)\left(\eta^{2}-\mathrm{C}_{2} \mathrm{H}_{4}\right)\right]\left[\mathrm{BAr}_{4}{ }_{4}\right]$ (2.4) in $97 \%$ isolated yield (Scheme 2.8). In the ${ }^{1} \mathrm{H}$ NMR spectrum of $\mathbf{2 . 4}$, a single resonance is observed at $4.14 \mathrm{ppm}$ for the coordinated ethylene, which indicates a fluxional process that is rapid on the NMR time scale (Figure 2.9). A suitable crystal of 2.4 was grown for an X-ray diffraction study (Figure 2.10). The Pt-N1 bond trans to the $\eta^{2}$-ethylene is shortened by $0.06 \AA$ relative to the Pt-N2 bond trans to the alkyl ligand, presumably due 
to the stronger trans influence of the alkyl ligand. ${ }^{23,53}$ The phenyl ring is oriented over the cis pyridyl ring, and the $\mathrm{Pt}-\mathrm{C} 44$ bond is distorted by $\sim 11.7^{\circ}$ out of the square plane. The $\mathrm{C}-\mathrm{C}$ bond of ethylene is oriented perpendicular to the coordination square plane and only slightly elongated $[1.393(6) \AA]$ relative to uncoordinated ethylene $(1.339 \AA),{ }^{54}$ which is more representative of a $\mathrm{C}=\mathrm{C}$ moiety than a metallacyclopropane, similar to that observed for other $\mathrm{Pt}^{\mathrm{II}}$ olefin complexes. ${ }^{23,53}$

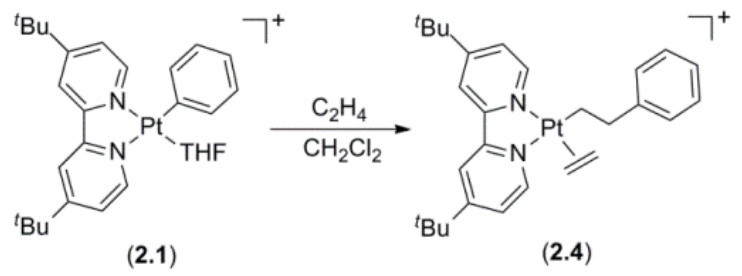

Scheme 2.8. Conversion of complex 2.1 and ethylene to $\left[\left({ }^{\mathrm{b}} \mathrm{bpy}\right) \mathrm{Pt}\left(\mathrm{CH}_{2} \mathrm{CH}_{2} \mathrm{Ph}\right)\left(\eta^{2}-\right.\right.$ $\left.\left.\mathrm{C}_{2} \mathrm{H}_{4}\right)\right]^{+}(\mathbf{2 . 4})$.

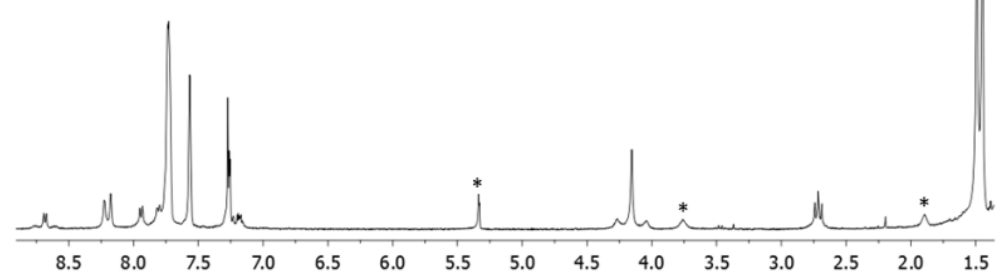

Figure 2.9. ${ }^{1} \mathrm{H}$ NMR spectrum of $\left[\left({ }^{t} b p y\right) P t\left(\mathrm{CH}_{2} \mathrm{CH}_{2} \mathrm{Ph}\right)\left(\eta^{2}-\mathrm{C}_{2} \mathrm{H}_{4}\right)\right]\left[\mathrm{BAr}_{4}{ }_{4}\right]$ (2.4) in $\mathrm{CD}_{2} \mathrm{Cl}_{2}$ at room temperature. Trace solvents $(*)$ are indicated. 

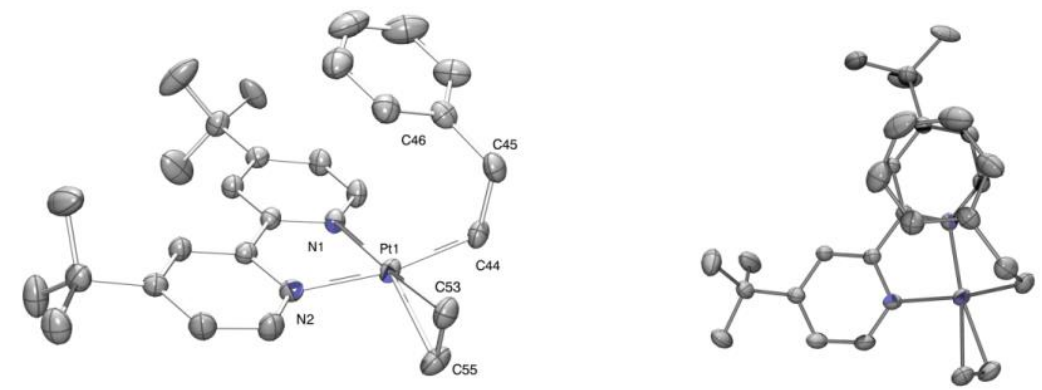

Figure 2.10. ORTEP of $\left[\left({ }^{\mathrm{b} p p y}\right) \mathrm{Pt}\left(\mathrm{CH}_{2} \mathrm{CH}_{2} \mathrm{Ph}\right)\left(\eta^{2}-\mathrm{C}_{2} \mathrm{H}_{4}\right)\right]\left[\mathrm{BAr}_{4}{ }_{4}\right]$ (2.4) (50\% probability; $\mathrm{H}$ atoms and $\mathrm{BAr}_{4}$ anion omitted for clarity) Selected bond lengths $(\AA)$ : Pt1-N1 2.069(4), Pt1-N2 2.127(4), Pt1-C44 2.052(5), Pt1-C53 2.144(5), Pt1-C55 2.118(4), C53-C55 1.393(6). Selected bond angles ( $\left.{ }^{\circ}\right)$ : N1-Pt-N2 78.4(1), Pt-C44-C45 111.3(3), C44-C45-C46 115.5(3). View on the right shows stacking of phenyl group of phenethyl ligand and pyridyl of tbpy ligand.

Monitoring the rate of conversion of $2.1(0.03 \mathrm{M})$ and ethylene $(0.1 \mathrm{M})$ to 2.4 in $\mathrm{CD}_{2} \mathrm{Cl}_{2}$ under pseudo-first-order conditions at $23{ }^{\circ} \mathrm{C}$ reveals a $k_{\mathrm{obs}}=1.05(4) \times 10^{-3} \mathrm{~s}^{-1}$ (Figure 2.11). Thus, complex $\mathbf{2 . 1}$ is capable of ethylene coordination and insertion at room temperature, and the reaction rate at this low temperature implicates that the process is a viable step in the catalytic ethylene hydrophenylation transformation at 100 ${ }^{\circ} \mathrm{C}$. The dependence of the rate of conversion of $\mathbf{2 . 1}$ and ethylene to 2.4 on ethylene concentration $(0.1$ to $1.2 \mathrm{M})$ was probed. The data implicate saturation kinetics (Figure 2.12). At approximately $1.5 \mathrm{M} \mathrm{C}_{2} \mathrm{H}_{4}$, the conversion of $\mathbf{2 . 1}$ to $\mathbf{2 . 4}$ proceeds with an observed rate of $2.1(1) \times 10^{-3} \mathrm{~s}^{-1}$, corresponding to a $\Delta G^{\ddagger}=21.0(1) \mathrm{kcal} / \mathrm{mol}\left(23{ }^{\circ} \mathrm{C}\right)$. The addition of 2,5 and 10 equivalents $(0.06$ to $0.3 \mathrm{M})$ of THF- $d_{8}$ (relative to 2.1 ) had negligible impact on the rate of insertion (Figure 2.13). 


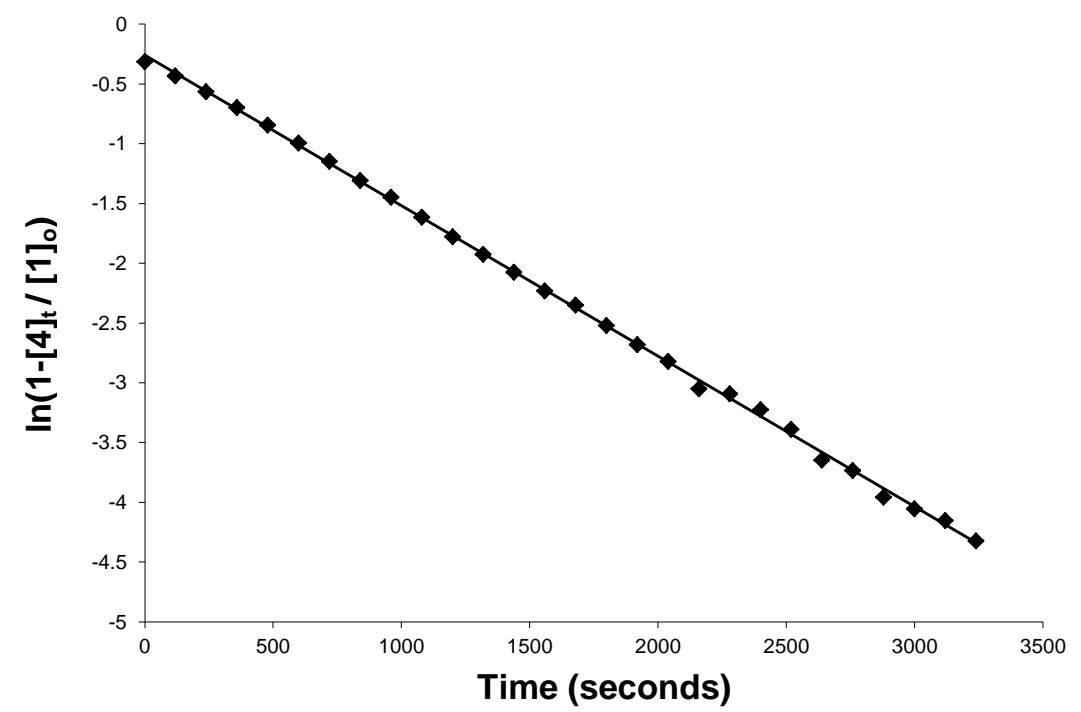

Figure 2.11. Representative kinetic plot for the conversion of 2.1 to 2.4 ([2.1] $=0.031 \mathrm{M}$, $\left.\left[\mathrm{C}_{2} \mathrm{H}_{4}\right]=0.1 \mathrm{M}, 23^{\circ} \mathrm{C}\right)$.

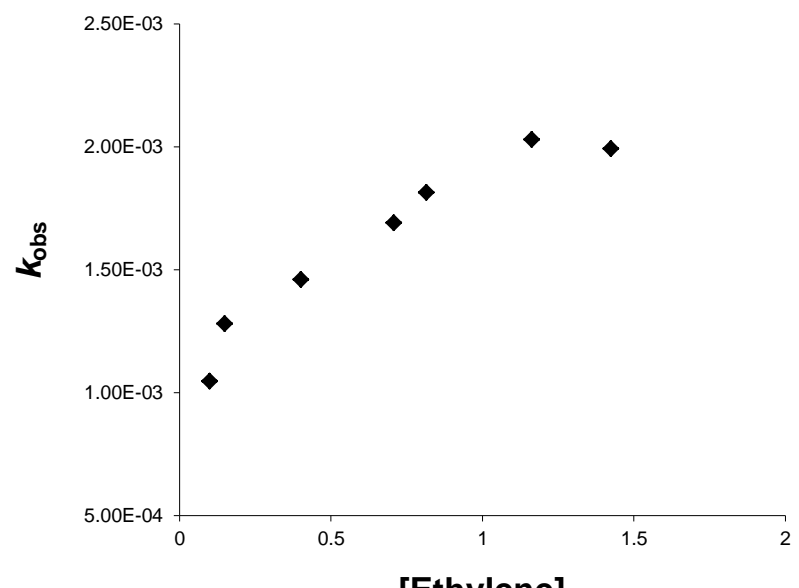

[Ethylene]

Figure 2.12. Plot of $k_{\mathrm{obs}}$ for the conversion of 2.1 and ethylene to 2.4 as a function of ethylene concentration $(\mathrm{M})\left([2.1]=0.03 \mathrm{M}, 23.0^{\circ} \mathrm{C}\right)$. 


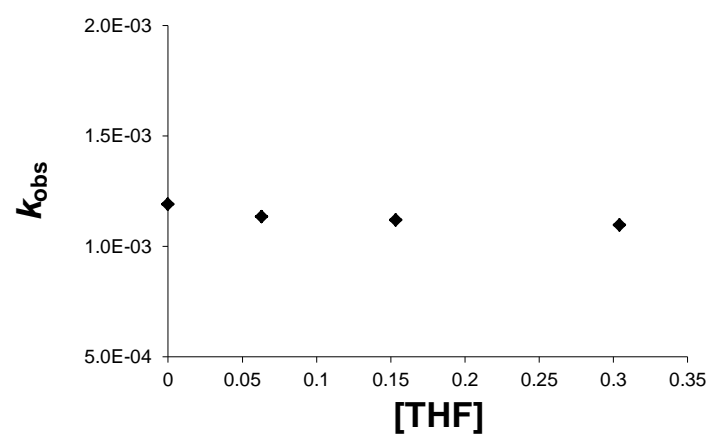

Figure 2.13. Ethylene insertion into the $\mathrm{Pt}-\mathrm{Ph}$ bond as a function of $\mathrm{THF}$ concentration (M) $\left\{[1]=0.03 \mathrm{M},\left[\mathrm{C}_{2} \mathrm{H}_{4}\right]=0.11(2) \mathrm{M}, 23.0^{\circ} \mathrm{C}\right\}$.

Two pathways were considered for ethylene coordination and insertion, an associative and a dissociative process. Scheme 2.9 shows the two reaction pathways and the corresponding rate laws. From the kinetic data, we propose an associative mechanism in which the labile ligand is not incorporated into the rate law, which is consistent with previous studies of $\mathrm{Pt}^{\mathrm{II}}$-mediated olefin insertion.

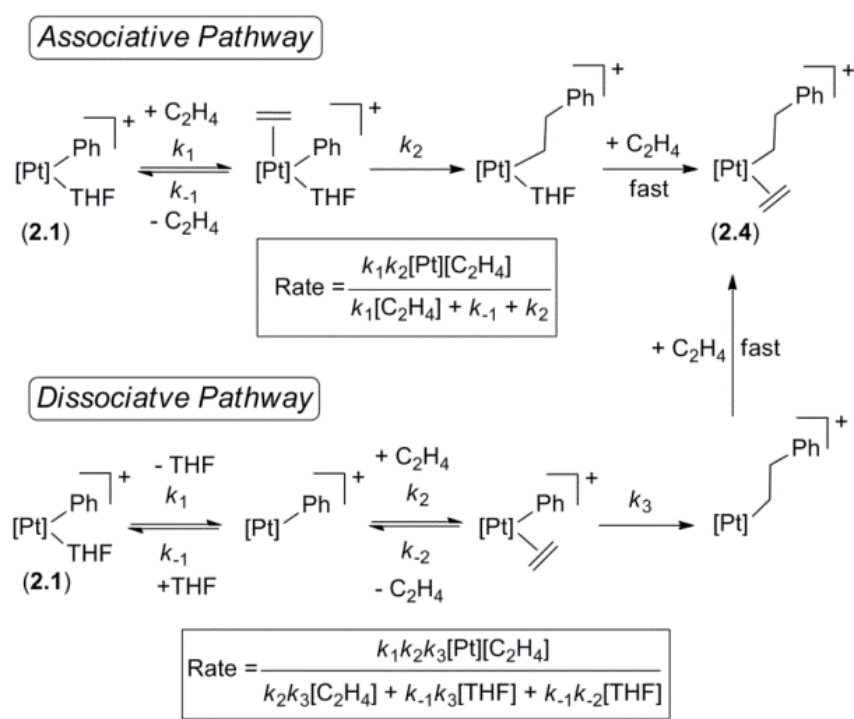

Scheme 2.9. Two possible mechanisms for the formation of $\mathbf{2 . 4}$ from $\mathbf{2 . 1}$ and ethylene. The kinetic data are consistent with the associative pathway. $[\mathrm{Pt}]=\left[\left({ }^{\mathrm{b} p \mathrm{p} y}\right) \mathrm{Pt}\right]$. 
In contrast to $\mathrm{Ni}$ and $\mathrm{Pd}, \mathrm{Pt}$ complexes have not been reported to be efficient catalysts for olefin polymerization, ${ }^{55}$ and five-coordinate $\mathrm{Pt}^{\mathrm{II}}$ complexes with coordinated olefin have been characterized. ${ }^{56-61}$ Studies of olefin insertion into $\mathrm{Pt}^{\mathrm{II}}$ hydrocarbyl bonds suggest that insertion of unactivated olefins into $\mathrm{Pt}-\mathrm{R}$ bonds is feasible for cationic systems when $\mathrm{R}=$ aryl. ${ }^{59-60,62}$ However, insertions appear to have more substantial barriers when $\mathrm{R}=$ alkyl $^{59-60,62}$ and for overall charge neutral systems. ${ }^{57,61}$ Ruffo et al. have reported the insertion of electron deficient olefins into the $\mathrm{Pt}^{\mathrm{II}}-\mathrm{Me}$ bond of a cationic system. ${ }^{63}$ The conversion of $\mathbf{2 . 1}$ to 2.4 suggests an activation barrier $\left(\Delta G^{\ddagger}=\right.$ $21.0(1) \mathrm{kcal} / \mathrm{mol})$ similar to the $\Delta G^{\ddagger}$ of $19.2 \mathrm{kcal} / \mathrm{mol}\left(64{ }^{\circ} \mathrm{C}\right)$ determined by Brookhart, Templeton et al. for ethylene insertion into the $\mathrm{Pt}-\mathrm{H}$ bond of $[(\mathrm{N} \sim \mathrm{N}) \mathrm{Pt}(\mathrm{H})(\text { ethylene })]^{+}$ $\left(\mathrm{N} \sim \mathrm{N}=\left(2,6-\mathrm{Me}_{2} \mathrm{C}_{6} \mathrm{H}_{3}\right) \mathrm{N}=\mathrm{C}(\mathrm{An})-\mathrm{C}(\mathrm{An})=\mathrm{N}\left(2,6-\mathrm{Me}_{2} \mathrm{C}_{6} \mathrm{H}_{3}\right) ; \mathrm{An}=1,8\right.$-naphthalenediyl $){ }^{23}$ In addition, Templeton and coworkers have reported ethylene insertion into a Pt-phenyl bond at $80{ }^{\circ} \mathrm{C}$, after which intramolecular $\mathrm{C}-\mathrm{H}$ activation of ethylbenzene occurs to form a stable $\mathrm{Pt}^{\mathrm{IV}}$ ortho-metallated phenethyl complex. ${ }^{21}$

Simulations were used to compare associative and dissociative mechanisms for ethylene insertion starting from $\left.[(\mathrm{bpy}) \mathrm{Pt}(\mathrm{Ph})(\mathrm{THF})]^{+} \mathbf{( 2 . 1}^{\prime}\right)$ (Scheme 2.10). The calculated $\Delta G^{\ddagger}$ s for the two processes $(19.0$ and $19.8 \mathrm{kcal} / \mathrm{mol})$ are close to the experimentally determined activation barrier of $21.0(1) \mathrm{kcal} / \mathrm{mol}\left(23.0^{\circ} \mathrm{C}\right)$. The displacement of THF with ethylene is calculated to be exergonic by $12.5 \mathrm{kcal} / \mathrm{mol}$ and features a free energy barrier of $19.8 \mathrm{kcal} / \mathrm{mol}$ for ethylene insertion into the $\mathrm{Pt}-$ phenyl bond from $\mathbf{2 . 7}$ to $\mathbf{( 2 . 7 -}$ 2.8)'. After evaluation of multiple coordination isomers for the associative pathway, the lowest energy isomer of the ethylene adduct, $\left[(\mathrm{bpy}) \mathrm{Pt}(\mathrm{Ph})(\mathrm{THF})\left(\mathrm{C}_{2} \mathrm{H}_{4}\right)\right]^{+}$, has the olefin 
bound to $\mathrm{Pt}$ with THF weakly associated, viz $\left[(\mathrm{bpy}) \mathrm{Pt}(\mathrm{Ph})\left(\mathrm{C}_{2} \mathrm{H}_{4}\right)\right]^{+} \cdot(\mathrm{THF})$. From $\left[(\text { bpy }) \mathrm{Pt}(\mathrm{Ph})\left(\mathrm{C}_{2} \mathrm{H}_{4}\right)\right]^{+} \cdot(\mathrm{THF})$, the most stable calculated transition state for ethylene insertion has THF in the outer coordination sphere and $19.0 \mathrm{kcal} / \mathrm{mol}$ relative to $\left[(\text { bpy }) \mathrm{Pt}(\mathrm{Ph})\left(\mathrm{C}_{2} \mathrm{H}_{4}\right)\right]^{+} \cdot(\mathrm{THF})$ (Scheme 2.10). Searches for transition states for $\mathrm{C}=\mathrm{C}$ insertion into the $\mathrm{Pt}-\mathrm{Ph}$ bond of $\left[(\mathrm{bpy}) \mathrm{Pt}(\mathrm{Ph})\left(\mathrm{C}_{2} \mathrm{H}_{4}\right)(\mathrm{THF})\right]^{+}$with THF in the inner coordination sphere resulted in a high-energy transition state with dissociation of one of the bpy arms. Thus, the combination of kinetic experiments and computational analyses of ethylene coordination and insertion are best explained by a process that has substantial associative character, and perhaps resembles an interchange associative pathway for ligand substitutions.

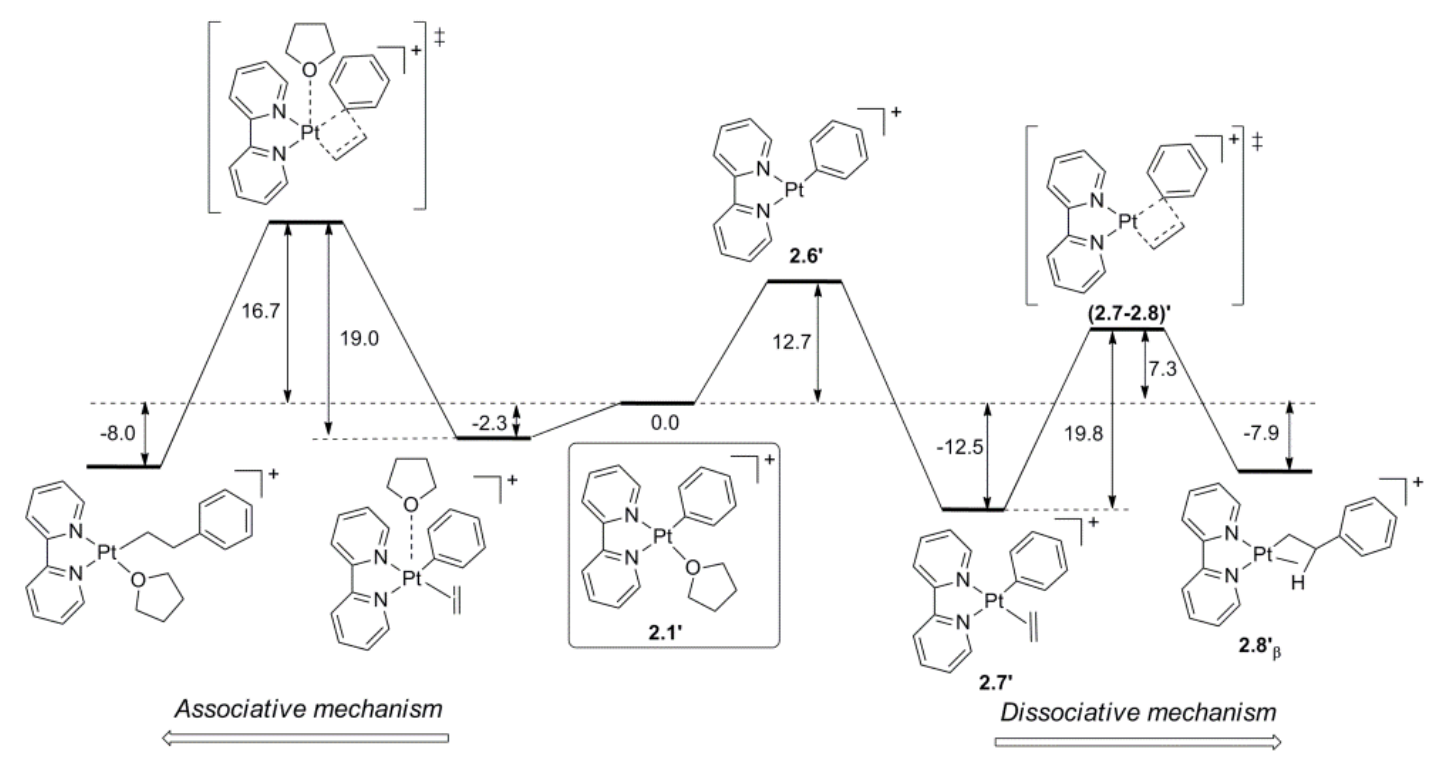

Scheme 2.10. Calculated energetics $(\Delta \mathrm{G}$ in THF, $\mathrm{kcal} / \mathrm{mol})$ for two possible mechanisms for ethylene insertion into $\mathrm{Pt}-\mathrm{Ph}$ bond starting from $\left.[(\mathrm{bpy}) \mathrm{Pt}(\mathrm{Ph})(\mathrm{THF})]\left[\mathrm{BAr}_{4}\right] \mathbf{( 2 . 1}^{\prime}\right)$. 


\subsubsection{Calculated Energetics of the Catalytic Cycle}

The energetics of the proposed catalytic cycle were probed using DFT calculations (Scheme 2.11). From $[(\mathrm{bpy}) \mathrm{Pt}(\mathrm{Ph})(\mathrm{THF})]^{+}(\mathbf{2 . 1})$, the calculated $\Delta \mathrm{G}$ (with a continuum THF solvent model) for dissociation of THF to form the three-coordinate [(bpy)Pt(Ph) $]^{+}$ (2.6') is $12.7 \mathrm{kcal} / \mathrm{mol}$ (Scheme 2.10). Complex 2.6' is calculated to maintain a T-shape coordination geometry at platinum, which provides an open site for ethylene coordination (Figure 2.14). Following the loss of THF, ethylene binds to platinum to form adduct 2.7' with a calculated $\Delta G$ of $-25.2 \mathrm{kcal} / \mathrm{mol}$, relative to $\mathbf{2 . 6}$. The calculated $\mathrm{C}=\mathrm{C}$ bond distance of ethylene in $\mathbf{2 . 7}$ ' is close to the experimental value for 2.4 [1.393(6) $\AA$, Figure 2.10 and Figure 2.14]. Ethylene insertion into the $\mathrm{Pt}-\mathrm{Ph}$ bond and THF dissociation forms the phenethyl complex $\left[\left(\text { bpy) } \mathrm{Pt}\left(\mathrm{CH}_{2} \mathrm{CH}_{2} \mathrm{Ph}\right)\right]^{+}(\mathbf{2 . 8})\right.$.

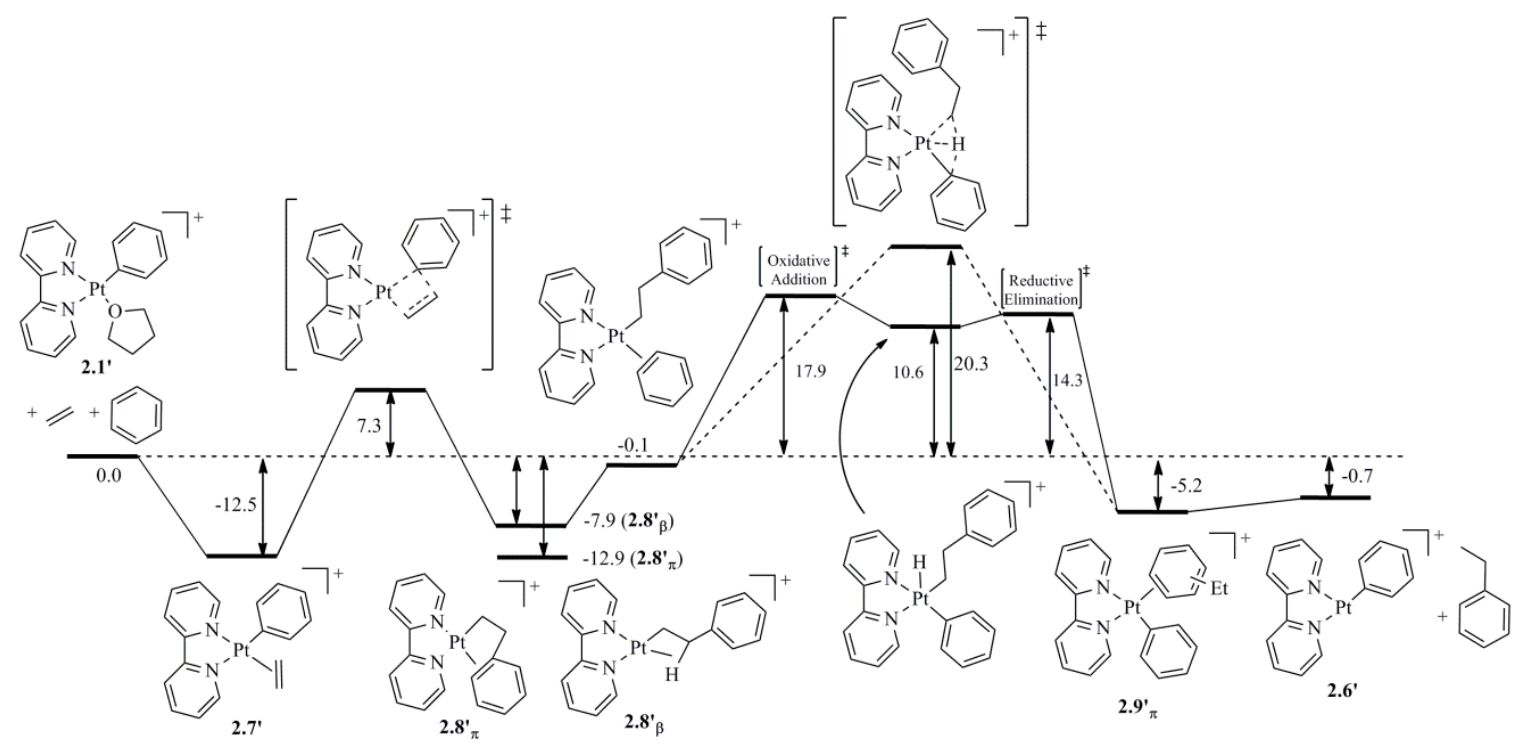

Scheme 2.11. Comparison of calculated Gibbs free energies ( $\mathrm{kcal} / \mathrm{mol}$, in THF) for proposed intermediates and transition states in catalytic ethylene hydrophenylation by $[(\mathrm{bpy}) \mathrm{Pt}(\mathrm{Ph})(\mathrm{THF})]^{+}$. 
The product of ethylene insertion $\mathbf{2 . \mathbf { 8 } ^ { \prime }}$ has two calculated conformers, a $\pi$ complex $\left(\mathbf{2 . 8}_{\pi}^{\prime}\right)$ and a $\beta$-agostic $\left(\mathbf{2 . 8}_{\beta}{ }_{\beta}\right)$ structure (Figure 2.14). In the latter conformer, one of the benzylic $\mathrm{C}-\mathrm{H}$ bonds of the phenethyl ligand occupies the vacant site in the $\mathrm{Pt}$ coordination sphere in an agostic interaction with the metal center, as opposed to $\eta^{2}$ coordination through a $\mathrm{C}=\mathrm{C}$ bond of the phenyl group for $\mathbf{2 . 8}_{\boldsymbol{\pi}}{ }^{\prime}$. Conformer $\mathbf{2 . 8}_{\boldsymbol{\pi}}$ is calculated to be more stable than $\mathbf{2 . 8}_{\beta}$ by $5 \mathrm{kcal} / \mathrm{mol}$. The calculated $\beta$-agostic structure for $\mathbf{2 . 8}_{\beta}$ shows a lengthening of one of the $\mathrm{C}-\mathrm{H}$ bonds $(1.33 \AA)$ of the $\beta-\mathrm{CH}_{2}$ group (Figure 2.14) by $0.2 \AA$ versus a typical $\mathrm{C}-\mathrm{H}$ bond length for $\mathbf{2 . 8}_{\beta}^{\prime}$. The $\mathrm{C}_{\mathrm{sp} 3}-\mathrm{C}_{\mathrm{sp} 3}$ bond length for $\mathbf{2 . 8}_{\boldsymbol{\beta}}^{\prime}$ is calculated to be relatively short at $1.49 \AA$, suggesting some $[(\text { bpy }) \mathrm{Pt}(\mathrm{H})(\text { styrene })]^{+}$character for this stationary point. 

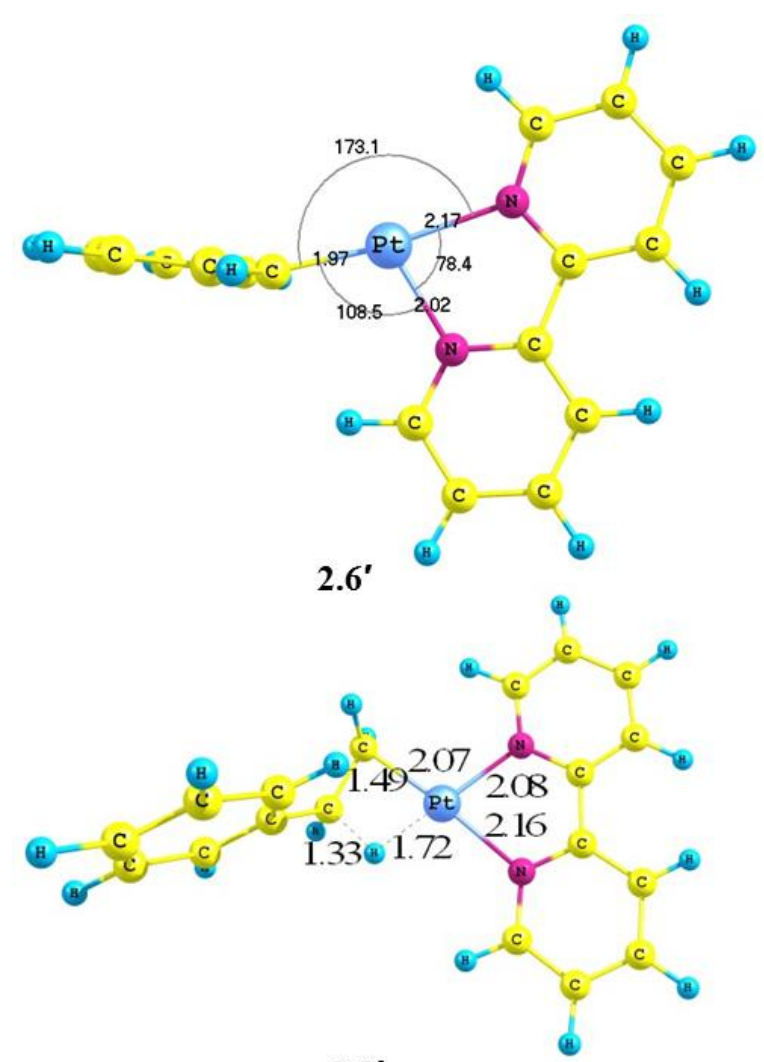

$2 . \mathbf{8}_{\beta}$

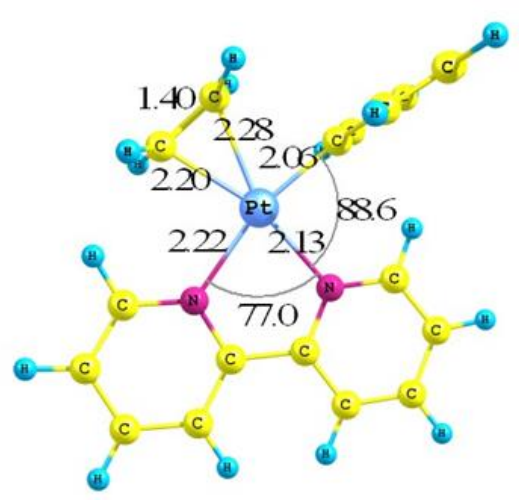

2.7'

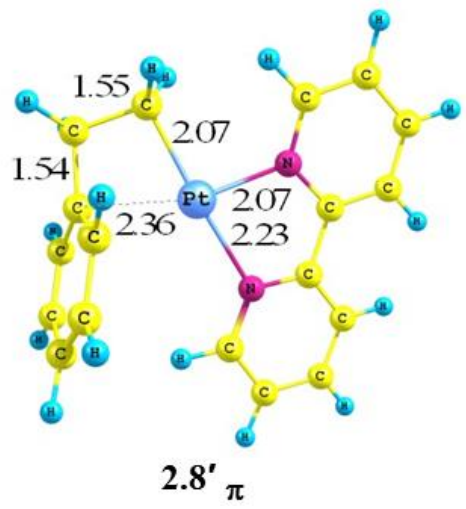

Figure 2.14. DFT calculated structures for $[(\mathrm{bpy}) \mathrm{Pt}(\mathrm{Ph})]^{+}(\mathbf{2 . 6}),\left[(\mathrm{bpy}) \mathrm{Pt}(\mathrm{Ph})\left(\eta^{2}-\mathrm{C}_{2} \mathrm{H}_{4}\right)\right]^{+}$ $\left(\mathbf{2 . 7}^{\prime}\right)$ and the two conformers of the resulting product $\left[(\mathrm{bpy}) \mathrm{Pt}\left(\mathrm{CH}_{2} \mathrm{CH}_{2} \mathrm{Ph}\right)\right]^{+}\left(\mathbf{2 . 8}_{\boldsymbol{\beta}}^{\prime}\right.$ and $\left.2 . \mathbf{8}^{\prime}{ }_{\pi}\right)$.

The complex $\left[(\mathrm{bpy}) \mathrm{Pt}\left(\mathrm{CH}_{2} \mathrm{CH}_{2} \mathrm{Ph}\right)\right]^{+}$(either $\mathbf{2 . 8}_{\boldsymbol{\beta}}^{\prime}$ or $\mathbf{2 . 8}_{\boldsymbol{\pi}}^{\prime}$ ) may coordinate and subsequently activate benzene for $\mathrm{C}-\mathrm{H}$ bond cleavage. The $\Delta G$ for binding of benzene to form $\left[(\mathrm{bpy}) \mathrm{Pt}\left(\mathrm{CH}_{2} \mathrm{CH}_{2} \mathrm{Ph}\right)\left(\eta^{2}-\mathrm{C}_{6} \mathrm{H}_{6}\right)\right]^{+}$is calculated to be endergonic at $+12.8 \mathrm{kcal} / \mathrm{mol}$ relative to $\mathbf{2 . 8}_{\boldsymbol{\pi}}{ }_{\boldsymbol{\pi}}$ (Scheme 2.11). Starting from $\mathbf{2 . 8}_{\boldsymbol{\pi}}$, the calculated $\Delta G^{\ddagger}$ for benzene $\mathrm{C}-\mathrm{H}$ activation by an oxidative addition/reductive elimination pathway is $30.8 \mathrm{kcal} / \mathrm{mol}$. Two low energy conformations of $[(\text { bpy }) \mathrm{Pt}(\mathrm{Ph})(\text { ethylbenzene })]^{+}\left(\mathbf{2 . 9}^{\prime}\right)$ were isolated via calculations, one in which the ethylbenzene coordinates by an agostic interaction with the $\mathrm{C}-\mathrm{H}$ bond of its methyl group, 2.9' ${ }^{\prime}$, and an $\eta^{2}-C, C \pi$-bonded conformation, $\mathbf{2 . 9}^{\prime} \boldsymbol{\pi}$. The 
latter is calculated to be more stable by $7.9 \mathrm{kcal} / \mathrm{mol}$ (Scheme 2.12). Thus, it appears reasonable to propose that $\mathbf{2 . 9}_{\text {ag }}$ will be the initial product of benzene $\mathrm{C}-\mathrm{H}$ activation by $\left[\left({ }^{\mathrm{b}} \mathrm{bpy}\right) \mathrm{Pt}\left(\mathrm{CH}_{2} \mathrm{CH}_{2} \mathrm{Ph}\right)\right]^{+}$, but that $\mathbf{2 . 9}^{\prime}$ ag will likely convert to $\mathbf{2 . 9}_{\boldsymbol{\pi}}$ or a related $\pi$-arene adduct of ethylbenzene. The ethylbenzene product is released and $[(\mathrm{bpy}) \mathrm{Pt}(\mathrm{Ph})]^{+}$is reformed. Loss of ethylbenzene from $\mathbf{2 . 9}^{\prime}$ was calculated to be endergonic by only 4.5 $\mathrm{kcal} / \mathrm{mol}$ (Scheme 2.11). Consistent with the experimental observation of a KIE for catalysis with perprotio versus perdeuterobenzene, the transition state for benzene $\mathrm{C}-\mathrm{H}$ activation is calculated to be the highest energy species on the reaction coordinate. Similar to $\mathrm{Ru}^{\mathrm{II}}$ systems, ${ }^{4}$ the calculations suggest that benzene $\mathrm{C}-\mathrm{H}$ activation is the turnover limiting step in catalytic hydrophenylation of ethylene.
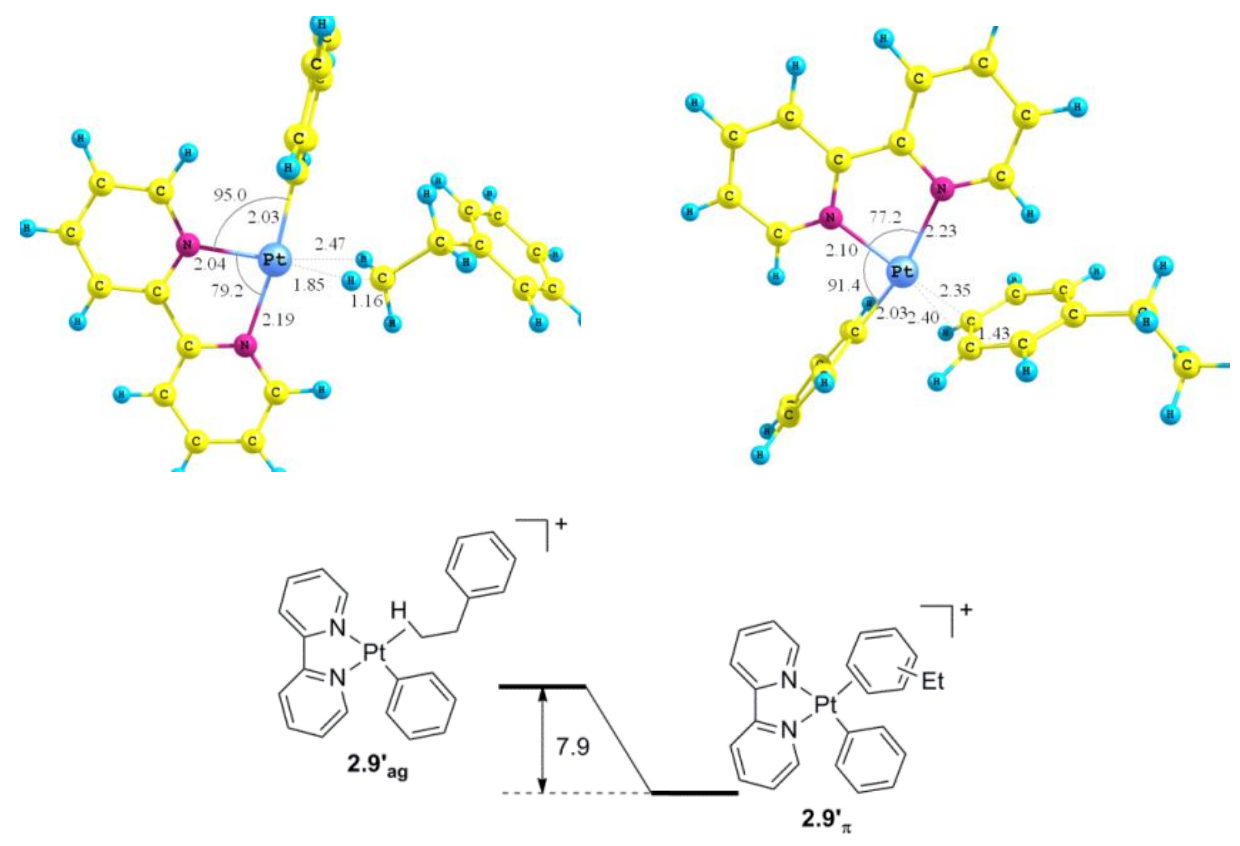

Scheme 2.12. DFT calculated structures for $\left[(\mathrm{bpy}) \mathrm{Pt}\left(\eta^{2}-C, C-\mathrm{C}_{6} \mathrm{H}_{5} \mathrm{Et}\right)(\mathrm{Ph})\right]^{+}\left(\mathbf{2 . 9}^{\prime}{ }_{\boldsymbol{\pi}}\right)$ and $\left.\left[(\mathrm{bpy}) \mathrm{Pt}\left(\eta^{2}-\mathrm{C}, H-\mathrm{C}_{6} \mathrm{H}_{5} \mathrm{Et}\right)(\mathrm{Ph})\right]^{+} \mathbf{( 2 . 9}^{\prime}{ }_{\mathrm{ag}}\right)$ with the relative energy difference between them $(\mathrm{kcal} / \mathrm{mol})$. 
When ethylene hydrophenylation is monitored in situ by ${ }^{1} \mathrm{H}$ NMR spectroscopy in $\mathrm{C}_{6} \mathrm{D}_{6}$, the only observable species during catalysis is $\left[\left({ }^{t} \mathrm{bpy}\right) \mathrm{Pt}\left(\mathrm{CH}_{2} \mathrm{CH}_{2} \mathrm{Ph}\right)\left(\eta^{2}-\right.\right.$ $\left.\left.\mathrm{C}_{2} \mathrm{H}_{4}\right)\right]\left[\mathrm{BAr}_{4}{ }_{4}\right](\mathbf{2 . 4})$. In the calculated catalytic cycle, complex $\mathbf{2 . 8}_{\boldsymbol{\pi}}{ }_{\boldsymbol{\pi}}$ is the lowest energy species (Scheme 2.11). Notably, coordination of ethylene to $\mathbf{2 . 8}_{\boldsymbol{\pi}}$ to form $\mathbf{2 . 4}$ ' is calculated to occur with a $\Delta G=-7.9 \mathrm{kcal} / \mathrm{mol}$ (Scheme 2.13). The DFT calculations are therefore consistent with the experimental observation of $\left[\left({ }^{t} \mathrm{bpy}\right) \mathrm{Pt}\left(\mathrm{CH}_{2} \mathrm{CH}_{2} \mathrm{Ph}\right)\left(\eta^{2}-\right.\right.$ $\left.\left.\mathrm{C}_{2} \mathrm{H}_{4}\right)\right]^{+}$as the catalyst resting state.

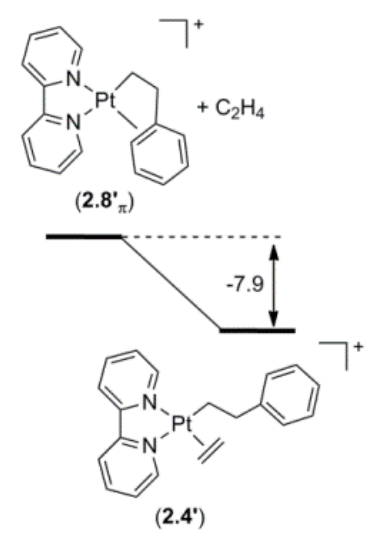

Scheme 2.13. Calculated difference in $\Delta G(\mathrm{kcal} / \mathrm{mol})$ for the formation of the proposed catalyst resting state $\mathbf{2 . 4}$ ' upon coordination of ethylene to $\mathbf{2 . 8}_{\boldsymbol{\pi}}{ }_{\text {. }}$.

\subsubsection{Competition between Cyclometallation and Benzene C-H/D Activation}

In a prior study, it was proposed that ethylbenzene produced from the reaction of (dmpp) $\mathrm{Pt}\left(\mathrm{CH}_{2} \mathrm{CH}_{2} \mathrm{Ph}\right)\left(\eta^{2}-\mathrm{C}_{2} \mathrm{H}_{4}\right)$ with benzene initializes via orthometallation of the phenethyl ligand to form Pt-o- $\mathrm{C}_{6} \mathrm{H}_{4} \mathrm{Et}$, followed by $\mathrm{C}-\mathrm{H}$ activation of coordinated benzene to release ethylbenzene. ${ }^{1}$ These results and proposed mechanism are similar to those reported by De Renzi et al. for stoichiometric reactions involving ethylene insertion 
into cationic Pt-Ph bonds. ${ }^{62,64}$ In the stoichiometric formation of ethylbenzene from $\mathbf{2 . 4}$ and 2.4- $\boldsymbol{d}_{\mathbf{5}}$, evidence suggests that a similar cyclometallation is likely in competition with direct elimination of ethylbenzene through $\mathrm{C}-\mathrm{D}$ activation of coordinated benzene (Scheme 2.14). For the thermolysis of 2.4- $\boldsymbol{d}_{5}$ in $\mathrm{C}_{6} \mathrm{H}_{6}$, the mass spectrum reveals fragmentation of the ethyl fragment with an $m / z=28$ (Figure 2.15A). If the isotopologues of ethylbenzene produced in this reaction possessed only per protio ethyl groups, as would be expected if ethylbenzene was exclusively produced through $\mathrm{C}-\mathrm{H}$ activation of coordinated benzene, then the ethyl fragments would only be observed at $\mathrm{m} / \mathrm{z}=27$ and 29

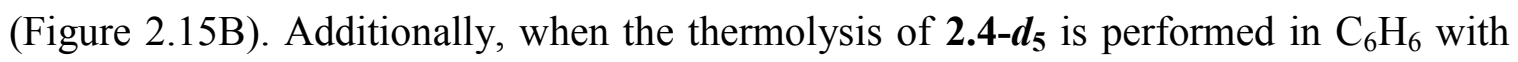
the addition of a Lewis base, an $\mathrm{m} / \mathrm{z}=30$ is observed for a mono deuterated $-\mathrm{CH}_{2} \mathrm{CH}_{2} \mathrm{D}$ fragment (Figure 2.15C). If THF is in competition with $\mathrm{C}_{6} \mathrm{H}_{6}$ for coordination to the $\mathrm{Pt}$ center, then cyclometalation of the $-\mathrm{CH}_{2} \mathrm{CH}_{2} \mathrm{Ph}-d_{5}$ ligand may become more accessible resulting in isotopologues of ethylbenzene containing a $-\mathrm{CH}_{2} \mathrm{CH}_{2} \mathrm{D}$ moiety. The abundance of ethyl- $d_{1}$ moieties, compared to the thermolysis of 2.4- $\boldsymbol{d}_{5}$ in $\mathrm{C}_{6} \mathrm{H}_{6}$ without added Lewis base, is consistent with $\mathrm{C}-\mathrm{H}$ activation of coordinated benzene being the predominant mode of producing ethylbenzene, but in cases where another ligand is in competition with benzene for coordination to the Pt center, cyclometallation of the phenethyl ligand becomes more competitive. 


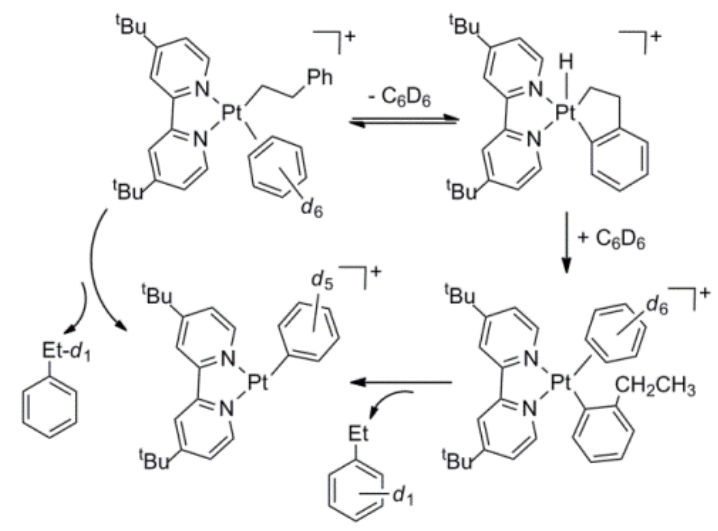

Scheme 2.14. The formation of ethylbenzene with an all protio $-\mathrm{CH}_{2} \mathrm{CH}_{3}$ group during the thermolysis of 2.4 in $\mathrm{C}_{6} \mathrm{D}_{6}$ contrasts with our proposed mechanism and suggests that orthometallation of the phenethyl group competes with direct $\mathrm{C}-\mathrm{D}$ activation.
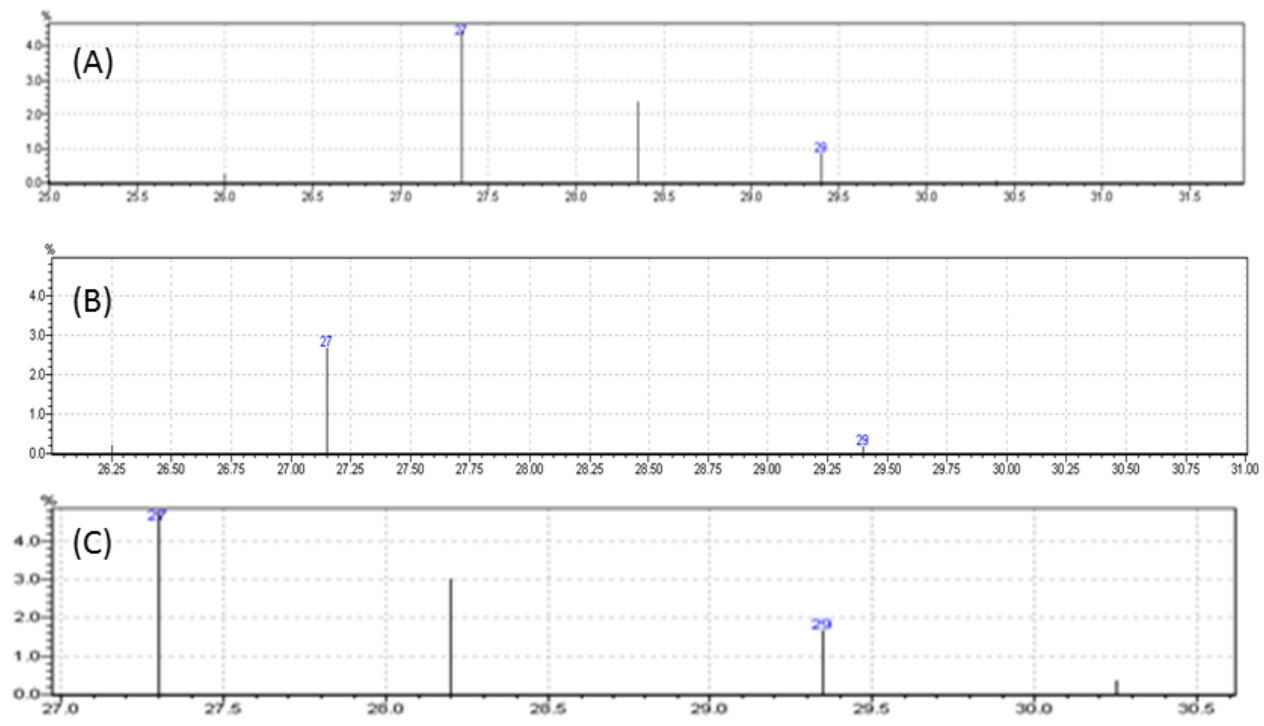

Figure 2.15. Mass spectra highlighting the fragmentation of the ethyl ion from the thermolysis of 2.4-d $\boldsymbol{d}_{\mathbf{5}}$ in $\mathrm{C}_{6} \mathrm{H}_{6}(\mathrm{~A}), \mathbf{2 . 4}$ in $\mathrm{C}_{6} \mathrm{H}_{6}$ (B), and 2.4-d $\boldsymbol{d}_{\mathbf{5}}$ in $\mathrm{C}_{6} \mathrm{H}_{6}$ with 100 equivalents of THF relative to $\mathbf{2 . 4 - d _ { 5 }}$

The thermolysis of $\mathbf{2 . 4}$ in $\mathrm{C}_{6} \mathrm{D}_{6}$ also provides evidence for cyclometallation of the phenethyl ligand. The ${ }^{1} \mathrm{H}$ NMR spectrum of the reaction mixture suggests two separate 
EtPh isotopologues in which the benzylic $-\mathrm{CH}_{2}$ - is coupled to a terminal $-\mathrm{CH}_{3}$ or $-\mathrm{CH}_{2} \mathrm{D}$. The resonance for the benzylic $-\mathrm{CH}_{2}$ - group $(\delta=2.43 \mathrm{ppm})$ is not a well-defined quartet, as would be expected if coupled to a terminal $-\mathrm{CH}_{3}$ moiety, and suggests that the ${ }^{1} \mathrm{H}$ NMR spectrum is likely a result of an overlap of resonances for the two ethylbenzene isotopologues (Figure 2.16A). The resonances for the terminal methyl groups cannot be observed due to overlap with the tert-butyl groups of the bipyridyl ligand.

When the thermolysis of $\mathbf{2 . 4}$ in $\mathrm{C}_{6} \mathrm{D}_{6}$ is performed with the presence of a Lewis base, the ${ }^{1} \mathrm{H}$ NMR spectrum of the reaction mixture reveals a resonance for the benzylic $-\mathrm{CH}_{2}$ group $(\delta=2.43 \mathrm{ppm}$ ) that is a well-defined quartet, albeit slightly broadened (Figure 2.16B). This further supports the claim that in the presence of ligands that can significantly compete with benzene for coordination to the Pt center, cyclometallation of the phenethyl ligand becomes more accessible.

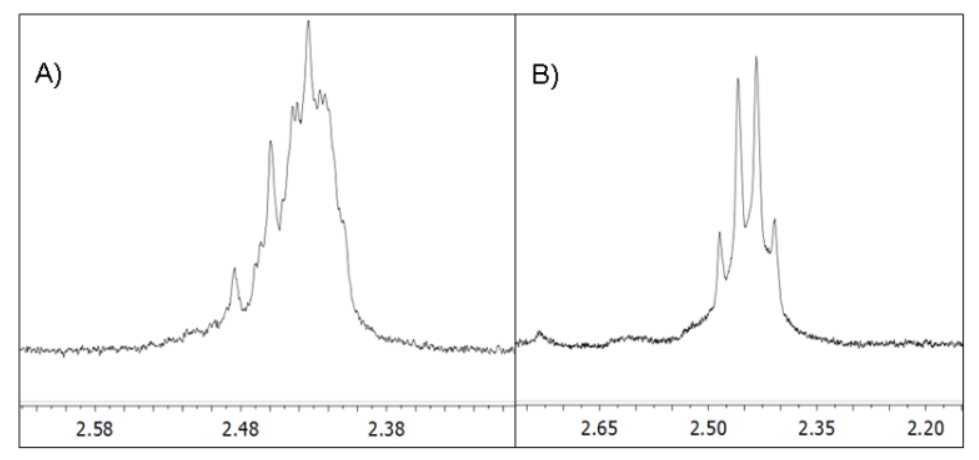

Figure 2.16. A) ${ }^{1} \mathrm{H}$ NMR spectrum for the thermolysis of 2.4 in $\mathrm{C}_{6} \mathrm{D}_{6}$, highlighting the benzylic resonances $(\delta=2.43 \mathrm{ppm})$ of the ethylbenzene isotopologues with $-\mathrm{CH}_{2} \mathrm{CH}_{3}$ and $-\mathrm{CH}_{2} \mathrm{CH}_{2} \mathrm{D}$ groups. The spectrum is consistent with an overlap of a quartet and a triplet $(1: 2: 1)$ of triplets $(1: 1: 1)$. B) ${ }^{1} \mathrm{H}$ NMR spectrum for the thermolysis of 2.4 in $\mathrm{C}_{6} \mathrm{D}_{6}$ with added THF- $d_{8}$. 


\subsubsection{Study of Multiple Insertions of Ethylene}

From complex 2.4, insertion of ethylene into the $\mathrm{Pt}-\mathrm{CH}_{2} \mathrm{CH}_{2} \mathrm{Ph}$ bond and subsequent benzene $\mathrm{C}-\mathrm{H}$ activation would form butylbenzene. In fact, using $\mathrm{TpRu}(\mathrm{CO})(\mathrm{NCMe})(\mathrm{Ph})$ as a catalyst precursor for the hydrophenylation of ethylene produces small amounts of butylbenzene at elevated ethylene pressures $\geq 1.7 \mathrm{MPa}^{5}$ Under the conditions probed for the Pt systems, including ethylene pressure up to $2.1 \mathrm{MPa}$ at $100{ }^{\circ} \mathrm{C}$, no evidence of butylbenzene is detected. The lack of butylbenzene production by the Pt catalyst is consistent with previous observations that suggest olefin insertion into $\mathrm{Pt}^{\mathrm{II}}$-aryl bonds is more facile than insertion into $\mathrm{Pt}^{\mathrm{II}}-$ alkyl bonds. ${ }^{59-60,62}$

From the solid-state structure of complex $\mathbf{2 . 4}$, ethylene insertion would require initial rotation of the ethylene such that the $\mathrm{C}=\mathrm{C}$ bond axis, which is perpendicular to the $\mathrm{Pt}$ square plane of 2.4 (Figure 2.10), becomes co-planar with the $\mathrm{Pt}-\mathrm{C}_{\mathrm{sp} 3}$ bond of the phenethyl ligand. The ${ }^{1} \mathrm{H}$ NMR spectrum of $\mathbf{2 . 4}$ at room temperature reveals a single resonance due to the coordinated ethylene at $4.14 \mathrm{ppm}$. A single resonance for coordinated ethylene is likely a result of either rapid ethylene rotation on the NMR timescale or facile and reversible ethylene dissociation. The observation of Pt satellites $\left({ }^{2} J_{\mathrm{PtH}}=69 \mathrm{~Hz}\right)$ for the resonance at $4.14 \mathrm{ppm}$ indicates that ethylene dissociation is not occurring and the exchange of ethylene hydrogen atoms is likely due to fast rotation about the Pt-ethylene bond, which has been reported for related $\mathrm{Pt}^{\mathrm{II}}$ systems. ${ }^{65}$ Cooling a $\mathrm{CD}_{2} \mathrm{Cl}_{2}$ solution of $\mathbf{2 . 4}$ results in decoalescence of the single resonance for coordinated ethylene into two broad resonances. At temperatures below $-60{ }^{\circ} \mathrm{C}$, the $\Delta \delta$ for the two resonances of coordinated ethylene does not change, which indicates that the slow exchange regime has been reached. The coalescence temperature is observed at $-33.4{ }^{\circ} \mathrm{C}$ 
(Figure 2.17), which gives $k=110 \mathrm{~s}^{-1}$ and $\Delta G^{\ddagger}$ of $11.7 \mathrm{kcal} / \mathrm{mol}$. The calculated energy of the rotamer with ethylene parallel to the square plane is $12.4 \mathrm{kcal} / \mathrm{mol}$, which is close to the experimental rotational barrier.
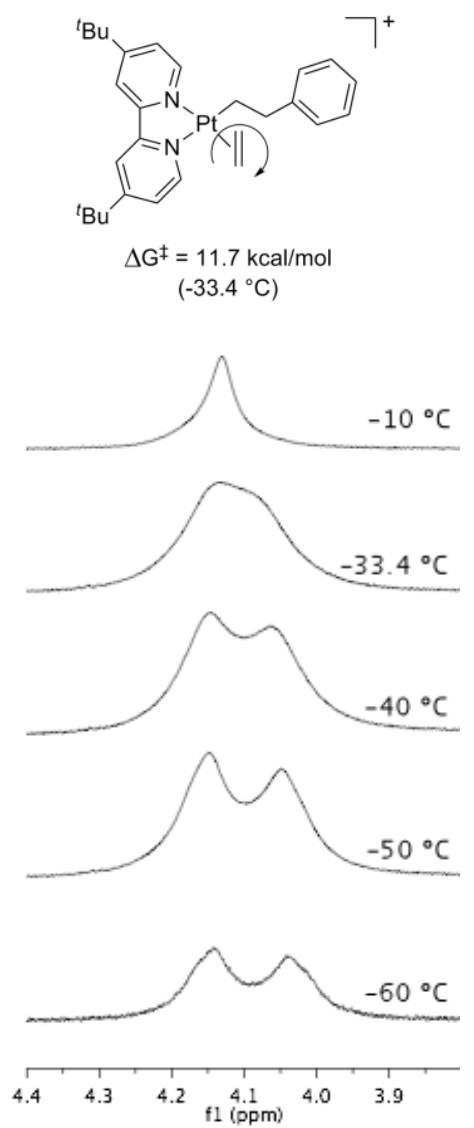

Figure 2.17. Variable temperature ${ }^{1} \mathrm{H}$ NMR spectra in the region of resonances due to coordinated ethylene for [( $\left.\left.{ }^{t} \mathrm{bpy}\right) \mathrm{Pt}\left(\mathrm{CH}_{2} \mathrm{CH}_{2} \mathrm{Ph}\right)\left(\eta^{2}-\mathrm{C}_{2} \mathrm{H}_{4}\right)\right]\left[\mathrm{BAr}_{4}\right]$ (2.4).

Upon addition of one equivalent of ethylene (as measured by NMR integration) to a solution $\left(\mathrm{CD}_{2} \mathrm{Cl}_{2}\right)$ of $\mathbf{2 . 4}$ the coordinated ethylene peak shifts downfield and a timeaveraged resonance for free and coordinated ethylene is observed at $\sim 4.8 \mathrm{ppm}$. These data are consistent with exchange between free and coordinated ethylene being rapid at room temperature. When this solution is cooled, decoalescence is not observed at $-90{ }^{\circ} \mathrm{C}$, 
suggesting that olefin exchange occurs very rapidly (Scheme 2.15). Using the known chemical shifts for coordinated and free ethylene, an upper limit of $\sim 8 \mathrm{kcal} / \mathrm{mol}$ can be placed on the rate of ethylene exchange. $\Delta G^{\ddagger}$ values for related systems range from $\sim 14.5$ $\mathrm{kcal} / \mathrm{mol}$ to $<9.5 \mathrm{kcal} / \mathrm{mol}^{65}$

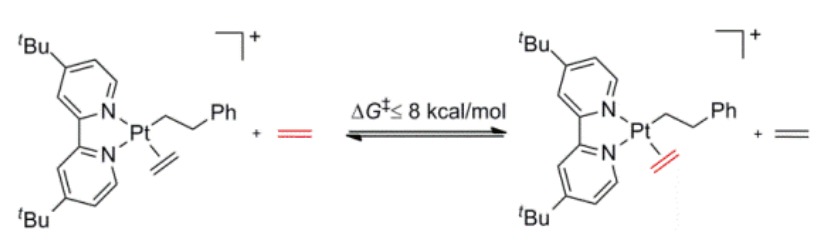

Scheme 2.15. Complex 2.4 undergoes rapid ethylene exchange at room temperature to $90{ }^{\circ} \mathrm{C}$.

We attempted to calculate the energetics of a second insertion of ethylene from $\left[\left(\text { bpy) } \mathrm{Pt}\left(\mathrm{CH}_{2} \mathrm{CH}_{2} \mathrm{Ph}\right)\left(\eta^{2}-\mathrm{C}_{2} \mathrm{H}_{4}\right)\right]^{+}\right.$. A conformation of the catalyst resting state in which the olefin is rotated by approximately $90^{\circ}$ was found, and this rotamer is calculated to be $12.4 \mathrm{kcal} / \mathrm{mol}$ higher than $\mathbf{2 . 4}$ ', consistent with the measured VT-NMR rotational barrier. The subsequent transition state wherein the ethylene inserts to form a phenbutyl ligand was not found computationally. Multiple conformational searches for the transition state all yield either transition states already observed or dissociation of the ethylene moiety. The most plausible explanation for these results is steric hindrance brought about by the hydrogen atoms of the phenethyl ligand, which are absent on the phenyl sp2 carbon for $\mathrm{C}=\mathrm{C}$ insertion into the $\mathrm{Pt}-\mathrm{Ph}$ bond. The $\Delta \mathrm{G}$ for a consecutive insertion of ethylene is calculated to be $15.6 \mathrm{kcal} / \mathrm{mol}$ relative to the resting state $2.4^{\prime}$ (Scheme 2.16). 


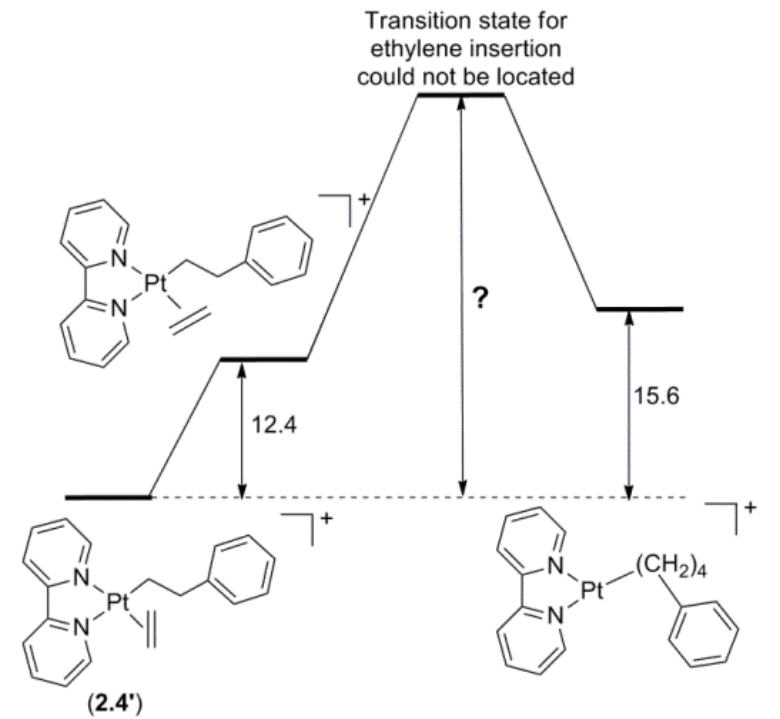

Scheme 2.16. Calculated Gibbs free energies ( $\mathrm{kcal} / \mathrm{mol}$ ) for consecutive ethylene insertion from 2.4'.

\subsubsection{0 $\beta$-Hydride Elimination}

Although direct oxidative hydroarylation of olefins to form vinyl arenes is an attractive synthetic target, the formation of vinyl arenes via $\beta$-hydride elimination is potentially problematic when alkyl arenes are desired. Olefin hydroarylation performed by $\mathbf{2 . 1}-\mathbf{2 . 3}$ typically results in $\leq 1 \mathrm{TO}$ of styrene. The formation of styrene likely occurs via $\beta-\mathrm{H}$ elimination from the phenethyl complex 2.4. The thermolysis $\left(80^{\circ} \mathrm{C}\right)$ of 2.4 with ethylene $(0.3 \mathrm{MPa})$ in nitromethane- $d_{3}$ produces styrene after approximately 10 hours in $\sim 80 \%$ yield by ${ }^{1} \mathrm{H}$ NMR spectroscopy. Although the initial reaction mixture is complex, the addition of acetonitrile to the solution results in the formation of $\left.\left[\left({ }^{t} \mathrm{bpy}\right) \mathrm{Pt}(\mathrm{Et})(\mathrm{NCMe})\right]\left[\mathrm{BAr}_{4}{ }_{4}\right] \mathbf{( 2 . 1 0}\right)$ in $\sim 70 \%$ isolated yield (Scheme 2.17). The formation of $\mathbf{2 . 1 0}$ was verified by comparison to an independently prepared sample. We presume that $\beta$-elimination from 2.4 results in the formation of $\left[\left({ }^{t} b p y\right) P t(H)\left(\eta^{2}\right.\right.$-styrene $\left.)\right]\left[\mathrm{BAr}_{4}{ }_{4}\right]$. 
The coordinated styrene is displaced by ethylene, regardless of the mechanism, and subsequent ethylene insertion into the $\mathrm{Pt}-\mathrm{H}$ bond forms the ethyl ligand. The coordination of an additional equivalent of ethylene would form $\left[\left({ }^{t} \mathrm{bpy}\right) \operatorname{Pt}(\mathrm{Et})\left(\eta^{2}-\right.\right.$ $\left.\left.\mathrm{C}_{2} \mathrm{H}_{4}\right)\right]\left[\mathrm{BAr}_{4}^{\prime}\right]$, but we have not been able to isolate this complex. These data are consistent with the following possibility: during catalysis, $\beta$-elimination occurs but is generally reversible; however, eventually styrene dissociation occurs (regardless of the exact pathway), and under catalytic conditions, the resulting Pt-hydride decomposes.

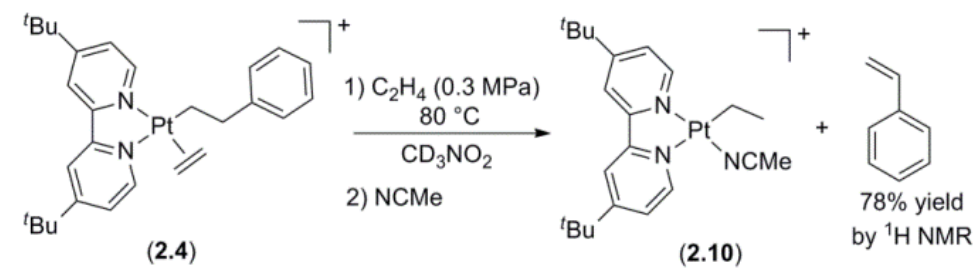

Scheme 2.17. Heating 2.4 in $\mathrm{CD}_{3} \mathrm{NO}_{2}$ produces styrene and a Pt-ethyl complex.

$\beta$-Hydride elimination from $\mathbf{2 . 8}_{\boldsymbol{\pi}}$ was calculated to have a $\Delta G^{\ddagger}$ of $5.0 \mathrm{kcal} / \mathrm{mol}$ and a $\Delta G$ of $-3.9 \mathrm{kcal} / \mathrm{mol}$ (Scheme 2.18$)$. The formation of three-coordinate $[(\mathrm{bpy}) \mathrm{Pt}(\mathrm{H})]^{+}$via styrene dissociation is unfavorable with a calculated $\Delta G$ of $7.6 \mathrm{kcal} / \mathrm{mol}$ from $\left[(\text { bpy }) \operatorname{Pt}(\mathrm{H})\left(\eta^{2} \text {-styrene }\right)\right]^{+}$. 


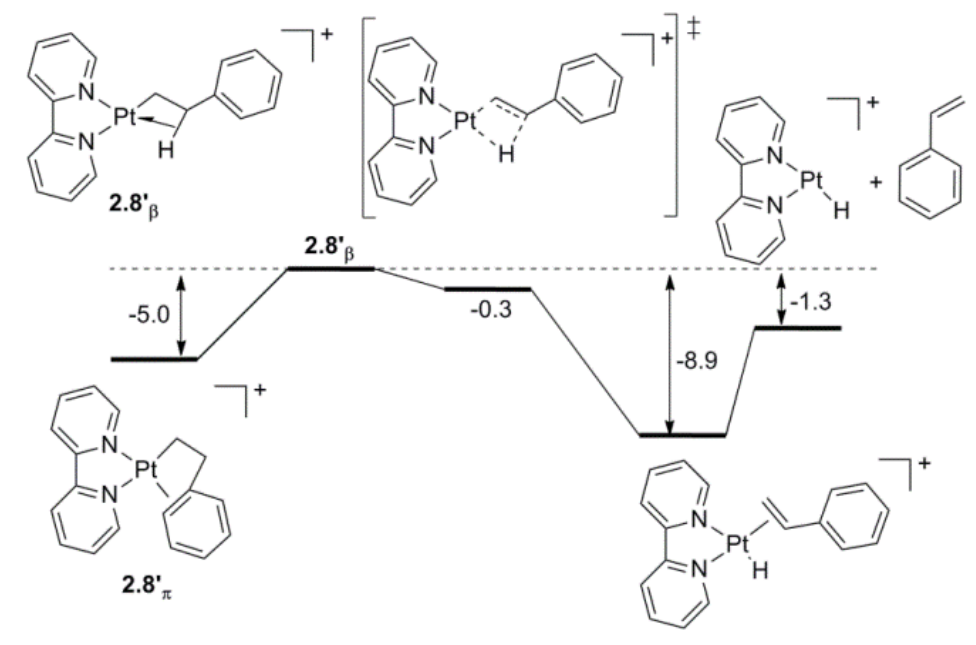

Scheme 2.18. $\Delta G^{\prime} \mathrm{s}(\mathrm{kcal} / \mathrm{mol})$ for styrene production via $\beta$-elimination from $\mathbf{2 . 8}_{\boldsymbol{\beta}}$.

\subsubsection{C-H Bond Activation of Ethylene}

A potentially problematic transformation for non-Friedel-Crafts olefin hydroarylation is $\mathrm{C}-\mathrm{H}$ activation of the coordinated olefin. Evidence for ethylene $\mathrm{C}-\mathrm{H}$ activation has not been observed experimentally using complexes $\mathbf{2 . 1}-\mathbf{2 . 3}$, but this potential side reaction has been investigated computationally. Simulations suggest that vinyl $\mathrm{C}-\mathrm{H}$ activation via $\sigma$-bond metathesis is energetically more favorable by $1.4 \mathrm{kcal} / \mathrm{mol}$ over an oxidative addition/reductive elimination pathway. After the binding of ethylene to $[(\mathrm{bpy}) \mathrm{Pt}(\mathrm{Ph})]^{+}$to form complex 2.7', a transition state for the activation of the vinylic $\mathrm{C}-\mathrm{H}$ bond is calculated to occur with a $\Delta G^{\ddagger}$ of $36.0 \mathrm{kcal} / \mathrm{mol}$ (Scheme 2.19). The resulting vinyl complex, [(bpy) $\left.\mathrm{Pt}\left(\eta^{2}-C, C-\mathrm{C}_{6} \mathrm{H}_{6}\right)\left(\mathrm{CH}=\mathrm{CH}_{2}\right)\right]^{+}$, has a $\Delta G$ of $+17.5 \mathrm{kcal} / \mathrm{mol}$ relative to 2.7'. The ensuing release of benzene and formation of $\left[(\mathrm{bpy}) \mathrm{Pt}\left(\mathrm{CHCH}_{2}\right)\right]^{+}$has a calculated $\Delta G$ of $22.4 \mathrm{kcal} / \mathrm{mol}$ relative to $\mathbf{2 . 7}$. 


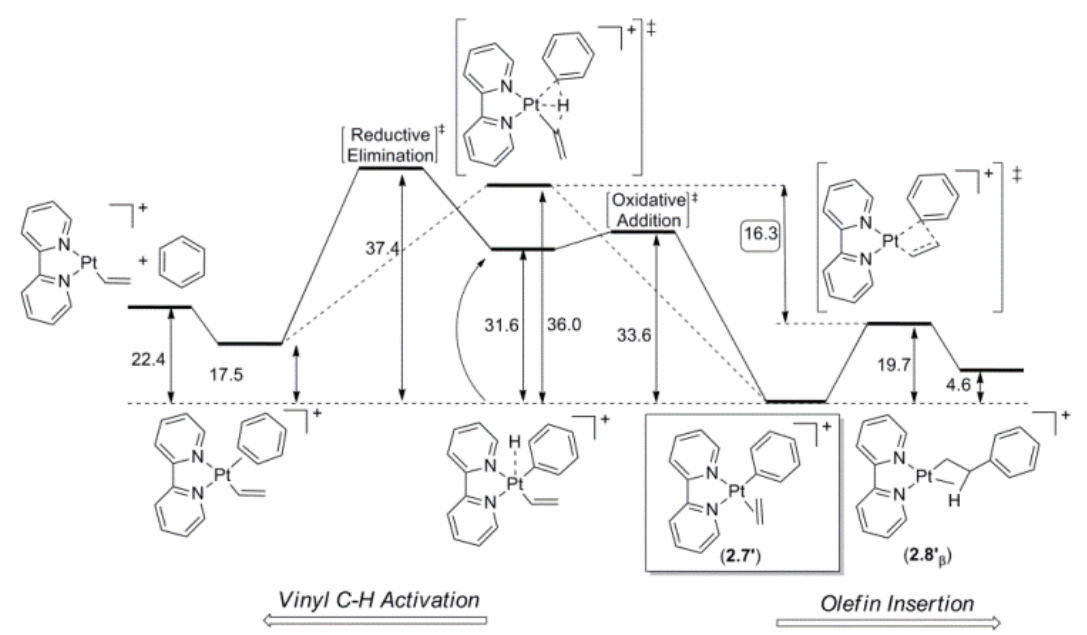

Scheme 2.19. Comparison of calculated Gibbs free energies (kcal/mol, THF) for ethylene insertion and ethylene $\mathrm{C}-\mathrm{H}$ activation by $\left[(\mathrm{bpy}) \mathrm{Pt}(\mathrm{Ph})\left(\eta^{2}-\mathrm{C}_{2} \mathrm{H}_{4}\right)\right]^{+}(\mathbf{2 . 7})$.

The barrier to vinyl $\mathrm{C}-\mathrm{H}$ activation is approximately $16.3 \mathrm{kcal} / \mathrm{mol}$ higher than the calculated activation barrier for the insertion of $\mathrm{C}=\mathrm{C}$ into the $\mathrm{Pt}-\mathrm{Ph}$ bond (vide supra), which is nearly double the calculated $\Delta \Delta G^{\ddagger}$ of $8.6 \mathrm{kcal} / \mathrm{mol}$ for the same two reactions with $\operatorname{TpRu}(\mathrm{CO})\left(\eta^{2}-\mathrm{C}_{2} \mathrm{H}_{4}\right)(\mathrm{Ph}) \quad($ Scheme 2.20$){ }^{4}$ For $\mathrm{TpRu}\left(\mathrm{PMe}_{3}\right)\left(\eta^{2}-\mathrm{C}_{2} \mathrm{H}_{4}\right)(\mathrm{Ph})$ the calculated $\Delta \Delta G^{\ddagger}$ for ethylene insertion and ethylene $\mathrm{C}-\mathrm{H}$ activation is only $3.1 \mathrm{kcal} / \mathrm{mol}$. As a result of the low activation barrier for ethylene $\mathrm{C}-\mathrm{H}$ activation (compared with the $\Delta G^{\ddagger}$ for ethylene insertion) by $\mathrm{TpRu}\left(\mathrm{PMe}_{3}\right)\left(\eta^{2}-\mathrm{C}_{2} \mathrm{H}_{4}\right)(\mathrm{Ph})$, this system is not a catalyst for ethylene hydrophenylation. ${ }^{4}$ For $\mathbf{2 . 7}$, the large kinetic preference for $\mathrm{C}=\mathrm{C}$ insertion over ethylene $\mathrm{C}-\mathrm{H}$ activation suggests substantial latitude with respect to potential nextgeneration catalyst refinement strategies before vinylic $\mathrm{C}-\mathrm{H}$ activation becomes problematic for this family of $\mathrm{Pt}^{\mathrm{II}}$ catalysts, thus providing one major advantage over reported $\mathrm{Ru}^{\mathrm{II}}$ catalysts (Scheme 2.20 ). 


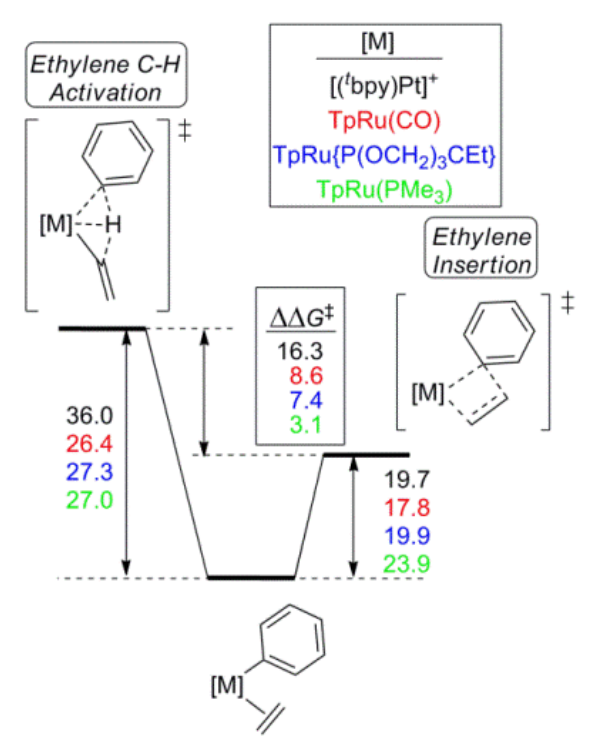

Scheme 2.20. Comparison of the calculated $\Delta G^{\ddagger}(\mathrm{kcal} / \mathrm{mol})$ for olefin insertion versus olefin $\mathrm{C}-\mathrm{H}$ activation between several reported olefin hydroarylation catalysts, with the $\Delta \Delta G^{\ddagger}$ between the two transformations highlighted.

\subsubsection{Polyalkylation of Benzene}

Ethylene hydrophenylation using complexes 2.1-2.3 produces significant quantities of diethylbenzenes that account for approximately $20 \%$ of the total alkyl arene products (Table 2.1). For the $\mathrm{Pt}$ catalysts $\left[\left({ }^{\mathrm{t}} \mathrm{bpy}\right) \mathrm{Pt}(\mathrm{Ph})(\mathrm{L})\right]^{+}$, the ratio of diethylbenzenes to ethylbenzene is approximately invariant as a function of the identity of the ligand L. In contrast, only $3 \%$ of the total alkyl arene product is diethylbenzene for ethylene hydrophenylation using a $\operatorname{Ir}^{\mathrm{III}}$ catalyst, $^{3,24}$ and catalytic ethylene hydrophenylation using $\mathrm{TpRu}(\mathrm{CO})(\mathrm{NCMe})(\mathrm{Ph})$ produces only trace amounts of diethylbenzene. ${ }^{5,24}$ Polyalkylated benzenes produced during catalytic ethylene hydrophenylation using the Pt catalyst precursor (dmpp)PtMe 3 [dmpp = 3,5-dimethyl-2-(2-pyridyl)pyrrolide] comprise $\sim 4 \%$ of the total alkyl arene product. ${ }^{1}$ One of the potential advantages of transition metal- 
catalyzed olefin hydroarylation (compared to Friedel-Crafts catalysis) is the inhibition of polyalkylation. We sought to determine the reason $\left[\left({ }^{t} \mathrm{bpy}\right) \mathrm{Pt}(\mathrm{Ph})(\mathrm{L})\right]^{+}$catalysts produce substantial quantities of diethylbenzenes. The simplest explanation is that the reaction of the Pt catalyst with ethylbenzene is substantially faster than the reaction with benzene, but the experimental data do not support this scenario.

Notably, the ratio of ethylbenzene to diethylbenzenes is approximately invariant through 16 hours of catalysis with a ratio of 4.4 and 4.8 after 4 and 16 hours, respectively, using complex 2.1. The catalytic conversion of ethylbenzene and ethylene $(0.1 \mathrm{MPa})$ to diethylbenzenes by $\mathbf{2 . 1}$ at $100{ }^{\circ} \mathrm{C}$ results in $5.8 \mathrm{TO}$ after 4 hours, corresponding to a TOF of $0.4 \times 10^{-3} \mathrm{~s}^{-1}$; whereas the hydrophenylation of ethylene by 2.1 under identical conditions occurs with a TOF of $1.3 \times 10^{-3} \mathrm{~s}^{-1}$. Thus, the rate of ethylbenzene production from benzene is $\sim 3$ times faster than the rate of diethylbenzene formation from ethylbenzene, and the production of significant quantities of diethylbenzenes during the hydrophenylation of ethylene cannot be attributed to reaction of the Pt catalyst with free ethylbenzene formed during the reaction.

A plausible mechanism to explain the production of diethylbenzenes is depicted in Scheme 2.21. The key steps follow benzene $\mathrm{C}-\mathrm{H}$ activation to produce $\left[\left({ }^{t} \text { bpy }\right) \operatorname{Pt}(\text { ethylbenzene })(\mathrm{Ph})\right]^{+}(\mathbf{A}$ in Scheme 2.21$)$. Dissociation of ethylbenzene from A completes the catalytic cycle for ethylene hydrophenylation. However, aromatic $\mathrm{C}-\mathrm{H}$ activation of ethylbenzene generates $\left[\left({ }^{t} \text { bpy }\right) \mathrm{Pt}\left(\mathrm{C}_{6} \mathrm{H}_{4} \mathrm{Et}\right)\left(\mathrm{C}_{6} \mathrm{H}_{6}\right)\right]^{+}(\mathbf{B}, 3$ isomers are possible). The conversion of $\mathbf{A}$ to $\mathbf{B}$ requires the conversion of alkyl-coordinated ethylbenzene to an arene-coordinated system. Such a rearrangement of alkyl arene to a $\pi$ arene complex has been observed for late transition metals. ${ }^{66}$ From complex B, 
coordination and insertion of a second equivalent of ethylene with subsequent benzene $\mathrm{C}-\mathrm{H}$ activation leads to diethylbenzene. The relatively "slow" dissociation of ethylbenzene, regardless of whether this occurs by a net associative or dissociative process, allows opportunity for a second $\mathrm{C}-\mathrm{H}$ activation and, hence, formation of diethylbenzene.

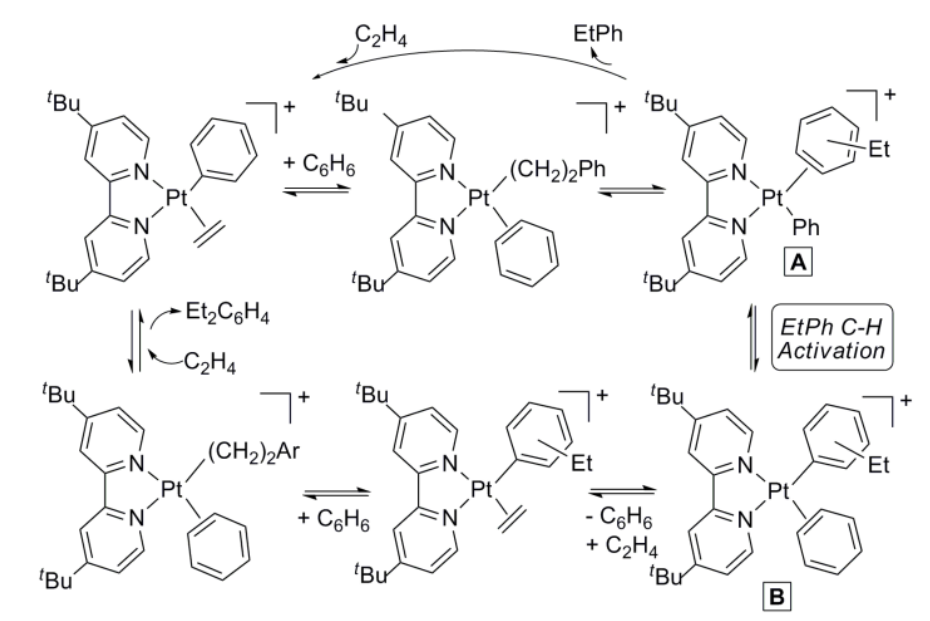

Scheme 2.21. Proposed pathway by which diethylbenzenes are formed during catalytic ethylene hydrophenylation catalyzed by $\left[\left({ }^{t} \mathrm{bpy}\right) \mathrm{Pt}(\mathrm{Ph})\right]^{+}\left(\mathrm{Ar}=\mathrm{C}_{6} \mathrm{H}_{4} \mathrm{Et}\right.$; note: three isomers of the $\mathrm{C}_{6} \mathrm{H}_{4} \mathrm{Et}$ ligand of $\mathbf{B}$ are possible).

GC/MS analysis of ethylbenzene produced from the reaction of $\mathrm{C}_{6} \mathrm{H}_{6}$ and $\mathrm{C}_{2} \mathrm{H}_{4}$ catalyzed by $\mathbf{2 . 2}$ reveals the major isotopologue as $\mathrm{PhCH}_{2} \mathrm{CH}_{3}(\mathrm{~m} / z=106)$ with observation of a fragment due to loss of $\mathrm{CH}_{3}(\mathrm{~m} / z=91)$. Similar analysis from the reaction of $\mathrm{C}_{6} \mathrm{D}_{6}$ and $\mathrm{C}_{2} \mathrm{H}_{4}$ affirms the major isotopologue as ethylbenzene- $d_{6}(\mathrm{~m} / \mathrm{z}=112)$ with an observed fragment due to loss of $\mathrm{CH}_{2} \mathrm{D}(\mathrm{m} / \mathrm{z}=96)$, which is consistent with the production of $d_{5}-\mathrm{PhCH}_{2} \mathrm{CH}_{2}$ D. It was anticipated that catalysis using a 1:1 ratio $(v: v)$ of $\mathrm{C}_{6} \mathrm{H}_{6}$ and $\mathrm{C}_{6} \mathrm{D}_{6}$ with $\mathrm{C}_{2} \mathrm{H}_{4}$ would produce ethylbenzene- $d_{\mathrm{n}}$ with $\mathrm{n}=0,1,5$ and 6 , which would arise from ethylene insertion into either $\mathrm{Pt}-\mathrm{Ph}$ or $\mathrm{Pt}-\mathrm{Ph}-d_{5}$ followed by activation 
of either $\mathrm{C}_{6} \mathrm{H}_{6}$ or $\mathrm{C}_{6} \mathrm{D}_{6}$ (Scheme 2.22), as observed for the same experiment using $\mathrm{TpRu}(\mathrm{CO})(\mathrm{NCMe}) \mathrm{Ph}$ as the catalyst. ${ }^{5}$ However, using complex 2.2 as the catalyst results in all isotopologues of ethylbenzene- $d_{\mathrm{n}}$ with $\mathrm{n}=0-6(\mathrm{~m} / \mathrm{z}=106-112)$ (Figure 2.18). The observation of substantial H/D exchange is consistent with our proposed mechanism for diethylbenzene formation in which relatively slow net dissociation of ethylbenzene from $\mathrm{Pt}^{\mathrm{II}}$ (regardless of the mechanism of dissociation) provides a pathway for $\mathrm{H} / \mathrm{D}$ scrambling to yield ethylbenzene- $d_{n}$ with $n=2,3$ and 4 in addition to the $n=0,1,5$ and 6 isotopes that are expected.

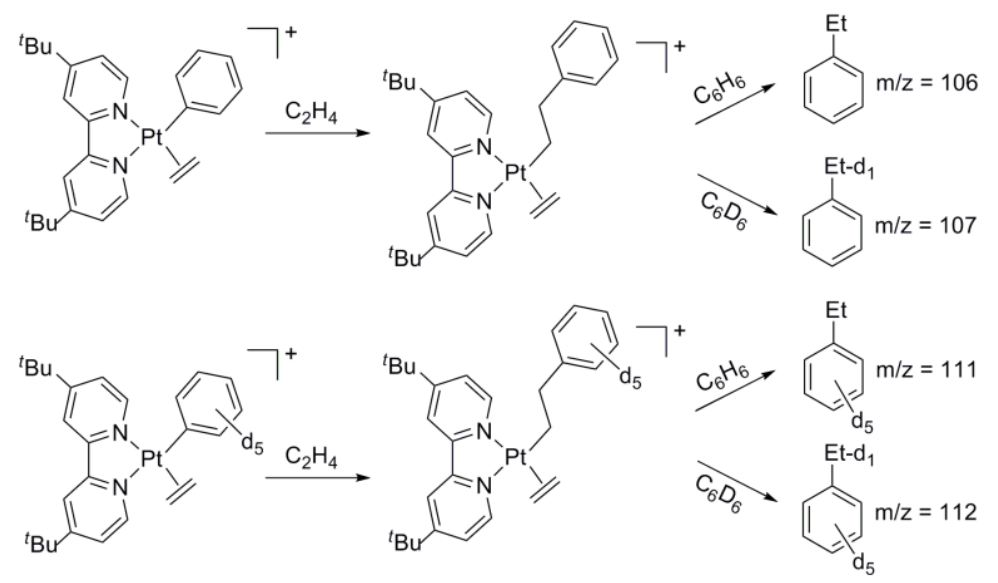

Scheme 2.22. Expected isotopologues of ethylbenzene- $d_{n}(n=0,1,5,6)$ that are produced from ethylene insertion into a $\mathrm{Pt}-\mathrm{Ph}$ or $\mathrm{Pt}-\mathrm{Ph}-d_{5}$ and subsequent $\mathrm{C}-\mathrm{H} / \mathrm{D}$ activation of either $\mathrm{C}_{6} \mathrm{H}_{6}$ or $\mathrm{C}_{6} \mathrm{D}_{6}$.

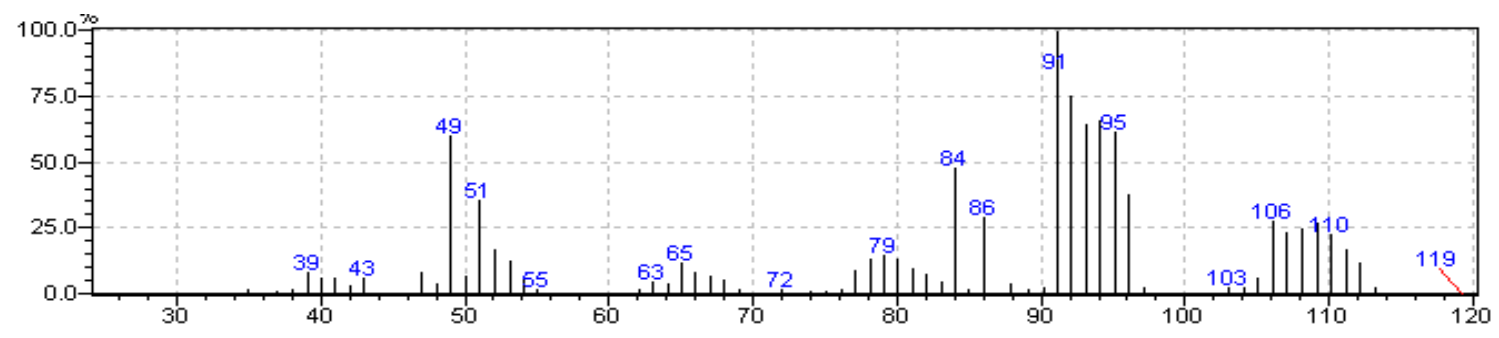

Figure 2.18. SEI mass spectrum of ethylbenzene- $d_{\mathrm{n}}, \mathrm{n}=0-6$, produced by ethylene hydrophenylation catalyzed by 2.2 in the presence of $\mathrm{C}_{6} \mathrm{H}_{6}$ and $\mathrm{C}_{6} \mathrm{D}_{6}(1: 1 \mathrm{v}: \mathrm{v})$. 
Heating complex 2.4 in benzene $\left(100^{\circ} \mathrm{C}\right)$ results in quantitative production of ethylbenzene (by GC/MS) (Scheme 2.23). Importantly, GC/MS analysis of the reaction of 2.4 in $\mathrm{C}_{6} \mathrm{D}_{6}$ reveals the production of ethylbenzene- $d_{\mathrm{n}}(\mathrm{n}=1-6)$. NMR spectroscopy and GC/MS analysis indicate that extensive deuteration does not occur in the ethyl fragment, other than the expected formation of $-\mathrm{CH}_{2} \mathrm{CH}_{2} \mathrm{D}$. If the conversion of $\mathbf{A}$ to $\mathbf{B}$ (Scheme 2.21) were inaccessible, then heating $\mathbf{2 . 4}$ in $\mathrm{C}_{6} \mathrm{D}_{6}$ should produce only ethylbenzene- $d_{1}$. The mass spectrum of ethylbenzene features peaks at mass range $\mathrm{m} / \mathrm{z}=$ 106-113, with $m / z=112$ having the greatest abundance, and fragmentation at mass range $m / z=91-97$ with $m / z=96$ of greatest abundance. From the mass spectrum it can be inferred that H/D scrambling occurs predominantly into the phenyl ring of ethylbenzene (Figure 2.19), which is consistent with the proposed mechanism in Scheme 2.24. Previously reported reactions between benzene and $\mathrm{Pt}^{\mathrm{II}}$ have also demonstrated H/D exchange in all ring positions. ${ }^{67}$ In addition, the mass spectrum of ethylbenzene produced from the thermolysis of complex 2.4 in $\mathrm{C}_{6} \mathrm{D}_{6}$ displays peaks in the range of $m / z=27-30$, which is indicative of the presence of $-\mathrm{CH}_{2} \mathrm{CH}_{2} \mathrm{D}(\mathrm{m} / \mathrm{z}=30)$ fragments (Figure 2.19). There is no evidence of a peak at $m / z=31$ (or greater) due to ethyl- $d_{\mathrm{n}}(\mathrm{n} \geq 2)$ fragments. The ${ }^{2} \mathrm{H}$ NMR spectrum of the reaction mixture supports the presence of a $-\mathrm{CH}_{2} \mathrm{CH}_{2} \mathrm{D}$ fragment $(\delta=1.03 \mathrm{ppm})$ and a lack of extensive H/D scrambling into the ethyl fragment, since a resonance consistent with deuterium incorporation into the benzylic position is not observed (Figure 2.20). 


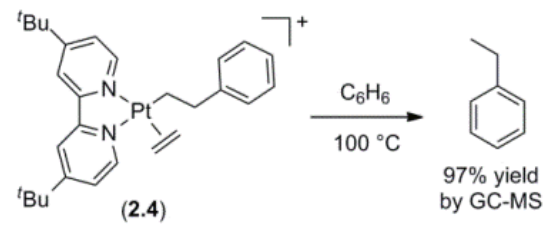

Scheme 2.23. Quantitative production of ethylbenzene (as determined by GC/MS) during the thermolysis of complex $\mathbf{2 . 4}$ in benzene.
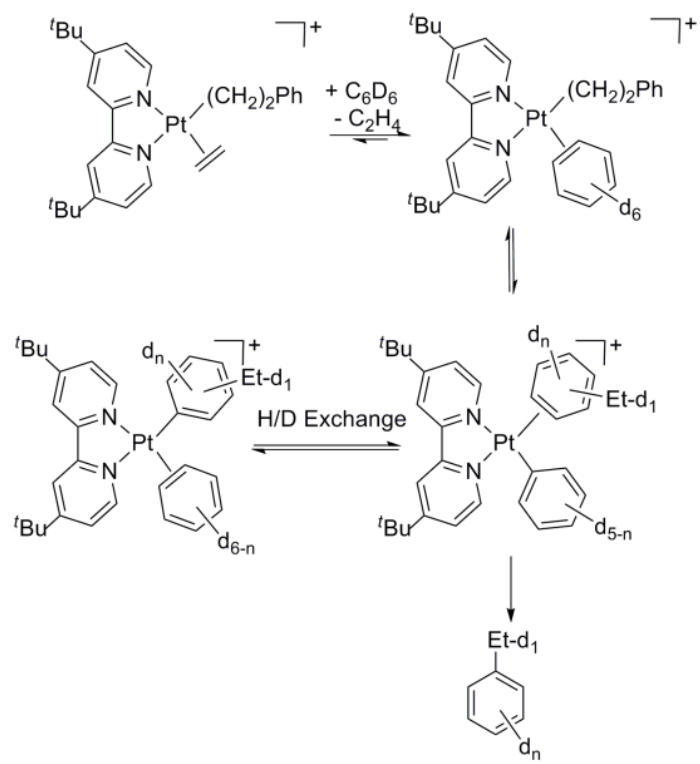

Scheme 2.24. Proposed mechanism for $\mathrm{H} / \mathrm{D}$ scrambling occurs during the thermolysis of $\left[\left({ }^{t}\right.\right.$ bpy $\left.) \mathrm{Pt}\left(\mathrm{CH}_{2} \mathrm{CH}_{2} \mathrm{Ph}\right)\left(\eta^{2}-\mathrm{C}_{2} \mathrm{H}_{4}\right)\right]\left[\mathrm{BAr}_{4}\right]$ (2.4) in $\mathrm{C}_{6} \mathrm{D}_{6}$. 

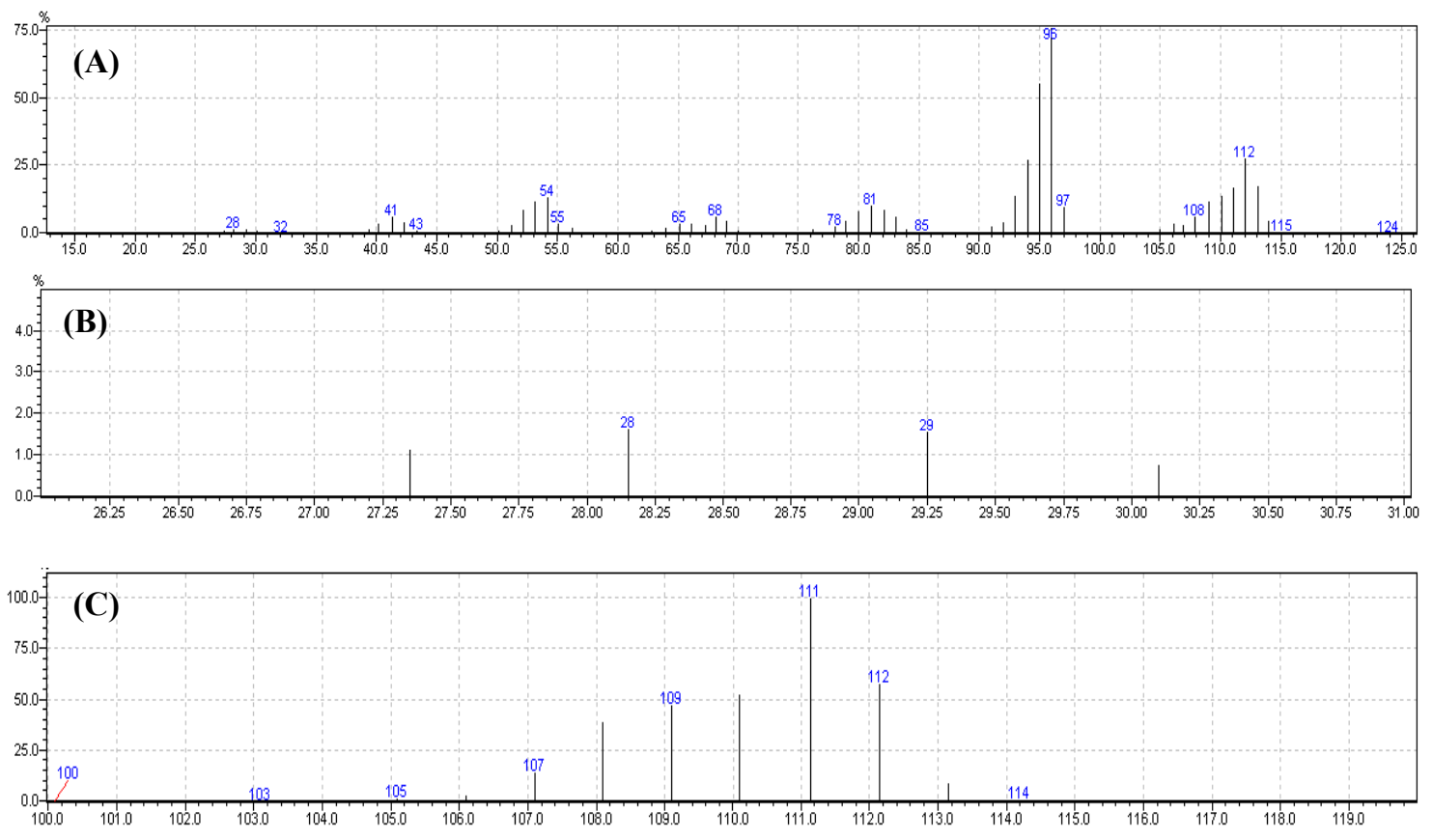

Figure 2.19. Selected mass spectra for the thermolysis of $\mathbf{2 . 4}$ in $\mathrm{C}_{6} \mathrm{D}_{6}$. (A) SEI mass spectrum of ethylbenzene. (B) Zoom of SEI mass spectrum highlighting the fragmentation of the ethyl ion. (C) NCI mass spectrum of ethylbenzene.

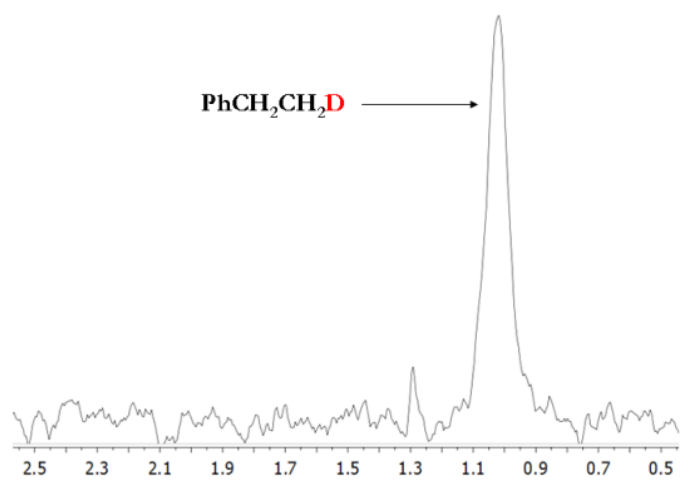

Figure 2.20. ${ }^{2} \mathrm{H}$ NMR spectrum for the product of thermolysis of 2.4 in $\mathrm{C}_{6} \mathrm{D}_{6}$, highlighting the resonance $(\delta=1.03 \mathrm{ppm})$ of the ethylbenzene isotopologues possessing an ethyl fragment with a terminal $-\mathrm{CH}_{2} \mathrm{D}$ group. Incorporation of deuterium into the benzylic position is not observed.

The addition of a Lewis base to the reaction of 2.4 with $\mathrm{C}_{6} \mathrm{D}_{6}$ might be expected to promote the loss of ethylbenzene from $\mathbf{A}$ (Scheme 2.21) via associative displacement and 
suppress the extent of H/D exchange. Indeed, the addition of THF (100 equivalents relative to 2.4) to the stoichiometric reaction of 2.4 in $\mathrm{C}_{6} \mathrm{D}_{6}$ results in a shift of the isotopic distribution from the major isotope of $m / z=111$ to $m / z=108$ (Figure 2.21). The addition of the Lewis base increases the prevalence of the lower mass ions $(\mathrm{m} / \mathrm{z}=105-$ 109) compared to the reaction without its addition. The inhibition of isotopic scrambling with added Lewis base is most readily explained by an associative mechanism for exchange of ethylbenzene with THF and mirrors the observations of isotope exchange from protonation of (diimine) $\mathrm{Pt}(\mathrm{Me})_{2}$ using DOTf, as well as positional $\mathrm{o} / \mathrm{m} / \mathrm{p}$ isomerization of Pt tolyl and xylyl complexes where NCMe was used as the Lewis base in both cases. ${ }^{18-19}$
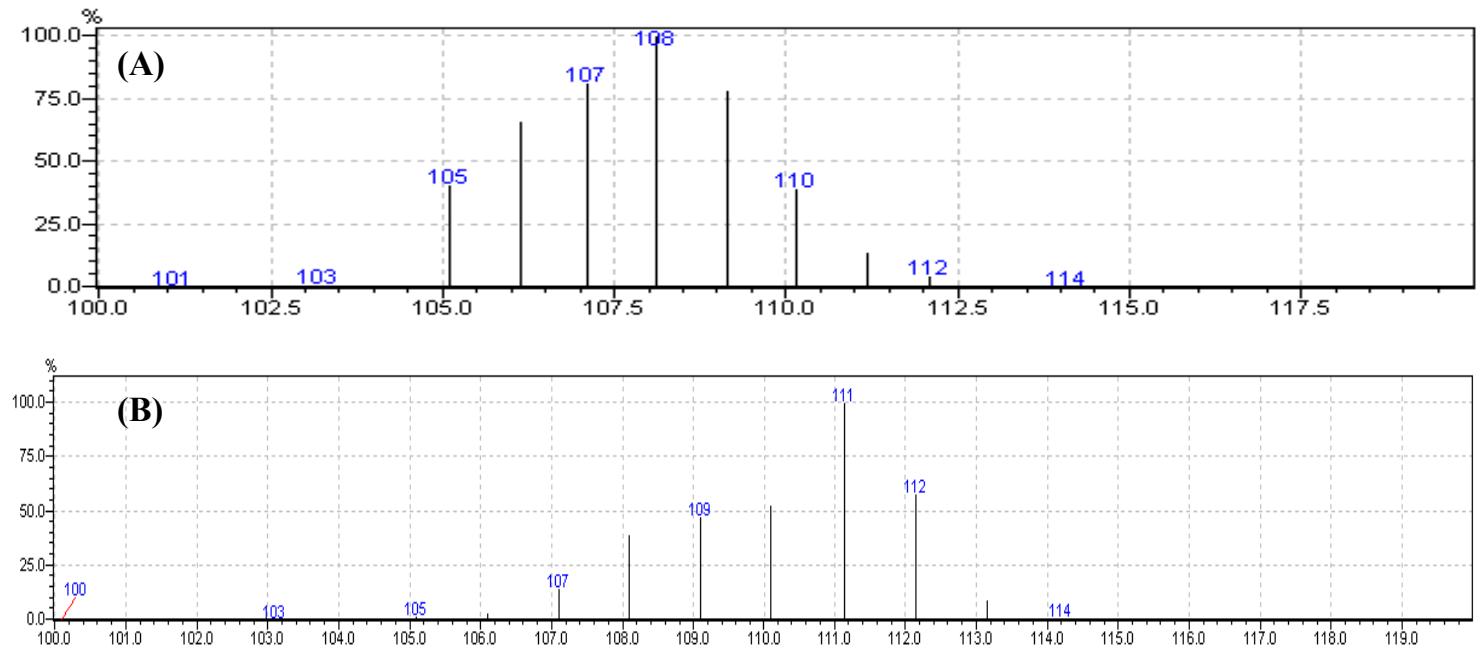

Figure 2.21. (A) NCI mass spectrum for the thermolysis of 2.4 in $\mathrm{C}_{6} \mathrm{D}_{6}$ with 100 equivalents of THF- $d_{8}$ relative to 2.4. (B) NCI mass spectrum for the thermolysis of 2.4 in $\mathrm{C}_{6} \mathrm{D}_{6}$ without the presence of a Lewis base. 
To test our interpretation of these results, $\left[\left({ }^{t} \mathrm{bpy}\right) \mathrm{Pt}\left(\mathrm{CH}_{2} \mathrm{CH}_{2} \mathrm{Ph}-d_{5}\right)\left(\eta^{2}-\mathrm{C}_{2} \mathrm{H}_{4}\right)\right]^{+}\left(\mathbf{2 . 4}-\boldsymbol{d}_{\mathbf{5}}\right)$ was synthesized with an all deutero $\mathrm{Ph}$ moiety. Heating $\mathbf{2 . 4 - \boldsymbol { d } _ { 5 }}$ in $\mathrm{C}_{6} \mathrm{D}_{6}$ results in quantitative formation of ethylbenzene- $d_{6}$. The reaction of 2.4-d $\boldsymbol{d}_{5}$ in $\mathrm{C}_{6} \mathrm{H}_{6}$ produces isotopologues with a mass range $m / z=106-111$, with $m / z=106$ having the greatest abundance (Figure 2.22). In addition, fragmentation at mass range $m / z=91-95$ with $m / z$ $=91$ of greatest abundance is observed, which indicates substantial formation of per protio $\left[\mathrm{PhCH}_{2}\right]^{+}$fragments by $\mathrm{H} / \mathrm{D}$ exchange. The observed selectivity for isotopologues of ethylbenzene is similar to that observed for the thermolysis of 2.4 in $\mathrm{C}_{6} \mathrm{D}_{6}$ with $\mathrm{H} / \mathrm{D}$ exchange occurring predominantly into the phenyl ring of ethylbenzene. Likewise, performing the reaction of $\mathbf{2 . 4 - d _ { 5 }}$ and $\mathrm{C}_{6} \mathrm{H}_{6}$ in the presence of THF results in isotopologues of ethylbenzene- $d_{\mathrm{n}}(\mathrm{n}=1-6)$ with a mass range $m / z=106-112$, with the peak at $m / z=109$ being in greatest abundance. Similar to 2.4 and $\mathrm{C}_{6} \mathrm{D}_{6}$, the addition of the Lewis base increases the prevalence of the higher mass ions $(m / z>108)$ compared to the reaction without its addition. 

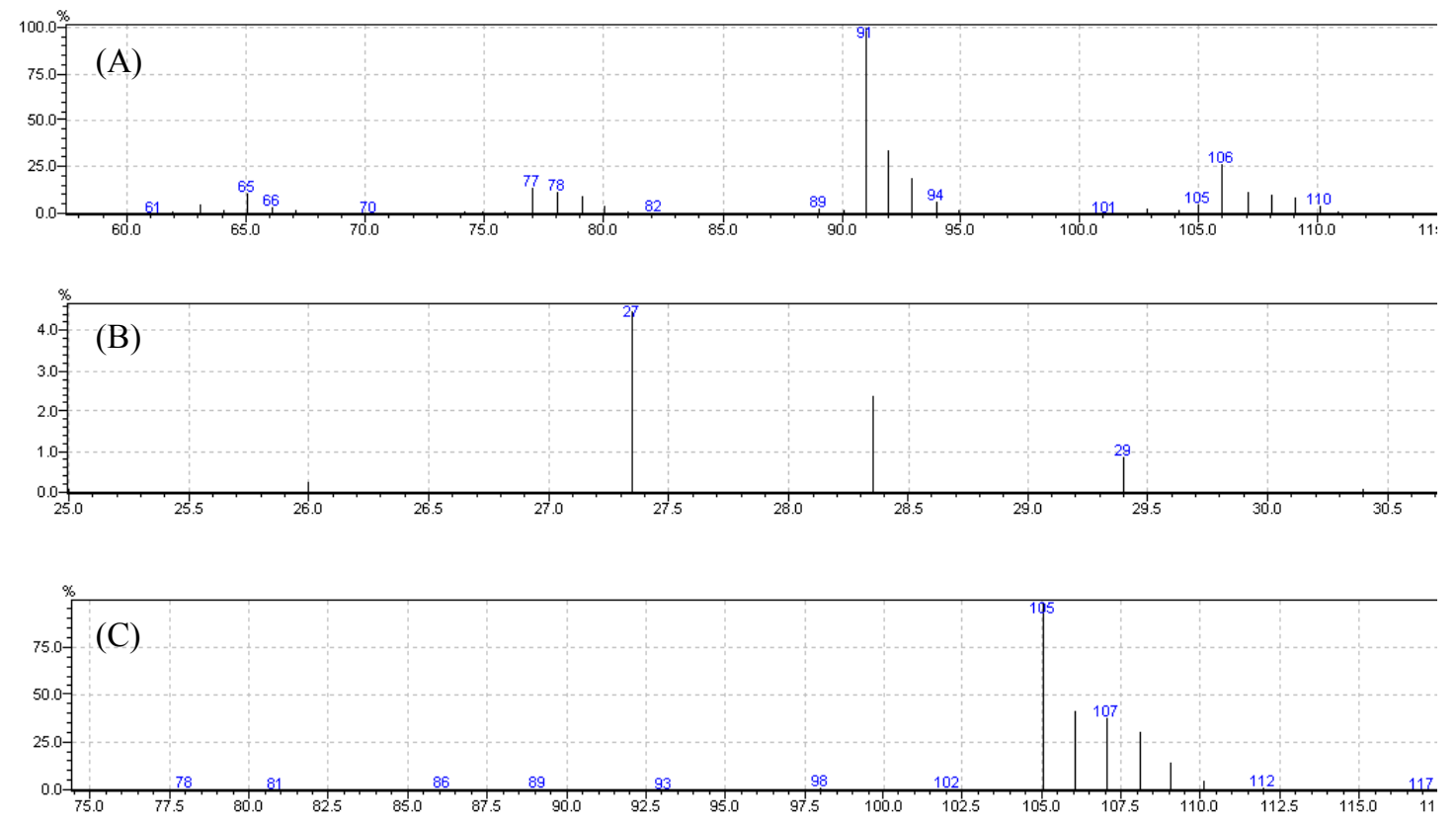

Figure 2.22. Selected mass spectra for the thermolysis of $\mathbf{2 . 4}-\boldsymbol{d}_{\mathbf{5}}$ in $\mathrm{C}_{6} \mathrm{H}_{6}$. (A) SEI mass spectrum of ethylbenzene (B) Zoom of SEI mass spectrum highlighting the fragmentation of the ethyl ion (C) NCI mass spectrum of ethylbenzene.

Benzene coordination and $\mathrm{C}-\mathrm{H}$ activation by $\left[(\mathrm{bpy}) \mathrm{Pt}\left(\mathrm{CH}_{2} \mathrm{CH}_{2} \mathrm{Ph}\right)\right]^{+}$forms $\left[(\text { bpy }) \operatorname{Pt}(\mathrm{Ph})\left(\eta^{2}-C, C-\mathrm{C}_{6} \mathrm{H}_{5} \mathrm{Et}\right)\right]^{+}\left(\mathbf{A}^{\prime}\right)$. Simulations were used to assess the potential for $\mathbf{A}^{\prime}$ to (a) undergo dissociation of ethylbenzene, (b) undergo a second aromatic $\mathrm{C}-\mathrm{H}$ activation event and (c) undergo $\mathrm{sp}^{3} \mathrm{C}-\mathrm{H}$ activation. The last process (i.e., $\mathrm{c}$ ), which forms $\left[(\text { bpy }) \mathrm{Pt}\left(\mathrm{CH}_{2} \mathrm{CH}_{2} \mathrm{Ph}\right)\left(\eta^{2}-C, C-\mathrm{C}_{6} \mathrm{H}_{6}\right)\right]^{+}$, has a high calculated barrier $\left(\Delta G^{\ddagger}=27.5\right.$ $\mathrm{kcal} / \mathrm{mol}$ ), consistent with the absence of extensive $\mathrm{H} / \mathrm{D}$ scrambling into the ethyl fragment. The free energy for dissociation of ethylbenzene from $\mathbf{A}^{\prime}$ is calculated to be $12.5 \mathrm{kcal} / \mathrm{mol}$, while arene $\mathrm{C}-\mathrm{H}$ activation barriers are calculated to be $16.2 \mathrm{kcal} / \mathrm{mol}$ (para $\mathrm{C}-\mathrm{H}$ activation), $16.7 \mathrm{kcal} / \mathrm{mol}$ (meta $\mathrm{C}-\mathrm{H}$ activation) and 18.7 (ortho $\mathrm{C}-\mathrm{H}$ activation). Thus, the calculations suggest that the energetics of ethylbenzene dissociation and a second $\mathrm{C}-\mathrm{H}$ activation are of similar magnitude. As a benchmark, the energetics of 
ethylbenzene dissociation were compared with the charge-neutral complex $(\mathrm{dmpp}) \mathrm{Pt}(\mathrm{Ph})\left(\eta^{2}-C, C\right.$-ethylbenzene $) \quad[\mathrm{dmpp} \quad=\quad$ 3,5-dimethyl-2-(2-pyridyl)pyrrolide] which exhibits less extensive formation of diethylbenzenes during catalytic hydrophenylation of ethylene. The barrier to ethylbenzene dissociation from $(\operatorname{dmpp}) \mathrm{Pt}(\mathrm{Ph})\left(\eta^{2}-C, C\right.$-ethylbenzene $) \quad$ was calculated to be only $0.6 \mathrm{kcal} / \mathrm{mol}$. Ethylbenzene dissociation from $\mathrm{TpRu}(\mathrm{CO})($ ethylbenzene) $(\mathrm{Ph})$ is calculated to be exergonic by $8 \mathrm{kcal} / \mathrm{mol}$.

A striking observation is the $o: m: p$ selectivity for diethylbenzenes as a function of aromatic substrate. For example, the o:m:p selectivity for the production of diethylbenzenes from 2.1 with ethylene and benzene is 1:2.6:1.6 after 4 hours (see Table 2.1). In contrast, for the reaction of ethylene with ethylbenzene under identical conditions, the o:m:p selectivity is 1.0:34.8:24.0 (Scheme 2.25). Notably, the $\mathrm{m} / \mathrm{p}$ selectivity ratio is approximately the same as the reaction with benzene while the ratio of $o$ to $m / p$ changes dramatically. The different selectivity suggests distinct pathways for diethylbenzene formation from $\mathrm{C}_{2} \mathrm{H}_{4} / \mathrm{C}_{6} \mathrm{H}_{6}$ and $\mathrm{C}_{2} \mathrm{H}_{4}$ /ethylbenzene reactions (Scheme 2.26). For the reaction of ethylene and benzene, the formation of diethylbenzene is proposed to originate via benzene $\mathrm{C}-\mathrm{H}$ activation to give $\mathbf{A}$, followed by $\mathrm{sp}^{2} \mathrm{C}-\mathrm{H}$ activation of the coordinated ethylbenzene (Scheme 2.21). In this scenario, $\mathrm{Pt}^{\mathrm{II}}$ migrates from the methyl group of coordinated ethylbenzene ( $\mathbf{C}$ in Scheme 2.26) to an $\eta^{2}-C, C$ intermediate involving the ortho carbon (D in Scheme 2.26). If the rate of aromatic $\mathrm{C}-\mathrm{H}$ activation is competitive with migration around the phenyl ring, it is expected that ortho $\mathrm{C}-\mathrm{H}$ activation, ultimately resulting in 1,2-diethylbenzene, will be competitive. For the 
catalytic ethylation of toluene, the $\mathrm{Pt}^{\mathrm{II}}$ catalyst reported by Goldberg et al. provided an $o / m+p$ selectivity of 7:93 (the meta and para isomers could not be separated). ${ }^{1}$

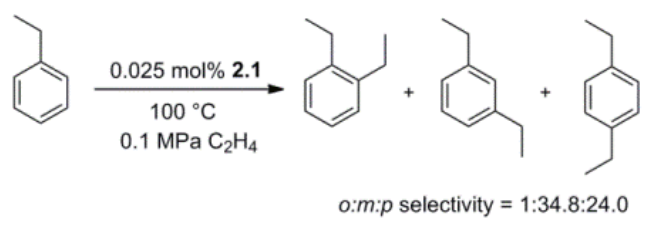

Scheme 2.25. Distribuition of regioisomers of diethylbenzene formed during ethylene hydroarylation using ethylbenzene and complex 2.1 .

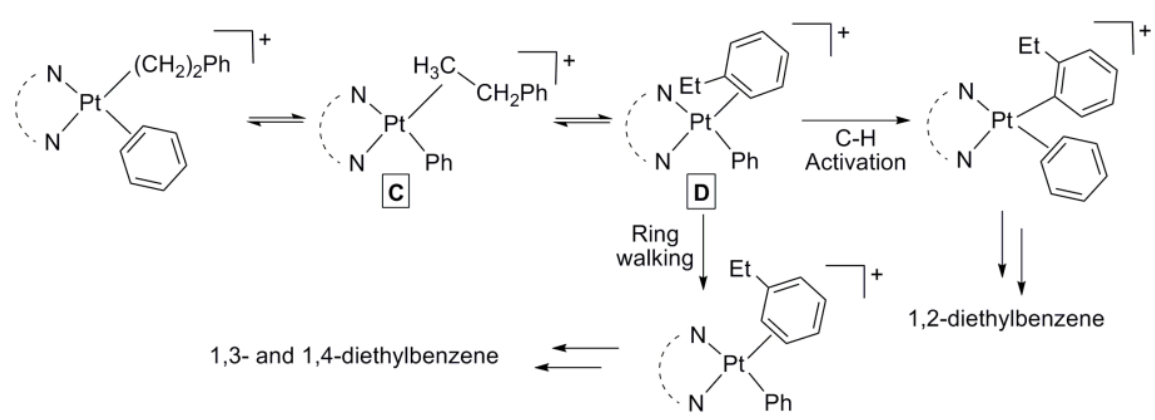

Scheme 2.26. Pathway for diethylbenzene formation from $\mathrm{C}_{6} \mathrm{H}_{6}$ and $\mathrm{C}_{2} \mathrm{H}_{4}$ requires $\mathrm{Pt}$ to interact with the 2-position carbon.

For the formation of diethylbenzenes from free ethylbenzene and ethylene, the $o: m: p$ selectivity is dictated by the coordination and $\mathrm{C}-\mathrm{H}$ activation of ethylbenzene. Here, free ethylbenzene likely coordinates to $\mathrm{Pt}^{\mathrm{II}}$ via an initial $\eta^{2}-C, C$ complex, likely with a preferred orientation of the ethyl group away from the $\mathrm{Pt}^{\mathrm{II}}$ center in order to reduce steric interactions. Hence, the aromatic $\mathrm{C}-\mathrm{H}$ activation can occur without $\mathrm{Pt}^{\mathrm{II}}$ directly interacting with the ortho carbon, which contrasts with diethylbenzene formed from ethylene and benzene, since the proposed pathway requires Pt to interact with the carbon 
ortho to the ethyl group. This results in the decreased selectivity for meta and para over ortho for diethylbenzene formation from benzene and ethylene.

\subsection{Conclusion}

The cationic fragment $\left[\left({ }^{t} \text { bpy }\right) \mathrm{Pt}(\mathrm{Ph})\right]^{+}$serves as a catalyst for the hydrophenylation of ethylene by a non-Friedel-Crafts pathway. One of the overarching goals of this work was a comparison of catalytic olefin hydroarylation using a late transition metal catalyst, traditionally considered electrophilic in character, with catalysts based on $\mathrm{d}^{6}$ systems that are considered more electron-rich (e.g., $\mathrm{Ru}^{\mathrm{II}}$ and $\mathrm{Ir}^{\mathrm{III}}$ catalysts). Based on this study, the following salient points are emphasized:

1) Experimental studies for the catalytic conversion of ethylene and benzene to ethylbenzene are consistent with a cycle that involves ethylene coordination and insertion followed by Pt-mediated benzene $\mathrm{C}-\mathrm{H}$ activation with the latter step as the turnover limiting step. Monitoring catalysis by ${ }^{1} \mathrm{H}$ NMR spectroscopy reveals that $\left[\left({ }^{\mathrm{b} p p y}\right) \mathrm{Pt}\left(\mathrm{CH}_{2} \mathrm{CH}_{2} \mathrm{Ph}\right)\left(\eta^{2}-\mathrm{C}_{2} \mathrm{H}_{4}\right)\right]^{+}$is likely that catalyst resting state. DFT calculations are consistent with these conclusions. Thus, despite studies that reveal alternative mechanisms for catalytic olefin hydroarylation initiated by $\mathrm{Pt}^{\mathrm{II}}$ systems, ${ }^{25-26}$ our results provide evidence that late transition metal systems can catalyze olefin hydroarylation by a pathway that involves olefin coordination, olefin insertion and metal-mediated aromatic $\mathrm{C}-\mathrm{H}$ activation. 
2) Starting with ethylbenzene, the $\left[\left({ }^{t} \mathrm{bpy}\right) \mathrm{Pt}(\mathrm{Ph})\right]^{+}$catalyst is highly selective for $1,3-$ and 1,4-diethylbenzene over 1,2-diethylbenzene, which is in contrast to the selectivity of traditional Friedel-Crafts catalysts.

3) The platinum catalysts related to $\left[\left({ }^{t} \mathrm{bpy}\right) \mathrm{Pt}(\mathrm{Ph})\right]^{+}$result in high yields under conditions in which ethylene is the limiting reagent. The catalyst also displays a tolerance towards exposure to aerobic conditions. The formation of vinyl arene via $\beta$-hydride elimination and olefin dissociation occurs only to a minor extent even though computational studies indicate that $\beta$-hydride elimination from $\left[\left({ }^{t} \text { bpy }\right) \mathrm{Pt}\left(\mathrm{CH}_{2} \mathrm{CH}_{2} \mathrm{Ph}\right)\right]^{+}$ should have a low $\Delta G^{\ddagger}$. Therefore, the lack of substantial styrene production may result from facile reinsertion relative to the rate of styrene dissociation.

4) The competition between olefin insertion and olefin $\mathrm{C}-\mathrm{H}$ activation is a key parameter for olefin hydroarylation catalysts. Compared with $\mathrm{TpRu}(\mathrm{L})(\mathrm{NCMe}) \mathrm{Ph}$ systems, calculations (supported by experimental studies) suggest that the Pt catalysts have a larger $\Delta \Delta G^{\ddagger}$ that favors the desired catalysis.

5) The formation of diethylbenzene products using $\mathbf{2 . 1}-\mathbf{2 . 3}$ as catalyst precursors is hypothesized to be a result of a second aromatic $\mathrm{C}-\mathrm{H}$ activation that competes with the dissociation of ethylbenzene. This is distinct from polyalkylation in Friedel-Crafts catalysis, which is thought to originate from enhanced rates of reaction of free alkyl arenes relative to the starting arene. ${ }^{68}$ The barrier to hydrocarbon dissociation using $\mathbf{2 . 1}$ is consistent with observations of other cationic late transition metal systems. ${ }^{69-70}$ Also relevant here are data consistent with alkane intermediates involved in $\mathrm{Pt}^{\mathrm{II}}$ systems, ${ }^{29,71}$ and implications of barriers for hydrocarbon dissociation which facilitate the 
polyfunctionalization of methane, best studied in cases of $\mathrm{H} / \mathrm{D}$ exchange. ${ }^{30}$ While previous studies of H/D exchange have implicated coordinated hydrocarbons as intermediates, ${ }^{27,72}$ to our knowledge this is a rare example of such an effect impacting the selectivity of a catalytic reaction, and it suggests an important consideration when designing catalysts for olefin hydroarylation using late transition metals. The present research implies that the cationic charge on $\left[\left({ }^{t} \mathrm{bpy}\right) \mathrm{Pt}(\mathrm{Ph})\right]^{+}$may play an important role in selectivity vis-a-vis mono- versus poly-alkylated products, a notion that is consistent with the neutral catalyst $(\mathrm{dmpp}) \mathrm{Pt}\left(\mathrm{CH}_{2} \mathrm{CH}_{2} \mathrm{Ph}\right)\left(\eta^{2}-\mathrm{C}_{2} \mathrm{H}_{4}\right)$ producing only small amounts of diethylbenzenes. ${ }^{1}$ This working hypothesis further hints at improved design strategies for olefin hydroarylation catalysts, e.g., via attenuation of the electrophilicity of the metal center with overall neutral catalysts.

\subsection{Experimental Section}

General Considerations. Unless otherwise noted, all synthetic procedures were performed under anaerobic conditions in a nitrogen-filled glovebox or by using standard Schlenk techniques. Glovebox purity was maintained by periodic nitrogen purges and was monitored by an oxygen analyzer $\left(\mathrm{O}_{2}<15 \mathrm{ppm}\right.$ for all reactions $)$. Tetrahydrofuran, and diethyl ether were dried by distillation from sodium/benzophenone. Pentafluoropyridine and $n$-pentane were distilled over $\mathrm{CaH}_{2}$ and $\mathrm{P}_{2} \mathrm{O}_{5}$, respectively. Methylene chloride and benzene were purified by passage through a column of activated alumina. Benzene- $d_{6}$, acetone- $d_{6}$, and $\mathrm{CD}_{2} \mathrm{Cl}_{2}$ were used as received and stored under a $\mathrm{N}_{2}$ atmosphere over $4 \AA$ molecular sieves. ${ }^{1} \mathrm{H}$ NMR spectra were recorded on a Varian 
Mercury 300 or $500 \mathrm{MHz}$ spectrometer. All ${ }^{1} \mathrm{H}$ spectra are referenced against residual proton signals of the deuterated solvents. ${ }^{19} \mathrm{~F}$ NMR (282 $\mathrm{MHz}$ operating frequency) spectra were obtained on a Varian $300 \mathrm{MHz}$ spectrometer and referenced against an external standard of hexafluorobenzene $(\delta=-164.9 \mathrm{ppm}) .{ }^{2} \mathrm{H}$ NMR (77 MHz operating frequency) spectra were obtained on a Varian Mercury $500 \mathrm{MHz}$ spectrometer. GC/MS was performed using a Shimadzu GCMS-QP2010 Plus system with a $30 \mathrm{~mm}$ x $0.25 \mathrm{~mm}$ SHRXI-5MS column with $0.25 \mathrm{~mm}$ film thickness using negative chemical ionization (NCI), which also allows for simulated electron impact (SEI) ionization. Ethylene (99.5\%) was purchased in a gas cylinder from GTS-Welco and used as received. All other reagents were used as purchased from commercial sources. The preparation, isolation, and characterization of $\left[\mathrm{H}\left(\mathrm{Et}_{2} \mathrm{O}\right)_{2}\right]\left[\mathrm{BAr}_{4}\right],{ }^{73}\left({ }^{t} \mathrm{bpy}\right) \mathrm{Pt}(\mathrm{Ph})_{2},{ }^{22} \mathrm{PhLi}-d_{5},{ }^{74}$ and $(\mathrm{COD}) \mathrm{Pt}(\mathrm{Et})_{2}{ }^{75}(\mathrm{COD}=1,5$-cyclooctadiene $)$ have been previously reported.

Computational Methods. All computations were performed by the Cundari group (University of North Texas) using 2,2'-bipyridyl as a model ligand for 4,4'-ditertbutyl2,2'-bipyridyl. The DFT calculations were carried out using the Gaussian 03 software package. All optimizations were done with B3LYP ${ }^{44-46}$ using the Stevens valence basis sets, CEP-31G (5d, 7f), ${ }^{47-50}$ and pseudopotentials. Extra polarization basis functions were added to the main group elements using values taken from the 6-31G(d) all-electron basis sets. Given that the majority of the species in this study are cationic, solvent effects were assessed for a more accurate description of energetics. The Conductor-like Polarized Continuum Method (CPCM) $)^{76-79}$ was used with both benzene and THF as the solvents selected to run the calculations. Little qualitative difference in the various steps was seen in the various solvent media. Reported free energies were determined at $298.15 \mathrm{~K}$ and 1 
atm using unscaled B3LYP frequencies. Unless stated otherwise, the calculated free energies are those modeled in THF solvent.

$\left[\left({ }^{t} \mathbf{b p y}\right) \mathbf{P t}(\mathbf{P h})(\mathbf{T H F})\right]\left[\mathbf{B A r}_{4}{ }_{4}\right] \quad \mathbf{( 2 . 1 )}$. To a cooled solution of $\left({ }^{t} \mathrm{bpy}\right) \mathrm{Pt}(\mathrm{Ph})_{2}(0.095 \mathrm{~g}$, $0.15 \mathrm{mmol})$ in THF $\left(\sim 20 \mathrm{~mL},-60{ }^{\circ} \mathrm{C}\right),\left[\mathrm{H}\left(\mathrm{Et}_{2} \mathrm{O}\right)_{2}\right]\left[\mathrm{BAr}_{4}\right](0.16 \mathrm{~g}, 0.15 \mathrm{mmol})$ in $\mathrm{THF}$ $\left(\sim 15 \mathrm{~mL},-60{ }^{\circ} \mathrm{C}\right)$ was added. After the addition, the volatiles were removed in vacuo. The crude solid was treated with $n$-pentane $(\sim 2 \mathrm{~mL})$, which was subsequently removed under vacuum to afford a fluffy yellow powder. The resulting product was then dried in vacuo $(0.21 \mathrm{~g}, 93 \%) .{ }^{1} \mathrm{H}$ NMR $\left(300 \mathrm{MHz}, \mathrm{CD}_{2} \mathrm{Cl}_{2}\right) \delta 8.36\left(\mathrm{~d}, 1 \mathrm{H},{ }^{3} \mathrm{~J}_{\mathrm{HH}}=6 \mathrm{~Hz}, \mathrm{H}^{6}{ }^{\mathrm{t}} \mathrm{bpy}\right)$, $8.14\left(\mathrm{~d}, 1 \mathrm{H},{ }^{3} \mathrm{~J}_{\mathrm{HH}}=6 \mathrm{~Hz}, \mathrm{H}^{6}-^{\mathrm{t}} \mathrm{bpy}\right), 8.09\left(\mathrm{~d}, 1 \mathrm{H},{ }^{4} \mathrm{~J}_{\mathrm{HH}}=2 \mathrm{~Hz}, \mathrm{H}^{3}{ }^{\mathrm{t}} \mathrm{bpy}\right), 7.97\left(\mathrm{~d}, 1 \mathrm{H},{ }^{4} \mathrm{~J}_{\mathrm{HH}}=\right.$ $\left.2 \mathrm{~Hz}, \mathrm{H}^{3-{ }^{t}} \mathrm{bpy}\right), 7.78\left(\mathrm{dd}, 1 \mathrm{H},{ }^{3} \mathrm{~J}_{\mathrm{HH}}=6 \mathrm{~Hz},{ }^{4} \mathrm{~J}_{\mathrm{HH}}=2 \mathrm{~Hz}, \mathrm{H}^{5-}{ }^{\mathrm{t}} \mathrm{bpy}\right), 7.71\left(\mathrm{br} \mathrm{s}, 8 \mathrm{H}, \mathrm{H}_{\mathrm{o}}\left(\mathrm{Ar}^{\prime}\right)\right)$, $7.55\left[\mathrm{br} \mathrm{s}, 4 \mathrm{H} \mathrm{H} \mathrm{p}_{\mathrm{p}}\left(\mathrm{Ar}^{\prime}\right)\right], 7.46\left[\mathrm{~d}, 1 \mathrm{H},{ }^{3} \mathrm{~J}_{\mathrm{HH}}=7 \mathrm{~Hz}, \mathrm{H}_{\mathrm{o}}(\mathrm{Ph})\right], 7.27\left(\mathrm{dd}, 1 \mathrm{H},{ }^{3} \mathrm{~J}_{\mathrm{HH}}=6 \mathrm{~Hz},{ }^{4} \mathrm{~J}_{\mathrm{HH}}\right.$ $\left.=2 \mathrm{~Hz}, \mathrm{H}^{5-} \mathrm{t}_{\mathrm{bpy}}\right), 7.16\left[\mathrm{~m}, 2 \mathrm{H}, \mathrm{H}_{\mathrm{m}}(\mathrm{Ph})\right], 7.06\left[\mathrm{~m}, 1 \mathrm{H}, \mathrm{H}_{\mathrm{p}}(\mathrm{Ph})\right], 4.14$ (br m, 4H, H $\left.{ }^{2}-\mathrm{THF}\right)$, 1.86 (br m, 4H, H ${ }^{3}$-THF), 1.46 (s, 9H, t-butyl ${ }^{\mathrm{t}}$ bpy), 1.38 (s, 9H, t-butyl ${ }^{\mathrm{t}}$ bpy). ${ }^{1} \mathrm{H}$ NMR (tetrahydrofuran- $\left.\mathrm{d}_{8}\right) \delta 8.54\left(\mathrm{~d}, 1 \mathrm{H},{ }^{3} \mathrm{~J}_{\mathrm{HH}}=6 \mathrm{~Hz}, \mathrm{H}^{6}-{ }^{\mathrm{t}} \mathrm{bpy}\right), 8.51\left(\mathrm{~s}, 1 \mathrm{H}, \mathrm{H}^{3}-^{\mathrm{t}} \mathrm{bpy}\right), 8.39(\mathrm{~s}$, $\left.1 \mathrm{H}, \mathrm{H}^{3}-{ }^{\mathrm{t}} \mathrm{bpy}\right), 8.17\left(\mathrm{~d}, 1 \mathrm{H},{ }^{3} \mathrm{~J}_{\mathrm{HH}}=6 \mathrm{~Hz}, \mathrm{H}^{6}{ }^{\mathrm{t}} \mathrm{bpy}\right), 7.89\left(\mathrm{~d}, 1 \mathrm{H},{ }^{3} \mathrm{~J}_{\mathrm{HH}}=6 \mathrm{~Hz}, \mathrm{H}^{5}-{ }^{\mathrm{t}} \mathrm{bpy}\right), 7.80$ [br s, 9H, $\mathrm{H}_{\mathrm{o}}\left(\mathrm{Ar}^{\prime}\right)$ and $\mathrm{H}^{5}$-bpy $^{\mathrm{t}}$ ], $7.58\left[\mathrm{br} \mathrm{s}, 4 \mathrm{H}, \mathrm{H}_{\mathrm{p}}\left(\mathrm{Ar}^{\prime}\right)\right], 7.50\left(\mathrm{~d}, 1 \mathrm{H},{ }^{3} \mathrm{~J}_{\mathrm{HH}}=7 \mathrm{~Hz}\right.$, $\left.\mathrm{H}_{\mathrm{o}}(\mathrm{Ph})\right], 7.13$ [m, 2H, $\mathrm{H}_{\mathrm{m}}(\mathrm{Ph}), 7.03\left(\mathrm{~m}, 1 \mathrm{H}, \mathrm{H}_{\mathrm{p}}(\mathrm{Ph})\right], 1.47$ (s, 9H, t-butyl tbpy), 1.39 (s, 9H, t-butyl bpy). Resonances due to coordinated THF were not observed due to rapid exchange with THF-d $\mathrm{d}_{8} \cdot{ }^{13} \mathrm{C}$ NMR $\left(75 \mathrm{MHz}\right.$, tetrahydrofuran- $\left.d_{8}\right) \delta 166.5,166.3,158.6$, $154.8,153.9,147.2,140.8,137.5,136.8,128.6,125.4,121.7,121.2$ ( ${ }^{t}$ bpy and Ph aromatic), 36.6 ( $t$-butyl, quaternary, $\left.{ }^{t} \mathrm{bpy}\right), 36.5$ ( $t$-butyl, quaternary, ${ }^{t}$ bpy), 30.0 ( $t$-butyl$\mathrm{CH}_{3},{ }^{t}$ bpy), 29.8 (t-butyl-CH $3{ }_{3}{ }^{t}$ bpy); 162.6 (q, Ar', $\left.{ }^{1} J_{\text {B-Cipso }}=50 \mathrm{~Hz}\right), 135.4\left(\mathrm{Ar}^{\prime}\right), 129.9$ $\left(\mathrm{q}, m-\mathrm{Ar}^{\prime},{ }^{2} J_{\mathrm{C}-\mathrm{F}}=32 \mathrm{~Hz}\right), 127.1\left(\mathrm{q}, \mathrm{CF}_{3}-\mathrm{Ar}^{\prime},{ }^{1} J_{\mathrm{C}-\mathrm{F}}=272 \mathrm{~Hz}\right), 118.0\left(\mathrm{Ar}^{\prime}\right) .{ }^{19} \mathrm{~F}$ NMR $(282$ 
$\left.\mathrm{MHz}, \mathrm{CD}_{2} \mathrm{Cl}_{2}\right) \delta-62.2$ (s, $\left.\mathrm{CF}_{3}-\mathrm{Ar}^{\prime}\right)$. Anal. calcd. for $\mathrm{PtBON}_{2} \mathrm{~F}_{24} \mathrm{C}_{60} \mathrm{H}_{49}(\%)$ : $\mathrm{C} 48.82, \mathrm{H}$ 3.35, N 1.90; found: C 48.27, H 3.13, N 2.12.

$\left[\left({ }^{t} \mathbf{b p y}\right) \operatorname{Pt}\left(\mathbf{P h}-\boldsymbol{d}_{\mathbf{5}}\right)(\mathbf{T H F})\right]\left[\mathbf{B A r}_{4}{ }_{4}\right] \quad\left(\mathbf{2 . 1}-\boldsymbol{d}_{\mathbf{5}}\right)$. This complex was synthesized by the procedure used for 2.1. In the preparation of the initial starting material, PhLi was substituted with $\mathrm{PhLi}-d_{5}$ to produce ( ${ }^{t}$ bpy) $\mathrm{Pt}\left(\mathrm{Ph}-d_{5}\right)_{2} \cdot{ }^{1} \mathrm{H}$ and ${ }^{13} \mathrm{C}$ NMR spectra are consistent with the all protio analogue minus the resonances for the phenyl ring in the ${ }^{1} \mathrm{H}$ NMR spectrum.

$\left[\left({ }^{t} \mathbf{b p y}\right) \mathbf{P t}\left(\mathbf{N C}_{5} \mathbf{F}_{5}\right)(\mathbf{P h})\right]\left[\mathbf{B A r}_{4}\right] \quad$ (2.2). To a cooled solution of $\left({ }^{t} \mathrm{bpy}\right) \mathrm{Pt}(\mathrm{Ph})_{2}(0.14 \mathrm{~g}$, $0.22 \mathrm{mmol})$ in THF $\left(\sim 20 \mathrm{~mL},-60{ }^{\circ} \mathrm{C}\right),\left[\mathrm{H}\left(\mathrm{Et}_{2} \mathrm{O}\right)_{2}\right]\left[\mathrm{BAr}_{4}\right](0.26 \mathrm{~g}, 0.22 \mathrm{mmol})$ in THF $\left(\sim 15 \mathrm{~mL},-60{ }^{\circ} \mathrm{C}\right)$ was added. After the addition, the volatiles were removed in vacuo. The crude solid was then reconstituted in pentafluoropyridine $(\sim 5 \mathrm{~mL})$. The solution was stirred at room temperature for 36 hrs. The volatiles were then removed. The crude solid was treated with $n$-pentane $(\sim 2 \mathrm{~mL})$, which was subsequently removed under vacuum to afford a fluffy orange powder. The resulting product was then dried in vacuo $(0.33 \mathrm{~g}$, $96 \%) .{ }^{1} \mathrm{H}$ NMR $\left(\mathrm{NC}_{5} \mathrm{~F}_{5}\right.$, acetone- $\mathrm{d}_{6}$ insert) $\delta 7.36$ (s, $\left.1 \mathrm{H}, \mathrm{H}^{3}{ }^{\mathrm{t}} \mathrm{bpy}\right), 7.30$ (s, $\left.1 \mathrm{H}, \mathrm{H}^{3}{ }^{-}{ }^{\mathrm{t}} \mathrm{bpy}\right)$, $7.06\left(\mathrm{~d}, 1 \mathrm{H},{ }^{3} \mathrm{~J}_{\mathrm{HH}}=6 \mathrm{~Hz}, \mathrm{H}^{6}-^{\mathrm{t}} \mathrm{bpy}\right), 6.92\left(\mathrm{~d}, 1 \mathrm{H},{ }^{3} \mathrm{~J}_{\mathrm{HH}}=6 \mathrm{~Hz}, \mathrm{H}^{6}-{ }^{\mathrm{t}} \mathrm{bpy}\right), 6.62[\mathrm{br} \mathrm{s}, 10 \mathrm{H}$, $\mathrm{H}_{\mathrm{o}}\left(\mathrm{Ar}^{\prime}\right)$ and $\left.\mathrm{H}_{\mathrm{o}}(\mathrm{Ph})\right], 6.56\left(\mathrm{~d}, 1 \mathrm{H},{ }^{3} \mathrm{~J}_{\mathrm{HH}}=6 \mathrm{~Hz}, \mathrm{H}^{5}-{ }^{\mathrm{b}} \mathrm{bpy}\right), 6.18$ [br s, 5H, $\mathrm{H}_{\mathrm{p}}\left(\mathrm{Ar}^{\prime}\right)$ and $\mathrm{H}^{5}-$ bpy], $5.63\left(\mathrm{t}, 2 \mathrm{H},{ }^{3} \mathrm{~J}_{\mathrm{HH}}=7 \mathrm{~Hz}, \mathrm{H}_{\mathrm{m}}(\mathrm{Ph})\right], 5.39\left[\mathrm{t}, 1 \mathrm{H},{ }^{3} \mathrm{~J}_{\mathrm{HH}}=7 \mathrm{~Hz}, \mathrm{H}_{\mathrm{p}}(\mathrm{Ph})\right], 0.36(\mathrm{~s}, 9 \mathrm{H}, \mathrm{t}-$ butyl $\left.{ }^{\mathrm{t} b p y}\right), 0.29$ (s, 9H, t-butyl ${ }^{\mathrm{t}}$ bpy). ${ }^{13} \mathrm{C} \mathrm{NMR}\left(75 \mathrm{MHz}, \mathrm{NC}_{5} \mathrm{~F}_{5}\right.$ with acetone- $\mathrm{d}_{6}$ insert) $\delta 166.3,156.0,153.2,150.6,145.9,126.3,124.3,123.9,122.9,119.1$ ('bpy and $\mathrm{Ph}$ aromatic), 34.6 (t-butyl, quaternary, ${ }^{\mathrm{t} b p y}$, coincidental overlap), 27.7 (t-butyl- $\mathrm{CH}_{3},{ }^{\mathrm{t}} \mathrm{bpy}$ ), 27.6 (t-butyl-CH ${ }_{3},{ }^{t}$ bpy); 160.9 (q, Ar', $\left.{ }^{1} \mathrm{~J}_{\mathrm{B}-\mathrm{Cipso}}=50 \mathrm{~Hz}\right), 127.6$ (q, m-Ar', $\left.{ }^{2} \mathrm{~J}_{\mathrm{C}-\mathrm{F}}=31 \mathrm{~Hz}\right)$, $123.4\left(\mathrm{q}, \mathrm{CF}_{3}-\mathrm{Ar}^{\prime},{ }^{1} \mathrm{~J}_{\mathrm{C}-\mathrm{F}}=272 \mathrm{~Hz}\right), 115.5$ (Ar'). Resonances for coordinated 
perfluoropyridine were not observed due to ligand exchange and resulting time averaged signals at room temperature. Remaining $5{ }^{t} \mathrm{bpy}, \mathrm{Ph}$, and $\mathrm{Ar}$ ' aromatic resonances are obscured due to broad $\mathrm{NC}_{5} \mathrm{~F}_{5}$ resonances or coincidental overlap. ${ }^{19} \mathrm{~F}$ NMR $(282 \mathrm{MHz}$, $\left.\mathrm{CD}_{2} \mathrm{Cl}_{2}\right) \delta-61.2\left(\mathrm{~s}, 24 \mathrm{~F}, \mathrm{CF}_{3}-\mathrm{Ar}^{\prime}\right),-74.3\left(\mathrm{~m}, 2 \mathrm{~F},{ }^{3} J_{\mathrm{Pt}-\mathrm{F}}=316 \mathrm{~Hz}\right.$ (Pt satellites), $o-\mathrm{NC}_{5} F_{5}$ ), $118.9\left(\mathrm{~m}, 1 \mathrm{~F}, p-\mathrm{NC}_{5} F_{5}\right),-154.2\left(\mathrm{~m}, 2 \mathrm{~F}, m-\mathrm{NC}_{5} F_{5}\right)$. Anal. calcd. for $\mathrm{PtBN}_{3} \mathrm{~F}_{29} \mathrm{C}_{61} \mathrm{H}_{41}(\%)$ : C 46.58, H 2.63, N 2.67; found: C 46.54, H 2.65, N 2.20.

$\left[\left({ }^{t} \mathbf{b p y}\right) \mathbf{P t}(\mathbf{N C M e})(\mathbf{P h})\right]\left[\mathbf{B A r}_{4}\right]$ (2.3). To a cooled solution of $\left({ }^{t} \mathrm{bpy}\right) \mathrm{Pt}(\mathrm{Ph})_{2}(0.090 \mathrm{~g}$,

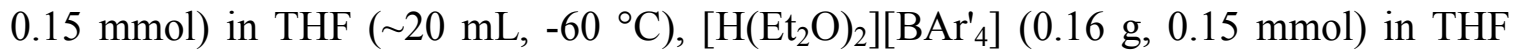
$\left(\sim 15 \mathrm{~mL},-60{ }^{\circ} \mathrm{C}\right)$ was added. After the addition, the volatiles were removed in vacuo. The crude solid was then reconstituted in acetonitrile $(\sim 5 \mathrm{~mL})$. The solution was stirred at room temperature for 15 minutes. The volatiles were then removed. The crude solid was treated with $n$-pentane $(\sim 2 \mathrm{~mL})$, which was subsequently removed under vacuum to afford a fluffy yellow powder. The resulting product was then dried in vacuo $(0.20 \mathrm{~g}$, 94\%).${ }^{1} \mathrm{H}$ NMR (acetone- $\left.\mathrm{d}_{6}\right) \delta 9.02\left(\mathrm{~d}, 1 \mathrm{H},{ }^{3} \mathrm{~J}_{\mathrm{HH}}=5.8 \mathrm{~Hz}, \mathrm{H}^{6}-\mathrm{b}^{\mathrm{t}} \mathrm{by}\right), 8.80\left(\mathrm{~d}, 1 \mathrm{H},{ }^{4} \mathrm{~J}_{\mathrm{HH}}=\right.$ $\left.1.9 \mathrm{~Hz}, \mathrm{H}^{3}-\mathrm{t}^{\mathrm{b} p y}\right), 8.73\left(\mathrm{~d}, 1 \mathrm{H},{ }^{4} \mathrm{~J}_{\mathrm{HH}}=2.1 \mathrm{~Hz}, \mathrm{H}^{3}{ }^{\mathrm{t}} \mathrm{bpy}\right), 8.25\left(\mathrm{~d}, 1 \mathrm{H},{ }^{3} \mathrm{~J}_{\mathrm{HH}}=6.3 \mathrm{~Hz}, \mathrm{H}^{6}-\right.$ bpy), $7.93\left(\mathrm{dd}, 1 \mathrm{H},{ }^{3} \mathrm{~J}_{\mathrm{HH}}=5.8,{ }^{4} \mathrm{~J}_{\mathrm{HH}}=1.9 \mathrm{~Hz}, \mathrm{H}^{5}-{ }^{\mathrm{t}}\right.$ bpy), 7.80 (br. s, 8H, $\left.\mathrm{H}_{\mathrm{o}}\left(\mathrm{Ar}^{\prime}\right)\right), 7.72$ (dd, $1 \mathrm{H},{ }^{3} \mathrm{~J}_{\mathrm{HH}}=6.3,{ }^{4} \mathrm{~J}_{\mathrm{HH}}=2.1, \mathrm{H}^{5}$ - ${ }^{\mathrm{t}}$ bpy), 7.68 (br. s, $\left.4 \mathrm{H}, \mathrm{H}_{\mathrm{p}}\left(\mathrm{Ar}^{\prime}\right)\right), 7.39\left(\mathrm{~m}, 2 \mathrm{H}, \mathrm{H}_{\mathrm{o}}(\mathrm{Ph})\right), 7.10$ (m, 3H, $\mathrm{H}_{\mathrm{m}}(\mathrm{Ph})$ and $\left.\mathrm{H}_{\mathrm{p}}(\mathrm{Ph})\right), 2.81$ (s, 3H, NCMe), 1.48 (s, 9H, t-butyl tbpy), 1.43 (s, 9H, t-butyl ${ }^{\mathrm{t} b p y)} .{ }^{13} \mathrm{C}$ NMR (75 MHz, acetone-d 6 ) $\delta 167.0,166.9,158.8,155.2,152.4,149.7$, $137.5,128.9,126.1,125.9,125.5,122.8,122.2,120.9$ ('bpy and Ph aromatic), 69.5 ( $t$ butyl, quaternary, ${ }^{t}$ bpy) , 68.2 ( $t$-butyl, quaternary, ${ }^{t}$ bpy), $37.0\left(t\right.$-butyl- $\mathrm{CH}_{3}$, coincidental overlap), $4.2\left(\mathrm{NCMe}, \mathrm{CH}_{3}\right) ; 162.8$ (q, Ar', $\left.{ }^{1} J_{\mathrm{B}-\mathrm{Cipso}}=50 \mathrm{~Hz}\right), 135.7$ (Ar'), 130.2 (q, $m$-Ar', $\left.{ }^{2} J_{\mathrm{C}-\mathrm{F}}=31 \mathrm{~Hz}\right), 125.5\left(\mathrm{q}, \mathrm{CF}_{3}-\mathrm{Ar}^{\prime},{ }^{1} J_{\mathrm{C}-\mathrm{F}}=272 \mathrm{~Hz}\right), 118.6\left(\mathrm{Ar}^{\prime}\right) .{ }^{19} \mathrm{~F}$ NMR $(282 \mathrm{MHz}$, 
acetone- $\left.d_{6}\right) \delta-60.6\left(\mathrm{~s}, \mathrm{CF}_{3}-\mathrm{Ar}^{\prime}\right)$. Anal. calcd. for $\mathrm{PtBN}_{3} \mathrm{~F}_{24} \mathrm{C}_{58} \mathrm{H}_{44}(\%)$ : C 48.21, H 3.08, N 2.91; found: C 48.43, H 3.05, N 3.03.

$\left[\left({ }^{t}\right.\right.$ bpy $\left.) \operatorname{Pt}\left(\mathbf{C H}_{2} \mathbf{C H}_{2} \mathbf{P h}\right)\left(\eta^{2}-\mathbf{C}_{2} \mathbf{H}_{4}\right)\right]\left[\mathrm{BAr}_{4}{ }_{4}\right] \quad$ (2.4). Complex 2.1 (0.033 g, 0.019 mmol) was dissolved in dichloromethane $(\sim 5 \mathrm{~mL})$. The reaction mixture was transferred to a stainless steel pressure reactor and pressurized with ethylene $(0.3 \mathrm{MPa})$ for $16 \mathrm{hrs}$. The volatiles were removed and pentane $(\sim 2 \mathrm{~mL})$ was added to the crude solid. The pentane was removed under vacuum to afford an orange solid. The solid was collected and dried in vacuo $(0.027 \mathrm{~g}, 97 \%) .{ }^{1} \mathrm{H} \mathrm{NMR}\left(\mathrm{CD}_{2} \mathrm{Cl}_{2}\right) \delta 8.67\left(\mathrm{~d}, 1 \mathrm{H},{ }^{3} \mathrm{~J}_{\mathrm{HH}}=6 \mathrm{~Hz}, \mathrm{H}^{6}-{ }^{\mathrm{t}} \mathrm{bpy}\right), 8.21(\mathrm{~s}$, $\left.1 \mathrm{H}, \mathrm{H}^{3}-{ }^{\mathrm{t}} \mathrm{bpy}\right), 8.16\left(\mathrm{~s}, 1 \mathrm{H}, \mathrm{H}^{3}-{ }^{\mathrm{t}} \mathrm{bpy}\right), 7.93\left(\mathrm{~d}, 1 \mathrm{H},{ }^{3} \mathrm{~J}_{\mathrm{HH}}=6 \mathrm{~Hz}, \mathrm{H}^{6}-{ }^{\mathrm{t}} \mathrm{bpy}\right), 7.79\left(\mathrm{~d}, 1 \mathrm{H},{ }^{3} \mathrm{~J}_{\mathrm{HH}}=\right.$ $\left.6 \mathrm{~Hz}, \mathrm{H}^{5}{ }^{\mathrm{t}} \mathrm{bpy}\right), 7.72$ [br s, 9H, $\mathrm{H}_{\mathrm{o}}\left(\mathrm{Ar}^{\prime}\right)$ and $\mathrm{H}^{5}$ - $\left.^{\mathrm{t}} \mathrm{bpy}\right], 7.55$ [br s, 4H, $\left.\mathrm{H}_{\mathrm{p}}\left(\mathrm{Ar}^{\prime}\right)\right], 7.28-7.12$ (m, 5H, Ph), 4.14 (br s with doublet $(\sim 33 \%)$ due to $\left.{ }^{2} \mathrm{~J}_{\mathrm{Pt}-\mathrm{H}}, 4 \mathrm{H},{ }^{2} \mathrm{~J}_{\mathrm{Pt}-\mathrm{H}}=69 \mathrm{~Hz}, \mathrm{C}_{2} \mathrm{H}_{4}\right), 2.70$ (t, $2 \mathrm{H},{ }^{3} \mathrm{~J}_{\mathrm{HH}}=8 \mathrm{~Hz}, \mathrm{Pt}-\mathrm{CH}_{2} \mathrm{CH}_{2} \mathrm{Ph}$ ), 1.48 and 1.43 (overlapping resonances, 20H, t-butyl bpy and $\left.\mathrm{PtCH}_{2} \mathrm{CH}_{2} \mathrm{Ph}\right) .{ }^{13} \mathrm{C}$ NMR $\left(75 \mathrm{MHz}, \mathrm{CD}_{2} \mathrm{Cl}_{2}\right) \delta 169.4,167.0,157.7,154.5$, $148.1,145.5,144.0,129.2,126.7,126.5,125.8,121.0,120.9$ ('bpy and $\mathrm{Ph}$ aromatic), 70.2 $\left(\mathrm{C}_{2} \mathrm{H}_{4}\right), 37.7\left(\mathrm{PtCH}_{2} \mathrm{CH}_{2} \mathrm{Ph},{ }^{2} \mathrm{~J}_{\mathrm{Pt}-\mathrm{C}}=28 \mathrm{~Hz}\right.$, Pt satellites), 36.9 (t-butyl, quaternary, $\left.{ }^{\mathrm{t}} \mathrm{bpy}\right)$, 36.6 (t-butyl, quaternary, $\left.{ }^{\mathrm{t}} \mathrm{bpy}\right), 30.3$ (t-butyl- $\mathrm{CH}_{3}$, ${ }^{\mathrm{t}} \mathrm{bpy}$, coincidental overlap), 17.0 $\left(\mathrm{PtCH}_{2} \mathrm{CH}_{2} \mathrm{Ph},{ }^{1} \mathrm{~J}_{\mathrm{Pt}-\mathrm{C}}=674 \mathrm{~Hz}, \mathrm{Pt}\right.$ satellites$) ; 162.3\left(\mathrm{q}, \mathrm{Ar}\right.$, $\left.{ }^{1} \mathrm{~J}_{\mathrm{B}-\mathrm{Cipso}}=49 \mathrm{~Hz}\right), 135.4\left(\mathrm{Ar}^{\prime}\right)$, $129.5\left(\mathrm{q}, \mathrm{m}-\mathrm{Ar}^{\prime},{ }^{2} \mathrm{~J}_{\mathrm{C}-\mathrm{F}}=32 \mathrm{~Hz}\right), 125.2\left(\mathrm{q}, \mathrm{Ar},{ }^{2} \mathrm{~J}_{\mathrm{C}-\mathrm{F}}=272 \mathrm{~Hz}\right), 118.1\left(\mathrm{Ar}^{\prime}\right)$. Remaining 3 ${ }^{t}$ bpy and $\mathrm{Ph}$ aromatic resonances are obscured due to broadening or coincidental overlap. ${ }^{19} \mathrm{~F}$ NMR $\left(282 \mathrm{MHz}, \mathrm{CD}_{2} \mathrm{Cl}_{2}\right) \delta-63.1$ (s, $\left.\mathrm{CF}_{3}-\mathrm{Ar}^{\prime}\right)$. Anal. calcd. for $\mathrm{PtBN}_{2} \mathrm{~F}_{24} \mathrm{C}_{60} \mathrm{H}_{49}(\%)$ : C 49.36, H 3.39, N 1.92; found: C 49.28, H 3.27, N 1.89. 
$\left[\left({ }^{t} \mathbf{b p y}\right) \operatorname{Pt}\left(\mathrm{CH}_{2} \mathrm{CH}_{2} \mathbf{P h}-\boldsymbol{d}_{5}\right)\left(\eta^{2}-\mathbf{C}_{2} \mathbf{H}_{4}\right)\right]\left[\mathrm{BAr}_{4}\right] \quad \mathbf{( 2 . 4 - d _ { 5 } ) .}$ This complex was synthesized using 2.1- $\boldsymbol{d}_{\mathbf{5}}$ by the procedure used for $\mathbf{2 . 4} .{ }^{1} \mathrm{H}$ and ${ }^{13} \mathrm{C}$ NMR spectra were consistent with the all protio analogue minus the resonances for the phenyl ring in the ${ }^{1} \mathrm{H}$ NMR spectrum.

Synthesis of ${ }^{t} \mathbf{b p y P t}(\mathbf{E t})_{2} \cdot(\mathrm{COD}) \mathrm{Pt}(\mathrm{Et})_{2}(\mathrm{COD}=1,5$-cyclooctadiene $)(0.14 \mathrm{~g}, 0.38$ mmol) and 4,4'-di-tert-butyl-2,2'-bipyridine (0.10 g, $0.38 \mathrm{mmol})$ were dissolved in toluene $(25 \mathrm{~mL})$ and refluxed for 8 hours. The solution was cooled and the toluene removed in vacuo. The crude material was reconstituted in diethyl ether and filtered through Celite ${ }^{\circledR}$. The solution was then reduced under vacuum to approximately $5 \mathrm{~mL}$, and a precipitate was observed. The solid $(0.057 \mathrm{~g})$ was collected and washed with cold hexanes $(3 \mathrm{~mL})$ and dried. To the filtrate, hexanes were added $(\sim 10 \mathrm{~mL})$, and the solution reduced under vacuum until further precipitation was observed. The solid was collected and washed, and the process repeated two additional times to achieve an overall yield of $0.098 \mathrm{~g}(51 \%) .{ }^{1} \mathrm{H}$ NMR (acetone- $\left.d_{6}\right) \delta 9.06\left(\mathrm{~d}, 2 \mathrm{H},{ }^{3} J_{\mathrm{HH}}=6 \mathrm{~Hz},{ }^{3} J_{\mathrm{Pt}-\mathrm{H}}=19 \mathrm{~Hz}, \mathrm{H}^{6}-\right.$ ${ }^{t}$ bpy), $8.45\left(\mathrm{~d}, 2 \mathrm{H},{ }^{4} J_{\mathrm{HH}}=2 \mathrm{~Hz}, \mathrm{H}^{3}-{ }^{t} \mathrm{bpy}\right), 7.74\left(\mathrm{dd}, 2 \mathrm{H},{ }^{3} J_{\mathrm{HH}}=6 \mathrm{~Hz},{ }^{4} J_{\mathrm{HH}}=2 \mathrm{~Hz}, \mathrm{H}^{5}-\right.$ ${ }^{t}$ bpy) . $1.65\left(\mathrm{q}, 4 \mathrm{H},{ }^{3} J_{\mathrm{HH}}=8 \mathrm{~Hz},{ }^{2} \mathrm{~J}_{\mathrm{Pt}-\mathrm{H}}=88 \mathrm{~Hz}, \mathrm{Pt}-\mathrm{CH}_{2} \mathrm{CH}_{3}\right), 1.44$ (s, 18H, $t$-butyl ${ }^{t}$ bpy $)$ $1.14\left(\mathrm{t}, 6 \mathrm{H},{ }^{3} J_{\mathrm{HH}}=8 \mathrm{~Hz},{ }^{3} J_{\mathrm{Pt}-\mathrm{H}}=82 \mathrm{~Hz}, \mathrm{Pt}-\mathrm{CH}_{2} \mathrm{CH}_{3}\right) .{ }^{13} \mathrm{C} \mathrm{NMR}\left(126 \mathrm{MHz}\right.$, acetone- $\left.d_{6}\right) \delta$ $162.21,157.78,147.63,125.44,121.63,36.92,30.83,19.32\left({ }^{2} J_{\mathrm{Pt}-\mathrm{C}}=37 \mathrm{~Hz}\right), 0.23\left({ }^{1} J_{\mathrm{Pt}-\mathrm{C}}\right.$ $=887 \mathrm{~Hz}$ ). Anal. calcd. for $\mathrm{PtN}_{2} \mathrm{C}_{22} \mathrm{H}_{34}(\%)$ : C 50.6, H 6.58, N 5.37; found: C 49.28, H $6.28, \mathrm{~N} 5.19$.

[('bpy)Pt(Et)(NCMe)][BAr' $\left.{ }_{4}{ }^{t}\right]$ (2.10). Method A: Complex $2.4(0.060$ g, 0.040 mmol) was dissolved in nitromethane- $d_{3}(0.4 \mathrm{~mL})$ and transferred to a high pressure NMR tube. The NMR tube was then degassed, pressurized with ethylene (0.3 MPa), and heated at 80 ${ }^{\circ} \mathrm{C}$ for 16 hours. To the solution, NCMe $(200 \mu \mathrm{L})$ was added. After 2 hours, the solution 
was filtered through Celite ${ }^{\circledR}$ using dichloromethane. The volatiles were removed from the filtrate in vacuo, and the resulting solid was collected $(0.039 \mathrm{~g}, 70 \%)$. The identity of the product was confirmed by comparison to a sample prepared by Method B. Method B: To a cooled solution of ( $\left.{ }^{\mathrm{b} p y}\right) \mathrm{Pt}(\mathrm{Et})_{2}(0.017 \mathrm{~g}, 0.030 \mathrm{mmol})$ in $\mathrm{THF}\left(\sim 15 \mathrm{~mL},-60{ }^{\circ} \mathrm{C}\right)$, $\left[\mathrm{H}\left(\mathrm{Et}_{2} \mathrm{O}\right)_{2}\right]\left[\mathrm{BAr}_{4}\right](0.033 \mathrm{~g}, 0.030 \mathrm{mmol})$ in THF $\left(\sim 5 \mathrm{~mL},-60^{\circ} \mathrm{C}\right)$ was added. After the addition, the solution immediately changed from red-orange to pale yellow. The solvent volume was reduced by $\sim 50 \%$ under vacuum. Acetonitrile $(1 \mathrm{~mL})$ was added. All volatiles were removed in vacuo. The crude solid was treated with $n$-pentane $(\sim 1 \mathrm{~mL})$, which was subsequently removed under vacuum to afford a fluffy yellow powder. The resulting product was dried in vacuo $(0.040 \mathrm{~g}, 92 \%) .{ }^{1} \mathrm{H} \mathrm{NMR}\left(\mathrm{CD}_{2} \mathrm{Cl}_{2}\right) \delta 8.79(\mathrm{~d}, 1 \mathrm{H}$, $\left.{ }^{3} J_{H H}=6 \mathrm{~Hz}, \mathrm{H}^{6}-\mathrm{t}^{\mathrm{b} p y}\right), 8.57\left(\mathrm{~d}, 1 \mathrm{H},{ }^{3} J_{H H}=6 \mathrm{~Hz}, \mathrm{H}^{6}-\mathrm{t}\right.$ bpy $), 8.10\left(\mathrm{~d}, 1 \mathrm{H},{ }^{4} J_{H H}=2 \mathrm{~Hz}, \mathrm{H}^{3}-\right.$ bpy), $8.07\left(\mathrm{~d}, 1 \mathrm{H},{ }^{4} J_{H H}=2 \mathrm{~Hz}, \mathrm{H}^{3}{ }^{\mathrm{t}}\right.$ bpy), $7.74\left[\mathrm{~s}, 8 \mathrm{H}, \mathrm{H}_{o}\left(\mathrm{Ar}^{\prime}\right)\right], 7.70\left(\mathrm{dd}, 1 \mathrm{H},{ }^{3} J_{H H}=6 \mathrm{~Hz}\right.$, ${ }^{4} J_{H H}=2 \mathrm{~Hz}, \mathrm{H}^{5}-{ }^{t}$ bpy $), 7.67\left(\mathrm{dd}, 1 \mathrm{H},{ }^{3} J_{H H}=6 \mathrm{~Hz},{ }^{4} J_{H H}=2 \mathrm{~Hz}, \mathrm{H}^{5}-{ }^{t}\right.$ bpy $), 7.57[\mathrm{~s}, 4 \mathrm{H}$, $\left.\mathrm{H}_{p}\left(\mathrm{Ar}^{\prime}\right)\right], 2.61$ (s, 3H, NCMe), 1.73 (q, 2H, ${ }^{3} J_{H H}=8 \mathrm{~Hz}, \mathrm{CH}_{2}$-Et), 1.45 (s, 9H, $t$-butyl bpy), 1.44 (s, 9H, $t$-butyl ${ }^{t}$ bpy), 1.00 (t, 3H, ${ }^{3} J_{H H}=8 \mathrm{~Hz}, \mathrm{CH}_{3}$-Et). ${ }^{13} \mathrm{C}$ NMR $(125 \mathrm{MHz}$, $\left.\mathrm{CD}_{2} \mathrm{Cl}_{2}\right) \delta 166.3,165.9,158.6,153.6,149.1,147.8,125.9,125.4,120.9,120.3$ ('bpy aromatic), 36.5 ( $t$-butyl, quaternary, ${ }^{t}$ bpy), 30.3 ( $t$-butyl- $\mathrm{CH}_{3}$, ${ }^{t}$ bpy, coincidental overlap), $16.7\left(\mathrm{NCCH}_{3}\right), 4.8\left(\mathrm{CH}_{2}-\mathrm{Et}\right), 1.8\left(\mathrm{CH}_{3}-\mathrm{Et}\right) ; 162.3\left(\mathrm{q}, \mathrm{Ar}^{\prime},{ }^{1} J_{\mathrm{B}-\mathrm{Cipso}}=49 \mathrm{~Hz}\right), 135.4\left(\mathrm{Ar}^{\prime}\right)$, $129.2\left(\mathrm{q}, m-\mathrm{Ar}^{\prime},{ }^{2} J_{\mathrm{C}-\mathrm{F}}=30 \mathrm{~Hz}\right), 125.2\left(\mathrm{q}, \mathrm{Ar},{ }^{2} J_{\mathrm{C}-\mathrm{F}}=272 \mathrm{~Hz}\right), 118.1\left(\mathrm{Ar}^{\prime}\right) .{ }^{19} \mathrm{~F}$ NMR $(282$ $\mathrm{MHz}, \mathrm{CD}_{2} \mathrm{Cl}_{2}$ ) $\delta-64.86$ (s, $\left.\mathrm{CF}_{3}-\mathrm{Ar}^{\prime}\right)$. Anal. calcd. for $\mathrm{PtBN}_{2} \mathrm{~F}_{24} \mathrm{C}_{60} \mathrm{H}_{41} \mathrm{D}_{3}(\%)$ : C 46.43, $\mathrm{H}$ 3.18, N 3.00; found: C 47.06, H 3.29, N 2.86.

Catalytic Olefin Hydrophenylation. A representative catalytic reaction is described. [('bpy) $\mathrm{Pt}(\mathrm{Ph})(\mathrm{THF})]\left[\mathrm{BAr}_{4}\right]$ (2.1) $(0.049 \mathrm{~g}, 0.033 \mathrm{mmol})$ was dissolved in $12.0 \mathrm{~mL}$ of 
benzene containing $0.025 \mathrm{~mol} \%$ hexamethylbenzene (HMB) relative to benzene as an internal standard. The reaction mixture was placed in a stainless steel pressure reactor, charged with ethylene, and heated to $100{ }^{\circ} \mathrm{C}$. After 4 and $16 \mathrm{hrs}$, the reaction mixture was cooled to room temperature and analyzed by GC/MS. Peak areas of the products and the internal standard were used to calculate product yields. Ethylbenzene production was quantified using linear regression analysis of gas chromatograms of standard samples. A set of five known standards were prepared consisting of 2:1, 3:1, 4:1, 5:1, and 6:1 molar ratios of ethylbenzene to hexamethylbenzene in benzene. A plot of the peak area ratios versus molar ratios gave a regression line. For the GC/MS system, the slope and correlation coefficient $\left(\mathrm{R}^{2}\right)$ for ethylbenzene were 0.53 and 0.98 , respectively. Identical procedures were used to quantify the production of 1,3-diethylbenzene, 1,4diethylbenzene and 1,2-diethylbenzene. The slope and correlation coefficients $\left(\mathrm{R}^{2}\right)$ for these species are $0.56,0.99 ; 0.56,0.99 ; 0.52,0.99$, respectively.

\section{Determination of Percent Yield for Catalytic Olefin Hydrophenylation. Complex}

$2.1(0.040 \mathrm{~g}, 0.027 \mathrm{mmol})$ was dissolved in $12.0 \mathrm{~mL}$ of benzene containing $0.02 \mathrm{~mol} \%$ HMB relative to benzene as an internal standard. The reaction mixture was placed inside a stainless steel pressure reactor with a gas burette $(300 \mathrm{~mL})$ attached. The burette was evacuated and backfilled with $\mathrm{N}_{2}$ (three times), evacuated, and pressurized with $\mathrm{C}_{2} \mathrm{H}_{4}$ (0.4 MPa). From the burette, the pressure reactor was charged with ethylene (0.03 MPa). The burette was then evacuated and backfilled with $\mathrm{N}_{2}$ (three times) and pressurized, along with the pressure reactor, with $\mathrm{N}_{2}(0.8 \mathrm{MPa})$. The solution was then heated for 4 hours at $120{ }^{\circ} \mathrm{C}$, cooled to room temperature, and analyzed by GC/MS. 


\section{Catalytic Olefin Hydrophenylation using $1: 1 \quad$ (v:v) $C_{6} H_{6}$ and $C_{6} D_{6}$.} [('bpy) Pt $\left.\left(\mathrm{NC}_{5} \mathrm{~F}_{5}\right)(\mathrm{Ph})\right]\left[\mathrm{BAr}_{4}\right]$ (2.2) $(0.009 \mathrm{~g}, 0.006 \mathrm{mmol})$ was dissolved in $2.0 \mathrm{~mL}$ of benzene $\left(1: 1 \mathrm{C}_{6} \mathrm{H}_{6}\right.$ and $\left.\mathrm{C}_{6} \mathrm{D}_{6}\right)$. The reaction mixture was placed in a stainless steel pressure reactor, charged with ethylene $(0.1 \mathrm{MPa})$, and heated to $100{ }^{\circ} \mathrm{C}$. After $16 \mathrm{hrs}$, the reaction mixture was cooled to room temperature and analyzed by GC/MS.

Catalytic Olefin Hydrophenylation as a Function of the Concentration of $\left[\left({ }^{t} \mathbf{b p y}\right) \mathbf{P t}(\mathbf{P h})(\mathbf{T H F})\right]\left[\mathbf{B A r}^{\prime}\right]$ (2.1). Solutions $(12 \mathrm{~mL})$ of benzene and $\mathbf{2 . 1}(0.001,0.005$, $0.01,0.015$, and $0.02 \mathrm{~mol} \%$ relative to benzene) containing equimolar amounts of HMB, relative to $\mathbf{2 . 1}$, were placed in stainless steel pressure reactors, charged with ethylene $(0.1$ $\mathrm{MPa}$ ), and heated to $100{ }^{\circ} \mathrm{C}$. After 30 minutes, the reaction mixture was cooled to room temperature and analyzed by GC/MS. Peak areas of the products and the internal standard were used to calculate product yields. Each reaction was performed in triplicate.

Catalytic Olefin Hydrophenylation as a Function of Benzene Concentration. A representative experiment is described. Complex $2.1(0.014 \mathrm{~g}, 0.010 \mathrm{mmol})$, benzene ( 8 $\mu \mathrm{L}$ ), and hexamethyldisilane (HMDS, $2 \mu \mathrm{L})$ were dissolved in $\mathrm{NC}_{5} \mathrm{~F}_{5}(292 \mu \mathrm{L})$. The reaction mixture was transferred to a J-Young NMR tube along with an insert tube containing acetone- $d_{6}$. The tube was purged and pressurized with ethylene $(0.1 \mathrm{MPa})$. An ${ }^{1} \mathrm{H}$ NMR spectrum was obtained, and the ethylene concentration was extracted after integration relative to HMDS. The solution was then heated at $100{ }^{\circ} \mathrm{C}$ for 2 hours, cooled to room temperature. An aliquot $(50 \mu \mathrm{L})$ of the reaction mixture and $\mathrm{HMB}(145 \mu \mathrm{L}$, $0.0104 \mathrm{M}$ in DCM) was dissolved in DCM $(2 \mathrm{~mL})$ and analyzed by GC/MS. Peak areas of the products and the internal standard were used to calculate product yields. 
Catalytic Olefin Hydrophenylation as a Function of Ethylene Concentration. A representative experiment is described. A solution of complex $2.1(0.01 \mathrm{~g}, 0.007 \mathrm{mmol})$ and $\mathrm{C}_{6} \mathrm{D}_{6}(2.45 \mathrm{~mL})$ containing $0.025 \mathrm{~mol} \% \mathrm{HMB}$ (relative to $\left.\mathrm{C}_{6} \mathrm{D}_{6}\right)$ was distributed $(0.4$ $\mathrm{mL}$ ) among six J-Young NMR tubes. The tubes were purged and pressurized with ethylene (0.3 MPa). The ethylene concentrations were determined after integration of the ethylene signal relative to HMB. The solutions were heated at $100{ }^{\circ} \mathrm{C}$ for 2 hours, cooled to room temperature, and analyzed by GC/MS.

Rate Law Derivations for the Catalytic Cycle. From kinetic and computational studies, two mechanisms by which $\left[{ }^{t}\right.$ bpy $\left.) \mathrm{Pt}(\mathrm{Ph})\right]^{+}$systems perform olefin hydroarylation have been proposed, and the rate laws for each have been derived using the King-Altman method. ${ }^{80}$ Benzene $\mathrm{C}-\mathrm{H}$ activation is considered rate limiting for both mechanisms. The rate law is not altered if steps following benzene $\mathrm{C}-\mathrm{H}$ activation are considered as rate limiting. In mechanism A, the catalyst resting state, $\left[\left({ }^{t} \text { bpy }\right) \mathrm{Pt}\left(\mathrm{CH}_{2} \mathrm{CH}_{2} \mathrm{Ph}\right)\left(\eta^{2}-\mathrm{C}_{2} \mathrm{H}_{4}\right)\right]^{+}$is incorporated into the catalytic cycle, and the coordination of benzene occurs through an associative process to yield $\left[\left({ }^{t} \mathrm{bpy}\right) \mathrm{Pt}\left(\mathrm{CH}_{2} \mathrm{CH}_{2} \mathrm{Ph}\right)\left(\eta^{2}-\mathrm{C}_{6} \mathrm{H}_{6}\right)\right]^{+}$. In mechanism B, the formation of the catalyst resting state removes $\mathrm{Pt}^{\mathrm{II}}$ from the catalytic cycle. Dissociation of ethylene allows for re-entry of $\mathrm{Pt}^{\mathrm{II}}$ into the cycle and is followed by the coordination of benzene to a three-coordinate intermediate, which precedes rate determining $\mathrm{C}-\mathrm{H}$ activation. 


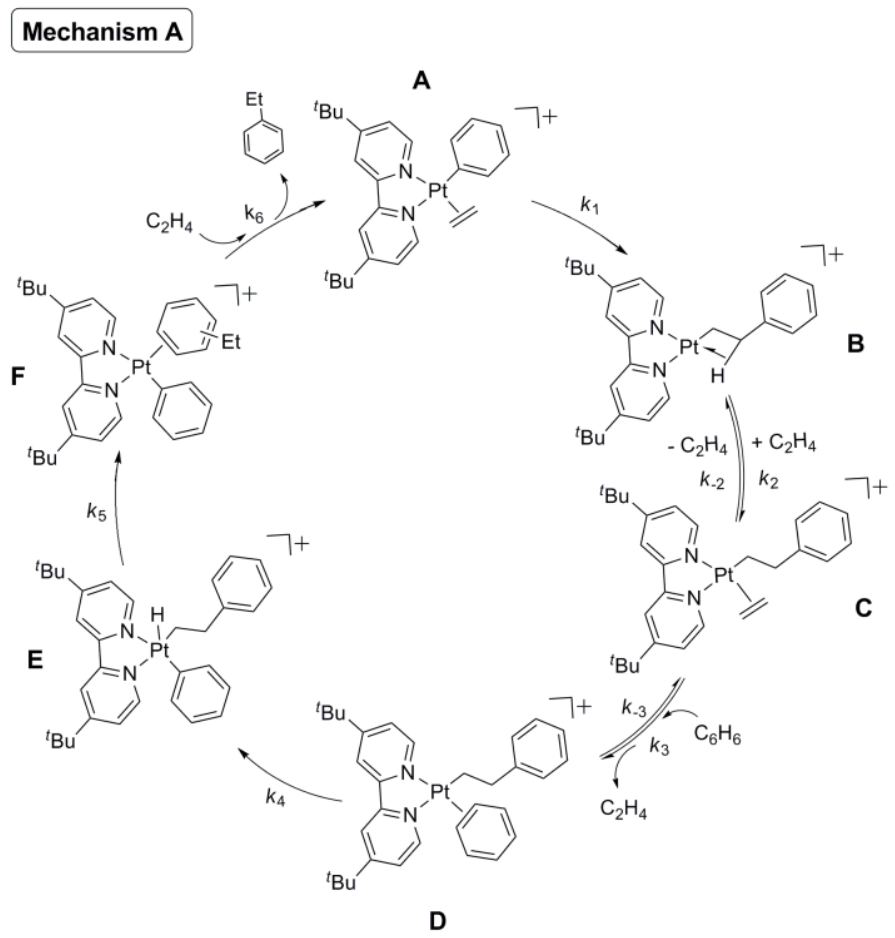

Open forms:

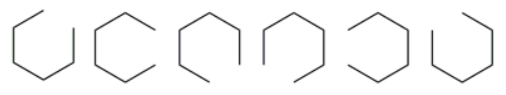

$[\mathbf{A}]=k_{2} k_{3} k_{4} k_{5} k_{6}\left[\mathrm{C}_{6} \mathrm{H}_{6}\right]\left[\mathrm{C}_{2} \mathrm{H}_{4}\right]^{2}$

$[\mathrm{B}]=k_{1} k_{3} k_{4} k_{5} k_{6}\left[\mathrm{C}_{6} \mathrm{H}_{6}\right]\left[\mathrm{C}_{2} \mathrm{H}_{4}\right]+k_{1} k_{-2} k_{4} k_{5} k_{6}\left[\mathrm{C}_{2} \mathrm{H}_{4}\right]+k_{1} k_{-2} k_{-3} k_{5} k_{6}\left[\mathrm{C}_{2} \mathrm{H}_{4}\right]$

$[\mathrm{C}]=k_{1} k_{2} k_{4} k_{5} k_{6}\left[\mathrm{C}_{2} \mathrm{H}_{4}\right]^{2}+k_{1} k_{2} k_{-3} k_{5} \mathrm{k}_{6}\left[\mathrm{C}_{2} \mathrm{H}_{4}\right]^{2}$

$[D]=k_{1} k_{2} k_{3} k_{5} k_{6}\left[\mathrm{C}_{6} \mathrm{H}_{6}\right]\left[\mathrm{C}_{2} \mathrm{H}_{4}\right]^{2}$

$[\mathrm{E}]=k_{1} k_{2} k_{3} k_{4} k_{6}\left[\mathrm{C}_{6} \mathrm{H}_{6}\right]\left[\mathrm{C}_{2} \mathrm{H}_{4}\right]^{2}$

$[\mathrm{F}]=k_{1} k_{2} k_{3} k_{4} k_{5}\left[\mathrm{C}_{6} \mathrm{H}_{6}\right]\left[\mathrm{C}_{2} \mathrm{H}_{4}\right]$

The total concentration of platinum equals the sum of each intermediate.

$[P t]_{t o t}=[A]+[B]+[C]+[D]+[E]+[F]$

$$
\frac{[\mathrm{Pt}]_{\text {tot }}}{[\mathrm{A}]+[\mathrm{B}]+[\mathrm{C}]+[\mathrm{D}]+[\mathrm{E}]+[\mathrm{F}]}=1
$$

Assuming step 4 is rate limiting

$$
\frac{\mathrm{d}[\mathrm{P}]}{\mathrm{dt}}=k_{4}[\mathrm{D}]=\frac{k_{4}[\mathrm{D}][\mathrm{Pt}]_{\mathrm{tot}}}{[\mathrm{A}]+[\mathrm{B}]+[\mathrm{C}]+[\mathrm{D}]+[\mathrm{E}]+[\mathrm{F}]}
$$




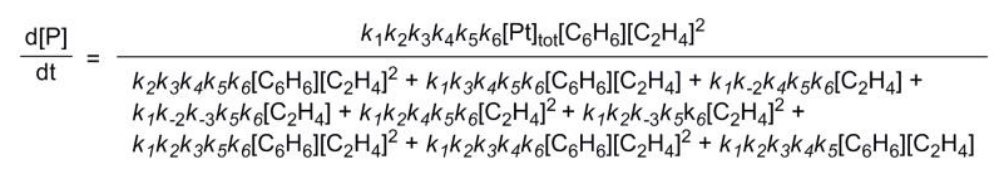

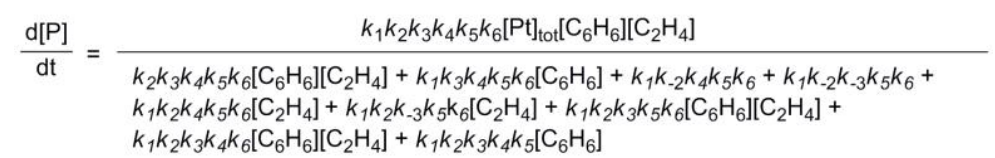

Saturation behavior is observed as the $\left[\mathrm{C}_{6} \mathrm{H}_{6}\right]$ is increased and catalysis is typically performed in neat $\mathrm{C}_{6} \mathrm{H}_{6}$, therefore the rate law can be further simplified.
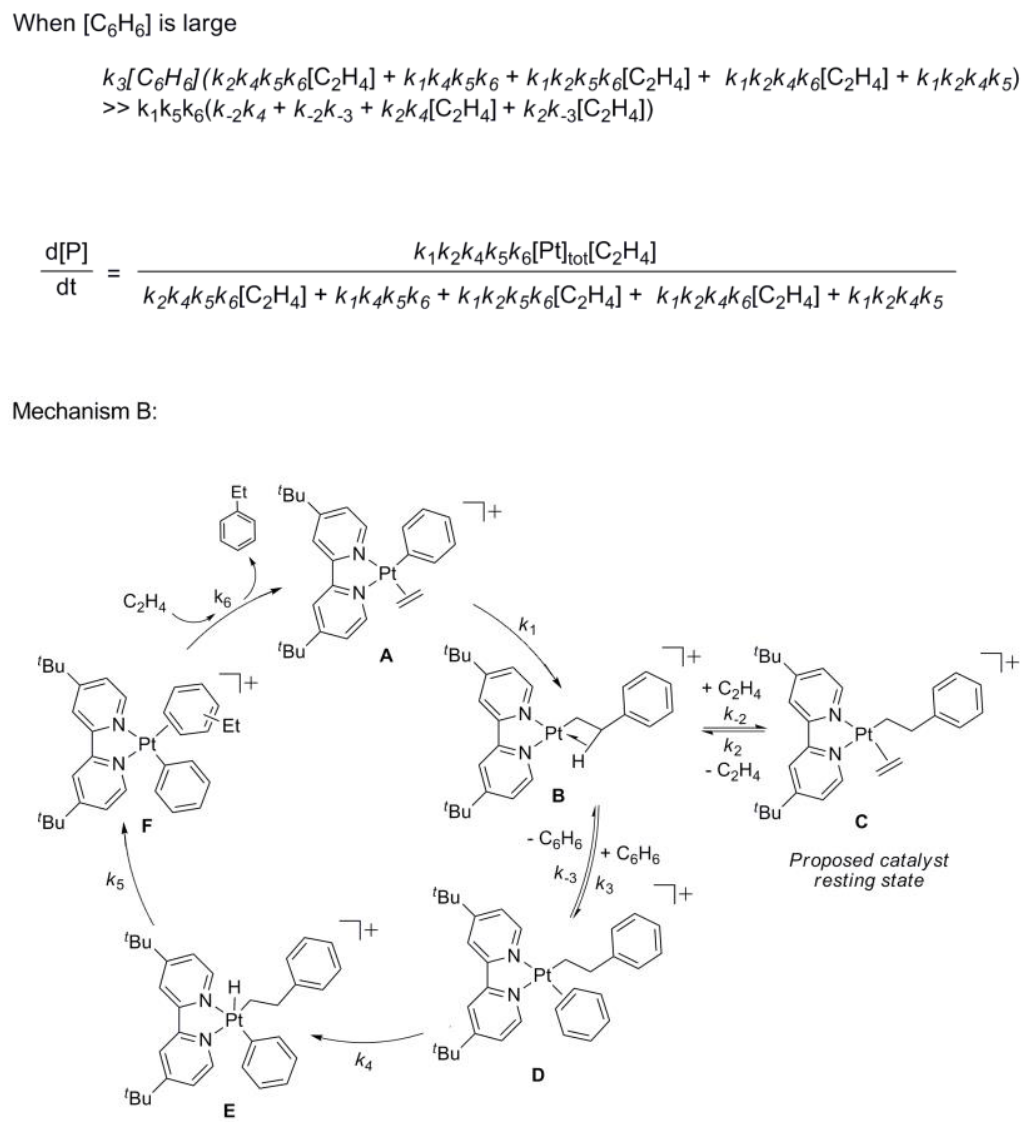
Open forms:

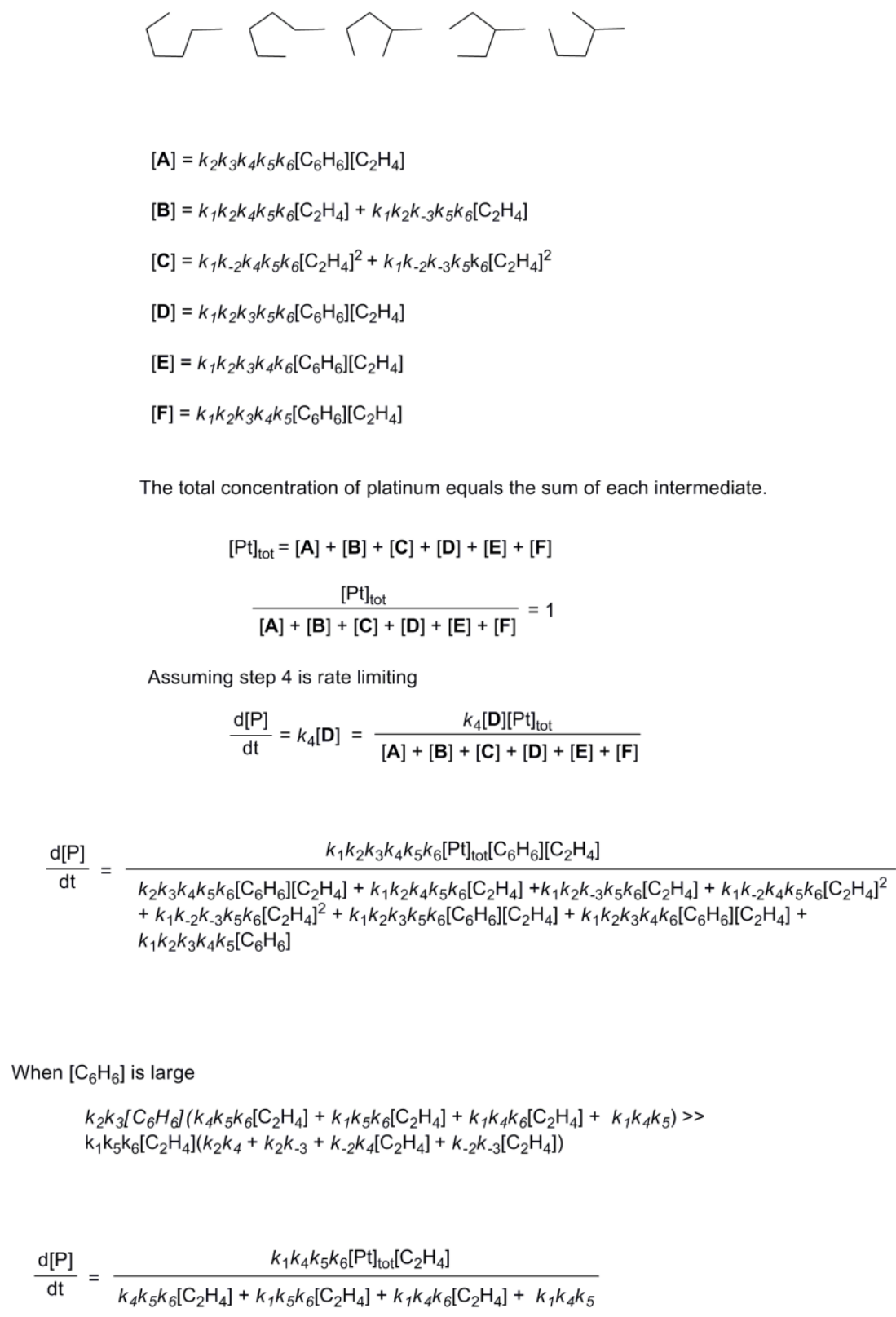

Kinetics of Ethylene Insertion. A representative kinetic experiment is described. Complex $2.1(0.060 \mathrm{~g}, 0.041 \mathrm{mmol})$ and HMDS $(5 \mu \mathrm{L})$, an internal standard, were dissolved in $1.3 \mathrm{~mL}$ of $\mathrm{CD}_{2} \mathrm{Cl}_{2}$. The solution was then divided ( $0.25 \mathrm{~mL}$ for each sample) 
and added to five high pressure NMR tubes. Each tube was degassed with a freeze-pumpthaw cycle, pressurized with $0.1 \mathrm{MPa}$ of ethylene, and cooled to $-78{ }^{\circ} \mathrm{C}$ until it was placed into a temperature equilibrated $\left(23{ }^{\circ} \mathrm{C}\right) \mathrm{NMR}$ probe. The temperature of the probe was determined using a sample of methanol- $d_{4}{ }^{81}$ The kinetic runs were performed in triplicate. The concentration of ethylene in solution was determined by integration against the internal standard. ${ }^{1} \mathrm{H}$ NMR spectra were collected every 2 minutes with 16 scans and a 2.0 second pulse delay. The product peaks were integrated against that of HMDS, and from a plot of $\ln \left(1-[2.4]_{t} /[2.1]_{\mathrm{o}}\right)$ vs. time (seconds), the rate constants were extracted. The rate of formation of complex 2.4, in the presence of $0.1(1) \mathrm{M} \mathrm{C}_{2} \mathrm{H}_{4}$, was $1.05(4) \times 10^{-3} \mathrm{~s}^{-1}$ with a correlation coefficient $\left(\mathrm{R}^{2}\right)$ of 0.99 for each plot.

Thermolysis of $\left[\left({ }^{t} \mathrm{bpy}\right) \mathrm{Pt}\left(\mathrm{CH}_{2} \mathrm{CH}_{2} \mathrm{Ph}\right)\left(\eta^{2}-\mathrm{C}_{2} \mathrm{H}_{4}\right)\right]\left[\mathrm{BAr}_{4}{ }_{4}\right](\mathbf{2 . 4})$ in $\mathrm{C}_{6} \mathrm{H}_{6}$. To a stainless steel pressure reactor, complex $2.4(0.016 \mathrm{~g}, 0.011 \mathrm{mmol})$ and $1 \mathrm{~mL}$ of benzene (containing $0.1 \mathrm{~mol} \% \mathrm{HMB}$ relative to benzene) were added. The reactor was sealed, pressurized with $0.9 \mathrm{MPa}$ of $\mathrm{N}_{2}$, and heated at $100{ }^{\circ} \mathrm{C}$ for 2 hours. At that time, the reactor was allowed to cool to room temperature. The reaction mixture was analyzed by GC/MS. Ethylbenzene was detected in 97\% yield along with $\sim 2 \%$ of 1,3-diethylbenzene (no evidence for 1,4- or 1,2-diethylbenzene formation was obtained).

Thermolysis of $\left[\left({ }^{t} \mathrm{bpy}\right) \operatorname{Pt}\left(\mathrm{CH}_{2} \mathrm{CH}_{2} \mathrm{Ph}\right)\left(\eta^{2}-\mathrm{C}_{2} \mathrm{H}_{4}\right)\right]\left[\mathrm{BAr}_{4}^{\prime}\right]$ (2.4) in $\mathrm{C}_{6} \mathrm{D}_{6}$. To a screwcap NMR tube, complex $2.4(0.014 \mathrm{~g}, 0.0094 \mathrm{mmol})$ and $0.5 \mathrm{~mL}$ of $\mathrm{C}_{6} \mathrm{D}_{6}$ were added. The reaction mixture was heated at $100{ }^{\circ} \mathrm{C}$ for 1 hour, and then analyzed using GC/MS.

Thermolysis of $\left[\left({ }^{t} \mathrm{bpy}\right) \operatorname{Pt}\left(\mathrm{CH}_{2} \mathrm{CH}_{2} \mathrm{Ph}\right)\left(\eta^{2}-\mathrm{C}_{2} \mathrm{H}_{4}\right)\right]\left[\mathrm{BAr}^{\prime}\right]$ (2.4) in $\mathrm{C}_{6} \mathrm{D}_{6}$ with added Lewis Base. To a screw-cap NMR tube, complex $2.4(0.020 \mathrm{~g}, 0.014 \mathrm{mmol}), 0.5 \mathrm{~mL}$ of 
$\mathrm{C}_{6} \mathrm{D}_{6}$, and tetrahydrofuran- $d_{8}$ (100 equivalents relative to $\mathbf{2 . 4}, 111 \mu \mathrm{L}$ ) were added. The reaction mixture was heated at $100{ }^{\circ} \mathrm{C}$ for $24 \mathrm{hrs}$, and analyzed via GC/MS.

Thermolysis of $\left[{ }^{t}\right.$ bpy) Pt $\left.\left(\mathrm{CH}_{2} \mathrm{CH}_{2} \mathrm{Ph}-\boldsymbol{d}_{5}\right)\left(\eta^{2}-\mathrm{C}_{2} \mathrm{H}_{4}\right)\right]\left[\mathrm{BAr}_{4}{ }_{4}\right]\left(\mathbf{2 . 4 - d _ { 5 } )}\right.$ in $\mathrm{C}_{6} \mathrm{D}_{6}$. To a screw-cap NMR tube, complex 2.4- $\boldsymbol{d}_{\mathbf{5}}(0.022 \mathrm{~g}, 0.015 \mathrm{mmol})$ and $0.5 \mathrm{~mL}$ of $\mathrm{C}_{6} \mathrm{D}_{6}$ were added, heated at $100{ }^{\circ} \mathrm{C}$ for 2 hours, and cooled to room temperature. The reaction mixture was analyzed by GC/MS

Thermolysis of $\left[\left({ }^{t}\right.\right.$ bpy)Pt $\left.\left(\mathrm{CH}_{2} \mathrm{CH}_{2} \mathrm{Ph}-\boldsymbol{d}_{5}\right)\left(\eta^{2}-\mathrm{C}_{2} \mathrm{H}_{4}\right)\right]\left[\mathrm{BAr}_{4}{ }_{4}\right]\left(\mathbf{2 . 4 - d _ { 5 } )}\right.$ in $\mathrm{C}_{6} \mathrm{H}_{6}$. To a screw-cap NMR tube, complex 2.4- $\boldsymbol{d}_{\mathbf{5}}(0.018 \mathrm{~g}, 0.012 \mathrm{mmol})$ and $0.5 \mathrm{~mL}$ of $\mathrm{C}_{6} \mathrm{H}_{6}$ were added, heated at $100{ }^{\circ} \mathrm{C}$ for 2 hours, and cooled to room temperature. The reaction mixture was analyzed by GC/MS.

Thermolysis of $\left[\left({ }^{t} \mathrm{bpy}\right) \operatorname{Pt}\left(\mathrm{CH}_{2} \mathrm{CH}_{2} \mathrm{Ph}-d_{5}\right)\left(\eta^{2}-\mathrm{C}_{2} \mathrm{H}_{4}\right)\right]\left[\mathrm{BAr}_{4}^{\prime}\right] \quad\left(2.4-d_{5}\right)$ in $\mathrm{C}_{6} \mathrm{D}_{6}$ with added Lewis Base. To a screw-cap NMR tube, complex 2.4-d5 (0.022 g, 0.015 mmol),

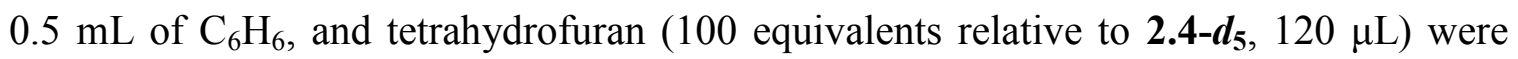
added. The reaction mixture was heated at $100^{\circ} \mathrm{C}$ for 2 hours, and analyzed via GC/MS.

\section{Variable Temperature ${ }^{1} \mathrm{H}$ NMR of $\left[\left({ }^{t}\right.\right.$ bpy $\left.) \operatorname{Pt}\left(\mathrm{CH}_{2} \mathrm{CH}_{2} \mathrm{Ph}\right)\left(\eta^{2}-\mathrm{C}_{2} \mathrm{H}_{4}\right)\right]\left[\mathrm{BAr}_{4}{ }_{4}\right] \quad$ (2.4).} A sample of $\left[\left({ }^{\prime} \mathrm{bpy}\right) \mathrm{Pt}\left(\mathrm{CH}_{2} \mathrm{CH}_{2} \mathrm{Ph}\right)\left(\eta^{2}-\mathrm{C}_{2} \mathrm{H}_{4}\right)\right]\left[\left(\mathrm{BAr}_{4}\right)\right]$ in $\mathrm{CD}_{2} \mathrm{Cl}_{2}$ was placed in a Varian $500 \mathrm{MHz}$ spectrometer. The temperature was cooled incrementally down to $-80{ }^{\circ} \mathrm{C}$, and ${ }^{1} \mathrm{H}$ NMR spectra were acquired after several minutes at each temperature to allow for equilibration. Temperatures were calibrated using a methanol- $d_{4}$ standard.

\section{Variable Temperature ${ }^{1} \mathrm{H}$ NMR of [ $\left({ }^{t}\right.$ bpy $\left.) \operatorname{Pt}\left(\mathrm{CH}_{2} \mathrm{CH}_{2} \mathrm{Ph}\right)\left(\eta^{2}-\mathrm{C}_{2} \mathrm{H}_{4}\right)\right]\left[\mathrm{BAr}_{4}{ }_{4}\right](2.4)$ in} the Presence of Free Ethylene. A ${ }^{1} \mathrm{H}$ NMR spectrum of a solution of 2.4 in $\mathrm{CD}_{2} \mathrm{Cl}_{2}$ with an internal HMB standard was acquired on a Varian $500 \mathrm{MHz}$ spectrometer. The solution 
was then charged with ethylene by bubbling into a screw-cap NMR tube. Acquisition of a

${ }^{1} \mathrm{H}$ NMR spectrum revealed a single coalesced resonance $(4.77 \mathrm{ppm})$ for coordinated and free ethylene. Cooling the NMR probe to $-90{ }^{\circ} \mathrm{C}$ did not result in decoalescence of the resonances.

\subsection{References}

1. Luedtke, A. T.; Goldberg, K. I., Angew. Chem. Int. Ed. 2008, 47, 7694-7696.

2. Oxgaard, J.; Periana, R. A.; Goddard III, W. A., J. Am. Chem. Soc. 2004, 126, $11658-11665$.

3. Oxgaard, J.; Muller, R. P.; Goddard III, W. A.; Periana, R. A., J. Am. Chem. Soc. 2004, 126, 352-363.

4. Foley, N. A.; Lee, J. P.; Ke, Z.; Gunnoe, T. B.; Cundari, T. R., Acc. Chem. Res. 2009, 42, 585-597.

5. Lail, M.; Bell, C. M.; Conner, D.; Cundari, T. R.; Gunnoe, T. B.; Petersen, J. L., Organometallics 2004, 23, 5007-5020.

6. Andreatta, J. R.; McKeown, B. A.; Gunnoe, T. B., J. Organomet. Chem. 2011, 696, 305-315.

7. Lail, M.; Arrowood, B. N.; Gunnoe, T. B., J. Am. Chem. Soc. 2003, 125, 75067507.

8. Foley, N. A.; Gunnoe, T. B.; Cundari, T. R.; Boyle, P. D.; Petersen, J. L., Angew. Chem. Int. Ed. 2007, 47, 726-730.

9. Foley, N. A.; Lail, M.; Lee, J. P.; Gunnoe, T. B.; Cundari, T. R.; Petersen, J. L., J. Am. Chem. Soc. 2007, 129, 6765-6781.

10. Foley, N. A.; Lail, M.; Gunnoe, T. B.; Cundari, T. R.; Boyle, P. D.; Petersen, J. L., Organometallics 2007, 26, 5507-5516.

11. Johansson, L.; Tilset, M.; Labinger, J. A.; Bercaw, J. E., J. Am. Chem. Soc. 2000, 122, 10846-10855. 
12. Zhong, H. A.; Labinger, J. A.; Bercaw, J. E., J. Am. Chem. Soc. 2002, 124, 13781399.

13. Heyduk, A. F.; Driver, T. G.; Labinger, J. A.; Bercaw, J. E., J. Am. Chem. Soc. 2004, 126, 15034-15035.

14. Wik, B. J.; Lersch, M.; Krivokapic, A.; Tilset, M., J. Am. Chem. Soc. 2006, 128, 2682-2696.

15. Zhang, F. B.; Kirby, C. W.; Hairsine, D. W.; Jennings, M. C.; Puddephatt, R. J., J. Am. Chem. Soc. 2005, 127, 14196-14197.

16. Reinartz, S.; White, P. S.; Brookhart, M.; Templeton, J. L., J. Am. Chem. Soc. 2001, 123, 12724-12725.

17. Wick, D. D.; Goldberg, K. I., J. Am. Chem. Soc. 1997, 119, 10235-10236.

18. Johansson, L.; Tilset, M., J. Am. Chem. Soc. 2001, 123, 739-740.

19. Johansson, L.; Ryan, O. B.; Romming, C.; Tilset, M., J. Am. Chem. Soc. 2001, 123, 6579-6590.

20. Lersch, M.; Tilset, M., Chem. Rev. 2005, 105, 2471-2526.

21. MacDonald, M. G.; Kostelansky, C. N.; White, P. S.; Templeton, J. L., Organometallics 2006, 25, 4560-4570.

22. Ong, C. M.; Jennings, M. C.; Puddephatt, R. J., Can. J. Chem. 2003, 81, 11961205.

23. Shiotsuki, M.; White, P. S.; Brookhart, M.; Templeton, J. L., J. Am. Chem. Soc. 2007, 129, 4058-4067.

24. Matsumoto, T.; Taube, D. J.; Periana, R. A.; Taube, H.; Yoshida, H., J. Am. Chem. Soc. 2000, 122, 7414-7415.

25. Cucciolito, M. E.; D'Amora, A.; Tuzi, A.; Vitagliano, A., Organometallics 2007, $26,5216-5223$.

26. Bowring, M. A.; Bergman, R. G.; Tilley, T. D., Organometallics 2011, 30, $1295-$ 1298.

27. Chen, G. S.; Labinger, J. A.; Bercaw, J. E., Proc. Natl. Acad. Sci. 2007, 104, 6915-6920. 
28. Owen, J. S.; Labinger, J. A.; Bercaw, J. E., J. Am. Chem. Soc. 2006, 128, 20052016.

29. Shilov, A. E.; Shul'pin, G. B., Chem. Rev. 1997, 97, 2879-2932.

30. Shilov, A. E.; Shul'pin, G. B., Activation and Catalytic Reactions of Saturated Hydrocarbons in the Presence of Metal Complexes. Kluwer Academic Publishers: New York, 2002.

31. Li, J.-L.; Geng, C.-Y.; Huang, X.-R.; Zhang, X.; Sun, C.-C., Organometallics 2007, 26, 2203-2210.

32. Stahl, S. S.; Labinger, J. A.; Bercaw, J. E., J. Am. Chem. Soc. 1996, 118, 59615976.

33. Wik, B. J.; Lersch, M.; Tilset, M., J. Am. Chem. Soc. 2002, 124, 12116-12117.

34. Hill, G. S.; Rendina, L. M.; Puddephatt, R. J., Organometallics 1995, 14, 49664968.

35. Driver, T. G.; Day, M. W.; Labinger, J. A.; Bercaw, J. E., Organometallics 2005, $24,3644-3654$.

36. Parmene, J.; Ivanovic-Burmazovic, I.; Tilset, M.; van Eldik, R., Inorg. Chem. 2009, 48, 9092-9103.

37. Oxgaard, J.; Tenn, I., W. J.; Nielson, R. J.; Periana, R. A.; Goddard III, W. A., Organometallics 2007, 26, 1565-1567.

38. Boutadla, Y.; Davies, D. L.; Macgregor, S. A.; Poblador-Bahamonde, A. I., J. Chem. Soc., Dalton Trans. 2009, 5820-5831.

39. Perutz, R. N.; Sabo-Etienne, S., Angew. Chem. Int. Ed. 2007, 46, 2578-2592.

40. Vastine, B. A.; Hall, M. B., J. Am. Chem. Soc. 2007, 129, 12068-12069.

41. Lam, W. H.; Jia, G.; Lin, Z.; Lau, C. P.; Eisenstein, O., Chem. Eur. J. 2003, 9, 2775-2782.

42. Feng, Y.; Lail, M.; Foley, N. A.; Gunnoe, T. B.; Barakat, K. A.; Cundari, T. R.; Petersen, J. L., J. Am. Chem. Soc. 2006, 128, 7982-7994.

43. DeYonker, N. J.; Foley, N. A.; Cundari, T. R.; Gunnoe, T. B.; Petersen, J. L., Organometallics 2007, 26, 6604-6611. 
44. Becke, A. D., J. Chem. Phys. 1993, 98, 5648-5652.

45. Becke, A. D., J. Chem. Phys. 1993, 98, 1372-1377.

46. Miehlich, B.; Savin, A.; Stoll, H.; Heinzwerner, P., Chem. Phys. Lett. 1989, 157, 200-206.

47. Cundari, T. R.; Stevens, W. J., J. Chem. Phys. 1993, 98, 5555-5565.

48. Lee, C.; Yang, W.; Parr, R. G., Phys. Rev., B 1988, 37, 785-789.

49. Stevens, W. J.; Basch, H.; Krauss, M., J. Chem. Phys. 1984, 81, 6026-6033.

50. Stevens, W. J.; Krauss, M.; Basch, H.; Jasien, P. G., Can. J. Chem. 1992, 70, 610613.

51. Campbell, A. N.; Gagne, M. R., Organometallics 2007, 26, 2788-2790.

52. Nakata, N.; Fukazawa, S.; Ishii, A., Organometallics 2009, 28, 534-538.

53. Fusto, M.; Giordano, F.; Orabona, I.; Ruffo, F.; Panunzi, A., Organometallics 1997, 16, 5981-5987.

54. Herzberg, G., Electronic spectra and electronic structure of polyatomic molecules. Van Nostrand: New York, 1966.

55. Ittel, S. D.; Johnson, L. K.; Brookhart, M., Chem. Rev. 2000, 100, 1169-1204.

56. Albano, V. G.; Demartin, F.; De Renzi, A.; Morelli, G.; Saporito, A., Inorg. Chem. 1985, 24, 2032-2039.

57. Cucciolito, M. E.; De Felice, V.; Panunzi, A.; Vitagliano, A., Organometallics 1989, 8, 1180-1187.

58. De Renzi, A.; Di Blasio, B.; Saporito, A.; Scalone, M.; Vitagliano, A., Inorg. Chem. 1980, 19, 960-966.

59. De Felice, V.; Cucciolito, M. E.; De Renzi, A.; Ruffo, F.; Tesauro, D., J. Organomet. Chem. 1995, 493, 1-11.

60. De Felice, V.; De Renzi, A.; Tesauro, D.; Vitagliano, A., Organometallics 1992, 11, 3669-3676.

61. Albano, V. G.; Braga, D.; De Felice, V.; Panunzi, A.; Vitagliano, A., Organometallics 1987, 6, 517-525. 
62. Cucciolito, M. E.; De Renzi, A.; Orabona, I.; Ruffo, F.; Tesauro, D., J. Chem. Soc., Dalton Trans. 1998, 1675-1678.

63. Ganis, P.; Orabona, I.; Ruffo, F.; Vitagliano, A., Organometallics 1998, 17, 26462650.

64. De Felice, V.; De Renzi, A.; Tesauro, D.; Vitagliano, A., Organometallics 1992, $11,3669-3676$.

65. Plutino, M. R.; Fenech, L.; Stoccoro, S.; Rizzato, S.; Castellano, C.; Albinati, A., Inorg. Chem. 2010, 49, 407-418.

66. Crabtree, R. H.; Mellea, M. F.; Quirk, J. M., J. Am. Chem. Soc. 1984, 106, 29132917.

67. Garnett, J. L.; West, J. C., Aust. J. Chem. 1974, 27, 129-142.

68. Olah, G. A.; Molnar, A., Hydrocarbon Chemistry. Wiley-Interscience: New York, 1995.

69. Bernskoetter, W. H.; Schauer, C. K.; Goldberg, K.; Brookhart, M., Science 2009, 326, 553-556.

70. Jensen, M. P.; Wick, D. D.; Reinartz, S.; White, P. S.; Templeton, J. L.; Goldberg, K. I., J. Am. Chem. Soc. 2003, 125, 8614-8624.

71. Lo, H. C.; Haskel, A.; Kapon, M.; Keinan, E., J. Am. Chem. Soc. 2002, 124, 3226-3228.

72. Jones, W. D., Acc. Chem. Res. 2003, 36, 140-146.

73. Brookhart, M.; Grant, B.; Volpe, A. F., Organometallics 2002, 11, 3920-3922.

74. Tanko, J. M.; Drumright, R. E., J. Am. Chem. Soc. 2002, 114, 1844-1854.

75. Clark, H. C.; Manzer, L. E., J. Organomet. Chem. 1973, 59, 411-428.

76. Barone, V.; Cossi, M.; Tomasi, J., J. Comput. Chem. 1998, 19, 404-417.

77. Barone, V.; Cossi, M., J. Phys. Chem. A 1998, 102, 1995-2001.

78. Cossi, M.; Rega, N.; Scalmani, G.; Barone, V., J. Comput. Chem. 2003, 24, 669681. 
79. Frisch, M. J., et al., Gaussian 03, Revision C.02. 2003.

80. King, E. L.; Altman, C., J. Phys. Chem. 1956, 60, 1375-1378.

81. Albeniz, A. C.; Espinet, P., J. Organomet. Chem. 1993, 452, 229-234. 


\section{Control of Olefin Hydroarylation Catalysis via a Sterically and Electronically Flexible Pt ${ }^{\text {II }}$ Catalyst Scaffold}

The proposed mechanism for cationic $\mathrm{Pt}^{\mathrm{II}}$ catalyzed ethylene hydrophenylation, based on detailed studies of $\left.\left[{ }^{\mathrm{t}} \mathrm{bpy}\right) \mathrm{Pt}(\mathrm{Ph})(\mathrm{THF})\right]\left[\mathrm{BAr}_{4}\right]$ (3.2b), is summarized in Scheme 3.1. ${ }^{1}$ Substitution of the THF ligand with ethylene initiates the cycle and is followed by ethylene insertion into the $\mathrm{Pt}-\mathrm{Ph}$ bond. After ethylene insertion, another equivalent of ethylene coordinates to form the catalyst resting state $\left[(\mathrm{bpy}) \mathrm{Pt}\left(\mathrm{CH}_{2} \mathrm{CH}_{2} \mathrm{Ph}\right)\left(\eta^{2}-\mathrm{C}_{2} \mathrm{H}_{4}\right)\right]^{+}$, which has been observed during catalysis by ${ }^{1} \mathrm{H}$ NMR spectroscopy and independently synthesized. Displacement of ethylene by benzene and rate-limiting $\mathrm{C}-\mathrm{H}$ activation result in the formation of $\left[(\mathrm{N} \sim \mathrm{N}) \mathrm{Pt}\left(\eta^{2}-C, C-\mathrm{C}_{6} \mathrm{H}_{5} \mathrm{Et}\right)(\mathrm{Ph})\right]^{+}$. Studies could not differentiate between associative or dissociative exchange of coordinated ethylene with benzene. ${ }^{1}$ Calculations for the ${ }^{\mathrm{t}}$ bpy-Pt complex suggest that benzene $\mathrm{C}-\mathrm{H}$ activation occurs by

oxidative addition to form a $\mathrm{Pt}^{\mathrm{IV}}$ intermediate. ${ }^{1}$ Exchange of ethylbenzene with ethylene completes the catalytic cycle. 


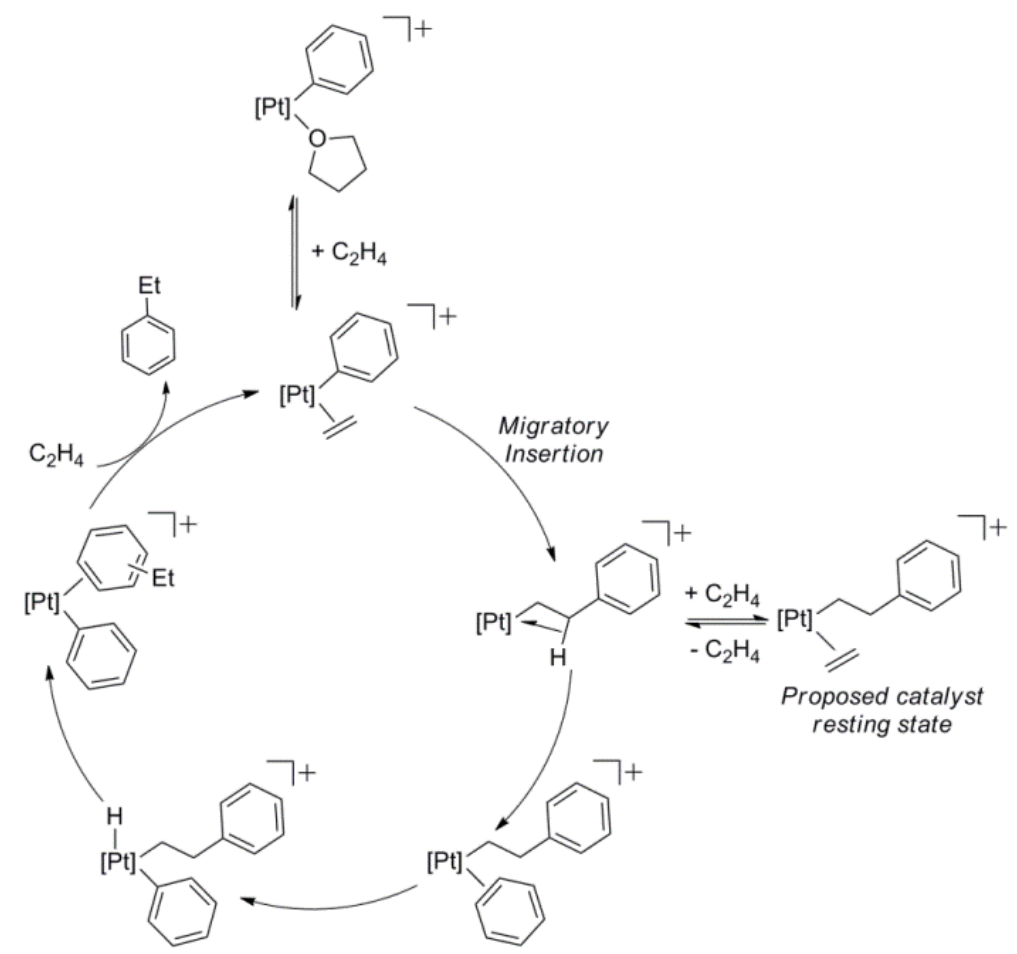

Scheme 3.1. Proposed catalytic cycle for cationic $\mathrm{Pt}^{\mathrm{II}}$ catalyzed ethylene hydrophenylation.

The development of cationic $\mathrm{Pt}^{\mathrm{II}}$ catalysts for olefin hydroarylation presents several challenges, such as selectivity for mono- versus poly-alkylation (starting from unsubstituted aromatic substrates), regioselective $\mathrm{C}-\mathrm{H}$ activation of substituted aromatic substrates, and selectivity for alkyl versus vinyl arene production. Despite these obstacles, few detailed structure/activity studies that could guide new catalyst design exist. $^{1-3}$ In order to design improved catalysts, it is important to understand how modifications to the transition metal complex influence these various selectivities.

Herein, the influence of ligand electron-donor ability on catalytic ethylene hydrophenylation by variation of the 4,4'-substituents of the 2,2'-bipyridyl ligand is investigated. In addition, $\mathrm{Pt}^{\mathrm{II}}$ complexes possessing increased steric congestion around 
the metal center are studied. It was posited that increased sterics might facilitate ethylbenzene displacement and provide increased selectivity for monoalkylated products.

\subsection{Bipyridine as an Electronically Tunable Ligand for the Platinum Catalyzed Synthesis of Alkylbenzenes}

In some cases, saturated alkyl arenes are desired while vinyl arenes are preferred for some applications. For transition metal catalyzed olefin hydroarylation, the selectivity for

vinyl arene (Pathway A) versus alkyl arene (Pathway B) formation is presumably controlled by relative kinetics of the steps shown in Scheme 3.2, and understanding how to use ligand modification to switch catalyst selectivity is a potentially important feature. Moreover, the formation of vinyl arenes likely involves $\beta$-hydride elimination, which is a plausible decomposition route for some catalysts that mediate alkyl arene synthesis.

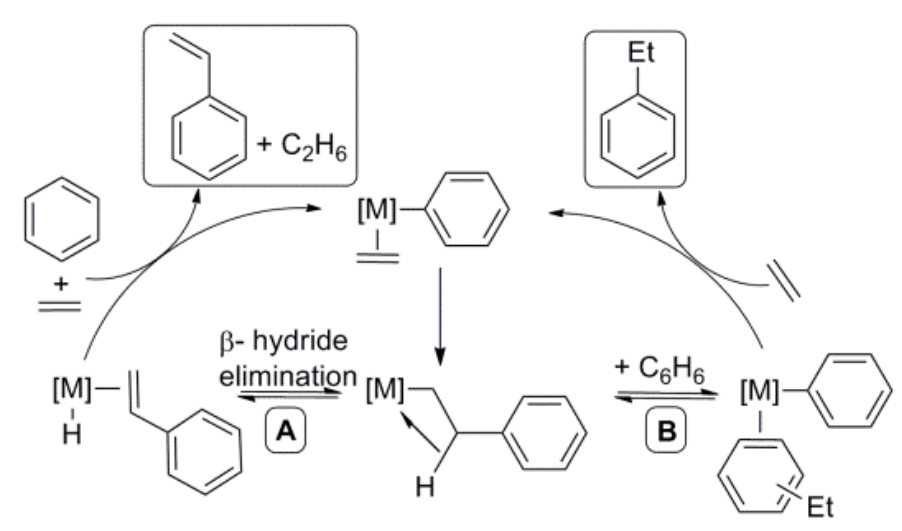

Scheme 3.2. The selectivity of alkyl arenes versus vinyl arenes (ethylbenzene versus styrene in this scheme) during catalytic ethylene hydrophenylation is likely controlled by the relative kinetics of divergent pathways (A and $\mathbf{B}$ ) that follow olefin insertion. 


\subsubsection{Synthesis of Pt Complexes and Probing Elementary Steps of Ethylene Hydrophenylation}

The bipyridyl ligand is easily modified to determine the impact of ligand donor ability on catalysis without altering the catalyst's steric profile. The complexes $\left[\left({ }^{\mathrm{x}} \mathrm{bpy}\right) \mathrm{Pt}(\mathrm{Ph})(\mathrm{THF})\right]\left[\mathrm{BAr}_{4}\right]\left[{ }^{\mathrm{x}} \mathrm{bpy}=4,4\right.$ '-X-2,2'-bipyridyl, $\mathrm{X}=\mathrm{OMe}(\mathbf{3 . 2 a}),{ }^{\mathrm{t}} \mathrm{Bu}(\mathbf{3 . 2 b}), \mathrm{H}$ (3.2c), $\mathrm{Br}(\mathbf{3 . 2 d}), \mathrm{CO}_{2} \mathrm{Et}(\mathbf{3 . 2 e}), \mathrm{NO}_{2}(\mathbf{3 . 2 f}) ; \mathrm{Ar}^{\prime}=3$, 5-bis(trifluoromethyl)phenyl] were prepared by protonation of the respective diphenyl complexes (3.1a-3.1f) in THF at -70 ${ }^{\circ} \mathrm{C}$ (Scheme 3.3 and Figure 3.1-Figure 3.5). A crystal of complex 3.2d suitable for an Xray diffraction study was grown (Figure 3.6). The N1-Pt-N2 bond angle is compressed to $79.4(2)^{\circ}$ relative to the ideal $90^{\circ}$ bond angles for a square planar complex, which is

characteristic of $\mathrm{Pt}^{\mathrm{II}}$ bipyridyl and diimine complexes. ${ }^{4-6}$ The $\mathrm{Pt}-\mathrm{N} 1$ bond is $0.08 \AA$ shorter than the Pt-N2 bond, indicative of a greater trans influence of the phenyl ligand relative to THF. Significant disorder exists for the THF ligand in the refined structure.

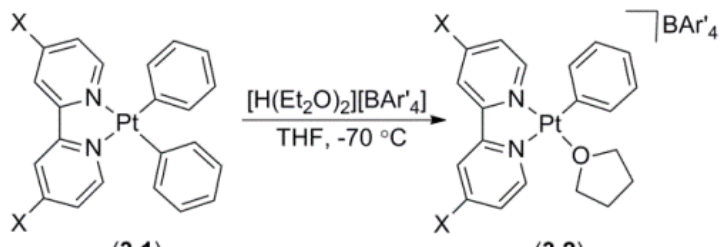

(3.1)

(3.2)

$X=$ OMe $(3.1 \mathrm{a}, 3.2 \mathrm{a}) \quad 80 \%$ isolated yield

${ }^{t} \mathrm{Bu} \quad(\mathbf{3 . 1 b}, \mathbf{3 . 2 b}) \quad 93 \%$ isolated yield

H (3.1c, 3.2c) $89 \%$ isolated yield

$\mathrm{Br}$ (3.1d, 3.2d) $94 \%$ isolated yield

$\mathrm{CO}_{2} \mathrm{Et}(3.1 \mathrm{e}, 3.2 \mathrm{e}) \quad 86 \%$ isolated yield

$\mathrm{NO}_{2} \quad$ (3.1f, 3.2f) $92 \%$ isolated yield

Scheme 3.3. Synthesis of $\left[\left({ }^{\mathrm{x}} \mathrm{bpy}\right) \mathrm{Pt}(\mathrm{Ph})(\mathrm{THF})\right]\left[\mathrm{BAr}_{4}{ }_{4}\right]$. 


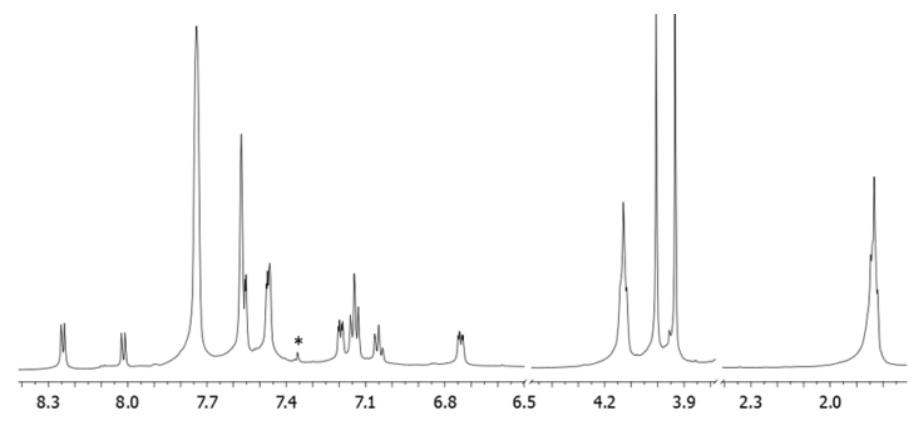

Figure 3.1. ${ }^{1} \mathrm{H}$ NMR spectrum of $\left[\left({ }^{\mathrm{m}} \mathrm{bpy}\right) \mathrm{Pt}(\mathrm{Ph})(\mathrm{THF})\right]\left[\mathrm{BAr}_{4}{ }_{4}\right]\left({ }^{\mathrm{m}} \mathrm{bpy}=4,4{ }^{\prime}-(\mathrm{OMe})_{2}-2,2{ }^{\prime}-\right.$ bipyridyl; 3.2a) in $\mathrm{CD}_{2} \mathrm{Cl}_{2}$ at room temperature. Trace solvents $(*)$ are indicated.

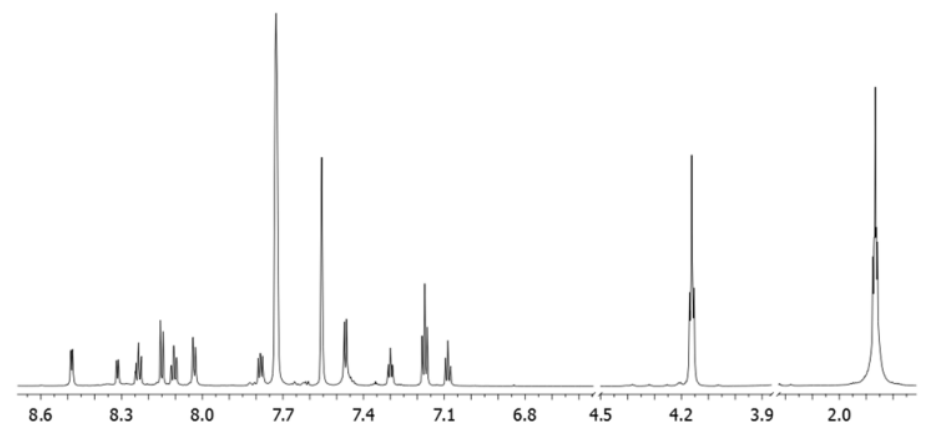

Figure 3.2. ${ }^{1} \mathrm{H}$ NMR spectrum of $[(\mathrm{bpy}) \mathrm{Pt}(\mathrm{Ph})(\mathrm{THF})]\left[\mathrm{BAr}_{4}{ }_{4}\right]\left(\mathrm{bpy}=2,2^{\prime}\right.$-bipyridyl; 3.2c) in $\mathrm{CD}_{2} \mathrm{Cl}_{2}$ at room temperature.

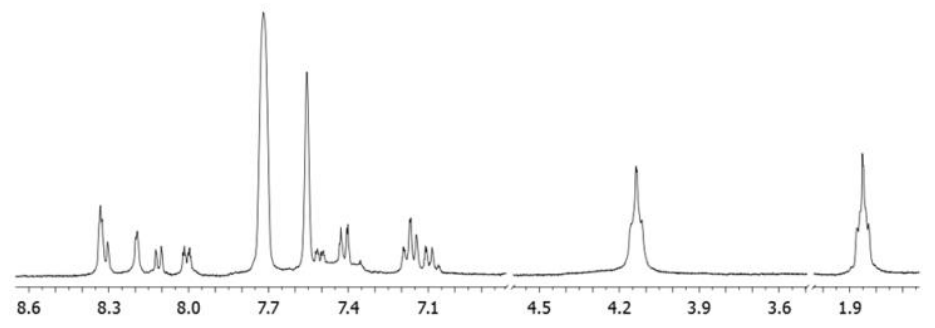

Figure 3.3. ${ }^{1} \mathrm{H}$ NMR spectrum of $\left[\left({ }^{\mathrm{Br}} \mathrm{bpy}\right) \mathrm{Pt}(\mathrm{Ph})(\mathrm{THF})\right]\left[\mathrm{BAr}_{4}^{\prime}\right]\left({ }^{\mathrm{Br}} \mathrm{bpy}=4,4{ }^{\prime}-\mathrm{Br}_{2}-2,2^{\prime}-\right.$ bipyridyl; 3.2d) in $\mathrm{CD}_{2} \mathrm{Cl}_{2}$ at room temperature. 


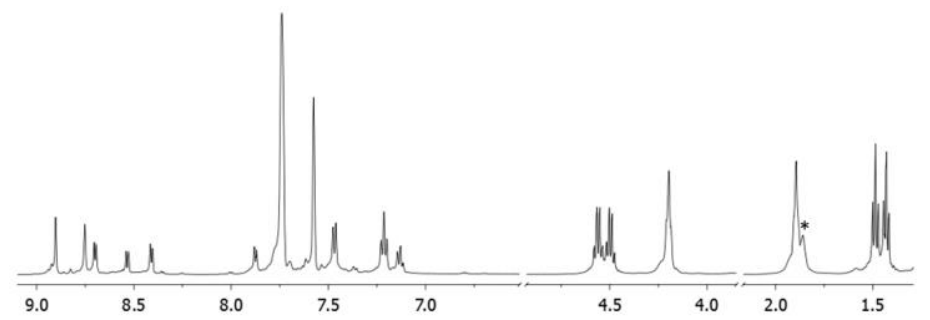

Figure 3.4. ${ }^{1} \mathrm{H}$ NMR spectrum of $\left[\left({ }^{\mathrm{c}} \mathrm{bpy}\right) \mathrm{Pt}(\mathrm{Ph})(\mathrm{THF})\right]\left[\mathrm{BAr}_{4}^{\prime}\right]\left({ }^{\mathrm{c}} \mathrm{bpy}=4,4{ }^{\prime}-\left(\mathrm{CO}_{2} \mathrm{Et}\right)_{2}-2,2^{\prime}-\right.$ bipyridyl; 3.2e) in $\mathrm{CD}_{2} \mathrm{Cl}_{2}$ at room temperature. Trace solvents $(*)$ are indicated.

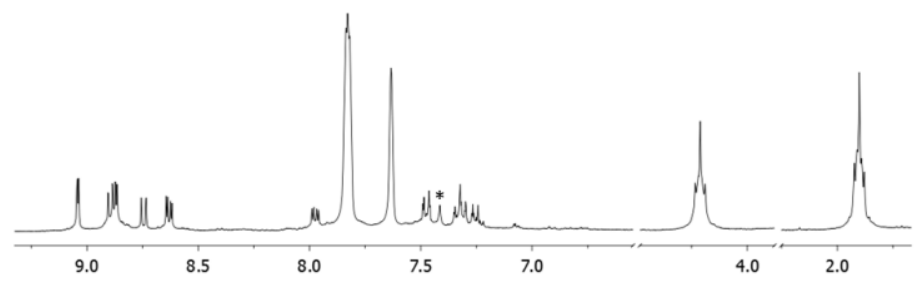

Figure 3.5. ${ }^{1} \mathrm{H}$ NMR spectrum of $\left[\left({ }^{\mathrm{NO} 2} \mathrm{bpy}\right) \mathrm{Pt}(\mathrm{Ph})(\mathrm{THF})\right]\left[\mathrm{BAr}_{4}^{\prime}\right]\left({ }^{\mathrm{c}} \mathrm{bpy}=4,4{ }^{\prime}-\left(\mathrm{NO}_{2}\right)_{2}-2,2^{\prime}-\right.$ bipyridyl; 3.2f) in $\mathrm{CD}_{2} \mathrm{Cl}_{2}$ at room temperature. Trace solvents $(*)$ are indicated.

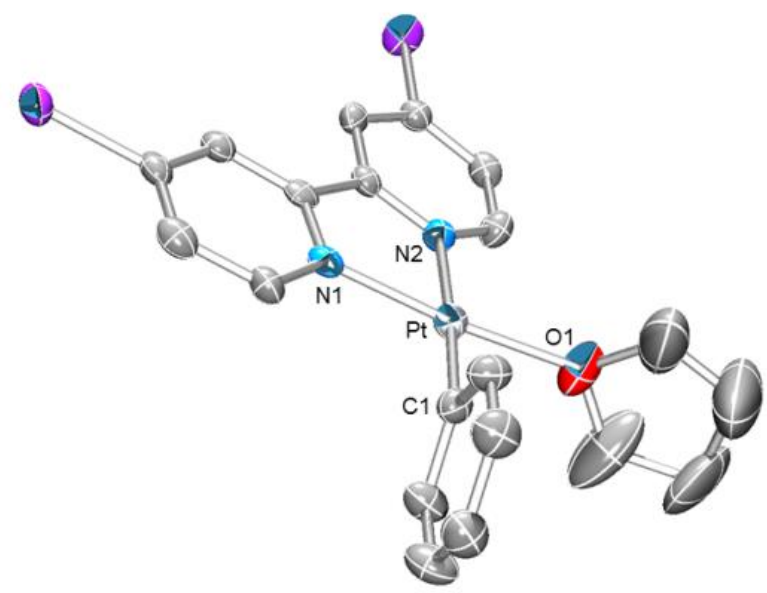

Figure 3.6. ORTEP of $\left[\left({ }^{\mathrm{Br}} \mathrm{bpy}\right) \mathrm{Pt}(\mathrm{Ph})(\mathrm{THF})\right]\left[\mathrm{BAr}_{4}{ }_{4}\right]$ (3.2d) (30\% probability; $\mathrm{H}$ atoms and $\mathrm{BAr}_{4}{ }_{4}$ anion omitted for clarity). Selected bond lengths $(\AA)$ : Pt-N1 1.998(6), Pt-N2 2.075(6), Pt-O1 2.060(7), Pt-C1 2.014(8). Selected bond angles ( $\left.{ }^{\circ}\right)$ : N1-Pt-N2 79.4(2), C1-Pt-O1 89.4(3). 
The influence of 4/4'-substituents on the individual steps of catalytic ethylene hydrophenylation (i.e., ethylene insertion into the $\mathrm{Pt}-\mathrm{Ph}$ bond and benzene $\mathrm{C}-\mathrm{H}$ activation) was studied. Ethylene readily inserts into the $\mathrm{Pt}-\mathrm{Ph}$ bond of $\mathbf{3 . 2 b}$ to form $\left[\left({ }^{\mathrm{b}} \mathrm{bpy}\right) \mathrm{Pt}\left(\mathrm{CH}_{2} \mathrm{CH}_{2} \mathrm{Ph}\right)\left(\eta^{2}-\mathrm{C}_{2} \mathrm{H}_{4}\right)\right]\left[\mathrm{BAr}_{4}^{\prime}\right]$ (3.3b). Under pseudo first-order conditions, the conversion of 3.2b to $\mathbf{3 . 3 b}$ in $\mathrm{CD}_{2} \mathrm{Cl}_{2}$ at $23{ }^{\circ} \mathrm{C}$ in the presence of $0.3 \mathrm{M} \mathrm{C}_{2} \mathrm{H}_{4}$ proceeded with an observed rate constant of $1.46 \times 10^{-3} \mathrm{~s}^{-1}$. Ethylene insertion into the $\mathrm{Pt}-\mathrm{Ph}$ bond using $\left[\left({ }^{\mathrm{NO} 2}\right.\right.$ bpy $\left.) \mathrm{Pt}(\mathrm{Ph})(\mathrm{THF})\right]\left[\mathrm{BAr}_{4}\right] \quad$ (3.2f) to form $\left[\left({ }^{\mathrm{NO} 2}\right.\right.$ bpy $) \mathrm{Pt}\left(\mathrm{CH}_{2} \mathrm{CH}_{2} \mathrm{Ph}\right)\left(\eta^{2}-\right.$ $\left.\left.\mathrm{C}_{2} \mathrm{H}_{4}\right)\right]\left[\mathrm{BAr}_{4}\right]$ under identical conditions was too rapid for accurate measurement by ${ }^{1} \mathrm{H}$ NMR spectroscopy. Performing the reaction at $-15{ }^{\circ} \mathrm{C}$ with $0.1 \mathrm{M} \mathrm{C}_{2} \mathrm{H}_{4}$ provided an observed rate constant of 5.1(3) x $10^{-4} \mathrm{~s}^{-1}$ for the conversion of 3.2f to 3.3f (Figure 3.7). At this temperature, the observed rate of ethylene insertion for $\mathbf{3 . 2 f}$ is much faster than 3.2b $\left(k_{\mathrm{obs}}=8.9(2) \times 10^{-6} \mathrm{~s}^{-1}\right)$ under similar conditions by a factor of $\sim 60$ (Scheme 3.4).

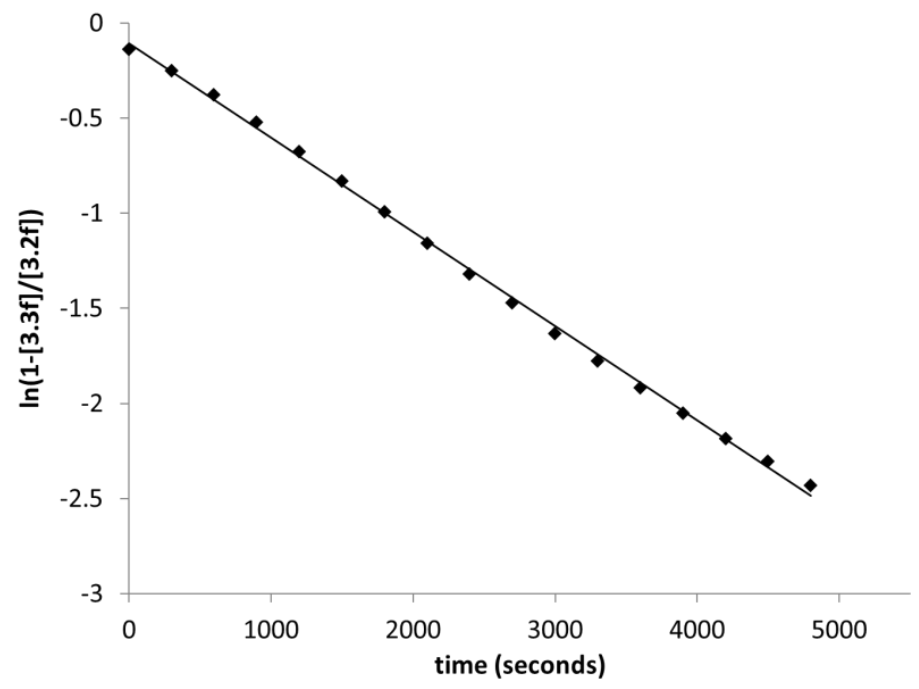

Figure 3.7. Representative kinetic plot for the conversion of $\mathbf{3 . 2 f}$ to $\mathbf{3 . 3 f}([\mathbf{3 . 2 f}]=0.03 \mathrm{M}$, $\left.\left[\mathrm{C}_{2} \mathrm{H}_{4}\right]=0.1 \mathrm{M},-15^{\circ} \mathrm{C}\right)$. 


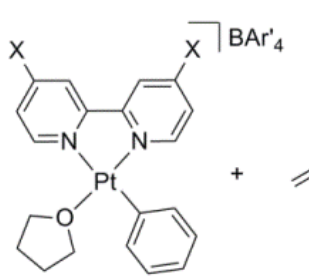

(3.2)

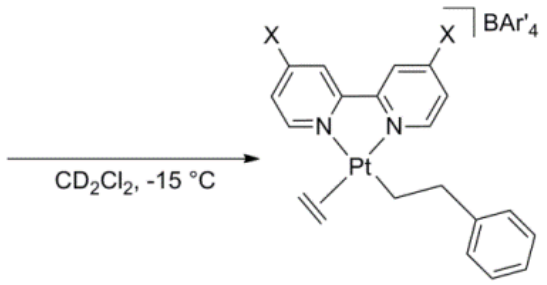

(3.3)

$$
\begin{array}{ccl}
\mathrm{X} & k_{\mathrm{obs}}\left(\times 10^{-4} \mathrm{~s}^{-1}\right) & {\left[\mathrm{C}_{2} \mathrm{H}_{4}\right]} \\
\hline \text { tBu (3.2b) } & 0.089(2) & 0.3(1) \\
\mathrm{NO}_{2}(3.2 \mathrm{f}) & 5.1(3) & 0.11(1)
\end{array}
$$

Scheme 3.4. Comparison of observed rates of ethylene insertion at $-15{ }^{\circ} \mathrm{C}$ for complexes 3.2b and 3.2f.

Comparative rates of benzene $\mathrm{C}-\mathrm{D}$ activation by complexes 3.2b-3.2e were studied using reactions with excess $\mathrm{C}_{6} \mathrm{D}_{6}$ to form the corresponding $\left[(\mathrm{N} \sim \mathrm{N}) \mathrm{Pt}\left(\mathrm{Ph}-d_{5}\right)(\mathrm{THF})\right]^{+}$ complex and free $\mathrm{C}_{6} \mathrm{H}_{5} \mathrm{D}$. Unlike ethylene insertion, the 4,4'-substituent exerts a negligible influence on the observed rate constants for benzene $\mathrm{C}-\mathrm{D}$ activation (Scheme 3.5). Complex 3.2f proved to be too unstable in solution for accurate measurement, as decomposition under the reaction conditions competed with $\mathrm{C}-\mathrm{D}$ activation.

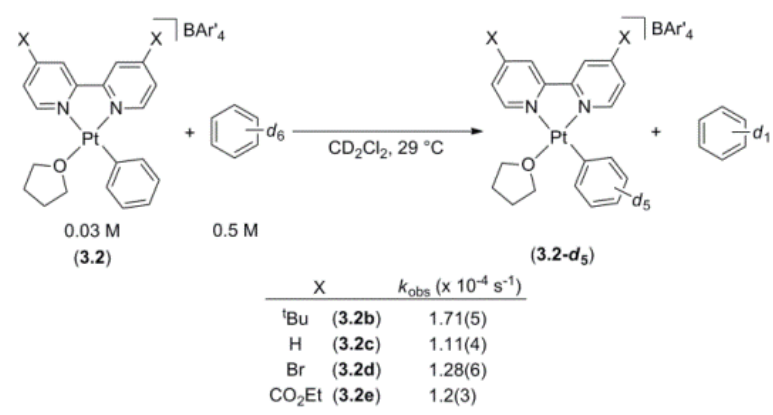

Scheme 3.5. Comparison of observed rates of $\mathrm{C}-\mathrm{D}$ activation using complexes 3.2b3.2e. 


\subsubsection{Evaluation of Catalytic Efficiency and Trends}

Catalytic ethylene hydrophenylation using complexes 3.2a-3.2f was probed by heating benzene solutions of $3.2(0.01 \mathrm{~mol} \%)$ at $100{ }^{\circ} \mathrm{C}$ with $0.1 \mathrm{MPa}$ of ethylene. The results are summarized in Table 3.1. Plots of turnovers (TO) versus time for 3.2a-3.2c provided no evidence of substantial catalyst deactivation after 4 hours (Figure 3.8). Thus, the TO after 4 hours for these catalysts should reasonably reflect relative catalyst activities. For complexes 3.2a-3.2c, the relative rates of catalysis (based on total product formation after $4 \mathrm{~h}$ ) is OMe (turnover frequency (TOF): $5.9 \times 10^{-4} \mathrm{~s}^{-1}$ ) $<{ }^{\mathrm{t}} \mathrm{Bu}\left(\mathrm{TOF}: 13.8 \times 10^{-4} \mathrm{~s}^{-1}\right.$ ) $<\mathrm{H}$ (TOF: $15.3 \times 10^{-4} \mathrm{~s}^{-1}$ ), which is consistent with less donating 4,4'-substituents providing a slight rate enhancement. Results with catalyst precursors 3.2d-3.2f, which possess less donating 4,4'-substituents than catalyst precursors 3.2a-3.2c, indicate less effective catalysis. Complex 3.2d provides only 2.3 total TO, with more styrene than ethylbenzene, after 4 hours, but a plot of TO versus time for $\mathbf{3 . 2 d}$ reveals no signs of catalyst deactivation after 4 hours (Figure 3.9). Although catalysis with 3.2e is more efficient than 3.2d, it also performs less effectively than complexes $3.2 \mathrm{a}-3.2 \mathrm{c}$ with no evidence of substantial deactivation after 24 hours. The nitro complex 3.2f provides slightly more than $1 \mathrm{TO}$ and undergoes relatively rapid deactivation to multiple intractable complexes within approximately 1 hour. 
Table 3.1. Catalytic ethylene hydrophenylation using complexes 3.2a-3.2f with $0.1 \mathrm{MPa}$ of ethylene. ${ }^{\text {a }}$

\begin{tabular}{|c|c|c|c|c|c|c|}
\hline$\sum_{N}^{x}$ & $=\rangle^{x}$ & $F+$ & & Et & $0: m: p^{b}$ & $\begin{array}{l}\operatorname{TOF}^{\mathrm{c}} \\
\left(10^{-4} \mathrm{~s}^{-1}\right)\end{array}$ \\
\hline $\begin{array}{c}\mathrm{OMe} \\
(\mathbf{3 . 2 a})\end{array}$ & -0.27 & $\begin{array}{c}6.8^{d} \\
(27.9)^{e} \\
{[78.0]^{\dagger}}\end{array}$ & $\begin{array}{c}0.2 \\
(0.3) \\
{[1.9]}\end{array}$ & $\begin{array}{c}1.5 \\
(10.7) \\
{[23.7]}\end{array}$ & $1: 2.5: 2.0$ & 5.9 \\
\hline $\begin{array}{c}{ }^{t} \mathrm{Bu} \\
(3.2 b)\end{array}$ & -0.2 & $\begin{array}{c}15.7 \\
(52.7) \\
{[63.9]}\end{array}$ & $\begin{array}{c}0.6 \\
(1.0) \\
{[1.6]}\end{array}$ & $\begin{array}{c}3.6 \\
(10.8) \\
{[18.8]}\end{array}$ & $1: 2.6: 1.6$ & 13.8 \\
\hline $\begin{array}{c}\mathrm{H} \\
(3.2 \mathrm{c})\end{array}$ & 0.0 & $\begin{array}{c}17.2 \\
(47.1) \\
{[93.6]}\end{array}$ & $\begin{array}{c}0.8 \\
(1.4) \\
{[3.6]}\end{array}$ & $\begin{array}{c}4.1 \\
(10.9) \\
{[29.4]}\end{array}$ & $1: 2.6: 1.5$ & 15.3 \\
\hline $\begin{array}{c}\mathrm{Br} \\
(\mathbf{3 . 2 d})\end{array}$ & 0.23 & $\begin{array}{c}0.9 \\
(2.7) \\
{[6.7]}\end{array}$ & $\begin{array}{c}1.4 \\
(3.9) \\
{[7.5]}\end{array}$ & $\begin{array}{c}0 \\
(0) \\
{[1.1]}\end{array}$ & - & 1.6 \\
\hline $\begin{array}{l}\mathrm{CO}_{2} \mathrm{Et} \\
(\mathbf{3 . 2 e})\end{array}$ & 0.45 & $\begin{array}{c}5.3 \\
(13.3) \\
{[46.2]}\end{array}$ & $\begin{array}{c}1.0 \\
(3.5) \\
{[6.2]}\end{array}$ & $\begin{array}{c}1.3 \\
(2.9) \\
{[11.3]}\end{array}$ & $1: 1.4: 1.3$ & 5.3 \\
\hline $\begin{array}{c}\mathrm{NO}_{2} \\
(\mathbf{3 . 2 f})\end{array}$ & 0.78 & $\begin{array}{c}0.1 \\
(0.2) \\
{[0.2]}\end{array}$ & $\begin{array}{c}1.0 \\
(1.1) \\
{[1.1]}\end{array}$ & $\begin{array}{c}0 \\
(0) \\
{[0]}\end{array}$ & - & - \\
\hline
\end{tabular}

${ }^{\text {a }} 0.01 \mathrm{~mol} \%$ catalyst dissolved in $\mathrm{C}_{6} \mathrm{H}_{6}$ with hexamethylbenzene as an internal standard at $100{ }^{\circ} \mathrm{C}$ with $0.1 \mathrm{MPa}$ of ethylene. ${ }^{\mathrm{b}}$ Ratio of 1,2-, 1,3- and 1,4-diethylbenzene after 4 hours. ${ }^{\mathrm{c}}$ TOF calculated based on total TO after 4 hours. ${ }^{\mathrm{d}}$ TO after 4 hours as determined by GC/MS. ${ }^{\mathrm{e}}$ Numbers in parentheses are TO after 16 hours. ${ }^{\mathrm{f}}$ Numbers in brackets are turnover numbers (TON) after catalyst deactivation. 


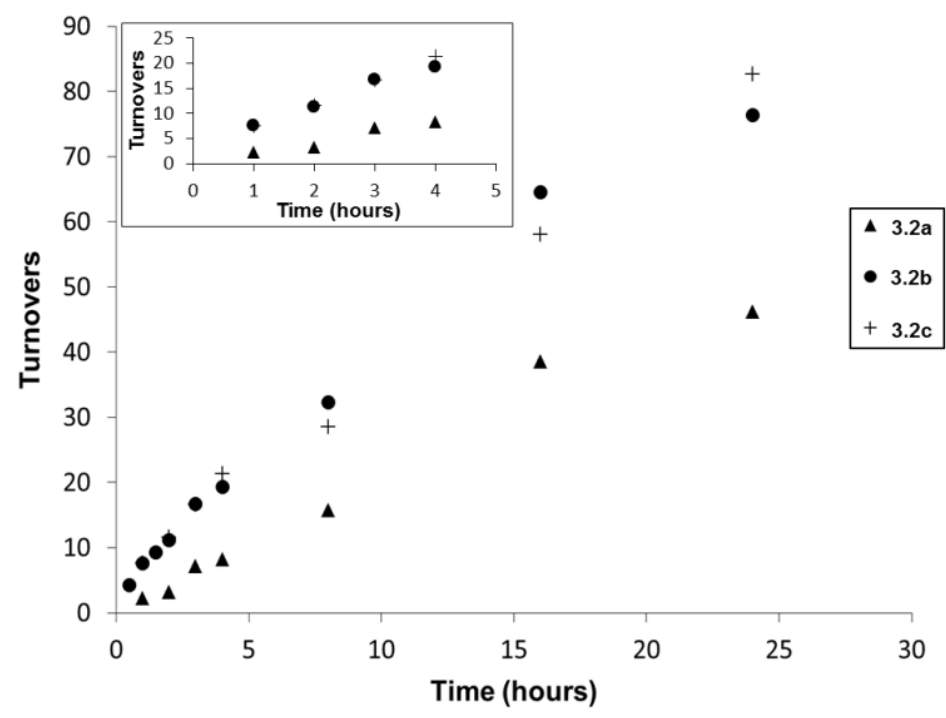

Figure 3.8. Plot of ethylbenzene and diethylbenzenes $\mathrm{TO}$ as a function of time for ethylene hydrophenylation catalyzed by complexes 3.2a-3.2c at $100{ }^{\circ} \mathrm{C}$ with $0.1 \mathrm{MPa}$ of ethylene pressure.

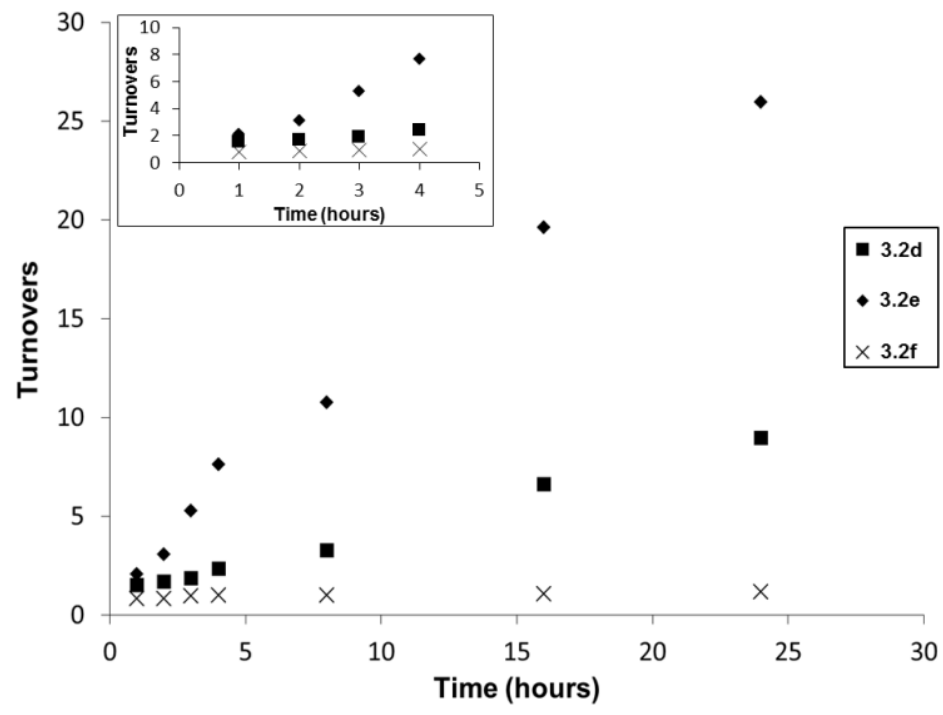

Figure 3.9. Plot of ethylbenzene and diethylbenzenes $\mathrm{TO}$ as a function of time for ethylene hydrophenylation catalyzed by complexes 3.2d-3.2f at $100{ }^{\circ} \mathrm{C}$ with $0.1 \mathrm{MPa}$ of ethylene pressure. 
The ratio of ethylbenzene to styrene is influenced by the donor ability of the 4,4'bipyridyl functional groups. For example, catalysis using complex 3.2a $\left(\mathrm{OMe}, \sigma_{\mathrm{p}}=\right.$ 0.27 ) and $0.1 \mathrm{MPa}$ of ethylene $\left(100^{\circ} \mathrm{C}\right)$ results in an ethylbenzene:styrene ratio of 27.8 (after 4 hours) compared to 0.1 for complex $3.2 \mathrm{f}\left(\mathrm{NO}_{2}, \sigma_{\mathrm{p}}=0.78\right)$. A Hammett plot was constructed using product ratios and the Hammett parameter $\sigma_{\mathrm{p}}$ (Figure 3.10). ${ }^{7}$ The effects of substituted pyridyl ligands are rarely amendable to Hammett correlations since Hammett $\sigma_{\mathrm{p}}$ parameters do not accurately reflect substituent effects upon the basicity of pyridine as the inductive and resonance interactions from the substituents differ from that found in benzoic acids. ${ }^{8}$ In addition, $\pi$-interactions with the metal center influences the correlation. ${ }^{8}$ Therefore, it is not surprising that the fit of the Hammett plot is not great $\left(R^{2}=0.77\right)$, the plot demonstrates that less donating 4,4'-substituents result in a decrease in the ratio of ethylbenzene to styrene. Using Hammett $\sigma_{\mathrm{p}}$ parameters as a relative gauge of substituted bipyridyl donation to $\mathrm{Pt}^{\mathrm{II}}$, a plot of ethylbenzene to styrene ratio (not a true Hammett plot) versus substituent Hammett parameter further demonstrates this trend (Figure 3.11). Complex 3.2d $\left(\mathrm{Br}, \sigma_{\mathrm{p}}=0.23\right)$ exhibits an ethylbenzene/styrene ratio similar to 3.2f and falls outside of the observed linear trend shown in Figure 3.11. The deviation of 3.2d from the remaining five catalysts is not currently understood. 


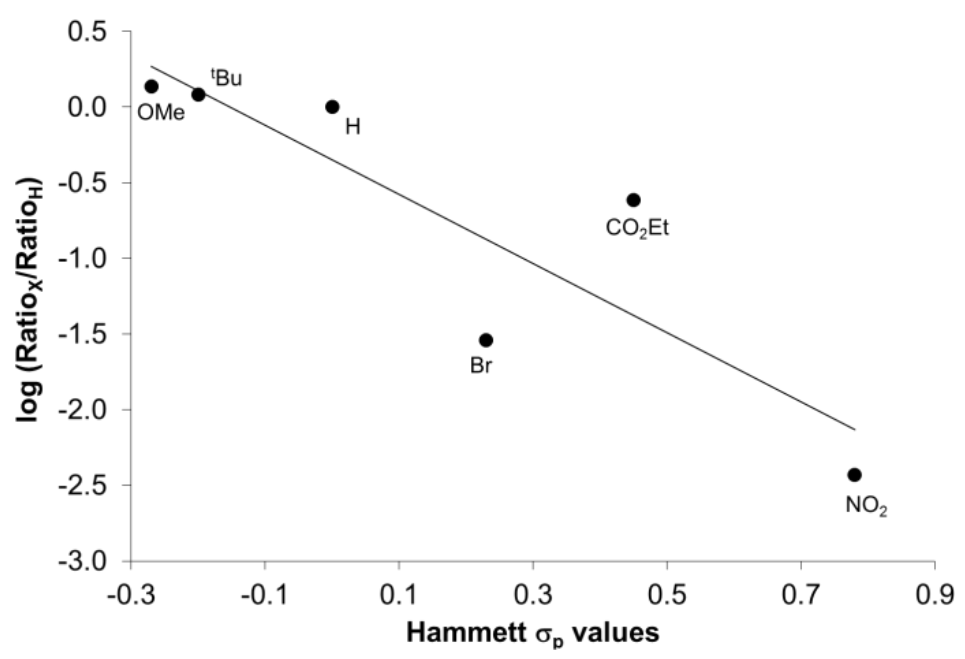

Figure 3.10. Hammett plot for the ratios of ethylbenzene to styrene from $\left[\left({ }^{\mathrm{x}} \mathrm{bpy}\right) \mathrm{Pt}(\mathrm{Ph})(\mathrm{THF})\right]^{+}$catalyzed ethylene hydrophenylation after 4 hours at $100{ }^{\circ} \mathrm{C}$ with $0.1 \mathrm{MPa}$ of ethylene (slope $=-2.3, \mathrm{R}^{2}=0.77$ ).

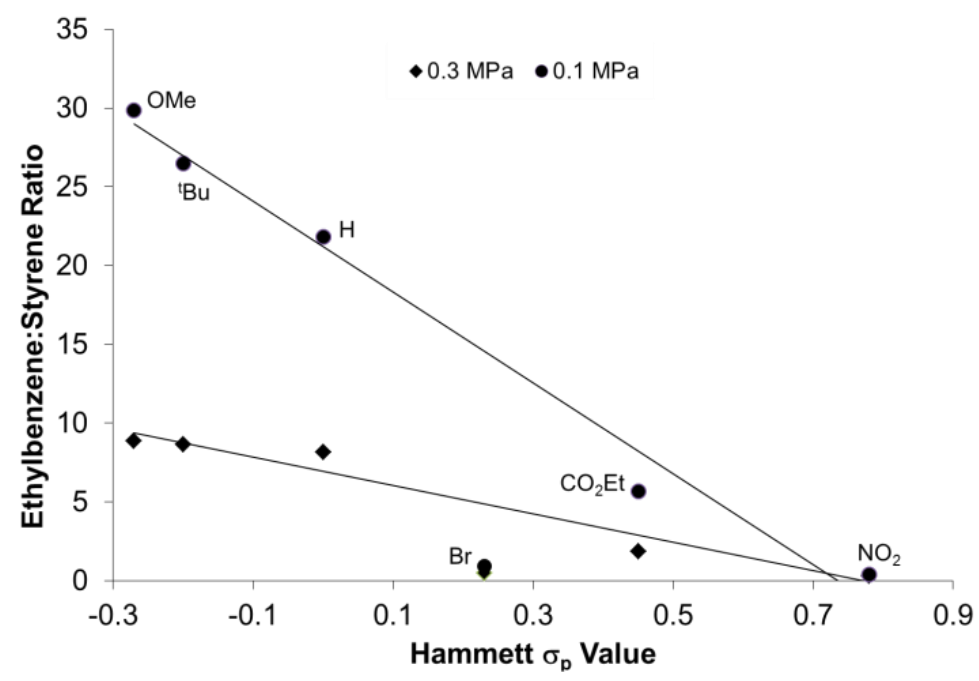

Figure 3.11. Ratios of ethylbenzene:styrene from $\left[\left({ }^{\mathrm{x}} \mathrm{bpy}\right) \mathrm{Pt}(\mathrm{Ph})(\mathrm{THF})\right]^{+}$catalyzed ethylene hydrophenylation after 4 hours at $100{ }^{\circ} \mathrm{C}$ with $0.1 \mathrm{MPa}$ and $0.3 \mathrm{MPa}$ of ethylene versus Hammett parameter $\left(\sigma_{\mathrm{p}}\right)$ for 4,4 '-substituent. Complex 3.2d $(\mathrm{X}=\mathrm{Br})$ is not included in either linear fit $\left(0.1 \mathrm{MPa}, \mathrm{R}^{2}=0.98\right.$, slope $=-27.9 ; 0.3 \mathrm{MPa}, \mathrm{R}^{2}=0.96$, slope $=-9.0)$.

Catalysis performed under the conditions outlined above but with $0.3 \mathrm{MPa}$ of ethylene results in decreased catalytic activity (Table 3.2). Two observations relevant to 
styrene/ethylbenzene production are made. First, for all complexes, the ethylbenzene:styrene ratio decreases at higher ethylene pressure (Table 3.3). Second, similar to reactions at $0.1 \mathrm{MPa}$ of ethylene, decreasing the donor ability of the 4,4'substituents results in a decrease in the ethylbenzene:styrene ratio (Figure 3.11). Again, complex 3.2d deviates from the observed linear correlation of ethylbenzene:styrene ratio versus Hammett $\sigma_{\mathrm{p}}$ value. At $0.3 \mathrm{MPa}$, complex $2 \mathbf{f}$ gives exclusive formation of styrene after 4 hours (Scheme 3.6). The dependence of ethylbenzene:styrene ratios for all catalyst precursors on ethylene concentration is consistent with the possibility that the rate of styrene displacement by ethylene is a key factor in these ratios.

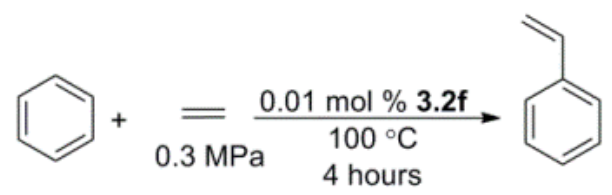

Scheme 3.6. Ethylene hydrophenylation using complex 3.2f is selective for styrene formation under $0.3 \mathrm{MPa}$ of ethylene. 
Table 3.2. Catalytic ethylene hydrophenylation using complexes 3.2a-3.2f with $0.3 \mathrm{MPa}$ of ethylene. ${ }^{\mathrm{a}}$

\begin{tabular}{|c|c|c|c|c|c|c|}
\hline & $\sigma_{\mathrm{p}}$ & & & Et & $o: m: p^{\mathrm{b}}$ & $\begin{array}{l}T O F^{c} \\
\left(10^{-4} s^{-1}\right)\end{array}$ \\
\hline $\begin{array}{c}\mathrm{OMe} \\
(\mathbf{3 . 2 a})\end{array}$ & -0.27 & $\begin{array}{c}3.3^{\mathrm{d}} \\
(10.0)^{\mathrm{e}}\end{array}$ & $\begin{array}{c}0.4 \\
(0.6)\end{array}$ & $\begin{array}{c}0.7 \\
(2.7)\end{array}$ & $1: 0.6: 1.1$ & 3.1 \\
\hline $\begin{array}{c}{ }^{\mathrm{t}} \mathrm{Bu} \\
(\mathbf{3 . 2 b})\end{array}$ & -0.2 & $\begin{array}{c}4.0 \\
(8.4)\end{array}$ & $\begin{array}{c}0.5 \\
(0.6)\end{array}$ & $\begin{array}{c}0.9 \\
(1.8)\end{array}$ & 1:1:1 & 3.8 \\
\hline $\begin{array}{c}\mathrm{H} \\
(3.2 \mathrm{c})\end{array}$ & 0.0 & $\begin{array}{c}5.5 \\
(19.9)\end{array}$ & $\begin{array}{c}0.7 \\
(1.4)\end{array}$ & $\begin{array}{c}1.4 \\
(5.2)\end{array}$ & 1:1:1 & 5.3 \\
\hline $\begin{array}{c}\mathrm{Br} \\
(\mathbf{3 . 2 d})\end{array}$ & 0.23 & $\begin{array}{c}0.2 \\
(0.4)\end{array}$ & $\begin{array}{c}1.3 \\
(2.1)\end{array}$ & $\begin{array}{c}0 \\
\text { (0) }\end{array}$ & - & 1.0 \\
\hline $\begin{array}{c}\mathrm{CO}_{2} \mathrm{Et} \\
(\mathbf{2 e})\end{array}$ & 0.45 & $\begin{array}{c}1.9 \\
(3.5)\end{array}$ & $\begin{array}{c}1.2 \\
(3.2)\end{array}$ & $\begin{array}{c}0.5 \\
(0.7)\end{array}$ & 1:0.6:1.1 & 2.5 \\
\hline $\begin{array}{l}\mathrm{NO}_{2} \\
(\mathbf{2 f})\end{array}$ & 0.78 & $\begin{array}{c}0 \\
(0.1)\end{array}$ & $\begin{array}{c}1.0 \\
(1.1)\end{array}$ & $\begin{array}{c}0 \\
(0)\end{array}$ & - & - \\
\hline
\end{tabular}

${ }^{a} 0.01 \mathrm{~mol} \%$ catalyst dissolved in $\mathrm{C}_{6} \mathrm{H}_{6}$ with hexamethylbenzene as an internal standard at $100{ }^{\circ} \mathrm{C}$ with $0.3 \mathrm{MPa}$ of ethylene. ${ }^{\mathrm{b}}$ Ratio of 1,2-, 1,3- and 1,4-diethylbenzene after 4 hours. ${ }^{\mathrm{c}} \mathrm{TOF}$ calculated based on total TO after 4 hours. ${ }^{\mathrm{d}} \mathrm{TO}$ after 4 hours as determined by GC/MS. ${ }^{\mathrm{e}}$ Numbers in parentheses are TO after 16 hours. 
Table 3.3. Ratio of ethylbenzene to styrene as a function of ethylene pressure.

\begin{tabular}{cccc}
\hline & & & \\
& & & \\
\hline
\end{tabular}

${ }^{\mathrm{a}}$ Ethylbenzene:styrene after 4 hours at $100{ }^{\circ} \mathrm{C}$. ${ }^{\mathrm{b}}$ Ratio after 4 hours with $0.3 \mathrm{MPa}$ of ethylene at $100^{\circ} \mathrm{C} .{ }^{c}$ Only styrene observed.

Complexes 3.2d and 3.2e produce $>1.0 \mathrm{TO}$ of styrene. For example, at $0.1 \mathrm{MPa}$ of ethylene, complex 3.2d produces a turnover number (TON) of 7.5 for styrene after 4 days at $100{ }^{\circ} \mathrm{C}$. The production of $\geq 1$ equivalent (relative to $\mathrm{Pt}$ ) of styrene requires a hydrogen acceptor. Heating a $\mathrm{CD}_{3} \mathrm{NO}_{2}$ solution of complex 3.2d and benzene under ethylene results in the formation of styrene and ethane as observed by ${ }^{1} \mathrm{H}$ NMR spectroscopy. Confirmation of ethane formation was achieved using isotopically labeled ${ }^{13} \mathrm{C}_{2} \mathrm{H}_{4}$. In the ${ }^{1} \mathrm{H}$ and ${ }^{13} \mathrm{C}$ NMR spectrum, ethane is clearly observed and identified using a comparison to an analytically pure standard (Figure 3.12 ). Therefore, the observed catalytic oxidative hydrophenylation of ethylene by $\mathbf{2 d}$ uses ethylene as the oxidant. 


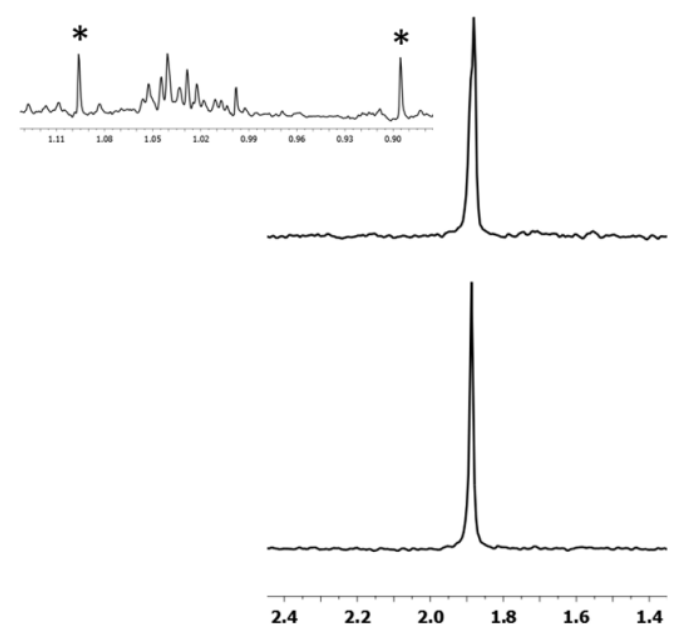

Figure 3.12. ${ }^{13} \mathrm{C}\left\{{ }^{1} \mathrm{H}\right\}$ NMR spectrum (top) and ${ }^{1} \mathrm{H}$ NMR spectrum (top inset, ${ }^{1} J_{\mathrm{CH}}=120$ $\mathrm{Hz}$ ) of ${ }^{13} \mathrm{C}_{2} \mathrm{H}_{6}$ in $\mathrm{CD}_{3} \mathrm{NO}_{2}$ resulting from the formation of styrene by complex $\mathbf{3 . 2 d}$ and benzene under ${ }^{13} \mathrm{C}_{2} \mathrm{H}_{4}$ pressure. ${ }^{13} \mathrm{C}\left\{{ }^{1} \mathrm{H}\right\}$ NMR spectrum (bottom) of analytically pure sample of $\mathrm{C}_{2} \mathrm{H}_{6}$ in a $\mathrm{CD}_{3} \mathrm{NO}_{2}$ /benzene solution.

The complex $\left[\left({ }^{t} \text { bpy) } \mathrm{Pt}\left(\mathrm{CH}_{2} \mathrm{CH}_{2} \mathrm{Ph}\right)\left(\eta^{2}-\mathrm{C}_{2} \mathrm{H}_{4}\right)\right]^{+}\right.$(3.3b) has been shown to be the catalyst resting state using $\mathbf{3 . 2 b}$ as the catalyst precursor. ${ }^{1}$ Catalysis using $\mathbf{3 . 2} \mathbf{a}-\mathbf{3 . 2 f}$ was monitored by ${ }^{1} \mathrm{H}$ NMR at $90{ }^{\circ} \mathrm{C}$ over 4 hours to confirm that $\left[\left({ }^{\mathrm{x}}\right.\right.$ bpy $) \mathrm{Pt}\left(\mathrm{CH}_{2} \mathrm{CH}_{2} \mathrm{Ph}\right)\left(\eta^{2}-\right.$ $\left.\left.\mathrm{C}_{2} \mathrm{H}_{4}\right)\right]^{+}$is the resting state for each ${ }^{\mathrm{x}}$ bpy ligand. This species is observed as the catalyst resting state using complexes 3.2a-3.2e. For complexes 3.2d and 3.2e, the insertion product $\left[\left({ }^{\mathrm{x}} \text { bpy }\right) \mathrm{Pt}\left(\mathrm{CH}_{2} \mathrm{CH}_{2} \mathrm{Ph}\right)\left(\eta^{2}-\mathrm{C}_{2} \mathrm{H}_{4}\right)\right]^{+}$is observed but is slowly consumed as resonances indicating the formation of $\left[\left({ }^{\mathrm{x}} \mathrm{bpy}\right) \mathrm{Pt}(\mathrm{Et})\left(\eta^{2}-\mathrm{C}_{2} \mathrm{H}_{4}\right)\right]^{+}$, which would result from $\beta$-hydride elimination and styrene displacement, are observed. The $\mathrm{Pt}^{\mathrm{II}}$ ethyl complexes $\left[\left({ }^{\mathrm{x}} \mathrm{bpy}\right) \mathrm{Pt}(\mathrm{Et})\left(\eta^{2}-\mathrm{C}_{2} \mathrm{H}_{4}\right)\right]^{+}$eventually decompose. Consistent with the observation of $\sim 1$ TO under catalytic conditions, complex $\mathbf{3 . 3 f}$ is unstable and is consumed within minutes to yield stoichiometric equivalents of ethylbenzene and styrene as well as multiple Pt decomposition products. 
Heating [('bpy) $\left.\mathrm{Pt}\left(\mathrm{CH}_{2} \mathrm{CH}_{2} \mathrm{Ph}\right)\left(\eta^{2}-\mathrm{C}_{2} \mathrm{H}_{4}\right)\right]^{+}$under ethylene pressure in $\mathrm{CD}_{3} \mathrm{NO}_{2}$ results in stoichiometric styrene production as well as the formation of $\left[{ }^{t}\right.$ bpy $) \mathrm{Pt}\left(\mathrm{C}_{2} \mathrm{H}_{5}\right)\left(\eta^{2}-\right.$ $\left.\left.\mathrm{C}_{2} \mathrm{H}_{4}\right)\right]^{+}$. Styrene formation is not observed in the absence of excess ethylene. For example, the thermolysis $\left(100{ }^{\circ} \mathrm{C}\right)$ of $\mathbf{3 . 3 f}$ in benzene results in the formation of ethylbenzene in quantitative yield (Scheme 3.7). Thus, for complex $\mathbf{3 . 3 f}$ the formation of styrene is dependent on the presence of ethylene, which indicates that ethylene plays a role in the formation of free styrene and is consistent with the trends in ethylbenzene:styrene ratios as a function of ethylene pressure. It is likely that release of styrene occurs via an associative ligand exchange with ethylene.

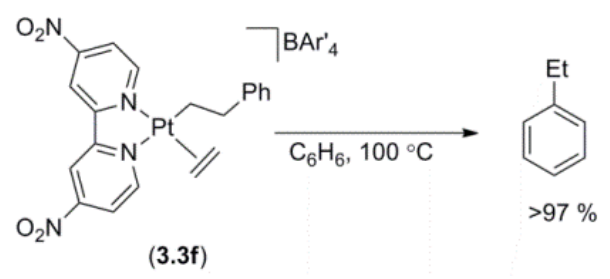

Scheme 3.7. Without the presence of ethylene, the Thermolysis of complex 3.3f in benzene results in quantitative ethylbenzene production.

The rates of stoichiometric styrene production from the thermolysis $\left(45^{\circ} \mathrm{C}\right)$ of $\left[\left({ }^{x} \mathrm{bpy}\right) \mathrm{Pt}\left(\mathrm{CH}_{2} \mathrm{CH}_{2} \mathrm{Ph}\right)\left(\eta^{2}-\mathrm{C}_{2} \mathrm{H}_{4}\right)\right]^{+}\left[\mathrm{X}=\mathrm{OMe}(\mathbf{3 . 3 a}),{ }^{\mathrm{t}} \mathrm{Bu}(\mathbf{3 . 3 b}), \mathrm{H}\right.$ (3.3c), $\mathrm{CO}_{2} \mathrm{Et}(\mathbf{3 . 3 e})$, and $\mathrm{NO}_{2}$ (3.3f)] were measured by ${ }^{1} \mathrm{H}$ NMR spectroscopy (Scheme 3.8). Similar to the Hammett plot for ethylbenzene and styrene ratios, a Hammett plot using the rate constants for styrene formation from 3.3a-3.3f (without 3.3d) reveals a reasonable linear correlation $\left(\mathrm{R}^{2}=0.83\right.$, Figure 3.13) but with some curvature. The non-linear nature of the plot in Figure 3.13 could reveal a change in rate determining step or mechanism for 
styrene formation. The identity of the $4,4^{\prime}$-substituent has a clear effect on the rate of styrene evolution (Figure 3.14). Decreasing the electron donor ability of the 4,4'substituent results in more rapid styrene production. For example, the formation of styrene from 3.3a occurs with a pseudo-first-order rate constant of $2.6(2) \times 10^{-6} \mathrm{~s}^{-1}$ with $0.3 \mathrm{M}$ ethylene at $45^{\circ} \mathrm{C}$, while complex 3.3f produces styrene $\sim 60$ times faster with an observed rate constant of $1.6(2) \times 10^{-4} \mathrm{~s}^{-1}$. The relative rates of styrene formation cannot be directly compared to the results from catalysis since the conditions used for catalysis and stoichiometric styrene production are different. In addition to the relative rates of styrene formation, the relative rates of ethylbenzene formation play a role in ethylbenzene:styrene ratios. It can be stated definitively that the trend in the rates of stoichiometric styrene production from the five complexes $\left[\left({ }^{x}\right.\right.$ bpy $) \mathrm{Pt}\left(\mathrm{CH}_{2} \mathrm{CH}_{2} \mathrm{Ph}\right)\left(\eta^{2}-\right.$ $\left.\left.\mathrm{C}_{2} \mathrm{H}_{4}\right)\right]^{+}($3.3a-3.3c and $\mathbf{3 e - 3 f})$ is identical to the trend in ethylbenzene:styrene ratios observed during catalysis. Interestingly, the rate of styrene formation from 3.3d, which is the complex that deviates from the linear plots in Figure 3.11, is much faster than the other complexes. For example, at room temperature the reaction of $\mathbf{3 . 2 d}$ with ethylene is complete within approximately ten minutes. 


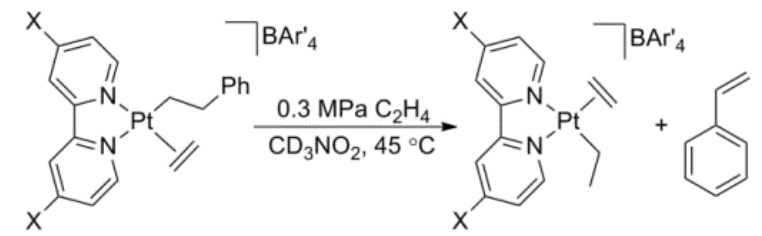

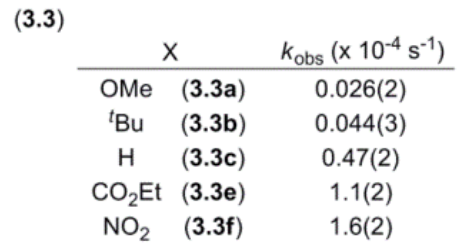

Scheme 3.8. Styrene formation occurs during the thermolysis $\left(45{ }^{\circ} \mathrm{C}\right)$ of $\left[\left({ }^{\mathrm{t}} \mathrm{bpy}\right) \mathrm{Pt}\left(\mathrm{CH}_{2} \mathrm{CH}_{2} \mathrm{Ph}\right)\left(\eta^{2}-\mathrm{C}_{2} \mathrm{H}_{4}\right)\right]\left[\mathrm{BAr}_{4}\right]$ in the absence of benzene under $0.3 \mathrm{MPa}$ of ethylene. Observed rate constants were determined by ${ }^{1} \mathrm{H}$ NMR spectroscopy using hexamethyldisilane as an internal standard.

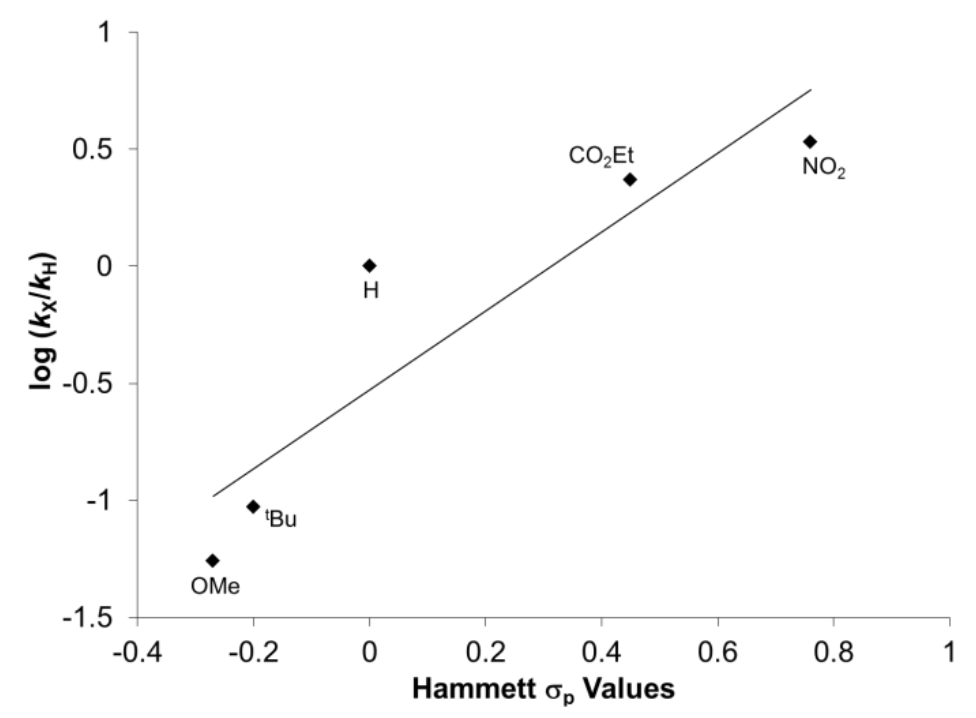

Figure 3.13. Hammett plot for styrene formation from $\left[\left({ }^{x} b p y\right) \mathrm{Pt}\left(\mathrm{CH}_{2} \mathrm{CH}_{2} \mathrm{Ph}\right)\left(\eta^{2}-\mathrm{C}_{2} \mathrm{H}_{4}\right)\right]^{+}$ at $45^{\circ} \mathrm{C}$ with $0.3 \mathrm{MPa}$ of ethylene $\left(\mathrm{R}^{2}=0.83\right)$. 


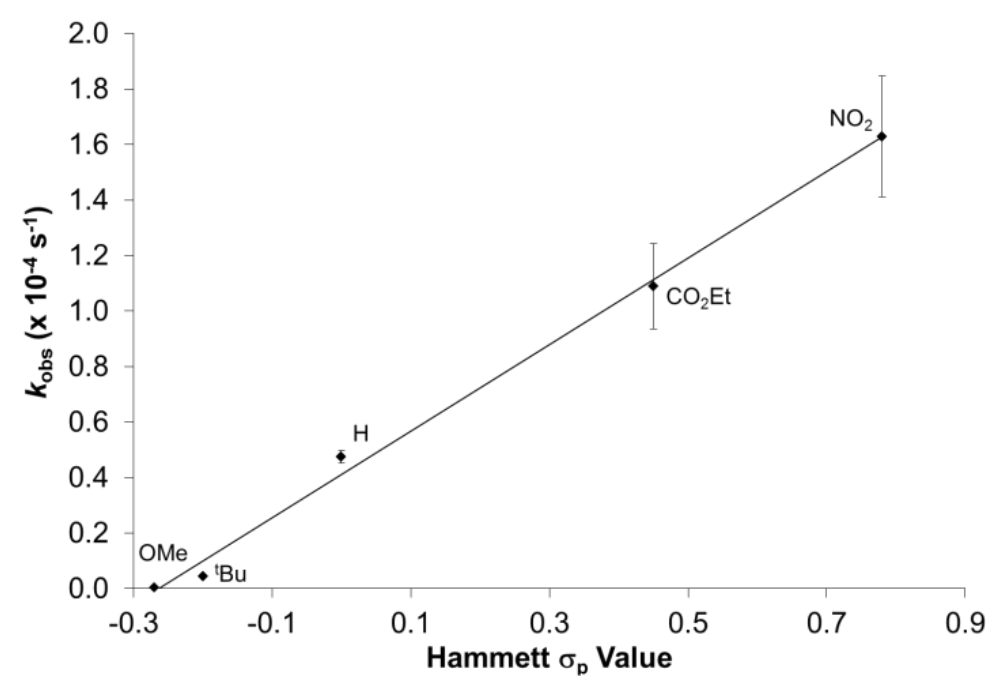

Figure 3.14. Plot of pseudo first-order rate constants $\left(k_{\mathrm{obs}}\right)$ for styrene formation from $\left[\left({ }^{\mathrm{x}} \text { bpy }\right) \mathrm{Pt}\left(\mathrm{CH}_{2} \mathrm{CH}_{2} \mathrm{Ph}\right)\left(\eta^{2}-\mathrm{C}_{2} \mathrm{H}_{4}\right)\right]^{+}$at $45^{\circ} \mathrm{C}$ with $0.3 \mathrm{MPa}$ of ethylene versus Hammett $\sigma_{\mathrm{p}}$ parameter of the 4,4'-bipyridyl functionality.

The production of styrene by these $\mathrm{Pt}^{\mathrm{II}}$ complexes is clearly facilitated by less donating bipyridyl ligands. The formation of styrene from complexes $\mathbf{3 . 3}$ is likely a multi-step reaction involving ethylene dissocation, $\beta$-hydride elimination and net dissociation of styrene. Possible explanations for the trends in styrene production include i) the barrier to the reinsertion of styrene after $\beta$-hydride elimination increases with less donating ligands, ii) styrene is more readily displaced by ethylene for the Pt complexes with less donating ligands or iii) a combination of both effects.

Measuring the rate of styrene displacement by ethylene as a function of the 4,4' substituent using $\left[\left({ }^{\mathrm{x}} \text { bpy) } \mathrm{Pt}(\mathrm{H})\left(\eta^{2} \text {-styrene }\right)\right]^{+}\left[\mathrm{X}={ }^{\mathrm{t}} \mathrm{Bu}\right.\right.$ and $\left.\mathrm{NO}_{2}\right]$ was targeted, but attempts to synthesize the $\mathrm{Pt}^{\mathrm{II}}$ hydride complexes were unsuccessful. Instead, the $\mathrm{Pt}^{\mathrm{II}}$ methyl complexes $\left[\left({ }^{\mathrm{x}} \text { bpy) } \mathrm{Pt}(\mathrm{Me})\left(\eta^{2} \text {-styrene }\right)\right]^{+}\left[\mathrm{X}={ }^{\mathrm{t}} \mathrm{Bu}(\mathbf{3 . 4 b})\right.\right.$ or $\left.\mathrm{NO}_{2}(\mathbf{3 . 4 f})\right]$ were used as models for the Pt-H variants. Unfortunately, the displacement of styrene by ethylene 
from both 3.4b and 3.4f was too rapid for measurement even at $-120{ }^{\circ} \mathrm{C}$. The $\mathrm{Pt}$ complexes were dissolved in a solvent mixture of $\mathrm{CD}_{2} \mathrm{Cl}_{2}, \mathrm{CDCl}_{3}$ and $\mathrm{CCl}_{4}(60: 27: 13$, $\mathrm{v}: \mathrm{v}: \mathrm{v})$ and then frozen. The tube was pressurized with $0.3 \mathrm{MPa}$ ethylene and allowed to thaw in the spectrometer. The first NMR spectrum showed complete conversion to $\left[\left({ }^{\mathrm{x}} \mathrm{bpy}\right) \mathrm{Pt}\left(\eta^{2}-\mathrm{C}_{2} \mathrm{H}_{4}\right)(\mathrm{Me})\right]^{+}$and free styrene. The structure of $\left[\left({ }^{\mathrm{NO} 2} \mathrm{bpy}\right) \mathrm{Pt}\left(\eta^{2}-\mathrm{C}_{2} \mathrm{H}_{4}\right)(\mathrm{Me})\right]^{+}$ (3.5f) is shown in Figure 3.15.

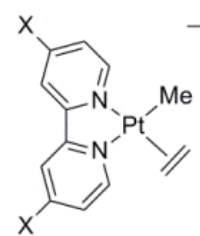

(3.4)

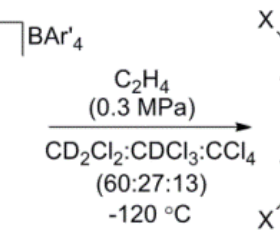
$-120^{\circ} \mathrm{C}$

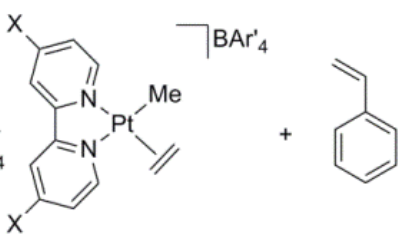

(3.5)

Scheme 3.9. Styrene displacement by ethylene $(0.3 \mathrm{MPa})$ from $\left[\left({ }^{\mathrm{x}} \mathrm{bpy}\right) \mathrm{Pt}(\mathrm{Me})\left(\eta^{2}-\right.\right.$ sytrene) $]\left[\mathrm{BAr}_{4}{ }_{4}\right]\left[\mathrm{X}={ }^{\mathrm{t}} \mathrm{Bu}(\mathbf{3 . 4 b})\right.$ or $\left.\mathrm{NO}_{2}(\mathbf{3 . 4 f})\right]$ at $-120{ }^{\circ} \mathrm{C}$ to generate $\left[\left({ }^{\mathrm{x}} \mathrm{bpy}\right) \mathrm{Pt}(\mathrm{Me})\left(\eta^{2}-\right.\right.$ $\left.\left.\mathrm{C}_{2} \mathrm{H}_{4}\right)\right]\left[\mathrm{BAr}_{4}^{\prime}\right]\left[\mathrm{X}={ }^{\mathrm{t}} \mathrm{Bu}(\mathbf{3 . 4 b})\right.$ or $\left.\mathrm{NO}_{2}(\mathbf{3 . 5 f})\right]$.

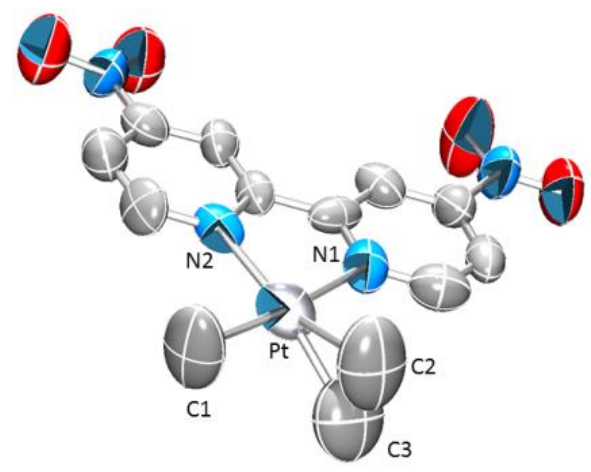

Figure 3.15. ORTEP of $\left[\left({ }^{\mathrm{NO} 2} \mathrm{bpy}\right) \mathrm{Pt}\left(\eta^{2}-\mathrm{C}_{2} \mathrm{H}_{4}\right)(\mathrm{Me})\right]\left[\mathrm{BAr}_{4}{ }_{4}\right](\mathbf{3 . 5 f})(50 \%$ probability; $\mathrm{H}$ atoms and $\mathrm{BAr}_{4}{ }_{4}$ anion omitted for clarity). Selected bond lengths $(\AA)$ : Pt-N1 2.113(7), Pt-N2 2.063(6), Pt-C1 2.021(9), Pt-C2 2.073(13), Pt-C3 2.113(12), C2-C3 1.349(16). Selected bond angles $\left(^{\circ}\right)$ : N1-Pt-N2 77.5(2), N1-Pt-C1 173.1(3). 
A plausible mechanism for styrene formation is shown in Scheme 3.10. Ethylene insertion into the $\mathrm{Pt}-\mathrm{Ph}$ bond results in a $\beta$-agostic phenethyl intermediate, which coordinates ethylene to form the catalyst resting state complex 3.3. Complex 3.3 may either exchange ethylene with benzene and continue along the ethylene hydrophenylation catalytic cycle, ${ }^{1}$ or dissociate ethylene and undergo $\beta$-hydride elimination to form $\left[\left({ }^{x} \mathrm{bpy}\right) \operatorname{Pt}(\mathrm{H})\left(\eta^{2} \text {-styrene }\right)\right]^{+}$. Displacement of styrene with ethylene completes the process for styrene formation. For most ${ }^{\mathrm{x}}$ bpyPt complexes (excluding 3.2d and 3.2e), we presume that the $\mathrm{Pt}^{\mathrm{II}}-\mathrm{H}$ complexes are unstable and result in catalyst decomposition since only $\sim 1$ $\mathrm{TO}$ of styrene is observed. For $\mathrm{X}=\mathrm{Br}$ (3.2d) or $\mathrm{CO}_{2} \mathrm{Et}$ (3.2e), ethylene insertion into the $\mathrm{Pt}-\mathrm{H}$ bond and subsequent benzene $\mathrm{C}-\mathrm{H}$ activation liberates ethane and regenerates the $\left[\left({ }^{x} \mathrm{bpy}\right) \mathrm{Pt}(\mathrm{Ph})\right]^{+}$fragment; however, catalytic production of styrene is not sustained over a long period as evidenced by the low TON for styrene production (Table 3.1).

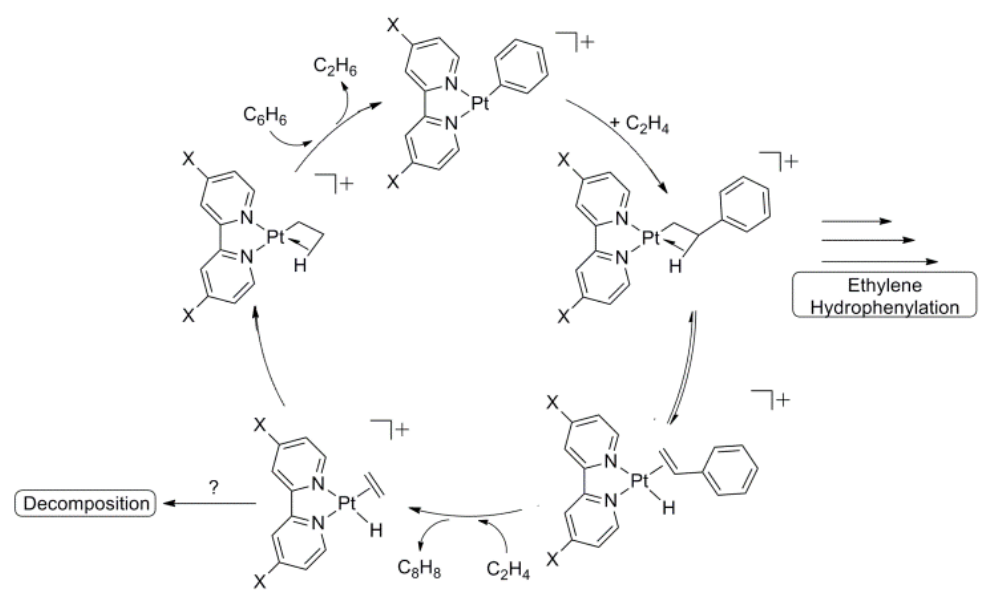

Scheme 3.10. Proposed mechanism for styrene formation during $\mathrm{Pt}^{\mathrm{II}}$ catalyzed ethylene hydrophenylation. 
The $\mathrm{Pt}^{\mathrm{II}}$ catalysts eventually decompose to multiple intractable complexes, and understanding the exact pathway for catalyst deactivation is challenging. Inspection of the TON for catalysts 3.2a-3.2f (Table 3.1) shows that complexes 3.2a-3.2c, which possess more donating bipyridyl ligands, give a higher TON than 3.2d-3.2f. Since the complexes 3.2d-3.2f, which possess less donating bipyridyl ligands, exhibit a greater predilection for styrene production, one possible explanation for reduced TON for 3.2d3.2f compared to 3.2a-3.2 $\mathrm{c}$ is that the $\mathrm{Pt}^{\mathrm{II}}-\mathrm{H}$ complexes that result from $\beta$-hydride elimination (Scheme 3.10) are more readily formed under catalytic conditions and are prone to decomposition. Thus, long lived catalysis with this class of complexes may require avoiding $\mathrm{Pt}^{\mathrm{II}}-\mathrm{H}$ intermediates or developing a strategy to suppress their decomposition.

\subsection{Using Dipyridyl Chelate Ring Size to Modulate Pt ${ }^{\text {II }}$ Catalyzed Ethylene Hydrophenylation}

Puddephatt et al. have shown that 'bpy and 2,2'-dipyridylmethane (dpm) have nearly identical donor ability when coordinated to $\mathrm{Pt}^{\mathrm{II}}$, as determined from a comparison of carbonyl stretching frequencies of model complexes $[(\mathrm{N} \sim \mathrm{N}) \mathrm{Pt}(\mathrm{CO})(\mathrm{Me})]^{+}\left(\mathrm{N} \sim \mathrm{N}={ }^{\mathrm{t}}\right.$ bpy or dpm). ${ }^{9}$ Ergo, the effect of chelate ring size on bis(pyridyl) $\mathrm{Pt}^{\mathrm{II}}$ catalyzed ethylene hydrophenylation can be directly evaluated without a substantial change in metal electron density by substituting tbpy with dpm. Complex 3.7 was prepared by protonation of (dpm) $\mathrm{Pt}(\mathrm{Ph})_{2}\left(\right.$ 3.6) with $\left[\mathrm{H}\left(\mathrm{Et}_{2} \mathrm{O}\right)_{2}\right]\left[\mathrm{BAr}_{4}^{\prime}\right]$ at $-70{ }^{\circ} \mathrm{C}$ in THF (Scheme 3.11). Catalytic ethylene hydrophenylation using $\mathbf{3 . 7}$ was evaluated, and the results are summarized in Table 3.4. 


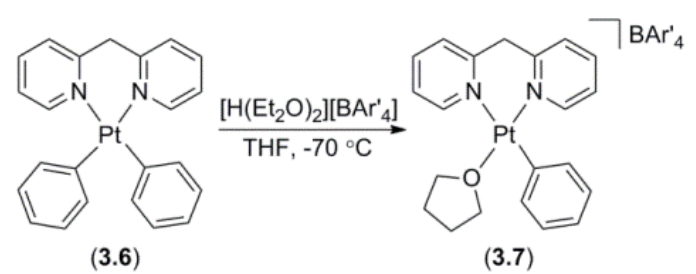

Scheme 3.11. Synthesis of $[(\mathrm{dpm}) \mathrm{Pt}(\mathrm{Ph})(\mathrm{THF})]\left[\mathrm{BAr}_{4}^{\prime}\right]($ 3.7).

Table 3.4. Catalytic ethylene hydrophenylation using complex 3.7. ${ }^{\text {a }}$

\begin{tabular}{|c|c|c|c|c|c|}
\hline $\begin{array}{c}\text { Temperature } \\
\left({ }^{\circ} \mathrm{C}\right)\end{array}$ & Et & & & $o: m: p^{b}$ & $\begin{array}{c}\operatorname{TOF}^{\mathrm{c}} \\
\left(10^{-3} \mathrm{~s}^{-1}\right)\end{array}$ \\
\hline 90 & $\begin{array}{c}16.8^{\mathrm{d}} \\
(74.7)^{\mathrm{e}} \\
{[135.2]^{\dagger}}\end{array}$ & $\begin{array}{c}0.0 \\
(0.2) \\
{[0.6]}\end{array}$ & $\begin{array}{c}4.0 \\
(26.6) \\
{[42.7]}\end{array}$ & $1: 12: 8$ & 1.4 \\
\hline 100 & $\begin{array}{c}55.3 \\
(194.9) \\
{[299.1]}\end{array}$ & $\begin{array}{c}0.4 \\
(1.1) \\
{[1.5]}\end{array}$ & $\begin{array}{c}10.6 \\
(39.2) \\
{[63.8]}\end{array}$ & $1: 10: 7$ & 4.6 \\
\hline 110 & $\begin{array}{c}199.2 \\
(252.8) \\
{[268.4]}\end{array}$ & $\begin{array}{c}0.6 \\
(0.9) \\
{[1.2]}\end{array}$ & $\begin{array}{c}40.5 \\
(53.5) \\
{[61.0]}\end{array}$ & $1: 30: 20$ & 16.7 \\
\hline 120 & $\begin{array}{c}211.9 \\
(233.3) \\
{[244.5]}\end{array}$ & $\begin{array}{l}1.2 \\
(1.5) \\
{[1.7]}\end{array}$ & $\begin{array}{c}44.5 \\
(50.7) \\
{[54.5]}\end{array}$ & $1: 32: 22$ & 17.9 \\
\hline
\end{tabular}

${ }^{\text {a }} 0.01 \mathrm{~mol} \%$ catalyst in $\mathrm{C}_{6} \mathrm{H}_{6}$ with $0.1 \mathrm{MPa}_{2} \mathrm{H}_{4}$ and hexamethylbenzene $(\mathrm{HMB})$ as an internal standard. ${ }^{\mathrm{b}}$ Ratio of 1,2-, 1,3- and 1,4-diethylbenzene after 4 hours. ${ }^{\mathrm{c}}$ TOF calculated based on total TO after 4 hours. ${ }^{\mathrm{d}}$ TO after 4 hours as determined by GC/MS. ${ }^{\mathrm{e}}$ Numbers in parentheses are TO after 16 hours. ${ }^{\mathrm{f}}$ Numbers in brackets are TO after 36 hours.

At $100{ }^{\circ} \mathrm{C}$ under $0.1 \mathrm{MPa}$ of ethylene, a solution of $0.01 \mathrm{~mol} \% 3.7$ (relative to benzene) results in 55.3 TO of ethylbenzene, 10.6 TO of diethylbenzenes and trace quantities of styrene after 4 hours, corresponding to a TOF of $4.6 \times 10^{-3} \mathrm{~s}^{-1}$. At temperatures $\leq 100^{\circ} \mathrm{C}$, plots of TO versus time reveal minimal catalyst deactivation after 4 hours (Figure 3.16 
and Figure 3.17). Prolonged reaction times gave 235.2 and 364.4 total TO of alkyl benzenes after 16 and 36 hours, respectively. A TON after 110 hours at $100^{\circ} \mathrm{C}$ is 469 .

The influence of temperature on catalyst activity and stability was evaluated. At $90{ }^{\circ} \mathrm{C}$ under $0.1 \mathrm{MPa}$ of ethylene pressure, a solution of $\mathbf{3 . 7}$ in benzene results in a TOF of $1.4 \times$ $10^{-3} \mathrm{~s}^{-1}$ (calculated after 4 hours). Thus, increasing the temperature to $100{ }^{\circ} \mathrm{C}$ and $110^{\circ} \mathrm{C}$ increases the rate of ethylene hydrophenylation compared to the reaction at $90{ }^{\circ} \mathrm{C}$ by a factor of $\sim 3$ and $\sim 17$, respectively; however, catalyst deactivation becomes more competitive at elevated temperatures. The TON after 36 hours at $110{ }^{\circ} \mathrm{C}(\sim 331)$ and 120 ${ }^{\circ} \mathrm{C}(\sim 301)$ are lower than that observed at $100{ }^{\circ} \mathrm{C}(\sim 364 \mathrm{TO})$.

To compare the rate of catalytic ethylene hydrophenylation between 3.7 and $\left.\left[{ }^{(} \mathrm{bpy}\right) \mathrm{Pt}(\mathrm{Ph})(\mathrm{THF})\right]\left[\mathrm{BAr}_{4}^{\prime}\right]$ (3.2b), we used TOFs calculated after 4 hours of reaction, which show that $\mathbf{3 . 7}$ catalyzes ethylene hydrophenylation $\sim 3.5$ times faster than $\mathbf{3 . 2} \mathbf{b}$ at $100{ }^{\circ} \mathrm{C} .{ }^{1}$ For example, catalysis at $100{ }^{\circ} \mathrm{C}$ under $0.1 \mathrm{MPa}$ of ethylene pressure with $\left.\left[{ }^{\mathrm{t}} \mathrm{bpy}\right) \mathrm{Pt}(\mathrm{Ph})(\mathrm{THF})\right]^{+}$exhibits a TOF of $1.3(2) \times 10^{-3} \mathrm{~s}^{-1}$ after 4 hours, while a TOF of 4.6(8) $\times 10^{-3} \mathrm{~s}^{-1}$ was observed for 3.7. TOF after 4 hours of reaction were selected for comparison since plots of TO versus time plots reveal little evidence of catalyst deactivation (Figure 3.16 and Figure 3.17). The linear regression in Figure 3.17 does not extrapolate through the origin due to the heating period required to bring the reaction solutions to $100^{\circ} \mathrm{C}$.

At $100{ }^{\circ} \mathrm{C}$ with $0.1 \mathrm{MPa}$ of ethylene, almost complete catalyst deactivation is observed after 24 hours for 3.2b, but 3.7 remains active over a period of more than 4 days (Figure 3.16). Monitoring catalysis using 3.7 until deactivation results in a TON of 469 , which is an $\sim 5.6$ fold increase compared to the tbpy catalyst (TON of 84) under identical 
conditions. The identities of the catalyst decomposition products are unknown as Pt black and several intractable products are observed by ${ }^{1} \mathrm{H}$ NMR spectroscopy at the end of the reaction. From examination of the TO versus time plots that highlight catalyst decay and assuming that TOF is proportional to the concentration of active catalyst in solution (i.e., catalysis is first-order in concentration of $\mathrm{Pt}$, which we have demonstrated experimentally), it is possible to determine the order in platinum during decomposition by kinetic modeling. Both complexes 3.7 and 3.2b display decomposition that is secondorder in platinum. From a plot of the inverse of TOF versus time, observed rate constants for decomposition were found to be 1.61(8) $\times 10^{-3} \mathrm{M}^{-1} \mathrm{~s}^{-1}$ and $1.0(2) \times 10^{-2} \mathrm{M}^{-1} \mathrm{~s}^{-1}$ for complex 3.7 and 3.2b, respectively (Figure 3.18). A similar treatment for first-order decomposition (a plot of the natural log of TOF versus time) provided a poorer linear correlation.

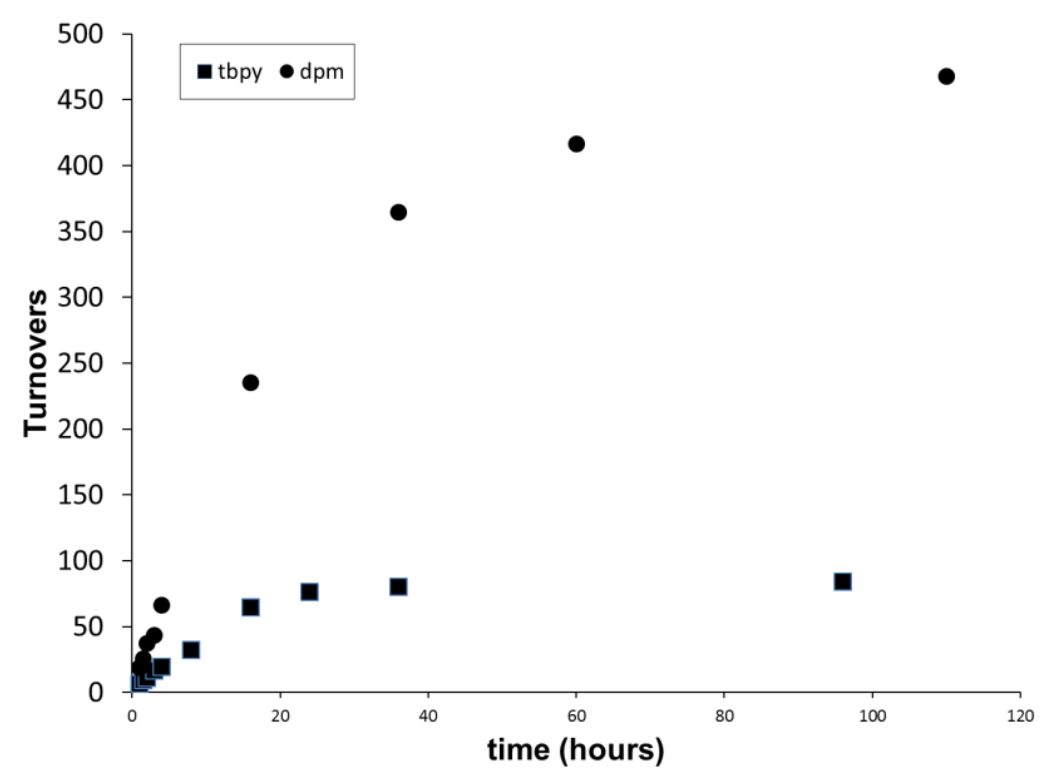

Figure 3.16. Comparison of $\mathrm{TO}$ versus time for ethylene hydrophenylation $\left(100{ }^{\circ} \mathrm{C}\right)$ catalyzed by $[(\mathrm{N} \sim \mathrm{N}) \mathrm{Pt}(\mathrm{Ph})(\mathrm{THF})]^{+}(\mathrm{N} \sim \mathrm{N})={ }^{\mathrm{t}}$ bpy $(\boldsymbol{\bullet})$; dpm $(\bullet) .0 .01 \mathrm{~mol} \% \mathrm{Pt}$ in $\mathrm{C}_{6} \mathrm{H}_{6}$ with $0.1 \mathrm{MPa} \mathrm{C}_{2} \mathrm{H}_{4}$ and $\mathrm{HMB}$ as an internal standard. 


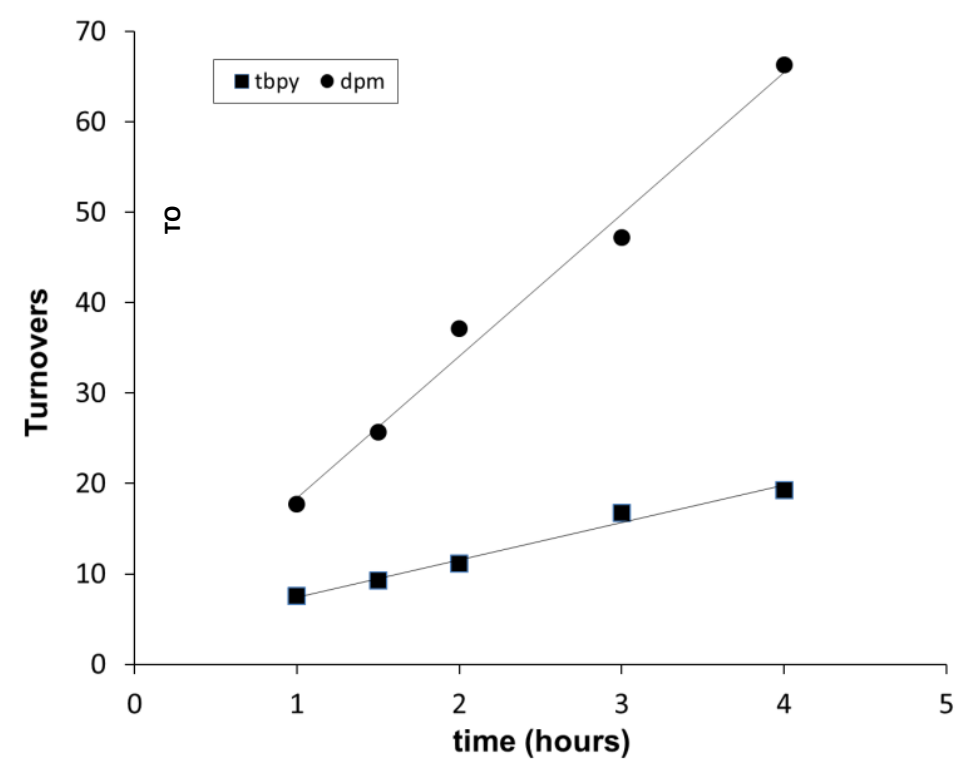

Figure 3.17. Comparison of TO versus time ( $\leq 4$ hours) for ethylene hydrophenylation $\left(100{ }^{\circ} \mathrm{C}\right)$ catalyzed by $[(\mathrm{N} \sim \mathrm{N}) \mathrm{Pt}(\mathrm{Ph})(\mathrm{THF})]^{+}\left(\mathrm{N} \sim \mathrm{N}={ }^{\mathrm{t}}\right.$ bpy $(\boldsymbol{\bullet}), \mathrm{R}^{2}=0.98 ; \operatorname{dpm}(\bullet), \mathrm{R}^{2}=$ 0.99). $0.01 \mathrm{~mol} \% \mathrm{Pt}$ in $\mathrm{C}_{6} \mathrm{H}_{6}$ with $0.1 \mathrm{MPa} \mathrm{C}_{2} \mathrm{H}_{4}$ and $\mathrm{HMB}$ as an internal standard.

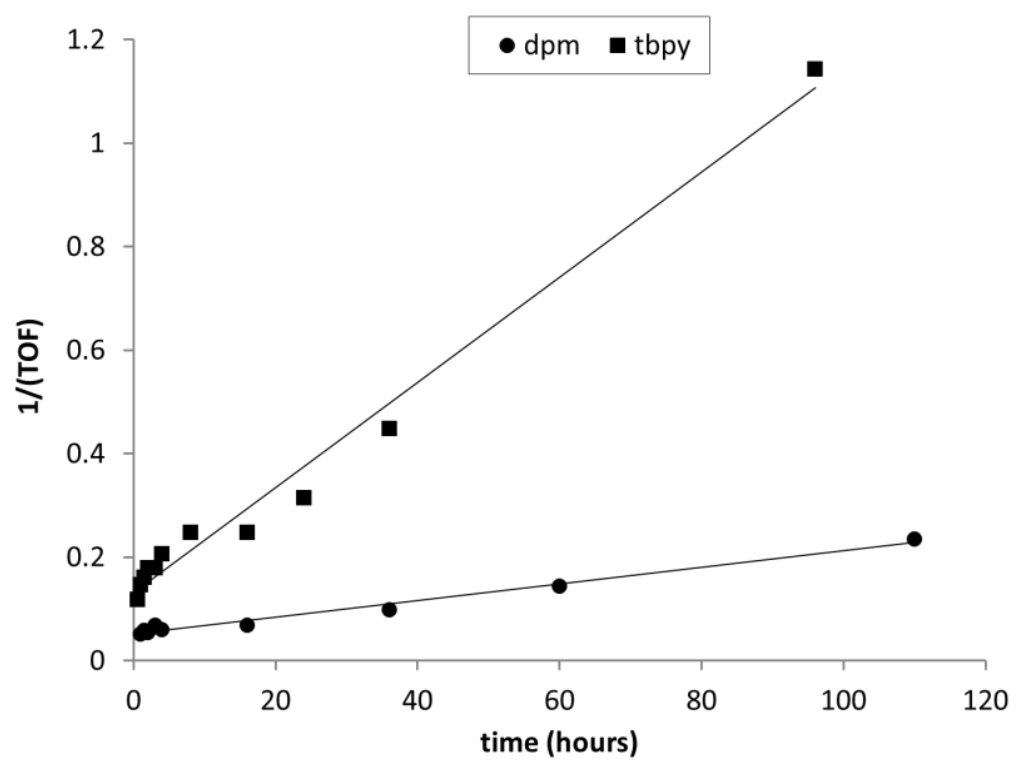

Figure 3.18. Plot of $1 /(\mathrm{TOF})$ as a function of time for ethylene hydrophenylation (100 $\left.{ }^{\circ} \mathrm{C}\right)$ catalyzed by $[(\mathrm{N} \sim \mathrm{N}) \mathrm{Pt}(\mathrm{Ph})(\mathrm{THF})]^{+}\left(\mathrm{N} \sim \mathrm{N}={ }^{\mathrm{t}}\right.$ bpy $\left.(\boldsymbol{\bullet}), \mathrm{R}^{2}=0.98 ; \mathrm{dpm}(\bullet), \mathrm{R}^{2}=0.98\right)$ indicates a pathway for decomposition that is second-order in Pt. 


\subsubsection{Evaluation of Catalytic Cycle Elementary Steps and Extraction of Activation Parameters}

In an effort to explain the difference in catalytic activity between $\mathbf{3 . 7}$ and $\mathbf{3 . 2} \mathbf{b}$, ethylene insertion into the $\mathrm{Pt}-\mathrm{Ph}$ bond and benzene $\mathrm{C}-\mathrm{H}$ activation were probed individually for complex 3.7. Ethylene readily inserts into the $\mathrm{Pt}-\mathrm{Ph}$ bond of $\mathbf{3 . 7}$ to form $\left[(\mathrm{dpm}) \mathrm{Pt}\left(\mathrm{CH}_{2} \mathrm{CH}_{2} \mathrm{Ph}\right)\left(\eta^{2}-\mathrm{C}_{2} \mathrm{H}_{4}\right)\right]\left[\mathrm{BAr}_{4}^{\prime}\right]$ (3.8). Under pseudo first-order conditions, the conversion of 3.7 to 3.8 in $\mathrm{CD}_{2} \mathrm{Cl}_{2}$ at $23{ }^{\circ} \mathrm{C}$ in the presence of $0.4 \mathrm{M} \mathrm{C}_{2} \mathrm{H}_{4}$ proceeds with an observed rate constant of 8.4(9) $\times 10^{-4} \mathrm{~s}^{-1}$ (Scheme 3.12 and Figure 3.19). Thus, the observed rate of ethylene insertion for 3.7 is slower than $\left.\left.\left[{ }^{t} \mathrm{bpy}\right) \mathrm{Pt}(\mathrm{Ph})(\mathrm{THF})\right]^{+} \mathbf{( 3 . 2 b}\right)\left(k_{\mathrm{obs}}\right.$ $=1.46 \times 10^{-3} \mathrm{~s}^{-1}$ ) under similar conditions by a factor of $\sim 1.7$.

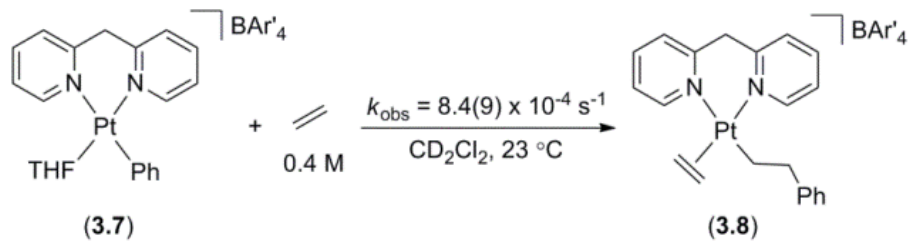

Scheme 3.12. Ethylene insertion into the $\mathrm{Pt}-\mathrm{Ph}$ bond of complex 3.7 to form $\left[(\mathrm{dpm}) \mathrm{Pt}\left(\mathrm{CH}_{2} \mathrm{CH}_{2} \mathrm{Ph}\right)\left(\eta^{2}-\mathrm{C}_{2} \mathrm{H}_{4}\right)\right]\left[\mathrm{BAr}_{4}^{\prime}\right](\mathbf{3 . 8})$. 


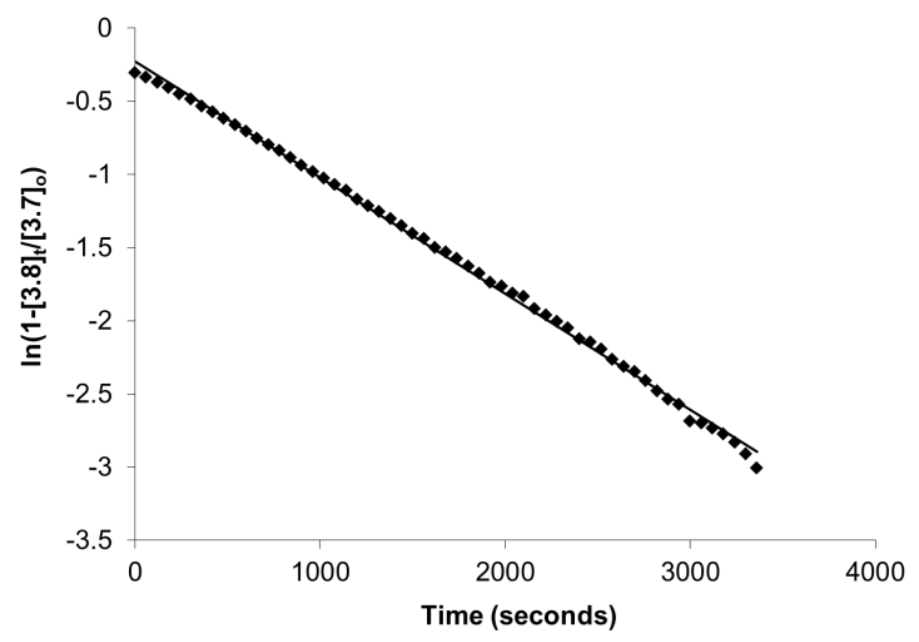

Figure 3.19. Representative kinetic plot for the conversion of $\mathbf{3 . 7}$ to $3.8([3.7]=0.03 \mathrm{M}$, $\left.\left[\mathrm{C}_{2} \mathrm{H}_{4}\right]=0.4 \mathrm{M}, 23^{\circ} \mathrm{C}\right)$.

Comparative rates of benzene $\mathrm{C}-\mathrm{D}$ activation by $\mathbf{3 . 7}$ and $\mathbf{3 . 2 b}$ were studied using reactions with excess $\mathrm{C}_{6} \mathrm{D}_{6}$ to form $\left[(\mathrm{N} \sim \mathrm{N}) \mathrm{Pt}\left(\mathrm{Ph}-d_{5}\right)(\mathrm{THF})\right]^{+}\left(\mathbf{3 . 7}-\boldsymbol{d}_{\mathbf{5}}\right.$ or $\left.\mathbf{3 . 2 b}-\boldsymbol{d}_{\mathbf{5}}\right)$ and free $\mathrm{C}_{6} \mathrm{H}_{5} \mathrm{D}$. The reaction of $\mathbf{3 . 7}$ and $\mathrm{C}_{6} \mathrm{D}_{6}(0.5 \mathrm{M})$ occurs with a $k_{\text {obs }}$ of $9.9(4) \times 10^{-5} \mathrm{~s}^{-1}$ at 29 ${ }^{\circ} \mathrm{C}$ in $\mathrm{CD}_{2} \mathrm{Cl}_{2}$ (Scheme 3.13 and Figure 3.20). As observed with olefin insertion, benzene $\mathrm{C}-\mathrm{D}$ activation by 3.7 is almost twice as slow as activation by $\left[\left({ }^{\mathrm{t}} \mathrm{bpy}\right) \mathrm{Pt}(\mathrm{Ph})(\mathrm{THF})\right]^{+}\left(k_{\mathrm{obs}}\right.$ $\left.=1.71(5) \times 10^{-4} \mathrm{~s}^{-1}\right)^{1}$

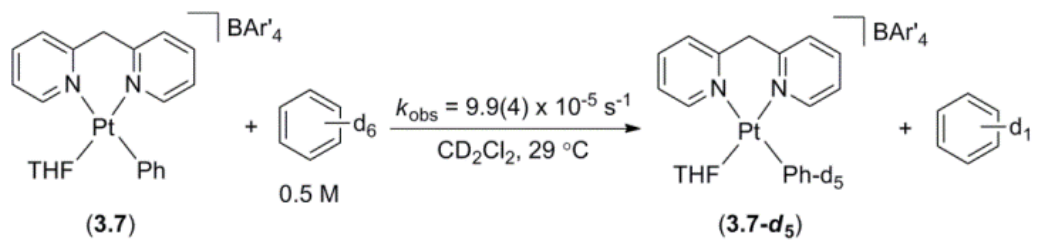

Scheme 3.13. Observation of stoichiometric benzene C-D activation by complex 3.7 to form 3.7-d in $\mathrm{CD}_{2} \mathrm{Cl}_{2}$ at $29^{\circ} \mathrm{C}$. 


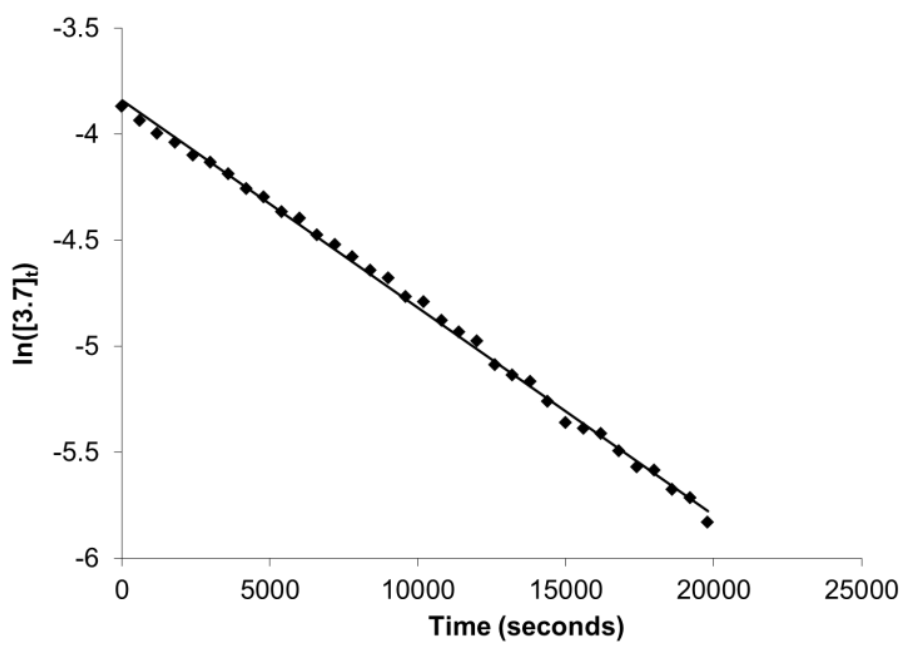

Figure 3.20. Representative kinetic plot for the conversion of 3.7 to $3.7-d_{5}([3.7]=0.03$ $\left.\mathrm{M},\left[\mathrm{C}_{6} \mathrm{H}_{6}\right]=0.5 \mathrm{M}, 29{ }^{\circ} \mathrm{C}\right)$.

The complexes $\left[(\mathrm{N} \sim \mathrm{N}) \operatorname{Pt}\left(\mathrm{CH}_{2} \mathrm{CH}_{2} \mathrm{Ph}\right)\left(\eta^{2}-\mathrm{C}_{2} \mathrm{H}_{4}\right)\right]^{+}\left[\mathrm{N} \sim \mathrm{N}=\operatorname{dpm}(\mathbf{3 . 8})\right.$ or ${ }^{\mathrm{t}}$ bpy (3.3b) $]$ have been identified as the resting states for catalytic ethylene hydrophenylation, and benzene $\mathrm{C}-\mathrm{H}$ activation is likely the catalytic rate limiting step for complex 3 . ${ }^{1}$ Relative rates of stoichiometric benzene activation by $\mathbf{3 . 8}$ or $\mathbf{3 . 3 b}$ to produce ethylbenzene and $\mathbf{3 . 7}$ or 3.2b are similar to that observed for $\mathrm{C}_{6} \mathrm{D}_{6}$ activation by $\mathbf{3 . 7}$ and $\mathbf{3 . 2 b}$. The dpm complex 3.8 reacts with benzene $(1.5 \mathrm{M})$ with an observed rate constant of $7.5(3) \times 10^{-5} \mathrm{~s}^{-}$ ${ }^{1}$ at $54{ }^{\circ} \mathrm{C}$. The reaction using $\mathbf{3 . 3 b}$ proceeds $\sim 5$ times faster with an observed rate constant of $\sim 4 \times 10^{-4} \mathrm{~s}^{-1}$. However, highly accurate integration of ${ }^{1} \mathrm{H}$ NMR spectra was prevented by coincidental overlap of resonances between $\mathbf{3 . 3 b}$ and ethylbenzene, and the ratio of rates is approximate.

The rates of the stoichiometric reactions $\left(<90^{\circ} \mathrm{C}\right)$ are reduced for the dpm complexes, whether utilizing complex $\mathbf{3 . 7}$ or $\mathbf{3 . 8}$, versus their ${ }^{t}$ bpy analogues $\mathbf{3 . 2 b}$ and $\mathbf{3 . 3 b}$, respectively. It was surmised that entropic factors might be important to the overall 
difference in activation barriers $\left(\Delta \Delta G^{\ddagger}\right)$ for catalytic ethylene hydrophenylation. The rates of catalytic and stoichiometric reactions were determined over a range of temperatures. Activation parameters for ethylene hydrophenylation by each complex were obtained from Eyring plots $\left(50-100{ }^{\circ} \mathrm{C}\right.$ ) (Figure 3.21). Ideally, the rates of catalysis could be determined using in situ ${ }^{1} \mathrm{H}$ NMR spectroscopy. However, significant overlap between the resonances of the catalyst resting state and the alkyl benzene products prevented accurate integration. We chose instead to compare TOFs calculated after reaction times in which catalyst decomposition is negligible (Figure 3.17 and Table 3.5). Using the second-order rate constants for catalyst decomposition (see above), the percent decrease in active catalyst concentration was determined for 1 hour at $100{ }^{\circ} \mathrm{C}$. For catalysis using complex 3.7, the decrease in active catalyst concentration is calculated to be less than $1 \%$. Catalysis with complex $\mathbf{3 . 2 b}$ is calculated to have $\sim 4 \%$ catalyst decomposition after 1 hour at $100{ }^{\circ} \mathrm{C}$. The negligible degree of catalyst decomposition at $100{ }^{\circ} \mathrm{C}$ and the fact that catalyst decomposition at lower temperatures will proceed at slower rates support the use of TOF in place of rate constants in an Eyring plot. The TOF and activation parameters are summarized in Table 3.5. The values of $\Delta H^{\ddagger}$ are $29(3) \mathrm{kcal} / \mathrm{mol}$ and 23(2) $\mathrm{kcal} / \mathrm{mol}$ for $\mathbf{3 . 7}$ and $\mathbf{3 . 2 b}$, respectively, with a $\Delta \Delta H^{\ddagger}$ of $6(4) \mathrm{kcal} / \mathrm{mol}$ in favor of the bipyridyl-supported complex 3.2b. Interestingly, the $\Delta S^{\ddagger}$ value for $3.7[6(9)$ eu] is positive while the $\Delta S^{\ddagger}$ value for $3.2 \mathbf{b}[-11(6)$ eu] is negative and larger in magnitude. Although the deviations for the $\Delta S^{\ddagger}$ values are relatively large, as is often observed, it is clear that 3.7 has an entropic advantage over 3.2b, and the Eyring plot (Figure 3.21) shows that $\mathbf{3 . 7}$ is a more active catalyst than $\mathbf{3 . 2} \mathbf{b}$ at temperatures $\geq 90{ }^{\circ} \mathrm{C}$. 
Table 3.5. Turnover frequencies for ethylene hydrophenylation $\left(50-100{ }^{\circ} \mathrm{C}\right)$ and

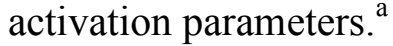

\begin{tabular}{|c|c|c|c|c|}
\hline \multirow{3}{*}{$\begin{array}{c}\text { Temperature } \\
\left({ }^{\circ} \mathrm{C}\right)\end{array}$} & \multicolumn{4}{|c|}{$[(\mathrm{N} \sim \mathrm{N}) \operatorname{Pt}(\mathrm{Ph})(\mathrm{THF})]^{+}$} \\
\hline & \multicolumn{2}{|c|}{ dpm (3.7) } & \multicolumn{2}{|c|}{ tbpy (3.2b) } \\
\hline & $\begin{array}{c}\mathrm{TOF} \\
\left(10^{-5} \mathrm{~s}^{-1}\right)\end{array}$ & $\begin{array}{l}\Delta G_{\text {calculate }}^{\ddagger} \\
(\mathrm{kcal} / \mathrm{mol})^{b}\end{array}$ & $\begin{array}{c}\text { TOF } \\
\left(10^{-5} s^{-1}\right)\end{array}$ & $\begin{array}{l}\Delta G^{\ddagger} \text { calculate } \\
(\mathrm{kcal} / \mathrm{mol})^{b}\end{array}$ \\
\hline $50^{c}$ & 1.1(3) & $27(3)$ & 1.1(1) & $27(2)$ \\
\hline $70^{c}$ & $6.6(5)$ & $27(3)$ & $9(1)$ & $27(2)$ \\
\hline $90^{d}$ & $140(60)$ & $27(3)$ & $44(5)$ & $27(2)$ \\
\hline $100^{e}$ & $510(20)$ & $27(3)$ & $210(30)$ & $27(2)$ \\
\hline$\Delta H^{\ddagger}(\mathrm{kcal} / \mathrm{mol})$ & \multicolumn{2}{|r|}{ (3) } & \multicolumn{2}{|c|}{$23(2)$} \\
\hline$\Delta S^{\ddagger}(\mathrm{eu})$ & \multicolumn{2}{|c|}{$6(9)$} & \multicolumn{2}{|c|}{$-11(6)$} \\
\hline
\end{tabular}

${ }^{\text {a }} 0.01$ mol \% catalyst in $\mathrm{C}_{6} \mathrm{H}_{6}$ with $\mathrm{HMB}$ as an internal standard. ${ }^{b}$ Free energy of activation calculated using experimental enthalpies and entropies of activation. ${ }^{\mathrm{c}} \mathrm{TOF}$ calculated after 16 hours. ${ }^{\mathrm{d}}$ TOF calculated after 4 hours. ${ }^{\mathrm{e}}$ TOF calculated after 1 hour.

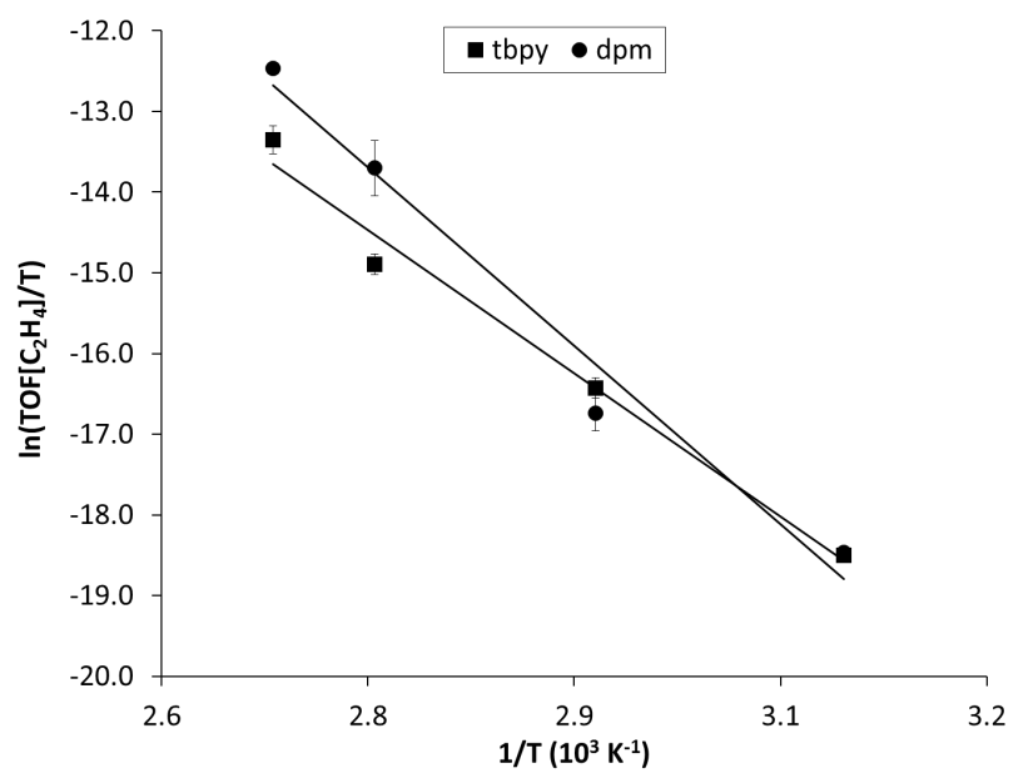

Figure 3.21. Eyring plots for ethylene hydrophenylation catalyzed by $[(\mathrm{N} \sim \mathrm{N}) \mathrm{Pt}(\mathrm{Ph})(\mathrm{THF})]^{+}\left(\mathrm{N} \sim \mathrm{N}={ }^{\mathrm{t}}\right.$ bpy $\left.(\boldsymbol{\bullet}), \mathrm{R}^{2}=0.98 ; \operatorname{dpm}(\bullet), \mathrm{R}^{2}=0.98\right)$. 
Due to a lack of highly accurate integration in ${ }^{1} \mathrm{H}$ NMR spectra for stoichiometric reactions with $\mathbf{3 . 8}$ and 3.3b with benzene, activation parameters for stoichiometric $\mathrm{C}-\mathrm{D}$ activation of $\mathrm{C}_{6} \mathrm{D}_{6}$ by $\mathbf{3 . 7}$ and 3.2b were obtained from Eyring plots $\left(29-59{ }^{\circ} \mathrm{C}\right.$, Figure 3.22). Enthalpies of activation for $\mathrm{C}_{6} \mathrm{D}_{6}(0.5 \mathrm{M}) \mathrm{C}-\mathrm{D}$ activation are statistically indistinguishable between the complexes with values of 23(2) $\mathrm{kcal} / \mathrm{mol}$ and 19(2) $\mathrm{kcal} / \mathrm{mol}$ for $\mathbf{3 . 7}$ and 3.2b, respectively (Table 3.6). Similar to the $\Delta S^{\ddagger}$ values for catalytic ethylene hydrophenylation, 3.2b suffers a larger entropic penalty, compared to 3.7, with a $\Delta S^{\ddagger}$ value of -10(6) eu for the activation of a $\mathrm{C}-\mathrm{D}$ bond of $\mathrm{C}_{6} \mathrm{D}_{6}$, while the reaction is almost entropically neutral for $3.7\left(\Delta S^{\ddagger}=0(4)\right.$ eu). Unfortunately, deviations in $\Delta S^{\ddagger}$ for $\mathrm{C}_{6} \mathrm{D}_{6}$ activation are too large to provide a meaningful comparison.

Table 3.6. Activation parameters and $k_{\mathrm{obs}}$ for $\mathrm{C}_{6} \mathrm{D}_{6} \mathrm{C}-\mathrm{D}$ activation $\left(29-59{ }^{\circ} \mathrm{C}\right){ }^{\mathrm{a}}$

\begin{tabular}{ccccc}
\hline \multirow{2}{*}{$\begin{array}{c}\text { Temperature } \\
\left({ }^{\circ} \mathrm{C}\right)\end{array}$} & \multicolumn{3}{c}{$\mathrm{dpm}(\mathbf{3 . 7})$} & \multicolumn{2}{c}{\begin{tabular}{c}
$\mathrm{t}$ bpy $(\mathbf{3 . 2 b})$ \\
\cline { 2 - 5 }
\end{tabular}} & $\begin{array}{c}k_{\text {obs }} \\
\left(10^{-4} \mathrm{~s}^{-1}\right)\end{array}$ & $\begin{array}{c}\Delta G_{\text {calculate }}^{\ddagger} \\
(\mathrm{kcal} / \mathrm{mol})^{\mathrm{b}}\end{array}$ & $\begin{array}{c}k_{\text {obs }} \\
\left(10^{-4} \mathrm{~s}^{-1}\right)\end{array}$ & $\begin{array}{c}\Delta G^{\ddagger} \text { calculate } \\
(\mathrm{kcal} / \mathrm{mol})^{\mathrm{b}}\end{array}$ \\
\hline 29 & $0.99(4)$ & $23(2)$ & $1.71(4)$ & $22(2)$ \\
37 & $2.00(5)$ & $23(2)$ & $5.7(3)$ & $22(2)$ \\
45 & $6.8(2)$ & $23(2)$ & $9.17(8)$ & $22(2)$ \\
54 & $17.3(4)$ & $23(2)$ & $18.5(5)$ & $22(2)$ \\
59 & $30(2)$ & $23(2)$ & $44(7)$ & $22(2)$ \\
\hline$\Delta H^{\ddagger}(\mathrm{kcal} / \mathrm{mol})$ & \multicolumn{2}{c}{$23(2)$} & \multicolumn{2}{c}{$19(2)$} \\
$\Delta S^{\ddagger}(\mathrm{eu})$ & \multicolumn{2}{c}{$0(4)$} & $-10(6)$
\end{tabular}

${ }^{\mathrm{a}}$ Determined by ${ }^{\mathrm{I}} \mathrm{H}$ NMR spectroscopy with $[\mathrm{Pt}]=0.03 \mathrm{M}$ and $\left[\mathrm{C}_{6} \mathrm{D}_{6}\right]=0.5 \mathrm{M}$ in $\mathrm{CD}_{2} \mathrm{Cl}_{2}$ with hexamethyldisilane as an internal standard. ${ }^{\mathrm{b}}$ Free energy of activation calculated using experimental enthalpies and entropies of activation. 


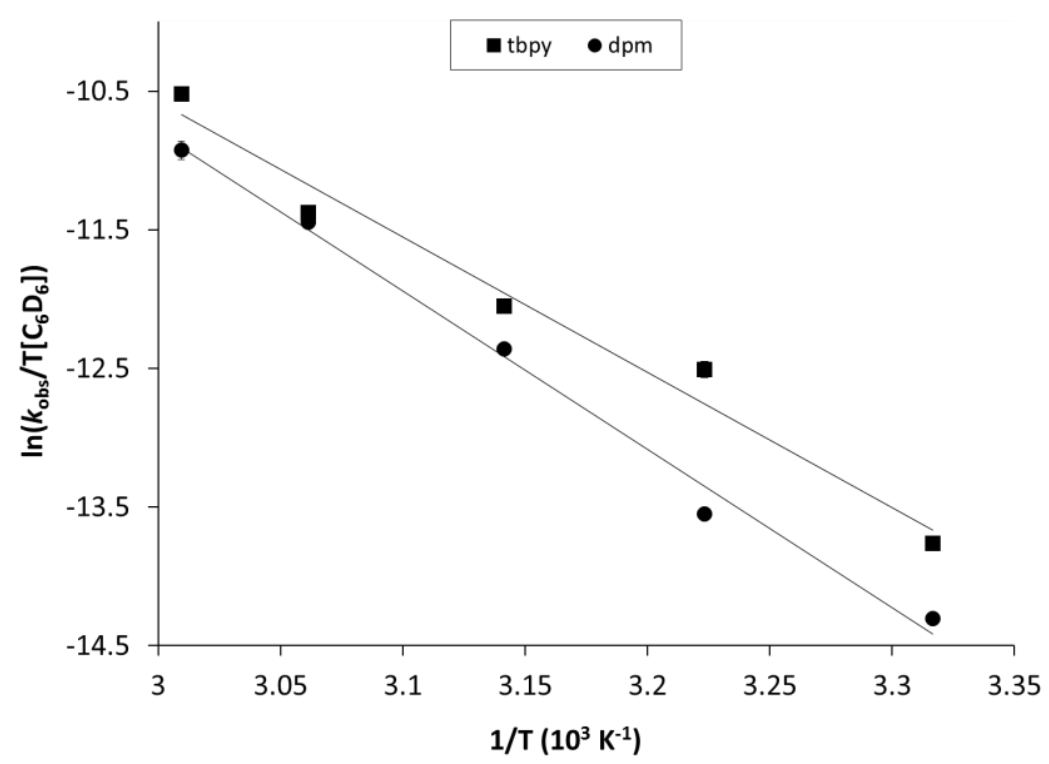

Figure 3.22. Eyring plots for $\mathrm{C}_{6} \mathrm{D}_{6} \mathrm{C}-\mathrm{D}$ activation by $[(\mathrm{N} \sim \mathrm{N}) \mathrm{Pt}(\mathrm{Ph})(\mathrm{THF})]^{+}$. $\mathrm{N} \sim \mathrm{N}={ }^{\mathrm{t}}$ bpy $(\bullet), \mathrm{R}^{2}=0.98 ; \operatorname{dpm}(\bullet), \mathrm{R}^{2}=0.99$. Due to their small value, the deviations are obscured by the size of the data point markers.

DFT studies, performed by the Cundari group (University of North Texas), were used to compare catalysis with the dpm and bpy complexes. Since $\left[(\mathrm{N} \sim \mathrm{N}) \mathrm{Pt}\left(\mathrm{CH}_{2} \mathrm{CH}_{2} \mathrm{Ph}\right)\left(\eta^{2}-\right.\right.$ $\left.\left.\mathrm{C}_{2} \mathrm{H}_{4}\right)\right]^{+}\left[\mathrm{N} \sim \mathrm{N}=\operatorname{dpm}(\mathbf{3 . 8})\right.$ or ${ }^{\mathrm{t}}$ bpy (3.3b) $]$ is observed as the catalyst resting state, ${ }^{1}$ activation parameters for benzene $\mathrm{C}-\mathrm{H}$ activation were calculated relative to these intermediates. A crystal suitable for an X-ray diffraction study was grown from slow diffusion of n-pentane into a solution of complex $\mathbf{3 . 8}$ in dichloromethane, and the structure of complex $\mathbf{3 . 8}$ is shown in Figure 3.23. As observed for the structure of $\left[\left({ }^{t} \mathrm{bpy}\right) \mathrm{Pt}\left(\mathrm{CH}_{2} \mathrm{CH}_{2} \mathrm{Ph}\right)\left(\eta^{2}-\mathrm{C}_{2} \mathrm{H}_{4}\right)\right]^{+}(\mathbf{3 . 3 b}),{ }^{1}$ the phenyl ring is juxtaposed over the cispyridyl ring, but the methylene group of the dpm ligand removes planarity, which increases the $\pi-\pi$ distance for the dpm complex $\mathbf{3 . 8}$ compared to bpy complex $\mathbf{3 . 3 b}$. In the solid state, the $\pi-\pi$ distance in $\mathbf{3 . 8}$ is $4.32 \AA$, whereas in $\mathbf{3 . 3 b}$ this distance is only 
$3.68 \AA .{ }^{10}$ Given $\pi$-arene stacking between a pyridine ring of $\mathrm{N} \sim \mathrm{N}$ and the phenyl group of the phenethyl ligand in the crystal structures of $\left[(\mathrm{N} \sim \mathrm{N}) \mathrm{Pt}\left(\mathrm{CH}_{2} \mathrm{CH}_{2} \mathrm{Ph}\right)\left(\eta^{2}-\mathrm{C}_{2} \mathrm{H}_{4}\right)\right]^{+}$, calculations with and without this interaction in the resting states and transition states were modeled. We focused on $\mathrm{C}-\mathrm{H}$ oxidative addition of benzene since previous research indicated this to be the preferred pathway for benzene $\mathrm{C}-\mathrm{H}$ activation. ${ }^{1}$

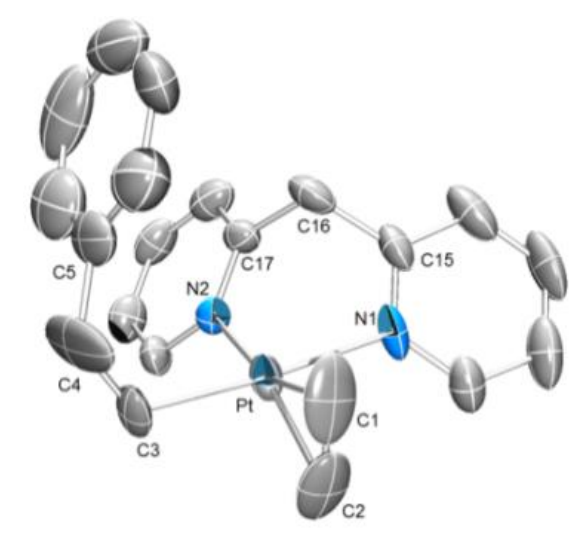

Figure 3.23. ORTEP of $\left[(\mathrm{dpm}) \mathrm{Pt}\left(\mathrm{CH}_{2} \mathrm{CH}_{2} \mathrm{Ph}\right)\left(\eta^{2}-\mathrm{C}_{2} \mathrm{H}_{4}\right)\right]\left[\mathrm{BAr}_{4}\right]$ (3.8) (50\% probability; $\mathrm{H}$ atoms and $\mathrm{BAr}_{4}$ anion omitted for clarity) Selected bond lengths ( $\AA$ ): Pt-N1 2.135(7), $\mathrm{Pt}-\mathrm{N} 2$ 2.068(6), Pt-C3 2.049(8), Pt-C1 2.113(9), Pt-C2 2.113(9), C1-C2 1.37(2). Selected bond angles $\left({ }^{\circ}\right)$ : N1-Pt-N2 85.3(3), Pt-C3-C4 118.9(8), C3-C4-C5 125.0(1).

For both the dpm and tbpy resting states, $\mathbf{3 . 8}$ and $\mathbf{3 . 3 b}$, the non-stacked conformations were calculated to be more favorable at $100{ }^{\circ} \mathrm{C}$ (Scheme 3.14) and were used to calculate activation parameters for benzene $\mathrm{C}-\mathrm{H}$ activation. Table 3.7 shows calculated activation parameters for the lowest energy conversions of $\mathbf{3 . 8}$ and $\mathbf{3 . 3} \mathbf{b}$ to the transition states for benzene $\mathrm{C}-\mathrm{H}$ activation. Consistent with experimental observations, calculated activation parameters for $\mathbf{3 . 8}$ and $\mathbf{3 . 3 \mathrm { b }}$ are similar. At $100{ }^{\circ} \mathrm{C}$, the model predicts complex $\mathbf{3 . 8}$ to have an $\sim 3 \mathrm{kcal} / \mathrm{mol}$ advantage over complex 3.3b. Importantly, DFT calculations indicate a more favorable $\Delta S^{\ddagger}$ for $\mathbf{3 . 8}$ compared with 3.3b. Given the anticipated limits of 
such calculations and experimental uncertainties, the DFT calculations are in agreement with experiment.

Our experimental and computational studies did not provide a definitive rationale to explain the influence of the chelate ring size on the relative entropy of activation. The $\mathrm{sp}^{3}$ methylene linker imparts more flexibility to the ancillary ligand. The adoption of the pseudo-boat conformation by complex $\mathbf{3 . 8}$ and the resulting out of plane rotation of the pyridyl rings (see above) could alleviate steric repulsions between the hydrocarbyl ligands and the $6 / 6$ '-positions of the dipyridyl ligand. ${ }^{11}$ Moreover, the lack of planarity could hinder the extent of solvent ordering in the transition state. The issue in using these explanations is that they are expected to impact both the ground state and transition states. Computational modeling provided no clear influences to resolve this issue.

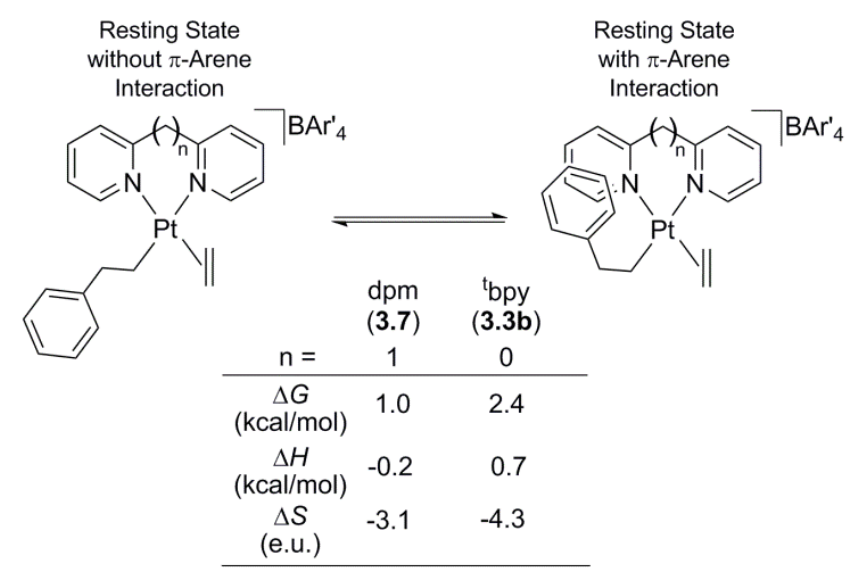

Scheme 3.14. Calculated equilibria $\left(100^{\circ} \mathrm{C}\right)$ between conformations of catalyst resting states containing or lacking $\pi-\pi$ arene interaction. 
Table 3.7. Calculated activation parameters $\left(100^{\circ} \mathrm{C}\right)$ for benzene activation by $\left[(\mathrm{N} \sim \mathrm{N}) \mathrm{Pt}\left(\mathrm{CH}_{2} \mathrm{CH}_{2} \mathrm{Ph}\right)\left(\eta^{2}-\mathrm{C}_{2} \mathrm{H}_{4}\right)\right]^{+}$.

\begin{tabular}{ccc}
\hline $\begin{array}{c}\text { Calculated } \\
\text { Activation } \\
\text { Parameters }\end{array}$ & $\begin{array}{c}\text { dpm } \\
(\mathbf{3 . 7})\end{array}$ & $\begin{array}{c}\text { tbpy } \\
(\mathbf{3 . 3 b})\end{array}$ \\
\hline $\begin{array}{c}\Delta G^{\ddagger} \\
(\mathrm{kcal} / \mathrm{mol}) \\
\Delta H^{\ddagger}\end{array}$ & 36.8 & 39.9 \\
$(\mathrm{kcal} / \mathrm{mol})$ & 37.0 & 39.4 \\
$\Delta S^{\ddagger}$ & 0.5 & -1.6 \\
\hline
\end{tabular}

\subsection{Further Steric and Electronic Ligand Modifications and the Influence on the Efficiency of $\mathrm{Pt}^{\mathrm{II}}$ Catalyzed Ethylene Hydroarylation}

The expansion of the dipyridyl ligand from a five- to six-membered chelate (i.e., using dpm in place of tbpy) provides an enhancement of catalyst activity and longevity. However, diethylbenzenes constitute a significant portion of the total alkyl arene products using bipyridyl and dipyridylmethane ligated $\mathrm{Pt}^{\mathrm{II}}$ catalyst precursors and likely result from aromatic $\mathrm{C}-\mathrm{H}$ activation competing with ethylbenzene dissociation. ${ }^{1}$ Increasing the steric congestion around the Pt center might facilitate ethylbenzene displacement and provide increased selectivity for monoalkylated products. Moreover, steric perturbations about the Pt center could have a marked effect on the regioselectivity of $\alpha$-olefin hydroarylation (i.e., selectivity for Markovnikov versus anti-Markovnikov products). Further steric modifications to the catalyst including 6/6'-pyridyl substitution, chelate ring size and the identity of the bridging pyridyl functionality on catalyst activity and selectivity were studied and compared to previously reported systems. 


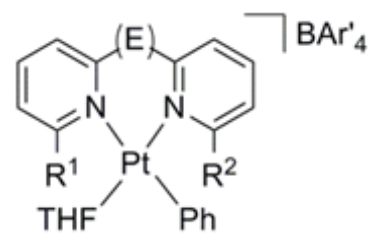

Chart 3.1. Generic structure for dipyridyl ligated $\mathrm{Pt}^{\mathrm{II}}$ complexes, highlighting the substituents studied in this report $\left(\mathrm{E}=\mathrm{CH}_{2}, \mathrm{CH}_{2} \mathrm{CH}_{2}, \mathrm{C}=\mathrm{O}, \mathrm{NH}\right.$ or $\mathrm{O} ; \mathrm{R}^{1}, \mathrm{R}^{2}=\mathrm{H}$ or $\left.\mathrm{Me}\right)$.

\subsubsection{Complex Synthesis and Characterization}

The complexes $(\mathrm{N} \sim \mathrm{N}) \mathrm{PtPh}_{2}[\mathrm{~N} \sim \mathrm{N}=6$-methyl-2,2'-dipyridylmethane (Me-dpm, 3.9); 6,6'-dimethyl-2,2'-dipyridylmethane ( $\mathrm{Me}_{2}$-dpm, 3.10); 6,6'-dimethyl-2,2'-bipyridine (Me 2 -bpy, 3.11); 1,2-bis(2-pyridyl)ethane (dpe, 3.12)] were prepared by reaction of the appropriate dipyridyl ligand with the binuclear platinum dimer $\left[\mathrm{Pt}(\mathrm{Ph})_{2}\left(\mu-\mathrm{Et}_{2} \mathrm{~S}\right)\right]_{2}$ (Scheme 3.15). Crystals suitable for an X-ray diffraction study were obtained for complexes $(\mathrm{dpm}) \mathrm{PtPh}_{2}\left(\mathrm{dpm}=2,2^{\prime}\right.$-dipyridylmethane, 3.6), 3.10 and 3.12 (Figure 3.24 and Table 3.8). For the dpm complex 3.6, the $\mathrm{N}-\mathrm{Pt}-\mathrm{N}$ angle is increased by $\sim 9^{\circ}$ to $86.0(3)^{\circ}$ relative to the reported structure of $\left({ }^{\mathrm{t}} \mathrm{bpy}\right) \mathrm{Pt}(\mathrm{Ph})_{2}\left(77.1(2)^{\circ} ;{ }^{\mathrm{t}} \mathrm{bpy}=4,4^{\prime}\right.$-di-tertbutyl-2,2'-bipyridine). ${ }^{4}$ The addition of methyl groups to the $6 / 6$ '-positions in complex 3.10 results in an approximate $3^{\circ}$ compression of the $\mathrm{N}-\mathrm{Pt}-\mathrm{N}$ bite angle $\left(83.51(8)^{\circ}\right)$ relative to 3.6. The additional methylene spacer to form a seven-membered chelate ring in complex 3.12 has a negligible effect on the $\mathrm{N}-\mathrm{Pt}-\mathrm{N}$ angle $\left(87.8(2)^{\circ}\right)$ compared to the dipyridylmethane variants. For 2,2'-bipyridyl ligated Pt complexes the pyridyl rings reside approximately in the Pt square plane. ${ }^{4,12}$ In contrast, the dpm complex 3.6 adopts a pseudo-boat conformation that causes the pyridyl rings to be contorted out of the $\mathrm{Pt}$ square plane by $\sim 42^{\circ}$ (average measurement of the $\mathrm{N}-\mathrm{Pt}-\mathrm{N}-\mathrm{C}_{2 \text {-pyridyl }}$ torsion angles). The 
methyl groups in the $6 / 6^{\prime}$-positions of complex $\mathbf{3 . 1 0}$ enhance this distortion with the pyridyl rings $\sim 52^{\circ}$ out of planarity. Coordination of dpe to the $\mathrm{PtPh}_{2}$ fragment results in the pyridyl rings being twisted out of the square plane by $\sim 58^{\circ}$. The $2,2^{\prime}$-bipyridyl complex ( $\left.{ }^{\mathrm{b} p y}\right) \mathrm{Pt}(\mathrm{Ph})_{2}$ possess shorter $\mathrm{Pt}-\mathrm{N}$ and longer $\mathrm{Pt}-\mathrm{C}$ bond lengths compared to complexes 3.6, 3.10 and 3.12, which is consistent with the tbpy ligand exerting a greater trans influence than dpm, 6,6'-dpm or dpe. This could be attributed to the twisting of the pyridyl groups out of the square plane with the addition of methylene spacers, which disrupts the $\pi$-accepting ability of the pyridyl rings due to decreased overlap between $\mathrm{Pt}$ $\mathrm{d} \pi$ and pyridyl $\pi^{*}$ orbitals.

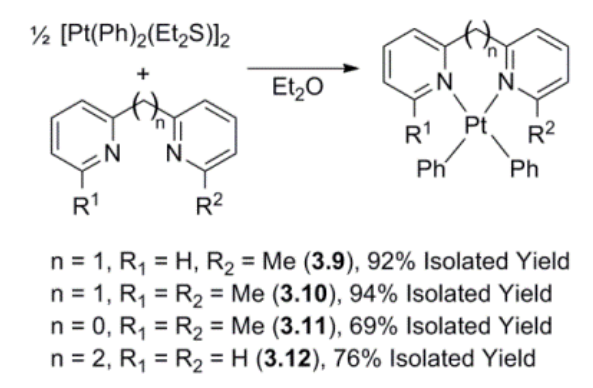

Scheme 3.15. Synthesis and isolated yields for complexes 3.9-3.12.

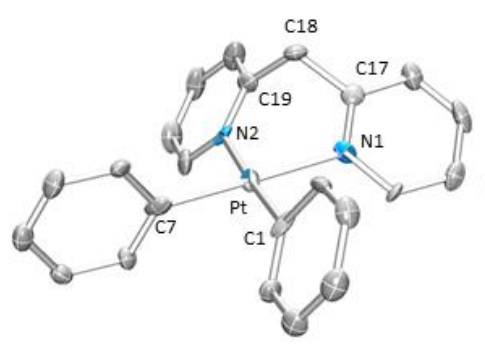

(3.6)

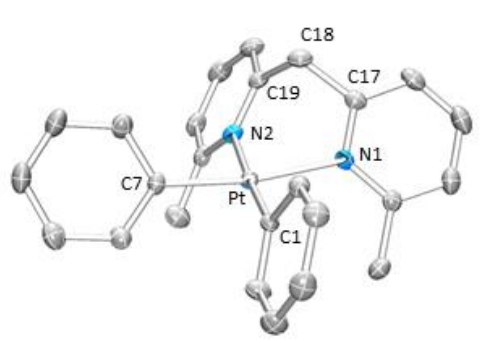

(3.10)

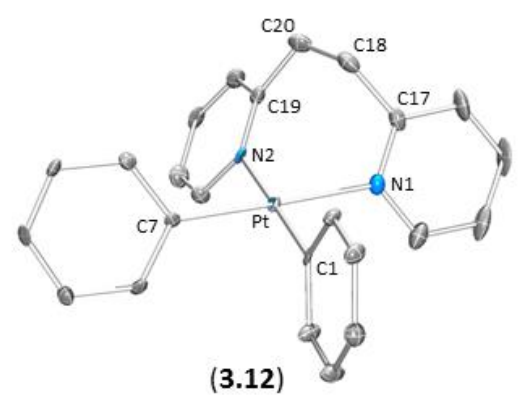

(3.12)

Figure 3.24. ORTEP of complexes $(\mathrm{dpm}) \mathrm{Pt}(\mathrm{Ph})_{2}$ (3.6), $\left(\mathrm{Me}_{2}-\mathrm{dpm}\right) \mathrm{Pt}(\mathrm{Ph})_{2}$ (3.10) and (dpe) $\mathrm{Pt}(\mathrm{Ph})_{2}$ (3.12) (50\% probability; $\mathrm{H}$ atoms omitted for clarity). 
Table 3.8. Comparison of selected bond lengths and angles between complexes $(\mathrm{dpm}) \mathrm{Pt}(\mathrm{Ph})_{2}$ (3.6), $\left(\mathrm{Me}_{2}-\mathrm{dpm}\right) \mathrm{Pt}(\mathrm{Ph})_{2}$ (3.10), (dpe) $\mathrm{Pt}(\mathrm{Ph})_{2}$ (3.12) and (tbpy) $\mathrm{Pt}(\mathrm{Ph})_{2}$.

\begin{tabular}{|c|c|c|c|c|}
\hline Complex & 3.6 & 3.10 & 3.12 & ('bpy)Pt(Ph) ${ }_{2}{ }^{\mathrm{a}}$ \\
\hline \multicolumn{5}{|c|}{ Bond Lengths $(\AA)$} \\
\hline Pt-N1 & $2.133(7)$ & $2.138(2)$ & $2.124(7)$ & $2.097(3)$ \\
\hline $\mathrm{Pt}-\mathrm{N} 2$ & $2.147(7)$ & $2.131(2)$ & $2.137(6)$ & $2.097(3)$ \\
\hline $\mathrm{Pt}-\mathrm{C} 1$ & $2.018(8)$ & $1.997(2)$ & $2.016(7)$ & $2.023(2)$ \\
\hline $\mathrm{Pt}-\mathrm{C} 7$ & $2.02(1)$ & $1.998(2)$ & $2.002(7)$ & $2.023(2)$ \\
\hline \multicolumn{5}{|c|}{ Bond Angles $\left({ }^{\circ}\right)$} \\
\hline $\mathrm{N} 1-\mathrm{Pt}-\mathrm{N} 2$ & $86.0(3)$ & $83.51(8)$ & $87.8(2)$ & $77.1(2)$ \\
\hline $\mathrm{N} 2-\mathrm{Pt}-\mathrm{C} 1$ & $176.9(4)$ & $176.44(8)$ & $178.6(3)$ & $174.5(1)$ \\
\hline $\mathrm{N} 1-\mathrm{Pt}-\mathrm{C} 1$ & $91.1(3)$ & $94.06(9)$ & $92.4(3)$ & $97.4(1)$ \\
\hline $\mathrm{C} 1-\mathrm{Pt}-\mathrm{C} 7$ & $88.2(4)$ & $89.0(1)$ & $89.3(3)$ & 88.2(2) \\
\hline C17-C18-C19 & $110.8(8)$ & $110.1(2)$ & - & - \\
\hline C19-C20-C18-C17 & - & - & $53.6(1)$ & - \\
\hline
\end{tabular}

${ }^{\mathrm{a}}$ Crystallographic data obtained from reference 4.

Complexes $[(\mathrm{N} \sim \mathrm{N}) \mathrm{Pt}(\mathrm{Ph})(\mathrm{THF})]\left[\mathrm{BAr}_{4}{ }_{4}\right]$ (3.13-3.16) were prepared by protonation of the corresponding diphenyl complex with $\left[\mathrm{H}\left(\mathrm{Et}_{2} \mathrm{O}\right)_{2}\right]\left[\mathrm{BAr}_{4}{ }_{4}\right]$ at $-70{ }^{\circ} \mathrm{C}$ in $\mathrm{THF}$ (Scheme 3.16). A suitable crystal of $[(\mathrm{dpe}) \mathrm{Pt}(\mathrm{Ph})(\mathrm{THF})]\left[\mathrm{BAr}_{4}\right]$ (3.16) was obtained for an $\mathrm{X}$-ray diffraction study (Figure 3.25). A search of the Cambridge Structural Database revealed only three examples of solid-state structures of $\mathrm{Pt}^{\mathrm{II}}-\mathrm{THF}$ complexes. ${ }^{13-15}$ Comparison of the previously reported structures of $\mathrm{Pt}^{\mathrm{II}}-\mathrm{THF}$ complexes suggests that dpe exerts the weakest trans influence with the $\mathrm{Pt}-\mathrm{O}$ bond length increasing along the series dpe $(2.048(4) \AA)<4,4^{\prime}-\mathrm{Br}_{2}-2,2^{\prime}$-bipyridine $(2.060(7) \AA)<$ cyclooctadiene $(2.077(2) \AA)<$ $\left[\mathrm{Ph}_{2} \mathrm{~B}\left(\mathrm{CH}_{2} \mathrm{PPh}_{2}\right)_{2}\right]^{-}(2.170(4) \AA)$. 


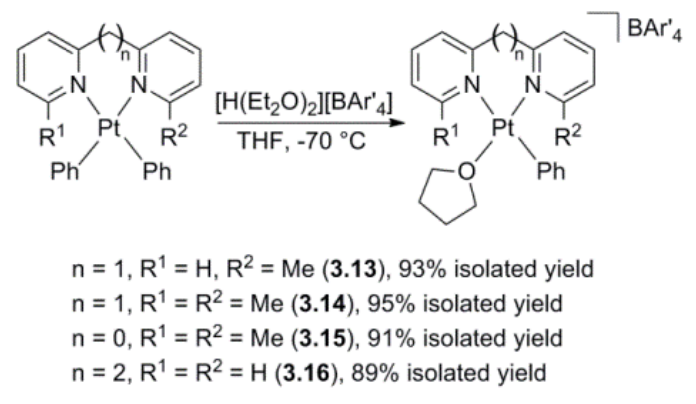

Scheme 3.16. Synthesis and isolated yields of $[(\mathrm{N} \sim \mathrm{N}) \mathrm{Pt}(\mathrm{Ph})(\mathrm{THF})]\left[\mathrm{BAr}_{4}^{\prime}\right]$ (3.13-3.16).

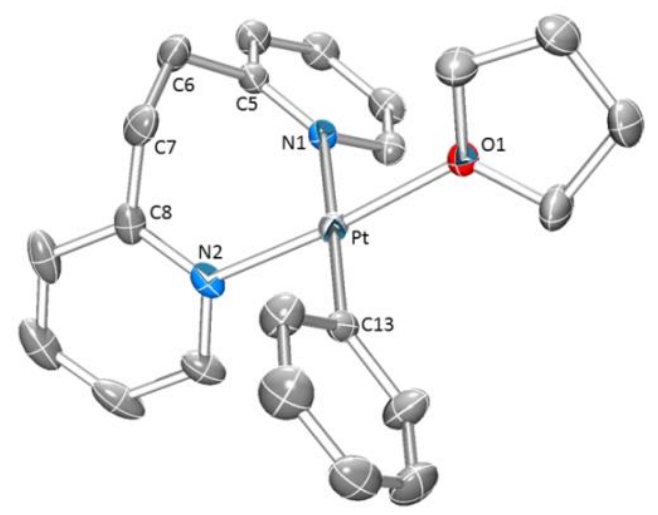

Figure 3.25. ORTEP of $[(\mathrm{dpe}) \mathrm{Pt}(\mathrm{Ph})(\mathrm{THF})]\left[\mathrm{BAr}_{4}{ }_{4}\right](\mathbf{3 . 1 6})\left(50 \%\right.$ probability; $\mathrm{BAr}_{4}{ }_{4}$ anion and $\mathrm{H}$ atoms omitted for clarity). Selected bond lengths $(\AA)$ : $\mathrm{Pt}-\mathrm{N} 12.141(4), \mathrm{Pt}-\mathrm{N} 2$ 1.980(4), Pt-O1 2.048(4), Pt-C13 2.001(5). Selected bond angles $\left(^{\circ}\right)$ : N1-Pt-N2 87.9(2), O1-Pt-C13 93.2(2).

\subsubsection{Catalytic Ethylene Hydroarylation using Complexes 3.13-3.16}

Ethylene hydrophenylation using 3.13-3.16 as catalyst precursors was evaluated, and the results are summarized in Table 3.9. Using data after 4 hours at $100{ }^{\circ} \mathrm{C}$ under 0.1 $\mathrm{MPa}$ of ethylene, complex 3.7 was the most effective catalyst with 65.9 TO of ethylbenzenes and trace styrene. Using 3.7, prolonged reaction times gave 235.2 and 
364.4 total TO of ethylbenzenes and styrene after 16 and 36 hours, respectively, with a TON of 469 after approximately 4 days. The incorporation of methyl substituents in the 6/6'-positions of dpm or 2,2'-bipyridine ligands (3.13-3.15) or an increase in the chelate ring size from a 6-membered to a 7-membered ring using 1,2-bis-(2-pyridyl)ethane (3.16) resulted in a decrease in overall catalyst efficiency relative to $\mathbf{3 . 7}$ (see Table 3.9 and Figure 3.26).

Table 3.9. Comparison of catalytic ethylene hydrophenylation using complexes 3.7 and 3.13-3.16. ${ }^{\mathrm{a}}$

\begin{tabular}{|c|c|c|c|c|c|c|}
\hline Entry & Complex & & & & $o: m: p^{b}$ & $\frac{\operatorname{TOF}^{\mathrm{C}}}{\left(10^{-3} \mathrm{~s}^{-1}\right)}$ \\
\hline 1 & 3.7 & $\begin{array}{c}55.3^{d} \\
(194.9)^{e} \\
{[370.9]^{f}}\end{array}$ & $\begin{array}{c}0.4 \\
(1.1) \\
{[2.3]}\end{array}$ & $\begin{array}{c}10.6 \\
(39.2) \\
{[95.9]}\end{array}$ & 1:9.8:6.8 & 5.1 \\
\hline 2 & 3.13 & $\begin{array}{c}31.2 \\
(54.1) \\
{[57.9]}\end{array}$ & $\begin{array}{c}2.7 \\
(4.2) \\
{[4.9]}\end{array}$ & $\begin{array}{c}1.3 \\
(2.3) \\
{[2.3]}\end{array}$ & 1:0.8:0.8 & 5.1 \\
\hline 3 & 3.14 & $\begin{array}{c}19.5 \\
(22.3) \\
{[26.6]}\end{array}$ & $\begin{array}{c}1.7 \\
(1.9) \\
{[2.3]}\end{array}$ & $\begin{array}{c}\text { trace } \\
(0.3) \\
{[0.5]}\end{array}$ & 1:0:0 & 4.6 \\
\hline 4 & 3.15 & $\begin{array}{c}0 \\
(0) \\
{[0]}\end{array}$ & $\begin{array}{c}0.7 \\
(0.7) \\
{[0.7]}\end{array}$ & $\begin{array}{c}0 \\
(0) \\
{[0]}\end{array}$ & - & - \\
\hline 5 & 3.16 & $\begin{array}{c}0.7 \\
(0.8) \\
{[0.8]}\end{array}$ & $\begin{array}{c}0.4 \\
(0.4) \\
{[0.4]}\end{array}$ & $\begin{array}{c}0 \\
(0) \\
{[0]}\end{array}$ & - & - \\
\hline
\end{tabular}

${ }^{\mathrm{a}} 0.01 \mathrm{~mol} \%$ catalyst dissolved in $\mathrm{C}_{6} \mathrm{H}_{6}$ with hexamethylbenzene as an internal standard at $100{ }^{\circ} \mathrm{C}$ with $0.1 \mathrm{Mpa} \mathrm{C}_{2} \mathrm{H}_{4} \cdot{ }^{\mathrm{b}}$ Ratio of 1,2-, 1,3- and 1,4-diethylbenzene after 4 hours. ${ }^{\mathrm{c}}$ TOF calculated after 1 hour. ${ }^{\mathrm{d}} \mathrm{TO}$ after 4 hours as determined by GC/MS. ${ }^{\mathrm{e}}$ Numbers in parentheses are TO after 16 hours. ${ }^{\mathrm{f}}$ Numbers in brackets are TON. 


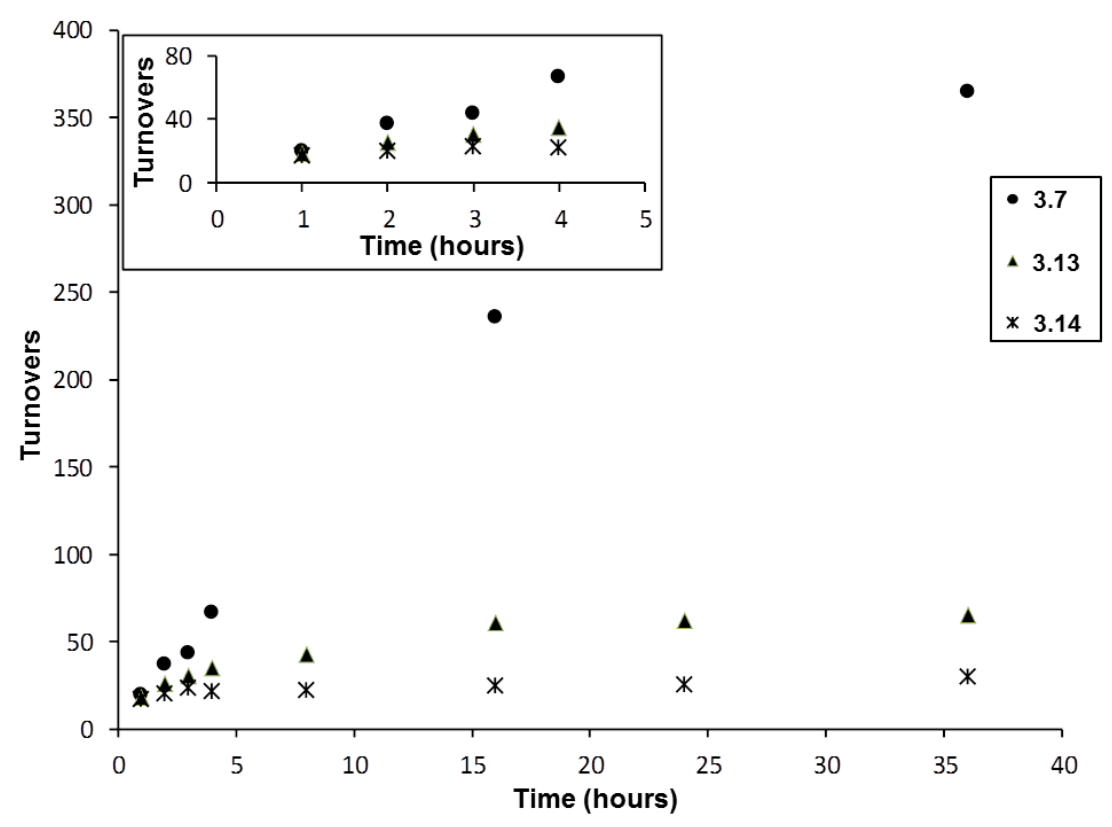

Figure 3.26. Plot of TO versus time for ethylene hydrophenylation $\left(100^{\circ} \mathrm{C}\right)$ catalyzed by complexes 3.7, 3.13 and 3.14 using 0.01 mol\% catalyst dissolved in $\mathrm{C}_{6} \mathrm{H}_{6}$ with $0.1 \mathrm{MPa}$ $\mathrm{C}_{2} \mathrm{H}_{4}$ and hexamethylbenzene as an internal standard. Inset highlights $\mathrm{TO}$ as function of time for the first 4 hours of catalysis.

The asymmetric complex 3.13, with a methyl group in the 6-position of one pyridyl ring, provides $35.2 \mathrm{TO}$ of ethylbenzenes and styrene after 4 hours. The inclusion of methyl groups into both 6-positions of the dipyridyl ligand (complex 3.14) results in a total of 21.2 TO of ethylbenzene and styrene after 4 hours. Between complexes 3.7, 3.13 and 3.14 using data after 4 hours of reaction, the addition of each methyl group reduces catalytic turnover by $\sim 40 \%$. Furthermore, the presence of $6 / 6^{\prime}$-substituents results in a marked change in ethylbenzene to styrene ratios. For example, after 4 hours, complex $\mathbf{3 . 7}$ produces ethylbenzene and styrene in an approximate 138:1 ratio, compared to $\sim 11: 1$ for both 3.13 and 3.14. Computational studies are consistent with $\beta$-hydride elimination following ethylene insertion into the $\mathrm{Pt}-\mathrm{Ph}$ bond to form $\left[\left({ }^{\mathrm{b} p p y}\right) \mathrm{Pt}(\mathrm{H})\left(\eta^{2}-\mathrm{CH}_{2} \mathrm{CHPh}\right)\right]^{+}$to 
be rapid and reversible. ${ }^{1}$ The increased sterics around the Pt center provided by the methyl substituents of $\mathbf{3 . 1 3}$ and $\mathbf{3 . 1 4}$ might facilitate styrene displacement and have the effect of decreasing the ethylbenzene/styrene ratio. Also, if the formation of unstable $\mathrm{Pt}^{\mathrm{II}}$ hydride complexes provides the primary pathway for catalyst decomposition, ${ }^{1}$ facilitating styrene dissociation would be expected to decrease TON, which is consistent with the data shown in entries 1-3 in Table 3.9.

Figure 3.26 shows TO versus time for the hydrophenylation of ethylene using catalysts 3.7, 3.13 and 3.14. Unlike 3.7, complexes 3.13 and 3.14 exhibit signs of decomposition in less than 4 hours at $100{ }^{\circ} \mathrm{C}$ with $0.01 \mathrm{~mol} \%$ Pt catalyst. In order to mitigate the influence of catalyst decomposition and offer a direct comparison between the complexes, TOF were evaluated early in the reaction. After 1 hour at $100{ }^{\circ} \mathrm{C}$, complex 3.7 catalyzes the formation of 18.6 TO of ethylbenzenes and styrene for a TOF of $5.1 \times 10^{-3} \mathrm{~s}^{-1}$. Complexes 3.13 and 3.14 perform similarly with $18.2\left(\mathrm{TOF}=5.1 \times 10^{-3} \mathrm{~s}^{-1}\right)$ and $16.5 \mathrm{TO}$ $\left(\mathrm{TOF}=4.6 \times 10^{-3} \mathrm{~s}^{-1}\right)$, respectively. Thus, the decreased catalytic TON observed with increasing $6 / 6^{\prime}$-substitution of the dpm ligand is a likely result of increased rates of catalyst decomposition as opposed to decreased catalytic activity.

Using $\left[\left(\mathrm{Me}_{2}\right.\right.$-bpy) $\left.\mathrm{Pt}(\mathrm{Ph})(\mathrm{THF})\right]\left[\mathrm{BAr}_{4}\right]$ (3.15) as a catalyst precursor for ethylene hydrophenylation resulted in styrene production in approximately $70 \%$ yield (relative to 3.15) along with isomers of (ethenyl)ethylbenzene, which were not quantified. No evidence for the formation of ethylbenzenes was obtained. The reaction of $\mathbf{3 . 1 5}$ with ethylene at room temperature in $\mathrm{CD}_{2} \mathrm{Cl}_{2}$ readily produced styrene quantitatively with the formation of multiple intractable Pt complexes as observed by ${ }^{1} \mathrm{H}$ NMR spectroscopy (Scheme 3.17). The putative intermediate $\left[\left(\mathrm{Me}_{2}-\mathrm{bpy}\right) \mathrm{Pt}\left(\mathrm{CH}_{2} \mathrm{CH}_{2} \mathrm{Ph}\right)\right]^{+}$likely undergoes 
rapid $\beta$-hydride elimination and net dissociation of styrene, and the resulting $\mathrm{Pt}-\mathrm{H}$ complex $\left[\left(\mathrm{Me}_{2}-\mathrm{bpy}\right) \mathrm{Pt}(\mathrm{H})\right]^{+}$decomposes rapidly. Expansion to a 7 -membered chelate using $[(\mathrm{dpe}) \mathrm{Pt}(\mathrm{Ph})(\mathrm{THF})]\left[\mathrm{BAr}_{4}{ }_{4}\right]$ (3.16) resulted in $1.2 \mathrm{TO}$ of ethylbenzene and styrene in an approximate 2:1 ratio upon heating in benzene with $0.1 \mathrm{MPa}$ of ethylene. Decreasing the temperature to $80{ }^{\circ} \mathrm{C}$ for complex $\mathbf{3 . 1 6}$ did not extend catalyst longevity as only 1.5 TO of ethylbenzene and styrene were observed. Rapid decomposition of the catalyst is likely due to poor stability of seven-membered chelates (compared to their 5- or 6membered counterparts) ${ }^{16}$ or facile displacement of 1,2-bis(pyridyl)ethane from transient $\mathrm{Pt}^{\mathrm{IV}}$ intermediates. $^{12}$

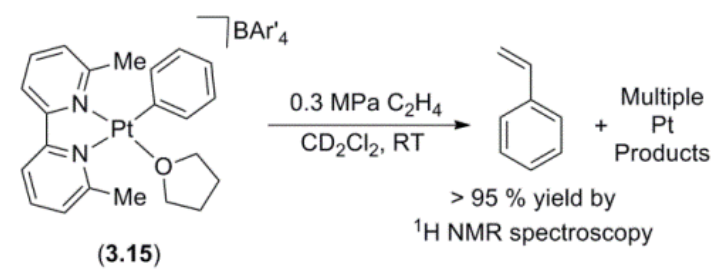

Scheme 3.17. The reaction of complex 3.15 and ethylene (0.3 $\mathrm{MPa})$ in $\mathrm{CD}_{2} \mathrm{Cl}_{2}$ at room temperature readily produces styrene quantitatively.

One issue with ethylene hydrophenylation catalyzed by formally cationic bipyridyl $\mathrm{Pt}^{\mathrm{II}}$ complexes is that the selectivity for monoalkylation of benzene is reduced by the formation of diethylbenzenes. ${ }^{1}$ Diethylbenzenes constitute approximately $20 \%$ of the total alkyl arene product from catalysis with 3.7 and $\left[\left({ }^{\mathrm{t}} \mathrm{bpy}\right) \mathrm{Pt}(\mathrm{Ph})(\mathrm{THF})\right]\left[\mathrm{BAr}_{4}{ }_{4}\right](\mathbf{3 . 2 b})$. This result has been attributed to competition between ethylbenzene $\mathrm{C}-\mathrm{H}$ activation and net dissociation of ethylbenzene from the metal center. ${ }^{1}$ While the percent composition of diethylbenzenes from catalysis using $\mathbf{3 . 7}$ is not improved relative to catalysis using $\mathbf{3 . 2} \mathbf{b}$, 
the regioselectivity of diethylbenzene formation is influenced. For complex $\mathbf{3 . 7}$, the ratio of meta/para to ortho diethylbenzenes is $\sim 17: 1$ at $100{ }^{\circ} \mathrm{C}$, which is four times greater than that reported for 3.2b (Scheme 3.18). Introducing steric perturbations in the $6 / 6^{\prime}$ positions of the dipyridylmethane ligand influences the selectivity for monoalkylation versus dialkylation of benzene. Analysis of the reaction mixture from a reaction of benzene and ethylene after 16 hours using complex 3.13 yields a total of 60.6 TO of which only $4 \%$ are diethylbenzenes, similar to the observation with a reported formally neutral $\mathrm{Pt}^{\mathrm{II}}$ catalyst precursor. ${ }^{17}$ With complex 3.14, diethylbenzenes represent $<2 \%$ of the total arene product after complete catalyst deactivation, and catalysis with complexes $\mathbf{3 . 1 5}$ and 3.16 results in no observable diethylbenzene formation. Therefore, while methyl groups in the 6-positions of the pyridyl rings decrease catalytic TO, the formation of diethylbenzenes is suppressed.

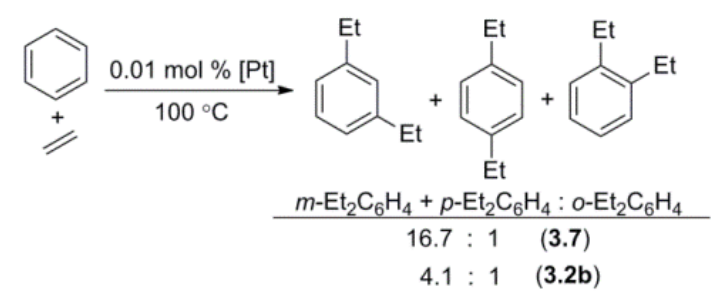

Scheme 3.18. Expansion to a six-membered chelate for $\mathrm{Pt}^{\mathrm{II}}$ catalyzed ethylene hydrophenylation decreases the extent of ortho-diethylbenzene formation, relative to the bipyridyl catalyst variants, which form 5-membered chelate rings.

Ethylene hydroarylation using ethylbenzene as the aromatic substrate was probed (Table 3.10). Using data after 4 hours of reaction, the observed catalytic activity is reduced compared to hydroarylation of ethylene using benzene for complexes $\mathbf{3 . 7}$ and 3.13-3.16 (Table 3.9). This comparison assumes negligible catalyst deactivation after 4 
hours. Thus, the observed relative rates of ethylene hydroarylation using benzene and ethylbenzene are opposite to catalysis using a Friedel-Crafts catalyst. ${ }^{18}$ For the $\mathrm{Pt}^{\mathrm{II}}$ catalysts, the decreased hydroarylation activity using ethylbenzene as the aromatic substrate and the low concentration of ethylbenzene during ethylene hydrophenylation (due to a low catalyst loading) strongly suggest that the formation of diethylbenzenes from the reaction of benzene with ethylene (see above) does not originate from the catalyst reacting with free ethylbenzene generated in situ.

Table 3.10. Comparison of catalytic ethylene hydroarylation with ethylbenzene using complexes 3.7 and 3.13-3.16. ${ }^{\mathrm{a}}$

\begin{tabular}{cccc}
\hline \multirow{3}{*}{3.7} & $5.6^{\mathrm{b}}$ & 4.1 & 0 \\
& $(13.6)^{\mathrm{c}}$ & $(9.4)$ & $($ trace $)$ \\
3.13 & 2.1 & 1.1 & 0 \\
& $(6.5)$ & $(3.0)$ & $($ trace $)$ \\
3.14 & 0.8 & 0.5 & 0.5 \\
& $(1.9)$ & $(1.0)$ & $(1.0)$ \\
3.15 & 0 & 0 & 0 \\
& $(0)$ & $(0)$ & $(0)$ \\
3.16 & 0 & 0 & 0 \\
& $($ trace $)$ & $(0)$ & $(0)$ \\
\hline
\end{tabular}

${ }^{\text {a }} 0.01 \mathrm{~mol} \%$ catalyst dissolved in $\mathrm{C}_{6} \mathrm{H}_{6}$ with hexamethylbenzene as an internal standard at $100{ }^{\circ} \mathrm{C}$ with $0.1 \mathrm{MPa} \mathrm{C}_{2} \mathrm{H}_{4}{ }^{\mathrm{b}}$ TO after 4 hours as determined by GC/MS. ${ }^{\mathrm{c}}$ Numbers in parentheses are TO after 16 hours.

Complex 3.7 catalyzed the formation of 9.7 and 23.0 TO of diethylbenzenes after 4 and 16 hours, respectively. The ratio of meta to para substitution was $\sim 1.4: 1$, and the formation 1,2-diethylbenzene was observed only in trace amounts. Using complex 3.13, the meta to para ratio is nearly identical to that observed for $\mathbf{3 . 7}$ and the formation of 1,2- 
diethylbenzene was not observed in quantifiable amounts. Catalysis with $\mathbf{3 . 1 4}$ exhibits little selectivity as the formation of 1,2-diethylbenzene was equal to the formation of 1,4diethylbenzene. No quantifiable amounts of diethylbenzenes were detected with complexes 3.15 and 3.16 over a period of 16 hours from the reaction with ethylene and ethylbenzene.

\subsubsection{Substitution of the Dipyridyl Linker of Dipyridylmethane}

The substitution of ${ }^{t}$ bpy with dpm provides enhanced activity and longevity for $\mathrm{Pt}^{\mathrm{II}}$ catalyzed ethylene hydrophenylation. A series of catalyst precursors were synthesized in which the methylene bridge between pyridyl rings of dpm was substituted with $\mathrm{C}=\mathrm{O}$ (3.17), $\mathrm{NH}$ (3.18) and O (3.19) following the procedure for complexe 3.7 (Scheme 3.19) to determine the influence of the dipyridyl linkage identity on catalytic activity and selectivity. Under conditions of $100{ }^{\circ} \mathrm{C}$ and $0.1 \mathrm{MPa}$ of ethylene, the catalytic activities of complexes 3.17-3.19 were evaluated (Table 3.11). Comparison of the TO observed after 4 hours demonstrates that catalytic efficiency decreases in the following order: $\mathrm{CH}_{2}$ (3.7) $>\mathrm{NH}(\mathbf{3 . 1 8})>\mathrm{CO}(\mathbf{3 . 1 7})>\mathrm{O}(\mathbf{3 . 1 9})$. However, catalyst decomposition complicates any quantitative comparison of rates using these data. The dipyridylamine complex $[(\mathrm{dpa}) \mathrm{Pt}(\mathrm{Ph})(\mathrm{THF})]\left[\mathrm{BAr}_{4}\right][\mathrm{dpa}=$ bis-(2-pyridyl)amine, $(\mathbf{3 . 1 8})]$ provided a total of 25.1 TO after 4 hours, which is more than a $60 \%$ decrease in TOs compared to 3.7. Catalysis with $[(\mathrm{dpk}) \mathrm{Pt}(\mathrm{Ph})(\mathrm{THF})]\left[\mathrm{BAr}_{4}\right][\mathrm{dpk}=$ bis-(2-pyridyl)ketone, (3.17)] resulted in only 3.3 and 1.9 TO of ethylbenzene and styrene, respectively, after 4 hours. Using dipyridyl ether in $[(\mathrm{dpo}) \mathrm{Pt}(\mathrm{Ph})(\mathrm{THF})]\left[\mathrm{BAr}_{4}\right][$ dpo = bis-(2-pyridyl)ether, (3.19) $]$ provided a total of 4.5 TO after 4 hours, favoring styrene production. In all cases, substitution of the methylene 
linkage reduced catalytic TO and longevity; the latter is evident by the marginal changes in TO after 16 hours compared to after 4 hours for catalysis using 3.17-3.19. Diethylbenzenes were only observed during catalysis with $\mathbf{3 . 1 8}$ and constituted $\sim 16 \%$ of the total arene products. As observed with bipyridyl donor variations, changing the identity of the pyridyl linkage has an influence on styrene production. As the linkage becomes more electron-withdrawing, the ratio of ethylbenzene to styrene decreases. For example, the amine linkage in complex $\mathbf{3 . 1 8}$ produces ethylbenzene and styrene in a 7.4:1 ratio, which is a $95 \%$ decrease compared to the parent dpm ligand. The ratio further decreases for carbonyl and ether linkages with observed ratios of 1.7:1 and 0.6:1 for complexes 3.17 and 3.19, respectively.

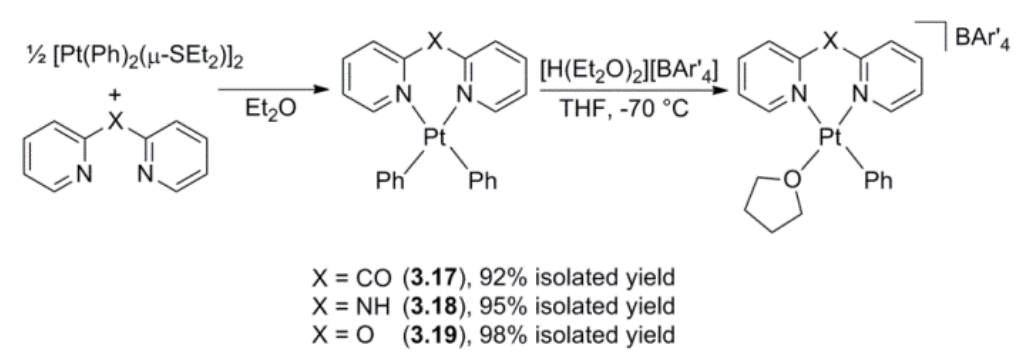

Scheme 3.19. Synthesis and isolated yields of $[(\mathrm{N} \sim \mathrm{N}) \mathrm{Pt}(\mathrm{Ph})(\mathrm{THF})]\left[\mathrm{BAr}_{4}\right]$ (3.17-3.19). 
Table 3.11. Comparison of catalytic ethylene hydrophenylation using complexes 3.173.19.

\begin{tabular}{ccccc}
\hline \multirow{2}{*}{ Complex } & $3.3^{\mathrm{c}}$ & 1.9 & 0 & - \\
& $(3.6)^{\mathrm{d}}$ & $(2.1)$ & $(0)$ & \\
3.17 & 18.6 & 2.5 & 4.0 & $5.6: 3.5: 1$ \\
3.18 & $(25.4)$ & $(3.4)$ & $(5.5)$ & \\
& 1.6 & 2.9 & 0 & - \\
3.19 & $(3.1)$ & $(4.6)$ & $(0)$ & - \\
& &
\end{tabular}

a $0.01 \mathrm{~mol} \%$ catalyst dissolved in $\mathrm{C}_{6} \mathrm{H}_{6}$ with hexamethylbenzene as an internal standard at $100{ }^{\circ} \mathrm{C}$ with $0.1 \mathrm{MPa} \mathrm{C}_{2} \mathrm{H}_{4} \cdot{ }^{\mathrm{b}}$ Ratio of $1,2-, 1,3-$ and 1,4 -diethylbenzene after 4 hours. ${ }^{\mathrm{c}}$ TO after 4 hours as determined by GC/MS. ${ }^{\mathrm{d}}$ Numbers in parentheses are TO after 16 hours.

The results of catalysis employing ethylbenzene as the aromatic substrate for complexes 3.17-3.19 are similar to that observed for dipyridylmethane complexes (Table 3.12). For all complexes, 1,2-diethylbenzene was not detected after 16 hours. Complex 4a produced approximately equimolar amounts of 1,3- and 1,4-diethylbenzene with complete cessation of catalytic activity after 4 hours. Meta and para substituted diethylbenzenes were also observed in an approximate 1:1 ratio using complex $\mathbf{4 b}$ after 4 hours with a total of 4.3 TO after 16 hours, slightly favoring meta substitution. Complex 4c yields substoichiometric amounts of diethylbenzenes for an approximate $50 \%$ yield after 16 hours, relative to catalyst loading. 
Table 3.12. Comparison of catalytic ethylene hydroarylation with ethylbenzene using complexes 3.17-3.19. ${ }^{\mathrm{a}}$

\begin{tabular}{cccc} 
Complex & $0.9^{\mathrm{b}}$ & 0.7 & 0 \\
3.17 & $(1.1)^{\mathrm{c}}$ & $(0.9)$ & $(0)$ \\
& 0.7 & 0.6 & 0 \\
3.18 & $(2.5)$ & $(1.8)$ & $(0)$ \\
& trace & trace & 0 \\
3.19 & $(0.2)$ & $(0.3)$ & $(0)$ \\
\hline
\end{tabular}

${ }^{\mathrm{a}} 0.01 \mathrm{~mol} \%$ catalyst dissolved in $\mathrm{C}_{6} \mathrm{H}_{6}$ with hexamethylbenzene as an internal standard at $100{ }^{\circ} \mathrm{C}$ with $0.1 \mathrm{MPa}_{2} \mathrm{H}_{4} .{ }^{\mathrm{b}}$ Turnovers after 4 hours as determined by GC/MS. ${ }^{\mathrm{c}}$ Numbers in parentheses are turnovers after 16 hours.

\subsection{Conclusion}

Catalyst selectivity for the production of vinyl arenes versus alkyl arenes can be controlled by the 4,4 '-substituents on the bipyridyl ligand. Less donating 4,4'-substituents result in an increased propensity toward styrene production. Such structure/activity relationships are important since the formation of vinyl arenes is a possible deactivation pathway for this series of $\mathrm{Pt}^{\mathrm{II}}$ catalysts and possibly for other transition metal catalysts. Direct oxidative olefin hydroarylation to produce vinyl arenes is a desirable target, and the availability of a tunable "switch" that dictates alkyl versus vinyl arene selectivity is potentially useful.

Increasing the chelate size for dipyridyl ligands on $\mathrm{Pt}^{\mathrm{II}}$ catalysts for ethylene hydrophenylation provides an enhancement in activity and longevity. Using the dpm catalyst precursor 3.7 provides a TON of $\sim 470$, which, is comparable to the best catalyst for ethylene hydrophenylation by a non-acidic pathway. For example, Periana, Goddard 
and co-workers have reported that $\left[\operatorname{Ir}\left(\mu \text {-acac-O,O,C } C^{3}\right)(\text { acac- } O, O)\left(\text { acac- } C^{3}\right)\right]_{2}$

catalyzes ethylene hydrophenylation with a TON of 455 after 3 hours at $180{ }^{\circ} \mathrm{C} .{ }^{19}$ Complex 3.20 is among the most effective transition metal catalysts for ethylene hydrophenylation. ${ }^{19}$ Complex $\mathbf{3 . 2 0}$ was tested for catalytic activity under the conditions used in this study. At $120{ }^{\circ} \mathrm{C}$ under $0.1 \mathrm{MPa}$ of ethylene, the iridium catalyzed reaction (0.01 mol \% of Ir) yielded 4.0 and 12.9 TO of ethylbenzene after 4 and 16 hours, respectively, which corresponds to a TOF of $2.8 \times 10^{-4} \mathrm{~s}^{-1}$. Complex 3.7 gives a TOF (120 ${ }^{\circ} \mathrm{C}$ ) of $1.8 \times 10^{-2} \mathrm{~s}^{-1}$, which is 65 times more active than the Ir catalyst. In addition, we probed the TON using the Ir catalyst 3.20 at $180{ }^{\circ} \mathrm{C}$ using the same catalyst loading as the Pt-catalyzed reactions (i.e., $0.01 \mathrm{~mol} \%$ ). Under these conditions, complex $\mathbf{3 . 2 0}$ provided an ethylbenzene TON of 161. Thus, complex 3.7 is among the most active and longest-lived catalysts for the non-acid catalyzed hydrophenylation of ethylene. Analyses of the elementary steps of the catalytic cycle (e.g., ethylene insertion and benzene $\mathrm{C}-\mathrm{H}$ activation) demonstrate that the larger chelate ring of the dpm ligand provides an entropic advantage compared to tbpy, which results in increased catalytic activity at elevated temperatures.

Compared to the parent dipyridylmethane ligated $\mathrm{Pt}^{\mathrm{II}}$ catalyst precursor, the introduction of steric modification proximal to the metal center with methyl groups in the $6 / 6^{\prime}$ positions of the pyridyl rings increases selectivity for mono-substituted benzenes with similar catalytic activity to the dpm complex 3.7 for ethylene hydrophenylation, but the rate of catalyst decomposition is accelerated. The ratios of ethylbenzene to styrene decrease with substitution in the 6-positions likely due to facilitation of styrene displacement that result in unstable Pt-hydrides. 2,2'-Bipyridyl ligated $\mathrm{Pt}^{\mathrm{II}}$ precursors 
featuring $6 / 6^{\prime}$-substitution are catalytically inactive as $\beta$-hydride elimination is preferred over aromatic $\mathrm{C}-\mathrm{H}$ activation. Replacing the methylene bridge with carbonyl, amine or ether groups also results in decreased catalytic activity for ethylene hydrophenylation. In all examples discussed, catalytic efficiency for ethylene hydroarylation using ethylbenzene is significantly reduced, which contrasts with acid-catalyzed pathways.

\subsection{Experimental Section}

General Methods. Unless otherwise noted, all synthetic procedures were performed under anaerobic conditions in a nitrogen-filled glove box or by using standard Schlenk techniques. Glove box purity was maintained by periodic nitrogen purges and was monitored by an oxygen analyzer $\left(\mathrm{O}_{2}<15\right.$ ppm for all reactions $)$. Diethyl ether was dried by distillation over $\mathrm{CaH}_{2}$. Tetrahydrofuran and $n$-Pentane were distilled over sodium/benzophenone and $\mathrm{P}_{2} \mathrm{O}_{5}$, respectively. Methylene chloride and benzene were purified by passage through a column of activated alumina. Benzene- $d_{6}$, acetone- $d_{6}$, and dichloromethane- $d_{2}$ were used as received and stored under a $\mathrm{N}_{2}$ atmosphere over $4 \AA$ molecular sieves. ${ }^{1} \mathrm{H}$ NMR spectra were recorded on a Varian Mercury $300 \mathrm{MHz}$, Unity Avance $500 \mathrm{MHz}$, Bruker $400 \mathrm{MHz}$ or Bruker $800 \mathrm{MHz}$ spectrometer. ${ }^{13} \mathrm{C}$ NMR spectra were recorded using a Varian Mercury $300 \mathrm{MHz}$ (operating frequency $75 \mathrm{MHz}$ ), Unity Avance $500 \mathrm{MHz}$ (operating frequency $125 \mathrm{MHz}$ ) or Bruker $800 \mathrm{MHz}$ (operating frequency $201 \mathrm{MHz}$ ) spectrometer. All ${ }^{1} \mathrm{H}$ and ${ }^{13} \mathrm{C}$ NMR spectra are referenced against residual proton signals $\left({ }^{1} \mathrm{H} \mathrm{NMR}\right)$ or the ${ }^{13} \mathrm{C}$ resonances $\left({ }^{13} \mathrm{C} \mathrm{NMR}\right)$ of the deuterated solvents. ${ }^{19} \mathrm{~F}$ NMR (282 MHz operating frequency) spectra were obtained on a Varian 
$300 \mathrm{MHz}$ spectrometer and referenced against an external standard of hexafluorobenzene $(\delta=-164.9 \mathrm{ppm})$. GC/MS was performed using a Shimadzu GCMS-QP2010 Plus system with a $30 \mathrm{~m} \times 0.25 \mathrm{~mm}$ SHRXI-5MS column with $0.25 \mathrm{~mm}$ film thickness using electron impact ionization (EI). Microwave synthesis was performed using a Biotage Initiator EXP, in addition to, caps and vials purchased from Biotage. The mass spectral data were obtained from a Bruker 9.4 Tesla Apex-Qe Hybrid Qe-Fourier Transform Ion Cyclotron Resonance (FT-ICR) mass spectrometer consisting of an Apollo II electrospray ionization source. The sample was reconstituted with $200 \mu \mathrm{L}$ acetonitrile, and a $3.5 \mu \mathrm{L}$ aliquot was diluted with $50 \mu \mathrm{L} 60 \%$ acetonitrile/ $0.1 \%$ formic acid prior to directly infusing into the FT-ICR MS via a TriVersa NanoMate (Advion BioScience). Exact masses were obtained for the entire broadband spectrum. Instrument parameters were adjusted to maximize the signals around the peak of interest. Bruker Daltonics DataAnalysis software (v.3.4) was utilized for the analysis of the data, and assignments were made based on exact mass measurements and fit of isotopic peaks to that of theoretical isotopic patterns (IsotopePattern algorithm, Bruker). Errors between observed and theoretical peaks are reported in ppm. Elemental analysis was performed by Atlantic Microlabs, Inc. Ethylene (99.5\%) was purchased in a gas cylinder from GTS-Welco and used as received. All other reagents were used as purchased from commercial sources. The preparation, isolation and characterization of $\left[\mathrm{H}\left(\mathrm{Et}_{2} \mathrm{O}\right)_{2}\right]\left[\mathrm{BAr}_{4}^{\prime}\right]\left[\mathrm{Ar}^{\prime}=3,5-\left(\mathrm{CF}_{3}\right)_{2} \mathrm{C}_{6} \mathrm{H}_{3}\right],{ }^{20}$ $\left[\mathrm{Pt}(\mathrm{Ph})_{2}\left(\mathrm{Et}_{2} \mathrm{~S}\right)\right]_{2},{ }^{21}(\mathrm{bpy}) \mathrm{Pt}(\mathrm{Ph})_{2}$ (bpy $=2,2^{\prime}$-bipyridine) $(\mathbf{3 . 1 c}),{ }^{22}\left({ }^{t} \mathrm{bpy}\right) \mathrm{Pt}(\mathrm{Ph})_{2}\left({ }^{t} \mathrm{bpy}=\right.$ 4,4'- $\quad$ di-tert-butyl-2,2'-bipyridine) $\quad(\mathbf{3 . 1 b}),{ }^{4} \quad\left[\left({ }^{\mathrm{t}} \mathrm{bpy}\right) \mathrm{Pt}(\mathrm{Ph})(\mathrm{THF})\right]\left[\mathrm{BAr}_{4}{ }_{4}\right] \quad(\mathbf{3 . 2 b}),{ }^{1}$ $\left[\left({ }^{\mathrm{t} b p y}\right) \mathrm{Pt}\left(\mathrm{CH}_{2} \mathrm{CH}_{2} \mathrm{Ph}\right)\left(\eta^{2}-\mathrm{C}_{2} \mathrm{H}_{4}\right)\right][\mathrm{BAr} 4](\mathbf{3 . 3 b}),{ }^{1}\left[\mathrm{Pt}(\mathrm{Me})_{2}\left(\mathrm{Et}_{2} \mathrm{~S}\right)\right]_{2},{ }^{23}{ }^{\mathrm{t}} \mathrm{bpyPtMe}_{2},{ }^{23} 2,2^{\prime}-$ dipyridylmethane $\quad(\mathrm{dpm}),{ }^{24} \quad$ 6-methyl-2,2'-dipyridylmethane, ${ }^{25} \quad 6,6^{\prime}$-dimethyl-2,2'- 
dipyridylmethane, ${ }^{25}$ 1,2-bis(2-pyridyl)ethane, ${ }^{26}$ and $\quad\left[\operatorname{Ir}\left(\mu\right.\right.$-acac- $\left.O, O, C_{3}\right)-(\operatorname{acac}-O, O)$ $\left(\right.$ acac- $\left.\left.C_{3}\right)\right]_{2}^{27}$ have been previously reported.

Computational Methods. All calculations were carried out utilizing the Gaussian03 package. ${ }^{28}$ The B3LYP ${ }^{29-30}$ functional was employed in conjunction with the Stevens effective core potentials and valence basis sets ${ }^{31}$ augmented by a d polarization function for carbon $\left(\xi_{\mathrm{C}}=0.8\right)$ and nitrogen $\left(\xi_{\mathrm{N}}=0.8\right)$, viz CEP-31G(d). Closed-shell (diamagnetic) species were modeled within the restricted Kohn-Sham formalism. All systems were fully optimized without symmetry constraint and analytic calculations of the energy Hessian were performed to confirm stationary points as minima or transition states and to obtain vibrational frequencies that were used in the calculation of gas-phase free energies at 1 bar and $298.15 \mathrm{~K}$.

Synthesis of di(2-pyridyl)ether (dpo). Prepared by the Crabtree group (Yale University). A method for synthesizing di(2-pyridyl) ether was developed from previous protocols $^{32}$ using convenient starting materials. Microwave-assisted synthesis in sealed vials reduces reaction times and increases the yield of desired product over prior work without resorting to high-boiling solvents such as DMF. To an oven-dried microwave vial with magnetic stir bar, 2-bromopyridine (1.0 g, $6.3 \mathrm{mmol})$, 2-hydroxypyridine (0.90 g, $9.5 \mathrm{mmol})$, cesium carbonate $(6.2 \mathrm{~g}, 19.0 \mathrm{mmol})$ and dry acetonitrile $(15 \mathrm{~mL})$ were added under a flow of nitrogen. The vial was sealed and subjected to microwave heating (Initiator EXP, Biotage ${ }^{\circledR}$ ) at $200{ }^{\circ} \mathrm{C}$ with a maximum pressure of $1.8 \mathrm{MPa}$ for 1 hour. The solid was removed by filtration and washed with acetonitrile. The deep orange filtrate was then dried by rotary evaporation to give a thick oily residue. Purification by column chromatography on silica gel with 3:2 ethyl acetate/hexanes afforded the product 
as an oil which solidifies at room temperature. Isolated yield $0.56 \mathrm{~g}(51 \%) .{ }^{1} \mathrm{H}$ NMR (400 $\left.\mathrm{MHz}, \mathrm{CDCl}_{3}\right) \delta 8.29\left(\mathrm{ddd},{ }^{3} J_{\mathrm{HH}}=5 \mathrm{~Hz},{ }^{4} J_{\mathrm{HH}}=2 \mathrm{~Hz},{ }^{5} J_{\mathrm{HH}}=1 \mathrm{~Hz}, 6\right.$-dpo, $2 \mathrm{H}$ ), 7.76 (ddd, $\left.{ }^{3} J_{\mathrm{HH}}=8 \mathrm{~Hz},{ }^{3} J_{\mathrm{HH}}=7 \mathrm{~Hz},{ }^{4} J_{\mathrm{HH}}=2 \mathrm{~Hz}, 4-\mathrm{dpo}, 2 \mathrm{H}\right), 7.09$ (m, 3- and 5-dpo, 4H). ${ }^{13} \mathrm{C} \mathrm{NMR}$ $\left(125 \mathrm{MHz}, \mathrm{CDCl}_{3}\right) \delta 162.3,148.5,139.9,120.3,114.4$. ESI-FTICR MS calcd for $\left[\mathrm{C}_{10} \mathrm{H}_{9} \mathrm{~N}_{2} \mathrm{O}\right]^{+}:$173.0709. Found: 173.0707. Anal. calcd. for $\mathrm{C}_{10} \mathrm{H}_{8} \mathrm{~N}_{2} \mathrm{O}$ (\%): C 69.76, $\mathrm{H}$ 4.68, N 16.27; found: C 69.55, H 4.77, N 16.32.

General procedure for the synthesis of $(\mathbf{N} \sim \mathbf{N}) \mathbf{P t P h}_{2}$ complexes. To a suspension of $\left[\mathrm{Pt}(\mathrm{Ph})_{2}\left(\mathrm{Et}_{2} \mathrm{~S}\right)\right]_{2}$ in diethyl ether $(30 \mathrm{~mL})$, two equivalents of the appropriate dipyridyl ligand were added. The solution was stirred at room temperature overnight. The solution was reduced in vacuo, and hexanes were added $(\sim 20 \mathrm{~mL})$. The solution was filtered, and the precipitate was dried under vacuum.

${ }^{\mathrm{m}} \mathrm{bpyPtPh}_{2}$ (3.1a). The bipyridyl ligand was 4,4 '-dimethoxy-2,2'-bipyridine ( ${ }^{\mathrm{m}} \mathrm{bpy}$; $96 \%$ isolated yield, $0.288 \mathrm{~g}) .{ }^{1} \mathrm{H}$ NMR $\left(300 \mathrm{MHz}, \mathrm{CD}_{2} \mathrm{Cl}_{2}\right) \delta 8.24\left(\mathrm{~d}, 2 \mathrm{H}, \mathrm{H}^{6}-{ }^{\mathrm{m}} \mathrm{bpy},{ }^{3} J_{\mathrm{HH}}=\right.$ $6 \mathrm{~Hz}), 7.52\left(\mathrm{~d}, 2 \mathrm{H}, \mathrm{H}^{3}{ }_{-}{ }^{\mathrm{m}} \mathrm{bpy},{ }^{4} J_{\mathrm{HH}}=3 \mathrm{~Hz}\right), 7.42\left(\mathrm{~d}, 4 \mathrm{H}, \mathrm{H}^{\mathrm{o}}-\mathrm{Ph},{ }^{3} J_{\mathrm{HH}}=8 \mathrm{~Hz},{ }^{3} J_{\mathrm{PtH}}=69\right.$ $\mathrm{Hz}$, Pt satellites), 6.95 (t, 4H, H $\left.{ }^{\mathrm{m}}-\mathrm{Ph},{ }^{3} J_{\mathrm{HH}}=7 \mathrm{~Hz}\right), 6.87$ (dd, $2 \mathrm{H}, \mathrm{H}^{5}-{ }^{\mathrm{m}} \mathrm{bpy},{ }^{3} J_{\mathrm{HH}}=6 \mathrm{~Hz}$, $\left.{ }^{4} J_{\mathrm{HH}}=2 \mathrm{~Hz}\right), 6.82\left(\mathrm{~m}, 2 \mathrm{H}, \mathrm{H}^{\mathrm{p}}-\mathrm{Ph}\right), 3.94\left(\mathrm{~s}, 6 \mathrm{H}, \mathrm{OMe}^{-}{ }^{\mathrm{m}} \mathrm{bpy}\right) .{ }^{13} \mathrm{C} \mathrm{NMR}(201 \mathrm{MHz}$, $\left.\mathrm{CD}_{2} \mathrm{Cl}_{2}\right) \delta 167.0,158.0,151.5,146.7,138.7,127.3,121.8,111.9,109.8$ (' ${ }^{\mathrm{m}}$ bpy and $\left.\mathrm{Ph}\right)$, 56.6 $\left(\mathrm{OCH}_{3}\right)$. Anal. calcd. for $\mathrm{PtN}_{2} \mathrm{O}_{2} \mathrm{C}_{24} \mathrm{H}_{22}$ : calcd: C 50.97, H 3.93, N 4.95; found: $\mathrm{C}$ 51.02, H 3.99, N 5.01.

${ }^{\mathrm{Br}}{ }^{\mathrm{bpyPtPh}} \mathbf{2}$ (3.1d). The bipyridyl ligand was $4,4^{\prime}$-dibromo-2,2'-bipyridine $\left({ }^{\mathrm{Br}} \mathrm{bpy}\right.$; $78 \%$ isolated yield, $0.176 \mathrm{~g}) .{ }^{1} \mathrm{H}$ NMR $\left(300 \mathrm{MHz}\right.$, acetone- $\left.d_{6}\right) \delta 8.90\left(\mathrm{~d}, 2 \mathrm{H}, \mathrm{H}^{3}-{ }^{\mathrm{Br}} \mathrm{bpy},{ }^{4} J_{\mathrm{HH}}=\right.$ $2 \mathrm{~Hz}$ ), $8.29\left(\mathrm{~d}, 2 \mathrm{H}, \mathrm{H}^{6}{ }_{-}^{\mathrm{Br}} \mathrm{bpy},{ }^{3} \mathrm{~J}_{\mathrm{HH}}=6 \mathrm{~Hz},{ }^{3} J_{\mathrm{PtH}}=21 \mathrm{~Hz}, \mathrm{Pt}\right.$ satellites$), 7.90\left(\mathrm{dd}, 2 \mathrm{H}, \mathrm{H}^{5}-\right.$ $\left.{ }^{\mathrm{Br}} \mathrm{bpy},{ }^{3} J_{\mathrm{HH}}=6 \mathrm{~Hz},{ }^{4} J_{\mathrm{HH}}=2 \mathrm{~Hz}\right), 7.40\left(\mathrm{~d}, 4 \mathrm{H}, \mathrm{H}^{\mathrm{o}}-\mathrm{Ph},{ }^{3} \mathrm{HH}=8 \mathrm{~Hz},{ }^{3} J_{\mathrm{PtH}}=71 \mathrm{~Hz}, \mathrm{Pt}\right.$ 
satellites), $6.89\left(\mathrm{t}, 4 \mathrm{H}, \mathrm{H}^{\mathrm{m}}-\mathrm{Ph},{ }^{3} J_{\mathrm{HH}}=8 \mathrm{~Hz}\right), 6.75\left(\mathrm{~m}, 2 \mathrm{H}, \mathrm{H}^{\mathrm{p}}-\mathrm{Ph}\right) .{ }^{13} \mathrm{C} \mathrm{NMR}(75 \mathrm{MHz}$, acetone- $\left.d_{6}\right) \delta 150.8,146.6,139.0,134.7,131.8,128.2,127.5,127.0,122.3\left({ }^{\mathrm{Br}}\right.$ bpy and $\mathrm{Ph}$ ). Anal. calcd. for $\mathrm{PtN}_{2} \mathrm{Br}_{2} \mathrm{C}_{22} \mathrm{H}_{16}$ : calcd: C 39.84, $\mathrm{H}$ 2.44, $\mathrm{N}$ 4.22; found: C 39.82, $\mathrm{H}$ 2.30, N 4.22.

${ }^{\mathbf{b}} \mathbf{b p y P t P h}_{2}$ (3.1e). The bipyridyl ligand was 4,4'-diethoxycarbonyl-2,2'-bipyridine ('bpy; 85\% isolated yield, $0.171 \mathrm{~g}) .{ }^{1} \mathrm{H}$ NMR $\left(300 \mathrm{MHz}\right.$, acetone- $\left.d_{6}\right) \delta 8.99\left(\mathrm{~d}, 2 \mathrm{H}, \mathrm{H}^{3}-\right.$ $\left.{ }^{\mathrm{c}} \mathrm{bpy},{ }^{4} J_{\mathrm{HH}}=1 \mathrm{~Hz}\right), 8.67\left(\mathrm{~d}, 2 \mathrm{H}, \mathrm{H}^{6}-{ }^{\mathrm{c}} \mathrm{bpy},{ }^{3} J_{\mathrm{HH}}=6 \mathrm{~Hz}\right), 8.10\left(\mathrm{dd}, 2 \mathrm{H}, \mathrm{H}^{5}-{ }^{\mathrm{c}} \mathrm{bpy},{ }^{3} J_{\mathrm{HH}}=6\right.$, $\left.{ }^{4} J_{\mathrm{HH}}=2 \mathrm{~Hz}\right), 7.40\left(\mathrm{~d}, 4 \mathrm{H}, \mathrm{H}^{\mathrm{o}}-\mathrm{Ph},{ }^{3} J_{\mathrm{HH}}=8 \mathrm{~Hz},{ }^{3} J_{\mathrm{PtH}}=70 \mathrm{~Hz}\right.$, Pt satellites), $6.91(\mathrm{t}, 4 \mathrm{H}$, $\left.\mathrm{H}^{\mathrm{m}}-\mathrm{Ph},{ }^{3} J_{\mathrm{HH}}=8 \mathrm{~Hz}\right), 6.77\left(\mathrm{~m}, 2 \mathrm{H}, \mathrm{H}^{\mathrm{p}}-\mathrm{Ph}\right), 4.48\left(\mathrm{q}, 4 \mathrm{H}, \mathrm{OCH}_{2} \mathrm{CH}_{3},{ }^{3} J_{\mathrm{HH}}=7 \mathrm{~Hz}\right), 1.43(\mathrm{t}$, $\left.6 \mathrm{H}, \mathrm{OCH}_{2} \mathrm{CH}_{3},{ }^{3} \mathrm{~J}_{\mathrm{HH}}=7 \mathrm{~Hz}, 3 \mathrm{H}\right) .{ }^{13} \mathrm{C} \mathrm{NMR}\left(75 \mathrm{MHz}\right.$, acetone- $\left.d_{6}\right) \delta 164.7,157.3,151.1$, 146.6, 140.1, 139.1, 127.8, 127.6, 123.8, 122.5 ('bpy and $\mathrm{Ph}), 63.2\left(\mathrm{OCH}_{2} \mathrm{CH}_{3}\right), 14.4$ $\left(\mathrm{OCH}_{2} \mathrm{CH}_{3}\right)$. Anal. calcd. for $\mathrm{PtN}_{2} \mathrm{O}_{4} \mathrm{C}_{28} \mathrm{H}_{26}$ : calcd: C 51.76, H 4.04, N 4.31; found: C 52.01, H 3.94, N 4.16.

${ }^{\text {NO2 }}{ }^{\text {bpyPtPh }} \mathbf{2}$ (3.1f). The bipyridyl ligand was 4,4'-dinitro-2,2'-bipyridine ( ${ }^{\mathrm{NO} 2} \mathrm{bpy} ; 89 \%$ isolated yield, $0.779 \mathrm{~g}) .{ }^{1} \mathrm{H} \mathrm{NMR}\left(300 \mathrm{MHz}, \mathrm{CD}_{2} \mathrm{Cl}_{2}\right) \delta 8.97\left(\mathrm{~d}, 2 \mathrm{H}, \mathrm{H}^{6}{ }_{-}{ }^{\mathrm{NO} 2} b p y,{ }^{3} J_{\mathrm{HH}}=6\right.$ $\mathrm{Hz}), 8.92\left(\mathrm{~d}, 2 \mathrm{H}, \mathrm{H}^{3}-{ }^{\mathrm{NO} 2} b p y,{ }^{4} J_{\mathrm{HH}}=2 \mathrm{~Hz}\right), 8.16\left(\mathrm{dd}, 2 \mathrm{H}, \mathrm{H}^{5}{ }_{-}{ }^{\mathrm{NO} 2} b p y,{ }^{3} J_{\mathrm{HH}}=6 \mathrm{~Hz},{ }^{4} J_{\mathrm{HH}}=2\right.$ $\mathrm{Hz}), 7.39\left(\mathrm{~d}, 4 \mathrm{H}, \mathrm{H}^{\mathrm{o}}-\mathrm{Ph},{ }^{3} J_{\mathrm{HH}}=8 \mathrm{~Hz}\right), 7.06\left(\mathrm{t}, 4 \mathrm{H}, \mathrm{H}^{\mathrm{m}}-\mathrm{Ph},{ }^{3} J_{\mathrm{HH}}=8 \mathrm{~Hz}\right), 6.91\left(\mathrm{t}, 2 \mathrm{H}, \mathrm{H}^{\mathrm{p}}-\right.$ $\left.\mathrm{Ph},{ }^{3} J_{\mathrm{HH}}=8 \mathrm{~Hz}\right) .{ }^{13} \mathrm{C} \mathrm{NMR}\left(201 \mathrm{MHz}, \mathrm{CD}_{2} \mathrm{Cl}_{2}\right) \delta 157.5,153.6,153.1,144.0,138.1$, 127.8, 123.2, 122.2, 117.1 $\left({ }^{\mathrm{NO} 2}\right.$ bpy and $\left.\mathrm{Ph}\right)$. Anal. calcd. for $\mathrm{PtN}_{4} \mathrm{O}_{4} \mathrm{C}_{22} \mathrm{H}_{16}$ : calcd: $\mathrm{C}$ 44.37, H 2.71, N 9.41; found: C 44.63, H 2.82, N 9.37.

(dpm)PtPh 2 (3.6). The ligand was 2,2'-dipyridylmethane. Isolated $0.35 \mathrm{~g}(83 \%) .{ }^{1} \mathrm{H}$ $\operatorname{NMR}\left(800 \mathrm{MHz}, \mathrm{CD}_{2} \mathrm{Cl}_{2}\right) \delta 8.45\left(\mathrm{~d},{ }^{3} J_{\mathrm{HH}}=6 \mathrm{~Hz}, 2 \mathrm{H}, \mathrm{dpm}\right), 7.76\left(\mathrm{td},{ }^{3} J_{\mathrm{HH}}=8 \mathrm{~Hz},{ }^{4} J_{\mathrm{HH}}=\right.$ $2 \mathrm{~Hz}, 2 \mathrm{H}, \mathrm{dpm}), 7.47\left(\mathrm{~m}, 6 \mathrm{H}, \mathrm{dpm}\right.$ and $\left.\mathrm{H}^{\mathrm{o}}-\mathrm{Ph}\right), 7.07\left(\mathrm{ddd},{ }^{3} J_{\mathrm{HH}}=8 \mathrm{~Hz},{ }^{3} J_{\mathrm{HH}}=6 \mathrm{~Hz},{ }^{4} J_{\mathrm{HH}}\right.$ 
$=2 \mathrm{~Hz}, 2 \mathrm{H}, \mathrm{dpm}), 6.90\left(\mathrm{t},{ }^{3} J_{\mathrm{HH}}=8 \mathrm{~Hz}, 4 \mathrm{H}, \mathrm{H}^{\mathrm{m}}-\mathrm{Ph}\right), 6.77\left(\mathrm{t},{ }^{3} J_{\mathrm{HH}}=7 \mathrm{~Hz}, 2 \mathrm{H}, \mathrm{H}^{\mathrm{p}}-\mathrm{Ph}\right)$, 4.74 (br s, $2 \mathrm{H}$, dpm- $\mathrm{CH}_{2}$ ). ${ }^{13} \mathrm{C}$ NMR (201 MHz, $\left.\mathrm{CD}_{2} \mathrm{Cl}_{2}\right) \delta 155.9,151.9,145.1,138.8$, 138.1, 127.0, 124.7, 124.2, 121.9 (dpm and $\mathrm{Ph}$ aromatic), $47.7\left(\mathrm{dpm}-\mathrm{CH}_{2}\right)$. Anal. calcd. for $\mathrm{PtN}_{2} \mathrm{C}_{23} \mathrm{H}_{20}$ (\%): C 53.17, H 3.89, N 5.39; found: C 52.65, H 3.98, N 5.31.

(Me-dpm)PtPh 2 (3.9). The ligand was 6-methyl-2,2'-dipyridylmethane (Me-dpm). Isolated $0.19 \mathrm{~g}(92 \%) .{ }^{1} \mathrm{H}$ NMR $\left(800 \mathrm{MHz}, \mathrm{CD}_{2 \mathrm{~b}} \mathrm{l}_{2}\right) \delta 8.54\left(\mathrm{ddd},{ }^{3} J_{\mathrm{HH}}=6 \mathrm{~Hz},{ }^{4} J_{\mathrm{HH}}=2\right.$, $\left.{ }^{5} J_{\mathrm{HH}}=1 \mathrm{~Hz}, 1 \mathrm{H}, 6-\mathrm{dpm}\right), 7.72\left(\mathrm{td},{ }^{3} J_{\mathrm{HH}}=8 \mathrm{~Hz},{ }^{4} J_{\mathrm{HH}}=2 \mathrm{~Hz}, 1 \mathrm{H}, 4-\mathrm{dpm}\right), 7.64\left(\mathrm{t},{ }^{3} J_{\mathrm{HH}}=\right.$ $8 \mathrm{~Hz}, 1 \mathrm{H}, 4-\mathrm{dpm}), 7.51\left(\mathrm{dd},{ }^{3} J_{\mathrm{HH}}=8 \mathrm{~Hz},{ }^{4} J_{\mathrm{HH}}=1 \mathrm{~Hz}, 2 \mathrm{H}, \mathrm{H}^{\mathrm{o}}-\mathrm{Ph}\right), 7.46\left(\mathrm{~d},{ }^{3} J_{\mathrm{HH}}=7 \mathrm{~Hz}\right.$, $1 \mathrm{H}, 3-\mathrm{dpm}), 7.37\left(\mathrm{~d},{ }^{3} J_{\mathrm{HH}}=8 \mathrm{~Hz}, 1 \mathrm{H}, 3-\mathrm{dpm}\right), 7.19\left(\mathrm{dd},{ }^{3} J_{\mathrm{HH}}=8 \mathrm{~Hz},{ }^{4} J_{\mathrm{HH}}=1 \mathrm{~Hz}, 1 \mathrm{H}, \mathrm{H}^{\mathrm{o}}-\right.$ $\mathrm{Ph}), 7.09\left(\mathrm{ddd},{ }^{3} J_{\mathrm{HH}}=7 \mathrm{~Hz},{ }^{3} J_{\mathrm{HH}}=6 \mathrm{~Hz},{ }^{4} J_{\mathrm{HH}}=1 \mathrm{~Hz}, 1 \mathrm{H}, 5-\mathrm{dpm}\right), 7.05\left(\mathrm{~d},{ }^{3} J_{\mathrm{HH}}=7 \mathrm{~Hz}\right.$, $1 \mathrm{H}, 5-\mathrm{dpm}), 6.88\left(\mathrm{t},{ }^{3} J_{\mathrm{HH}}=8 \mathrm{~Hz}, 2 \mathrm{H}, \mathrm{H}^{\mathrm{m}}-\mathrm{Ph}\right), 6.77-6.72\left(\mathrm{~m}, 3 \mathrm{H}, \mathrm{H}^{\mathrm{m}}-\right.$ and $\left.\mathrm{H}^{\mathrm{p}}-\mathrm{Ph}\right), 6.68$ $\left(\mathrm{tt},{ }^{3} J_{\mathrm{HH}}=8 \mathrm{~Hz},{ }^{4} J_{\mathrm{HH}}=1 \mathrm{~Hz}, 1 \mathrm{H}, \mathrm{H}^{\mathrm{p}}-\mathrm{Ph}\right), 5.67\left(\mathrm{~d},{ }^{2} J_{\mathrm{HH}}=14 \mathrm{~Hz}, 1 \mathrm{H}, \mathrm{dpm}-\mathrm{CH}_{2}\right), 4.26(\mathrm{~d}$, $\left.{ }^{2} J_{\mathrm{HH}}=14 \mathrm{~Hz}, 1 \mathrm{H}, \mathrm{dpm}-\mathrm{CH}_{2}\right), 2.38(\mathrm{~s}, 3 \mathrm{H}, \mathrm{dpm}-\mathrm{Me}) .{ }^{13} \mathrm{C} \mathrm{NMR}\left(201 \mathrm{MHz}, \mathrm{CD}_{2 \mathrm{~b}} \mathrm{l}_{2}\right) \delta$ $162.7,156.3,156.1,151.1,146.2,141.0,138.5,138.4,137.9,137.8,126.9,126.2,124.9$, 124.7, 123.8, 121.9, 121.5, 121.5 (Me-dpm and Ph aromatic), $47.7\left(\mathrm{dpm}-\mathrm{CH}_{2}\right), 26.7$ (dpm-Me). Anal. calcd. for $\mathrm{PtN}_{2 b 24} \mathrm{H}_{22}$ (\%): C 54.02, H 4.16, N 5.25; found: C 54.06, H 4.28, N 5.21 .

$\left(\mathbf{M e}_{2}-\mathbf{d p m}\right) \mathbf{P t P h}_{2} \mathbf{( 3 . 1 0 )}$. The ligand was 6,6'-dimethyl-2,2'-dipyridylmethane $\left(\mathrm{Me}_{2}-\right.$ dpm). Isolated $0.32 \mathrm{~g}(94 \%) .{ }^{1} \mathrm{H}$ NMR $\left(800 \mathrm{MHz}\right.$, acetone- $\left.d_{6}\right) \delta 7.75\left(\mathrm{t},{ }^{3} J_{\mathrm{HH}}=8 \mathrm{~Hz}, 2 \mathrm{H}\right.$, 4-dpm), $7.60\left(\mathrm{~d},{ }^{3} J_{\mathrm{HH}}=8 \mathrm{~Hz}, 2 \mathrm{H}, 3-\mathrm{dpm}\right), 7.37\left(\mathrm{dd},{ }^{3} J_{\mathrm{HH}}=8 \mathrm{~Hz},{ }^{4} J_{\mathrm{HH}}=1 \mathrm{~Hz}, 4 \mathrm{H}, \mathrm{H}^{\mathrm{o}}-\mathrm{Ph}\right)$, $7.15\left(\mathrm{~d},{ }^{3} J_{\mathrm{HH}}=8 \mathrm{~Hz}, 1 \mathrm{H}, 5-\mathrm{dpm}\right), 6.68\left(\mathrm{t},{ }^{3} J_{\mathrm{HH}}=8 \mathrm{~Hz}, 4 \mathrm{H}, \mathrm{H}^{\mathrm{m}}-\mathrm{Ph}\right), 6.57\left(\mathrm{t},{ }^{3} J_{\mathrm{HH}}=8 \mathrm{~Hz}\right.$, $\left.2 \mathrm{H}, \mathrm{H}^{\mathrm{p}}-\mathrm{Ph}\right), 6.11\left(\mathrm{~d},{ }^{2} J_{\mathrm{HH}}=14 \mathrm{~Hz}, 1 \mathrm{H}, \mathrm{dpm}-\mathrm{CH}_{2}\right), 4.69\left(\mathrm{~d},{ }^{2} J_{\mathrm{HH}}=14 \mathrm{~Hz}, 1 \mathrm{H}, \mathrm{dpm}-\mathrm{CH}_{2}\right)$, 2.53 (s, 6H, dpm-Me). ${ }^{13} \mathrm{C}$ NMR (201 MHz, acetone- $\left.d_{6}\right) \delta$ 162.4, 157.3, 141.6, 139.1, 
138.8, 126.4, 124.9, 122.7, 121.4 (dpm and $\mathrm{Ph}$ aromatic), $47.5\left(\mathrm{dpm}-\mathrm{CH}_{2}\right), 26.1$ (dpmMe). Anal. calcd. for $\mathrm{PtN}_{2 \mathrm{~b} 25} \mathrm{H}_{24}$ (\%): C 54.83, H 4.43, N 5.12; found: C 54.33, H 4.30, N 5.11 .

(Me $\mathbf{M}_{2}$-bpy) $\mathbf{P t P h}_{2}$ (3.11). The ligand was 6,6'-dimethyl-2,2'-bipyridine ( $\mathrm{Me}_{2}$-bpy). Isolated $0.230 \mathrm{~g}(69 \%) .{ }^{1} \mathrm{H}$ NMR $\left(800 \mathrm{MHz}\right.$, acetone- $\left.d_{6}\right) \delta 8.38\left(\mathrm{~d},{ }^{3} J_{\mathrm{HH}}=8 \mathrm{~Hz}, 2 \mathrm{H}\right.$, $\mathrm{Me}_{2 \mathrm{a}}$ py), $8.16\left(\mathrm{t},{ }^{3} J_{\mathrm{HH}}=8 \mathrm{~Hz}, 2 \mathrm{H}, \mathrm{Me}_{2 \mathrm{a}} \mathrm{py}\right), 7.48\left(\mathrm{~d},{ }^{3} J_{\mathrm{HH}}=7 \mathrm{~Hz}, 2 \mathrm{H}, \mathrm{Me}_{2 \mathrm{a}} \mathrm{py}\right), 7.40$ (d, $\left.{ }^{3} J_{\mathrm{HH}}=7 \mathrm{~Hz}, 4 \mathrm{H}, \mathrm{H}^{\mathrm{o}}-\mathrm{Ph}\right), 6.80\left(\mathrm{t},{ }^{3} J_{\mathrm{HH}}=7 \mathrm{~Hz}, 4 \mathrm{H}, \mathrm{H}^{\mathrm{m}}-\mathrm{Ph}\right), 6.69\left(\mathrm{t},{ }^{3} J_{\mathrm{HH}}=7 \mathrm{~Hz}, 2 \mathrm{H}, \mathrm{H}^{\mathrm{p}}-\right.$ $\mathrm{Ph}) .{ }^{13} \mathrm{C}$ NMR (201 MHz, acetone- $\left.d_{6}\right) \delta 163.3,157.8,142.8,139.4,139.0,127.5,126.8$, 121.6, 120.3, 26.7. Anal. calcd. for $\mathrm{PtN}_{2 \mathrm{~b} 24} \mathrm{H}_{22}$ (\%): C 54.02, H 4.16, N 5.25; found: C 54.26, H 4.32, N 5.17.

(dpe) $\mathrm{PtPh}_{2}$ (3.12). The ligand was 1, 2-bis(2-pyridyl)ethane (dpe). Isolated $0.19 \mathrm{~g}$ (76\%). ${ }^{1} \mathrm{H}$ NMR (500 MHz, $\left.\mathrm{CD}_{2 \mathrm{~b}} \mathrm{l}_{2}\right) \delta 8.71\left(\mathrm{dd},{ }^{3} J_{\mathrm{HH}}=6 \mathrm{~Hz},{ }^{4} J_{\mathrm{HH}}=2 \mathrm{~Hz}, 2 \mathrm{H}, 6-\mathrm{dpe}\right)$, $7.57\left(\mathrm{td},{ }^{3} J_{\mathrm{HH}}=8 \mathrm{~Hz},{ }^{4} J_{\mathrm{HH}}=2 \mathrm{~Hz}, 2 \mathrm{H}, 4-\mathrm{dpe}\right), 7.45\left(\mathrm{dd},{ }^{3} J_{\mathrm{HH}}=8 \mathrm{~Hz},{ }^{3} J_{\mathrm{HH}}=1 \mathrm{~Hz},{ }^{3} J_{\mathrm{PtH}}=\right.$ $72 \mathrm{~Hz}$ Pt satellites, 4H, $\mathrm{H}^{\mathrm{o}}-\mathrm{Ph}$ ), 7.23 (d, ${ }^{3} \mathrm{~J}_{\mathrm{HH}}=8 \mathrm{~Hz}, 2 \mathrm{H}, 3$-dpe), 6.99 (ddd, ${ }^{3} J_{\mathrm{HH}}=8 \mathrm{~Hz}$, $\left.{ }^{3} J_{\mathrm{HH}}=6 \mathrm{~Hz},{ }^{4} J_{\mathrm{HH}}=1 \mathrm{~Hz}, 2 \mathrm{H}, 5-\mathrm{dpe}\right), 6.82\left(\mathrm{t},{ }^{3} J_{\mathrm{HH}}=7 \mathrm{~Hz}, 4 \mathrm{H}, \mathrm{H}^{\mathrm{m}}-\mathrm{Ph}\right), 6.71\left(\mathrm{t},{ }^{3} J_{\mathrm{HH}}=7\right.$ $\left.\mathrm{Hz}, 2 \mathrm{H}, \mathrm{H}^{\mathrm{p}}-\mathrm{Ph}\right), 4.21$ (br. s, 4H, dpe-CH$) .{ }^{13} \mathrm{C}$ NMR (125 MHz, $\left.\mathrm{c}_{6} \mathrm{~d}_{6}\right) \delta 160.40,151.52$, $143.01,138.81,137.30,126.57,126.35,122.99,121.60$ (dpe and $\mathrm{Ph}$ aromatic), 34.83 (dpe- $\mathrm{CH}_{2}$ ). Anal. calcd. for $\mathrm{PtN}_{2 \mathrm{~b} 24} \mathrm{H}_{22}$ (\%): C 54.02, H 4.16, N 5.25; found: C 53.98, H $4.13, \mathrm{~N} 5.17$.

(dpk)PtPh . The ligand was bis(2-pyridyl)ketone (dpk). Isolated $0.21 \mathrm{~g}(91 \%) .{ }^{1} \mathrm{H}$ NMR $\left(300 \mathrm{MHz}\right.$, acetone- $\left.d_{6}\right) \delta 8.49\left(\mathrm{ddd},{ }^{3} J_{\mathrm{HH}}=6 \mathrm{~Hz},{ }^{4} J_{\mathrm{HH}}=2 \mathrm{~Hz},{ }^{5} J_{\mathrm{HH}}=1 \mathrm{~Hz}, 2 \mathrm{H}, 6-\right.$ dpk), $8.25\left(\mathrm{td},{ }^{3} J_{\mathrm{HH}}=8 \mathrm{~Hz},{ }^{4} J_{\mathrm{HH}}=2 \mathrm{~Hz}, 2 \mathrm{H}, 4-\mathrm{dpk}\right), 8.14\left(\mathrm{ddd},{ }^{3} J_{\mathrm{HH}}=8 \mathrm{~Hz},{ }^{3} J_{\mathrm{HH}}=2\right.$ $\left.\mathrm{Hz},{ }^{5} J_{\mathrm{HH}}=1 \mathrm{~Hz}, 2 \mathrm{H}, 3-\mathrm{dpk}\right), 7.59\left(\mathrm{ddd},{ }^{3} J_{\mathrm{HH}}=8 \mathrm{~Hz},{ }^{3} J_{\mathrm{HH}}=6 \mathrm{~Hz},{ }^{4} J_{\mathrm{HH}}=2 \mathrm{~Hz}, 2 \mathrm{H}, 5-\right.$ 
dpk), $7.28\left(\mathrm{dd},{ }^{3} J_{\mathrm{HH}}=8 \mathrm{~Hz},{ }^{4} J_{\mathrm{HH}}=2 \mathrm{~Hz},{ }^{3} J_{P t H}=71 \mathrm{~Hz}\right.$ Pt satellites, 4H, H $\left.{ }^{\mathrm{o}}-\mathrm{Ph}\right), 6.77(\mathrm{t}$, $\left.{ }^{3} J_{\mathrm{HH}}=7 \mathrm{~Hz}, 4 \mathrm{H}, \mathrm{H}^{\mathrm{m}}-\mathrm{Ph}\right), 6.65\left(\mathrm{tt},{ }^{3} J_{\mathrm{HH}}=7 \mathrm{~Hz},{ }^{4} J_{\mathrm{HH}}=2 \mathrm{~Hz}, 2 \mathrm{H}, \mathrm{H}^{\mathrm{p}}-\mathrm{Ph}\right) .{ }^{13} \mathrm{C} \mathrm{NMR}(125$ $\left.\mathrm{MHz}, \mathrm{CD}_{2 \mathrm{~b}} \mathrm{l}_{2}\right) \delta 189.4$ (CO-dpk), 153.3, 152.1, 143.9, 138.8, 138.4, 128.4, 127.1, 125.9, 122.4, 113.4 (dpk and $\mathrm{Ph}$ aromatic). Anal. calcd. for $\mathrm{PtN}_{2 \mathrm{~b} 24} \mathrm{H}_{22}(\%)$ : C 51.80, H 3.41, N 5.25; found: C 51.70, H 3.54, N 5.21.

(dpa)PtPh . The ligand was bis(2-pyridyl)amine (dpa). Isolated $0.16 \mathrm{~g}(84 \%) .{ }^{1} \mathrm{H}$ NMR $\left(500 \mathrm{MHz}\right.$, acetone- $\left.d_{6}\right) \delta 9.51(\mathrm{~s}, 1 \mathrm{H}, \mathrm{NH}-\mathrm{dpa}), 8.06\left(\mathrm{dd},{ }^{3} J_{\mathrm{HH}}=6 \mathrm{~Hz},{ }^{4} J_{\mathrm{HH}}=2 \mathrm{~Hz}\right.$, 2H, 6-dpa), $7.82\left(\mathrm{ddd},{ }^{3} J_{\mathrm{HH}}=8 \mathrm{~Hz},{ }^{3} J_{\mathrm{HH}}=7 \mathrm{~Hz},{ }^{4} J_{\mathrm{HH}}=2 \mathrm{~Hz}, 2 \mathrm{H}, 4-\mathrm{dpa}\right), 7.39\left(\mathrm{dd},{ }^{3} J_{\mathrm{HH}}\right.$ $=8 \mathrm{~Hz},{ }^{4} J_{\mathrm{HH}}=2 \mathrm{~Hz},{ }^{3} J_{\mathrm{PtH}}=70 \mathrm{~Hz}$ Pt satellites, $\left.4 \mathrm{H} \mathrm{H}^{\mathrm{o}}-\mathrm{Ph}\right), 7.27\left(\mathrm{~d},{ }^{3} J_{\mathrm{HH}}=8 \mathrm{~Hz}, 2 \mathrm{H}, 3-\right.$ dpa), $6.76\left(\mathrm{t},{ }^{3} J_{\mathrm{HH}}=8 \mathrm{~Hz}, 4 \mathrm{H}, \mathrm{H}^{\mathrm{m}}-\mathrm{Ph}\right), 6.72\left(\mathrm{ddd},{ }^{3} J_{\mathrm{HH}}=7 \mathrm{~Hz},{ }^{3} J_{\mathrm{HH}}=6 \mathrm{~Hz},{ }^{4} J_{\mathrm{HH}}=2 \mathrm{~Hz}\right.$, 2H, 5-dpa), $6.62\left(\mathrm{t},{ }^{3} J_{\mathrm{HH}}=7 \mathrm{~Hz}, 2 \mathrm{H}, \mathrm{H}^{\mathrm{p}}-\mathrm{Ph}\right) .{ }^{13} \mathrm{C}$ NMR (201 MHz, acetone-d 6 ) $\delta 152.4$, 151.1, 146.7, 139.5, 139.4, 127.2, 121.6, 119.0, 114.7. Anal. calcd. for $\mathrm{PtN}_{3} \mathrm{C}_{22} \mathrm{H}_{19}(\%)$ : C 50.76, H 3.69, N 8.07; found: C 50.97, H 3.79, N 7.90.

(dpo)PtPh . The ligand was bis(2-pyridyl)ether (dpo). Isolated $0.14 \mathrm{~g}(93 \%) .{ }^{1} \mathrm{H}$ NMR $\left(300 \mathrm{MHz}, \mathrm{CD}_{2 \mathrm{~b}} \mathrm{l}_{2}\right) \delta 8.19\left(\mathrm{~d},{ }^{3} J_{\mathrm{HH}}=6 \mathrm{~Hz},{ }^{3} J_{\mathrm{PtH}}=25 \mathrm{~Hz}\right.$ Pt satellite, $\left.2 \mathrm{H}, \mathrm{H}^{6}-\mathrm{dpo}\right), 7.94(\mathrm{t}$, $\left.{ }^{3} J_{\mathrm{HH}}=8 \mathrm{~Hz}, 2 \mathrm{H}, \mathrm{H}^{4}-\mathrm{dpo}\right), 7.42\left(\mathrm{~m}, 6 \mathrm{H}, \mathrm{H}^{\mathrm{o}}-\mathrm{Ph}\right.$ and $\left.\mathrm{H}^{3}-\mathrm{dpo}\right), 7.06\left(\mathrm{t},{ }^{3} J_{\mathrm{HH}}=7 \mathrm{~Hz}, 2 \mathrm{H}, \mathrm{H}^{5}-\right.$ dpo), $6.91\left(\mathrm{t},{ }^{3} J_{\mathrm{HH}}=7 \mathrm{~Hz}, 4 \mathrm{H}, \mathrm{H}^{\mathrm{m}}-\mathrm{Ph}\right), 6.79\left(\mathrm{t},{ }^{3} J_{\mathrm{HH}}=7 \mathrm{~Hz}, 2 \mathrm{H}, \mathrm{H}^{\mathrm{p}}-\mathrm{Ph}\right) .{ }^{13} \mathrm{C} \mathrm{NMR}(75$ $\left.\mathrm{MHz}, \mathrm{cd}_{2 \mathrm{~b}} \mathrm{l}_{2}\right) \delta 159.1,150.0,143.7,141.4,138.5,127.2,123.1,122.0,115.9$ (dpo and Ph aromatic). Anal. calcd. for $\mathrm{PtON}_{2 \mathrm{~b} 22} \mathrm{H}_{18}$ (\%): C 50.67, H 3.49, N 5.37; found: C 50.68, H 3.56, N 5.21 .

General procedure for the synthesis of $[(\mathrm{N} \sim \mathrm{N}) \operatorname{Pt}(\mathrm{Ph})(\mathrm{THF})]\left[\mathrm{BAr}_{4}{ }_{4}\right]$ complexes. A solution/suspension of $\left({ }^{\mathrm{x}} \mathrm{bpy}\right) \mathrm{Pt}(\mathrm{Ph})_{2}$ in $\mathrm{THF}(30 \mathrm{~mL})$ was cooled to approximately -70 ${ }^{\circ} \mathrm{C}$. One equivalent of $\left[\mathrm{H}\left(\mathrm{Et}_{2} \mathrm{O}\right)_{2}\right]\left[\mathrm{BAr}_{4}^{\prime}\right]$ dissolved in THF $\left(\sim 10 \mathrm{~mL},-70{ }^{\circ} \mathrm{C}\right)$ was added. 
The volatiles were removed in vacuo. The residue was treated with $n$-pentane $(\sim 2 \mathrm{~mL})$, which was then removed under vacuum to afford a low-density solid. The solid was dried in vacuo.

Spectroscopic data for BAr' $_{4}$ anion. The chemical shifts for the $\mathrm{BAr}_{4}{ }_{4}$ anion of various Pt complexes are virtually identical. The NMR spectroscopy data for the anion are as follows. ${ }^{1} \mathrm{H}$ NMR $\left(300 \mathrm{MHz}, \mathrm{CD}_{2} \mathrm{Cl}_{2}\right) \delta 7.72\left(\mathrm{~s}, 8 \mathrm{H}, \mathrm{H}^{\mathrm{o}}-\mathrm{BAr}_{4}{ }^{\prime}\right), 7.56\left(\mathrm{~s}, 4 \mathrm{H}, \mathrm{H}^{\mathrm{p}}-\right.$ $\left.\mathrm{BAr}_{4}^{\prime}\right){ }^{13} \mathrm{C}$ NMR $\left(75 \mathrm{MHz}, \mathrm{CD}_{2} \mathrm{Cl}_{2}\right) \delta 162.3$ (q, Ar', $\left.{ }^{1} J_{\mathrm{B}-\mathrm{Cipso}}=49 \mathrm{~Hz}\right), 135.4\left(\mathrm{Ar}^{\prime}\right), 129.5$ (q, $\left.m-\mathrm{Ar}^{\prime},{ }^{2} J_{\mathrm{C}-\mathrm{F}}=32 \mathrm{~Hz}\right), 125.2\left(\mathrm{q}, \mathrm{Ar},{ }^{2} J_{\mathrm{C}-\mathrm{F}}=272 \mathrm{~Hz}\right), 118.1\left(\mathrm{Ar}^{\prime}\right) .{ }^{19} \mathrm{~F}$ NMR $(282 \mathrm{MHz}$, $\left.\mathrm{CD}_{2} \mathrm{Cl}_{2}\right) \delta-63.1\left(\mathrm{~s}, \mathrm{CF}_{3}-\mathrm{Ar}^{\prime}\right)$.

$\left[\left({ }^{\mathrm{m}} \mathbf{b p y}\right) \mathbf{P t}(\mathbf{P h})(\mathbf{T H F})\right]\left[\mathbf{B A r}_{4}{ }_{4}\right]$ (3.2a). $80 \%$ isolated yield, 0.148 g. ${ }^{1} \mathrm{H}$ NMR $(300 \mathrm{MHz}$, $\left.\mathrm{CD}_{2} \mathrm{Cl}_{2}\right) \delta 8.24\left(\mathrm{~d}, 1 \mathrm{H}, \mathrm{H}^{6}{ }_{-}{ }^{\mathrm{m}}\right.$ bpy, $\left.{ }^{3} J_{\mathrm{HH}}=6 \mathrm{~Hz}\right), 8.01\left(\mathrm{~d}, 1 \mathrm{H}, \mathrm{H}^{6}{ }_{-}{ }^{\mathrm{m}}\right.$ bpy, $\left.{ }^{3} J_{\mathrm{HH}}=7 \mathrm{~Hz}\right), 7.55$ (d, $1 \mathrm{H}, \mathrm{H}^{3}{ }^{\mathrm{m}}{ }^{\mathrm{m}}$ bpy, ${ }^{4} \mathrm{~J}_{\mathrm{HH}}=2 \mathrm{~Hz}$ ), 7.45 (m, 3H, $\mathrm{H}^{3}{ }^{\mathrm{m}}{ }^{\mathrm{b}} \mathrm{bpy}$ and $\mathrm{H}^{\mathrm{o}}-\mathrm{Ph}$ ), 7.21 (dd, $1 \mathrm{H}, \mathrm{H}^{5}{ }^{\mathrm{m}} \mathrm{bpy}$, $\left.{ }^{3} J_{\mathrm{HH}}=6 \mathrm{~Hz},{ }^{4} J_{\mathrm{HH}}=2 \mathrm{~Hz}\right), 7.14\left(\mathrm{t}, 2 \mathrm{H}, \mathrm{H}^{\mathrm{m}}-\mathrm{Ph},{ }^{3} J_{\mathrm{HH}}=7 \mathrm{~Hz}\right), 7.04\left(\mathrm{~m}, 1 \mathrm{H}, \mathrm{H}^{\mathrm{p}}-\mathrm{Ph}\right), 6.74$ (dd, $\left.1 \mathrm{H}, \mathrm{H}^{5}-{ }^{\mathrm{m}} \mathrm{bpy},{ }^{3} J_{\mathrm{HH}}=7 \mathrm{~Hz},{ }^{4} J_{\mathrm{HH}}=3 \mathrm{~Hz}\right), 4.12(\mathrm{~m}, 4 \mathrm{H}, \alpha-\mathrm{THF}), 4.02\left(\mathrm{~s}, 3 \mathrm{H}, \mathrm{OCH}_{3}\right)$, 3.95 (s, 3H, OCH $\left.H_{3}\right), 1.84$ (m, 4H, $\beta$-THF). ${ }^{13} \mathrm{C}$ NMR $\left(126 \mathrm{MHz}, \mathrm{CD}_{2} \mathrm{Cl}_{2}\right) \delta 169.0,168.5$, $159.1,155.5,155.2,148.1,139.2,136.5,128.5,125.3,112.7,112.1,111.2,110.5$ ( $^{\mathrm{m}}$ bpy and $\mathrm{Ph}), 77.8$ ( $\beta$-THF), $57.3\left(\mathrm{OCH}_{3}\right), 57.1\left(\mathrm{OCH}_{3}\right), 25.1$ ( $\beta$-THF). Anal. calcd. for $\mathrm{PtN}_{2} \mathrm{O}_{3} \mathrm{BF}_{24} \mathrm{C}_{54} \mathrm{H}_{37}$ : calcd: C 45.55, H 2.62, N 1.97; found: C 45.38, H 2.81, N 2.10.

[(bpy)Pt(Ph)(THF)][BAr' $\left.{ }_{4}\right]$ (3.2c). 89\% isolated yield, 0.201 g. ${ }^{1} \mathrm{H}$ NMR $(800 \mathrm{MHz}$, $\left.\mathrm{CD}_{2} \mathrm{Cl}_{2}\right) \delta 8.49\left(\mathrm{~d}, 1 \mathrm{H}, \mathrm{H}^{6}-\mathrm{bpy},{ }^{3} J_{\mathrm{HH}}=5 \mathrm{~Hz}\right), 8.31\left(\mathrm{~d}, 1 \mathrm{H}, \mathrm{H}^{6}-\mathrm{bpy},{ }^{3} J_{\mathrm{HH}}=6 \mathrm{~Hz}\right), 8.24(\mathrm{td}$, $1 \mathrm{H}, \mathrm{H}^{4}$-bpy, $\left.{ }^{3} J_{\mathrm{HH}}=8 \mathrm{~Hz},{ }^{4} J_{\mathrm{HH}}=2 \mathrm{~Hz}\right), 8.15\left(\mathrm{~d}, 1 \mathrm{H}, \mathrm{H}^{3}\right.$-bpy, $\left.{ }^{3} J_{\mathrm{HH}}=8 \mathrm{~Hz}\right), 8.11(\mathrm{td}, 1 \mathrm{H}$, $\mathrm{H}^{4}$-bpy, $\left.{ }^{3} J_{\mathrm{HH}}=8 \mathrm{~Hz},{ }^{4} J_{\mathrm{HH}}=1 \mathrm{~Hz}\right), 8.03\left(\mathrm{~d}, 1 \mathrm{H}, \mathrm{H}^{3}\right.$-bpy, $\left.{ }^{3} J_{\mathrm{HH}}=8 \mathrm{~Hz}\right), 7.78\left(\mathrm{ddd}, \mathrm{H}^{5}\right.$-bpy, $\left.{ }^{3} J_{\mathrm{HH}}=8 \mathrm{~Hz},{ }^{3} J_{\mathrm{HH}}=5 \mathrm{~Hz},{ }^{4} J_{\mathrm{HH}}=1 \mathrm{~Hz}\right), 7.47\left(\mathrm{~d}, 2 \mathrm{H}, \mathrm{H}^{\mathrm{o}}-\mathrm{Ph},{ }^{3} J_{\mathrm{HH}}=8 \mathrm{~Hz}\right), 7.30(\mathrm{ddd}, 1 \mathrm{H}$, 
$\mathrm{H}^{5}$-bpy, $\left.{ }^{3} J_{\mathrm{HH}}=8 \mathrm{~Hz},{ }^{3} J_{\mathrm{HH}}=6 \mathrm{~Hz},{ }^{3} J_{\mathrm{HH}}=2 \mathrm{~Hz}\right), 7.17\left(\mathrm{t}, 2 \mathrm{H}, \mathrm{H}^{\mathrm{m}}-\mathrm{Ph},{ }^{3} J_{\mathrm{HH}}=8 \mathrm{~Hz}\right), 7.09$ $\left(\mathrm{m}, 1 \mathrm{H}, \mathrm{H}^{\mathrm{p}}-\mathrm{Ph}\right), 4.16\left(\mathrm{~m}, 4 \mathrm{H}, \alpha\right.$-THF), $1.88(\mathrm{~m}, 4 \mathrm{H}, \beta-\mathrm{THF}) .{ }^{13} \mathrm{C}$ NMR $(126 \mathrm{MHz}$, $\left.\mathrm{CD}_{2} \mathrm{Cl}_{2}\right) \delta 158.0,154.4,154.0,146.9,141.0,140.5,138.8,136.1,128.7,128.4,128.2$, 125.6, 123.7, 123.4 (bpy and Ph), 77.9 ( $\alpha$-THF), 25.1 ( $\beta$-THF). Anal. calcd. for $\mathrm{PtN}_{2} \mathrm{OBF}_{24} \mathrm{C}_{52} \mathrm{H}_{33}$ : calcd: C 45.80, H 2.44, N 2.05; found: C 45.76, H 2.34, N 2.01.

$\left[\left({ }^{\mathbf{B r}} \mathbf{b p y}\right) \mathbf{P t}(\mathbf{P h})(\mathbf{T H F})\right]\left[\mathbf{B A r}{ }_{4}\right]$ (3.2d). 94\% isolated yield, 0.105 g. ${ }^{1} \mathrm{H}$ NMR (300 $\left.\mathrm{MHz}, \mathrm{CD}_{2} \mathrm{Cl}_{2}\right) \delta 8.32\left(\mathrm{~m}, 2 \mathrm{H}, \mathrm{H}^{3}\right.$-bpy and $\mathrm{H}^{6}$-bpy), 8.20 (d, $1 \mathrm{H}, \mathrm{H}^{3}$-bpy, ${ }^{3} \mathrm{~J}_{\mathrm{HH}}=2 \mathrm{~Hz}$ ), $8.12\left(\mathrm{~d}, 1 \mathrm{H}, \mathrm{H}^{6}\right.$-bpy, $\left.{ }^{3} J_{\mathrm{HH}}=6 \mathrm{~Hz}\right), 8.00\left(\mathrm{dd}, 1 \mathrm{H}, \mathrm{H}^{5}-\mathrm{bpy},{ }^{3} J_{\mathrm{HH}}=6 \mathrm{~Hz},{ }^{4} J_{\mathrm{HH}}=2 \mathrm{~Hz}\right), 7.50$ (dd, $\left.1 \mathrm{H}, \mathrm{H}^{5}-\mathrm{bpy},{ }^{3} J_{\mathrm{HH}}=6 \mathrm{~Hz},{ }^{4} J_{\mathrm{HH}}=2 \mathrm{~Hz}\right), 7.42\left(\mathrm{~d}, 2 \mathrm{H}, \mathrm{H}^{\mathrm{o}}-\mathrm{Ph},{ }^{3} J_{\mathrm{HH}}=7 \mathrm{~Hz}\right), 7.17(\mathrm{t}, 2 \mathrm{H}$, $\left.\mathrm{H}^{\mathrm{m}}-\mathrm{Ph},{ }^{3} J_{\mathrm{HH}}=7 \mathrm{~Hz}\right), 7.08\left(\mathrm{~m}, 1 \mathrm{H}, \mathrm{H}^{\mathrm{p}}-\mathrm{Ph}\right), 4.14(\mathrm{~m}, 4 \mathrm{H}, \alpha-\mathrm{THF}), 1.84$ (m, 4H, $\left.\beta-\mathrm{THF}\right)$. ${ }^{13} \mathrm{C}$ NMR $\left(75 \mathrm{MHz}, \mathrm{CD}_{2} \mathrm{Cl}_{2}\right) \delta 157.6,154.5,147.3,138.1,138.0,135.8,132.3,132.1$, 128.1, 127.9, 127.5, $126.8\left({ }^{\mathrm{Br}}\right.$ bpy and Ph), 78.3 ( $\alpha$-THF), 25.0 ( $\beta$-THF). Remaining 2 aromatic resonances are obscured due to coincidental overlap. Anal. calcd. for $\mathrm{PtN}_{2} \mathrm{Br}_{2} \mathrm{BF}_{24} \mathrm{C}_{52} \mathrm{H}_{31}$ : calcd: C 41.05, H 2.06, N 1.84; found: C 41.27, H 2.05, N 1.83.

[('bpy)Pt(Ph)(THF)][BAr' $\left.{ }_{4}\right]$ (3.2e). 86\% isolated yield, 0.099 g. ${ }^{1} \mathrm{H}$ NMR (300 MHz, $\left.\mathrm{CD}_{2} \mathrm{Cl}_{2}\right) \delta 8.87\left(\mathrm{~s}, 1 \mathrm{H}, \mathrm{H}^{3}-\mathrm{c}\right.$ bpy), $8.73\left(\mathrm{~d}, 1 \mathrm{H}, \mathrm{H}^{3}-{ }^{\mathrm{c}} \mathrm{bpy},{ }^{4} J_{\mathrm{HH}}=2 \mathrm{~Hz}\right), 8.68\left(\mathrm{~d}, 1 \mathrm{H}, \mathrm{H}^{6}-\right.$ $\left.{ }^{\mathrm{c}} \mathrm{bpy},{ }^{3} J_{\mathrm{HH}}=6 \mathrm{~Hz}\right), 8.51\left(\mathrm{~d}, 1 \mathrm{H}, \mathrm{H}^{6}-{ }^{\mathrm{c}} \mathrm{bpy},{ }^{3} J_{\mathrm{HH}}=6 \mathrm{~Hz}\right), 8.39\left(\mathrm{dd}, 1 \mathrm{H}, \mathrm{H}^{5}-{ }^{\mathrm{c}} \mathrm{bpy},{ }^{3} J_{\mathrm{HH}}=6\right.$ $\left.\mathrm{Hz},{ }^{4} J_{\mathrm{HH}}=2 \mathrm{~Hz}\right), 7.85\left(\mathrm{dd}, 1 \mathrm{H}, \mathrm{H}^{5}-{ }^{\mathrm{c}} \mathrm{bpy},{ }^{3} J_{\mathrm{HH}}=6 \mathrm{~Hz},{ }^{4} J_{\mathrm{HH}}=2 \mathrm{~Hz}\right), 7.45\left(\mathrm{~d}, 2 \mathrm{H}, \mathrm{H}^{\mathrm{o}}-\mathrm{Ph}\right.$, $\left.{ }^{3} J_{\mathrm{HH}}=8 \mathrm{~Hz}\right), 7.20\left(\mathrm{t}, 2 \mathrm{H}, \mathrm{H}^{\mathrm{m}}-\mathrm{Ph},{ }^{3} J_{\mathrm{HH}}=8 \mathrm{~Hz}\right), 7.11\left(\mathrm{~m}, 1 \mathrm{H}, \mathrm{H}^{\mathrm{p}}-\mathrm{Ph}\right), 4.55(\mathrm{q}, 2 \mathrm{H}$, $\left.\mathrm{OCH}_{2} \mathrm{CH}_{3},{ }^{3} J_{\mathrm{HH}}=7 \mathrm{~Hz}\right), 4.48\left(\mathrm{q}, 2 \mathrm{H}, \mathrm{OCH}_{2} \mathrm{CH}_{3},{ }^{3} \mathrm{~J}_{\mathrm{HH}}=7 \mathrm{~Hz}\right), 4.18(\mathrm{~m}, 4 \mathrm{H}, \alpha-\mathrm{THF})$, $1.88(\mathrm{~m}, 4 \mathrm{H}, \beta-\mathrm{THF}), 1.47\left(\mathrm{t}, 3 \mathrm{H},, \mathrm{OCH}_{2} \mathrm{CH}_{3},{ }^{3} J_{\mathrm{HH}}=7 \mathrm{~Hz}\right), 1.42\left(\mathrm{t}, 3 \mathrm{H}, \mathrm{OCH}_{2} \mathrm{CH}_{3},{ }^{3} J_{\mathrm{HH}}\right.$ $=7 \mathrm{~Hz}) .{ }^{13} \mathrm{C} \mathrm{NMR}\left(126 \mathrm{MHz}, \mathrm{CD}_{2} \mathrm{Cl}_{2}\right) \delta 163.0,162.8,158.3,155.3,154.4,147.8,142.6$, 
141.7, 135.8, 128.3, 128.0, 123.7, 123.5 (' ${ }^{(b p y, ~ P h ~ a n d ~} \mathrm{CO}_{2} \mathrm{Et}$ ), 78.3( $\alpha$-THF), 64.0 $\left(\mathrm{OCH}_{2} \mathrm{CH}_{3}\right), 25.1$ ( $\beta$-THF), $14.3\left(\mathrm{OCH}_{2} \mathrm{CH}_{3}\right)$. Remaining 5 resonances are obscured due to coincidental overlap. Anal. calcd. for $\mathrm{PtN}_{2} \mathrm{O}_{5} \mathrm{BF}_{24} \mathrm{C}_{58} \mathrm{H}_{41}$ : calcd: C 46.20, H 2.75, N 1.86; found: C 46.22, H 2.79, N 1.91 .

$\left[\left({ }^{\mathbf{N O} 2} \mathbf{b p y}\right) \mathbf{P t}(\mathbf{P h})(\mathbf{T H F})\right]\left[\mathbf{B A r}_{4}{ }_{4}\right]$ (3.2f). Isolated $0.334 \mathrm{~g}(92 \%) .{ }^{1} \mathrm{H} \mathrm{NMR}(300 \mathrm{MHz}$, $\left.\mathrm{CD}_{2} \mathrm{Cl}_{2}\right) \delta 9.13\left(\mathrm{~d}, 1 \mathrm{H}, \mathrm{H}^{3}-{ }^{\mathrm{NO} 2} b p y,{ }^{4} J_{\mathrm{HH}}=2 \mathrm{~Hz}\right), 8.97\left(\mathrm{~d}, 1 \mathrm{H}, \mathrm{H}^{3}-{ }^{\mathrm{NO} 2} b p y,{ }^{4} J_{\mathrm{HH}}=2 \mathrm{~Hz}\right)$, $8.95\left(\mathrm{~d}, 1 \mathrm{H}, \mathrm{H}^{6}{ }^{-}{ }^{\mathrm{NO} 2} b p y,{ }^{3} J_{\mathrm{HH}}=6 \mathrm{~Hz}\right), 8.81\left(\mathrm{~d}, 1 \mathrm{H}, \mathrm{H}^{6}{ }^{\mathrm{NO} 2} b p y,{ }^{3} J_{\mathrm{HH}}=6 \mathrm{~Hz}\right), 8.68(\mathrm{dd}, 1 \mathrm{H}$, $\left.\mathrm{H}^{5}{ }_{-}{ }^{\mathrm{NO} 2} \mathrm{bpy},{ }^{3} J_{\mathrm{HH}}=6 \mathrm{~Hz},{ }^{4} J_{\mathrm{HH}}=2 \mathrm{~Hz}\right), 8.16\left(\mathrm{dd}, 1 \mathrm{H}, \mathrm{H}^{5}-{ }^{\mathrm{NO} 2} \mathrm{bpy},{ }^{3} J_{\mathrm{HH}}=6 \mathrm{~Hz},{ }^{4} J_{\mathrm{HH}}=2\right.$ $\mathrm{Hz}), 7.43\left(\mathrm{~m}, 2 \mathrm{H}, \mathrm{H}^{\mathrm{o}}-\mathrm{Ph}\right), 7.25\left(\mathrm{~m}, 2 \mathrm{H}, \mathrm{H}^{\mathrm{m}}-\mathrm{Ph}\right), 7.17\left(\mathrm{~m}, 1 \mathrm{H}, \mathrm{H}^{\mathrm{p}}-\mathrm{Ph}\right), 4.21(\mathrm{~m}, 4 \mathrm{H}, \alpha-$ THF), 1.91 ( $\mathrm{m}, 4 \mathrm{H}, \beta$-THF). Note: Complex 3.2f decomposes over extended periods at room temperature in $\mathrm{CD}_{2} \mathrm{Cl}_{2}$, which prevented the acquisition of ${ }^{13} \mathrm{C}$ NMR data. Anal. calcd. for $\mathrm{PtBN}_{4} \mathrm{O}_{5} \mathrm{~F}_{24} \mathrm{C}_{52} \mathrm{H}_{31}$ : calcd: C 44.08, H 2.58, N 3.67; found: C 43.71, H 2.38, N 3.93 .

[(dpm)Pt(Ph)(THF)][BAr' 4 ] (3.7). Isolated 0.17 g (90\%). ${ }^{1} \mathrm{H}$ NMR $(500 \mathrm{MHz}$, $\left.\mathrm{CD}_{2} \mathrm{Cl}_{2}\right) \delta 8.47\left(\mathrm{t},{ }^{3} J_{\mathrm{HH}}=6 \mathrm{~Hz}, 2 \mathrm{H}, \mathrm{dpm}\right), 7.92\left(\mathrm{td},{ }^{3} J_{\mathrm{HH}}=8 \mathrm{~Hz},{ }^{4} J_{\mathrm{HH}}=2 \mathrm{~Hz}, 1 \mathrm{H}, \mathrm{dpm}\right)$, $7.80\left(\mathrm{td},{ }^{3} J_{\mathrm{HH}}=8 \mathrm{~Hz},{ }^{4} J_{\mathrm{HH}}=2 \mathrm{~Hz}, 1 \mathrm{H}, \mathrm{dpm}\right), 7.73\left(\mathrm{~s}, 8 \mathrm{H}, \mathrm{H}^{\mathrm{o}}-\mathrm{Ar}^{\prime}\right), 7.62\left(\mathrm{~d},{ }^{3} J_{\mathrm{HH}}=8 \mathrm{~Hz}\right.$, $1 \mathrm{H}, \mathrm{dpm}), 7.56$ (s, 4H, H $-\mathrm{H}^{\mathrm{p}}$ ), 7.48 (overlapping m, 2H, dpm), $7.37\left(\mathrm{dd},{ }^{3} \mathrm{~J}_{\mathrm{HH}}=8 \mathrm{~Hz}\right.$, $\left.{ }^{4} J_{\mathrm{HH}}=1 \mathrm{~Hz}, 2 \mathrm{H}, \mathrm{H}^{\mathrm{o}}-\mathrm{Ph}\right), 7.09\left(\mathrm{t},{ }^{3} J_{\mathrm{HH}}=8 \mathrm{~Hz}, 2 \mathrm{H}, \mathrm{H}^{\mathrm{m}}-\mathrm{Ph}\right), 7.04\left(\mathrm{ddd},{ }^{3} J_{\mathrm{HH}}=8 \mathrm{~Hz},{ }^{3} J_{\mathrm{HH}}=\right.$ $\left.6 \mathrm{~Hz},{ }^{4} J_{\mathrm{HH}}=2 \mathrm{~Hz}, 1 \mathrm{H}, \mathrm{dpm}\right) 6.98\left(\mathrm{t},{ }^{3} J_{\mathrm{HH}}=7 \mathrm{~Hz}, 1 \mathrm{H}, \mathrm{H}^{\mathrm{p}}-\mathrm{Ph}\right), 4.64$ (v br s, 2H, dpm$\mathrm{CH}_{2}$ ), 4.05 (s, 4H, $\alpha$-THF), 1.78 (s, 4H, $\beta$-THF). ${ }^{13} \mathrm{C}$ NMR $\left(75 \mathrm{MHz}, \mathrm{CD}_{2} \mathrm{Cl}_{2}\right.$ ) $\delta 162.3$ (q, Ar', $\left.{ }^{1} J_{\mathrm{BCipso}}=49 \mathrm{~Hz}\right), 156.7,154.6,153.7,149.8,140.8,140.3,136.5,135.2$ (Ar'), 129.4 $\left(\mathrm{q}, m-\mathrm{Ar}^{\prime},{ }^{2} J_{\mathrm{CF}}=32 \mathrm{~Hz}\right), 128.7,128.2,126.4,125.9,125.5,125.4,125.2(\mathrm{dpm}$ and $\mathrm{Ph}$ 
aromatic), 125.0 (q, $\left.\mathrm{CF}_{3}-\mathrm{Ar}^{\prime},{ }^{1} J_{\mathrm{CF}}=272 \mathrm{~Hz}\right), 117.9\left(\mathrm{Ar}^{\prime}\right), 77.4(\alpha-\mathrm{THF}), 47.4\left(\mathrm{dpm}-\mathrm{CH}_{2}\right)$, 24.9 ( $\beta$-THF). Anal. calcd. for $\mathrm{PtN}_{2} \mathrm{OBF}_{24} \mathrm{C}_{53} \mathrm{H}_{35}$ (\%): C 46.20, H 2.57, N 2.03; found: $\mathrm{C}$ 45.96, H 2.44, N 2.13.

[(Me-dpm)Pt(Ph)(THF)][BAr' $\left.{ }_{4}\right]$ (3.13). Isolated $0.14 \mathrm{~g}(93 \%) .{ }^{1} \mathrm{H}$ NMR (800 MHz, $\left.\mathrm{CD}_{2} \mathrm{Cl}_{2}\right) \delta 8.56\left(\mathrm{~d},{ }^{3} J_{\mathrm{HH}}=6 \mathrm{~Hz}, 1 \mathrm{H}, 6-\mathrm{dpm}\right), 7.90\left(\mathrm{td},{ }^{3} J_{\mathrm{HH}}=8 \mathrm{~Hz},{ }^{3} J_{\mathrm{HH}}=2 \mathrm{~Hz}, 1 \mathrm{H}, 4-\right.$ dpm), $7.69\left(\mathrm{t},{ }^{3} J_{\mathrm{HH}}=8 \mathrm{~Hz}, 1 \mathrm{H}, 4-\mathrm{dpm}\right), 7.63\left(\mathrm{~d},{ }^{3} J_{\mathrm{HH}}=8 \mathrm{~Hz}, 1 \mathrm{H}, 3-\mathrm{dpm}\right), 7.48\left(\mathrm{t},{ }^{3} J_{\mathrm{HH}}=\right.$ $7 \mathrm{~Hz}, 1 \mathrm{H}, 5$-dpm), 7.42 (d, ${ }^{3} J_{\mathrm{HH}}=8 \mathrm{~Hz}, 1 \mathrm{H}, 3$-dpm), 7.08 (d, ${ }^{3} J_{\mathrm{HH}}=8.0 \mathrm{~Hz}, 1 \mathrm{H}, 5$-dpm), $6.99-6.90(\mathrm{~m}, 5 \mathrm{H}, \mathrm{Ph}), 5.55\left(\mathrm{~d},{ }^{2} J_{\mathrm{HH}}=15 \mathrm{~Hz}, 1 \mathrm{H}, \mathrm{dpm}-\mathrm{CH}_{2}\right), 4.44\left(\mathrm{~d},{ }^{3} J_{\mathrm{HH}}=15 \mathrm{~Hz}\right.$, 1H, dpm-CH $\mathrm{CH}_{2}$ ), 4.17 (m, 2H, $\alpha$-THF), 3.98 (m, 2H, $\alpha$-THF), 2.55 (s, 3H, dpm-Me), 1.88 (m, 4H, $\beta$-THF). ${ }^{13} \mathrm{C}$ NMR (201 MHz, $\left.\mathrm{CD}_{2} \mathrm{Cl}_{2}\right) \delta 165.2,157.3,154.2,150.8,140.6$, 134.0, 136.1, 127.4, 126.1, 125.9, 125.3, 125.2, 123.4 (Me-dpm and Ph aromatic), 77.2 ( $\alpha$-THF), 48.3 (dpm- $\mathrm{CH}_{2}$ ), 29.1 ( $\beta$-THF), 25.4 (dpm-Me). Remaining aromatic resonance obscured due to broadening or coincidental overlap. Anal. calcd. for $\mathrm{PtN}_{2} \mathrm{OBF}_{24} \mathrm{C}_{54} \mathrm{H}_{37}$ (\%): C 46.60, H 2.69, N 2.01; found: C 46.51, H 2.70, N 2.07.

[(Me 2 -dpm)Pt(Ph)(THF)][BAr' $\left.{ }_{4}\right]$ (3.14). Isolated 0.18 g (95\%). ${ }^{1} \mathrm{H}$ NMR (300 MHz, $\left.\mathrm{CD}_{2} \mathrm{Cl}_{2}\right) \delta 7.76\left(\mathrm{t},{ }^{3} J_{\mathrm{HH}}=8 \mathrm{~Hz}, 1 \mathrm{H}, 4-\mathrm{dpm}\right), 7.64\left(\mathrm{t},{ }^{3} J_{\mathrm{HH}}=8 \mathrm{~Hz}, 1 \mathrm{H}, 4-\mathrm{dpm}\right), 7.46(\mathrm{~d}$, $\left.{ }^{3} J_{\mathrm{HH}}=8 \mathrm{~Hz}, 1 \mathrm{H}, 3-\mathrm{dpm}\right), 7.38\left(\mathrm{~d},{ }^{3} J_{\mathrm{HH}}=8 \mathrm{~Hz}, 1 \mathrm{H}, 5-\mathrm{dpm}\right), 7.33\left(\mathrm{~d},{ }^{3} J_{\mathrm{HH}}=8 \mathrm{~Hz}, 1 \mathrm{H}, 3-\right.$ dpm), $7.12\left(\mathrm{~d},{ }^{3} J_{\mathrm{HH}}=7 \mathrm{~Hz}, 2 \mathrm{H}, \mathrm{H}^{\mathrm{o}}-\mathrm{Ph}\right), 7.04\left(\mathrm{~d},{ }^{3} J_{\mathrm{HH}}=8 \mathrm{~Hz}, 1 \mathrm{H}, 5-\mathrm{dpm}\right), 7.02-6.86$ (m, $3 \mathrm{H}, \mathrm{H}^{\mathrm{m}}$ and $\left.\mathrm{H}^{\mathrm{p}}-\mathrm{Ph}\right), 5.82\left(\mathrm{~d},{ }^{2} J_{\mathrm{HH}}=15 \mathrm{~Hz}, 1 \mathrm{H}, \mathrm{dpm}-\mathrm{CH}_{2}\right), 4.48\left(\mathrm{~d},{ }^{2} J_{\mathrm{HH}}=15 \mathrm{~Hz}, 1 \mathrm{H}\right.$, dpm-CH$H_{2}$ ), 3.92 (m, 4H, $\alpha$-THF), 2.94 (s, 3H, dpm-Me), 2.67 (s, 3H, dpm-Me), 1.73 (m, 4H, $\beta$-THF). ${ }^{13} \mathrm{C}$ NMR (201 MHz, $\left.\mathrm{CD}_{2} \mathrm{Cl}_{2}\right) \delta 164.7,160.8,157.5,154.0,140.5,139.9$, 137.2, 128.7, 127.4, 125.8, 125.5, 125.3, 123.38, 123.34 ( $\mathrm{Me}_{2}$-dpm and $\mathrm{Ph}$ aromatic), 
76.6 ( $\alpha$-THF), 48.4 (dpm- $\mathrm{CH}_{2}$ ), 28.7 (dpm-Me), 24.8 ( $\beta$-THF), 24.5 (dpm-Me). Anal. calcd. for $\mathrm{PtN}_{2} \mathrm{OBF}_{24} \mathrm{C}_{54} \mathrm{H}_{37}$ (\%): C 46.99, H 2.80, N 1.99; found: C 46.79, H 2.76, N 2.05 .

[(Me 2 -bpy)Pt(Ph)(THF)][BAr' 4 ] (3.15). Isolated $0.13 \mathrm{~g} \mathrm{(91 \% ).}{ }^{1} \mathrm{H}$ NMR (300 MHz, $\left.\mathrm{CD}_{2} \mathrm{Cl}_{2}\right) \delta 8.09-7.79$ (m, 4H, bpy), $7.51\left(\mathrm{~d},{ }^{3} J_{\mathrm{HH}}=7 \mathrm{~Hz}, 1 \mathrm{H}\right.$, bpy), 7.17 (m, 3H, bpy and $\left.\mathrm{H}^{\mathrm{o}}-\mathrm{Ph}\right), 6.98\left(\mathrm{~m}, 3 \mathrm{H}, \mathrm{H}^{\mathrm{m}}\right.$ and $\left.\mathrm{H}^{\mathrm{p}}-\mathrm{Ph}\right), 3.96(\mathrm{~m}, 4 \mathrm{H}, \alpha-\mathrm{THF}), 2.66$ (s, 3H, bpy-Me), 2.05 (s, 3H, bpy-Me), 1.70 (m, 4H, $\beta$-THF). ${ }^{13} \mathrm{C}$ NMR $\left(125 \mathrm{MHz}, \mathrm{CD}_{2} \mathrm{Cl}_{2}\right) \delta 167.0,160.7$, $159.3,155.7,140.2,139.8,137.0,128.7,128.4,128.0,127.5,125.5,120.6,120.3$ (bpy and Ph aromatic), 76.2 ( $\alpha$-THF), 29.1 (bpy-Me), 24.7 ( $\beta$-THF), 23.7 (bpy-Me). Anal. calcd. for $\mathrm{PtN}_{2} \mathrm{OBF}_{24} \mathrm{C}_{54} \mathrm{H}_{37}$ (\%): C 46.60, H 2.69, N 2.01; found: C 46.18, H 2.52, N 1.92 .

[(dpe)Pt(Ph)(THF)][BAr' 4 ] (3.16). Isolated 0.12 g (89\%). ${ }^{1} \mathrm{H}$ NMR (500 MHz, $\left.\mathrm{CD}_{2} \mathrm{Cl}_{2}\right) \delta 8.69\left(\mathrm{~d},{ }^{3} J_{\mathrm{HH}}=6 \mathrm{~Hz}, 1 \mathrm{H}, 6\right.$-dpe), $8.52\left(\mathrm{~d},{ }^{3} J_{\mathrm{HH}}=6 \mathrm{~Hz}, 1 \mathrm{H}, 6\right.$-dpe $), 7.69(\mathrm{~m}$, 10H, $\mathrm{H}^{\mathrm{o}}-\mathrm{Ar}^{\prime}$ and 4-dpe), $7.56\left(\mathrm{~s}, 4 \mathrm{H}, \mathrm{H}^{\mathrm{p}}-\mathrm{Ar}^{\prime}\right), 7.33$ (m, 5H, $\mathrm{H}^{\mathrm{o}}-\mathrm{Ph}, 3$-dpe and 5-dpe), 7.02 (t, ${ }^{3} J_{\mathrm{HH}}=7 \mathrm{~Hz}, 3 \mathrm{H}, \mathrm{H}^{\mathrm{m}}-\mathrm{Ph}$ and 5-dpe), $6.91\left(\mathrm{t},{ }^{3} J_{\mathrm{HH}}=7 \mathrm{~Hz}, 1 \mathrm{H}, \mathrm{H}^{\mathrm{p}}-\mathrm{Ph}\right), 3.88$ (br. m, 8H, dpe- $\mathrm{CH}_{2}$ and $\alpha$-THF), 1.77 (s, $4 \mathrm{H}, \beta$-THF). ${ }^{13} \mathrm{C}$ NMR $\left(125 \mathrm{MHz}, \mathrm{CD}_{2} \mathrm{Cl}_{2}\right) \delta 162.5,159.8$, $153.4,150.8,139.5,139.4,136.6,130.5,128.7,127.8,126.3,125.2,124.8,124.0$ (dpe and $\mathrm{Ph}$ aromatic), 77.3 ( $\alpha$-THF), $36.16\left(\mathrm{dpe}-\mathrm{CH}_{2}\right), 34.07\left(\mathrm{dpe}-\mathrm{CH}_{2}\right), 25.08$ ( $\beta$-THF). Anal. calcd. for $\mathrm{PtN}_{2} \mathrm{OBF}_{24} \mathrm{C}_{54} \mathrm{H}_{37}$ (\%): C 46.60, H 2.69, N 2.01; found: C 46.85, H 2.81, N 2.14.

[(dpk)Pt(Ph)(THF)][BAr' $\left.{ }_{4}\right] \quad$ (3.17). Isolated 0.22 g (92\%). ${ }^{1} \mathrm{H}$ NMR (300 MHz, $\left.\mathrm{CD}_{2} \mathrm{Cl}_{2}\right) \delta 8.63\left(\mathrm{~d},{ }^{3} J_{\mathrm{HH}}=6 \mathrm{~Hz}, 1 \mathrm{H}, \mathrm{dpk}\right), 8.33\left(\mathrm{~d},{ }^{3} J_{\mathrm{HH}}=6 \mathrm{~Hz}, 1 \mathrm{H}, \mathrm{dpk}\right), 8.24\left(\mathrm{td},{ }^{3} J_{\mathrm{HH}}\right.$ 
$\left.=8 \mathrm{~Hz},{ }^{4} J_{\mathrm{HH}}=2 \mathrm{~Hz}, 1 \mathrm{H}, \mathrm{dpk}\right), 8.10(\mathrm{~m}, 2 \mathrm{H}, \mathrm{dpk}), 7.85\left(\mathrm{~m}, 10 \mathrm{H}, \mathrm{H}^{\mathrm{o}}-\mathrm{BAr}\right.$ and dpk), 7.63 (s, 4H, $\mathrm{H}^{\mathrm{p}}-\mathrm{BAr}$ ), $7.37\left(\mathrm{~m}, 3 \mathrm{H}\right.$, dpk and $\left.\mathrm{H}^{\mathrm{o}}-\mathrm{Ph}\right), 7.11\left(\mathrm{~m}, 3 \mathrm{H}, \mathrm{H}^{\mathrm{m}}-\right.$ and $\left.\mathrm{H}^{\mathrm{p}}-\mathrm{Ph}\right), 4.06(\mathrm{~m}$, 4H, $\alpha$-THF), 1.78 (m, 4H, $\beta$-THF). ${ }^{13} \mathrm{C}$ NMR (126 MHz, $\left.\mathrm{CD}_{2} \mathrm{Cl}_{2}\right) \delta 185.8$ (CO-dpk), $154.6,153.3,150.8,149.3,141.4,141.1,136.1,130.2,128.6,128.5,127.0$ (dpk and $\mathrm{Ph}$ aromatic), 77.8 ( $\alpha$-THF), 24.9 ( $\beta$-THF). Remaining 3 aromatic resonances obscured due to broadening or coincidental overlap. Anal. calcd. for $\mathrm{PtN}_{2} \mathrm{O}_{2} \mathrm{BF}_{24} \mathrm{C}_{53} \mathrm{H}_{33}$ (\%): C 45.74, H 2.39, N 2.01; found: C 45.76, H 2.57, N 2.15.

[(dpa)Pt(Ph)(THF)][BAr' $\left.{ }_{4}\right]$ (3.18). Isolated 0.19 g (95\%). ${ }^{1} \mathrm{H}$ NMR (800 MHz, $\left.\mathrm{CD}_{2} \mathrm{Cl}_{2}\right) \delta 8.20\left(\mathrm{dd},{ }^{3} J_{\mathrm{HH}}=6 \mathrm{~Hz},{ }^{4} J_{\mathrm{HH}}=2 \mathrm{~Hz}, 1 \mathrm{H}, \mathrm{dpa}\right), 8.11\left(\mathrm{dd},{ }^{3} J_{\mathrm{HH}}=6 \mathrm{~Hz},{ }^{4} J_{\mathrm{HH}}=2\right.$ $\mathrm{Hz}, 1 \mathrm{H}, \mathrm{dpa}), 8.06$ (s, 1H, NH-dpa), $7.88\left(\mathrm{ddd},{ }^{3} J_{\mathrm{HH}}=8 \mathrm{~Hz},{ }^{3} J_{\mathrm{HH}}=7 \mathrm{~Hz},{ }^{4} J_{\mathrm{HH}}=2 \mathrm{~Hz}\right.$, 1H, dpa), $7.74\left(\mathrm{~m}, 9 \mathrm{H}, \mathrm{H}^{\mathrm{o}}-\mathrm{BAr}\right.$ ' and dpa), $7.56\left(\mathrm{~s}, 4 \mathrm{H}, \mathrm{H}^{\mathrm{p}}-\mathrm{BAr}\right), 7.36\left(\mathrm{dd},{ }^{3} J_{\mathrm{HH}}=8 \mathrm{~Hz}\right.$, $\left.{ }^{4} J_{\mathrm{HH}}=2 \mathrm{~Hz}, 2 \mathrm{H}, \mathrm{H}^{\mathrm{o}}-\mathrm{Ph}\right), 7.18\left(\mathrm{ddd},{ }^{3} J_{\mathrm{HH}}=7 \mathrm{~Hz},{ }^{3} J_{\mathrm{HH}}=6 \mathrm{~Hz},{ }^{4} J_{\mathrm{HH}}=1 \mathrm{~Hz}, 1 \mathrm{H}, \mathrm{dpa}\right)$, $7.13\left(\mathrm{~d},{ }^{3} J_{\mathrm{HH}}=8 \mathrm{~Hz}, 1 \mathrm{H}, \mathrm{dpa}\right), 7.07\left(\mathrm{t},{ }^{3} J_{\mathrm{HH}}=8 \mathrm{~Hz}, 2 \mathrm{H}, \mathrm{H}^{\mathrm{m}}-\mathrm{Ph}\right), 6.98\left(\mathrm{~m}, 2 \mathrm{H}, \mathrm{H}^{\mathrm{p}}-\mathrm{Ph}\right.$ and dpa), $6.65\left(\mathrm{ddd},{ }^{3} J_{\mathrm{HH}}=7 \mathrm{~Hz},{ }^{3} J_{\mathrm{HH}}=6 \mathrm{~Hz},{ }^{4} J_{\mathrm{HH}}=1 \mathrm{~Hz}, 1 \mathrm{H}, \mathrm{dpa}\right), 4.01(\mathrm{~m}, 4 \mathrm{H}, \alpha-\mathrm{THF})$, $1.73(\mathrm{~m}, 4 \mathrm{H}, \beta-\mathrm{THF}) .{ }^{13} \mathrm{C}$ NMR $\left(201 \mathrm{MHz}, \mathrm{CD}_{2} \mathrm{Cl}_{2}\right) \delta 153.4,151.7,149.7,146.1,141.2$, 141.0, 136.4, 128.3, 125.3, 120.7, 119.8, 115.5, 114.4 (dpa and $\mathrm{Ph}$ aromatic), 77.2 ( $\alpha$ THF), 24.9 ( $\beta$-THF). Remaining aromatic resonance obscured due to broadening or coincidental overlap. Anal. calcd. for $\mathrm{PtN}_{3} \mathrm{OBF}_{24} \mathrm{C}_{52} \mathrm{H}_{34}$ (\%): C 45.30, H 2.49, N 3.05; found: C 45.45, H 2.63, N 3.03.

[(dpo)Pt(Ph)(THF)][BAr' $\left.{ }_{4}\right]$ (3.19). Isolated $0.12 \mathrm{~g}(98 \%) .{ }^{1} \mathrm{H}$ NMR $(500 \mathrm{MHz}$, $\left.\mathrm{CD}_{2} \mathrm{Cl}_{2}\right) \delta 8.25\left(\mathrm{dd},{ }^{3} J_{\mathrm{HH}}=6 \mathrm{~Hz},{ }^{4} J_{\mathrm{HH}}=2 \mathrm{~Hz}, 1 \mathrm{H}, \mathrm{dpo}\right), 8.22\left(\mathrm{dd},{ }^{3} J_{\mathrm{HH}}=6 \mathrm{~Hz},{ }^{4} J_{\mathrm{HH}}=2\right.$ $\mathrm{Hz}, 1 \mathrm{H}, \mathrm{dpo}), 8.11\left(\mathrm{td},{ }^{3} J_{\mathrm{HH}}=8 \mathrm{~Hz},{ }^{4} J_{\mathrm{HH}}=2 \mathrm{~Hz}, 1 \mathrm{H}, \mathrm{dpo}\right), 7.99\left(\mathrm{td},{ }^{3} J_{\mathrm{HH}}=8 \mathrm{~Hz},{ }^{4} J_{\mathrm{HH}}=2\right.$ 
$\mathrm{Hz}, 1 \mathrm{H}, \mathrm{dpo}), 7.72\left(\mathrm{~s}, 8 \mathrm{H}, \mathrm{H}^{\mathrm{o}}-\mathrm{Ar}^{\prime}\right), 7.54\left(\mathrm{~m}, 5 \mathrm{H}, \mathrm{H}^{\mathrm{p}}-\mathrm{Ar}^{\prime}\right.$ and dpo), $7.50\left(\mathrm{ddd},{ }^{3} J_{\mathrm{HH}}=7 \mathrm{~Hz}\right.$, $\left.{ }^{3} J_{\mathrm{HH}}=6 \mathrm{~Hz},{ }^{4} J_{\mathrm{HH}}=1 \mathrm{~Hz}, 1 \mathrm{H}, \mathrm{dpo}\right), 7.39\left(\mathrm{~m}, 3 \mathrm{H}, \mathrm{H}^{\mathrm{o}}-\mathrm{Ph}\right.$ and dpo $), 7.11\left(\mathrm{t},{ }^{3} J_{\mathrm{HH}}=8 \mathrm{~Hz}\right.$, 2H, $\left.\mathrm{H}^{\mathrm{m}}-\mathrm{Ph}\right), 7.02\left(\mathrm{~m}, 2 \mathrm{H}, \mathrm{H}^{\mathrm{p}}-\mathrm{Ph}\right.$ and dpo), 4.09 (m, 4H, $\left.\alpha-\mathrm{THF}\right), 1.77$ (m, 4H, $\left.\beta-\mathrm{THF}\right)$. ${ }^{13} \mathrm{C}$ NMR $\left(125 \mathrm{MHz}, \mathrm{CD}_{2} \mathrm{Cl}_{2}\right) \delta 157.6,152.9,146.6,144.1,143.8,136.1,128.7,128.5$, 125.8, 124.5, 123.9, 117.5, 116.6 (dpo and Ph aromatic), 77.9 ( $\alpha$-THF), 24.9 ( $\beta$-THF). Remaining aromatic resonances obscured due to broadening or coincidental overlap. Anal. calcd. for $\mathrm{PtN}_{2} \mathrm{O}_{2} \mathrm{BF}_{24} \mathrm{C}_{52} \mathrm{H}_{33}$ (\%): C 45.26, H 2.42, N 2.03; found: C 45.00, H 2.38, N 2.15.

\section{General procedure for the synthesis of $\left[(\mathrm{N} \sim \mathrm{N}) \mathrm{Pt}\left(\mathrm{CH}_{2} \mathrm{CH}_{2} \mathrm{Ph}\right)\left(\eta^{2}-\mathrm{C}_{2} \mathrm{H}_{4}\right)\right]\left[\mathrm{BAr}{ }_{4}\right]$}

complexes. Complex 3.2b was dissolved in dichloromethane $(\sim 5 \mathrm{~mL})$. The solution was transferred to a stainless steel pressure reactor and pressurized with ethylene (50 psi). After 12 hours, the volatiles were removed in vacuo, and $n$-pentane $(\sim 2 \mathrm{~mL})$ was added to the crude solid. The pentane was removed under vacuum to afford a low-density solid. The solid was collected and dried in vacuo.

$\left[\left({ }^{\mathrm{m}} \mathbf{b p y}\right) \mathbf{P t}\left(\mathbf{C H}_{2} \mathbf{C H}_{2} \mathbf{P h}\right)\left(\eta^{2}-\mathbf{C}_{2} \mathbf{H}_{4}\right)\right]\left[\mathbf{B A r}_{4}{ }_{4}\right] \quad$ (3.3a). 92\% isolated yield, 0.087 g. ${ }^{1} \mathrm{H}$ $\operatorname{NMR}\left(300 \mathrm{MHz}, \mathrm{CD}_{2} \mathrm{Cl}_{2}\right) \delta 8.61\left(\mathrm{brd}, 1 \mathrm{H}, \mathrm{bpy},{ }^{3} J_{\mathrm{HH}}=7 \mathrm{~Hz}\right), 7.81\left(\mathrm{brd}, 1 \mathrm{H}\right.$, bpy, ${ }^{3} J_{\mathrm{HH}}=$ $7 \mathrm{~Hz}$ ), 7.64 (br s, 1H, bpy), 7.61 (br s, 1H, bpy), 7.30-7.10 (m, 6H, bpy and Ph), 4.173.88 (overlapping resonances, $10 \mathrm{H}, \mathrm{OMe}$ and $\left.\mathrm{C}_{2} \mathrm{H}_{4}\right), 2.68\left(\mathrm{t}, 2 \mathrm{H}, \mathrm{Pt}-\mathrm{CH}_{2} \mathrm{CH}_{2} \mathrm{Ph},{ }^{3} J_{\mathrm{HH}}=8\right.$ $\mathrm{Hz}), 1.39\left(\mathrm{t}, 2 \mathrm{H}, \mathrm{Pt}-\mathrm{CH}_{2} \mathrm{CH}_{2} \mathrm{Ph},{ }^{3} J_{\mathrm{HH}}=8 \mathrm{~Hz}\right) .{ }^{13} \mathrm{C} \mathrm{NMR}\left(201 \mathrm{MHz}, \mathrm{CD}_{2} \mathrm{Cl}_{2}\right) \delta$ 170.68, $169.4,169.0,159.5,156.2,150.3,147.3,144.0,129.3,128.9,128.8,126.8,126.1$ ( $^{\mathrm{m}} \mathrm{bpy}$ and $\mathrm{Ph}), 69.0\left(\mathrm{C}_{2} \mathrm{H}_{4}\right), 58.0(\mathrm{OMe}), 57.6(\mathrm{OMe}), 37.7\left(\mathrm{CH}_{2} \mathrm{CH}_{2} \mathrm{Ph}\right), 16.4\left(\mathrm{CH}_{2} \mathrm{CH}_{2} \mathrm{Ph}\right)$. 
Remaining resonance is obscured due to coincidental overlap. Anal. calcd. for $\mathrm{PtBN}_{2} \mathrm{O}_{2} \mathrm{~F}_{24} \mathrm{C}_{54} \mathrm{H}_{37}$ : calcd: C 46.07, H 2.65, N 1.99; found: C 46.24, H 2.61, N 2.11.

[(bpy)Pt $\left.\left(\mathbf{C H}_{2} \mathbf{C H}_{2} \mathbf{P h}\right)\left(\eta^{2}-\mathbf{C}_{2} \mathbf{H}_{4}\right)\right]\left[\mathbf{B A r}_{4}{ }_{4}\right]$ (3.3c). 81\% isolated yield, $0.098 \mathrm{~g} .{ }^{1} \mathrm{H}$ NMR (800 MHz, $\left.\mathrm{CD}_{2} \mathrm{Cl}_{2}\right) \delta 8.80$ (br s, $1 \mathrm{H}$, bpy), 8.34-8.22 (br m, $4 \mathrm{H}$, bpy), 8.05 (br s, $1 \mathrm{H}$, bpy), 7.84 (br s, 1H, bpy), 7.26 (m, 4H, H $\left.\mathrm{H}^{\mathrm{o} / \mathrm{m}}-\mathrm{Ph}\right), 7.17$ (m, 1H, $\left.\mathrm{H}^{\mathrm{p}}-\mathrm{Ph}\right), 4.19$ (br s, 4H, $\left.\mathrm{C}_{2} \mathrm{H}_{4}\right), 2.72\left(\mathrm{t}, 2 \mathrm{H}, \mathrm{Pt}-\mathrm{CH}_{2} \mathrm{CH}_{2} \mathrm{Ph},{ }^{3} \mathrm{~J}_{\mathrm{HH}}=8 \mathrm{~Hz}\right), 1.54\left(\mathrm{t}, 2 \mathrm{H}, \mathrm{Pt}-\mathrm{CH}_{2} \mathrm{CH}_{2} \mathrm{Ph},{ }^{3} J_{\mathrm{HH}}=8\right.$ Hz). ${ }^{13} \mathrm{C}$ NMR $\left(126 \mathrm{MHz}, \mathrm{CD}_{2} \mathrm{Cl}_{2}\right) \delta 157.5,154.1,148.5,145.8,143.5,141.4,130.5$, 129.4, 128.6, 126.6, 124.1 (bpy and $\mathrm{Ph}), 70.6\left(\mathrm{C}_{2} \mathrm{H}_{4}\right), 37.4\left(\mathrm{CH}_{2} \mathrm{CH}_{2} \mathrm{Ph}\right), 17.0$ $\left(\mathrm{CH}_{2} \mathrm{CH}_{2} \mathrm{Ph}\right)$. Remaining 3 resonances are obscured due to coincidental overlap. Anal. calcd. for PtBN ${ }_{2} \mathrm{~F}_{24} \mathrm{C}_{52} \mathrm{H}_{31}$ : calcd: C 46.41, H 2.33, N 2.08; found: C 46.61, H 2.41, N 2.19 .

[(' ${ }^{\mathrm{c}}$ bpy $\left.) \mathbf{P t}\left(\mathbf{C H}_{2} \mathbf{C} \mathbf{H}_{2} \mathbf{P h}\right)\left(\eta^{2}-\mathbf{C}_{2} \mathbf{H}_{4}\right)\right]\left[\mathbf{B A r}{ }_{4}\right]$ (3.3e). $88 \%$ isolated yield, $0.127 \mathrm{~g} .{ }^{1} \mathrm{H}$ NMR (300 MHz, $\left.\mathrm{CD}_{2} \mathrm{Cl}_{2}\right) \delta 8.90\left(\mathrm{~m}, 3 \mathrm{H},{ }^{\mathrm{c}} \mathrm{bpy}\right), 8.28$ (m, 3H, $\left.{ }^{\mathrm{c}} \mathrm{bpy}\right), 7.26(\mathrm{~m}, 5 \mathrm{H}, \mathrm{Ph}), 4.54$ (overlapping m's, $4 \mathrm{H}, \mathrm{OCH}_{2} \mathrm{CH}_{3}$ ), 4.30 (br s, $4 \mathrm{H}, \mathrm{C}_{2} \mathrm{H}_{4},{ }^{3} \mathrm{~J}_{\mathrm{PtH}}=34 \mathrm{~Hz}$, Pt satellites), 2.71 (t, 2H, Pt- $\mathrm{CH}_{2} \mathrm{CH}_{2} \mathrm{Ph},{ }^{3} J_{\mathrm{HH}}=8 \mathrm{~Hz}$ ), $1.60\left(\mathrm{t}, 2 \mathrm{H}, \mathrm{Pt}-\mathrm{CH}_{2} \mathrm{CH}_{2} \mathrm{Ph},{ }^{3} J_{\mathrm{HH}}=8 \mathrm{~Hz}\right.$ ), 1.47 (overlapping m's, $\left.6 \mathrm{H}, \mathrm{OCH}_{2} \mathrm{CH}_{3}\right) .{ }^{13} \mathrm{C}$ NMR $\left(201 \mathrm{MHz}, \mathrm{CD}_{2} \mathrm{Cl}_{2}\right) \delta 157.8,154.7,149.8$, $146.9,144.3,143.2,142.9,129.2,128.6,128.3,126.8,124.2$ ('bpy and $\mathrm{Ph}), 71.9\left(\mathrm{C}_{2} \mathrm{H}_{4}\right)$, $64.4\left(\mathrm{OCH}_{2} \mathrm{CH}_{3}\right), \quad 64.2 \quad\left(\mathrm{OCH}_{2} \mathrm{CH}_{3}\right), \quad 37.5 \quad\left(\mathrm{CH}_{2} \mathrm{CH}_{2} \mathrm{Ph}\right), \quad 17.5 \quad\left(\mathrm{OCH}_{2} \mathrm{CH}_{3}\right), \quad 14.3$ $\left(\mathrm{CH}_{2} \mathrm{CH}_{2} \mathrm{Ph}\right)$. Remaining 5 resonances are obscured due to coincidental overlap. Anal. calcd. for $\mathrm{PtBN}_{2} \mathrm{O}_{4} \mathrm{~F}_{24} \mathrm{C}_{58} \mathrm{H}_{41}$ : calcd: C 46.69, H 2.78, N 1.88; found: C 46.90, H 2.78, N 2.00 .

$\left[\left({ }^{\mathrm{NO2}} \mathbf{b p y}\right) \mathbf{P t}\left(\mathbf{C H}_{2} \mathbf{C H}_{2} \mathbf{P h}\right)\left(\eta^{2}-\mathbf{C}_{2} \mathbf{H}_{4}\right)\right]\left[\mathbf{B A r}_{4}{ }_{4}\right]$ (3.3f). 87\% isolated yield, 0.108 g. ${ }^{1} \mathrm{H}$ NMR (300 MHz, $\left.\mathrm{CD}_{2} \mathrm{Cl}_{2}\right) \delta 9.14\left(\mathrm{~d}, 1 \mathrm{H},{ }^{\mathrm{NO} 2} \mathrm{bpy},{ }^{3} \mathrm{~J}_{\mathrm{HH}}=2 \mathrm{~Hz}\right.$ ), 8.57 (br m, $2 \mathrm{H},{ }^{\mathrm{NO} 2}$ bpy), 
$7.28\left(\right.$ br d, $\left.2 \mathrm{H}, \mathrm{H}^{\mathrm{o}}-\mathrm{Ph},{ }^{3} \mathrm{~J}_{\mathrm{HH}}=7 \mathrm{~Hz}\right), 7.23-7.06\left(\mathrm{~m}, 3 \mathrm{H}, \mathrm{H}^{\mathrm{m}}\right.$ and $\left.\mathrm{H}^{\mathrm{p}}-\mathrm{Ph}\right), 4.42($ br s, $4 \mathrm{H}$, $\left.\eta^{2}-\mathrm{C}_{2} \mathrm{H}_{4}\right), 2.70\left(\mathrm{t}, 2 \mathrm{H}, \mathrm{Pt}-\mathrm{CH}_{2} \mathrm{CH}_{2} \mathrm{Ph},{ }^{3} J_{\mathrm{HH}}=7 \mathrm{~Hz}\right), 1.71\left(\mathrm{t}, 2 \mathrm{H}, \mathrm{Pt}-\mathrm{CH}_{2} \mathrm{CH}_{2} \mathrm{Ph},{ }^{3} J_{\mathrm{HH}}=7\right.$ $\mathrm{Hz}$ ), Remaining ${ }^{\mathrm{NO} 2}$ bpy signals obscured due to broadening or coincidental overlap. ${ }^{13} \mathrm{C}$ NMR $\left(201 \mathrm{MHz}, \mathrm{CD}_{2} \mathrm{Cl}_{2}\right) \delta 152.3,149.1,142.3,128.9,128.5,126.8,123.3,118.2$ ( ${ }^{\mathrm{NO}}$ bpy and $\left.\mathrm{Ph}\right), 68.1\left(\mathrm{C}_{2} \mathrm{H}_{4}\right), 37.0\left(\mathrm{CH}_{2} \mathrm{CH}_{2} \mathrm{Ph}\right), 18.0\left(\mathrm{CH}_{2} \mathrm{CH}_{2} \mathrm{Ph}\right)$. Remaining 5 resonances are obscured due to coincidental overlap. Anal. calcd. for $\mathrm{PtBN}_{4} \mathrm{O}_{4} \mathrm{~F}_{24} \mathrm{C}_{52} \mathrm{H}_{31}$ : calcd: C 43.44, H 2.18, N 3.90; found: C 43.73, H 2.15, N 3.86.

$\left[(\mathbf{d p m}) \mathbf{P t}\left(\mathbf{C H}_{2} \mathbf{C H}_{2} \mathbf{P h}\right)\left(\eta^{2}-\mathbf{C}_{2} \mathbf{H}_{4}\right)\right]\left[\mathbf{B A r}_{4}\right]$ (3.8). Isolated $0.037 \mathrm{~g}(89 \%) .{ }^{1} \mathrm{H}$ NMR $\left(500 \mathrm{MHz}, \mathrm{CD}_{2} \mathrm{Cl}_{2}\right) \delta 8.62\left(\mathrm{~d},{ }^{3} J_{\mathrm{HH}}=6 \mathrm{~Hz}, 1 \mathrm{H}, \mathrm{dpm}\right), 8.19\left(\mathrm{~d},{ }^{3} J_{\mathrm{HH}}=6 \mathrm{~Hz}, 1 \mathrm{H}, \mathrm{dpm}\right)$, $8.01\left(\mathrm{td},{ }^{3} J_{\mathrm{HH}}=8 \mathrm{~Hz},{ }^{4} J_{\mathrm{HH}}=2 \mathrm{~Hz}, 1 \mathrm{H}, \mathrm{dpm}\right), 7.85\left(\mathrm{td},{ }^{3} J_{\mathrm{HH}}=8 \mathrm{~Hz},{ }^{4} J_{\mathrm{HH}}=2 \mathrm{~Hz}, 1 \mathrm{H}\right.$, dpm), $7.74\left(\mathrm{~s}, 8 \mathrm{H}, \mathrm{H}^{\mathrm{o}}-\mathrm{Ar}^{\prime}\right), 7.62-7.45\left(\mathrm{~m}, 7 \mathrm{H}, \mathrm{H}^{\mathrm{p}}-\mathrm{Ar}^{\prime}, \mathrm{H}^{\mathrm{o}}-\mathrm{Ph}\right.$ and dpm), $7.40\left(\mathrm{ddd},{ }^{3} J_{\mathrm{HH}}=\right.$ $\left.8 \mathrm{~Hz},{ }^{3} J_{\mathrm{HH}}=6 \mathrm{~Hz},{ }^{4} J_{\mathrm{HH}}=2 \mathrm{~Hz}, 1 \mathrm{H}, \mathrm{dpm}\right), 7.18-7.04$ (m, 3H, $\mathrm{H}^{\mathrm{m}}-\mathrm{Ph}$ and $\left.\mathrm{H}^{\mathrm{p}}-\mathrm{Ph}\right), 6.99-$ $6.93(\mathrm{~m}, 2 \mathrm{H}, \mathrm{dpm}), 4.15-3.91\left(\mathrm{~m}, 6 \mathrm{H}, \mathrm{dpm}-\mathrm{CH}_{2}\right.$ and $\left.\mathrm{C}_{2} \mathrm{H}_{4}\right), 2.25\left(\mathrm{t},{ }^{3} \mathrm{JHH}_{\mathrm{HH}}=7 \mathrm{~Hz}, 2 \mathrm{H}\right.$, $-\mathrm{CH}_{2} \mathrm{CH}_{2} \mathrm{Ph}$ ), 1.45-1.23 (m, 2H, $\left.-\mathrm{CH}_{2} \mathrm{CH}_{2} \mathrm{Ph}\right) .{ }^{13} \mathrm{C} \mathrm{NMR}\left(125 \mathrm{MHz}, \mathrm{CD}_{2} \mathrm{Cl}_{2}\right) \delta 162.2$ (q, Ar', $\left.{ }^{1} J_{\mathrm{BCipso}}=49 \mathrm{~Hz}\right), 154.7,153.0,149.6,147.8,143.6,142.3,141.2,135.2\left(\right.$ Ar'$\left.^{\prime}\right), 129.3$ $\left(\mathrm{q}, m-\mathrm{Ar}^{\prime},{ }^{2} J_{\mathrm{CF}}=32 \mathrm{~Hz}\right), 129.0,128.3,127.0,126.7,126.4,126.1,125.0\left(\mathrm{q}, \mathrm{Ar}^{\prime},{ }^{1} J_{\mathrm{CF}}=\right.$ $272 \mathrm{~Hz}$ ), 117.9 (Ar'), 100.9 (dpm and Ph aromatic), 73.0 (s with Pt satellites, ${ }^{1} J_{\mathrm{PtC}}=210$ $\left.\mathrm{Hz}, \mathrm{C}_{2} \mathrm{H}_{4}\right), 46.2\left(\mathrm{dpm}-\mathrm{CH}_{2}\right), 36.9\left(-\mathrm{CH}_{2} \mathrm{CH}_{2} \mathrm{Ph}\right), 15.3\left(-\mathrm{CH}_{2} \mathrm{CH}_{2} \mathrm{Ph}\right)$. Anal. calcd. for $\mathrm{PtN}_{2} \mathrm{BF}_{24} \mathrm{C}_{53} \mathrm{H}_{35}$ (\%): C 46.74, H 2.60, N 2.06; found: C 46.35, H 2.73, N 2.10.

Synthesis of $\left({ }^{\mathrm{NO}^{2}}\right.$ bpy)PtMe 2 . A heterogeneous mixture of $\left[(\mathrm{Me})_{2} \mathrm{Pt}\left(\mu-\mathrm{SEt}_{2}\right)\right]_{2}(0.526 \mathrm{~g}$, $0.834 \mathrm{mmol})$ and ${ }^{\mathrm{NO}}$ bpy $(0.4125 \mathrm{~g}, 1.68 \mathrm{mmol})$ in diethyl ether was stirred at room temperature for 16 hours. The solvent volume was partially reduced under vacuum, and the resulting mixture was filtered. The filtrate was discarded, and the solid was dried in 
vacuo to afford a purple solid $(0.737 \mathrm{~g}, 94 \%) .{ }^{1} \mathrm{H}$ NMR (300 MHz, acetone- $\left.d_{6}\right) \delta 9.78(\mathrm{~d}$, $2 \mathrm{H}, \mathrm{H}^{6}-{ }^{\mathrm{NO} 2} \mathrm{bpy},{ }^{3} J_{\mathrm{HH}}=6 \mathrm{~Hz},{ }^{3} J_{\mathrm{Pt}-\mathrm{H}}=21 \mathrm{~Hz}$, Pt satellites), $9.44\left(\mathrm{~d}, 2 \mathrm{H}, \mathrm{H}^{3}-{ }^{\mathrm{NO} 2} \mathrm{bpy},{ }^{4} J_{\mathrm{HH}}=\right.$ $2 \mathrm{~Hz}), 8.53\left(\mathrm{dd}, 2 \mathrm{H}, \mathrm{H}^{5}-{ }^{\mathrm{NO} 2} \mathrm{bpy},{ }^{3} J_{\mathrm{HH}}=6 \mathrm{~Hz},{ }^{4} J_{\mathrm{HH}}=2 \mathrm{~Hz}\right), 1.38\left(\mathrm{~s}, 6 \mathrm{H}, \mathrm{Pt}-\mathrm{CH}_{3},{ }^{2} J_{\mathrm{Pt}-\mathrm{H}}=\right.$ $91 \mathrm{~Hz}$, Pt satellites). The complex was too insoluble in organic solvents to obtain ${ }^{13} \mathrm{C}$ NMR data. Anal. calcd. for $\mathrm{PtN}_{4} \mathrm{O}_{4} \mathrm{C}_{12} \mathrm{H}_{12}$ : cacld: $\mathrm{C} 30.58, \mathrm{H}$ 2.57, N 11.89; found: C 30.70, H 2.56, N 11.622.

\section{General procedure for the synthesis of $\left[\left(^{\mathrm{x}} \mathrm{bpy}\right) \operatorname{Pt}(\mathrm{Me})\left(\eta^{2}\right.\right.$-styrene $\left.)\right]\left[\mathrm{BAr}_{4}{ }_{4}\right]\left(\mathrm{x}={ }^{\mathrm{t}} \mathrm{Bu}\right.$}

or $\mathrm{NO}_{2}$ ). A solution of ( $\left.{ }^{\mathrm{x}} \mathrm{bpy}\right) \mathrm{Pt}(\mathrm{Me})_{2}$ and an equivalent of styrene in dichloromethane $(30 \mathrm{~mL})$ was cooled to approximately $-70{ }^{\circ} \mathrm{C}$. One equivalent of $\left[\mathrm{H}\left(\mathrm{Et}_{2} \mathrm{O}\right)_{2}\right]\left[\mathrm{BAr}_{4}\right]$ dissolved in dichloromethane $\left(\sim 10 \mathrm{~mL},-70{ }^{\circ} \mathrm{C}\right)$ was added to the Pt solution. The solution was reduced to approximately half volume in vacuo and filtered through Celite with dichloromethane as eluent. The volatiles were removed from the filtrate in vacuo. The residue was treated with $n$-pentane $(\sim 2 \mathrm{~mL})$, which was then removed under vacuum to afford a low-density solid. The solid was dried in vacuo.

[('bpy)Pt(Me)( $\eta^{2}$-styrene)][BAr' $\left.{ }_{4}\right]$ (3.4b). 87\% isolated yield, 0.084 g. ${ }^{1} \mathrm{H}$ NMR (300 $\left.\mathrm{MHz}, \mathrm{CD}_{2} \mathrm{Cl}_{2}\right) \delta 8.68\left(\mathrm{~d}, 1 \mathrm{H}, \mathrm{H}^{6}{ }_{-}^{\mathrm{t}} \mathrm{bpy},{ }^{3} J_{\mathrm{HH}}=6 \mathrm{~Hz},{ }^{3} \mathrm{~J}_{\mathrm{Pt}-\mathrm{H}}=48 \mathrm{~Hz}\right.$, Pt satellites), $8.17(\mathrm{~s}$, 1H, $\left.\mathrm{H}^{3}{ }^{\mathrm{t}} \mathrm{bpy}\right), 8.09$ (s, 1H, $\mathrm{H}^{3}$-tbpy), 7.85 (m, 3H, tbpy), 7.59 (m, 2H, $\left.\mathrm{H}^{\mathrm{o}}-\mathrm{Ph}\right), 7.33$ (m, $\left.3 \mathrm{H}, \mathrm{H}^{\mathrm{m}} / \mathrm{H}^{\mathrm{p}}-\mathrm{Ph}\right), 6.29\left(\mathrm{dd}, 1 \mathrm{H}, \mathrm{PhCH}=\mathrm{CH}_{2},{ }^{3} J_{\mathrm{HHTrans}}=14 \mathrm{~Hz},{ }^{3} J_{\mathrm{HHCis}}=8 \mathrm{~Hz}\right) 4.49(\mathrm{~d}, 1 \mathrm{H}$, $\left.\mathrm{PhCH}=\mathrm{CH}_{2},{ }^{3} J_{\mathrm{HHTrans}}=14 \mathrm{~Hz}\right), 4.19\left(\mathrm{~d}, 1 \mathrm{H}, \mathrm{PhCH}=\mathrm{CH}_{2},{ }^{3} J_{\mathrm{HHCis}}=8 \mathrm{~Hz}\right), 1.44(\mathrm{~s}, 9 \mathrm{H}$, bpy), 1.37 (s, 9H, bpy), 0.67 (br s, 3H, Me, ${ }^{2} J_{\mathrm{Pt}-\mathrm{H}}=71 \mathrm{~Hz}$, Pt satellites). ${ }^{13} \mathrm{C}$ NMR (126 $\left.\mathrm{MHz}, \mathrm{CD}_{2} \mathrm{Cl}_{2}\right) \delta 175.2,168.6,165.8,157.3,154.0,147.6,145.7,136.0,130.1,129.1$, 128.8, 125.2, 124.8, 120.3, 120.2, 90.9 ('bpy and styrene), $36.2\left(\mathrm{CCH}_{3}\right), 35.8\left(\mathrm{CCH}_{3}\right)$, $29.7\left(\mathrm{CCH}_{3}\right), 29.6\left(\mathrm{CCH}_{3}\right)$. Methyl resonance not observed due to broadening. Anal. 
calcd. for PtBN $\mathrm{F}_{24} \mathrm{C}_{59} \mathrm{H}_{47}$ : calcd: C 49.01, H 3.28, N 1.94; found: C 49.31, H 3.42, N 2.10 .

$\left[\left({ }^{\text {NO2 }}\right.\right.$ bpy)Pt(Me)$\left(\eta^{2}\right.$-styrene) $]\left[\right.$ BAr $\left._{4}^{\prime}\right]$ (3.4f). 96\% isolated yield, 0.582 g. ${ }^{1} \mathrm{H}$ NMR $\left(300 \mathrm{MHz}, \mathrm{CD}_{2} \mathrm{Cl}_{2}\right) \delta 9.25\left(\right.$ br d, $\left.1 \mathrm{H}, \mathrm{H}^{6}{ }_{-}^{\mathrm{NO} 2} b p y,{ }^{3} J_{\mathrm{HH}}=5 \mathrm{~Hz}\right), 9.14\left(\right.$ br s, $1 \mathrm{H}, \mathrm{H}^{3}-$ ${ }^{\mathrm{NO} 2}$ bpy), 9.04 (br s, $\left.1 \mathrm{H}, \mathrm{H}^{3}{ }_{-}{ }^{\mathrm{NO}} b p y\right), 8.65$ (br s, $\left.1 \mathrm{H}, \mathrm{H}^{6}{ }_{-}^{\mathrm{NO} 2} b p y\right), 8.30$ (br s, $1 \mathrm{H}, \mathrm{H}^{5}-$ ${ }^{\mathrm{NO} 2}$ bpy), $8.23\left(\mathrm{br} \mathrm{d}, 1 \mathrm{H}, \mathrm{H}^{5}{ }_{-}^{\mathrm{NO} 2} b p y,{ }^{3} J_{\mathrm{HH}}=6 \mathrm{~Hz}\right), 7.60\left(\mathrm{~m}, 2 \mathrm{H}, \mathrm{H}^{\mathrm{o}}\right.$-styrene $), 7.42(\mathrm{~m}, 1 \mathrm{H}$, $\mathrm{H}^{\mathrm{p}}$-styrene), $7.33\left(\mathrm{~m}, 2 \mathrm{H}, \mathrm{H}^{\mathrm{m}}\right.$-styrene $), 6.64\left(\mathrm{dd}, 1 \mathrm{H}, \mathrm{PhCH}=\mathrm{CH}_{2},{ }^{3} J_{\mathrm{HH} \text { trans }}=15 \mathrm{~Hz}\right.$, $\left.{ }^{3} J_{\mathrm{HHcis}}=8 \mathrm{~Hz}\right), 4.78\left(\mathrm{dd}, 1 \mathrm{H}, \mathrm{PhCH}=\mathrm{CH}_{2},{ }^{3} J_{\mathrm{HH} \text { trans }}=15 \mathrm{~Hz},{ }^{2} J_{\mathrm{HHgem}}=1 \mathrm{~Hz}\right), 4.50(\mathrm{dd}$, $\left.1 \mathrm{H}, \mathrm{PhCH}=\mathrm{CH}_{2},{ }^{3} J_{\mathrm{HHcis}}=8 \mathrm{~Hz},{ }^{2} J_{\mathrm{HHgem}}=1 \mathrm{~Hz}\right), 1.04\left(\mathrm{~s}, 3 \mathrm{H}, \mathrm{Pt}-\mathrm{CH}_{3},{ }^{2} J_{\mathrm{Pt}-\mathrm{H}}=74 \mathrm{~Hz}, \mathrm{Pt}\right.$ satellites). ${ }^{13} \mathrm{C}$ NMR $\left(126 \mathrm{MHz}, \mathrm{CD}_{2} \mathrm{Cl}_{2}\right) \delta 158.9,156.5,155.5,155.2,152.5,150.7$, $135.7,131.5,129.6,129.4,122.7,118.7,118.3,100.5,68.1$ ( ${ }^{\mathrm{NO} 2}$ bpy and styrene),-0.8 (s, $\mathrm{Pt}-\mathrm{CH}_{3},{ }^{1} \mathrm{~J}_{\mathrm{Pt}-\mathrm{C}}=684 \mathrm{~Hz}$, Pt satellites). Remaining resonance obscured due to coincidental overlap. Anal. calcd. for $\mathrm{PtBN}_{4} \mathrm{O}_{4} \mathrm{~F}_{24} \mathrm{C}_{51} \mathrm{H}_{29}$ : calcd: C 43.03, H 2.05, N 3.94; found: C 43.33, H 1.92, N 3.90 .

Catalytic Olefin Hydrophenylation. A representative catalytic reaction is described. $\left[\left({ }^{\mathrm{m}}\right.\right.$ bpy) $\left.\mathrm{Pt}(\mathrm{Ph})(\mathrm{THF})\right]\left[\mathrm{BAr}_{4}\right]$ (3.2a) $(0.019 \mathrm{~g}, 0.013 \mathrm{mmol})$ was dissolved in $12.0 \mathrm{~mL}$ of benzene containing $0.01 \mathrm{~mol} \%$ (relative to benzene) of hexamethylbenzene (HMB) as an internal standard. The reaction mixture was placed in a stainless steel pressure reactor, charged with ethylene, pressurized to a total of $0.8 \mathrm{MPa}$ with $\mathrm{N}_{2}$ and heated to $100{ }^{\circ} \mathrm{C}$. After 4 and $16 \mathrm{~h}$, the reaction mixture was cooled to room temperature and analyzed by GC/MS. Peak areas of the products and the internal standard were used to calculate product yields. Ethylbenzene, diethylbenzene and styrene amounts were quantified using linear regression analysis of gas chromatograms of standard samples. For example, a set 
of five known standards were prepared consisting of $2: 1,4: 1,6: 1,8: 1$, and 10:1 molar ratios of ethylbenzene to $\mathrm{HMB}$ in benzene. A plot of the peak area ratios versus molar ratios gave a regression line. For the GC/MS system, the slope and correlation coefficient $\left(\mathrm{R}^{2}\right)$ for ethylbenzene were 0.53 and 0.98 , respectively. Identical procedures were used to quantify the production of styrene, 1,3-diethylbenzene, 1,4-diethylbenzene and 1,2diethylbenzene. The slope and correlation coefficients $\left(\mathrm{R}^{2}\right)$ for these species are 0.55 , $0.99 ; 0.56,0.99 ; 0.56,0.99 ; 0.52,0.99$, respectively.

Kinetics of styrene formation. A representative kinetic experiment is described. Complex 3.3e (0.044 g, $0.029 \mathrm{mmol})$ and hexamethyldisilane (HMDS, $1.5 \mu \mathrm{L}$ ), an internal standard, were dissolved in $1.0 \mathrm{~mL}$ of nitromethane- $d_{3}$. The solution was then divided (0.3 $\mathrm{mL}$ for each sample) and added to three high-pressure NMR tubes. The tube was pressurized with $0.3 \mathrm{MPa}$ of ethylene and placed into a temperature equilibrated (45 $\left.{ }^{\circ} \mathrm{C}\right)$ NMR probe. The temperature of the probe was determined using a solution of $80 \%$ ethylene glycol in DMSO- $d_{6}$. Kinetic runs were performed in triplicate, and standard deviations are based on the average $k_{\mathrm{obs}}$ values from the three experiments. The concentration of ethylene in solution was determined by integration against the internal standard. ${ }^{1} \mathrm{H}$ NMR spectra were collected every 10 minutes with 8 scans and a 5.0 second pulse delay. Styrene resonances were integrated against that of HMDS, and from a plot of $\ln \left(1-[\text { styrene }]_{\mathrm{t}} /[\text { starting material }]_{\mathrm{o}}\right)$ versus time (seconds) the rate constants were extracted. The rate of formation of styrene from complex 3.3e, in the presence of $0.34 \mathrm{M}$ $\mathrm{C}_{2} \mathrm{H}_{4}$, was $1.1(2) \times 10^{-4} \mathrm{~s}^{-1}$ with a correlation coefficient $\left(\mathrm{R}^{2}\right)$ of 0.99 for each plot.

Thermolysis of $\left[\left({ }^{\mathrm{NO} 2}\right.\right.$ bpy $\left.) \operatorname{Pt}\left(\mathrm{CH}_{2} \mathrm{CH}_{2} \mathrm{Ph}\right)\left(\eta^{2}-\mathrm{C}_{2} \mathrm{H}_{4}\right)\right]\left[\mathrm{BAr}{ }_{4}\right]$ in $\mathrm{C}_{6} \mathrm{H}_{6}$. To a glass pressure tube, complex 3.3f (0.024 g, $0.02 \mathrm{mmol})$ and benzene (4 mL) containing HMB 
as an internal standard were added. The reaction mixture was heated at $100{ }^{\circ} \mathrm{C}$ for $4 \mathrm{~h}$, cooled to room temperature and analyzed by GC/MS. Only ethylbenzene was detected (in quantitative yield).

\section{Determination of Catalyst Resting State for Ethylene Hydrophenylation using}

Complex 3.7. Complex 3.7 (0.02 g, $0.01 \mathrm{mmol})$ was massed into a J-Young NMR tube and dissolved in $\mathrm{C}_{6} \mathrm{D}_{6}(0.4 \mathrm{~mL})$. The tube was then pressurized with $0.1 \mathrm{MPa}$ of ethylene, and placed in a temperature-equilibrated NMR probe $\left(90{ }^{\circ} \mathrm{C}\right.$ setting). The actual temperature of the probe $\left(89^{\circ} \mathrm{C}\right)$ was determined using a solution of $80 \%$ ethylene glycol in DMSO- $d_{6}{ }^{33}$ Spectra were collected every 15 minutes for 4 hours with 8 scans and a 5.0 second pulse delay. Beginning with the initial spectrum, the only observable Pt species in solution was $\left[(\mathrm{dpm}) \mathrm{Pt}\left(\mathrm{CH}_{2} \mathrm{CH}_{2} \mathrm{Ph}\right)\left(\eta^{2}-\mathrm{C}_{2} \mathrm{H}_{4}\right)\right]\left[\mathrm{BAr}_{4}^{\prime}\right]$.

Kinetics of Ethylene Insertion. A representative kinetic experiment is described. Complex $3.7(0.057 \mathrm{~g}, 0.041 \mathrm{mmol})$ and hexamethyldisilane (HMDS, $2.0 \mu \mathrm{L}$ as an internal standard) were dissolved in $1.3 \mathrm{~mL}$ of $\mathrm{CD}_{2} \mathrm{Cl}_{2}$. The solution was then divided ( $0.4 \mathrm{~mL}$ for each sample) and added to three high pressure NMR tubes. Each tube was pressurized with $0.4 \mathrm{MPa}$ of ethylene and placed into a temperature equilibrated $\left(25^{\circ} \mathrm{C}\right.$ setting) NMR probe. The actual temperature of the probe $\left(23^{\circ} \mathrm{C}\right)$ was determined using a sample of methanol- $d_{4} \cdot{ }^{34}$ Kinetic runs were performed in triplicate. The concentration of ethylene in solution was determined by integration against the internal standard, HMDS. ${ }^{1} \mathrm{H}$ NMR spectra were collected every 1 minute with 4 scans and a 5.0 second pulse delay. The product peaks were integrated against that of HMDS, and from a plot of $\ln (1-$ $\left.[3.8]_{t} /[3.7]_{\mathrm{o}}\right)$ vs. time (seconds), the rate constants were extracted. The rate of formation 
of 3.8 from complex 3.7, in the presence of $0.5 \mathrm{M} \mathrm{C}_{2} \mathrm{H}_{4}$, was 8.4(9) x $10^{-4} \mathrm{~s}^{-1}$ with a correlation coefficient $\left(\mathrm{R}^{2}\right)$ of 0.99 for each plot.

Kinetics of Benzene- $d_{6}$ C-D Activation. A representative kinetic experiment is described. Complex 3.7 (0.064 g, $0.046 \mathrm{mmol})$ and hexamethyldisilane (HMDS, $2.0 \mu \mathrm{L}$ as an internal standard) were dissolved in $1.2 \mathrm{~mL}$ of $\mathrm{CD}_{2} \mathrm{Cl}_{2}$. The solution was then divided $\left(0.375 \mathrm{~mL}\right.$ for each sample) and added to three NMR tubes. To each tube, $\mathrm{C}_{6} \mathrm{D}_{6}$ $(0.019 \mathrm{~mL}, 0.21 \mathrm{mmol})$ was added. The tube was placed into a temperature equilibrated $\left(30{ }^{\circ} \mathrm{C}\right.$ setting) NMR probe. The actual temperature of the probe $\left(29^{\circ} \mathrm{C}\right)$ was determined using a solution of $80 \%$ ethylene glycol in DMSO- $d_{6} \cdot{ }^{33}$ Kinetic runs were performed in triplicate. ${ }^{1} \mathrm{H}$ NMR spectra were collected every 10 minutes with 8 scans and a 5.0 second pulse delay. Resonances for complex 3.7 were integrated against that of the internal standard, HMDS, and from a plot of $\ln \left([3.7]_{\mathrm{t}}\right)$ vs. time (seconds), the rate constants were extracted. The rate of formation of complex 3.7- $\boldsymbol{d}_{5}$ and $\mathrm{C}_{6} \mathrm{H}_{5} \mathrm{D}$ in the presence of $0.5 \mathrm{M} \mathrm{C}_{6} \mathrm{D}_{6}$, was $9.9(4) \times 10^{-5} \mathrm{~s}^{-1}$ with a correlation coefficient $\left(\mathrm{R}^{2}\right)$ of 0.99 for each plot.

\section{Substrate Concentration Corrections for Determination of Catalytic Activation}

Parameters. Catalysis with complexes 3.7 and 3.2b was performed under conditions that are inverse $1^{\text {st }}$-order in ethylene concentration. Therefore, for the Eyring analysis, the observed rate constants were multiplied by the concentration of ethylene. The ethylene concentration under catalytic conditions was simulated by sparging a sample of $\mathrm{C}_{6} \mathrm{D}_{6}$ in a J-Young NMR tube with ethylene and pressurizing it according to the preparation of catalytic reactions. The concentration of ethylene was then determined in triplicate by integration of the ethylene resonance versus the internal standard, HMDS, at $90{ }^{\circ} \mathrm{C}$. 


\section{Substrate Concentration Corrections for Determination of $\mathbf{C}_{6} \mathbf{D}_{6}$ Activation}

Parameters. The reactions with $\mathrm{C}_{6} \mathrm{D}_{6}$ and complexes $\mathbf{3 . 7}$ and $\mathbf{3 . 2 b}$ were performed under conditions that are $1^{\text {st }}$-order in the concentration of $\mathrm{C}_{6} \mathrm{D}_{6}$. Thus, for Eyring analysis, the observed rate constants were divided by the concentration of $\mathrm{C}_{6} \mathrm{D}_{6}$.

\subsection{References}

1. McKeown, B. A.; Gonzalez, H. E.; Friedfeld, M. R.; Gunnoe, T. B.; Cundari, T. R.; Sabat, M., J. Am. Chem. Soc. 2011, 133, 19131-19152.

2. Foley, N. A.; Lee, J. P.; Ke, Z.; Gunnoe, T. B.; Cundari, T. R., Acc. Chem. Res. 2009, 42, 585-597.

3. Oxgaard, J.; Periana, R. A.; Goddard III, W. A., J. Am. Chem. Soc. 2004, 126, 11658-11665.

4. Ong, C. M.; Jennings, M. C.; Puddephatt, R. J., Can. J. Chem. 2003, 81, 11961205.

5. Wik, B. J.; Lersch, M.; Krivokapic, A.; Tilset, M., J. Am. Chem. Soc. 2006, 128, 2682-2696.

6. Shiotsuki, M.; White, P. S.; Brookhart, M.; Templeton, J. L., J. Am. Chem. Soc. 2007, 129, 4058-4067.

7. Hansch, C.; Leo, A.; Taft, R. W., Chem. Rev. 1991, 91, 165-195.

8. Tomasik, P.; Ratajewicz, Z., Pyridine-Metal Complexes. John Wiley \& Sons, Inc.: New York, 1985; Vol. 14.

9. Zhang, F. B.; Kirby, C. W.; Hairsine, D. W.; Jennings, M. C.; Puddephatt, R. J., J. Am. Chem. Soc. 2005, 127, 14196-14197. 
10. Distance was measured from $P h$ centroid to cis-pyridyl centroid using the graphical program, ChemCraft, and atom coordinates from single crystal X-ray diffraction.

11. Maheshwari, V.; Carlone, M.; Fronczek, F. R.; Marzilli, L. G., Acta Crystallographica Section B 2007, 63, 603-611.

12. Safa, M.; Jennings, M. C.; Puddephatt, R. J., Organometallics 2011, 30, 56255635.

13. Szuromi, E.; Sharp, P. R., Organometallics 2006, 25, 558-559.

14. Thomas, J. C.; Peters, J. C., J. Am. Chem. Soc. 2001, 123, 5100-5101.

15. McKeown, B. A.; Gonzalez, H. E.; Friedfeld, M. R.; Brosnahan, A. M.; Gunnoe, T. B.; Cundari, T. R.; Sabat, M., Organometallics 2013, ASAP.

16. Hancock, R. D.; Martell, A. E., Chem. Rev. 1989, 89, 1875-1914.

17. Luedtke, A. T.; Goldberg, K. I., Angew. Chem. 2008, 120, 7808-7810.

18. Olah, G. A., Acc. Chem. Res. 1971, 4, 240-248.

19. Matsumoto, T.; Taube, D. J.; Periana, R. A.; Taube, H.; Yoshida, H., J. Am. Chem. Soc. 2000, 122, 7414-7415.

20. Brookhart, M.; Grant, B.; Volpe, A. F., Organometallics 2002, 11, 3920-3922.

21. Steele, B. R.; Vrieze, K., Transition Met. Chem. 1977, 2, 140-144.

22. Rashidi, M.; Fakhroeian, Z.; Puddephatt, R. J., J. Organomet. Chem. 1991, 406, 261-267.

23. Achar, S.; Scott, J. D.; Vittal, J. J.; Puddephatt, R. J., Organometallics 1993, 12, 4592-4598. 
24. Canty, A.; Minchin, N., Aust. J. Chem. 1986, 39, 1063-1069.

25. Vedernikov, N.; Miftakhov, R.; Borisoglebski, S. V.; Caulton, K. G.; Solomonov, B. N., Chem. Heterocycl. Compd. 2002, 38, 406-416.

26. Quagliotto, P.; Viscardi, G.; Barolo, C.; Barni, E.; Bellinvia, S.; Fisicaro, E.; Compari, C., J. Org. Chem. 2003, 68, 7651-7660.

27. Bennett, M. A.; Mitchell, T. R. B., Inorg. Chem. 1976, 15, 2936-2938.

28. de Graaf, W.; Boersma, J.; Smeets, W. J. J.; Spek, A. L.; van Koten, G., Organometallics 1989, 8, 2907-2917.

29. Becke, A. D., J. Chem. Phys. 1993, 98, 1372-1377.

30. Lee, C.; Yang, W.; Parr, R. G., Phys. Rev. 1998, B37, 785-789.

31. Stevens, W. J.; Krauss, M.; Basch, H.; Jasien, P. G., Can. J. Chem. 1992, 70, 610613.

32. Hodges, A. S.; Lee, S. Y.; Hardcastle, K. I.; Saadein, M. R.; Eichler, J. F., Inorg. Chim. Acta 2011, 368, 252-256.

33. The temperature was verified using the following equation provided by Bruker Instruments, Inc. VT-Calibration Manual: $T(K)=(4.218-X) / 0.009132$, where $X=$ $\operatorname{ppm}(\mathrm{OH})-\operatorname{ppm}\left(\mathrm{CH}_{2}\right)$

34. The temperature was verified using the following equation provided by experimental data from the Univ. of Nebraska (2001): $T(K)=-23.1902 x^{2}$ $31.1062 x+399.081$, where $x=\operatorname{ppm}(O D)$ vs. $p p m\left(C D_{3}\right)$. 


\section{$4 \quad$ Pt $^{\mathrm{II}}$ Catalyzed Olefin Hydroarylation: Substrate and Ligand Scope}

While there is utility in non-acid catalyzed olefin hydroarylation using unfunctionalized substrates (e.g., ethylene and benzene), catalysts that are active for and compatible with activated substrates possessing heteroatomic functionality are necessary for engendering broader application of this methodology for $\mathrm{C}-\mathrm{C}$ bond formation. Therefore, dipyridyl $\mathrm{Pt}^{\mathrm{II}}$ catalyst efficiency with activated arenes and olefins is evaluated. The reported examples of $\mathrm{Pt}^{\mathrm{II}}$ non-acid catalyzed olefin hydroarylation feature nitrogen bis-chelating

ligands containing at least one pyridyl ring. ${ }^{1-6}$ Catalytic ethylene hydrophenylation is also explored with ligands outside the dipyridyl motif to gauge the impact of the ancillary ligand on catalytic activity and selectivity.

\subsection{Ethylene Hydroarylation using Activated Benzenes and Heteroaromatic Substrates}

The influence of substituents on benzene for cationic $\mathrm{Pt}^{\mathrm{II}}$ catalyzed ethylene hydroarylation was evaluated using anisole, chlorobenzene and nitrobenzene (Table 4.1). At $100{ }^{\circ} \mathrm{C}$ under $0.1 \mathrm{MPa}$ of ethylene, $\left[\left({ }^{\mathrm{b}} \mathrm{bpy}\right) \mathrm{Pt}(\mathrm{Ph})(\mathrm{THF})\right]\left[\mathrm{BAr}_{4}\right] \mathbf{( 4 . 1 \mathbf { b } )}$ catalyzes the formation of 10.7 turnovers (TO) and $61.2 \mathrm{TO}$ of ethylanisoles after 4 and 16 hours, respectively, which is comparable to catalytic efficiency using benzene and ethylene to form ethylbenzene. A statistical distribution between meta- and para-substituted isomers is observed. Increasing the donor ability of the benzene substituent slightly reduces the regioselectivity of phenyl $\mathrm{C}-\mathrm{H}$ bond activation. For example, the ratio of meta- to para- 
substituted diethylbenzenes from ethylene hydroarylation using ethylbenzene with complex $4.1 \mathrm{~b}$ is $1.5: 1$.

Ethylene hydroarylation using substituted benzenes with electron-withdrawing functionality (i.e., chlorobenzene or nitrobenzene) is less efficient than with anisole. Under identical conditions, catalysis using chlorobenzene results in $3.2 \mathrm{TO}$ of 3ethylchlorobenzene and 4-ethylchlorobenzene in a 4.3:1 ratio after 4 hours and displays increased preference for meta-C-H activation, relative to catalysis with anisole. Catalysis with nitrobenzene results in approximately 2 TO of ethylnitrobenzenes. Two constitutional isomers are observed by GC/MS, but their identity has not been unambiguously determined. Catalysis was also performed with naphthalene. As the aromatic substrate is a solid, chlorinated solvents were chosen to minimize inhibition of catalysis due to solvent coordination to the metal center. Methylene chloride was found to provide better catalysis over 1,2-dichloroethane. At $100{ }^{\circ} \mathrm{C}$ under $0.1 \mathrm{MPa}$ of ethylene, the formation of 2-ethylnaphthalene was preferred over that of 1-ethylnaphthalene with 13.2 and 1.6 TO observed after 16 hours, respectively. Friedel-Crafts catalysis, under conditions that do not facilitate isomerization, is selective for alkylation at the 1-position of naphthalene. ${ }^{7-8}$

For ethylene hydroarylation of substituted benzenes, catalyst efficiency is reduced relative to ethylene hydroarylation using benzene. However, a better comparison is catalytic ethylene hydroarylation using ethylbenzene, which provides 5.8 and $20.3 \mathrm{TO}$ after 4 and 16 hours. The decrease in catalyst efficiency for ethylene hydroarylation using ethylbenzene, compared to benzene, is likely due to steric hindrance afforded by benzene substitution. Increasing the electron-donor ability of the benzene substituent by 
substitution of the ethyl group with a methoxy group enhances catalyst efficiency, while less effective catalysis is observed with increasing the electron-withdrawing properties of the benzene functionality.

Table 4.1. Comparison of ethylene hydroarylation using substituted benzenes catalyzed by $\left[\left({ }^{t} \mathrm{bpy}\right) \mathrm{Pt}(\mathrm{Ph})(\mathrm{THF})\right]\left[\mathrm{BAr}_{4}\right](\mathbf{4 . 1 b}){ }^{\mathrm{a}}$

(39.3)

a $0.01 \mathrm{~mol} \%$ catalyst dissolved in the arene with hexamethylbenzene as an internal standard at $100{ }^{\circ} \mathrm{C}$. ${ }^{\mathrm{b}}$ TO after 4 hours as determined by GC/MS. ${ }^{\mathrm{c}}$ Numbers in parentheses are TO after 16 hours. ${ }^{\mathrm{d}}$ Identity of constitutional isomers not determined. ${ }^{\mathrm{e}}$ $\mathrm{CH}_{2} \mathrm{Cl}_{2}$ used as the reaction solvent.

Substitution of 4,4'-di-tert-butyl-2,2'-bipyridine for 2,2'-dipyridylmethane (dpm) has been shown to increase the longevity and activity of dipyridyl $\mathrm{Pt}^{\mathrm{II}}$ catalyzed ethylene hydrophenylation. ${ }^{5}$ Catalytic hydroarylation of ethylene using chlorobenzene with the dpm complex $[(\mathrm{dpm}) \mathrm{Pt}(\mathrm{Ph})(\mathrm{THF})]\left[\mathrm{BAr}_{4}\right]$ (4.2a) was performed for comparison to its tbpy analogue. The increased catalyst efficiency observed for ethylene hydrophenylation by 4.2a is not transferred to ethylene hydroarylation using chlorobenzene (Scheme 4.1). 
At $100{ }^{\circ} \mathrm{C}$ under $0.1 \mathrm{MPa}$ of ethylene, complex 4.2a catalyzes the formation of 3.2 and 10.4 TO of chloroethylbenzenes after 4 and 16 hours, respectively, which is comparable to the results obtained using the tbpy complex 4.1b.

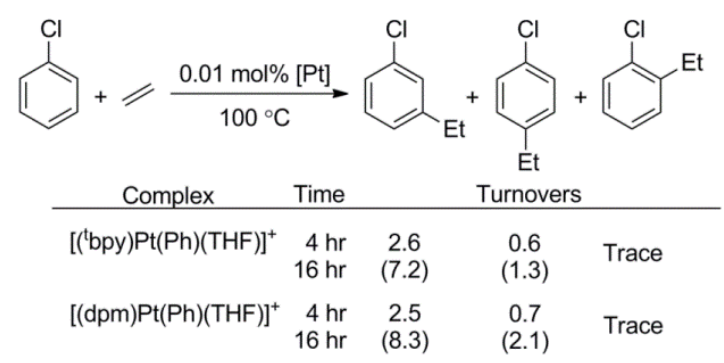

Scheme 4.1. Comparison of ethylene hydroarylation using chlorobenzene catalyzed by $\left[\left({ }^{\prime} \mathrm{bpy}\right) \mathrm{Pt}(\mathrm{Ph})(\mathrm{THF})\right]\left[\mathrm{BAr}_{4}\right]$ (4.1b) and $[(\mathrm{dpm}) \mathrm{Pt}(\mathrm{Ph})(\mathrm{THF})]\left[\mathrm{BAr}_{4}\right]$ (4.2a).

Analysis of the reaction mixture for $\mathrm{Pt}^{\mathrm{II}}$ catalyzed ethylene hydroarylation using chlorobenzene with complex $4.1 \mathrm{~b}$ reveals no evidence for the oxidative addition of the $\mathrm{Ph}-\mathrm{Cl}$ bond. In fact, there are very few examples of oxidative addition reactions between aryl halides and $\mathrm{Pt}^{\mathrm{II}}$ complexes. ${ }^{9}$ Reported reactions have been intramolecular in nature with the $\mathrm{Ar}-\mathrm{X}$ bond incorporated into the chelating ligand. ${ }^{10-13}$ Stoichiometric reactions between complex 4.1b and $\mathrm{C}_{6} \mathrm{H}_{5} \mathrm{X}(\mathrm{X}=\mathrm{Br}$ and $\mathrm{I})$ were performed to determine if oxidative addition could compete with aromatic $\mathrm{C}-\mathrm{H}$ activation using a cationic bipyridyl $\mathrm{Pt}-\mathrm{Ph}$ complex. The reaction of $4.1 \mathrm{~b}$ with 5 equivalents of bromobenzene in $\mathrm{CD}_{2} \mathrm{Cl}_{2}$ at $35{ }^{\circ} \mathrm{C}$ readily forms the $\mathrm{C}-\mathrm{H}$ activation product in near quantitative yield. The ${ }^{1} \mathrm{H}$ NMR spectrum is most consistent with preferential ortho- $\mathrm{C}-\mathrm{H}$ bond activation to form $\left[\left({ }^{\text {bpy }}\right) \mathrm{Pt}\left(o-\mathrm{C}_{6} \mathrm{H}_{4} \mathrm{Br}\right)(\mathrm{THF})\right]\left[\mathrm{BAr}{ }_{4}\right]$ (Figure 4.1). The 4 aromatic resonances of the bromophenyl have multiplicities ( 2 doublets of doublets and 2 triplets of doublets) 
expected for the $\mathrm{Pt}-\mathrm{C}$ bond located ortho to the halogen. In addition, the $\alpha-\mathrm{THF}$ resonances are inequivalent with 2 multiplets observed at 4.26 and $4.16 \mathrm{ppm}$ and integrating for two protons each in the ${ }^{1} \mathrm{H}$ NMR spectrum. The analogous reaction of 4.1b with 5 equivalents of iodobenzene does not result in $\mathrm{C}-\mathrm{H}$ activation of the phenyl ring to form [('bpy) $\left.\mathrm{Pt}\left(o-\mathrm{C}_{6} \mathrm{H}_{4} \mathrm{I}\right)(\mathrm{THF})\right]\left[\mathrm{BAr}_{4}\right]$. The ${ }^{1} \mathrm{H}$ NMR spectrum of the reaction mixture is consistent with oxidative addition of the $\mathrm{Ph}-\mathrm{I}$ bond to give the iodine bridged $\mathrm{Pt}^{\mathrm{IV}}$ complex $\left[\left({ }^{\mathrm{t}} \mathrm{bpy}\right) \mathrm{Pt}(\mathrm{Ph})_{2}(\mu-\mathrm{I})\right]_{2}\left[\mathrm{BAr}_{4}\right]_{2}$. Attempts to obtain suitable crystals for structure determination by an X-ray diffraction study were unsuccessful.

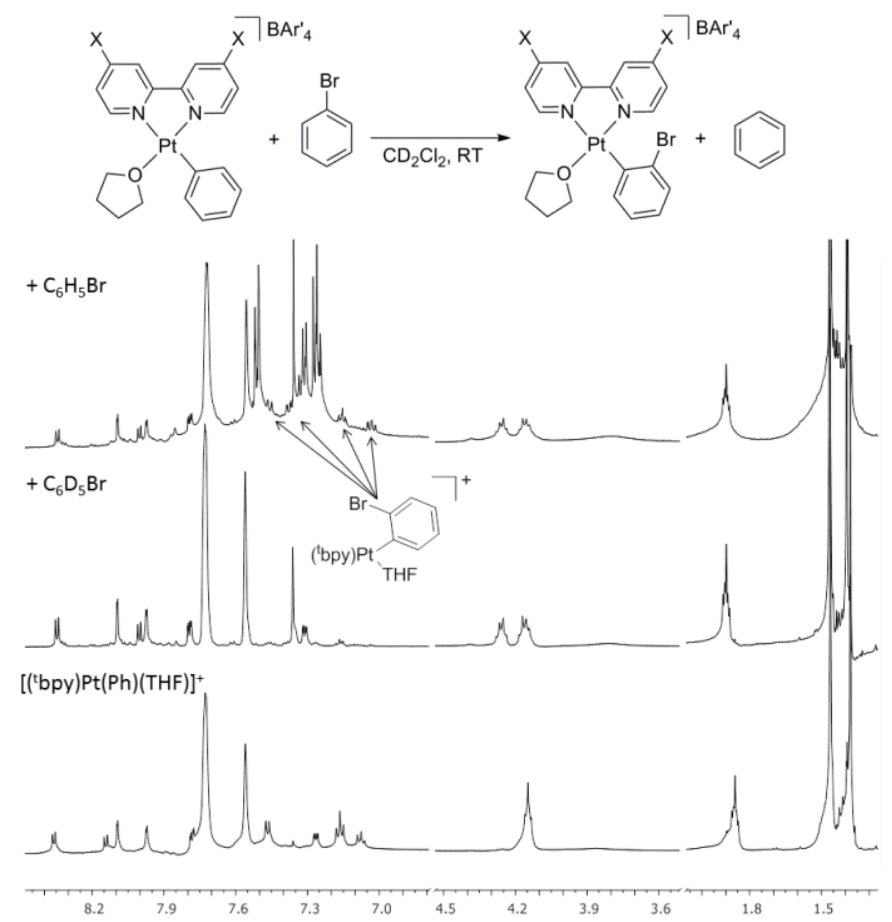

Figure 4.1. Observation of $\mathrm{Pt}^{\mathrm{II}}$ mediated ortho-C-H/D activation of $\mathrm{C}_{6} \mathrm{H}_{5} \mathrm{Br}$ or $\mathrm{C}_{6} \mathrm{D}_{5} \mathrm{Br}$ by ${ }^{1} \mathrm{H}$ NMR spectroscopy. 


\subsubsection{Dipyridyl $\mathrm{Pt}^{\mathrm{II}}$ Catalyzed Ethylene Hydroarylation with Heteroaromatic Substrates}

Much effort in our group has been devoted toward developing transition metal mediated olefin hydroarylation for aromatic hydrocarbons. However, catalysts that can also selectively transform heteroaromatic substrates could find utility in synthetic sequences of biologically relevant compounds. There have been several examples of stoichiometric transition metal mediated transformations of heteroaromatic compounds, ${ }^{14-}$

${ }^{18}$ but examples of catalytic coupling of alkenes or alkynes with heteroarenes are rare. ${ }^{19-23}$ Therefore, olefin hydroarylation catalyzed by $\mathrm{Pt}^{\mathrm{II}}$ dipyridyl complexes has been extended to studies of heteroaromatic substrates (Table 4.2).

Combining the ${ }^{\mathrm{t}}$ bpy complex $4.1 \mathrm{~b}(0.01 \mathrm{~mol} \%)$ with furan under $0.1 \mathrm{MPa}$ of ethylene at $100{ }^{\circ} \mathrm{C}$ results in the selective production of 75.1 and $120.2 \mathrm{TO}$ of 2 -ethylfuran after 4 and 16 hours, respectively. Substitution of thiophene for furan results in 43.1 TO of 2ethylthiophene and 6.6 TO of 3-ethylthiophene after 4 hours with negligible activity observed with continued heating. The reaction with pyrrole and $N$-methylpyrrole required temperatures of $120^{\circ} \mathrm{C}$ for catalysis to occur. For pyrrole only $\sim 6 \mathrm{TO}$ of 2-ethylpyrrole were observed with no evidence for $\mathrm{N}-\mathrm{H}$ activation from analysis of the reaction mixture by GC/MS. The introduction of the methyl group in $N$-methylpyrrole resulted in an increase in catalyst efficiency (19.7 and 86.3 TO after 4 and 16 hours) but also a switch in regioselectivity as formation of 3-ethyl- $N$-methylpyrrole is preferred over 2-ethyl- $N$ methylpyrrole, presumably due the methyl group providing a steric hinderance to activation of an $\alpha-\mathrm{C}-\mathrm{H}$ bond. 
Table 4.2. Ethylene hydroarylation using heteroaromatic substrates catalyzed by complex $4.1 b$.

\begin{tabular}{|c|c|c|}
\hline+ & $\begin{array}{l}\text { hol\% } \\
\text { THF)][BAr' }{ }_{4} \text {. } \\
{ }^{\circ} \mathrm{C}\end{array}$ & \\
\hline$X=$ & \multicolumn{2}{|c|}{ Turnovers } \\
\hline $\mathrm{O}$ & $\begin{array}{c}75.1^{\mathrm{b}} \\
(120.2)^{\mathrm{c}}\end{array}$ & trace \\
\hline$S$ & $\begin{array}{c}43.1 \\
(46.9)\end{array}$ & $\begin{array}{c}6.6 \\
(7.3)\end{array}$ \\
\hline $\mathrm{NH}^{\mathrm{d}}$ & $\begin{array}{c}3.2 \\
(5.9)\end{array}$ & $\mathrm{N} / \mathrm{A}$ \\
\hline $\mathrm{NMe}^{\mathrm{d}}$ & $\begin{array}{c}3.1 \\
(14.6)\end{array}$ & $\begin{array}{c}16.6 \\
(71.7)\end{array}$ \\
\hline
\end{tabular}

a $0.01 \mathrm{~mol} \%$ catalyst dissolved in the arene with hexamethylbenzene as an internal standard at $100{ }^{\circ} \mathrm{C}$. ${ }^{\mathrm{b}}$ TO after 4 hours as determined by GC/MS. ${ }^{\mathrm{c}}$ Numbers in parentheses are TO after 16 hours. ${ }^{\mathrm{d}}$ Reaction performed at $120^{\circ} \mathrm{C}$.

Catalytic ethylene hydroarylation using furan with the dpm complex $[(\mathrm{dpm}) \mathrm{Pt}(\mathrm{Ph})(\mathrm{THF})]\left[\mathrm{BAr}_{4}\right]$ (4.2a) was performed for comparison to the ${ }^{\mathrm{t}}$ bpy analogue. A substantial increase in catalyst efficiency was not observed for the transition from a 5membered to 6-membered dipyridyl chelate, which is in contrast to catalytic ethylene hydrophenylation using complex $4.2 a^{5}$ Complex $4.2 a$ catalyzes the formation of 117.7 TO and 169.7 TO of 2-ethylfuran at $100{ }^{\circ} \mathrm{C}$ after 4 and 16 hours, respectively.

The reaction of the bipyridyl $\mathrm{Pt}^{\mathrm{II}}$ catalyst containing strongly electron-withdrawing nitro groups in the 4,4'-positions $\left[\left({ }^{\mathrm{NO} 2} \mathrm{bpy}\right) \mathrm{Pt}(\mathrm{Ph})(\mathrm{THF})\right]\left[\mathrm{BAr}_{4}\right]$ (4.1f) with benzene and ethylene provides stoichiometric quantities of ethylbenzene and styrene, while ethylene hydroarylation of heteroaromatics using complex 4.1f results in increased catalyst efficiency relative to ethylene hydrophenylation (Table 4.3). After 16 hours under 
identical conditions used for catalysis with complex $4.1 \mathrm{~b}$, complex $4.1 \mathrm{f}$ catalyzes the formation of 34.0 TO of 2-ethylfuran, 3.7 TO of 2-ethylpyrrole, 10.1 TO of 2-ethyl- $\mathrm{N}$ methylpyrrole and 17.3 TO of 3-ethyl- $N$-methylpyrrole from reactions with furan, pyrrole and $N$-methylpyrrole, respectively. The observed increase in catalyst efficiency may be a result of increased stabilization of catalytic intermediates due to more facile coordination of the heteroarene, relative to benzene, to the metal center.

Table 4.3. Ethylene hydroarylation using heteroaromatic substrates catalyzed by complex 4.1f. ${ }^{\mathrm{a}}$

\begin{tabular}{|c|c|c|}
\hline+1 & $\begin{array}{l}\text { nol\% } \\
)(\mathrm{THF})][\mathrm{BA} \\
{ }^{\circ} \mathrm{C}\end{array}$ & $+\llbracket$ \\
\hline$X=$ & \multicolumn{2}{|c|}{ Turnovers } \\
\hline & $\frac{\text { 2-ethyl- }}{34.0^{\circ}}$ & 3-ethyl- \\
\hline $\mathrm{NH}^{\mathrm{c}}$ & 3.7 & - \\
\hline $\mathrm{NMe}^{\mathrm{C}}$ & 10.6 & 17.3 \\
\hline
\end{tabular}

a $0.01 \mathrm{~mol} \%$ catalyst dissolved in the arene with hexamethylbenzene as an internal standard at $100{ }^{\circ} \mathrm{C} .{ }^{\mathrm{b}} \mathrm{TO}$ after 16 hours as determined by GC/MS. ${ }^{\mathrm{c}}$ Reaction performed at $120^{\circ} \mathrm{C}$.

\subsection{Catalytic Hydrophenylation of $\alpha$-olefins and Michael Acceptors with Dipyridyl Pt ${ }^{\mathrm{II}}$ Precursors}

Catalytic olefin hydroarylation using substituted olefins and a non-acidic pathway offers an opportunity to control the regioselectivity of olefin insertion into the M-aryl bond and, hence, the selectivity for Markovnikov/anti-Markovnikov products. ${ }^{3,24}$ For example, catalysts that can bias 2,1- over 1,2-insertion with $\alpha$-olefins could selectively 
produce linear alkyl arenes, which is not accessible with current acid-based methodologies (Scheme 4.2). Hydrophenylation of $\alpha$-olefins using $\mathrm{Ru}$ or $\mathrm{Ir}$ catalyst precursors has been reported to favor the formation of the anti-Markovnikov over Markovnikov addition products, but the selectivity is moderate with an $\sim 1.5: 1$ linear to branched ratio observed for both catalysts. ${ }^{24-26}$
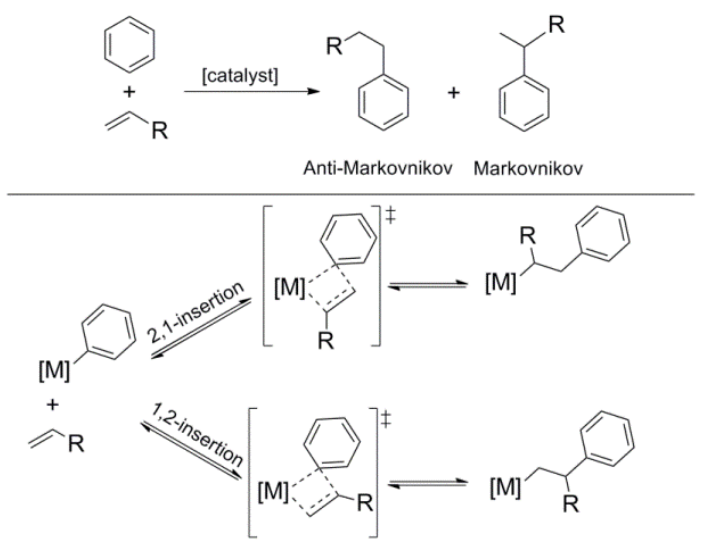

Scheme 4.2. Transition metal mediated olefin hydroarylation offers an opportunity to control the selectivity of alkyl arene products. Product selectivity could be dictated by the regioselectivity of $\alpha$-olefin insertion into the $\mathrm{Pt}-\mathrm{Ph}$ bond.

Vitagliano and Tesauro have studied stoichiometric $\mathrm{C}-\mathrm{C}$ bond formation from cationic $\mathrm{Pt}^{\mathrm{II}}(\operatorname{aryl})\left(\right.$ olefin) $\left(\right.$ aryl $=\mathrm{C}_{6} \mathrm{H}_{5}, 4-\mathrm{C}_{6} \mathrm{H}_{4} \mathrm{R}$ or $3-\mathrm{C}_{6} \mathrm{H}_{4} \mathrm{R} ; \mathrm{R}=$ OMe or Me) complexes containing N,N chelating ligands. ${ }^{27-29}$ These complexes effectively promote the migratory insertion of $\mathrm{CH}_{2}=\mathrm{CHR}(\mathrm{R}=\mathrm{H}, \mathrm{Me}$ or $\mathrm{Ph})$ into the $\mathrm{Pt}-\mathrm{C}_{\text {aryl }} \sigma$ bond. In all cases, platinum forms a bond with the $\alpha$-carbon of the alkene, resulting from 1,2-insertion (Scheme 4.2). In the absence of a competing ligand for coordination (e.g., excess olefin or aniline), the insertion product undergoes facile rearrangement to form a $\mathrm{Pt}-2-\mathrm{C}_{6} \mathrm{H}_{4}($ alkyl) species by orthometallation. It was also observed that certain diimine ligands such as 2,9- $\mathrm{Me}_{2}-1,10$ - 
phenathroline inhibit the migratory insertion due to stabilization of the preceding 5coordinate intermediate. $^{27}$

The proposed mechanism for transition metal catalyzed olefin hydrophenylation, based on previous experimental and computational studies, should be independent of the identity of the olefinic substrate..$^{3-4,}{ }^{24-26,30-36}$ The complex $\left[\left({ }^{\mathrm{b}} \mathrm{bpy}\right) \mathrm{Pt}(\mathrm{Ph})(\mathrm{THF})\right]\left[\mathrm{BAr}{ }_{4}\right]$ ('bpy $=4,4^{\prime}$-di-tert-butyl-2,2'-bipyridyl; $\left.\mathrm{BAr}_{4}^{\prime}=3,5-\left(\mathrm{CF}_{3}\right)_{2}-\mathrm{C}_{6} \mathrm{H}_{3} ; 4.1 \mathbf{b}\right)$ has been demonstrated to insert ethylene into the $\mathrm{Pt}-\mathrm{Ph}$ bond in the presence of excess olefin to yield $\left[\left({ }^{\mathrm{t}} \mathrm{bpy}\right) \mathrm{Pt}\left(\mathrm{CH}_{2} \mathrm{CH}_{2} \mathrm{Ph}\right)\left(\eta^{2}-\mathrm{C}_{2} \mathrm{H}_{4}\right)\right]^{+},{ }^{4}$ which is the proposed resting state for catalytic ethylene hydrophenylation. $\mathrm{Pt}^{\mathrm{II}}$ catalyzed olefin hydroarylation substituting ethylene for propylene was studied to evaluate the selectivity for migratory insertion and the resulting alkyl arene. Furthermore, the influence of electronic and steric modifications on product selectivity was also examined.

\subsubsection{Catalytic Hydrophenylation of $\alpha$-olefins and Michael Acceptors using $\left[\left({ }^{t} \mathrm{bpy}\right) \mathbf{P t}(\mathbf{P h})\left(\mathrm{C}_{2} \mathbf{H}_{4}\right)\right]^{+}$}

Propylene hydrophenylation was evaluated initially using the complex $\left[\left({ }^{\mathrm{t} b p y}\right) \mathrm{Pt}(\mathrm{Ph})(\mathrm{THF})\right]\left[\mathrm{BAr}_{4}^{\prime}\right] \mathbf{( 4 . 1 b )}$. Under conditions of $0.01 \mathrm{~mol} \%$ catalyst relative to benzene and $0.1 \mathrm{MPa}$ propylene at $100{ }^{\circ} \mathrm{C}$, catalysis with complex $4.1 \mathrm{~b}$ results in 33.5 and 39.8 TO of cumene and $n$-propylbenzene in an approximate 3:1 ratio after 4 and 16 hours, respectively (Table 4.4). Several isomers of di- and tri-propylbenzenes were also detected but not quantified. While the formation of the Markovnikov addition product, cumene, is favored, the observation of significant quantities of the anti-Markovnikov 
addition product $n$-propylbenzene ( $\sim 10 \mathrm{TO}$ after 16 hours) provides further support for a non-acid catalyzed mechanism since acid-based catalysts are selective for Markovnikov addition due to the intermediacy of carbocationic intermediates.

Table 4.4. Hydrophenylation of alkenes with $\left[\left({ }^{\mathrm{t}} \mathrm{bpy}\right) \mathrm{Pt}(\mathrm{Ph})(\mathrm{THF})\right]\left[\mathrm{BAr}_{4}\right]$ (4.1b). ${ }^{\mathrm{a}}$

Olefin Alkylbenzene

${ }^{a} 0.01 \mathrm{~mol} \%$ catalyst dissolved in $\mathrm{C}_{6} \mathrm{H}_{6}$ with hexamethylbenzene as an internal standard at $100{ }^{\circ} \mathrm{C} .{ }^{\mathrm{b}}$ Ratio of branched to linear isomer after 4 hours. ${ }^{\mathrm{c}} 0.1 \mathrm{MPa}_{3} \mathrm{H}_{6} .{ }^{\mathrm{d}} 150$ equivalents relative to Pt loading. ${ }^{\mathrm{e}} \mathrm{TO}$ after 4 hours as determined by GC/MS. ${ }^{\mathrm{f}}$ Numbers in parentheses are TO after 16 hours.

Increasing the length of the carbon chain upon substitution of 1-pentene for propylene has a minimal influence on catalyst efficiency and selectivity. Using 150 equivalents of 1-pentene (relative to $4.1 \mathrm{~b}$ ), 40.0 TO of 2-phenylpentane and $n$-pentylbenzene were observed after 4 hours at $100{ }^{\circ} \mathrm{C}$ in an $\sim 3: 1$ ratio with no further activity observed with continued reaction. 3-Phenylpentane was observed in small quantities, which indicates that olefin isomerization is accessible but not significantly competive with olefin hydroarylation. The catalyst is also compatible with di-substituted olefins, as the analogous reaction with cyclohexene results in $\sim 20$ TO of phenylcyclohexane after 16 hours at $100{ }^{\circ} \mathrm{C}$. 
The efficiency of catalytic hydrophenylation of substituted olefins using $[(\mathrm{dpm}) \mathrm{Pt}(\mathrm{Ph})(\mathrm{THF})]\left[\mathrm{BAr}_{4}^{\prime}\right]\left(\mathrm{dpm}=2,2^{\prime}\right.$-dipyridylmethane; 4.2a) is reduced compared to the ${ }^{t}$ bpy supported complex. Propylene hydrophenylation results in 11.8 and 26.0 TO of cumene and $n$-propylbenzene after 4 and 16 hours, respectively, in a 4.4:1 ratio (calculated after 4 hours; Table 4.7). Catalysis with 1-pentene and cyclohexene using 4.2a also has a significant reduction in TO compared to the bpy complex $\mathbf{4 . 1 b}$ (Scheme 4.3 and Scheme 4.4).

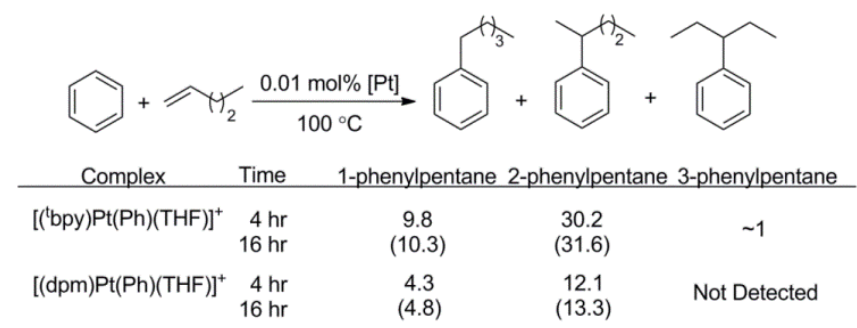

Scheme 4.3. Comparison of catalytic hydrophenylation of 1-pentene (150 equivalents relative to $\mathrm{Pt}$ ) using complexes $\mathbf{4 . 1 b}$ and $\mathbf{4 . 2 a}$ and hexamethylbenzene as an internal standard.

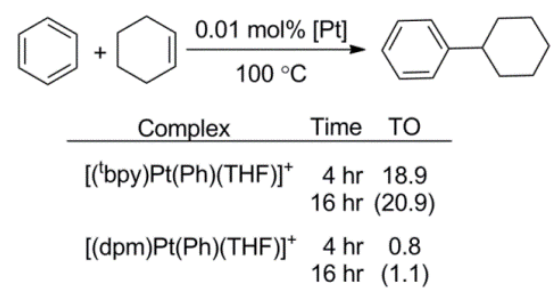

Scheme 4.4. Comparison of catalytic hydrophenylation of cyclohexene (150 equivalents relative to $\mathrm{Pt}$ ) using complexes $\mathbf{4 . 1 b}$ and $\mathbf{4 . 2 a}$ and hexamethylbenzene as an internal standard.

Whether the ratio of Markovnikov to anti-Markovnikov products is controlled by the regioselectivity of olefin insertion or by the relative rates of subsequent reactions (i.e., 
Curtin-Hammett conditions) is not known. For $\mathrm{Pt}^{\mathrm{II}}$ catalyzed hydrophenylation of propylene, binding of the olefin perpendicular to the coordination plane can result in four possible isomers (Scheme 4.5). Product selectivity could depend on the kinetic selectivity for formation and equilibrium constants between the four isomers, or their relative rates of subsequent transformation might dictate the overall distribution of propyl benzenes.

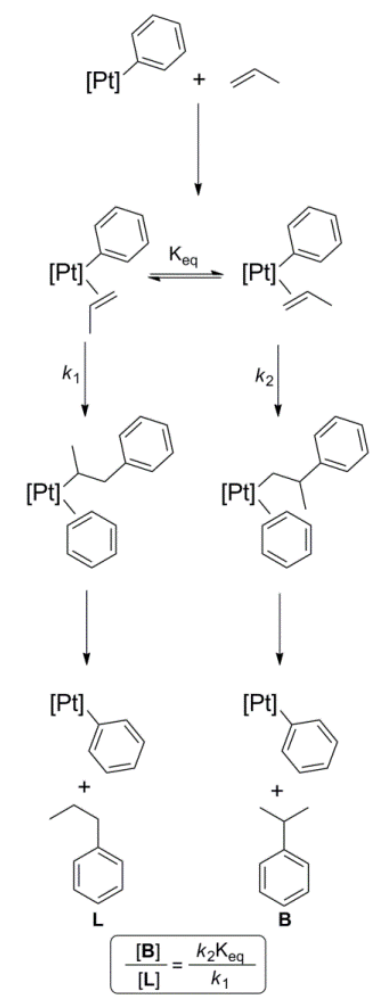

Scheme 4.5. Pathways leading to linear and branched alkyl benzene products during bipyridyl $\mathrm{Pt}^{\mathrm{II}}$ catalyzed propylene hydropyhenylation.

Intramolecular hydroarylation was attempted with allylbenzene to form indane. Heating complex 4.1b or 4.2a in neat allylbenzene at $100{ }^{\circ} \mathrm{C}$ resulted in trace amounts of indane, as observed by GC/MS. The dearth of cyclized product is not surprising as successful catalysis would require activation of an ortho- $\mathrm{C}-\mathrm{H}$ bond of allylbenzene, and product distributions from ethylene hydroarylation using substituted benzenes demonstrate that 
ortho-activation is not favored relative to meta- or para-activation. Cationic $\mathrm{Pt}^{\mathrm{II}}$ complexes containing phenyl ligands have been reported to be highly active for the isomerization of allylbenzene to the internal olefin, 1-phenyl-1-propylene. ${ }^{37}$ Analysis of the reaction mixture from catalysis for both the tbpy complex $\mathbf{4 . 1 b}$ and the dpm complex 4.2a reveals extensive isomerization occurs instead of hydroarylation. Monitoring the reaction of $4.1 \mathrm{~b}$ ( $20 \mathrm{~mol} \%$ relative to substrate) and allylbenzene in $\mathrm{CD}_{2} \mathrm{Cl}_{2}$ by ${ }^{1} \mathrm{H} \mathrm{NMR}$ spectroscopy shows complete conversion of allylbenzene to 1-phenyl-1-propylene in approximately 1 hour at room temperature (Figure 4.2).

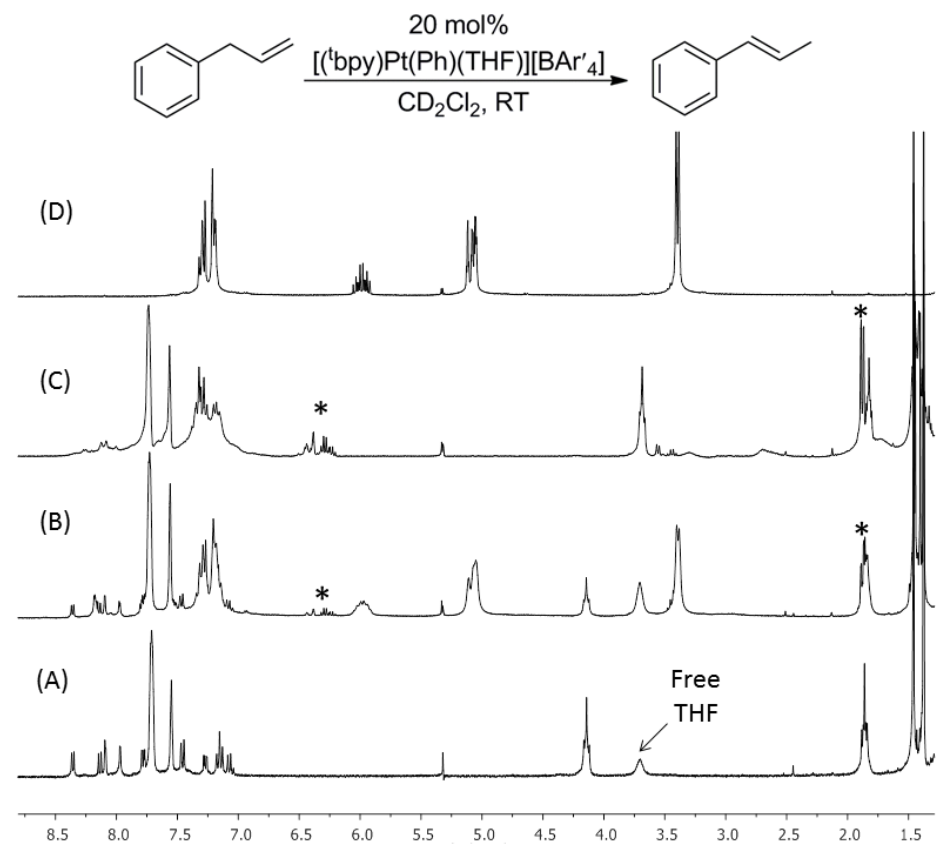

Figure 4.2. Observation of $\mathrm{Pt}^{\mathrm{II}}$ catalyzed isomerization of allylbenzene to 1-phenyl-1propylene (denoted by *) using complex 4.1b. (A) ${ }^{1} \mathrm{H}$ NMR spectrum of [('bpy) $\mathrm{Pt}(\mathrm{Ph})(\mathrm{THF})]\left[\mathrm{BAr}_{4}\right]$ (4.1b). (B) 15 minutes after addition of allylbenzene. (C) 1 hour after addition. (D) ${ }^{1} \mathrm{H}$ NMR spectrum of an allylbenzene standard. 
Olefin hydrophenylation using $\alpha, \beta$-unsaturated carbonyl compounds (i.e., activated olefins) and complex 4.1b was performed to probe catalyst tolerance towards olefinic heteroatomic functionality and the influence on product selectivity (Table 4.5). In all cases, catalysis was selective for the Michael addition product. Catalysis in benzene with $0.01 \mathrm{~mol} \% \mathrm{Pt}$ and 150 equivalents of methacrylate relative to $\mathrm{Pt}$ at $100{ }^{\circ} \mathrm{C}$ results in the formation $6.8 \mathrm{TO}$ of methyl 3-phenylpropanoate. Methyl cinnamate is also observed with 4.9 TO after 4 hours, which corresponds to a $1.4: 1$ ratio of saturated to unsaturated products. No further activity was observed with continued reaction. The same reaction was performed using methyl methacrylate to determine if the presence of an $\alpha$-methyl group would inhibit $\beta$-hydride elimination after insertion into the $\mathrm{Pt}-\mathrm{Ph}$ bond and increase selectivity for the saturated addition product. Indeed, the dominant product from catalysis was methyl 2-methyl-3-phenylpropanoate, which was identified by GC/MS and comparison of the ${ }^{1} \mathrm{H}$ NMR spectrum of the reaction mixture after catalysis to reported spectroscopy data. ${ }^{38}$ Only trace amounts of methyl 2-methyl-3-phenyl-2-propenoate were observed. Due to a lack of analytically pure material, linear regressions for quantification were not performed, but using the ratio of product to internal standard peak areas, approximately 7 TO of methyl 2-methyl-3-phenylpropanoate were estimated from catalysis with 4.1b and methyl methacrylate in benzene. Catalysis with methyl vinyl ketone (MVK) or cyclohexenone is less efficient than the analogous reactions with the ester derivatives. For MVK, increased temperature $\left(120^{\circ} \mathrm{C}\right)$ was required to observe the addition product 4-phenylbutan-2-one, but only in near stoichiometric amounts. Approximately $2 \mathrm{TO}$ of 3-phenylcyclohexanone are observed after 16 hours at $100{ }^{\circ} \mathrm{C}$ for the hydrophenylation of cyclohexenone. 
Table 4.5. Hydrophenylation of Michael Acceptors using [('bpy)Pt(Ph)(THF)][BAr' $\left.{ }_{4}\right]$ (4.1b). ${ }^{\mathrm{a}}$

Olefin

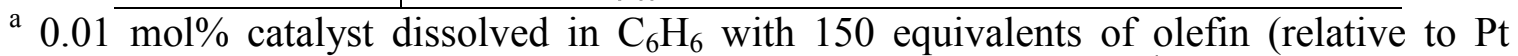
loading) and hexamethylbenzene as an internal standard at $100{ }^{\circ} \mathrm{C} .{ }^{\mathrm{b}} \mathrm{TO}$ after 4 hours as determined by GC/MS. ${ }^{\mathrm{c}}$ Numbers in parentheses are TO after 16 hours. ${ }^{\mathrm{d}}$ Catalysis performed at $120^{\circ} \mathrm{C}$.

\subsubsection{Influence of 4,4'-Bipyridyl Substituents on Product Selectivity for the Hydrophenylation of Propylene}

The series of complexes [( ${ }^{\mathrm{x}}$ bpy $\left.) \mathrm{Pt}(\mathrm{Ph})(\mathrm{THF})\right]\left[\mathrm{BAr}_{4}\right]\left({ }^{\mathrm{X}}\right.$ bpy $=4,4^{\prime}-\mathrm{X}_{2}-2,2^{\prime}$-bipyridyl; $\mathrm{X}$

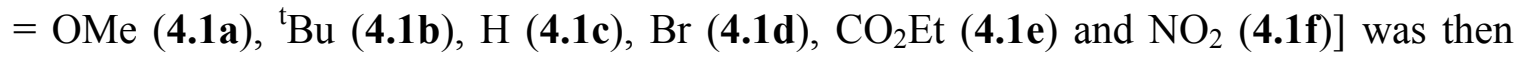
screened for propylene hydrophenylation to evaluate the influence of ligand donor ability on product selectivity

Table 4.6). Comparison of TO after 16 hours reveals a similar trend in efficiency to that for ethylene hydrophenylation. Catalysis with complexes 4.1a-4.1c demonstrates a slight enhancement in catalytic efficiency with decreasing the donor ability of the 4,4'substituent. The results with catalyst precursors 4.1d-4.1f, possessing less donating 4,4'substituents, indicate less effective catalysis with a greater predilection for the formation of several isomers of (propenyl)benzene, as observed by GC/MS, relative to 4.1a-4.1c. After 16 hours at $100{ }^{\circ} \mathrm{C}$, the nitro substituted complex 1 f gives $8.1 \mathrm{TO}$ of 
propylbenzenes with a branched to linear ratio of $4.6: 1$, which is in contrast to the near stoichiometric yield of ethylbenzene and styrene from the analogous reaction with ethylene. ${ }^{6}$ If product selectivity is controlled by mode of insertion, then 1,2-insertion of propylene into the $\mathrm{Pt}-\mathrm{Ph}$ bond to form the intermediate $\left.\left[{ }^{\mathrm{NO} 2} \mathrm{bpy}\right) \mathrm{Pt}\left(\mathrm{CH}_{2} \mathrm{CH}(\mathrm{Me}) \mathrm{Ph}\right)\right]^{+}$ would place a methyl group on the $\beta$-carbon and may alter the difference in activation barriers between $\beta$-hydride elimination (relative to elimination of styrene from $\left[\left({ }^{\mathrm{NO} 2} \text { bpy }\right) \mathrm{Pt}\left(\mathrm{CH}_{2} \mathrm{CH}_{2} \mathrm{Ph}\right)\right]^{+}$during ethylene hydrophenylation) and benzene $\mathrm{C}-\mathrm{H}$ activation to yield alkyl benzenes. ${ }^{39}$

Table 4.6. Comparison of catalytic propylene hydrophenylation using complexes 4.1a-f. ${ }^{\mathrm{a}}$

\begin{tabular}{|c|c|c|c|c|}
\hline$x$ & $=x^{x}$ & iPr & & $B: L^{b}$ \\
\hline $\begin{array}{c}\mathrm{OMe} \\
(\mathbf{4 . 1 a})\end{array}$ & -0.27 & $\begin{array}{c}10.6^{\mathrm{c}} \\
(26.9)^{\mathrm{d}}\end{array}$ & $\begin{array}{c}3.7 \\
(9.7)\end{array}$ & 2.9 \\
\hline $\begin{array}{c}{ }^{\mathrm{t}} \mathrm{Bu} \\
(\mathbf{4 . 1 6})\end{array}$ & -0.2 & $\begin{array}{l}25.0 \\
(29.7)\end{array}$ & $\begin{array}{c}8.5 \\
(10.1)\end{array}$ & 2.9 \\
\hline$\underset{(4.1 \mathrm{c})}{\mathrm{H}}$ & 0.0 & $\begin{array}{l}25.8 \\
(31.6)\end{array}$ & $\begin{array}{c}8.0 \\
(10.3)\end{array}$ & 3.2 \\
\hline $\begin{array}{c}\mathrm{Br} \\
(\mathbf{4 . 1 d})\end{array}$ & 0.23 & $\begin{array}{c}2.5 \\
(4.2)\end{array}$ & $\begin{array}{c}0.7 \\
(1.4)\end{array}$ & 3.8 \\
\hline $\begin{array}{l}\mathrm{CO}_{2} \mathrm{Et} \\
(\mathbf{4 . 1 e})\end{array}$ & 0.45 & $\begin{array}{c}12.1 \\
(18.3)\end{array}$ & $\begin{array}{c}3.3 \\
(5.1)\end{array}$ & 3.7 \\
\hline $\begin{array}{c}\mathrm{NO}_{2} \\
(\mathbf{4 . 1 f})\end{array}$ & 0.78 & $\begin{array}{c}4.1 \\
(6.5)\end{array}$ & $\begin{array}{c}0.9 \\
(1.6)\end{array}$ & 4.6 \\
\hline
\end{tabular}

${ }^{a} 0.01 \mathrm{~mol} \%$ catalyst dissolved in $\mathrm{C}_{6} \mathrm{H}_{6}$ with hexamethylbenzene as an internal standard at $100{ }^{\circ} \mathrm{C}$ with $0.1 \mathrm{MPa}_{3} \mathrm{H}_{6}$. ${ }^{\mathrm{b}}$ Ratio of cumene to $n$-propylbenzene after 4 hours. ${ }^{\mathrm{c}} \mathrm{TO}$ after 4 hours as determined by GC/MS. ${ }^{\mathrm{d}}$ Numbers in parentheses are TO after 16 hours.

As observed with ethylene hydrophenylation, a strong correlation is observed between the Hammett $\sigma_{\mathrm{p}}$ parameter of the 4,4'-substituents and product selectivity. The ratio of 
cumeme: $n$-propylbenzene is influenced by the change in bipyridyl donor ability due to the identity of the 4,4'-bipyridyl functional groups. For example, catalysis using complex 4.1a $\left(\mathrm{OMe}, \sigma_{\mathrm{p}}=-0.27\right)$ and $0.1 \mathrm{MPa}$ of propylene $\left(100{ }^{\circ} \mathrm{C}\right)$ results in a cumeme:npropylbenzene ratio of 2.9 (after 4 hours) compared to 4.6 for complex $4.1 \mathbf{f}\left(\mathrm{NO}_{2}, \sigma_{\mathrm{p}}=\right.$ 0.78). A Hammett plot was constructed using product ratios and the Hammett parameter $\sigma_{\mathrm{p}}$ (Figure 4.3). ${ }^{40}$ Although the effects of substituted pyridyl ligands are rarely amendable to Hammett correlations, ${ }^{41}$ a good linear correlation is observed $\left(\mathrm{R}^{2}=0.94\right)$. The plot demonstrates that less donating 4,4'-substituents result in an increase in the ratio of cumeme: $n$-propylbenzene, but the magnitude of the slope $(\rho=0.2)$ suggests that the ligand donor ability has minimal influence on the selectivity for propylene insertion into the $\mathrm{Pt}-\mathrm{Ph}$ bond and/or overall product selectivity.

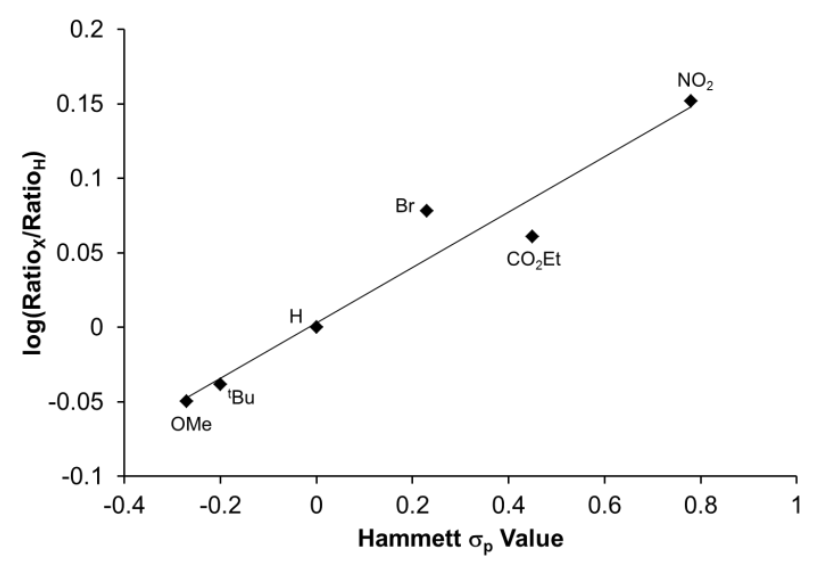

Figure 4.3. Hammett plot for the ratios of cumene to $n$-propylbenzene from $\left[\left({ }^{\mathrm{x}} \mathrm{bpy}\right) \mathrm{Pt}(\mathrm{Ph})(\mathrm{THF})\right]^{+}$catalyzed propylene hydrophenylation after 4 hours at $100{ }^{\circ} \mathrm{C}$ with $0.1 \mathrm{MPa}$ of ethylene (slope $=0.2, \mathrm{R}^{2}=0.94$ ). 


\subsubsection{Influence of Migrating Group Identity on the Selectivity of Propylene Hydrophenylation}

As the selectivity of Markovnikov versus anti-Markovnikov addition products from propylene hydrophenylation was observed to be moderately influenced by the identity of the bipyridyl 4,4'-substituent, the effect of benzene para-substitution on product selectivity was investigated. The constitutional isomers of propylene hydroarylation using anisole, benzene and chlorobenzene can be resolved during analysis by GC/MS. Comparison of the peak area ratios of $4-{ }^{\mathrm{i}} \mathrm{Pr}-1-\mathrm{X}-\mathrm{C}_{6} \mathrm{H}_{4}$ and $4-{ }^{\mathrm{n}} \mathrm{Pr}-1-\mathrm{X}-\mathrm{C}_{6} \mathrm{H}_{4}(\mathrm{X}=\mathrm{OMe}, \mathrm{H}$ and $\mathrm{Cl}$ ) after 4 hours of heating at $100{ }^{\circ} \mathrm{C}$ under $0.1 \mathrm{MPa}$ of propylene with $0.2 \mathrm{~mol} \%$ 4.1b demonstrates no correlation between the Hammett $\sigma$ parameter of the benzene functionality and Markovnikov/anti-Markovnikov selectivity in the resulting alkyl arenes (Scheme 4.6 and Figure 4.4). For example, catalysis with both anisole $\left(\mathrm{OMe}, \sigma_{\mathrm{p}}=-0.27\right)$ and chlorobenzene $\left(\mathrm{Cl}, \sigma_{\mathrm{p}}=0.23\right)$ provides a greater predilection for formation of the isopropyl functionalized arene compared to that of benzene.

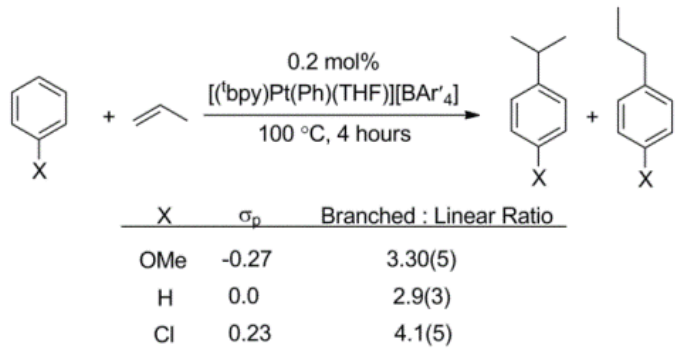

Scheme 4.6. Comparison of branched to linear ratios of propylene $(0.1 \mathrm{MPa})$ hydroarylation using substituted xylenes. 


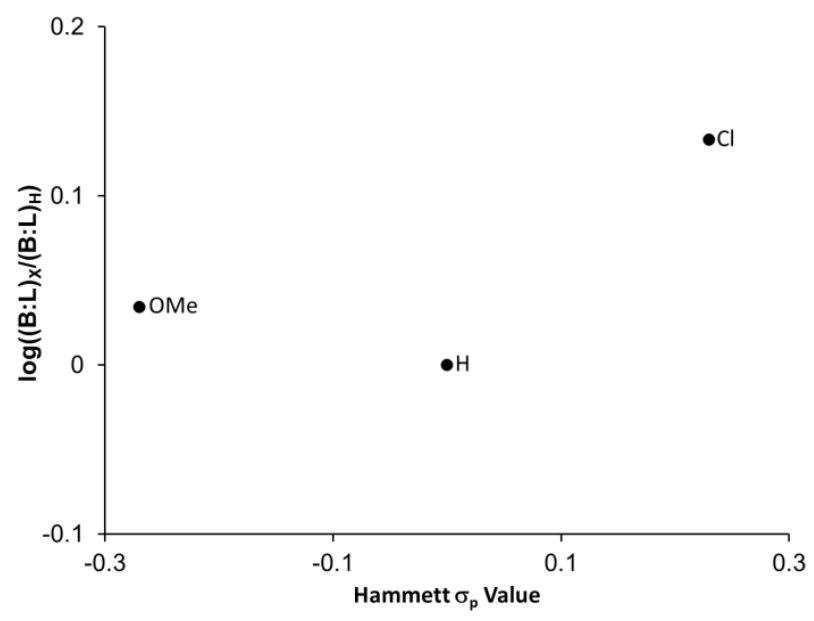

Figure 4.4. Hammett plot for the ratios of para-substituted isomers of benzene from $\left[\left({ }^{\circ} \mathrm{bpy}\right) \mathrm{Pt}(\mathrm{Ph})(\mathrm{THF})\right]^{+}$catalyzed propylene hydroarylation after 4 hours at $100{ }^{\circ} \mathrm{C}$ with 0.1 $\mathrm{MPa}$ of propylene versus Hammett parameter $\left(\sigma_{\mathrm{p}}\right)$ for the benzene substituent.

Substituted xylenes of the type 2,6- $\mathrm{Me}_{2}-1-\mathrm{X}-\mathrm{C}_{6} \mathrm{H}_{3}(\mathrm{X}=\mathrm{OMe}, \mathrm{H}$ and $\mathrm{Cl})$ were used to limit the number of constitutional isomers since $\mathrm{Pt}^{\mathrm{II}}$ catalyzed olefin hydroarylation of substituted arenes demonstrates a preference for meta- over ortho- $\mathrm{C}-\mathrm{H}$ activation. Comparison of peak area ratios of isopropyl versus $n$-propyl substituted xylenes after heating at $100{ }^{\circ} \mathrm{C}$ under $0.1 \mathrm{MPa}$ of propylene with $0.2 \mathrm{~mol} \% \mathbf{4 . 1 b}$ reveals no correlation between product selectivity and Hammett $\sigma$ parameter of the para-substituent (Scheme 4.7). The branched to linear ratios for $\mathrm{OMe}\left[\sigma_{\mathrm{p}}=-0.27 ; \mathrm{B}: \mathrm{L}=3.3(4)\right]$ and $\mathrm{Cl}\left[\sigma_{\mathrm{p}}=0.23\right.$; $\mathrm{B}: \mathrm{L}=4.4(9)]$ substituted xylenes are again higher than the ratio observed for the parent $m$-xylene $[\mathrm{B}: \mathrm{L}=2.6(1)]$. Large deviations for the ratio of 1-chloro-4- ${ }^{\mathrm{i}} \mathrm{Pr}-2,6-\mathrm{Me}_{2}$-benzene to 1-chloro-4- ${ }^{\mathrm{n}} \mathrm{Pr}-2,6-\mathrm{Me}_{2}$-benzene $[\mathrm{B}: \mathrm{L}=4.4(9)]$ were obtained. 


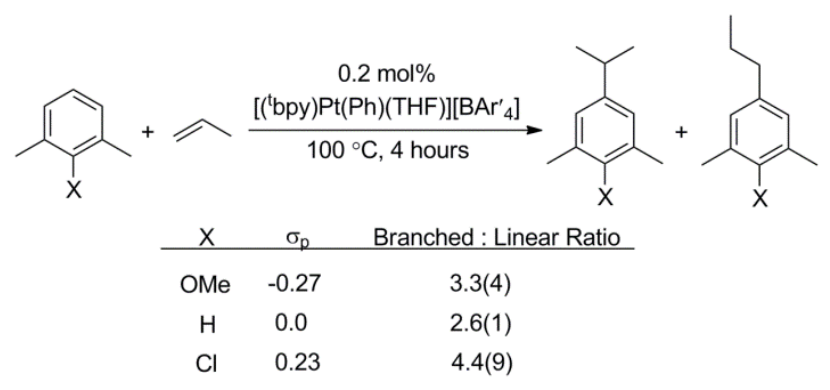

Scheme 4.7. Comparison of branched to linear ratios of propylene $(0.1 \mathrm{MPa})$ hydroarylation using substituted xylenes.

Substituents on benzene exert little influence on selectivity of product formation during propylene hydroarylation. However, the substitution of benzene for furan greatly biases the reaction to favor the Markovnikov addition product. After 4 hours at $100{ }^{\circ} \mathrm{C}$, complex 4.1b catalyzes the formation of 2-isopropylfuran and 2-n-propylfuran in an approximate 44:1 ratio, as determined by comparison of peak areas from GC/MS analysis.

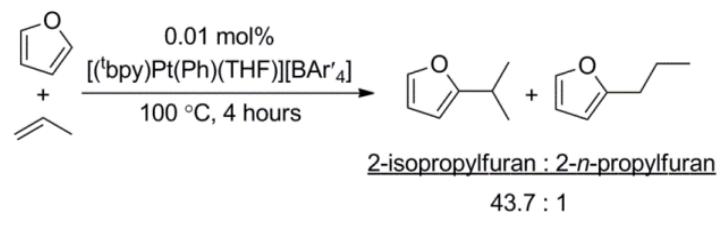

Scheme 4.8. Ratio of 2-isopropylfuran and 2-n-propylfuran from propylene (0.1 $\mathrm{MPa})$ hydroarylation with furan and $\left[\left({ }^{(} \mathrm{bpy}\right) \mathrm{Pt}(\mathrm{Ph})(\mathrm{THF})\right]^{+}$at $100{ }^{\circ} \mathrm{C}$ after 4 hours, as determined from peak area ratios from analysis by GC/MS.

\subsubsection{Ramifications of Steric Perturbations and Bridging Group Identity on Dipyridyl Pt ${ }^{\mathrm{II}}$ Catalyzed Propylene Hydrophenylation}

Catalysis using propylene and benzene with the complexes $[(\mathrm{N} \sim \mathrm{N}) \mathrm{Pt}(\mathrm{Ph})(\mathrm{THF})]\left[\mathrm{BAr}_{4}\right]$ $\left[\mathrm{N} \sim \mathrm{N}=2,2^{\prime}\right.$-dipyridylmethane (dpm, 4.2a); 6-methyl-2,2'-dipyridylmethane (Me-dpm, 
4.2b); 6,6'-dimethyl-2,2'-dipyridylmethane $\quad\left(\mathrm{Me}_{2}\right.$-dpm, 4.2c); 6,6'-dimethyl-2,2'bipyridine ( $\mathrm{Me}_{2}$-bpy, 4.2d); 1,2-bis(2-pyridyl)ethane (dpe, 4.2e); 2,2'-dipyridylketone (4.3a); 2,2'-dipyridylamine (4.3b); 2,2'-dipyridylether (4.3c)] was performed to determine the influence of steric modifications on regioselectivity (Chart 4.1 and Table 4.7). At 100 ${ }^{\circ} \mathrm{C}$ under $0.1 \mathrm{MPa}$ of propylene, cumene (9.6 TO) and $n$-propylbenzene (2.2) are produced in a 4.4:1 ratio after 4 hours with complex 4.2a. The ratio of branched to linear products is almost invariant with time. Thus, the 6-membered chelate of 4.2a increases the branched to linear ratio by $\sim 50 \%$ compared to that observed for the bipyridyl supported catalyst. The sequential addition of methyl groups to the 6-positions of the pyridyl rings of dipyridylmethane heightens the propensity of cumene formation over $n$ propylbenzene. Using complex $\mathbf{4 . 2 b}$, a ratio of branched to linear isomers of 5.3 is observed after 4 hours of catalysis. The symmetrically substituted $\mathrm{Me}_{2}-\mathrm{dpm}$ complex $\mathbf{4 . 2 c}$ is completely selective for the formation of cumene in sub-stoichiometric amounts. The formation of several isomers of (propenyl)propylbenzene was detected by GC/MS but not quantified. As observed during catalysis with ethylene, 4.2d readily undergoes $\beta$-hydride elimination, and only 2-phenylpropylene was observed after 16 hours. Complex $\mathbf{4 . 2 e}$ is selective for the formation of cumene in $\sim 40 \%$ yield, relative to 4.2e. Whether the cumene: $n$-propylbenzene ratio is controlled by the regioselectivity of propylene insertion or by the relative rates of subsequent reactions (i.e., Curtin-Hammett conditions) is not known. 


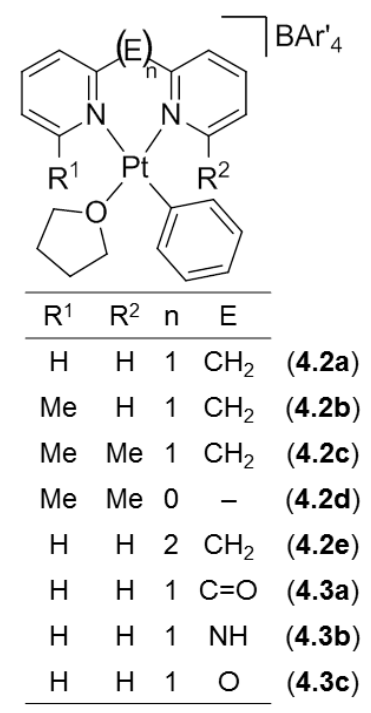

Chart 4.1. Variations in dipyridyl $\mathrm{Pt}^{\mathrm{II}}$ catalyst precursor architecture.

Table 4.7. Comparison of catalytic propylene hydrophenylation using complexes $\mathbf{4 . 2 a -}$ 4.2e. ${ }^{\mathrm{a}}$

\begin{tabular}{|c|c|c|c|}
\hline Complex & $\operatorname{Pr}$ & ${ }^{\mathrm{n} P r}$ & $B: L^{b}$ \\
\hline $4.2 a$ & $\begin{array}{c}9.6^{c} \\
(20.9)^{d}\end{array}$ & $\begin{array}{c}2.2 \\
(5.1)\end{array}$ & 4.4 \\
\hline $4.2 b$ & $\begin{array}{l}2.1 \\
(3.8)\end{array}$ & $\begin{array}{c}0.4 \\
(0.9)\end{array}$ & 5.3 \\
\hline $4.2 \mathrm{c}$ & $\begin{array}{c}0.6 \\
(0.7)\end{array}$ & $\begin{array}{c}0 \\
(0)\end{array}$ & - \\
\hline $4.2 d$ & $\begin{array}{c}0 \\
(0)\end{array}$ & $\begin{array}{c}0 \\
(0)\end{array}$ & - \\
\hline $4.2 \mathrm{e}$ & $\begin{array}{c}0.3 \\
(0.4)\end{array}$ & $\begin{array}{c}0 \\
(0)\end{array}$ & - \\
\hline
\end{tabular}

${ }^{\text {a }} 0.01 \mathrm{~mol} \%$ catalyst dissolved in $\mathrm{C}_{6} \mathrm{H}_{6}$ with hexamethylbenzene as an internal standard at $100{ }^{\circ} \mathrm{C}$ with $0.1 \mathrm{MPa} \mathrm{C}_{3} \mathrm{H}_{6} \cdot{ }^{\mathrm{b}}$ Ratio of cumene to $n$-propylbenzene after 4 hours. ${ }^{\mathrm{c}} \mathrm{TO}$ after 4 hours as determined by GC/MS. ${ }^{d}$ Numbers in parentheses are TO after 16 hours.

Catalysis using propylene and benzene with complexes 4.3a-4.3c (Chart 4.1) was then studied to probe the influence of pyridyl linker on catalyst activity and product selectivity (Table 4.8). For 4.3a-4.3c, catalysis is biased towards cumene formation, and the ratio of 
Markovnikov to anti-Markovnikov addition products increases slightly for $\mathbf{4 . 3 a - 4 . 3 c}$ (compared to $4.2 \mathrm{a}$ ). At $100{ }^{\circ} \mathrm{C}$ under $0.1 \mathrm{MPa}$ of propylene, complex $4.3 \mathrm{~b}$ was found to be the most active catalyst precursor for propylene hydrophenylation with $25.4 \mathrm{TO}$ of cumene and $n$-propylbenzene in a 5.2:1 ratio after 4 hours. Using complex 4.3a, only 5.0 TO were observed after 4 hours with a branched:linear ratio of 6.1:1, and extended reaction times result in no further catalytic activity. Propylene hydrophenylation with the dipyridyl ether complex $4.3 \mathrm{c}$ after 4 hours resulted in a product distribution nearly identical to that of $4.3 \mathrm{a}$ with $4.9 \mathrm{TO}$ of cumene and n-propylbenzene in a 7.2:1 ratio. However, as the TO of cumene are the same for $4.3 \mathrm{a}$ and $4.3 \mathrm{c}$ and the TO of $n$ propylbenzene differ by only 0.1 , the regioselectivity of insertion into the $\mathrm{Pt}-\mathrm{Ph}$ bond is approximately the same for these complexes.

Table 4.8. Comparison of catalytic propylene hydrophenylation using complexes $\mathbf{4 . 3 a -}$ 4.3c. ${ }^{\mathrm{a}}$

\begin{tabular}{cccc}
\hline & & \\
Complex & & & \\
4.3a & $(4.4)^{\mathrm{d}}$ & $(0.7)$ & 6.1 \\
& 21.3 & 4.1 & \\
$4.3 \mathrm{~b}$ & $(27.9)$ & $(5.5)$ & 5.2 \\
& 4.3 & 0.6 & \\
$4.3 \mathrm{c}$ & $(4.9)$ & $(0.7)$ & 7.2 \\
\end{tabular}

${ }^{\text {a }} 0.01 \mathrm{~mol} \%$ catalyst dissolved in $\mathrm{C}_{6} \mathrm{H}_{6}$ with hexamethylbenzene as an internal standard at $100{ }^{\circ} \mathrm{C}$ with $0.1 \mathrm{MPa} \mathrm{C}_{3} \mathrm{H}_{6} \cdot{ }^{\mathrm{b}}$ Ratio of cumene and $n$-propylbenzene after 4 hours. ${ }^{\mathrm{c}} \mathrm{TO}$ after 4 hours as determined by GC/MS. ${ }^{\mathrm{d}}$ Numbers in parentheses are TO after 16 hours. 


\subsection{Ethylene Hydrophenylation Catalyzed by Cationic $\mathrm{Pt}^{\mathrm{II}}$ Complexes Supported by non-Bipyridyl $N$ - and $S$-Based Chelates}

Previous examples of olefin hydroarylation catalyzed by $\mathrm{Pt}^{\mathrm{II}}$ via a non-acidic pathway have relied on dipyridyl or (2-pyridyl)pyrrolide supporting ligands. ${ }^{1}$ A series of bischelating nitrogen ligands were studied for catalytic ethylene hydrophenylation in $\mathrm{Pt}^{\mathrm{II}}$ complexes $[(\mathrm{N} \sim \mathrm{N}) \mathrm{Pt}(\mathrm{Ph})(\mathrm{THF})]\left[\mathrm{BAr}_{4}{ }_{4}\right][\mathrm{N} \sim \mathrm{N}=1,10$-phenanthroline (phen; 4.4), 4,5diazafluoren-9-one (dfo; 4.5), 2-(methylamine)-pyridine (map; 4.6), N,N'-bis(2,4,6trimethylphenyl)-1,2-bis(methyl)ethanediimine (MesIm; 4.7), 2,2'-bisoxazoline (bozo; 4.8) and 2-(2-pyridyl)-4-(phenyl)triazole (tripy; 4.9); Scheme 4.9]. The results of catalysis at $100{ }^{\circ} \mathrm{C}$ under $0.1 \mathrm{MPa}$ of ethylene are summarized in Table 4.9.

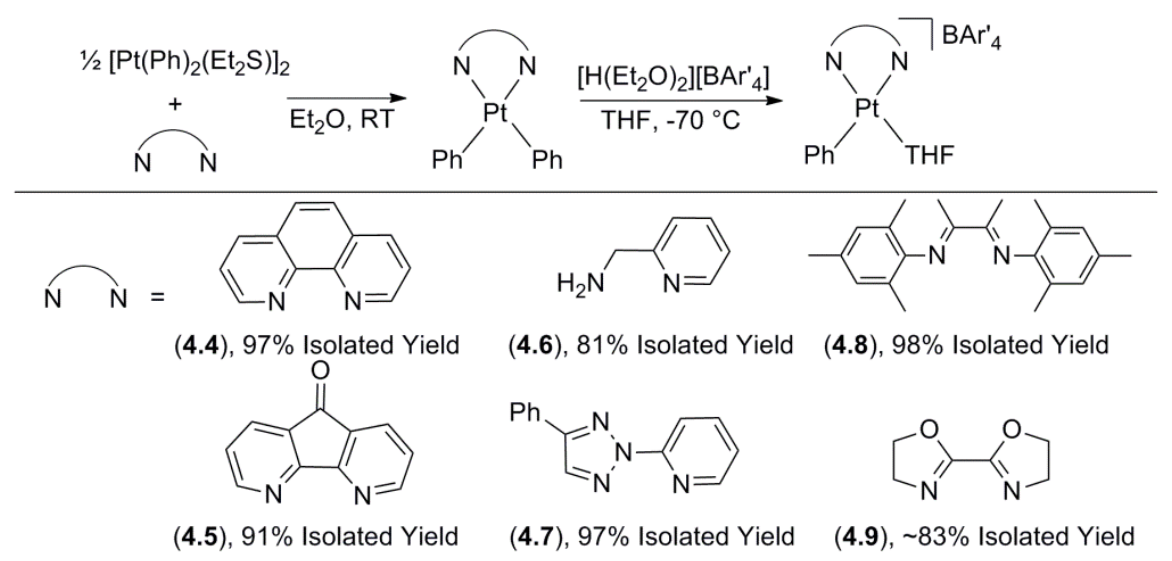

Scheme 4.9. Synthesis of cationic $\mathrm{Pt}^{\mathrm{II}}$ catalyst complexes with bis-chelating nitrogen ligands. 
Table 4.9. Ethylene hydrophenylation catalyzed by $\mathrm{Pt}^{\mathrm{II}}$ precursors 4.4-4.9. ${ }^{\mathrm{a}}$

\begin{tabular}{|c|c|c|c|c|c|}
\hline Complex & Ligand & & & & $o: m: p^{b}$ \\
\hline 4.4 & phen & $\begin{array}{c}12.6^{c} \\
(75.6)^{d}\end{array}$ & $\begin{array}{c}0.8 \\
(1.6)\end{array}$ & $\begin{array}{c}3.6 \\
(19.6)\end{array}$ & $1: 2.1: 1.4$ \\
\hline 4.5 & dfo & $\begin{array}{c}0 \\
(0.8)\end{array}$ & $\begin{array}{c}1.1 \\
(2.1)\end{array}$ & - & - \\
\hline 4.6 & map & $\begin{array}{c}3.3 \\
(9.0)\end{array}$ & $\begin{array}{c}0.4 \\
(0.8)\end{array}$ & $\begin{array}{c}1.7 \\
(5.1)\end{array}$ & $0: 1: 1.2$ \\
\hline 4.7 & tripy & - & $\begin{array}{c}\text { Trace } \\
(0.9)\end{array}$ & - & - \\
\hline 4.8 & Meslm & $\begin{array}{c}1.2 \\
(2.1)\end{array}$ & $\begin{array}{c}0.7 \\
(0.7)\end{array}$ & - & - \\
\hline 4.9 & bozo & $\begin{array}{l}0.1 \\
(0.2)\end{array}$ & $\begin{array}{c}0.7 \\
(1.2)\end{array}$ & - & - \\
\hline
\end{tabular}

${ }^{a} 0.01 \mathrm{~mol} \%$ catalyst dissolved in $\mathrm{C}_{6} \mathrm{H}_{6}$ with hexamethylbenzene as an internal standard at $100{ }^{\circ} \mathrm{C}$ with $0.1 \mathrm{MPa} \mathrm{C}_{2} \mathrm{H}_{4} \cdot{ }^{\mathrm{b}}$ Calculated using TO after 4 hours. ${ }^{\mathrm{c}} \mathrm{TO}$ after 4 hours as determined by GC/MS. ${ }^{d}$ Numbers in parentheses are TO after 16 hours.

Ethylene hydrophenylation with $[(\mathrm{phen}) \mathrm{Pt}(\mathrm{Ph})(\mathrm{THF})]\left[\mathrm{BAr}_{4}^{\prime}\right]$ (4.4) is not markedly different from that observed for $[(\mathrm{bpy}) \mathrm{Pt}(\mathrm{Ph})(\mathrm{THF})]\left[\mathrm{BAr}_{4}^{\prime}\right]$ (see Chapter 3). After 16 hours, a total of $96.8 \mathrm{TO}$ were observed with $\sim 20 \%$ of the total alkyl arene product composed of diethylbenzenes. The fused ring system of 4,5-diazafluoren-9-one (dfo) of $\left[(\mathrm{dfo}) \mathrm{Pt}(\mathrm{Ph})(\mathrm{THF}]\left[\mathrm{BAr}_{4}{ }_{4}\right] \quad\right.$ (4.5) is a 5-membered chelate analogue of (di-2pyridyl)ketone. Catalysis at $100{ }^{\circ} \mathrm{C}$ under $0.1 \mathrm{MPa} \mathrm{C}_{2} \mathrm{H}_{4}$ was selective for the formation of styrene over ethylbenzene in an $\sim 2: 1$ ratio after 16 hours using complex 4.5, contrasting with the selectivity observed with $[(\mathrm{dpk}) \mathrm{Pt}(\mathrm{Ph})(\mathrm{THF})]\left[\mathrm{BAr}_{4}\right]$ that gave an $\sim 1: 2$ ratio of styrene to ethylbenzene (see Chapter 3). 
Asymmetric ligands in which a pyridyl ring of bipyridine is substituted for more weakly $\sigma$-donating functionality results in a substantial decrease in the efficiency of $\mathrm{Pt}^{\mathrm{II}}$ catalyzed ethylene hydrophenylation. The complex $[(\operatorname{map}) \mathrm{Pt}(\mathrm{Ph})(\mathrm{THF})]\left[\mathrm{BAr}_{4}{ }_{4}\right](\mathbf{4 . 6})$ with an asymmetric pyridyl-amine ligand catalyzed the formation of $9.0 \mathrm{TO}$ of ethylbenzene and 5.1 TO of diethylbenzenes with $\sim 1$ equivalent of styrene after 16 hours. For $\mathrm{Pt}^{\mathrm{II}}$ catalyzed ethylene hydrophenylation, the composition of diethylbenzenes in the total alkyl arene product increased $\sim 50 \%$ upon the substitution of a pyridyl ring of bipyridine by an amine group. Only stoichiometric amounts of styrene were produced under catalytic conditions using complex 4.7 ligated by 2-(2-pyridyl)-4-(phenyl)triazole.

Diimine ligands, as in complex 4.8, have been extensively utilized in the study of $\mathrm{C}-\mathrm{H}$ activation by cationic $\mathrm{Pt}^{\mathrm{II}}$ complexes. ${ }^{42-54}$ However, these ligands do not appear to be compatible with ethylene hydrophenylation as only $\sim 3$ turnovers of ethylbenzene and styrene were observed in a 2:1 ratio after 16 hours under catalytic conditions using $[(\mathrm{MesIm}) \mathrm{Pt}(\mathrm{Ph})(\mathrm{THF})]\left[\mathrm{BAr}_{4}\right]$ (4.8). The more electron-deficient diimine ligand 2,2'bisoxazoline in complex 4.9 preferentially formed slightly more than stoichiometric amounts of styrene with only trace amounts of ethylbenzene detected.

Two platinum complexes $\left[\left(\kappa^{3}-\mathrm{Mp}^{\prime}\right) \mathrm{Pt}(\mathrm{H})(\mathrm{Ph})_{2}\right]\left[\mathrm{BAr}_{4}\right] \quad\left(\mathrm{Mp}^{\prime}=\operatorname{tris}(3,5-\operatorname{dimethyl}-1-\right.$ pyrazolyl)methane; 4.11) and $($ dpms $) \mathrm{Pt}(\mathrm{MeOH})(\mathrm{Ph})\left(\mathrm{dpms}=2,2^{\prime}\right.$-dipyridylmethane sulfonate; 4.12) containing tripodal ligands, which coordinate to $\mathrm{Pt}^{\mathrm{II}}$ and $\mathrm{Pt}^{\mathrm{IV}}$ in a $\kappa^{2}$ - or $\kappa^{3}$-fashion, respectively, were screened for catalytic activity (Table 4.10). It was anticipated that these ligands could improve catalyst selectivity for ethylbenzene over diethylbenzenes during catalytic ethylene hydrophenylation due to axial interactions of 
the uncoordinated donor functionality with the metal center, which could facilitate ethylbenzene dissociation. Protonation of $\left(\kappa^{2}-\mathrm{Mp}^{\prime}\right) \mathrm{Pt}(\mathrm{Ph})_{2}(\mathbf{4 . 1 0})$ results in the formation of the cationic $\mathrm{Pt}^{\mathrm{IV}}$ complex $\left[\left(\kappa^{3}-\mathrm{Mp}^{\prime}\right) \mathrm{Pt}(\mathrm{H})(\mathrm{Ph})_{2}\right]\left[\mathrm{BAr}_{4}^{\prime}\right]$ (4.11; Scheme 4.10). Under catalytic conditions with $0.1 \mathrm{MPa}$ of ethylene using complex 4.11, ethylbenzene was formed selectively but only in stoichiometric quantities, likely due to thermal instability of the complex at conditions necessary to dissociate a coordinated pyrazolyl group of the ligand in order to provide a pathway for ethylene insertion or reductive elimination. A derivative of dipyridylmethane that includes a sulfonate group on the pyridyl bridge was investigated. The complex $\left(\kappa^{2}-\mathrm{dpms}\right) \mathrm{Pt}(\mathrm{MeOH})(\mathrm{Ph}) \mathbf{( 4 . 1 2 )}$ is synthesized by reductive elimination of benzene from $\left(\kappa^{3}-\operatorname{dpms}\right) \mathrm{Pt}(\mathrm{H})(\mathrm{Ph})_{2}$ in methanol under mild conditions. ${ }^{55}$ Despite the ease of reductive elimination in the synthesis of complex 4.12, no alkyl benzenes were observed until the reaction was heated to $140^{\circ} \mathrm{C}$, but only stoichiometric amounts of ethylbenzene and complex decomposition were obtained.

Table 4.10. Ethylene hydrophenylation from catalyst precursors bearing potential for $\kappa^{3}-$ coordination. ${ }^{a}$

\begin{tabular}{ccccc}
\hline Complex Ligand & $\begin{array}{c}\text { Temp } \\
\left({ }^{\circ} \mathrm{C}\right)\end{array}$ & \\
\hline 4.11 & $\mathrm{Mp}^{\prime}$ & 140 & $\begin{array}{c}1.0^{\mathrm{b}} \\
(1.0)^{\mathrm{c}}\end{array}$ & trace \\
4.12 & $\mathrm{dpms}$ & 140 & $\begin{array}{c}1.4 \\
(1.6)\end{array}$ & - \\
4.13 & $9 \mathrm{~S} 3$ & 120 & $\begin{array}{c}9.3 \\
(24.6)\end{array}$ & $\begin{array}{c}1.4 \\
(2.7)\end{array}$ \\
\hline
\end{tabular}

${ }^{\text {a }} 0.01 \mathrm{~mol} \%$ catalyst dissolved in $\mathrm{C}_{6} \mathrm{H}_{6}$ with hexamethylbenzene as an internal standard at $100{ }^{\circ} \mathrm{C}$ with $0.1 \mathrm{MPa} \mathrm{C}_{2} \mathrm{H}_{4}{ }^{\mathrm{b}}$ TO after 4 hours as determined by GC/MS. ${ }^{\mathrm{c}}$ Numbers in parentheses are $\mathrm{TO}$ after 16 hours. 

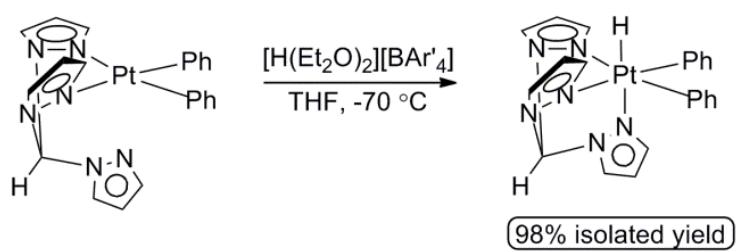

Scheme 4.10. Synthesis of $\left[\mathrm{Mp}{ }^{\prime} \mathrm{Pt}(\mathrm{H})(\mathrm{Ph})_{2}\right]\left[\mathrm{BAr}_{4}\right]$ (4.11).

From the reported solid-state structure of $(9 \mathrm{~S} 3) \mathrm{PhPh}_{2}(9 \mathrm{~S} 3=1,4,7$-trithiacyclononane), the thioether ligand coordinates in a bidentate fashion with the uncoordinated sulfur atom oriented away from the Pt center (exodentate). ${ }^{56}$ However, weak axial interactions are inferred from variable temperature NMR spectroscopy studies and structural comparison to other 9S3 ligated Pt complexes. ${ }^{56}$ Protonation in the presence of acetonitrile affords the complex $\left[\left(\kappa^{2}-9 \mathrm{~S} 3\right) \operatorname{Pt}(\mathrm{NCMe})(\mathrm{Ph})\right]\left[\mathrm{BAr}_{4}\right]$ (4.13; Scheme 4.11). Unlike complexes 4.11 and 4.12, the sulfur containing macrocycle does not appear to impart significant stability to transient $\mathrm{Pt}^{\mathrm{IV}}-\mathrm{H}$ intermediates and hinder catalysis. Weak axial interactions from the uncoordinated sulfur atom may also facilitate ethylbenzene dissociation from $\mathrm{Pt}^{\mathrm{II}}$ resulting in a decrease in diethylbenzene production. Ethylene hydrophenylation catalyzed by complex 4.13 at $120{ }^{\circ} \mathrm{C}$ yields 10.7 and $27.3 \mathrm{TO}$ of ethylbenzene and styrene after 4 and 16 hours, respectively. No diethylbenzenes were observed. For propylene hydrophenylation, complex $\mathbf{4 . 1 3}$ is more selective for anti-Markovnikov addition products, compared to the reaction with dipyridyl catalyst precursors, as $18.8 \mathrm{TO}$ of cumene and $n$-propylbenzene are provided after 16 hours in a 2.4:1 ratio (Scheme 4.12). 


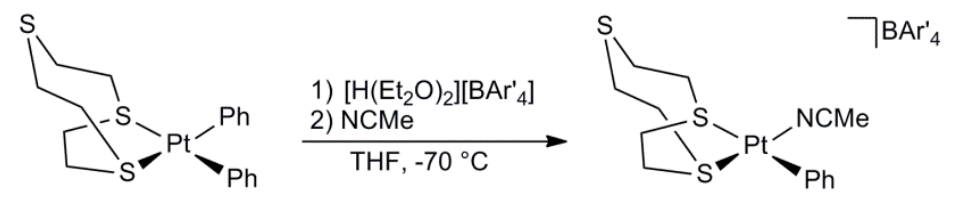

Scheme 4.11. Synthesis of $\left[\left(\kappa^{2}-9 \mathrm{~S} 3\right) \mathrm{Pt}(\mathrm{NCMe})(\mathrm{Ph})\right]\left[\mathrm{BAr}_{4}\right]$ (4.13).

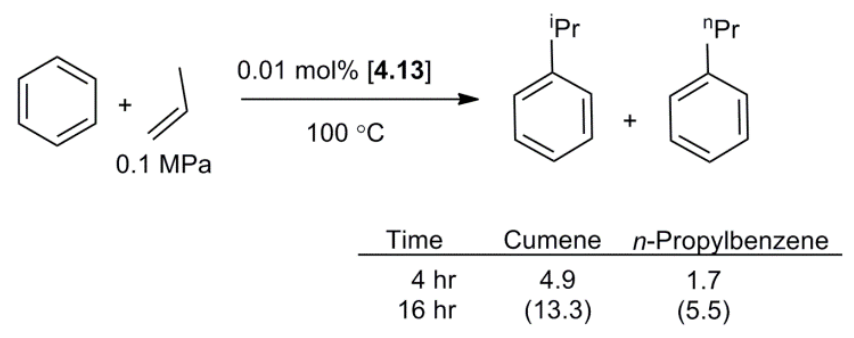

Scheme 4.12. Propylene hydrophenylation catalyzed by $\left[\left(\kappa^{2}-9 \mathrm{~S} 3\right) \mathrm{Pt}(\mathrm{NCMe})\left(\mathrm{Ph}^{2}\right]\left[\mathrm{BAr}_{4}\right]\right.$ (4.13).

\subsection{Viability of Cationic $\mathrm{Pt}^{\mathrm{II}}$ complexes Containing Phosphorous Ligands as Catalytic Precursors for Ethylene Hydrophenylation}

Nitrogen-donor ligands have been recognized to impart greater stability to $\mathrm{Pt}^{\mathrm{IV}}$ products from oxidative addition compared to tertiary phosphine ligands. ${ }^{9,}{ }^{57}$ The greater stability is most likely due to favorable electronic and steric properties of nitrogendonors. Typically, nitrogen-based ligands are strong $\sigma$-donors and weak $\pi$-acceptors, which increases the nucleophilicity of the $\mathrm{Pt}^{\mathrm{II}}$ center. In addition, nitrogen ligands possess a reduced steric profile compared to their phosphine analogues. It was hypothesized that phosphine ligands for $\mathrm{Pt}^{\mathrm{II}}$ catalyzed ethylene hydrophenylation could have a significant influence on catalyst efficiency and product selectivity. A range of bis-chelating phosphorus ligands were studied in $\mathrm{Pt}^{\mathrm{II}}$ complexes $[(\mathrm{P} \sim \mathrm{P}) \mathrm{Pt}(\mathrm{NCMe})(\mathrm{Ph})]\left[\mathrm{BAr}_{4}^{\prime}\right][\mathrm{P} \sim \mathrm{P}=$ 1,2-bis(dimethylphosphino)ethane (dmpe; 4.14a), 1,2-bis(diphenylphosphino)ethane 
(dppe; 4.14b), 1,2-bis(di-N-pyrrolylphosphino)ethane $\quad$ (bppe; $\quad 4.14 c), \quad 1,3-$ bis(diphenylphosphino)propane (dppp; 4.15), 1,1'-bis(diphenylphosphino)ferrocene (dppf; 4.16) and bis-((diphenylphosphino)methyl)methylamine (bma; 4.17); Scheme 4.13]. The acetonitrile adducts were targeted due to an account of phosphorus ligated $\mathrm{Pt}^{\mathrm{II}}-(\mathrm{Ph})(\mathrm{THF})$ complexes undergoing facile aryl coupling to yield stable biphenylbridged binuclear species (Scheme 4.14). ${ }^{58}$

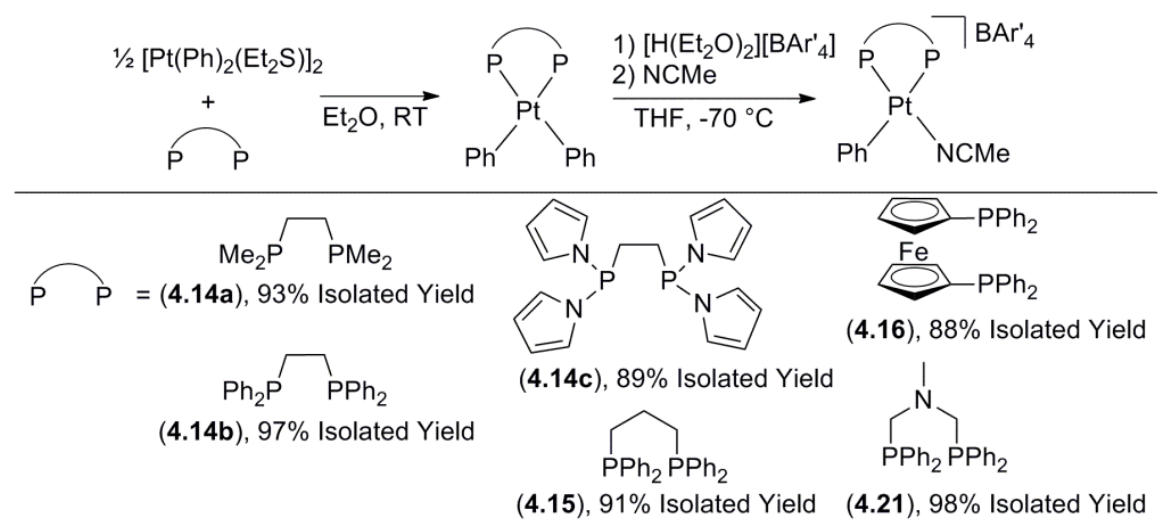

Scheme 4.13. Synthesis of cationic $\mathrm{Pt}^{\mathrm{II}}$ catalyst complexes with bis-chelating phosphorus ligands.

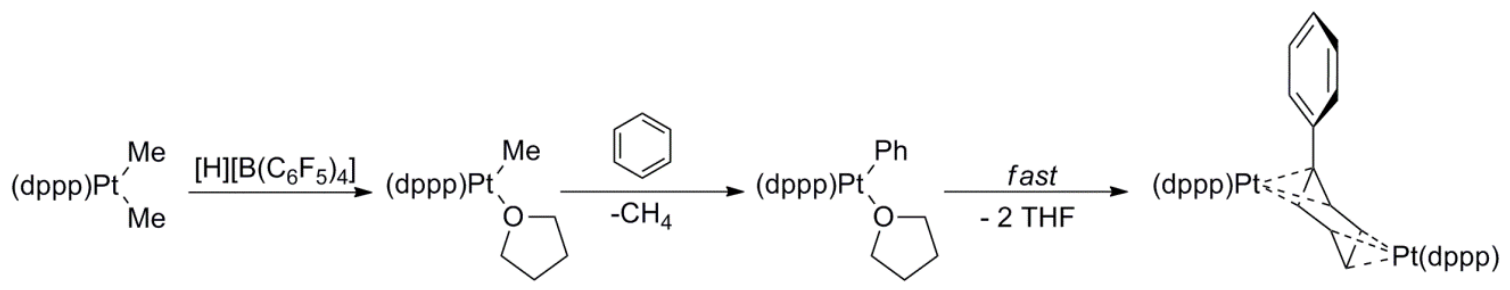

Scheme 4.14. Previously reported aryl coupling leading to a stable biphenyl-bridged dicationic bis- $\mathrm{Pt}^{\mathrm{II}}$ complex following benzene $\mathrm{C}-\mathrm{H}$ activation. ${ }^{58}$ 
Under conditions of $100{ }^{\circ} \mathrm{C}$ and $0.1 \mathrm{MPa}$ of $\mathrm{C}_{2} \mathrm{H}_{4}$, complexes 4.14-4.16 were found to be ineffective catalysts for ethylene hydrophenylation and highly susceptible to $\beta$-hydride elimination following ethylene insertion into the $\mathrm{Pt}-\mathrm{Ph}$ bond. Styrene was formed selectively in most cases with few catalytic TO observed (Table 4.11). Negligible changes in catalyst efficiency are observed with variations of the ligand structure. For example, complexes $4.14 a-4.14 c$ possess the 5-membered chelating phosphine ligands dmpe, dppe and bppe. With the decreasing $\sigma$-donor ability of the phosphine ligand as the phosphorus substituents are varied from Me to $\mathrm{N}$-pyrrolyl, ${ }^{59}$ a slight decrease in turnover number (TON) after 16 hours of catalysis is observed. ${ }^{59}$ A decrease in catalyst activity is also predicated by increasing bite angle of the phosphine ligand. For example, catalysis with 4.14b, 4.15 and 4.16 results in $2.0,1.8$ and $1.4 \mathrm{TO}$ of styrene after 16 hours, respectively. 
Table 4.11. Ethylene hydrophenylation catalyzed by phosphine ligated $\mathrm{Pt}^{\mathrm{II}}$ precursors. ${ }^{\mathrm{a}}$

\begin{tabular}{|c|c|c|c|c|c|}
\hline Complex & Ligand & & Complex & Ligand & \\
\hline $4.14 a$ & dmpe & $\begin{array}{c}1.5^{b} \\
(3.3)^{c}\end{array}$ & 4.16 & dppf & $\begin{array}{c}1.2 \\
(1.4)\end{array}$ \\
\hline $4.14 b$ & dppe & $\begin{array}{c}1.9 \\
(2.0)\end{array}$ & 4.18 & diq & - \\
\hline $4.14 c$ & bppe & $\begin{array}{c}0.9 \\
(0.9)\end{array}$ & $4.21^{d}$ & bma & $\begin{array}{c}1.2 \\
(1.3)\end{array}$ \\
\hline 4.15 & dppp & $\begin{array}{c}1.5 \\
(1.8)\end{array}$ & & & \\
\hline
\end{tabular}

${ }^{\text {a }} 0.01 \mathrm{~mol} \%$ catalyst dissolved in $\mathrm{C}_{6} \mathrm{H}_{6}$ with hexamethylbenzene as an internal standard at $100{ }^{\circ} \mathrm{C}$ with $0.1 \mathrm{MPa} \mathrm{C}_{2} \mathrm{H}_{4}{ }^{\mathrm{b}}$ TO after 4 hours as determined by GC/MS. ${ }^{\mathrm{c}}$ Numbers in parentheses are TO after 16 hours. ${ }^{\mathrm{d}}$ Ethylbenzene observed in sub-stoichiometric amounts.

A mixed chelate ligand was targeted as it was hypothesized that catalyst efficiency for ethylene hydrophenylation might more closely mimic that observed for bipyridyl supported catalyst precursors. The diphenyl complex (diq) $\operatorname{Pt}(\mathrm{Ph})_{2} \quad(4.17 ;$ diq $=8$ (diisopropylphosphino)quinoline) was isolated in $85 \%$ yield and a crystal suitable for an X-ray diffraction study was grown from the slow evaporation of a dilute ether solution (Figure 4.5). From the protonation of complex 4.17 in $\mathrm{THF}$ at $-70{ }^{\circ} \mathrm{C}$, the cationic $\mathrm{THF}$ adduct $[($ diq $) \mathrm{Pt}(\mathrm{Ph})(\mathrm{THF})]\left[\mathrm{BAr}_{4}\right]$ (4.18) was isolated. However, the mixed N,P-chelate was found to be inactive for ethylene hydrophenylation, as no ethylbenzene or styrene was observed. 


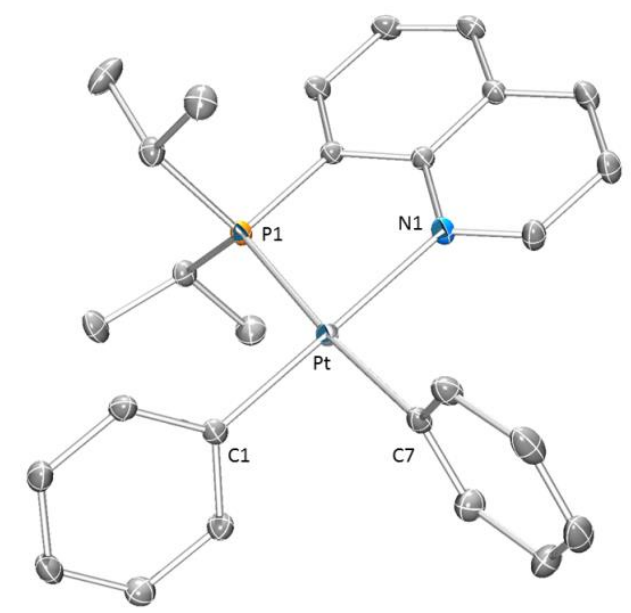

Figure 4.5. ORTEP of (DIQ) $\mathrm{Pt}(\mathrm{Ph})_{2}$ (4.17) (50\% probability; $\mathrm{H}$ atoms omitted for clarity). Selected bond lengths ( $\mathrm{A})$ : $\mathrm{Pt}-\mathrm{P} 1$ 2.2739(7), Pt-N1 2.152(2), $\mathrm{Pt}-\mathrm{C} 1$ 2.011(3), $\mathrm{Pt}-\mathrm{C} 7$ 2.051(3). Selected bond angles $\left({ }^{\circ}\right)$ : P1-Pt-N1 83.01(7), C1-Pt-C7 89.1(1).

While catalytic ethylene hydrophenylation using phosphine ligated $\mathrm{Pt}^{\mathrm{II}}$ complexes to produce ethylbenzene was not realized, their selective production of styrene from benzene and ethylene suggests that complexes of this type could be applicable for oxidative olefin hydroarylation to produce vinyl arenes. This would require stabilization of $\mathrm{Pt}-\mathrm{H}$ intermediates, which are suspected to provide a facile pathway for catalyst decomposition. One way to accomplish this is to site-isolate catalyst precursors on a solid support, as catalyst decomposition has been demonstrated to be second-order in Pt, at least for dipyridyl supported catalysts. Complex (dats) $\mathrm{Pt}(\mathrm{Ph})_{2} \quad$ (4.19; $\quad$ (3$\{$ bis[(diphenylphosphino)methyl]amino\}propyl)triethoxysilane (dats)] was synthesized for grafting onto mesoporous silica nanoparticles. The protonation of 4.19 led to formation of several products by ${ }^{1} \mathrm{H}$ NMR spectroscopy, including ethanol. This indicates that protonolysis of the $\mathrm{Si}-\mathrm{O}$ bonds is competitive with the $\mathrm{Pt}-\mathrm{Ph}$ bond. Therefore, an

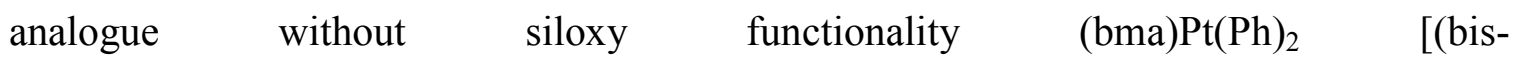


(diphenylphosphino)methyl)methylamine (bma); 4.20] was synthesized to provide a molecular system for comparison to the "heterogenized" catalyst. Solid-state structures of complexes 4.19 and 4.20 were obtained, and show that the nitrogen substituent exerts little influence on ligand binding (Figure 4.6 and Figure 4.7).

Catalysis with the molecular variant $[(\mathrm{bma}) \mathrm{Pt}(\mathrm{NCMe})(\mathrm{Ph})]\left[\mathrm{BAr}_{4}^{\prime}\right]$ (4.21) was comparable to the other phosphine precursors explored with little more than stoichiometric equivalents of styrene observed after 16 hours at $100{ }^{\circ} \mathrm{C}$ (Table 4.11 ). Preliminary studies indicate that immobilizing the catalyst results in a switch in product selectivity with substantial quantities of ethylbenzene observed. Continued investigation, including quantification and reaction optimization, is ongoing.

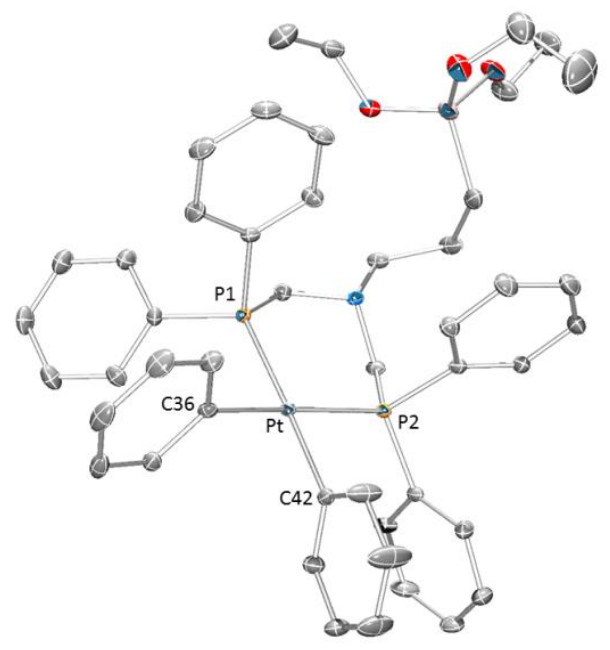

Figure 4.6. ORTEP of (dats) $\mathrm{Pt}(\mathrm{Ph})_{2}$ (4.19) (50\% probability; $\mathrm{H}$ atoms omitted for clarity). Selected bond lengths ( $\AA$ ): Pt-P1 2.2787(8), Pt-P2 2.2666(8), Pt-C36 2.052(3), $\mathrm{Pt}-\mathrm{C} 42$ 2.057(3). Selected bond angles $\left({ }^{\circ}\right)$ : P1-Pt-P2 93.43(3), P2-Pt-C36 170.88(9), C36-Pt-C42 83.7(1). 


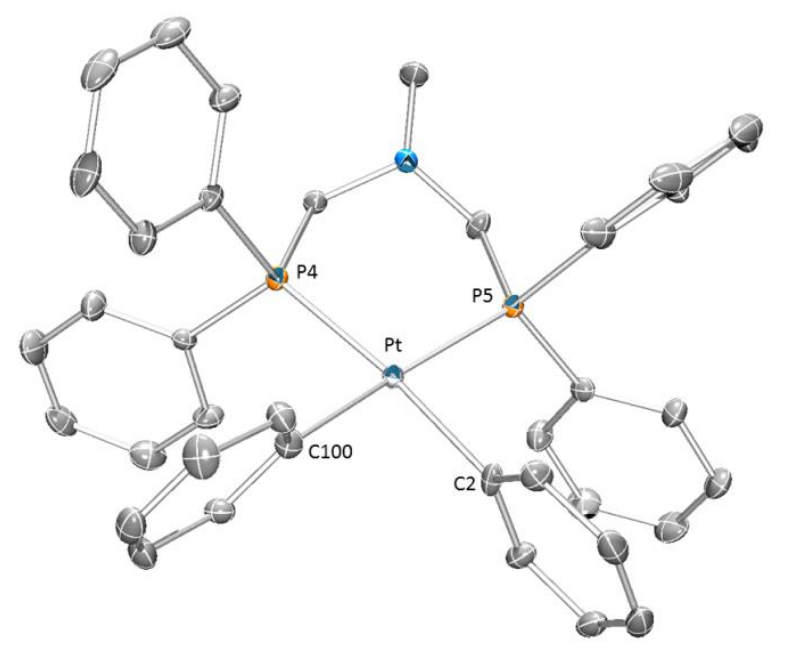

Figure 4.7. ORTEP of (bma) $\mathrm{Pt}(\mathrm{Ph})_{2}$ (4.20) (50\% probability; $\mathrm{H}$ atoms omitted for clarity). Selected bond lengths ( $\mathrm{A})$ : Pt-P4 2.301(1), Pt-P2 2.288(1), Pt-C100 2.047(5), $\mathrm{Pt}-\mathrm{C} 2$ 2.076(4). Selected bond angles $\left(^{\circ}\right)$ : P4-Pt-P5 94.39(4), P5-Pt-C100 174.1(2), $\mathrm{C} 100-\mathrm{Pt}-\mathrm{C} 2$ 85.8(2).

\subsection{Experimental Section}

General Methods. Unless otherwise noted, all synthetic procedures were performed under anaerobic conditions in a nitrogen-filled glove box or by using standard Schlenk techniques. Glove box purity was maintained by periodic nitrogen purges and was monitored by an oxygen analyzer $\left(\mathrm{O}_{2}<15 \mathrm{ppm}\right.$ for all reactions $)$. Acetonitrile and diethyl ether were dried by distillation over $\mathrm{CaH}_{2}$. Tetrahydrofuran and $n$-pentane were distilled over sodium/benzophenone and $\mathrm{P}_{2} \mathrm{O}_{5}$, respectively. Methylene chloride and benzene were purified by passage through a column of activated alumina. Acetone- $d_{6}$, DMSO- $d_{6}$ and $\mathrm{CD}_{2} \mathrm{Cl}_{2}$ were used as received and stored under a $\mathrm{N}_{2}$ atmosphere over $4 \AA$ molecular sieves. ${ }^{1} \mathrm{H}$ NMR spectra were recorded on a Varian Mercury 300 or $500 \mathrm{MHz}$ or on a 
Bruker $800 \mathrm{MHz}$ spectrometer. ${ }^{13} \mathrm{C}$ NMR spectra were recorded using a Varian Mercury 300 or $500 \mathrm{MHz}$ (operating frequency 75 or $125 \mathrm{MHz}$, respectively) or using a Bruker $800 \mathrm{MHz}$ spectrometer (operating frequency $201 \mathrm{MHz}$ ). All ${ }^{1} \mathrm{H}$ and ${ }^{13} \mathrm{C}$ NMR spectra are referenced against residual proton signals $\left({ }^{1} \mathrm{H}\right.$ NMR) or the ${ }^{13} \mathrm{C}$ resonances $\left({ }^{13} \mathrm{C} \mathrm{NMR}\right)$ of the deuterated solvents. ${ }^{19} \mathrm{~F}$ NMR (282 MHz operating frequency) spectra were obtained on a Varian $300 \mathrm{MHz}$ spectrometer and referenced against an external standard of hexafluorobenzene $(\delta=-164.9 \mathrm{ppm})$. GC/MS was performed using a Shimadzu GCMSQP2010 Plus system with a $30 \mathrm{~m}$ x $0.25 \mathrm{~mm}$ SHRXI-5MS column with $0.25 \mathrm{~mm}$ film thickness using negative chemical ionization (NCI), which also allows for simulated electron impact (SEI) ionization. Ethylene (99.5\%) and Propylene (99.5\%) were purchased in a gas cylinder from GTS-Welco and used as received. All other reagents were used as purchased from commercial sources. The preparation, isolation and characterization of 2-ethyl-1-methylpyrrole, ${ }^{60} \quad$ 3-ethyl-1-methylpyrrole, ${ }^{61}$ 3phenylcyclohexanone, ${ }^{62}\left[\mathrm{H}\left(\mathrm{Et}_{2} \mathrm{O}\right)_{2}\right]\left[\mathrm{BAr}_{4}^{\prime}\right]\left[\mathrm{Ar}^{\prime}=3,5-\left(\mathrm{CF}_{3}\right)_{2} \mathrm{C}_{6} \mathrm{H}_{3}\right],{ }^{63}\left[\mathrm{Pt}(\mathrm{Ph})_{2}\left(\mathrm{Et}_{2} \mathrm{~S}\right)\right]_{2},{ }^{64}$ 2-(2-pyridyl)-4-(phenyl)triazole (tripy), ${ }^{65}$ tris(3,5-dimethyl-1-pyrazolyl)methane, ${ }^{66}(\mathrm{~N}-$ pyrrolyl $)_{2} \mathrm{P}\left(\mathrm{CH}_{2}\right)_{2} \mathrm{P}(\mathrm{N}-\text { pyrrolyl })_{2}$ (bppe), ${ }^{67}$ (bis-(diphenylphosphino)methyl)methylamine (bma) ${ }^{68}$ (3-\{bis[(diphenylphosphino)methyl]amino $\}$ propyl)triethoxysilane (dats), ${ }^{69} 8$ (diisopropylphosphino)quinolone (diq), ${ }^{70} \operatorname{tris}\left(3,5\right.$-dimethyl-1-pyrazolyl)methane $\left(\mathrm{Mp}^{\prime}\right),{ }^{66}$ $(9 \mathrm{~S} 3) \mathrm{Pt}(\mathrm{Ph})_{2} \quad(9 \mathrm{~S} 3=1,4,7$-trithiacyclononane $),{ }^{56}(\operatorname{dmpe}) \mathrm{Pt}(\mathrm{Ph})_{2},{ }^{71} \quad(\operatorname{dppp}) \mathrm{Pt}(\mathrm{Ph})_{2},{ }^{72}$ (dppe)Pt(Ph) $)_{2}{ }^{73}$ (dppf)PtPh $2,{ }^{74-75}$ (di(2-pyridyl)methanesulfonate) $\mathrm{Pt}(\mathrm{MeOH})(\mathrm{Ph})$ (4.12), ${ }^{55}$ (phen) $\mathrm{PtPh}_{2},{ }^{76}\left(\mathrm{MesIm} \mathrm{PtPh}_{2},{ }^{52}\right.$ and $[(\mathrm{N} \sim \mathrm{N}) \mathrm{Pt}(\mathrm{Ph})(\mathrm{THF})]\left[\mathrm{BAr}_{4}\right]$ (4.1a-4.1f, 4.2a-4.2e and 4.3a-4.3c) have been reported elsewhere. 
General procedure for the synthesis of $\left(\mathrm{L}_{2}\right) \mathrm{PtPh}_{2}$ complexes. To a suspension of $\left[\mathrm{Pt}(\mathrm{Ph})_{2}\left(\mathrm{Et}_{2} \mathrm{~S}\right)\right]_{2}$ in $\mathrm{Et}_{2} \mathrm{O}(30 \mathrm{~mL})$, two equivalents of the appropriate ligand were added. The solution was stirred at room temperature for approximately 12 hours. The solution was reduced in vacuo and hexanes were added $(\sim 20 \mathrm{~mL})$. The solution was filtered, and the precipitate was washed with $\mathrm{Et}_{2} \mathrm{O}(1 \times 5 \mathrm{~mL})$ and hexanes $(2 \times 5 \mathrm{~mL})$ and dried under vacuum.

(dfo)PtPh $\mathbf{h}_{2}$. The ligand was 4,5-diazafluoren-9-one. Isolated $0.15 \mathrm{~g}(96 \%) .{ }^{1} \mathrm{H}$ NMR $\left(300 \mathrm{MHz}, \mathrm{DMSO}-d_{6}\right) \delta 8.81\left(\mathrm{dd},{ }^{3} J_{\mathrm{HH}}=5 \mathrm{~Hz},{ }^{4} J_{\mathrm{HH}}=1 \mathrm{~Hz}, 2 \mathrm{H}, 3-\mathrm{DFO}\right), 8.10\left(\mathrm{dd},{ }^{3} J_{\mathrm{HH}}\right.$ $\left.=8 \mathrm{~Hz},{ }^{4} J_{\mathrm{HH}}=1 \mathrm{~Hz}, 2 \mathrm{H}, 1-\mathrm{DFO}\right), 7.52\left(\mathrm{dd},{ }^{3} J_{\mathrm{HH}}=8 \mathrm{~Hz},{ }^{3} J_{\mathrm{HH}}=5 \mathrm{~Hz}, 2 \mathrm{H}, 1-\mathrm{DFO}\right), 7.25$ $\left(\mathrm{d},{ }^{3} J_{\mathrm{HH}}=7 \mathrm{~Hz}, 4 \mathrm{H}, \mathrm{H}^{\mathrm{o}}-\mathrm{Ph}\right), 6.89\left(\mathrm{t},{ }^{3} J_{\mathrm{HH}}=7 \mathrm{~Hz}, 4 \mathrm{H}, \mathrm{H}^{\mathrm{m}}-\mathrm{Ph}\right), 6.75\left(\mathrm{t},{ }^{3} J_{\mathrm{HH}}=7 \mathrm{~Hz}, 2 \mathrm{H}\right.$, $\mathrm{H}^{\mathrm{p}}-\mathrm{Ph} .{ }^{13} \mathrm{C}$ NMR $\left(75 \mathrm{MHz}, \mathrm{DMSO}-d_{6}\right) \delta 189.4,162.8,154.9,146.6,136.1,131.6,129.2$, 127.2, 125.2, 123.0. Anal. calcd. for $\mathrm{PtN}_{2} \mathrm{OC}_{23} \mathrm{H}_{16}$ (\%): C 51.97, H 3.04, N 5.27; found: $\mathrm{C}$ 51.94, H 3.03, N 5.26.

(map)PtPh 2 . The ligand was 2-(methylamine)-pyridine. Isolated $0.19 \mathrm{~g}(86 \%) .{ }^{1} \mathrm{H}$ $\operatorname{NMR}\left(300 \mathrm{MHz}\right.$, acetone- $\left.d_{6}\right) \delta 8.16\left(\mathrm{~d},{ }^{3} J_{\mathrm{HH}}=6 \mathrm{~Hz}, 1 \mathrm{H}, 2-\mathrm{py}\right), 7.99\left(\mathrm{td},{ }^{3} J_{\mathrm{HH}}=8,{ }^{4} J_{\mathrm{HH}}=\right.$ $1 \mathrm{~Hz}, 1 \mathrm{H}, 4-\mathrm{py}), 7.59$ (d, $\left.{ }^{3} J_{\mathrm{HH}}=8 \mathrm{~Hz}, 1 \mathrm{H}, 3-\mathrm{py}\right), 7.38\left(\mathrm{~d},{ }^{3} J_{\mathrm{HH}}=7 \mathrm{~Hz}, 1 \mathrm{H}, \mathrm{H}^{\mathrm{o}}-\mathrm{Ph}\right), 7.19$ (m, 3H, 5-py and $\left.\mathrm{H}^{\mathrm{o}}-\mathrm{Ph}\right), 6.82\left(\mathrm{t},{ }^{3} J_{\mathrm{HH}}=7 \mathrm{~Hz}, 2 \mathrm{H}, \mathrm{H}^{\mathrm{m}}-\mathrm{Ph}\right), 6.68\left(\mathrm{~m}, 4 \mathrm{H}, \mathrm{H}^{\mathrm{m}}-\mathrm{Ph}\right.$ and $\mathrm{H}^{\mathrm{p}}-$ $\mathrm{Ph}), 4.52\left(\mathrm{t},{ }^{3} \mathrm{~J}_{\mathrm{HH}}=6 \mathrm{~Hz}, 2 \mathrm{H}, \mathrm{CH}_{2}\right), 4.35\left(\mathrm{br} \mathrm{s}, 2 \mathrm{H}, \mathrm{NH}_{2}\right) .{ }^{13} \mathrm{C}$ NMR $\left(75 \mathrm{MHz}\right.$, acetone- $\left.d_{6}\right)$ $\delta 192.5,149.4,139.7,139.5,137.8,127.2,126.5,124.5,122.6,121.6,121.3,51.1$. Remaining 2 resonances obscured due to broadening or coincidental overlap. Anal. calcd. for $\mathrm{PtN}_{2} \mathrm{C}_{18} \mathrm{H}_{18}$ (\%): C 47.26, H 3.97, N 6.13; found: C 47.45, H 4.08, N 6.03.

(bozo)PtPh ${ }_{2}$. The ligand was 2,2'-bisoxazoline. Isolated $0.19 \mathrm{~g}$ (79\%). ${ }^{1} \mathrm{H}$ NMR (500 $\left.\mathrm{MHz}, \mathrm{CD}_{2} \mathrm{Cl}_{2}\right) \delta 7.24\left(\mathrm{~d},{ }^{3} J_{\mathrm{HH}}=8 \mathrm{~Hz}, 4 \mathrm{H}, \mathrm{H}^{\mathrm{o}}-\mathrm{Ph}\right), 6.89\left(\mathrm{t},{ }^{3} J_{\mathrm{HH}}=7 \mathrm{~Hz}, 4 \mathrm{H}, \mathrm{H}^{\mathrm{m}}-\mathrm{Ph}\right), 6.80$ 
$\left(\mathrm{t},{ }^{3} J_{\mathrm{HH}}=7 \mathrm{~Hz}, 2 \mathrm{H}, \mathrm{H}^{\mathrm{p}}-\mathrm{Ph}\right), 4.81\left(\mathrm{t},{ }^{3} J_{\mathrm{HH}}=10 \mathrm{~Hz}, 4 \mathrm{H}, \mathrm{BOZ}\right), 3.98\left(\mathrm{t},{ }^{3} J_{\mathrm{HH}}=10 \mathrm{~Hz}, 4 \mathrm{H}\right.$, BOZ). ${ }^{13} \mathrm{C}$ NMR (125 MHz, $\left.\mathrm{CD}_{2} \mathrm{Cl}_{2}\right) \delta 162.5,139.6,138.9,127.0,122.5,74.1,52.3$. Anal. calcd. for $\mathrm{PtN}_{2} \mathrm{O}_{2} \mathrm{C}_{18} \mathrm{H}_{18}$ (\%): C 44.17, H 3.71, N 5.72; found: C 44.45, H 3.75, N 5.59 .

(tripy)PtPh ${ }_{2}$. The ligand was 2-(2-pyridyl)-4-(phenyl)triazole. Isolated $0.13 \mathrm{~g}(87 \%)$. ${ }^{1} \mathrm{H}$ NMR (300 MHz, $\left.\mathrm{CD}_{2} \mathrm{Cl}_{2}\right) \delta 8.73$ (s, 1H, 5-Triazole), $8.45\left(\mathrm{~d},{ }^{3} \mathrm{~J}_{\mathrm{HH}}=6 \mathrm{~Hz}, 1 \mathrm{H}, 6-\mathrm{Py}\right)$, $8.28\left(\mathrm{td},{ }^{3} J_{\mathrm{HH}}=8 \mathrm{~Hz},{ }^{3} J_{\mathrm{HH}}=2 \mathrm{~Hz}, 1 \mathrm{H}, 4-\mathrm{Py}\right), 7.94\left(\mathrm{dd},{ }^{3} J_{\mathrm{HH}}=8 \mathrm{~Hz},{ }^{3} J_{\mathrm{HH}}=2 \mathrm{~Hz}, 1 \mathrm{H}, 3-\right.$ Py), $7.80\left(\mathrm{~d},{ }^{3} \mathrm{~J}_{\mathrm{HH}}=8 \mathrm{~Hz}, 1 \mathrm{H}, 3-\mathrm{Py}\right), 7.51(\mathrm{~m}, 8 \mathrm{H}, \mathrm{Ph}), 7.03$ (m, 7H, Ph). The complex was too insoluble in organic solvents to obtain ${ }^{13} \mathrm{C}$ NMR data. Anal. calcd. for $\mathrm{PtN}_{4} \mathrm{C}_{25} \mathrm{H}_{20}$ (\%): C 52.53, H 3.53, N 9.80; found: C 52.91, H 3.71, N 9.59.

(Mp')PtPh 2 (4.10). The ligand was tris(3,5-dimethyl-1-pyrazolyl)methane (Mp'). Isolated $0.62 \mathrm{~g}(84 \%) .{ }^{1} \mathrm{H}$ NMR $\left(300 \mathrm{MHz}\right.$, acetone- $\left.d_{6}\right) \delta 8.36\left(\mathrm{~s}, 1 \mathrm{H}, \mathrm{CH}-\mathrm{Mp}{ }^{\prime}\right), 7.34(\mathrm{~d}$, ${ }^{3} J_{\mathrm{HH}}=8 \mathrm{~Hz},{ }^{3} J_{\mathrm{PtH}}=73 \mathrm{~Hz}$ (Pt satellites), 4H, $\left.\mathrm{H}^{\mathrm{o}}-\mathrm{Ph}\right), 6.62\left(\mathrm{t},{ }^{3} J_{\mathrm{HH}}=8 \mathrm{~Hz}, 4 \mathrm{H}, \mathrm{H}^{\mathrm{m}}-\mathrm{Ph}\right)$, $6.50\left(\mathrm{t},{ }^{3} \mathrm{~J}_{\mathrm{HH}}=8 \mathrm{~Hz}, 2 \mathrm{H}, \mathrm{H}^{\mathrm{p}}-\mathrm{Ph}\right), 6.13\left(\mathrm{~s}, 1 \mathrm{H}, \mathrm{Mp}\right.$ ) $, 6.08\left(\mathrm{~s}, 2 \mathrm{H}, \mathrm{Mp}^{\prime}\right), 2.64\left(\mathrm{~s}, 6 \mathrm{H}, \mathrm{CH}_{3}-\right.$ $\left.\mathrm{Mp}^{\prime}\right), 2.19$ (s, 3H, $\left.\mathrm{CH}_{3}-\mathrm{Mp}^{\prime}\right), 1.72$ (s, 3H, $\left.\mathrm{CH}_{3}-\mathrm{Mp}^{\prime}\right), 1.66$ (s, 6H, $\left.\mathrm{CH}_{3}-\mathrm{Mp}^{\prime}\right) .{ }^{13} \mathrm{C} \mathrm{NMR}$ $\left(125 \mathrm{MHz}, \mathrm{CD}_{2} \mathrm{Cl}_{2}\right) \delta 154.0,148.7,143.5,142.4,141.1,139.6,125.9,120.9,110.2$, 109.0, 76.0, 14.5, 13.9, 11.5, 11.2. Anal. calcd. for $\mathrm{PtN}_{6} \mathrm{C}_{28} \mathrm{H}_{32}$ (\%): C 51.92, H 4.99, N 12.98; found: C 51.73, H 5.05, N 12.71.

(diq)PtPh 2 (4.17). The ligand was 8-(diisopropylphosphino)quinoline. Isolated $0.13 \mathrm{~g}$ (85\%). ${ }^{1} \mathrm{H}$ NMR (600 MHz, $\left.\mathrm{CD}_{2} \mathrm{Cl}_{2}\right) \delta 8.97\left(\mathrm{dd},{ }^{3} J_{\mathrm{HH}}=5 \mathrm{~Hz},{ }^{4} J_{\mathrm{HH}}=2 \mathrm{~Hz}, 1 \mathrm{H}, \mathrm{diq}\right), 8.46$ $\left(\mathrm{d},{ }^{3} J_{\mathrm{HH}}=8 \mathrm{~Hz}, 1 \mathrm{H}, \mathrm{diq}\right), 8.06\left(\mathrm{td},{ }^{3} J_{\mathrm{HH}}=7 \mathrm{~Hz},{ }^{3} J_{\mathrm{HH}}=1 \mathrm{~Hz}, 1 \mathrm{H}, \mathrm{diq}\right), 8.03\left(\mathrm{~d},{ }^{3} J_{\mathrm{HH}}=8\right.$ $\mathrm{Hz}, 2 \mathrm{H}, \mathrm{H}^{\mathrm{o}}-\mathrm{Ph}$ ), 7.74 (t, $\left.{ }^{3} J_{\mathrm{HH}}=8 \mathrm{~Hz}, 1 \mathrm{H}, \mathrm{diq}\right), 7.54$ (t, $\left.{ }^{3} J_{\mathrm{HH}}=8 \mathrm{~Hz}, 1 \mathrm{H}, \mathrm{diq}\right), 7.48$ (d, $\left.{ }^{3} J_{\mathrm{HH}}=8 \mathrm{~Hz}, 2 \mathrm{H}, \mathrm{H}^{\mathrm{o}}-\mathrm{Ph}\right), 7.32\left(\mathrm{dd},{ }^{3} J_{\mathrm{HH}}=8 \mathrm{~Hz},{ }^{3} J_{\mathrm{HH}}=5 \mathrm{~Hz}, 1 \mathrm{H}, \mathrm{diq}\right), 7.09\left(\mathrm{~m}, 2 \mathrm{H}, \mathrm{H}^{\mathrm{m}}-\right.$ 
$\mathrm{Ph}), 6.88\left(\mathrm{~m}, 3 \mathrm{H}, \mathrm{H}^{\mathrm{m}}\right.$ and $\left.\mathrm{H}^{\mathrm{p}}-\mathrm{Ph}\right), 6.70\left(\mathrm{~m}, 1 \mathrm{H}, \mathrm{H}^{\mathrm{p}}-\mathrm{Ph}\right), 2.66\left(\mathrm{~m}, 2 \mathrm{H}, \mathrm{CH}-{ }^{\mathrm{i}} \mathrm{Pr}\right), 1.18(\mathrm{~d}$, $\left.{ }^{3} J_{\mathrm{HH}}=7 \mathrm{~Hz}, 3 \mathrm{H}, \mathrm{Me}-{ }^{\mathrm{i}} \mathrm{Pr}\right), 1.16\left(\mathrm{~d},{ }^{3} J_{\mathrm{HH}}=7 \mathrm{~Hz}, 3 \mathrm{H}, \mathrm{Me}-{ }^{\mathrm{i}} \mathrm{Pr}\right), 0.96\left(\mathrm{~d},{ }^{3} J_{\mathrm{HH}}=7 \mathrm{~Hz}, 3 \mathrm{H}\right.$, Me- $\left.{ }^{\mathrm{i}} \mathrm{Pr}\right), 0.93\left(\mathrm{~d},{ }^{3} J_{\mathrm{HH}}=7 \mathrm{~Hz}, 3 \mathrm{H}, \mathrm{Me}-{ }^{\mathrm{i}} \mathrm{Pr}\right) .{ }^{31} \mathrm{P} \mathrm{NMR}\left(121 \mathrm{MHz}, \mathrm{CD}_{2} \mathrm{Cl}_{2}\right) \delta 41.58\left(\mathrm{~s},{ }^{1} J_{\mathrm{PtP}}\right.$ $=1937 \mathrm{~Hz}$, Pt satellites). Anal. calcd. for $\mathrm{PtPNC}_{27} \mathrm{H}_{30}$ (\%): C 54.53, H 5.09, N 2.36; found: C 54.38, H 5.26, N 2.30.

(bppe)PtPh . The ligand was 1,2-(bis-N-pyrrolylphosphino)ethane. Isolated $0.17 \mathrm{~g}$ (72\%). ${ }^{1} \mathrm{H}$ NMR $\left(800 \mathrm{MHz}\right.$, acetone- $\left.d_{6}\right) \delta 7.31\left(\mathrm{~m}, 4 \mathrm{H}, \mathrm{H}^{\mathrm{o}}-\mathrm{Ph}\right), 7.01(\mathrm{~m}, 8 \mathrm{H}, \alpha-\mathrm{N}-$ pyrrole), $6.90\left(\mathrm{t},{ }^{3} J_{\mathrm{HH}}=8 \mathrm{~Hz}, 4 \mathrm{H}, \mathrm{H}^{\mathrm{m}}-\mathrm{Ph}\right), 6.75\left(\mathrm{tt},{ }^{3} J_{\mathrm{HH}}=8 \mathrm{~Hz},{ }^{4} J_{\mathrm{HH}}=1 \mathrm{~Hz}, 2 \mathrm{H}, \mathrm{H}^{\mathrm{p}}-\mathrm{Ph}\right)$, $6.30\left(\mathrm{~m}, 8 \mathrm{H}, \beta\right.$-N-pyrrole), $2.80\left(\mathrm{~d},{ }^{2} J_{\mathrm{HH}}=22 \mathrm{~Hz}, 4 \mathrm{H}, \mathrm{CH}_{2}\right.$-bppe). ${ }^{31} \mathrm{P} \mathrm{NMR}(121 \mathrm{MHz}$, acetone- $\left.d_{6}\right) \delta 108.37\left({ }^{1} J_{\mathrm{PtP}}=2123 \mathrm{~Hz}\right.$, Pt satellites). Anal. calcd. for $\mathrm{PtN}_{4} \mathrm{P}_{2} \mathrm{C}_{30} \mathrm{H}_{30}(\%): \mathrm{C}$ 51.20, H 4.31, N 7.96; found: C 51.35, H 4.58, N 7.57.

(dats) $\mathrm{PtPh}_{2} \quad$ (4.19). The ligand $\quad$ (3\{bis[(diphenylphosphino)methyl]amino\}propyl)triethoxysilane (dats). The solution was reduced to approximately $5 \mathrm{~mL}$ under reduced pressure. Hexanes $(\sim 15 \mathrm{~mL})$ were added. The complex was isolated after recrystallization by slow evaporation. Isolated $0.82 \mathrm{~g}$ (45\%). ${ }^{1} \mathrm{H}$ NMR (500 MHz, $\left.\mathrm{CD}_{2} \mathrm{Cl}_{2}\right) \delta 7.51$ (m, 8H, $\mathrm{H}^{\mathrm{o}}$-dats), 7.38 (m, 4H, $\mathrm{H}^{\mathrm{p}}$-dats), 7.31 $\left(\mathrm{m}, 8 \mathrm{H}, \mathrm{H}^{\mathrm{m}}\right.$-dats), $6.96\left(\mathrm{~m},{ }^{3} J_{\mathrm{PtH}}=59 \mathrm{~Hz}\right.$ Pt satellites, $\left.4 \mathrm{H}, \mathrm{H}^{\mathrm{o}}-\mathrm{Ph}\right), 6.55\left(\mathrm{t},{ }^{3} J_{\mathrm{HH}}=7 \mathrm{~Hz}\right.$, $\left.4 \mathrm{H}, \mathrm{H}^{\mathrm{m}}-\mathrm{Ph}\right), 6.45\left(\mathrm{t},{ }^{3} J_{\mathrm{HH}}=7 \mathrm{~Hz}, 2 \mathrm{H}, \mathrm{H}^{\mathrm{p}}-\mathrm{Ph}\right), 3.70\left(\mathrm{q},{ }^{3} J_{\mathrm{HH}}=7 \mathrm{~Hz}, 6 \mathrm{H}, \mathrm{OCH}_{2} \mathrm{CH}_{3}\right), 3.52$ $\left(\mathrm{s},{ }^{3} J_{\mathrm{PtH}}=14 \mathrm{~Hz}\right.$ Pt satellites, $4 \mathrm{H}, \mathrm{CH}_{2}$-dats), $2.41\left(\mathrm{t},{ }^{3} \mathrm{~J}_{\mathrm{HH}}=7 \mathrm{~Hz}, 2 \mathrm{H}, \mathrm{NCH}_{2} \mathrm{CH}_{2} \mathrm{CH}_{2} \mathrm{Si}\right.$ ), 1.24 (quintet, ${ }^{3} J_{\mathrm{HH}}=8 \mathrm{~Hz}, 2 \mathrm{H}, \mathrm{NCH}_{2} \mathrm{CH}_{2} \mathrm{CH}_{2} \mathrm{Si}$ ), $1.14\left(\mathrm{t},{ }^{3} J_{\mathrm{HH}}=7 \mathrm{~Hz}, 9 \mathrm{H}, \mathrm{OCH}_{2} \mathrm{CH}_{3}\right.$ ), $0.20\left(\mathrm{~m}, 2 \mathrm{H}, \mathrm{NCH}_{2} \mathrm{CH}_{2} \mathrm{CH}_{2} \mathrm{Si}\right) .{ }^{31} \mathrm{P} \mathrm{NMR}\left(121 \mathrm{MHz}, \mathrm{CD}_{2} \mathrm{Cl}_{2}\right) \delta-4.86\left(\mathrm{~s},{ }^{1} J_{\mathrm{PtP}}=1700 \mathrm{~Hz}\right.$ Pt satellites). Anal. calcd. for $\mathrm{PtNSiO}_{3} \mathrm{P}_{2} \mathrm{C}_{47} \mathrm{H}_{55}$ (\%): C 58.36, H 5.74, N 1.45; found: C 58.42, H 5.61, N 1.55. 


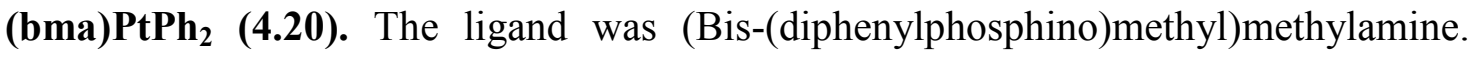
Isolated $0.62 \mathrm{~g}(91 \%) .{ }^{1} \mathrm{H}$ NMR $\left(500 \mathrm{MHz}\right.$, acetone- $\left.d_{6}\right) \delta 7.57(\mathrm{~m}, 8 \mathrm{H}, \mathrm{bma}), 7.36(\mathrm{~m}$, 12H, bma), 6.97 (m, 4H, H $\left.\mathrm{H}^{\mathrm{o}}-\mathrm{Ph}\right), 6.44\left(\mathrm{t},{ }^{3} J_{\mathrm{HH}}=7 \mathrm{~Hz}, 4 \mathrm{H}, \mathrm{H}^{\mathrm{m}}-\mathrm{Ph}\right), 6.31\left(\mathrm{t},{ }^{3} J_{\mathrm{HH}}=7 \mathrm{~Hz}\right.$, $\left.2 \mathrm{H}, \mathrm{H}^{\mathrm{p}}-\mathrm{Ph}\right), 3.59$ (s, ${ }^{3} \mathrm{~J}_{\mathrm{PtH}}=14 \mathrm{~Hz}$ Pt satellites, $4 \mathrm{H}, \mathrm{CH}_{2}$-bma), 2.32 (s, $\left.3 \mathrm{H}, \mathrm{Me}-\mathrm{N}\right) .{ }^{31} \mathrm{P}$ NMR $\left(121 \mathrm{MHz}\right.$, acetone- $\left.d_{6}\right) \delta-4.94\left(\mathrm{~s},{ }^{1} J_{\mathrm{PtP}}=1693 \mathrm{~Hz}\right.$, Pt satellites). Anal. calcd. for $\mathrm{PtNP}_{2} \mathrm{C}_{39} \mathrm{H}_{37}$ (\%): C 60.30, H 4.81, N 1.80; found: C 60.45, H 4.73, N 1.92.

General procedure for the synthesis of $\left[\left(\mathrm{L}_{2}\right) \operatorname{Pt}(\mathrm{Ph})(\mathrm{THF})\right]\left[\mathrm{BAr}_{4}\right]$ complexes. A solution/suspension of $\left(\mathrm{L}_{2}\right) \mathrm{Pt}(\mathrm{Ph})_{2}$ in THF $(30 \mathrm{~mL})$ was cooled to approximately $-70{ }^{\circ} \mathrm{C}$.

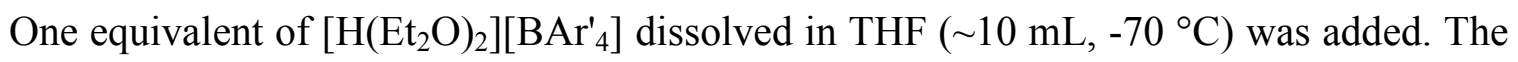
solution was immediately placed under vacuum, and the volitiles were removed. The residue was treated with $n$-pentane $(\sim 2 \mathrm{~mL})$, which was then removed under vacuum to afford a solid. The solid was dried in vacuo.

Spectroscopic data for $\left[\mathrm{BAr}_{4}{ }_{4}\right]$ anion. The resonances for the $\mathrm{BAr}_{4}{ }_{4}$ anion demonstrate negligible difference in chemical shift between the complexes. Therefore, for simplicity the NMR data for the anion is given here. ${ }^{1} \mathrm{H}$ NMR $(300 \mathrm{MHz}) \delta 7.72(\mathrm{~s}$, $\left.8 \mathrm{H}, \mathrm{H}^{\mathrm{o}}-\mathrm{BAr}_{4}{ }_{4}\right), 7.56\left(\mathrm{~s}, 4 \mathrm{H}, \mathrm{H}^{\mathrm{p}}-\mathrm{BAr}_{4}{ }^{\prime}\right) .{ }^{13} \mathrm{C} \mathrm{NMR}(75 \mathrm{MHz}) \delta 162.3$ (q, Ar', ${ }^{1} J_{\text {B-Cipso }}: 49$ $\mathrm{Hz}), 135.4\left(\mathrm{Ar}^{\prime}\right), 129.5$ (q, $\left.m-\mathrm{Ar}^{\prime},{ }^{2} J_{\mathrm{C}-\mathrm{F}}=32 \mathrm{~Hz}\right), 125.2\left(\mathrm{q}, \mathrm{Ar},{ }^{2} J_{\mathrm{C}-\mathrm{F}}=272 \mathrm{~Hz}\right), 118.1$ (Ar'). ${ }^{19}$ F NMR (282 MHz) $\delta-63.1\left(\mathrm{~s}, \mathrm{CF}_{3}-\mathrm{Ar}^{\prime}\right)$.

[(phen)Pt(Ph)(THF)][BAr' $\left.{ }_{4}\right] \quad$ (4.4). Isolated 0.09 g (97\%). ${ }^{1} \mathrm{H}$ NMR (300 MHz, $\left.\mathrm{CD}_{2} \mathrm{Cl}_{2}\right) \delta 8.89\left(\mathrm{~d},{ }^{3} J_{\mathrm{HH}}=5 \mathrm{~Hz}, 1 \mathrm{H}, 2 / 9-\right.$ phen $), 8.79\left(\mathrm{~d},{ }^{3} J_{\mathrm{HH}}=8 \mathrm{~Hz}, 1 \mathrm{H}, 4 / 7-\right.$ phen$), 8.67$ (d, ${ }^{3} J_{\mathrm{HH}}=8 \mathrm{~Hz}, 1 \mathrm{H}, 4 / 7$-phen), $8.60\left(\mathrm{~d},{ }^{3} J_{\mathrm{HH}}=5 \mathrm{~Hz}, 1 \mathrm{H}, 2 / 9\right.$-phen), 8.12 (m, 2H, 3/8phen), $7.68\left(\mathrm{~m}, 16 \mathrm{H}, \mathrm{Ar}\right.$, 5/6-phen and $\left.\mathrm{H}^{\mathrm{o}}-\mathrm{Ph}\right), 7.26\left(\mathrm{t},{ }^{3} J_{\mathrm{HH}}=7 \mathrm{~Hz}, 2 \mathrm{H}, \mathrm{H}^{\mathrm{m}}-\mathrm{Ph}\right), 7.17(\mathrm{t}$, $\left.{ }^{3} J_{\mathrm{HH}}=7 \mathrm{~Hz}, 1 \mathrm{H}, \mathrm{H}^{\mathrm{p}}-\mathrm{Ph}\right), 4.31$ (m, 4H, $\left.\alpha-\mathrm{THF}\right), 1.98$ (m, 4H, $\beta$-THF). ${ }^{13} \mathrm{C}$ NMR $(125$ 
$\left.\mathrm{MHz}, \mathrm{CD}_{2} \mathrm{Cl}_{2}\right) \delta 154.3,147.8,139.9,139.8,137.4,136.6,136.3,131.3,131.1,128.7$, $128.4,128.2,126.7,126.3,125.8,78.3,25.2$. Remaining aromatic resonance obscured due broadening or coincidental overlap. Anal. calcd. for $\mathrm{PtN}_{2} \mathrm{OBF}_{24} \mathrm{C}_{54} \mathrm{H}_{33}$ (\%): C 46.73, H 2.40, N 2.02; found: C 46.37, H 2.40, N 2.10.

[(dfo)Pt(Ph)(THF)][BAr' $\left.{ }_{4}\right]$ (4.5). Isolated $0.11 \mathrm{~g}(91 \%) .{ }^{1} \mathrm{H}$ NMR $\left(300 \mathrm{MHz}, \mathrm{CD}_{2} \mathrm{Cl}_{2}\right)$ $\delta 8.50\left(\mathrm{dd},{ }^{3} J_{\mathrm{HH}}=5 \mathrm{~Hz},{ }^{4} J_{\mathrm{HH}}=1 \mathrm{~Hz}, 1 \mathrm{H}, 3 / 6-\mathrm{dfo}\right), 8.35\left(\mathrm{dd},{ }^{3} J_{\mathrm{HH}}=8 \mathrm{~Hz},{ }^{4} J_{\mathrm{HH}}=1 \mathrm{~Hz}, 1 \mathrm{H}\right.$, $3 / 6$-dfo), $8.25\left(\mathrm{dd},{ }^{3} J_{\mathrm{HH}}=8 \mathrm{~Hz},{ }^{4} J_{\mathrm{HH}}=1 \mathrm{~Hz}, 1 \mathrm{H}, 1 / 8-\mathrm{dfo}\right), 7.85\left(\mathrm{dd},{ }^{3} J_{\mathrm{HH}}=8 \mathrm{~Hz},{ }^{3} J_{\mathrm{HH}}=5\right.$ $\mathrm{Hz}, 1 \mathrm{H}, 2 / 7-\mathrm{dfo}), 7.82\left(\mathrm{~d},{ }^{3} J_{\mathrm{HH}}=5 \mathrm{~Hz}, 1 \mathrm{H}, 1 / 8\right.$-dfo), $7.45\left(\mathrm{dd},{ }^{3} J_{\mathrm{HH}}=8 \mathrm{~Hz},{ }^{3} J_{\mathrm{HH}}=5 \mathrm{~Hz}\right.$, 1H, 2/7-dfo), 7.35 (m, 2H, $\left.\mathrm{H}^{\mathrm{o}}-\mathrm{Ph}\right), 7.12\left(\mathrm{~m}, 3 \mathrm{H}, \mathrm{H}^{\mathrm{m}}\right.$ - and $\left.\mathrm{H}^{\mathrm{p}}-\mathrm{Ph}\right), 4.18$ (m, 4H, $\left.\alpha-\mathrm{THF}\right)$, 1.93 (m, 4H, $\beta$-THF). ${ }^{13} \mathrm{C}$ NMR (125 MHz, $\left.\mathrm{CD}_{2} \mathrm{Cl}_{2}\right) \delta 153.0,152.6,136.7,136.1,135.8$, $135.5,133.1,128.8,128.7,126.4,126.3,125.5,120.9,120.8,78.7,25.2$. Remaining resonance obscured due to broadening or coincidental overalp. Anal. calcd. for $\mathrm{PtN}_{2} \mathrm{O}_{2} \mathrm{BF}_{24} \mathrm{C}_{53} \mathrm{H}_{31}(\%)$ : C 45.80, H 2.25, N 2.02; found: C 45.53, H 2.21, N 2.15.

$\left.[(\mathbf{m a p}) \operatorname{Pt}(\mathbf{P h})(\mathbf{T H F})]\left[\mathrm{BAr}^{\prime}\right]\right]$ (4.6). Isolated $0.06 \mathrm{~g}(81 \%)$. Mixture of two isomers likely as a result of the THF ligand being trans to the pyridyl or amine moieties. ${ }^{1} \mathrm{H}$ NMR data provided for the dominant isomer. ${ }^{1} \mathrm{H}$ NMR $\left(500 \mathrm{MHz}, \mathrm{CD}_{2} \mathrm{Cl}_{2}\right) \delta 8.31\left(\mathrm{~d},{ }^{3} J_{\mathrm{HH}}=6\right.$ $\mathrm{Hz}, 1 \mathrm{H}, \mathrm{py}), 8.04\left(\mathrm{td},{ }^{3} J_{\mathrm{HH}}=8 \mathrm{~Hz},{ }^{4} J_{\mathrm{HH}}=2 \mathrm{~Hz}, 1 \mathrm{H}, \mathrm{py}\right), 7.81\left(\mathrm{~d},{ }^{3} J_{\mathrm{HH}}=8 \mathrm{~Hz}, 1 \mathrm{H}, \mathrm{py}\right)$, $7.22\left(\mathrm{~d},{ }^{3} J_{\mathrm{HH}}=8 \mathrm{~Hz}, 2 \mathrm{H}, \mathrm{H}^{\mathrm{o}}-\mathrm{Ph}\right), 7.09\left(\mathrm{t},{ }^{3} J_{\mathrm{HH}}=8 \mathrm{~Hz}, 2 \mathrm{H}, \mathrm{H}^{\mathrm{m}}-\mathrm{Ph}\right), 6.98\left(\mathrm{t},{ }^{3} J_{\mathrm{HH}}=7 \mathrm{~Hz}\right.$, $\left.1 \mathrm{H}, \mathrm{H}^{\mathrm{p}}-\mathrm{Ph}\right), 4.41\left(\mathrm{~s}, 2 \mathrm{H}, \mathrm{NH}_{2}\right), 4.10(\mathrm{~m}, 4 \mathrm{H}, \alpha-\mathrm{THF}), 3.91\left(\mathrm{t},{ }^{3} J_{\mathrm{HH}}=6 \mathrm{~Hz}, 2 \mathrm{H}, \mathrm{CH}_{2}\right), 1.89$ (m, 4H, $\beta-\mathrm{THF}$ ). Remaining resonance obscured due to overlap with $\mathrm{H}^{\mathrm{p}}-\mathrm{Ar}^{\prime}$ resonance. Anal. calcd. for $\mathrm{PtN}_{2} \mathrm{OBF}_{24} \mathrm{C}_{64} \mathrm{H}_{53}$ (\%): C 43.82, H 2.53, N 2.13; found: C 43.67, H 2.71, N 2.24. 
[(tripy)Pt(Ph)(THF)][BAr' $\left.{ }_{4}\right]$ (4.7). Isolated $0.13 \mathrm{~g}(97 \%) .{ }^{1} \mathrm{H}$ NMR data is convoluted due to overlapping resonances, likely a result of two constitutional isomers in solution in which the THF ligand is trans to the pyridyl ring or 4-phenyltriazole moieties, respectively. Anal. calcd. for $\mathrm{PtN}_{2} \mathrm{OBF}_{24} \mathrm{C}_{54} \mathrm{H}_{33}$ (\%): C 46.04 H 2.46, N 3.91; found: $\mathrm{C}$ 45.79, H 2.22, N 4.00.

[(MesIm)Pt(Ph)(THF)][BAr' $\left.{ }_{4}\right]$ (4.8). Isolated 0.13 g (98\%). ${ }^{1} \mathrm{H}$ NMR (500 MHz, $\left.\mathrm{CD}_{2} \mathrm{Cl}_{2}\right) \delta 6.97$ (s, 2H, $\mathrm{H}^{\mathrm{m}}$-Mes), 6.60 (m, 7H, $\mathrm{H}^{\mathrm{m}}$-Mes and $\mathrm{Ph}$ ), 3.31 (m, 4H, $\alpha-\mathrm{THF}$ ), 2.23 (s, 9H, 2,6-( $\left.\mathrm{CH}_{3}\right)_{2}$-Mes and Me-Imine) 2.04 (s, 3H, Me-Imine), 2.03 (s, 6H, 2,6$\left(\mathrm{CH}_{3}\right)_{2}$-Mes), 1.95 (s, 3H, 4-CH $\mathrm{CH}_{3}$-Mes), 1.77 (s, 3H, 4-CH $\left.\mathrm{CH}_{3}-\mathrm{Mes}\right), 1.26$ (m, 4H, $\beta$-THF). ${ }^{13} \mathrm{C}$ NMR $\left(126 \mathrm{MHz}, \mathrm{CD}_{2} \mathrm{Cl}_{2}\right) \delta 181.1,174.9,142.5,140.7,139.3,139.1,134.5,130.2$, 130.1, 129.6, 128.5, 128.4, 127.1, 124.9, (Mes-Imine and Ph aromatic) 76.4 ( $\alpha$-THF), 24.6, 21.1, 20.9, 20.4, 19.4, 17.9, 17.8 (Mes and Imine $\mathrm{CH}_{3}$ and $\beta$-THF). Anal. calcd. for $\mathrm{PtN}_{2} \mathrm{OBF}_{24} \mathrm{C}_{64} \mathrm{H}_{53}(\%)$ : C 50.30, H 3.50, N 1.83; found: C 50.45, H 3.57, N 1.98.

[(bozo)Pt(Ph)(THF)][BAr' 4 ] (4.9). Isolated $0.08 \mathrm{~g}(83 \%)$ in approximately $90 \%$ purity by ${ }^{1} \mathrm{H}$ NMR spectroscopy. ${ }^{1} \mathrm{H}$ NMR $\left(500 \mathrm{MHz}, \mathrm{CD}_{2} \mathrm{Cl}_{2}\right) \delta 7.23\left(\mathrm{~d},{ }^{3} \mathrm{~J}_{\mathrm{HH}}=8 \mathrm{~Hz}, 2 \mathrm{H}, \mathrm{H}^{\circ}-\right.$ $\mathrm{Ph}), 7.06\left(\mathrm{t},{ }^{3} J_{\mathrm{HH}}=8 \mathrm{~Hz}, 2 \mathrm{H}, \mathrm{H}^{\mathrm{m}}-\mathrm{Ph}\right), 6.98\left(\mathrm{t},{ }^{3} J_{\mathrm{HH}}=7 \mathrm{~Hz}, 1 \mathrm{H}, \mathrm{H}^{\mathrm{p}}-\mathrm{Ph}\right), 5.03\left(\mathrm{t},{ }^{3} J_{\mathrm{HH}}=10\right.$ $\mathrm{Hz}, 2 \mathrm{H}$, bozo), $4.91\left(\mathrm{t},{ }^{3} J_{\mathrm{HH}}=10 \mathrm{~Hz}, 2 \mathrm{H}\right.$, bozo), $4.13\left(\mathrm{t},{ }^{3} J_{\mathrm{HH}}=10 \mathrm{~Hz}, 2 \mathrm{H}\right.$, bozo), 3.96 (m, 4H, $\alpha$-THF), $3.62\left(\mathrm{t},{ }^{3} J_{\mathrm{HH}}=10 \mathrm{~Hz}, 2 \mathrm{H}\right.$, bozo), 1.86 (m, 4H, $\beta$-THF).

$\left[(\mathbf{M p}) \mathbf{P t}(\mathbf{H})(\mathbf{P h})_{2}\right]\left[\mathbf{B A r}_{4}\right]$ (4.11). Isolated $0.05 \mathrm{~g}(98 \%) .{ }^{1} \mathrm{H}$ NMR $\left(300 \mathrm{MHz}, \mathrm{CD}_{2} \mathrm{Cl}_{2}\right)$ $\delta 7.96$ (s, 1H, CH-Mp'), 7.31 (br m, 4H, $\left.\mathrm{H}^{\mathrm{o}}-\mathrm{Ph}\right), 7.04\left(\mathrm{~m}, 6 \mathrm{H}, \mathrm{H}^{\mathrm{m}}-\right.$ and $\left.\mathrm{H}^{\mathrm{p}}-\mathrm{Ph}\right), 6.30$ (s, 1H, Mp'), 6.07 (s, 2H, Mp'), 2.66 (s, 3H, Me-Mp'), 2.56 (s, 6H, Me-Mp'), 1.71 (s, 3H, Me-Mp'), 1.57 (s, 6H, Me-Mp'), -19.54 (s, $\left.{ }^{1} J_{\mathrm{PtH}}=1493 \mathrm{~Hz}, 1 \mathrm{H}, \mathrm{Pt}-\mathrm{H}\right) .{ }^{13} \mathrm{C}$ NMR (151 
$\left.\mathrm{MHz}, \mathrm{CD}_{2} \mathrm{Cl}_{2}\right) \delta 155.9,155.5,141.8,141.7,137.6,128.6,125.8,120.1,110.8,110.0$ (Mp' and $\mathrm{Ph}$ aromatic), $70.3\left(\mathrm{CH}-\mathrm{Mp}^{\prime}\right), 15.2,14.1,11.4\left(\mathrm{CH}_{3}-\mathrm{Mp}^{\prime}\right)$. Remaining resonance obscured due to coincidental overlap. Anal. calcd. for $\mathrm{PtN}_{6} \mathrm{BF}_{24} \mathrm{C}_{60} \mathrm{H}_{45}$ (\%): C 47.66, $\mathrm{H}$ 3.01, N 5.56; found: C 47.84, H 3.02, N 5.40.

[(9S3)Pt(Ph)(NCMe)][BAr' $\left.{ }_{4}\right]$ (4.13). Isolated $0.09 \mathrm{~g}(88 \%) .{ }^{1} \mathrm{H}$ NMR $(500 \mathrm{MHz}$, $\left.\mathrm{CD}_{2} \mathrm{Cl}_{2}\right) \delta 7.36\left(\mathrm{~m}, 2 \mathrm{H}, \mathrm{H}^{\mathrm{o}}-\mathrm{Ph}\right), 7.12\left(\mathrm{~m}, 3 \mathrm{H}, \mathrm{H}^{\mathrm{m}}\right.$ and $\left.\mathrm{H}^{\mathrm{p}}-\mathrm{Ph}\right), 3.07\left(\mathrm{~m}, 12 \mathrm{H}, \mathrm{CH}_{2}-9 \mathrm{~S} 3\right)$, $2.41\left(\mathrm{~s},{ }^{4} \mathrm{~J}_{\mathrm{PtH}}=12 \mathrm{~Hz}, 3 \mathrm{H}, \mathrm{NCMe}\right)$. Anal. calcd. for $\mathrm{PtNS}_{3} \mathrm{BF}_{24} \mathrm{C}_{46} \mathrm{H}_{32}(\%)$ : C 40.72, H 2.38, N 1.03; found: C 40.83, H 2.57, N 0.44 .

[(diq)Pt(Ph)(THF)][BAr' 4 ] (4.18). Isolated 0.08 g (89\%). ${ }^{1} \mathrm{H}$ NMR $(500 \mathrm{MHz}$, $\left.\mathrm{CD}_{2} \mathrm{Cl}_{2}\right) \delta 8.99$ (s, 1H, diq), $8.63\left(\mathrm{~d},{ }^{3} J_{\mathrm{HH}}=8 \mathrm{~Hz}, 1 \mathrm{H}, \mathrm{diq}\right), 8.19\left(\mathrm{~d},{ }^{3} J_{\mathrm{HH}}=8 \mathrm{~Hz}, 1 \mathrm{H}, \mathrm{diq}\right)$, $8.08\left(\mathrm{t},{ }^{3} J_{\mathrm{HH}}=8 \mathrm{~Hz}, 1 \mathrm{H}, \mathrm{diq}\right), 7.83\left(\mathrm{t},{ }^{3} J_{\mathrm{HH}}=8 \mathrm{~Hz}, 1 \mathrm{H}, \mathrm{diq}\right), 7.42\left(\mathrm{~d},{ }^{3} J_{\mathrm{HH}}=7 \mathrm{~Hz}, 2 \mathrm{H}, \mathrm{H}^{\mathrm{o}}-\right.$ $\mathrm{Ph}), 7.13\left(\mathrm{~d},{ }^{3} J_{\mathrm{HH}}=7 \mathrm{~Hz}, 2 \mathrm{H}, \mathrm{H}^{\mathrm{m}}-\mathrm{Ph}\right), 7.08\left(\mathrm{t},{ }^{3} J_{\mathrm{HH}}=7 \mathrm{~Hz}, 1 \mathrm{H}, \mathrm{H}^{\mathrm{p}}-\mathrm{Ph}\right), 4.11$ (br s, 4H, $\alpha-$ THF), 2.68 (m, 2H, CH- ${ }^{\mathrm{i}} \mathrm{Pr}$ ), 1.88 (br s, $\left.4 \mathrm{H}, \beta-\mathrm{THF}\right), 1.20\left(\mathrm{~d},{ }^{3} J_{\mathrm{HH}}=7 \mathrm{~Hz}, 3 \mathrm{H}, \mathrm{Me}-{ }^{\mathrm{i}} \mathrm{Pr}\right.$ ), $1.17\left(\mathrm{~d},{ }^{3} J_{\mathrm{HH}}=7 \mathrm{~Hz}, 3 \mathrm{H}, \mathrm{Me}-{ }^{\mathrm{i}} \mathrm{Pr}\right), 0.96\left(\mathrm{~d},{ }^{3} J_{\mathrm{HH}}=7 \mathrm{~Hz}, 3 \mathrm{H}, \mathrm{Me}-{ }^{\mathrm{i}} \mathrm{Pr}\right), 0.92\left(\mathrm{~d},{ }^{3} J_{\mathrm{HH}}=7\right.$ $\left.\mathrm{Hz}, 3 \mathrm{H}, \mathrm{Me}-{ }^{\mathrm{i}} \mathrm{Pr}\right) .{ }^{31} \mathrm{P} \mathrm{NMR}\left(121 \mathrm{MHz}, \mathrm{CD}_{2} \mathrm{Cl}_{2}\right) \delta 38.33$ (s, ${ }^{1} J_{\mathrm{PtP}}=4851 \mathrm{~Hz}$, Pt satellites). Anal. calcd. for PtNPOBF${ }_{24} \mathrm{C}_{57} \mathrm{H}_{45}$ (\%): C 47.12, H 3.13, N 0.96; found: C 47.32, H 3.10, N 1.08 .

General procedure for the synthesis of $[(\mathrm{P} \sim \mathrm{P}) \mathrm{Pt}(\mathrm{NCMe})(\mathrm{Ph})]\left[\mathrm{BAr}_{4}{ }_{4}\right]$ complexes. A solution/suspension of $(\mathrm{P} \sim \mathrm{P}) \mathrm{Pt}(\mathrm{Ph})_{2}$ in THF $(30 \mathrm{~mL})$ was cooled to approximately -70 ${ }^{\circ} \mathrm{C}$. One equivalent of $\left[\mathrm{H}\left(\mathrm{Et}_{2} \mathrm{O}\right)_{2}\right]\left[\mathrm{BAr}_{4}\right]$ dissolved in THF $\left(\sim 10 \mathrm{~mL},-70{ }^{\circ} \mathrm{C}\right)$ was added. The solution was allowed to stir for approximately 1 minute. Acetonitrile $(\sim 2 \mathrm{~mL})$ was added. The solution was immediately placed under vacuum, and the volatiles removed. 
The residue was treated with $n$-pentane $(\sim 2 \mathrm{~mL})$, which was then removed under vacuum to afford a solid. The solid was dried in vacuo.

[(dmpe)Pt(NCMe)(Ph)][BAr' $\left.{ }_{4}\right]$ (4.14a). Isolated $0.13 \mathrm{~g}(93 \%) .{ }^{1} \mathrm{H}$ NMR $(300 \mathrm{MHz}$, $\left.\mathrm{cd}_{2} \mathrm{cl}_{2}\right) \delta 7.30\left(\mathrm{~m}, 2 \mathrm{H}, \mathrm{H}^{\mathrm{o}}-\mathrm{Ph}\right), 7.17\left(\mathrm{t},{ }^{3} J_{\mathrm{HH}}=7 \mathrm{~Hz}, 2 \mathrm{H}, \mathrm{H}^{\mathrm{m}}-\mathrm{Ph}\right), 7.01\left(\mathrm{t},{ }^{3} J_{\mathrm{HH}}=7 \mathrm{~Hz}, 1 \mathrm{H}\right.$, $\left.\mathrm{H}^{\mathrm{p}}-\mathrm{Ph}\right), 2.31(\mathrm{~s}, 3 \mathrm{H}, \mathrm{NCMe}), 1.86\left(\mathrm{~m}, 4 \mathrm{H}, \mathrm{PCH}_{2} \mathrm{CH}_{2} \mathrm{P}\right), 1.63\left(\mathrm{~d},{ }^{2} J_{\mathrm{PH}}=10 \mathrm{~Hz}, \mathrm{Pt}\right.$ satellites overlap with resonance, $6 \mathrm{H}, \mathrm{Me}-\mathrm{dmpe}), 1.42\left(\mathrm{~d},{ }^{2} J_{\mathrm{PH}}=12 \mathrm{~Hz},{ }^{3} J_{\mathrm{HH}}=52 \mathrm{~Hz} \mathrm{Pt}\right.$ satellites, 6H, Me-DMPE). ${ }^{31} \mathrm{P}$ NMR (121 MHz, $\left.\mathrm{CD}_{2} \mathrm{Cl}_{2}\right) \delta 29.99\left(\mathrm{~s},{ }^{1} J_{\mathrm{PtH}}=1667 \mathrm{~Hz}, \mathrm{Pt}\right.$ satellites), $15.29\left(\mathrm{~s},{ }^{1} J_{\mathrm{PtH}}=4076 \mathrm{~Hz}\right.$, Pt satellites). Anal. calcd. for $\mathrm{PtP}_{2} \mathrm{NBF}_{24} \mathrm{C}_{46} \mathrm{H}_{36}(\%)$ : C 41.64, H 2.74, N 1.06; found: C 41.86, H 2.65, N 0.97.

[(dppe)Pt(NCMe)(Ph)][BAr' $\left.{ }_{4}\right]$ (4.14b). Isolated 0.13 g (97\%). ${ }^{1} \mathrm{H}$ NMR $(300 \mathrm{MHz}$, $\left.\mathrm{CD}_{2} \mathrm{Cl}_{2}\right) \delta 7.57\left(\mathrm{~m}, 32 \mathrm{H}, \mathrm{Ar}^{\prime}\right.$ and dppe), $6.90(\mathrm{~m}, 5 \mathrm{H}, \mathrm{Ph}), 2.42\left(\mathrm{~m}, 4 \mathrm{H}, \mathrm{PCH}_{2} \mathrm{CH}_{2} \mathrm{P}\right), 2.12$ (s, 3H, NCMe). ${ }^{31} \mathrm{P}$ NMR (121 MHz, $\left.\mathrm{CD}_{2} \mathrm{Cl}_{2}\right) \delta 47.44\left(\mathrm{~s},{ }^{1} J_{\mathrm{PtP}}=1671 \mathrm{~Hz}\right.$, Pt satellites),

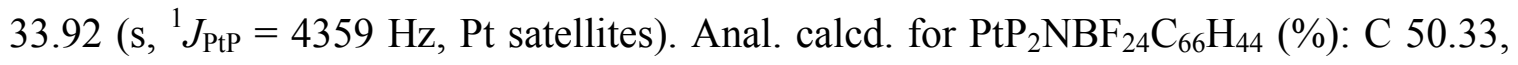
H 2.82, N 0.89; found: C 50.37, H 2.99, N 1.02 .

[(bppe)Pt(NCMe)(Ph)][BAr' $\left.{ }_{4}\right]$ (4.14c). Isolated $0.09 \mathrm{~g}(89 \%) .{ }^{1} \mathrm{H}$ NMR $(300 \mathrm{MHz}$, $\left.\mathrm{CD}_{2} \mathrm{Cl}_{2}\right) \delta 7.08(\mathrm{~m}, 9 \mathrm{H}, \alpha-N$-pyrrole and $\mathrm{Ph}), 6.75(\mathrm{~m}, 4 \mathrm{H}, \alpha-N$-pyrrole $), 6.64(\mathrm{~m}, 4 \mathrm{H}, \beta-$ $N$-pyrrole), 6.48 (m, 4H, $\beta$ - $N$-pyrrole) 2.75 (m, 4H, $\mathrm{CH}_{2} \mathrm{CH}_{2}$-bppe), 2.44 (s, 3H, NCMe). ${ }^{31} \mathrm{P}$ NMR $\left(121 \mathrm{MHz}, \mathrm{CD}_{2} \mathrm{Cl}_{2}\right) \delta 109.56\left(\mathrm{~s},{ }^{1} J_{\mathrm{PtP}}=2539 \mathrm{~Hz}\right.$, Pt satellites $), 80.68\left(\mathrm{~s},{ }^{1} J_{\mathrm{PtP}}=\right.$ $5599 \mathrm{~Hz}$, Pt satellites). Anal. calcd. for $\mathrm{PtN}_{5} \mathrm{P}_{2} \mathrm{BF}_{24} \mathrm{C}_{58} \mathrm{H}_{40}(\%)$ : C 45.50, H 2.64, N 4.58; found: C 45.13, H 2.70, N 4.17.

[(dppp)Pt(NCMe)(Ph)][BAr' $\left.{ }_{4}\right]$ (4.15). Isolated 0.09 g (91\%). ${ }^{1} \mathrm{H}$ NMR $(800 \mathrm{MHz}$, $\left.\mathrm{CD}_{2} \mathrm{Cl}_{2}\right) \delta 7.58(\mathrm{~m}, 8 \mathrm{H}, \mathrm{dppp}), 7.34(\mathrm{~m}, 8 \mathrm{H}, \mathrm{dppp}), 7.23\left(\mathrm{td},{ }^{3} J_{\mathrm{HH}}=8 \mathrm{~Hz},{ }^{4} J_{\mathrm{HH}}=3 \mathrm{~Hz}\right.$, 4H, dppp), $6.93\left(\mathrm{t},{ }^{3} J_{\mathrm{HH}}=7 \mathrm{~Hz}, 2 \mathrm{H}, \mathrm{H}^{\mathrm{o}}-\mathrm{Ph}\right), 6.69\left(\mathrm{t},{ }^{3} J_{\mathrm{HH}}=7 \mathrm{~Hz}, 2 \mathrm{H}, \mathrm{H}^{\mathrm{m}}-\mathrm{Ph}\right), 6.64(\mathrm{t}$, 
$\left.{ }^{3} J_{\mathrm{HH}}=7 \mathrm{~Hz}, 1 \mathrm{H}, \mathrm{H}^{\mathrm{p}}-\mathrm{Ph}\right), 2.74(\mathrm{~m}, 2 \mathrm{H}), 2.66(\mathrm{~m}, 2 \mathrm{H}), 1.99(\mathrm{~m}, 2 \mathrm{H}), 1.70(\mathrm{~s}, 3 \mathrm{H}, \mathrm{NCMe})$.

${ }^{31} \mathrm{P}$ NMR $\left(121 \mathrm{MHz}, \mathrm{CD}_{2} \mathrm{Cl}_{2}\right) \delta-0.06\left(\mathrm{~d},{ }^{2} J_{\mathrm{PP}}=26 \mathrm{~Hz}\right),-4.20\left(\mathrm{~d},{ }^{2} J_{\mathrm{PP}}=26 \mathrm{~Hz}\right) . \mathrm{Pt}$ coupling not resolved due to poor signal intensity. Anal. calcd. for $\mathrm{PtP}_{2} \mathrm{NBF}_{24} \mathrm{C}_{67} \mathrm{H}_{46}(\%)$ : C 50.64, H 2.92, N 0.88; found: C 50.84, H 2.92, N 0.81.

[(dppf)Pt(NCMe)(Ph)][BAr' $\left.{ }_{4}\right]$ (4.16). Isolated $0.07 \mathrm{~g}(88 \%) .{ }^{1} \mathrm{H}$ NMR $(300 \mathrm{MHz}$, $\left.\mathrm{CD}_{3} \mathrm{CN}\right) \delta 7.90(\mathrm{~m}, 4 \mathrm{H}, \mathrm{dppf}), 7.57\left(\mathrm{~m}, 17 \mathrm{H}, \mathrm{Ar}^{\prime}\right.$ and dppf), $7.41\left(\mathrm{~m}, 7 \mathrm{H}, \mathrm{H}^{\circ}-\mathrm{Ph}\right.$ and dppf), 7.20 (m, 4H, dppf), 6.96 (m, 2H, $\left.\mathrm{H}^{\mathrm{m}}-\mathrm{Ph}\right), 6.62$ (m, 3H, $\mathrm{H}^{\mathrm{p}}-\mathrm{Ph}$ and dppf), 4.79 (m, 2H, Cp-dppf), 4.62 (s, 2H, Cp-dppf), 4.36 (s, 2H, Cp-dppf), 3.90 (m, 2H, Cp-dppf). Coordinated NCMe not observed due to rapid exchange with $\mathrm{CD}_{3} \mathrm{CN}$. ${ }^{31} \mathrm{P}$ NMR (121 $\left.\mathrm{MHz}, \mathrm{CD}_{3} \mathrm{CN}\right) \delta 18.95\left(\mathrm{~d},{ }^{2} J_{\mathrm{PP}}=17 \mathrm{~Hz},{ }^{1} J_{\mathrm{PtP}}=1717 \mathrm{~Hz}\right.$, Pt satellites $), 11.00\left(\mathrm{~d},{ }^{2} J_{\mathrm{PP}}=17\right.$ $\mathrm{Hz},{ }^{1} J_{\mathrm{PtP}}=4674 \mathrm{~Hz}$, Pt satellites). Anal. calcd. for $\mathrm{PtFeP}_{2} \mathrm{NBF}_{24} \mathrm{C}_{74} \mathrm{H}_{48}(\%)$ : C 51.35, H 2.80, N 0.81; found: C 51.27, H 2.92, N 0.82 .

[(bma)Pt(NCMe)(Ph)][BAr' $\left.{ }_{4}\right]$ (4.21). Isolated 0.05 g (98\%). ${ }^{1} \mathrm{H}$ NMR $(300 \mathrm{MHz}$, $\left.\mathrm{cd}_{3} \mathrm{cn}\right) \delta 7.54\left(\mathrm{~m}, 32 \mathrm{H}, \mathrm{Ar}\right.$ ', bma and Ph), $7.03\left(\mathrm{t},{ }^{3} \mathrm{~J}_{\mathrm{HH}}=7 \mathrm{~Hz}, 2 \mathrm{H}, \mathrm{H}^{\mathrm{m}}-\mathrm{Ph}\right), 6.72(\mathrm{~m}, 3 \mathrm{H}$, bma and $\mathrm{H}^{\mathrm{p}}-\mathrm{Ph}$ ), 3.80 (br s, 4H, CH $\mathrm{H}_{2}$-bma), 2.34 (s, 3H, Me-N). ${ }^{31} \mathrm{P}$ NMR (121 MHz, $\left.\mathrm{CD}_{3} \mathrm{CN}\right) \delta-4.82\left(\mathrm{~d},{ }^{2} J_{\mathrm{PP}}=26 \mathrm{~Hz},{ }^{1} J_{\mathrm{PtP}}=1530\right.$, Pt Satellites $),-7.03\left(\mathrm{~d},{ }^{2} J_{\mathrm{PP}}=26 \mathrm{~Hz},{ }^{1} J_{\mathrm{PtP}}\right.$ $=4243 \mathrm{~Hz}$, Pt satellites). Anal. calcd. for $\mathrm{PtN}_{2} \mathrm{P}_{2} \mathrm{BF}_{24} \mathrm{C}_{67} \mathrm{H}_{47}$ (\%): C 50.17, H 2.96, N 1.75; found: C 49.83, H 2.94, N 1.16 .

Catalytic Olefin Hydrophenylation with Ethylene and Propylene. A representative catalytic reaction is described. [('bpy) $\mathrm{Pt}(\mathrm{Ph})(\mathrm{THF})]\left[\mathrm{BAr}_{4}\right]$ (4.1b) $(0.019 \mathrm{~g}, 0.013 \mathrm{mmol})$ was dissolved in $12.0 \mathrm{~mL}$ of benzene containing $0.01 \mathrm{~mol} \%$ hexamethylbenzene (HMB) relative to benzene as an internal standard. The reaction mixture was placed in a stainless steel pressure reactor, charged with ethylene (1.0 bar), pressurized to a total of 7.5 bar 
with $\mathrm{N}_{2}$, and heated to $373 \mathrm{~K}$. After a given time period, the reaction mixture was allowed to cool to room temperature and was analyzed by GC/MS. Peak areas of the products and the internal standard were used to calculate product yields. Ethylbenzene production was quantified using linear regression analysis of gas chromatograms of standard samples. A set of five known standards were prepared consisting of 2:1, 4:1, 6:1, 8:1, and 10:1 molar ratios of ethylbenzene to HMB in benzene. A plot of the peak area ratios versus molar ratios gave a regression line. For the GC/MS system, the slope and correlation coefficient $\left(\mathrm{R}^{2}\right)$ for ethylbenzene were 0.68 and 0.99 , respectively. Identical procedures were used to quantify the production of styrene $(0.51 ; 0.99), 1,3-$ diethylbenzene $(0.52 ; 0.99), 1,4$-diethylbenzene $(0.53 ; 0.99)$, 1,2-diethylbenzene $(0.55$; $0.99)$, cumene $(0.89 ; 0.99), n$-propylbenzene $(1.19 ; 0.99)$, 2-ethylanisole $(0.63 ; 0.99)$, 4ethylanisole (1.09; 0.99), 2-ethyl-N-methylpyrrole ( $0.37 ; 0.99)$, 3-ethyl-N-methylpyrrole (0.31;0.99), 2-ethylpyrrole ( $0.41 ; 0.99)$, 2-ethylfuran $(0.27 ; 0.99)$, 1-ethylnaphthalene (0.93; 0.99), 2-ethylnaphthalene $(0.90 ; 0.99)$, 4-ethylchlorobenzene $(0.56 ; 0.99), 2$ ethylthiophene $(0.41 ; 0.99)$ and 3-ethylthiophene $(0.37 ; 0.99)$. Quantification of 3ethylanisole and 3-ethylchlorobenzene was estimated using the correlation coefficients for their respective para-substituted analogues. Turnovers of ethylnitrobenzene isomers were estimated from ratio of product to internal standard (HMB) peak areas in the chromatogram.

Catalytic Olefin Hydrophenylation with non-Gaseous Olefinic Substrates. A representative catalytic reaction is described. [( $\left.\left.{ }^{\mathrm{t}} \mathrm{bpy}\right) \mathrm{Pt}(\mathrm{Ph})(\mathrm{THF})\right]\left[\mathrm{BAr}_{4}\right] \mathbf{( 4 . 1 b )}(0.005 \mathrm{~g}$, $0.003 \mathrm{mmol})$ was dissolved in $3.0 \mathrm{~mL}$ of benzene containing 1-pentene $(55 \mu \mathrm{L}, 150$ equivalents relative to $\mathrm{Pt}$, ) and $0.01 \mathrm{~mol} \%$ hexamethylbenzene (HMB) relative to 
benzene as an internal standard. The reaction mixture was placed in a glass pressure tube and heated to $100{ }^{\circ} \mathrm{C}$. After a given time period, the reaction mixture was allowed to cool to room temperature and analyzed by GC/MS. Peak areas of the products and the internal standard were used to calculate product yields from linear regression analysis of standard samples. A set of five known standards were prepared consisting of 2:1, 4:1, 6:1, 8:1, and 10:1 molar ratios of alkylbenzene to $\mathrm{HMB}$ in $\mathrm{CH}_{2} \mathrm{Cl}_{2}$. A plot of the peak area ratios versus molar ratios gave a regression line. For the GC/MS system, the slope and correlation coefficient $\left(\mathrm{R}^{2}\right)$ for each alkylbenzene is as follows: $n$-pentylbenzene $(1.10$; 0.99), 2-phenylpentane $(1.33 ; 0.99), \quad$ phenylcyclohexane $\quad(0.33 ; 0.99), \quad 3-$ phenylcyclohexanone $(0.33 ; 0.99)$, 4-phenylbutan-2-one $(0.31 ; 0.99)$, methyl cinnamate (0.50; 0.99), and methyl 3-phenylpropanoate $(0.53 ; 0.99)$.

\subsection{References}

1. Luedtke, A. T.; Goldberg, K. I., Angew. Chem. Int. Ed. 2008, 47, 7694-7696.

2. McKeown, B. A.; Foley, N. A.; Lee, J. P.; Gunnoe, T. B., Organometallics 2008, 27, 4031-4033.

3. Andreatta, J. R.; McKeown, B. A.; Gunnoe, T. B., J. Organomet. Chem. 2011, 696, 305-315.

4. McKeown, B. A.; Gonzalez, H. E.; Friedfeld, M. R.; Gunnoe, T. B.; Cundari, T. R.; Sabat, M., J. Am. Chem. Soc. 2011, 133, 19131-19152.

5. McKeown, B. A.; Gonzalez, H. E.; Gunnoe, T. B.; Cundari, T. R.; Sabat, M., ACS Catalysis 2013, 3, 1165-1171.

6. McKeown, B. A.; Gonzalez, H. E.; Friedfeld, M. R.; Brosnahan, A. M.; Gunnoe, T. B.; Cundari, T. R.; Sabat, M., Organometallics 2013, ASAP. 
7. Bridwell B. W. (Brookhaven, M., Johnson, Carl E. (Brookhaven, MS) Monoalkylation of naphthalene. 1976.

8. Olah, G. A.; Olah, J. A., J. Am. Chem. Soc. 1976, 98, 1839-1842.

9. $\quad$ Rendina, L. M.; Puddephatt, R. J., Chem. Rev. 1997, 97, 1735-1754.

10. Anderson, C. M.; Puddephatt, R. J.; Ferguson, G.; Lough, A. J., J. Chem. Soc., Chem. Commun. 1989, 1297-1298.

11. Canty, A. J.; Honeyman, R. T.; Skelton, B. W.; White, A. H., J. Organomet. Chem. 1990, 389, 277-288.

12. Crespo, M.; Martinez, M.; Sales, J., J. Chem. Soc., Chem. Commun. 1992, 822823.

13. Anderson, C. M.; Crespo, M.; Jennings, M. C.; Lough, A. J.; Ferguson, G.; Puddephatt, R. J., Organometallics 1991, 10, 2672-2679.

14. DuBois, M. R.; Parker, K. G.; Ohman, C.; Noll, B. C., Organometallics 1997, 16, 2325-2334.

15. DuBois, M. R.; Vasquez, L. D.; Peslherbe, L.; Noll, B. C., Organometallics 1999, $18,2230-2240$.

16. Harman, W. D., Chem. Rev. 1997, 97, 1953-1978.

17. Friedman, L. A.; Harman, W. D., J. Am. Chem. Soc. 2001, 123, 8967-8973.

18. Friedman, L. A.; Sabat, M.; Harman, W. D., J. Am. Chem. Soc. 2002, 124, 73957404.

19. Tan, K. L.; Bergman, R. G.; Ellman, J. A., J. Am. Chem. Soc. 2001, 123, 26852686.

20. Murakami, M.; Hori, S., J. Am. Chem. Soc. 2003, 125, 4720-4721.

21. Jordan, R. F.; Taylor, D. F., J. Am. Chem. Soc. 1989, 111, 778-779.

22. Sezen, B.; Sames, D., J. Am. Chem. Soc. 2003, 125, 5274-5275.

23. Pittard, K. A.; Lee, J. P.; Cundari, T. R.; Gunnoe, T. B.; Petersen, J. L., Organometallics 2004, 23, 5514-5523. 
24. Foley, N. A.; Lee, J. P.; Ke, Z.; Gunnoe, T. B.; Cundari, T. R., Acc. Chem. Res. 2009, 42, 585-597.

25. Lail, M.; Bell, C. M.; Conner, D.; Cundari, T. R.; Gunnoe, T. B.; Petersen, J. L., Organometallics 2004, 23, 5007-5020.

26. Matsumoto, T.; Taube, D. J.; Periana, R. A.; Taube, H.; Yoshida, H., J. Am. Chem. Soc. 2000, 122, 7414-7415.

27. De Felice, V.; De Renzi, A.; Tesauro, D.; Vitagliano, A., Organometallics 1992, 11, 3669-3676.

28. De Felice, V.; Cucciolito, M. E.; De Renzi, A.; Ruffo, F.; Tesauro, D., J. Organomet. Chem. 1995, 493, 1-11.

29. Cucciolito, M. E.; De Renzi, A.; Orabona, I.; Ruffo, F.; Tesauro, D., J. Chem. Soc., Dalton Trans. 1998, 1675-1678.

30. Bhalla, G.; Bischof, S. M.; Ganesh, S. K.; Liu, X. Y.; Jones, C. J.; Borzenko, A.; Tenn III, W. J.; Ess, D. H.; Hashiguchi, B. G.; Lokare, K. S.; Leung, C. H.; Oxgaard, J.; Goddard III, W. A.; Periana, R. A., Green Chem. 2011, 13, 69-81.

31. Oxgaard, J.; Muller, R. P.; Goddard III, W. A.; Periana, R. A., J. Am. Chem. Soc. 2004, 126, 352-363.

32. Oxgaard, J.; Periana, R. A.; Goddard III, W. A., J. Am. Chem. Soc. 2004, 126, 11658-11665.

33. Matsumoto, T.; Periana, R. A.; Taube, D. J.; Yoshida, H., J. Mol. Catal. A.: Chem. 2002, 180, 1-18.

34. Joslin, E. E.; McMullin, C. L.; Gunnoe, T. B.; Cundari, T. R.; Sabat, M.; Myers, W. H., Organometallics 2012, 31, 6851-6860.

35. Goj, L. A.; Gunnoe, T. B., Curr. Org. Chem. 2005, 9, 671-685.

36. Lail, M.; Arrowood, B. N.; Gunnoe, T. B., J. Am. Chem. Soc. 2003, 125, 75067507.

37. Scarso, A.; Colladon, M.; Sgarbossa, P.; Santo, C.; Michelin, R. A.; Strukul, G., Organometallics 2010, 29, 1487-1497.

38. Liu, Y.; Mao, D.; Xu, D.; Xu, Z.; Zhang, Y., Synth. Commun. 2007, 37, 43894397. 
39. Suzuki, Y.; Yasumoto, T.; Mashima, K.; Okuda, J., J. Am. Chem. Soc. 2006, 128, 13017-13025.

40. Hansch, C.; Leo, A.; Taft, R. W., Chem. Rev. 1991, 91, 165-195.

41. Tomasik, P.; Ratajewicz, Z., Pyridine-Metal Complexes. John Wiley \& Sons, Inc.: New York, 1985; Vol. 14.

42. Williams, T. J.; Caffyn, A. J. M.; Hazari, N.; Oblad, P. F.; Labinger, J. A.; Bercaw, J., J. Am. Chem. Soc. 2008, 130, 2418-2419.

43. Driver, T. G.; Williams, T. J.; Labinger, J. A.; Bercaw, J. E., Organometallics 2007, 26, 294-301.

44. Williams, T. J.; Labinger, J. A.; Bercaw, J. E., Organometallics 2007, 26, 281287.

45. Driver, T. G.; Day, M. W.; Labinger, J. A.; Bercaw, J. E., Organometallics 2005, 24, 3644-3654.

46. Heyduk, A. F.; Driver, T. G.; Labinger, J. A.; Bercaw, J. E., J. Am. Chem. Soc. 2004, 126, 15034-15035.

47. Zhong, H. A.; Labinger, J. A.; Bercaw, J. E., J. Am. Chem. Soc. 2002, 124, 13781399.

48. Bercaw, J. E.; Labinger, J. A.; Zhong, H. A., Abstracts of Papers of the American Chemical Society 2001, 222, U412-U413.

49. Johansson, L.; Tilset, M.; Labinger, J. A.; Bercaw, J. E., J. Am. Chem. Soc. 2000, 122, 10846-10855.

50. Holtcamp, M. W.; Labinger, J. A.; Bercaw, J. E., J. Am. Chem. Soc. 1997, 119, 848-849.

51. Parmene, J.; Ivanovic-Burmazovic, I.; Tilset, M.; van Eldik, R., Inorg. Chem. 2009, 48, 9092-9103.

52. Wik, B. J.; Lersch, M.; Krivokapic, A.; Tilset, M., J. Am. Chem. Soc. 2006, 128, 2682-2696.

53. Wik, B. J.; Lersch, M.; Tilset, M., J. Am. Chem. Soc. 2002, 124, 12116-12117.

54. Johansson, L.; Ryan, O. B.; Romming, C.; Tilset, M., J. Am. Chem. Soc. 2001, $123,6579-6590$. 
55. Khusnutdinova, J. R.; Zavalij, P. Y.; Vedernikov, A. N., Can. J. Chem. 2009, 87, 110-120.

56. Bennett, M. A.; Canty, A. J.; Felixberger, J. K.; Rendina, L. M.; Sunderland, C.; Willis, A. C., Inorg. Chem. 1993, 32, 1951-1958.

57. van Leeuwen, P. W. N. M., Homogeneous Catalysis: Understanding the Art. Kluwer Academic Publishers: Netherlands, 2004.

58. Thomas, J. C.; Peters, J. C., J. Am. Chem. Soc. 2003, 125, 8870-8888.

59. Smith, D. C.; Haar, C. M.; Stevens, E. D.; Nolan, S. P.; Marshall, W. J.; Moloy, K. G., Organometallics 2000, 19, 1427-1433.

60. Brittain, J. M.; Jones, R. A.; Arques, J. S.; Saliente, T. A., Synth. Commun. 1982, $12,231-248$.

61. Li, G.; Rowland, G. B.; Rowland, E. B.; Antilla, J. C., Org. Lett. 2007, 9, 40654068.

62. Hayashi, T.; Sasaki, K., Chem. Lett. 2008, 37, 842-843.

63. Brookhart, M.; Grant, B.; Volpe, A. F., Organometallics 2002, 11, 3920-3922.

64. Steele, B. R.; Vrieze, K., Transition Met. Chem. 1977, 2, 140-144.

65. Yan, W.; Wang, Q.; Lin, Q.; Li, M.; Petersen, J. L.; Shi, X., Chemistry - A European Journal 2011, 17, 5011-5018.

66. Neves, P.; Gago, S.; Balula, S. S.; Lopes, A. D.; Valente, A. A.; Cunha-Silva, L.; Paz, F. A. A.; Pillinger, M.; Rocha, J.; Silva, C. M.; Gonçalves, I. S., Inorg. Chem. 2011, 50, 3490-3500.

67. Moloy, K. G.; Petersen, J. L., J. Am. Chem. Soc. 1995, 117, 7696-7710.

68. Redin, K.; Wilson, A. D.; Newell, R.; DuBois, M. R.; DuBois, D. L., Inorg. Chem. 2007, 46, 1268-1276.

69. Del Zotto, A.; Greco, C.; Baratta, W.; Siega, K.; Rigo, P., Eur. J. Inorg. Chem. 2007, 2007, 2909-2916.

70. Sirbu, D.; Consiglio, G.; Gischig, S., J. Organomet. Chem. 2006, 691, 1143-1150.

71. Peters, R. G.; White, S.; Roddick, D. M., Organometallics 1998, 17, 4493-4499. 
72. Alibrandi, G.; Bruno, G.; Lanza, S.; Minniti, D.; Romeo, R.; Tobe, M. L., Inorg. Chem. 1987, 26, 185-190.

73. Korenaga, T.; Abe, K.; Ko, A.; Maenishi, R.; Sakai, T., Organometallics 2010, $29,4025-4035$.

74. Shekhar, S.; Hartwig, J. F., J. Am. Chem. Soc. 2004, 126, 13016-13027.

75. Colacot, T. J.; Fair, R. J.; Boyko, W. J., Phosphorus, Sulfur, and Silicon and the Related Elements 1999, 144, 49-52.

76. Lanza, S.; Minniti, D.; Moore, P.; Sachinidis, J.; Romeo, R.; Tobe, M. L., Inorg. Chem. 1984, 23, 4428-33. 


\section{Summary and Future Outlook}

\subsection{Olefin Hydroarylation by Dipyrdyl Ligated Pt ${ }^{\mathrm{II}}$ Complexes}

For the investigation of $\mathrm{Pt}^{\mathrm{II}}$ catalyzed olefin hydroarylation, a series of $\mathrm{Pt}^{\mathrm{II}}-\mathrm{Ph}$ complexes bearing dipyridyl ligands were synthesized. ${ }^{1-4}$ Related $\mathrm{Pt}^{\mathrm{II}}$ systems have been well documented to perform benzene $\mathrm{C}-\mathrm{H}$ activation and olefin insertion into $\mathrm{Pt}-\mathrm{Ph}$ bonds (see Chapter 1). Thus, $\mathrm{Pt}^{\mathrm{II}}$ complexes should be viable candidates for olefin hydroarylation, which is exemplified by moderate success with (pyridyl)pyrrolide ligated platinum complexes for olefin hydroarylation that was reported concurrent with this work. ${ }^{5} \quad$ Initial studies of ethylene hydrophenylation catalyzed by $\left[\left({ }^{\mathrm{b} p p y}\right) \mathrm{Pt}(\mathrm{Ph})(\mathrm{THF})\right]\left[\mathrm{BAr}_{4}\right]$ demonstrated that formally cationic $\mathrm{Pt}^{\mathrm{II}}$ complexes can perform both decisive steps of the catalytic cycle (i.e., olefin insertion into $\mathrm{Pt}-\mathrm{Ph}$ bonds and benzene $\mathrm{C}-\mathrm{H}$ activation) under ambient conditions. Under catalytic conditions, $\left[\left({ }^{t} \mathrm{bpy}\right) \mathrm{Pt}(\mathrm{Ph})(\mathrm{THF})\right]\left[\mathrm{BAr}_{4}\right]$ displays modest efficiency for the formation of alkyl benzenes from benzene and ethylene. Elevated temperatures are required due to the formation of the catalyst resting state $\left[{ }^{t}\right.$ bpy $\left.) \mathrm{Pt}\left(\mathrm{CH}_{2} \mathrm{CH}_{2} \mathrm{Ph}\right)\left(\eta^{2}-\mathrm{C}_{2} \mathrm{H}_{4}\right)\right]\left[\mathrm{BAr}{ }_{4}\right]$ but also accelerate catalyst decomposition. The likely pathway for catalyst decomposition involves $\beta$-hydride elimination following ethylene insertion to form $\left[{ }^{\mathrm{t}} \mathrm{bpy}\right) \operatorname{Pt}(\mathrm{H})\left(\eta^{2}-\right.$ $\left.\left.\mathrm{CH}_{2}=\mathrm{CHPh}\right)\right]^{+}$. Upon displacement of styrene, the resulting $\mathrm{Pt}-\mathrm{H}$ is likely prone to decomposition through a process that is second-order in Pt (see Chapter 3).

The bipyridyl ligand is easily modified to probe the influence of ligand sterics and electron-donor ability on catalyst performance. A series of $\mathrm{Pt}^{\mathrm{II}}$ complexes 
$\left[\left({ }^{\mathrm{x}} \mathrm{bpy}\right) \mathrm{Pt}(\mathrm{Ph})(\mathrm{THF})\right]\left[\mathrm{BAr}_{4}\right]\left(4,4^{\prime}-\mathrm{X}_{2}=\mathrm{OMe},{ }^{\mathrm{t}} \mathrm{Bu}, \mathrm{H}, \mathrm{Br}, \mathrm{CO}_{2} \mathrm{Et}\right.$ and $\left.\mathrm{NO}_{2}\right)$ were screened to determine the influence of bipyridyl donor ability on catalytic ethylene hydrophenylation with negligible alteration of catalyst sterics. As bipyridyl donor ability is reduced by decorating the $4,4^{\prime}$-positions of the bipyridyl ligand with increasingly electron-withdrawing substituents, catalyst efficiency is decreased due a change in selectivity for vinyl benzenes over alkyl benzenes presumably due to an increased predilection of $\beta$-hydride elimination and subsequent styrene displacement.

Increasing the chelate ring size from a 5- to 6-membered chelate in $[(\mathrm{dpm}) \mathrm{Pt}(\mathrm{Ph})(\mathrm{THF})]\left[\mathrm{BAr}_{4}\right]$ results in an approximate 3 -fold increase in catalyst efficiency. The increased catalytic activity, relative to the bipyridyl analogue, is a result of a favorable increase in entropy of activation, which provides enhanced catalysis at elevated temperatures. Further steric modifications, such as increasing to a 7 -membered chelate using 1,2-(dipyridyl)ethane or introducing methyl groups proximal to the metal center in the 6,6'-positions of the pyridyl ring, result in either increased thermal instability or an increased selectivity for styrene formation and subsequent decomposition.

Extension of $\mathrm{Pt}^{\mathrm{II}}$ catalyzed olefin hydroarylation to substrates other than ethylene and benzene (e.g., propylene or methyl vinyl ketone) results in subdued catalytic activity relative to that observed for ethylene. Using $\alpha$-olefins such as propylene or 1-pentene, product selectivity is biased towards Markovnikov over anti-Markovnikov addition products. The observance of substantial anti-Markovnikov addition products (e.g., linear alkyl benzenes) suggests a non-acid catalyzed mechanism is operative. Similar to FriedelCrafts alkylation of mono-substituted benzenes, an increase in catalytic efficiency is 
observed for increasingly donating substituents on benzene in the order: $\mathrm{OMe}>\mathrm{C}_{2} \mathrm{H}_{5}>$ $\mathrm{Cl}>\mathrm{NO}_{2}$

Electron-difficient dipyridyl chelates and nitrogen based ancillary ligands outside the dipyridyl motif have been demonstrated to provide less effective catalysis for ethylene hydrophenylation, as few catalytic turnovers and small ethylbenzene to styrene ratios are observed. Ligands capable of $\kappa^{3}$-coordination result in stabilization of transient $\mathrm{Pt}^{\mathrm{IV}}$ intermediates following benzene $\mathrm{C}-\mathrm{H}$ activation, which is predicted to proceed via oxidative addition. The near stoichiometric yield of ethylbenzene suggests that catalyst decomposition is highly competitive at the elevated temperatures $\left(\geq 140^{\circ} \mathrm{C}\right)$ necessary to instigate ligand dissociation to provide a 5-coordinate intermediate for reductive elimination and product release. Similar to electron-deficient bipyridine ligated $\mathrm{Pt}^{\mathrm{II}}$ catalyst precursors, complexes featuring phosphine ligands are selective for the formation of styrene over ethylbenzene under catalytic conditions. Few catalytic turnovers are observed, and no definite correlations between phosphine chelate bite angle or donor ability can be drawn.

It is clear that square planar $\mathrm{Pt}^{\mathrm{II}}$ complexes provide a sterically and electronically flexible catalyst platform for modulating both activity and selectivity for the synthesis of $\mathrm{C}_{\text {aryl }}-\mathrm{C}_{\mathrm{sp} 3}$ linkages from hydrocarbon starting materials without the need for intermediate functionalization steps. In terms of future olefin hydroarylation catalyst design, these results suggest that the key to long lived catalytic production of alkyl arenes involves avoiding vinyl arene formation. More strongly electron-donating ancillary ligands appear to promote high alkyl to vinyl arene ratios. N-Heterocyclic carbenes are known to be strong $\sigma$-donors and are easily tuned to alter steric and electronic properties (Chart 5.1). 
Furthermore, the increased steric bulk around the metal center is expected to increase the selectivity for monoalkylated benzenes. A steric balance must be identified that promotes alkyl benzene dissociation but does not inhibit hydrocarbon coordination. Another potential ligand class that merits further investigation is macrocycles (Chart 5.1). Ethylene hydrophenylation catalyzed by $[(9 \mathrm{~S} 3) \mathrm{Pt}(\mathrm{NCMe})(\mathrm{Ph})]\left[\mathrm{BAr}{ }_{4}\right]$ was selective for mono-functionalization of benzene with TON comparable to that observed for several of the dipyridyl based catalysts. The weak axial interactions appear to facilitate product displacement without halting catalysis by trapping $\mathrm{Pt}^{\mathrm{IV}}$ intermediates via $\kappa^{3}$-coordination to the metal center. ${ }^{6-7}$

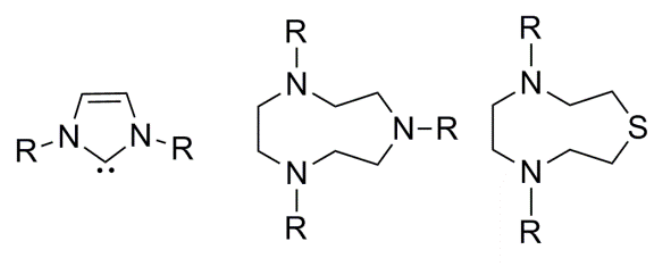

$\mathrm{R}=\mathrm{H}$, hydrocarbyl or aryl

Chart 5.1. Potential ligands for future $\mathrm{Pt}^{\mathrm{II}}$ catalyzed olefin hydroarylation studies.

If vinyl arene production is desired, a sterically crowded ligand is preferred, such as 6,6'- $\mathrm{Me}_{2}-2,2^{\prime}$-bipyridine. For efficient styrene production, the issue of catalyst decomposition will need to be overcome, which is possibly due to the formation of unstable $\mathrm{Pt}-\mathrm{H}$ intermediates that result from $\beta$-hydride elimination and styrene dissociation. A more suitable metal for the production of vinyl arenes may be palladium, as $\beta$-hydride elimination is an important step in several Pd catalyzed processes. However, conditions must be identified to deter olefin oligomerization and favor aromatic $\mathrm{C}-\mathrm{H}$ 
activation. Fujiwara and coworkers have previously reported the catalytic oxidative hydroarylation of olefins using $\operatorname{Pd}(\mathrm{OAc})_{2}$, acetic acid and oxidants based on silver or

copper. ${ }^{8}$ However, oxidative hydroarylation of unactivated substrates only show modest activity ( $<4$ total turnovers), a preference for the formation of bis-arylated olefins over mono-arylated product, and formation of biphenyl likely via a decomposition pathway. The introduction of ancillary ligands to adjust catalyst activity and selectivity could produce a viable methodology for the generation of vinyl arenes from aromatic moieties and olefins.

\subsection{References}

1. McKeown, B. A.; Foley, N. A.; Lee, J. P.; Gunnoe, T. B., Organometallics 2008, 27, 4031-4033.

2. McKeown, B. A.; Gonzalez, H. E.; Friedfeld, M. R.; Gunnoe, T. B.; Cundari, T. R.; Sabat, M., J. Am. Chem. Soc. 2011, 133, 19131-19152.

3. McKeown, B. A.; Gonzalez, H. E.; Friedfeld, M. R.; Brosnahan, A. M.; Gunnoe, T. B.; Cundari, T. R.; Sabat, M., Organometallics 2013, ASAP.

4. McKeown, B. A.; Gonzalez, H. E.; Gunnoe, T. B.; Cundari, T. R.; Sabat, M., ACS Catalysis 2013, 3, 1165-1171.

5. Luedtke, A. T.; Goldberg, K. I., Angew. Chem. 2008, 120, 7808-7810.

6. Bennett, M. A.; Canty, A. J.; Felixberger, J. K.; Rendina, L. M.; Sunderland, C.; Willis, A. C., Inorg. Chem. 1993, 32, 1951-1958.

7. Abel, E. W.; Bhargava, S. K.; Orrell, K. G., The Stereodynamics of Metal Complexes of Sulfur-, Selenium-, and Tellurium-Containing Ligands. In Prog. Inorg. Chem., John Wiley \& Sons, Inc.: 2007; pp 1-118.

8. Fujiwara, Y.; Moritani, I.; Danno, S.; Asano, R.; Teranishi, S., J. Am. Chem. Soc. 1969, 91, 7166-7169. 